a

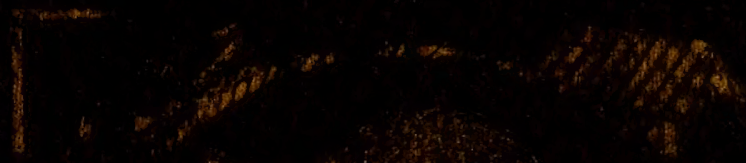

is 1 कर:
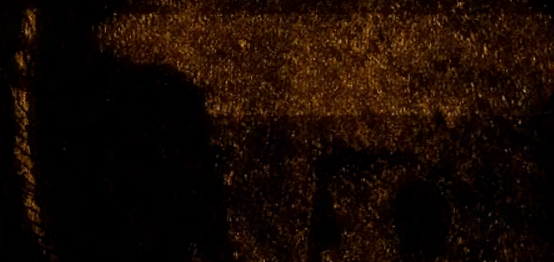

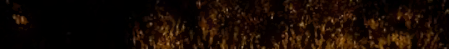

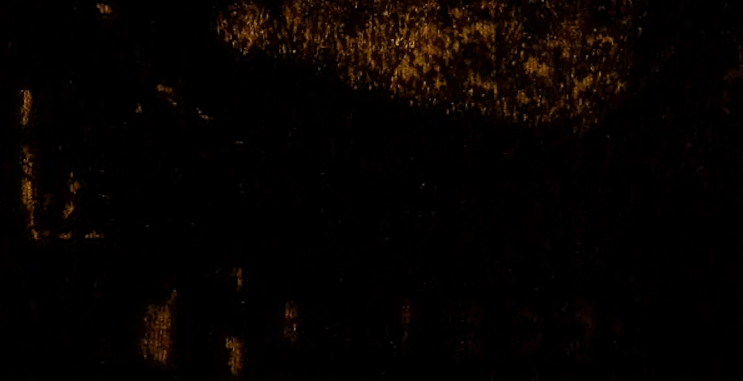




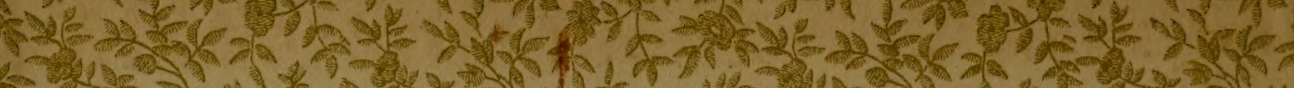

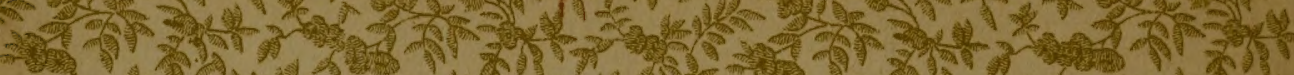

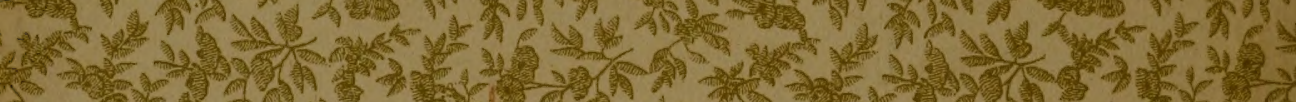

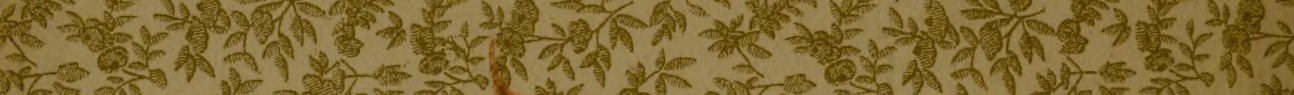

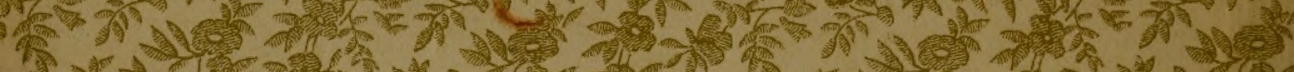

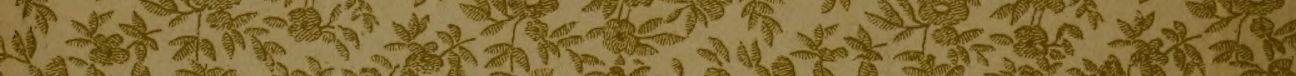
4. 1 -

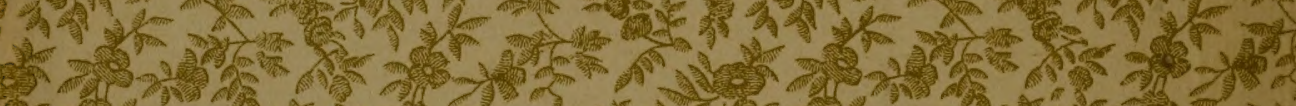
20

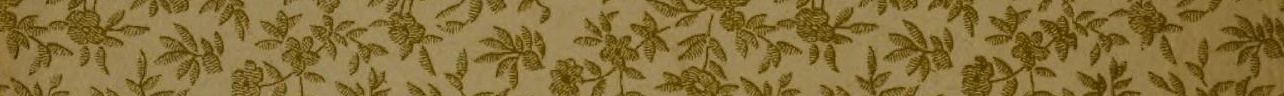
Fy-2 - 1.

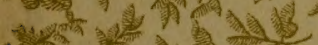
26. की -151 H.

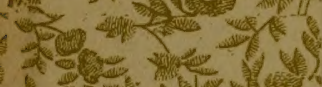

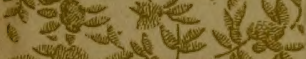

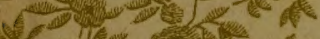
6 . on $\Rightarrow+4 \times 1 x^{2}$ $4006 x^{2}$

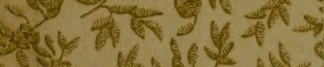

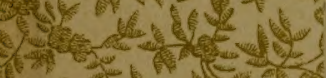
ef I.

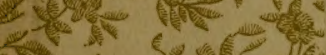
$y=y+x$ xis $210-10$

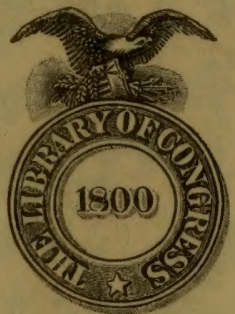

Class $S K 283$

Book A 55

Copyright $\mathrm{N}^{\mathrm{o}}$.

COPYRIGHT DEPOSYI.

初?

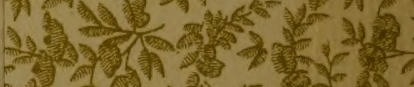
in 0 . 15. 35 $-142 \times 2=2$ He 18 se -

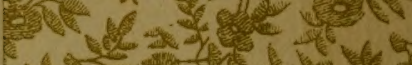
$10 x+4=$

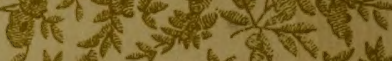
S4.

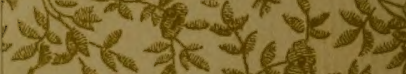
be tore $-7 \rightarrow 3 x+y$ are $x=3$.

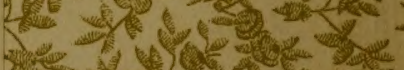
Le

-

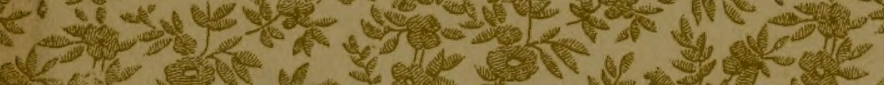

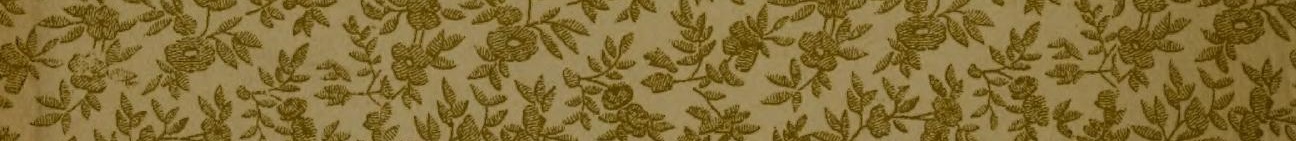

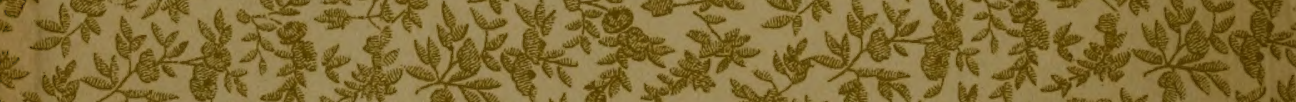

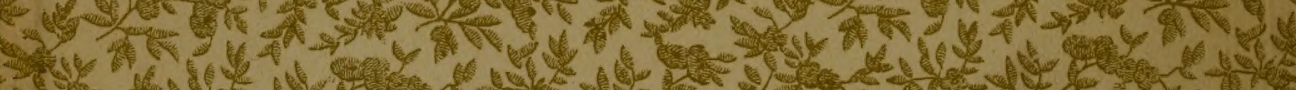

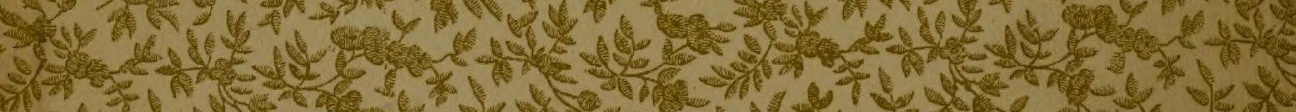

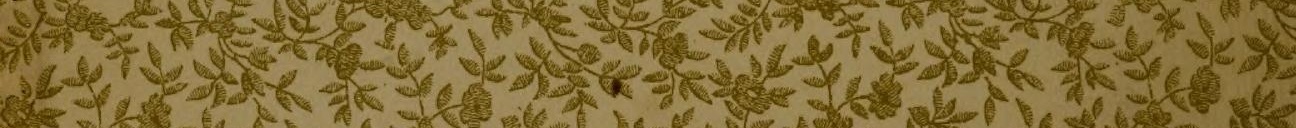

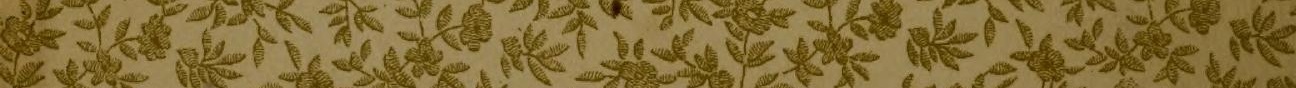

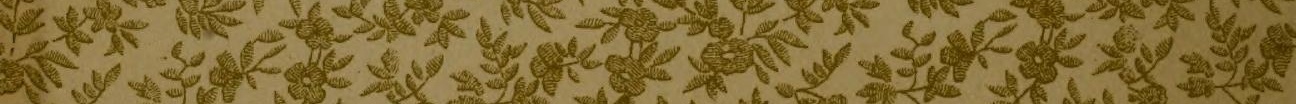
(1)

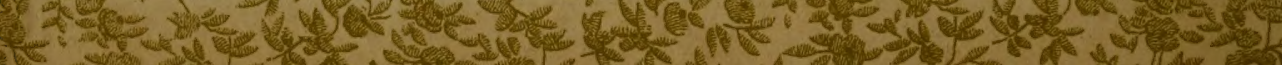




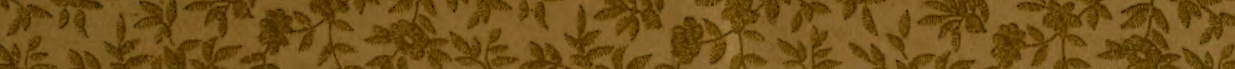

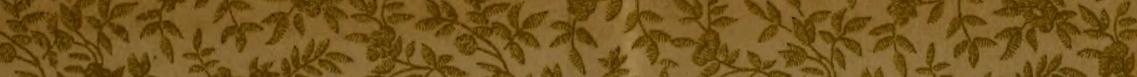

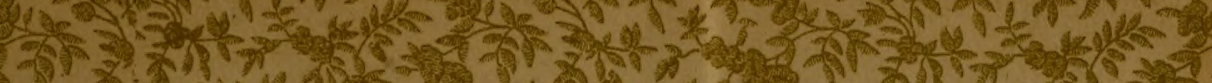

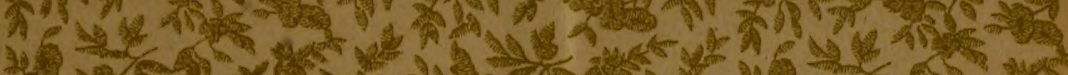
(20)

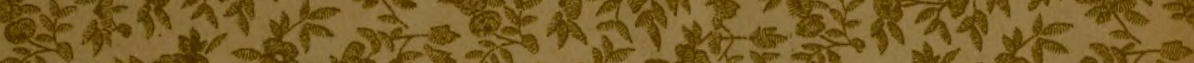

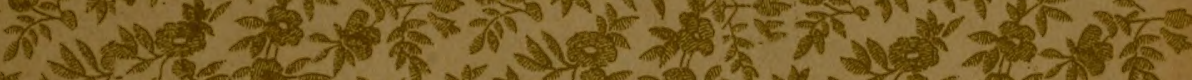

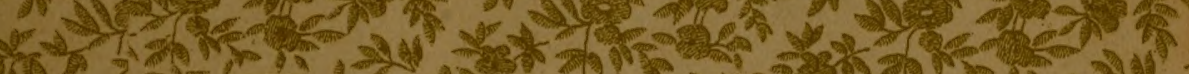

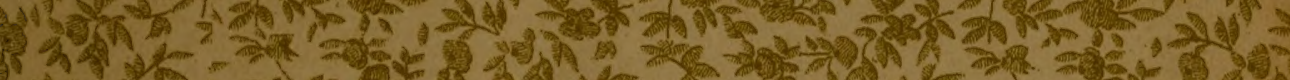
D)

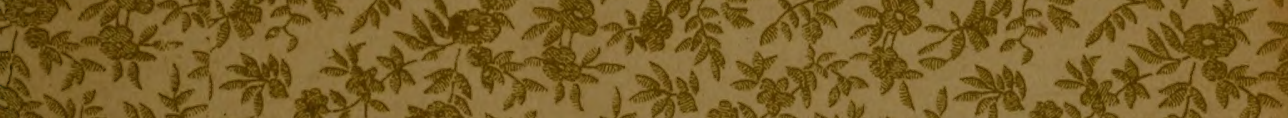

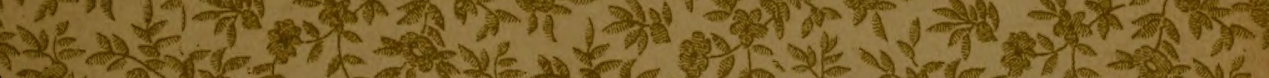

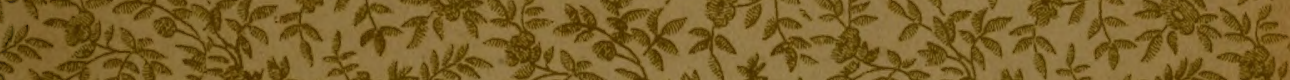
(1) 4. 9 .

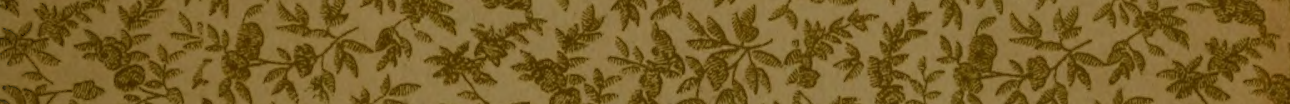
7)

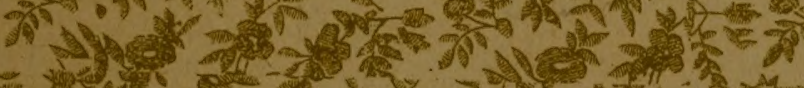

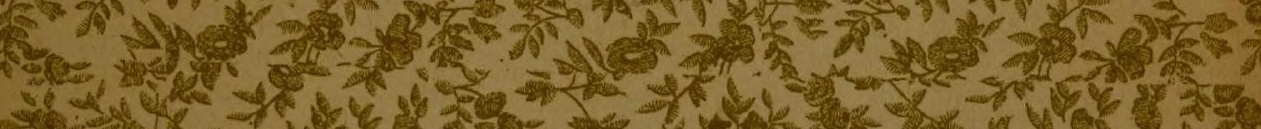
-

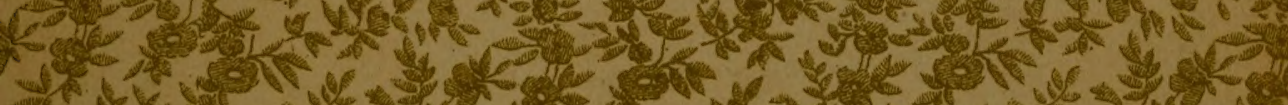

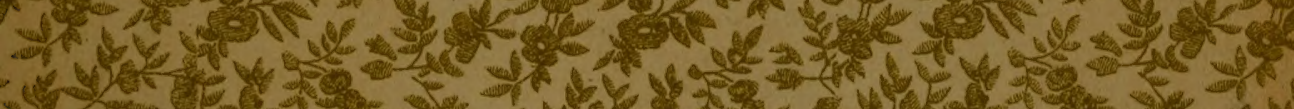

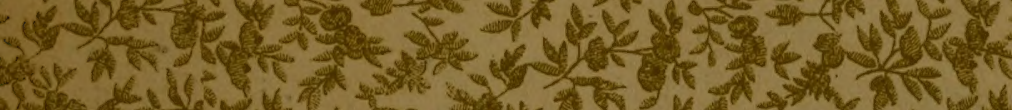

(1)

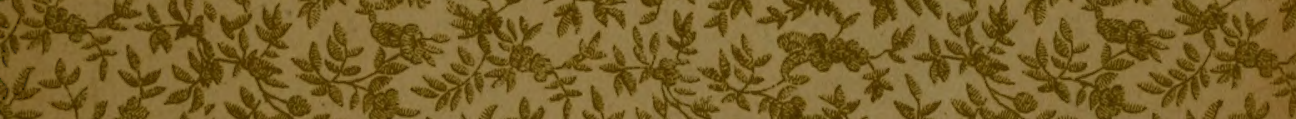

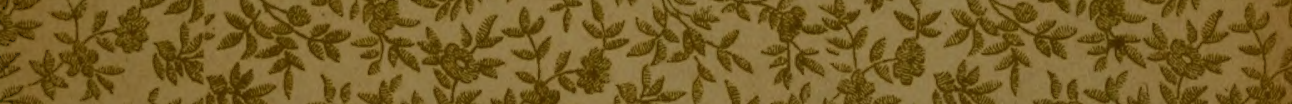
25 21-20

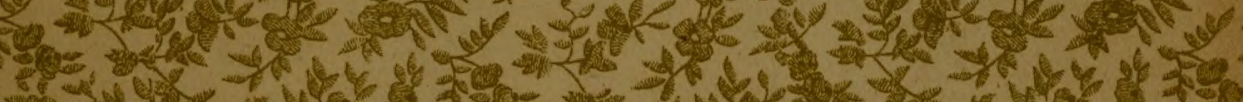

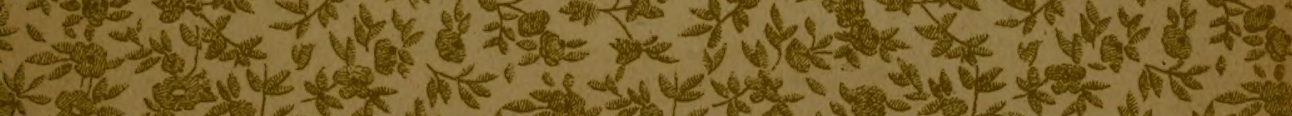

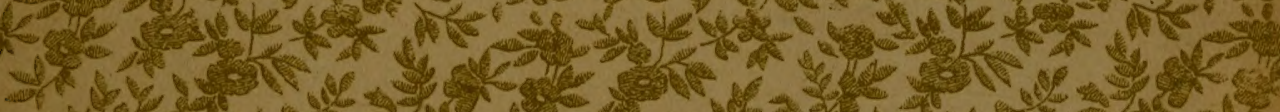

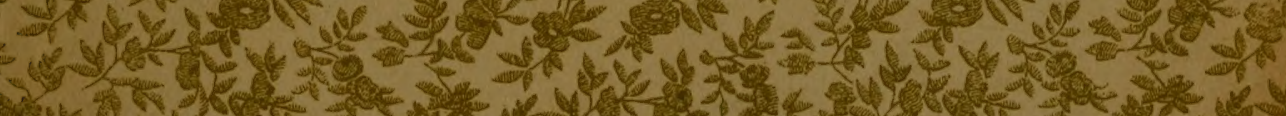

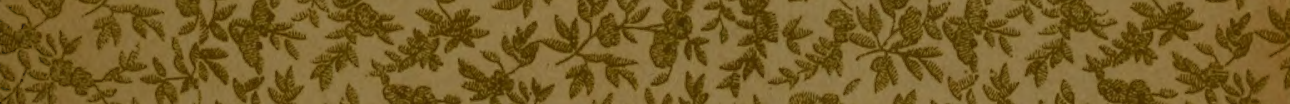

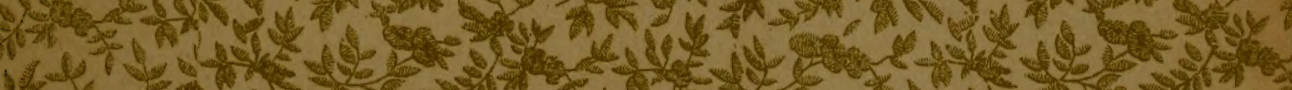

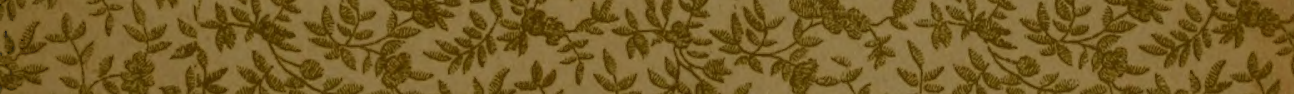
2.

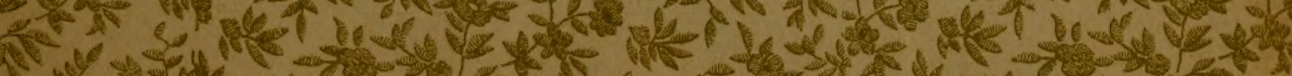

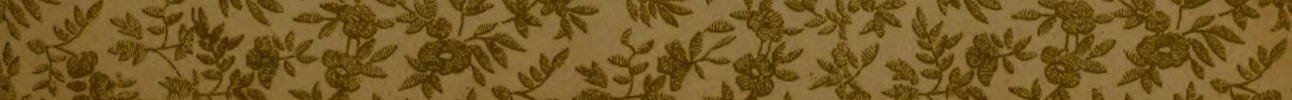
2. 






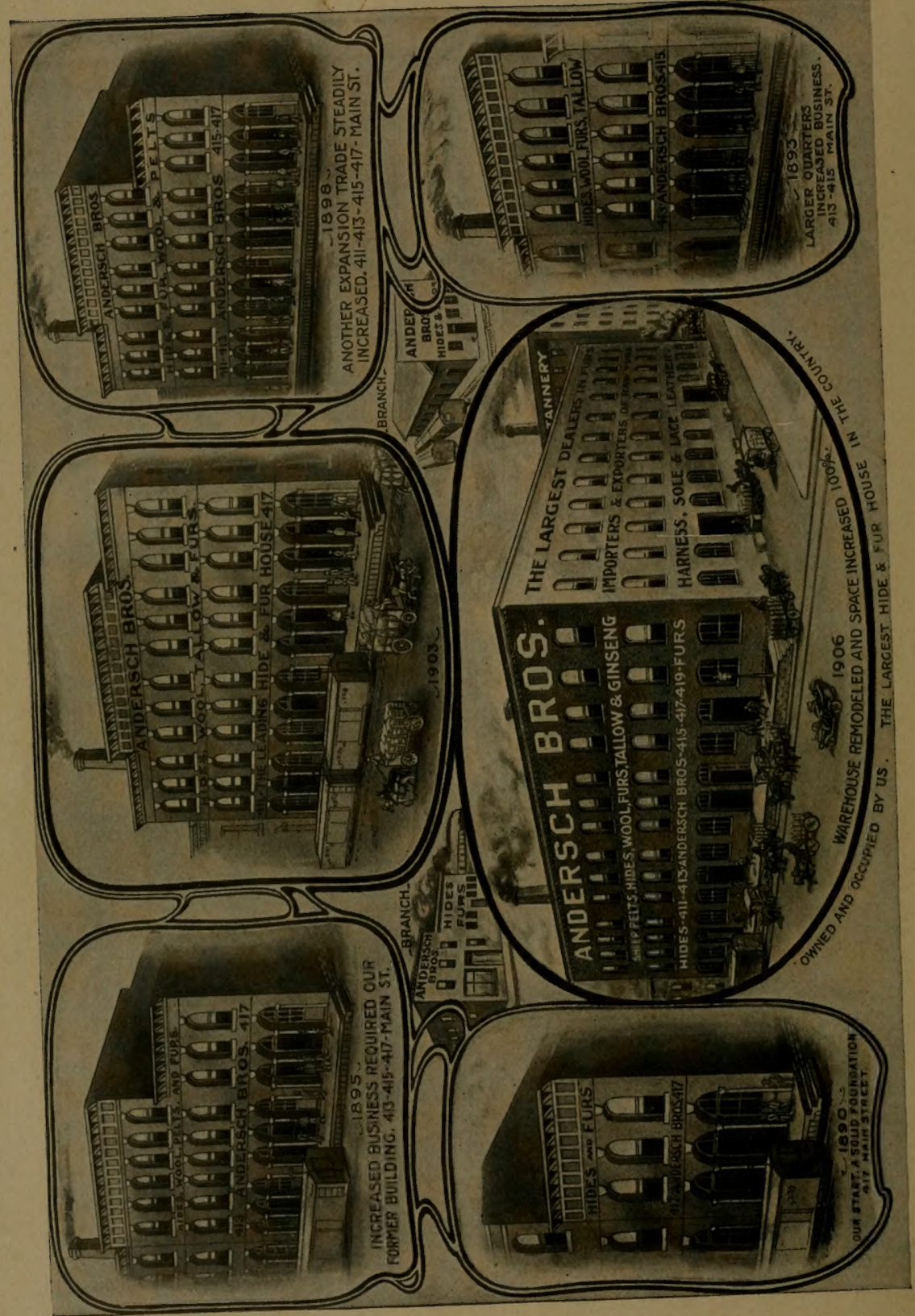


"SECOND, REVISED AND ENLARGED EDITION OF"

\section{ANDERSCH BROS.}

\section{Hunters and Trappers Guide}

ILLUSTRATING THE

Fur Bearing Animals

OF

North America

THE SKINS OF WHICH HAVE A MARKET VALUE.

Describing the Various Animals, Geographical Location, Habits, Mode of Living, Propagation, and how to

\section{Hunt and Trap Them}

WITH REVISED

\section{Game Laws}

OF ALI, THE

States and Territories in the U.S.

How to Skin Animals, Manner of Stretching Skins, Trappers'

Secrets, with Illustrations of Various

Standard Traps, describes

Skunk, Mink, Fox and Opossum Farms

and how and where to raise these animals for profit, number required to start with, size of farm, how to breed,

kind of food, etc.

BY ANDERSCH BROS., - MINNEAPOLIS, MINN. 


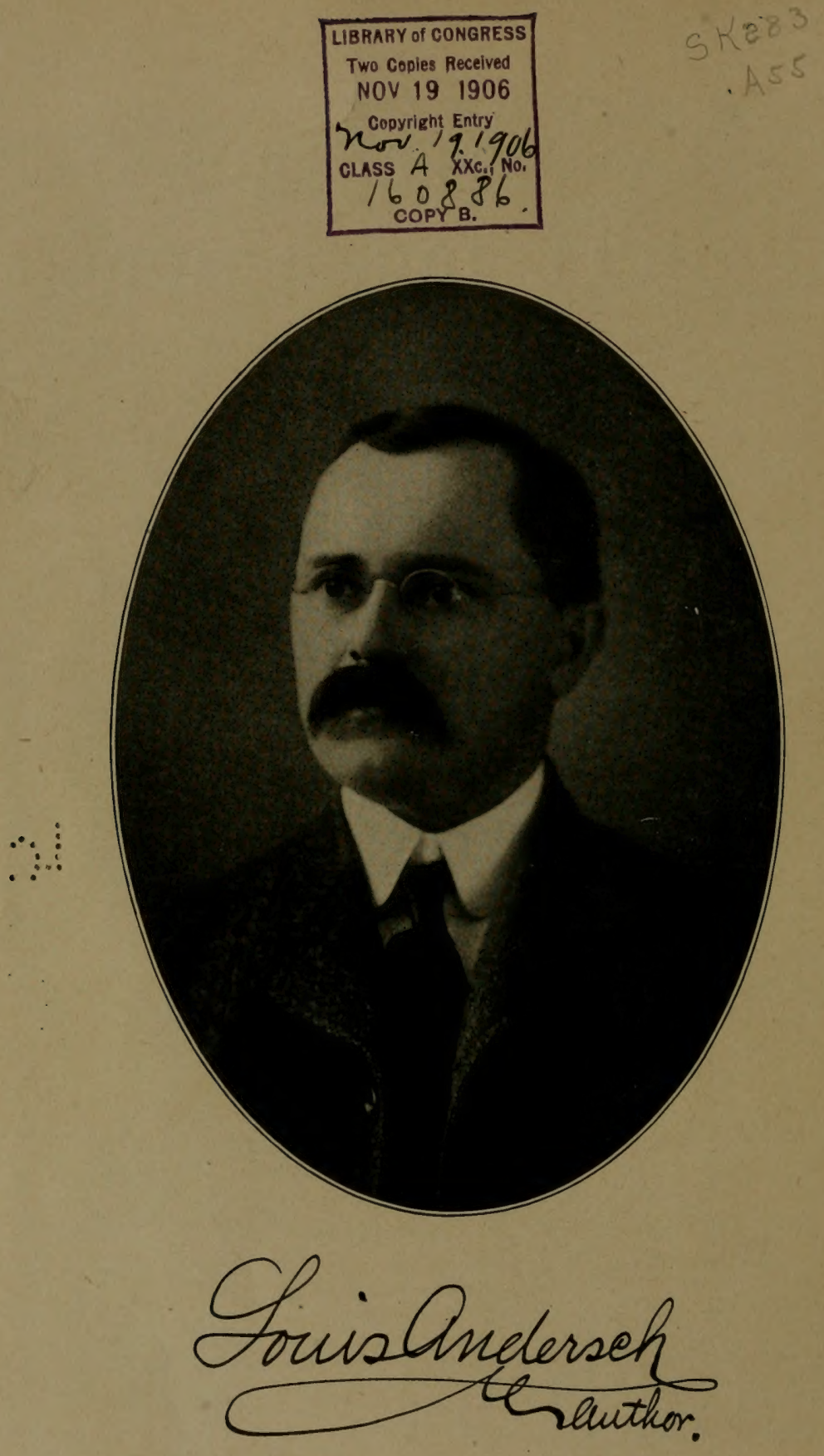




\section{Introductony Prefiace.}

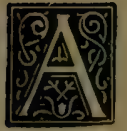

SPACE of three years has now elapsed since the first edition of this book was given to the public; the appreciation of that volume is shown by the remarkable demand that bared the shelves before the trade was really aware of the existence of this publication. Scarcely a year had passed before the necessity for a second edition or re-print dawned upon the author, who, only after due deliberation, intelligent inquiry and assurance of co-operation, undertook to improve and enlarge the scope of its usefulness by embodying in a comprehensive and thorough manner, new secret methods and the experience of hundreds of experts in the vocation of hunting and trapping.

The deep rooted interest in this volume manifested by those associated with the occupations of Hunting and Trapping, the public in general and the Fur Trade in particular, is greatly appreciated. The nature of the subject will lead the reader, as it has the author, over the entire New World, and the ecliptic penumbra of our observation is extended northward to the frozen seas and southward to the pampas.

To the willing observer and studen, Natural History, like Astronomy, is ever reaching, and when once taken up, the subject is extremely interesting. Lower animals play an important part in man's every day life, and we largely owe our existence and sustenance to them. They are useful in life and death, furnishing us with meat, fat, milk, fur, wool, drugs, and many useful and ornamental articles; they carry our burdens and supply us with comfort, protection and companionship.

This work, covering as it does a field not hitherto occupied, embellislied with artistic and superb illustrations true to nature, all technical and scientific terms and descriptions eliminated by the use of plain, common language throughout, should be acceptable to the people to whom it is particularly dedicated.

The form of this work has necessarily been modified in order to bring the whole matter within reasonable compass, as well as to adapt it more perfectly to the wants of hunters and trappers, which it is designed to meet. The technical and critical information has been condensed as far as was deemed compatible with a book of this nature, but any one desiring knowledge of a distinctively scientific character should peruse the works of Muller, Haeckel, Wallace, Owen, Darwin, Von Baer, Cuvier, Brehm, Linneaus, or our own Audubon, Bachman, Coues, and other authors.

We are greatly indebted to the many hunters and trappers, also to some of the publishers, for the kindly assistance and courtesies extended, in the compilation of this book, and many thanks are accorded them for their generous co-operation.

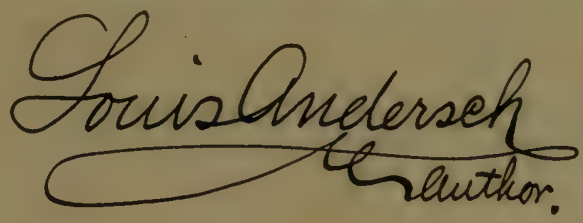




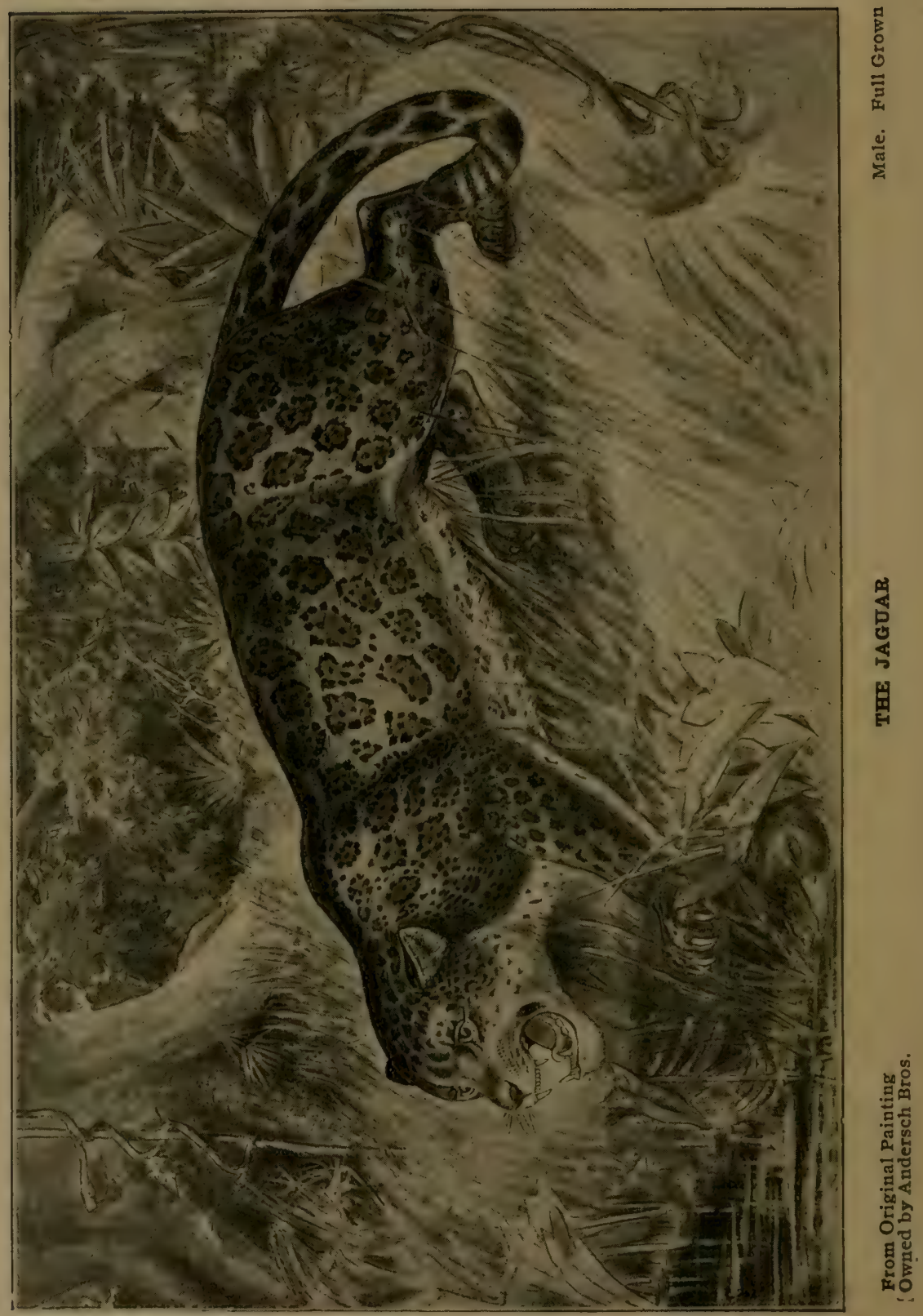




\title{
Origin and Evolution
}

\author{
OF \\ Man, Beast, Weapons and Traps.
}

POF. HAECHEL has satisfactorily traced man in the process of evolution through animal and vegetable life to the very lowest form of life consisting of a minute cell, and he supposes that this cell was produced by or from inorganic matter by some occult process, technically denominated as spontaneous generation. Darwin never withdrew, even in his last work, the sentence in which he intimated his belief "that life may have been originally breathed by the Creator into a few forms or into one." He traced man to the humble and unarmored molluscs, called Ascideans, whence man's line of ancestry ran through the lower vertebrata; thence to the monotrematous mammals, and finally to the anthropoid apes.

In the process of evolution, when animal life was engendered from the vegetable, the resultance of some form of copulation, the conception of which seems impossible for local realization and description. The theological version of Creation and division of life falls asunder, excepting when leaning upon Darwin's popular intimation, "that at some remote period life may have been breathed into one or more forms by the Creator," but very probably the infinite spark of life was inborn in the very existence of being.

Leaving the vegetable and animal transmigrative period and skipping a million years, we find the evolutionary epoch has somewhat specialized the living forms, but man is yet at a great distance. Nature, or the natural selection and survival of the fittest has conspicuously developed higher and higher species, and finally, after an elapse of ages and ages, omitting some detailed histological differentiations, we behold the concrete result-man. The mind can scarcely perceive the slow progress in the advancement of man, and the necessary ages required to produce man as we are, and as we find him today. 
Animal Instinct in Man.

The pregnant crude conception of animal instinct in man as relegated to us from the lower forms, seems fair to be exterminated in the future progress of evolution. One can perceive the marked comparative abatement of these instincts when the highest order of man, as represented by the American, English, German and French, is compared with the low barbarous and uncivilized tribes.

This energetic progress and advancement is not only noticeable in the human family but also in domestic animals, and the influence of the two, coupled with the ever forward evolutionary progress, will spread to wild animals, birds, reptiles and fishes, and in the ages to come, the will of man in a still higher form, will be supreme and alone accountable to nature and the creative mind.

\section{As Man and Beast Come They Will Ğo.}

The origin; as well as the destiny of each individual is from nothing to nothing. The past is written by historians, the future anticipated by scientists, and as each generation passes along the path of existence, familiarizing and learning by their investigation, they each leave behind some useful achievements from which others profit. What is true in the human family is reasonably true in a milder sense of animals, but notwithstanding the latter's limited powers of beneficial conception they, like the human race, learn by lessons. A burnt child dreads the fire; so does a trap-nipped fox or wolf dread iron or man's contrivance to capture him. The animal language, be it a facial expression, action of the body, or sounds from the mouth, are all expressive and the meaning intelligently conveyed.

The bodies of the first animals were of diminutive size and form and that the

The Lost Species and

Extermination of Animals. change from plant to animal life took place in some tropical climate seems reasonable; also that ages were required in the climatical distribution of life species, especially of terrestrial habitat. The existence of the mammoth before the glacial period, and that these and other monstrous animals were killed by the cave dwellers, is demonstrated by the weapons, remains, and other items found in the excavations. Dawkins found engraved ivory with the cave men of Pleisteone, in the cave of La Madeline. Tools, hunting weapons, dug-outs, traps, spears, snares, and remains of bodies indicating extinct species, were found in many parts of Europe, Asia, and in America. Thousands of species were lost in the glacial period, also in the Bibli- 
cal denudation of Asia, still others became extinct by disease, ravages of strong animals, and by confusion of propagation. That many species became extinct by being zealously hunted and trapped by man cannot be doubted. Even in our day, we grasp the passing of the buffalo, the beaver, and the otter, and scores of other animals and fishes, and notwithstanding the severe laws, the period of total extermination of the above mentioned species is not centuries but years. In our own period of evolutionary changes, we harbor the true belief of total extermination of the American Indian, many species of animals and kinds of plant life. On the other hand we see the many herds of cattle, sheep, swine, and the human family numerously enlarged and improved. We ponder at the many inventions, discoveries, manipulations, watch the winters and the summers pass each other, see our friends go, hear of distant calamities, note earthy disturbances, energetic changes, progress-call it all evolution.

Origin of Weapons and Traps.

Man's earliest implement of defense, the first assistance to his physical prowess in the chase and in combat, was when he stooped, picked up a stone, and hurled it at his adversary. A club was the second. The third and fourth in order was the spear or the sling. We now pass to the stone age and we find the first true implements, the result of man's study and labor, the commonest, most widely distributed, was the Imperforate axe, of roughly dressed flint, diorite, greenstone, or almost any material workable into desired forms and that retained the requisite sharpness of edgie. Daggers, swords, spear heads, made ont of bronze came next in order. The bow and arrow is traced to the bronze age, but whether its use predominated in an earlier period is lost in obscurity. The earliest tools were flaked stones and cracked bones, and one can conceive the possible result from such tools in the forms of weapons.

The capture of animals by snares was first introduced in the bronze age and the existence of deadfalls at times when Europe had a tropical climate is augmented by discoveries made in glacial deposits. Historians relate that prisoners were set at liberty during the early ages for the purpose of capturing wild beasts of prey, and upon their return with evidence of success were pardoned, but invariably they were devoured by the beasts that they set out to kill or capture. Many that were fortunate in this pursuit returned to join those that were not, and these men soon became the expert hunters and trappers of those days. These men killed or captured the wild beasts by running them into self constructed dens, dug-outs, enclosures, or waylaid them in 
paths and killed them with clubs, slings, spears, lances, arrows, etc.

The American Indian, probably greater developed in the trait of hunting and trapping, confined himself largely to hunting such beasts that gave him food and clothing and such skins as were mediums of barter with more distant tribes. The bow and arrow, battle axe of simplest form, and spears, predominated, but in later years, or in places where game was not plentiful, figure four arrangements, dug-outs, pit and deadfalls were resorted to. Probably no other tribe or nation were as successful in the art of lassoing and snaring large and small animals as the American Indian, likewise the original American race as constituted by the many tribes were more proficient and still greater experts with the bow and arrow.

The use of poison in the destruction of animals is recorded by Chinese long before the Biblical version. Poisoned spears and arrows were used in warfare long before the Christian era, and the American Indian knew the effect of poison hundreds of years before Columbus touched our shores.

Modern Traps and Weapons.
Leaving ancient arms, weapons, traps, dug-outs, pitfalls, box traps, bows, spears, slings, set arrows, drop-weights, and disregarding the doubt as to whether gunpowder was used in China and India at a remote period and whether the combination of potassium nitrate, carbon and sulphur was discovered in the I th century, we skip this period to study the weapons, traps and methods employed by the native Indian and hunters and trappers operating in the United States and Canada, during the Igth and 2oth century. The interested reader will now please peruse the following pages, first to form a thorough acquaintance of the animal by studying the descriptive articles in the fore part of this volume, later digesting the modern methods of hunting and trapping, and finishing up by reading the hundreds of original articles from experienced hunters and trappers. 


\title{
The Fur Bearing Animals
}

\author{
of \\ North America \\ WHOSE SKINS HAVE A MARKET VALUE
}

Minutely Describing, Illustrating and Classifying the Various Animals, their Characteristics and Habits, Mode of

Living, Propogation, Food, Geographical

Location, Etc., Etc.

\section{THE WEASEL.}

(Ger. Wicsel, Szv. Vessla, Lat. Putorius Vulgaris.)

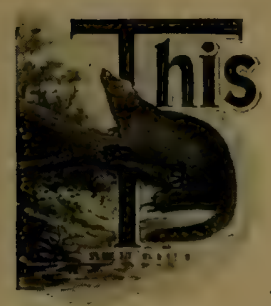

LITTLE carnivorous animal, the smallest of the marten or weasel family, is found in nearly every state and territory in the Union, Audubon says, "also in Alaska." What Dr. Coues says of the Putorius erminea, with slight modifications, is also true of the weasel: "A creature of thoroughly and conspicuous circumpolar distribution, extending probably as near the pole as any land animal, it is modified, when changed at all, by latitude as expressed in the climate to which it is subjected, state of its food supply, etc."

The American weasel resembles the European, but a difference of length in the vertabrae and color of fur on the tip of tail, is noticeable, and climatic conditions of Europe, like that of this hemisphere, are responsible for the variation in body, size, color, etc.

On this continent we can divide this little courageous animal into separate groups, so as to give a closer and more definite description of their size, color, habits and respective value of their skins from the manufacturer's point of view.

First: The smallest weasel on this continent is chiefly found in the southern and middle states, often seen and known to inhabit western as well as Atlantic states. It is sometimes confused with young northern species during the summer months, 
which it closely resembles, and perhaps occasionally, at least it is so claimed by naturalists, seen in northern states as far as New York, Minnesota and Washington. This species is easily distinguished from the larger variety by its short tail, smallness of body and continued brown, chestnut or chocolate dress, winter and summer. The belly portion however, is covered with a strip of light colored fur, beginning with extreme end of upper lip, continuing along its neck, belly, and ending at the anus, though somewhat dividing and terminating systematically at the inner portion of the knee.

The body measures six to seven and one-half inches, rarely eight inches, to which a tail varying from two, two and one-hali or three incles, must be added. The black furred tip of tail is less conspicuous. The animal is equally ferocious, and its small size enables it to enter openings apparently not exceeding one inch in diameter.

Second: Probably the best known amongst the weasel is the large, brown, chocolate, chestnut colored animal that inhabits the middle, northern, eastern and western states. Is found sparingly in the southern. states and Canada.

The body of this species measures ten to fourteen inches from nose to root of tail, the latter attaining a length of from four to eight and one-half inches, depending upon the maturity of the animal. The body is more cylindrical and plump, as compared with the first described species. Has an unusually long neck, and its tail (of variable length), attains a greater length as compared with either of the other two species. The ears are large, high, and orbicular. The legs are much stouter and its toes fairly covered with long, coarse hair over-lapping the claws. The habits of this species, like all others, is terrestrial, arboreal and not aquatic.

During the late spring, stmmer and fall months, the body is covered with rather a thin pelage of brown, chocolate or chestnut color with a somewhat lighter colored undergrowth of fur fibres. The belly portion, beginning with the under lip is of a yellowish cast, and this color extends to the inner portion of the legs. Quite often a white strip of fur is noticed extending from the lip, neck and chest, and terminating near the anus. At other times the under lip is covered with clear white pelage and the belly with the aforesaid yellow or whitish fur. The above described change in the animal's pelage is especially true of those inhabiting the extreme northern parts of the United States. The clear white pelage covers the entire bodv, head, limbs and tail, with the exception of the extreme pencil-like tip. It should be noted that not all the animals change their outer garment from the brown 
to the white color, especially in the middle section of this country where the climatic conditions are not as favorable as compared with the animals inhabiting the more northern part of the United States.

1 have seen and examined as many as three thousand skins in one season that more or less indicated the change from the white to the brown and the brown to the white fur, and at intervals examined hundreds of skins taken from animals during the winter months that failed to realize for the owner any remuneration, due to the predominating brown color, occasionally partly colored with intermingled white and brown guard hairs, and semibrown undergrowth of fur fibres. Only such skins having a clear white coat of fur, have any commercial value. These are sold as ermine skins, at a lower range of prices, though objections are plentiful. This species is easily distinguished by the furrier, due to its long tail and smallness of body as compared with the Siberian ermine.

On approach of cold weather, (October, November), the outer garment gradually changes from brown to the white ermine coat of fur, and by December or latter part of November the animal's outward appearance resembles that of the ermine.

Third: The last species, often called the "American Ermine" is found in the northern part of the United States, Canada, and Alaska. It resembles the Siberian ermine more closely than the other two species above described. (See article under Ermine.)

\section{General Descrip- tion and Habits.}

I know of no animal that is more courageous when size and ferocity is considered, than the weasel. It openly wages war upon many of the larger quadrupeds, and by its quickness, ferocity and deadly attack, causes dreadful ravages amongst them.

The body is extremely elongated and appears longer on account of its neck and head being of same circumference, and its ability to stretch its body, especially when seeking to enter small crevices of rocks, knot-holes, as well as other openings made by such animals as the mouse, rat or squirrel. The legs arc very short and thin, and the paws extremely tender, being covered with a hairy growth, and its toes are the possessors of sharp claws which are used to great advantage by the animal in climbing. It inhabits plains as well as mountains, and is known to roam in the forests where it seeks its principal food supply. Even the large muskrat falls prey to the little weasel, also moles and rabbits; is known to enter the chicken coop, killing as many as twenty-five birds in one night. It is ex- 
tremely fond of killing small animals and birds, not only for food purposes, but more so for pleasure. It possesses unusual courage and seemingly with unlimited daring and boldness, affronts large animals; is known to pounce upon sheep, calves and other domestic animals, who rid same off their backs with difficulty. No small animal possesses immunity from the weasel, but in its turn is also hunted and destroyed by the larger species of its tribe, such as the mink, marten and other carnivora.

Its favorite hold or bite is on the victim's neck, head or throat. Not only will the weasel or ermine lay in wait for a possible victim, but stealthily follow the tracks and pounce upon the victim's back, which, unaware of the danger, succumbs in a rather one-sided combat. It pursues birds of all kinds and it is common for hunters to disturb the animal while so occupied.

A certain European writer relates an instance where a large birdi of prey captured a weasel, and with it in its talons, rose in the air. In a few minutes, however, the bird began to show signs of uneasiness, rising rapidly in the air, or as quickly falling, and wheeling irregularly around, whilst it was evidently enceavoring to force some obnoxious thing from it with its feet. After a short, but sharp contest, the bird fell suddenly to the earth, not far from the observer who intently witnessed the interesting maneuver, and saw the weasel, apparently unhurt, scamper away. Upon examination he found that the weasel had severed a large blood vessel, also ate a big hole under the bird's wing.

The animal frequently visits nests located in the loftiest trees, in clefts and rocks, in search of eggs, young and old birds. Many a mother bird has lost her life in protecting her young, and often in such battle the weasel, in misjudgment of distance, weakness of branch or limb, and at other times due to the savage attack of the mother, is hurled to the earth.

The mother brings forth a litter of four to eight young at a time, which are born blind, and generally in a hollow tree or $\log$, under a pile of rocks or in some burrow, softly padded with hay, dry leaves and similar vegetation. If the young are in danger, the mother will carry them off in cat fashion to a place of safety and protects them with unusual courage, and if necessary, with her life. The mother loves her young dearly, who, like kittens are amusing and playful. An instance is recited where the mother sacrificed her life in protecting her young in a desperate encounter against a dog, who upon the close of the combat was bleeding furiously about the lip, head, ears and neck. At the age of twelve months the young have generally attained their maturity and the life of the animal is from six to ten years. 
One must accede to this animal a wider and more extended range of activity against a greater variety of objects; possessing persevering and enduring powers of chase, with a natural love of destructiveness, taking more life than is necessary for its actual wants. The great cats, who procure their food supply by particular mode of attack, their hunger being satisfied, quietly wait until again prompted by hunger. This is not so with the weasel or ermine. No animal or bird with insufficient strength or other powers of self defence, is beyond their ruthless and relentless pursuit. This enemy assails them not only on the ground, but under it, on trees, and some claim, in the water. Swift and sure of foot, keen of scent, he is able to track, run down his prey, and make the fatal spring upon them unawares; owing to litheness and slenderness of body he is able to follow the smaller animals through the intricacies of their hidden abodes and kill them in their homes. It is evident that if he does not kill simply in gratification of supreme bloodthirstiness, he at any rate deliberately kills more than is necessary for his requirements. His parallel cannot be found among the larger Carnivora. Yet which one of the larger animals will defend itself or its young at such hazardous risks? The physiognomy of the weasel will suffice to betray its character. The teeth are almost of the highest known raptorial character; the jaws are worked by enormous masses of muscles covering all the side of the skull. The forehead is low, the nose sharp, the eyes small, penetrating, cunning and glitter with an angry, green light. There is something peculiar, moreover, in the way that this fierce face surmounts a body extraordinarily wiry, lithe, and muscular. When the creature is glancing around, with the neck stretched up, and flat triangular head bent forward, swaying from one side to the other, we catch the likeness in a moment-the image of a serpent. 


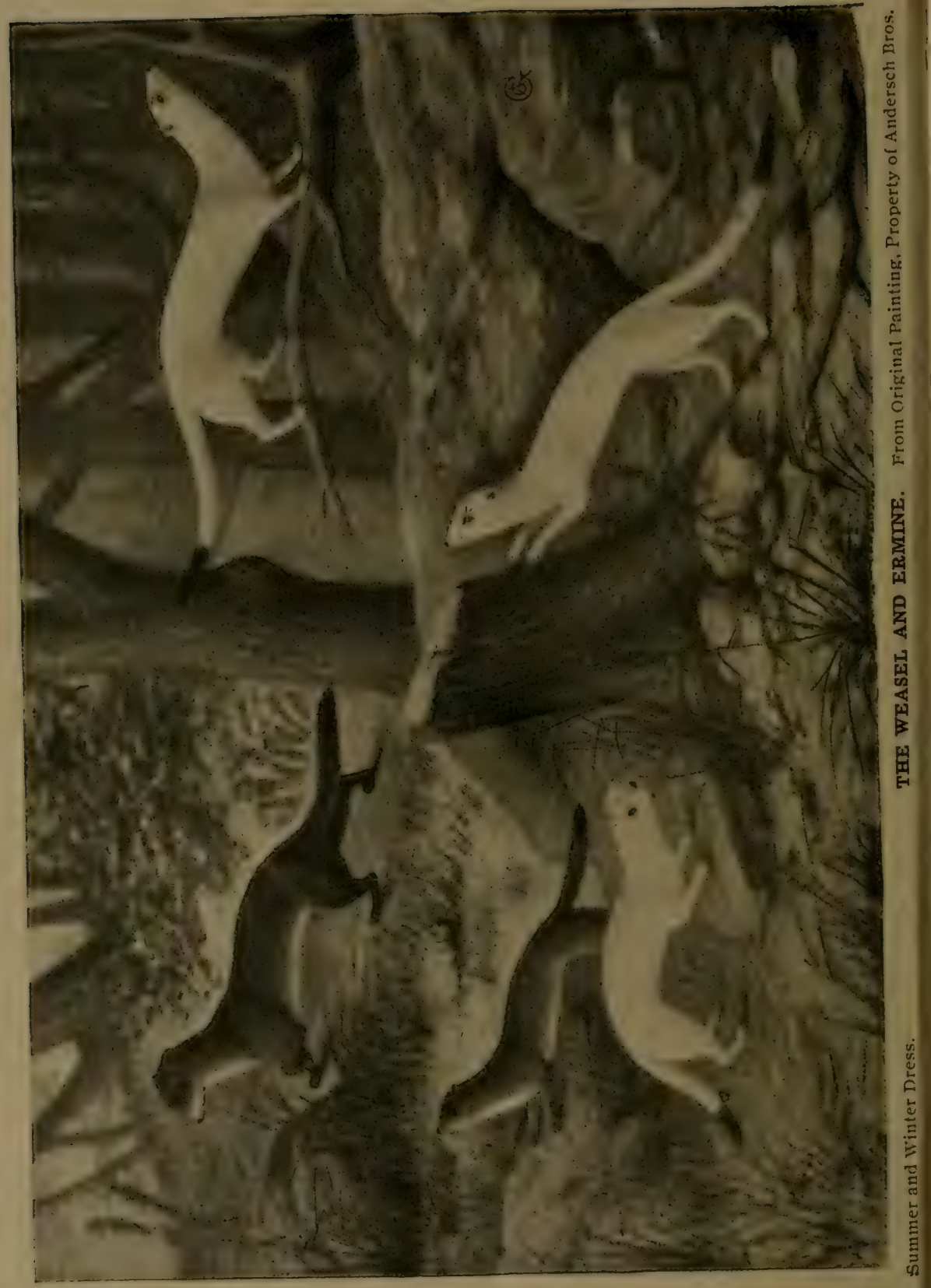




\section{THE NORTH AMERICAN ERMINE.}

\section{(White IVcasel. Ger. Hermelin, Sw. Hermelin, Eng. Stoat \& Ermine, Lat. Putorius Ermineai)}

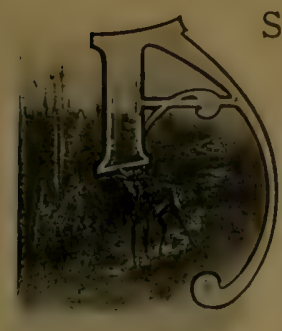

S STATED elsewhere, this animal resembles the Siberian Ermine very closely and there is no apparent good reason why the change in name from White Weasel to Ermine is improper from a commercial and scientific standpoint. Dr. Coues, after a thorough examination, heralds the change, and in his view we fully concur. The only difference noticeable is that the body is slightly smaller, the fur not as long, neither quite as silky. The peculiar sulphur-like yellow color is noticeable in all species of the erminea, also the pencil-like formation on tip of tail.

The animal does change its outer garment periodically but the change is not so sudden as certain authors relate. Bell states: "The winter change of color which this species so universally assumes in the northern climates is affected not by loss of the summer coat, and the substitution of the new one for the winter, but by the actual change of the color of the existing fur." Another prominent author states his views in the following words: "The transition from the summer to the winter colors, is primarily occasioned by actual change of temperature, and not by the mere advance of the season." Mr. Blyth, commenting upon the above two assertions, has the following to say: "Authors are wrong in what they have advanced respecting the mode in which this animal changes its color, at least in autumn; for in a specimen which I lately examined, which was killed during the autumnal change, it was clearly perceivable that the white hairs were all new, not the brown changed in color."

Close observation of the animal and more so in the handling of thousands of skins from animals killed at different periods of the year, give one the opinion that the animal changes, rather sheds, its coat twice a year. In autumn, September and November, varying somewhat in the different latitudes, the summer hair, gradually, almost imperceptibly, drops out, and is immediately succeeded by a fresh coat. which in the course of ten to twenty days becomes white. In the spring months the change in color is just the opposite. The change is natural, not only from the outward appearance, but also from the flesh part of the skin. The inner part of the skin, after all flesh and fat is removed and 
becomes dry, has the natural white and prime color. The skin is thin and clear, not so when the skin is removed from the animal during its shedding period in the spring, at which period the outer portion of the skin is black and unprime. At this period the new fur fibers are still perceptible and the old guard or outer hairs are loose in their respective cells. Subsequently the change in color of this animal's fur comes in periods when other animals shed their outer garment to a greater or less extent.

The male is invariably larger than the female. Both are provided with glands from which the animal when under the influence of fear, anger or sexual passion, emits a peculiar fluid of a highly penetrating, offensive and horrible odor. In color the fluid is yellow, and it is believed that this fluid is responsible for the yellowish, sulphur-like color of the pelt. Others again state positively that this peculiar color on the fur is the result of the animal's unclean habits, abode, and continued contact with their own or the mate's water. The fluid containers or glands are situated one on each side of the anus just upon the verge of the opening. On the animal slightly averting the antus, these papillae may be readily perceived. Slight pressure will cause them to stand erect, and at the animal's pleasure may squirt and distribute its fluid in a firm spray at a variable distance not exceeding two feet. At other times the fluid trickles in drops or in a strean about its parts.

The average measurement of skins received from Canada and northern part of United States indicate that the body of the largest animal is 15 inches in length and the yearlings about 8 to 9 inches. Many skins are received indicating that they were taken off from kittens measuring 5 to 6 inches in length and $3 / 4$ to $I$ inch in width. The large skins usually measure I3 to I5 inches long, $2^{1 / 2}$ to $3^{1} / 2$ wide. The length of tail, varying somewhat, is usually 2 to 4 inches. Once in a great while a clear white skin with a longer tail, is received, but presumably this is an exception, and possibly the animal emigrated from a more southern latitude. A large number of brown skins (summer) from the same region received during the late spring and summer months, are practically of the same size and dimensions. See illustrations of skins elsewhere in this volume, also article "Trapping and Preparing Skins."

This animal as well as the weasel, shows no sign of becoming exterminated. Higher prices for their pelts has a tendency to increase the activity $n n$ the part of the hunter and trapper in pursuing same, as will be seen in the table of number of skins marketed in this country and London. In former years the ermine fur was controlled by royalty, and certain penalties by 
law were attached to outside persons wearing garments made from these skins, but of late years, owing to the large number marketed, and from other causes, the skins are used for various purposes and by all classes of people, not only in Europe, but also in the United States and Canada.

The price of the skins varies considerably, depending upon the demand and supply. The skins of the European ermine ranges from $50 \mathrm{c}$ to $\$ 2.50$ while that of the American species including the white northern weasel, very seldom exceeds $\$ 1$. O and in most cases 25 to 75 cents being paid the trapper. The last two years however, are an exception, and the ruling price for good skins ranged from 75 cents to $\$ 1.25$, one American concern alone marketing in London 60,000 skins.

The skins are used for various purposes, principally for ladies. wearing apparel, on royal clothes and garments, at other times in connection with other furs, principally with krimmer, Persian lamb, seal, etc. The yellowish, sulphur-like parts are used in conjunction with the black pencil-like tip of the tail. Manufacturers dislike the sulphur-like color on the skins; such skins are commercially called "stained" and bring a less price than those that are clear white. (For mode of propagation and habits, see article under Weasel.)

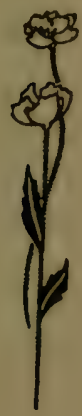




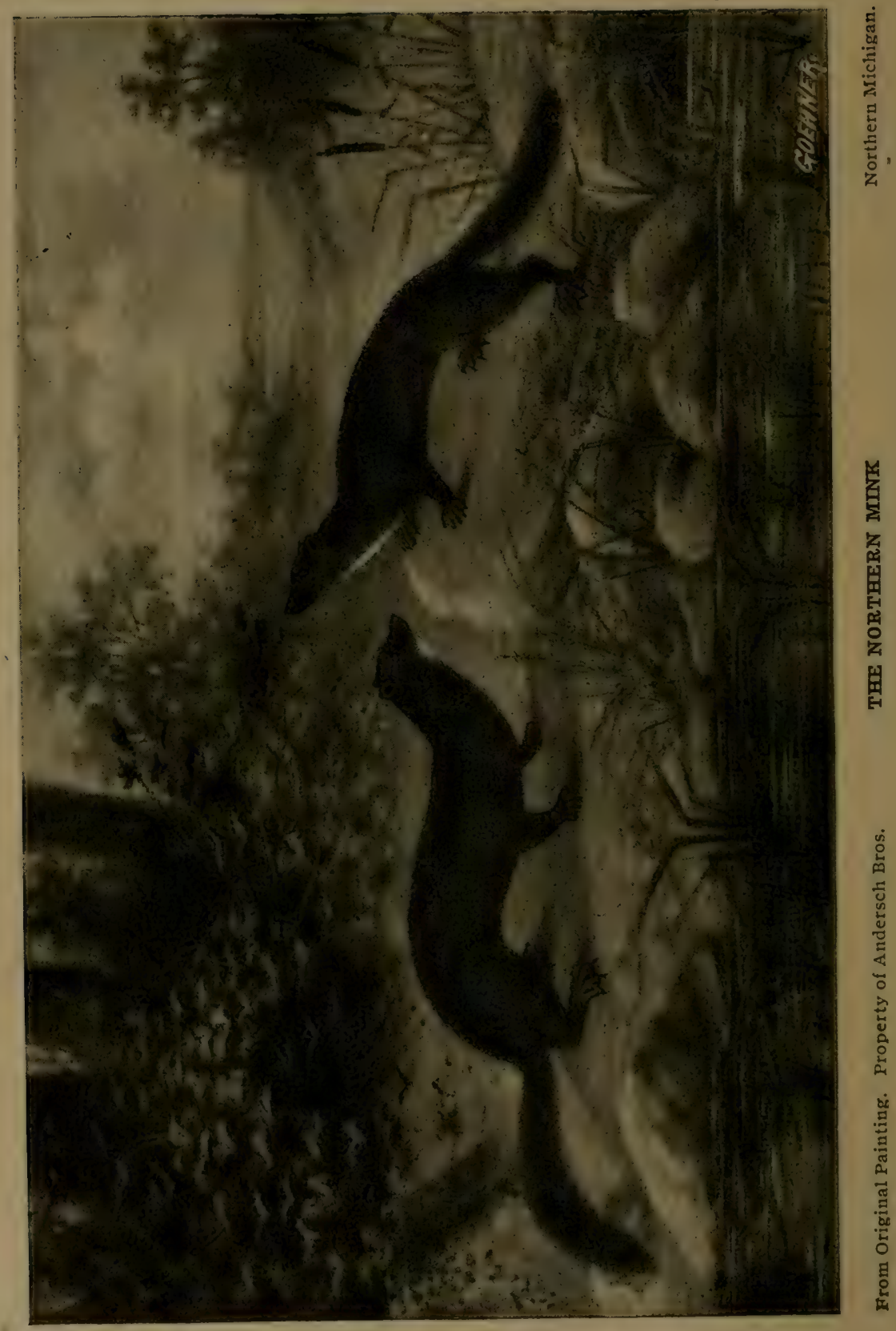




\title{
THE MINK.
}

\author{
(Ger. Nertz, Lat. Putorius (Lutreola) vison.)
}

T IS not commonly known that mink and skunk are now the greatest producers of revenue to the American hunter and trapper; the reader can judge for himself, especially after perusing the table on a subsequent page, which gives the number of skins marketed in a given period.

The mink belongs to the weasel family anci is found in North America, Europe and Asia. Naturalists divide the North American mink into two, sometimes into three, separate species, but I believe that there is no good occasion to make such division. If same is desirable from a descriptive and scientific point of view there can easily be made as many as two or three divisions of animals in a single state, and probably twenty or thirty in the entire northern hemisphere. Thu fur trade has its own division, for instance: Southern, Southwestern, Central, Eastern, Northern, Fish, Prairie, Cotton and the fine. Northeastern and Canadian.

Description. This animal differs notably from the weasel or ermine in its larger size, much stouter form, and lasting color of its pelage. It resembles the marten, also the wild ferret. The ears are short, well rounded, furred both sides, and the adjacent fur covers members in certain altitudes. The head is small, rather low and flat, sub-triangular, with a rather well rounded otter like mouth. The lower portion of its mouth is small. The extremity of the snout is protuberant and definitely naked.

Its legs are stout, short, and well proportioned. The front legs measure $13 / 4$ to $21 / 4$ inches in length, the rear ones always exceeding the front by $1 / 2$ to $3 / 4$ inches. Each of the four feet have five rather long toes, which are armed with short, crooked claws. The legs and feet, excepting the pads, are covered with fur. The claws are retractable at will by the animal. The body is long, slender, and with its slender neck has a general vermiform appearance, and measures from nose to root of tail i2 to 26 inches in length, to which a tail of 6 to 9 inches is to be added. The above variation in size is further explained elsewhere. The male always exceeds the female by $I / 4$ to I- 3 its size.

Its pelage varies extensively in color, length, quality, and density, according to the section the animal inhabits, but the fundmmental color is brown. The further south one goes, the coat of the animal becomes paler, while just the opposite is true 
in the rorthern latitudes. The tail is always a few shades darker than the fur on the body and invariably is this also true of the animal's back as compared with the fur on its belly. A white spot is common on the animal's breast, other times this spot appears only on the lower lip. Once in a while a mink will have a few white hairs on the extreme tip of its tail, otherwise the color of its pelage is fairly uniform.

The outer garment consists of two distinct sets of fibers, the inner or undergrowth of fur fibers proper, and the outer or guard hairs. The former are soft, silky, downy, adhering very closely together, and in color are usually lighter than the predominating guard hairs. While the former are $3 / 8$ to $1 / 2$ inch long, the latter always protrude $1 / 4$ to $3 / 8$ of an inch above the undergrowth, consequently $3 / 4$ to $\mathrm{I} / 4$ inches long. The guard hairs are coarse, smooth, glossy, rather pointed and well distributed all over the body, becoming shorter about the head and feet and longer at the tail; on the latter the hairs are inclined to stand out horizontally, giving it a bushy appearance.

These are found in all parts of the southern states.

Mink. tail 6 to 8 inches in length. Its fur is rather coarse, especially is this true of the lower growth. The guard hairs are also coarse and comparatively pale and void of lustre.

Southwestern Mink.

Are found in these states along rivers, creeks and lakes. Are about the same in size as the more southern species, but are better furred, more robust, and their skins always command a better price from the dealer and furrier. The fur is more dense and of better color and larger individual specimens are also noticeable.

Northeastern

Mink.

The animal that inhabits Maine, New Brunswick, parts of Quebec and that particular section, is comparatively small. The body is ro to I4 inches, with a tail 5 to 6 inches long. The fur during the latter part of December and January is extremely beautiful. The rarest, best and highest priced skins come from that section, especially when its small size is considered. The fur is soft, silky, not so deep or long, but very dark, rather of the wavy and changeable color type.

Prairie

Mink.

As the name indicates, the animal is found chiefly in prairie sections, about streams or in light growth of timber. He becomes very large in northern states, notably so in Dakota and Manitoba. While the ordinary size of the prairie mink, especially those inhabiting the open sections of the middle west, and west, is from 22 to 30 inches, the writer has seen minks and their skins measuring 32 to 36 inches from 
nose to root of tail, and with the latter a total of 43 inches over all. The animal and skin, while extraordinarily long, were othe. wise well proportioned. The former in a natural position at middle of body measured 12 to $12 \mathrm{I} / 2$ inches in circumference and $3 \mathrm{I} / 2$ to 4 inches in diameter, the skin averaging in width from shoulder to rear portion, $4 \frac{1}{2}$ to 5 inches. The pelage of this species is somewhat coarse, but of fair color and very suitable for coat collars, cuffs, etc. Under no circumstances must the pelage of the prairie mink be compared with southern coarse mink, as these northern skins are worth twice to three times as much. The female is much smaller than the male, and has a more valued coat, being finer in texture and darker in color.

Fish These attain an average size, are more aquatic, live in Mink. and about water more than other species and their food consists chiefly of fish. The fur is more evenly distributed, the outer guard hairs protrude less over the fur fibres or lower growth, as is the case with the other species. In general the fur is more sleek, top hairs shorter and all are of more uniform color, in this respect resembling a lot of dark, brown, glazed coffee beans. The odor of the animal is constantly that of fish and seemingly this odor remains in the skin for a long time.

Cotton It is claimed that the white underground species is

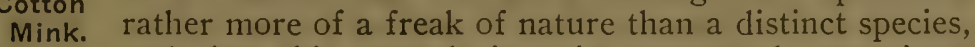
and that this growth is quite unnatural, sometimes caused by sickness, other times by confinement. Some naturalists seem to think that this peculiar color crops out at intervals, and for explanation go back generations when it was claimed that there were no mink, but ermine, and that in the ages of evolution as explained by Darwin, such are the reminders of the changes that were brought about in the natural course of evolution. Such minks are found sparingly in the central, western and middle states. Apparently the theory that this species is more of a freak, must give room for additional thought, as hundreds and thousands of skins are annually marketed showing these particular characteristics. The general construction of its body, size, habits, etc., resembles the other minks. It does not breed separately, but in connection with the regular species, thus indicating harmony amongst them. The outer garment is f ractically the same as on other species, and the only difference noticeable is that instead of having brown or dark colored fur fibres, its undergrowth of fur resembles cotton, being clear white. Occasionally this white cotton like growth is noticeable only on sections of the skin, particularly on the top of the animal extending 4 to 6 inches from the root of its tail, other parts having the normal color. On account of the animal resembling the other very closely, 
hundreds of trappers are annually disappointed, being obliged to accept a lesser price for such skins; many unexperienced buyers purchase these skins without knowing the difference until they come to sell them. The easiest way to detect these cotton or white underground mink, is by blowing into the fur at various places, especially just beyond the tail. Such skins cannot be used advantageously in their natural condition and are either dyed or blended.

Habits. The mink is very active, light of foot, carnivorous, and its essential aquatic nature leads it to seek in general well-ivatered sections; will scarcely ever be found far away from water except it be caught during the journey it makes from one stream or lake to another. Its amphibious mode of liie is well known to all hunters, trappers and those that come in contact with this carnivora. His movement on land lacks something of the extraordinary agility displayed by the more slender bodied weasel. It habitually prowls about stone piles, frequents underground retreats, and is altogether a more openly aggressive marauder, not less persistent or courageous in its attack. In swimming most of its body is submerged and in smooth water its coming and going is almost imperceptible. Its ability to climb trees is unquestioned; it scarcely frequents them but will take to the tree if it thinks its capture can be averted.

Its keen sense of smell enables it to track and trace other animals, consequently is less concerned for a fresh supply of food than most other animals. Its principal food is fish, frogs, reptiles, muskrats, mice, and rats; birds and fowls of all kinds are relished. Much to the detriment of the farmer, it frequents the hen roost, but in this respect it is not as much an unnecessary slayer as the weasel or ermine, though instances are recorded where as many as forty chickens were killed by a single mink in one night. Its ability to gain entrance through openings of $I / 2$ to 2 inches in diameter, is well noted, and in the event that the opening is too small, it can increase it in a remarkably short time. The male and the female can at their pleasure, emit from their respective glands a horrible smelling odor. For further description of this fluid and manner of discharge, see article under Weasel.

The rutting season usually begins in latter part of February or first part of March. At this time the male wanders carelessly along the shore of streams and lakes, having in mind only the search for the female. Apparently the male is on foot day and night and during this period is more easily trapped. The female is scarcely seen at this time being in some abode, obviously to keep away from the male as much as possible. 
During the month of April, or early part of May, the mother brings forth a litter of four to six young, which are carefully hidden in some hollow $\log$, burrow or cave. The mother continues with her young until they are about half-grown, and pays particular attention to keeping them away from the male, who, if opportunity presents, will kill its offspring. The animal attains its maturity in one year, the female arriving at age of puterty at the end of this period. The young are born blind and remain so for four or five weeks.

Mink can be tamed if taken young, especially before they have their sight. It is unwise to attempt to tame the animal after the age of three to six months, and especially if he or she is of a vicious disposition. If taken young, by continued petting and handling, they become like domesticated ratters and have all the playfulness of young kittens. At a later period they become extremely mischievous as their keen scent leads them to pantries, hen houses, dovecotes, and a canary bird in a room is very annoying to them. The animal's extensive power with the mouth can hardly be estimated unless one has seen the animal in a trap, cage, box or other place of captivity. When wild minks are confined with tame ones, the latter always prove stronger and come off victorious in the contest that ensues.

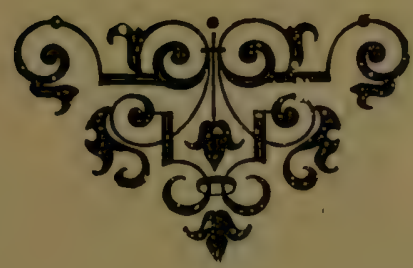




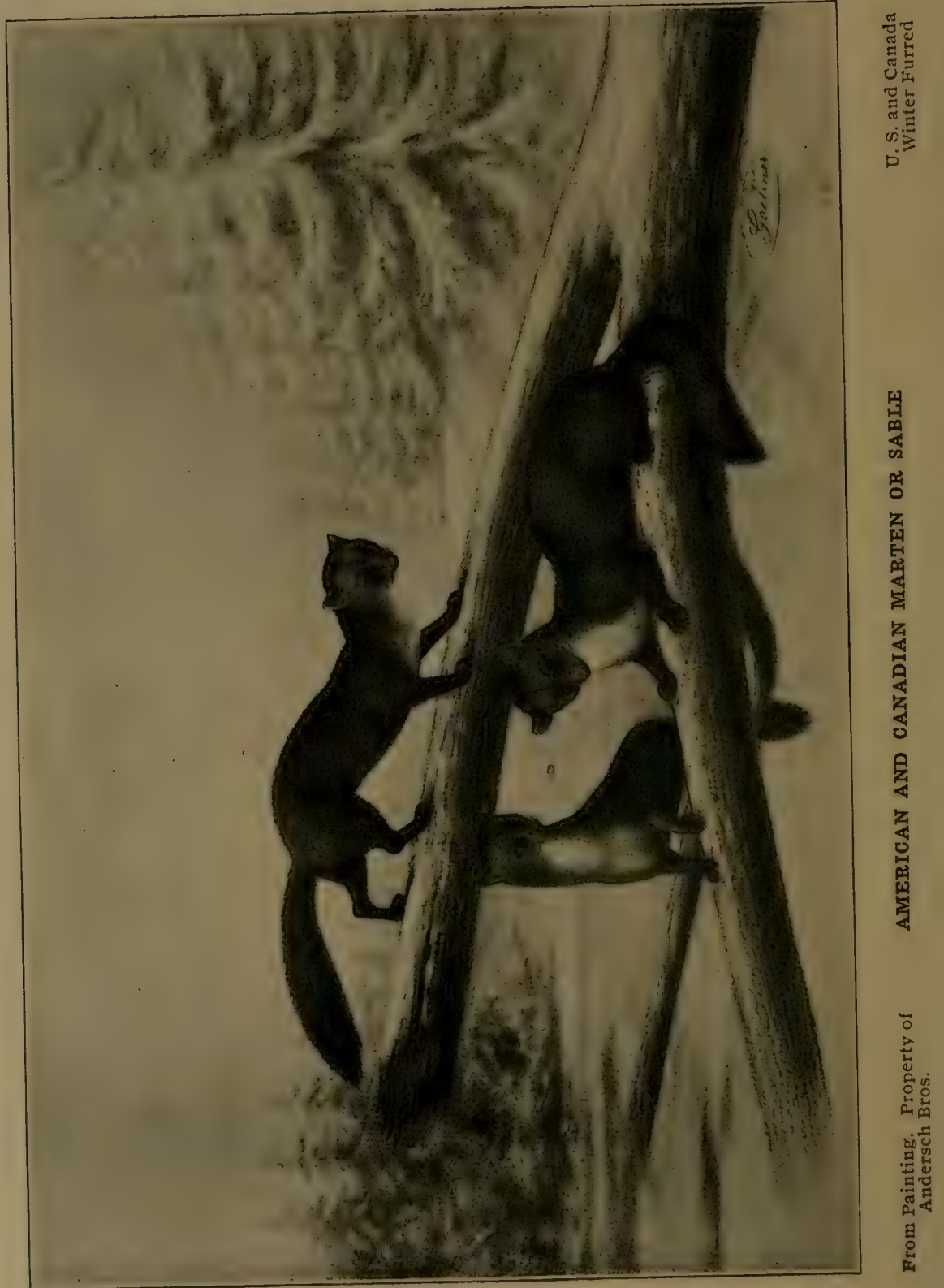




\section{THE MARTEN.}

(Ger. Marder, Lat. Mustela Americana.)

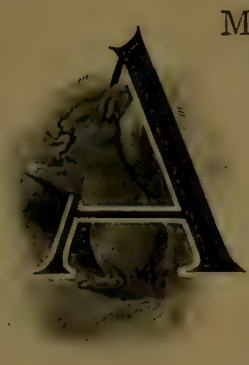

MONGST the fur bearing animals of the weasel kind, the marten with its various species, is most important, especially since their skins command high prices and ready sale. In all zoological works the martens oscillate with the sable. The latter, however, is simply a large marten found in higher latitudes.

The Beach, or Stone marten, which inhabits Europe, is distinguished from the Pine marten by its pure and large, white furred throat, also by its other external features and size.

The Pine marten of Europe resembles the American marten, but in that country like in the New World, marked contrast and difference between animals from one, to that of another section, occur. Thus the marten from Scandinavia differs in size and color, but not in habits, from that found in Germany, Austria, Spain and Italy. The former is large in stature, its pelage is finer, darker, denser, and in general, longer.

The sable, or Asiatic species, as the name implies, is found in Russia and northerly portions of islands belonging to Japan; also equally large and similar furred animals are found in the extreme portions of North America, but these receive a sectional name and are commercially known as Hudson Bay sable. The fur of the sable as compared with the marten, has a mellow character, is darker, longer, finer in texture, the skin larger and more beautiful and for that reason commands a much higher price.

The Russian sable measures in body 20 to 24 inches from nose to root of tail and the latter from body to extreme tip, 10 to 12 inches. Some individual hairs on the tail are 3 to 4 inches long. The latter are very glossy, dark brown or black and invariably three to four shades darker than the fur on the body.

The American marten in respect to size, resembles the European Pine marten. The animal inhabits the northerly Atlantic, as well as the Pacific states, is found in mountainous regions, principally in forests, in the latitudes extending from Maine to Oregon, although its existence in the middle states as far south as Pennsylvania and Ohio, Colorado and Wyoming, is, and has been established; but of late years most of the skins have been received from Canada where the animal is still plentiful. Beautiful, as well as high-priced skins are received from Maine, Lake Superior, region around Lake of the Woods, Northern Minnesota, Michigan, 
IVisconsin, and notably from the St. Lawrence River and Hudson Bay region, also along the Canadian Pacific Railway from Selkirk to. Port Arthur.

The color of the skins from Montana, Washington, Wyoming, Oregon, and extending along the Pacific coast, up ti Alaska, excluding the extreme northern or inland portions, are geucrally of a canary or light brown, intermingled with steel-like colored hairs. Similar colored skins are also received from different sections, which are all dyed to imitate the darker kinds, but in this state are readily distinguished by the manufacturer who fails to pay the same price he would for the beautiful natural colored skins.

The color of the American marten during the winter months is almost indescribable, due to the endless diversities occasioned by age, sex, season and climatic conditions. Its fur is long, extremely soft and full. It can be divided into three kind of fibres; the first is very short, fine, soft and downy; the second about the same, but in addition wavy, $1 / 4$ to $1 / 2$ inch longer, and becomes noticeable from the outside; the third represents the long, beautiful outer or guard hairs. These are fully twice as long as those on the mink. The predominating color of fur ranges from a light canary, orange, light brown, dark brown, dark and almost black, excepting the fur on the throat, which is rather yellowish or clear white. The legs are short and covered with black fur. The tail seems bushy and that member is very valuable in the fur trade.

Habits. The American marten, like the sable has carnivorous and arboreal habits; its home is in the forests, scarcely ever found in open sections and being of a sly and suspicous nature it is one of the first to disappear, amongst the smaller animals, with the advance of civilization entering it's woody resorts. Mr. Ross has recorded a remarkable fact of the animal's periodical disappearance. "It occurs in decades or thereabouts with regularity, and it is quite uncommon what becomes of them. They are not found dead. The failure extends throughout the Hudson Bay section at the same time, and there is no tract or region to which they migrate where we have not posts, or into which our hunters have not penetrated."

Making its home away from civilization, it is not guilty of invading the farmyard, but otherwise is very active, industrinus, cunning and predaceous, and finds its subsistance in the weaker rodents, mice, moles, insects, squirrels, frogs, birds and fish. If forced by hunger wili eat nuts and berries.

Its odor is mild as compared with the musk of the mink or ermine. It rarely kills after its hunger is appeased, nor does 
a blind ferocity lead t to attack animals larger than itself.

The mother brings forth a litter of three, seldom exceeding six, young, which she nourishes for some time, and Steller says that the mother will readily protect them from the male by carrying them out of danger in her mouth cat-fashion, usually to some crevice or hole in the bank of a hill, the opening of which she closes with her body and presents the intruder with a ferocious look.

\section{THE FISHER.}

(Pennants, Marten, Pekan, Lat. Mustcla Pennants.)

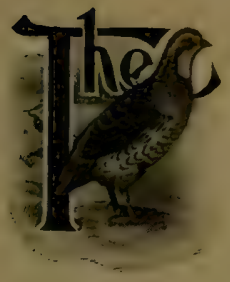

FISHER is strictly a North American animal, and naturalists claim that he forms the connecting link between the Mustela and Gula. He is rated as belonging to the weasel family, of which, with the exception of the wolverene, he is the largest and strongest of the entire species. The scarcity of the animal can be noted by reviewing the table found elsewhere in this volume. They are chiefly found in Canadian timber sections, are very scarce in the heavily timbered sections of the northern states. A few skins are annually received from the timbered sections of Washington, Oregon, Montana, Minnesota, Wisconsin and Michigan, but as above noted, the animal is chiefly found in Canada. It weighs from 12 to 16 pounds.

In his habits he resembles the marten, being arboreal, carnivorous, and occasionally seen in the early morning or later in the afternoon, preying after small animals, but as a rule the fisher possesses nocturnal habits. He is known to rob traps of their victims, and is occasionally nipped himself. They are scarcely ever seen in open sections, but like the marten live in forests and away from civilization.

The specimens before us now indicate that the animal measures 24 to 30 inches from tip of nose to root of tail, the latter measuring 14 to 19 inches, the tail in the largest specimen measuring $16^{1 / 2} \cdot{ }^{\cdot}$ inches, in the smallest $13^{1 / 4}$ inches. Its black furred legs are stout and on the largest specimen 4 to 5 inches long.

In color the pelage varies unusually much, and each individual skin viewed, indicates a variation from light steel grey on the head and fore part of the body, terminating and blending into a rich brown, nicely topped with long black guard hairs. The 
long slender tail is considerably darker furred. The undergrowth or fur fibres are shorter by $1 / 4$ to $3 / 4$ of an inch, as compared with the top guard hairs, which are much coarser but gradually become more pointed at the tip. The nature of the fur is mellow and soft, and furriers say that it works up handsomely.

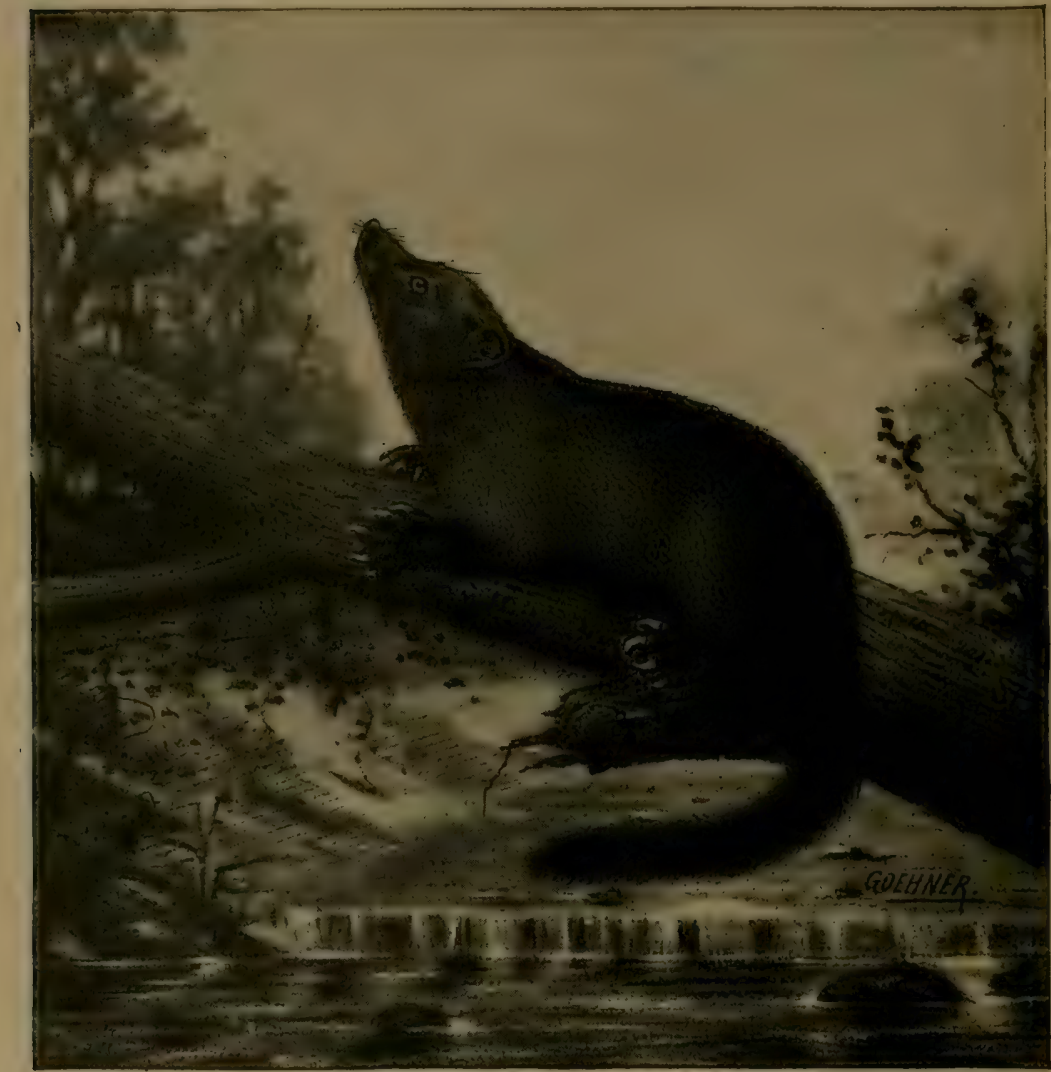

From Original Painting. Property of Andersch Bros.

The following account from B. R. Ross, covering his experience in the Mackenzie River region (Canada), is interesting: "In this district it (the fisher) is not found except in the vicinity of Fort Resolution, which may be considered as its northern limit. In the numerous deltas of the mouth of the Slave 
River it is abunlant, frequenting the large grassy marshes or prairies, for the purpose of catching mice, its principal food. In appearance it bears a strong family likeness to both the marten and the wolverene. Its general shape assimilates more to the former, but the head and ears have a greater similitude to those of the latter. It is named by the Chippewayan Indians 'Tha cho' or great marten. Its legs and feet are stouter in proportion than those of the marten, and its claws much stronger. In color and size it varies greatly. Young, full-furred specimens, or those born the previous spring, can scarcely be distinguished from a large marten except by a darker pelage and a less full, moré pointed tail. As it advances toward old age, the color of the fur grows lighter, the long hairs become coarser, and the grayish markings are of greater extent and more conspicuous.

"The largest fisher which I have seen was killed by myself on the Rivier de Argent, one of the channels of the mouth of the Slave River, about I5 miles from Fort Resolution. It was fully as long as a Fulvus fox, much more muscular, and weighed I8 pounds. In the color of its fur the greyish tints predominated, extending from half way down the back to the nose. The fur was comparatively coarse; though thick and full. The tail was long and pointed, and the whole shade of the pelage was very light and had rather a faded look. Its claws were very strong and of brown color; and as if to mark its extreme old age the teeth were a good deal worn and very much decayed. I caught it with difficulty. For about two weeks it had been infesting my marten road, tearing down the traps and devouring the bait. So I resolved to destroy it. I made a strong wooden trap. It climbed up this, entered from above, and ate the meat. A gun was next set with no better success, it cut the line and run off with the bone that was tied to the end of it. As a 'dernier resort' I put a steel trap in the middle of the road, covered it carefully, and set a bait at some distance on each side. Into this it tumbled. From the size of its footprints my impression all along was that it was a small wolverine that was annoying me, and I was surprised to find it to be a fisher. It showed good fight, hissed at me much like an enraged cat, biting at the iron trap, and snapping at my legs. A blow on the nose turned it over, when I completed its death by compressing the heart with my foot until it ceased to beat. The skin when stretched for drying was fully as large as a middle-sized otter, and very strong, in this respect resembling that of wolverene.

"In their habits the fishers resemble the martens. Their food is much the same, but they do not seem to keep so generally in the woods. They are not so nocturnal in their wanderings as the 
foxes. An old fisher is nearly as great an infliction to a marten trapper as a wolverene. It is an exceedingly powerful animal for its size, and will tear down the wooden traps with ease. Its regularity in visiting them is exemplary. In one quality however it is superior to the wolverene, which is that it leaves the sticks of the traps where they were planted; while the other beast if it can discover nothing better to hide, will cache them some distance off. It prefers meat to fish, is not very cunning, and is caught without difficulty in the steel trap."

Habits. Its habits, as will be noticed, are arboreal, carnivorous and nocturnal. It is liberally claimed that the animal, as its name implies, is an expert fisher, but this is again forcibly contradicted. One trapper claims that the fisher will crouch down with head slightly in the water and lie in wait for the swift pickerel or trout three to five hours at a time, seemingly without moving a muscle. Its favorite position as claimed by this trapper, is on a fallen log across a brook or stream on a bank where the water is shaded by willows. Nevertheless all agree that one of his principal articles of diet is fish, notably the speckled Mountain trout.

The breeding season is in the early spring, and the female brings forth a litter of 3 to 5 young, which are kept away from the male until they are able to defend themselves and live upon their own resources. Strange to say the father will kill his offspring and for that reason the mother takes the young to snme isolated place and protects them against all foes, and readily risks her life to protect the young from all intruders.

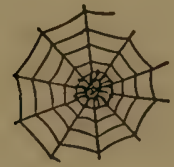




\section{THE WOLVERENE.}

(Ger. Viclfrass, Fr. Glouton, Eng. Ghutton, Lat. Gulo luscus.)

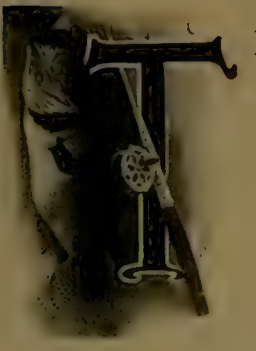

HIS carnivorous animal, the clumsiest of the marten or weasel species, is known under various names, and its nomenclature may be interesting as well as amusing to the average hunter and trapper: Latin-Gulo antiquorum, Murtela rufo-fusca, Medio dorsi nigro, Murtela gulo, Ursùs gulo, Meles gulo, Taxus gulo, Gulo sibircus, Gulo arcticus, Gulo volgaris, Gulo $\mathrm{Cu}-$ curis; Russian-Rossamaka, Rossamack, Rosomak; German-Vielfrass, Vielfras; DutchVeelvraat; French-Goulon, Glouton; EnglishGlutton; Norwegian-Jerf, Jerv, Filfras; Swedish-Jarf, Jerf, Filfrass; Laplander-Gieddk; American and Canadian-Wolverene, Carcajou; Indian-Okeeroohawgew, Okeecockwgees, Oueequehatch.

It inhabits the whole of British possessions in North America, is sparingly found in the United States, but has been known and still exists in some of the Northern States from the Atlantic to the Pacific Coast, especially in the regions of the Rocky Mountains. Has formerly been seen and was captured in Maine, Masschusetts, very recently in Michigan, Wisconsin and Minnesota, and in the Rocky Mountain regions of Wyoming and Montana; and specimens are still in existence showing that it inhabited to a greater or less extent the states of Utah and Colorado. Very few skins are now received from the northern states and the supply principally comes from Canada. The European species, which is still in existence, resembles that of the American to a great extent.

The wolverene is a night prowler and makes his home in burrows, hollow logs and crevices of rocks; often he partakes of sleep in dens of foxes as well as former dens of wolves, and, in fact, seeks rest and sleep wherever it may be found.

Its principal food is mice, rabbits, mink, marten and similar animals. It follows the wolf and the fox in the hope of obtaining a portion of their prey. Is known to climb low-limbed trees from which it pounces upon its prey, and succeeds in a remarkably short time in subduing its victims. It then proceeds to devour the body, and what it cannot consume is carried away and hidden below the surface of the ground or snow. It is particularly 
known to follow lines of traps for many miles, partaking of the bait and victim, and even if unable to devour the food so found, it will delight to break into the traps or spring them as the case may be.

The wolverene is very seldom captured; is known to enter the

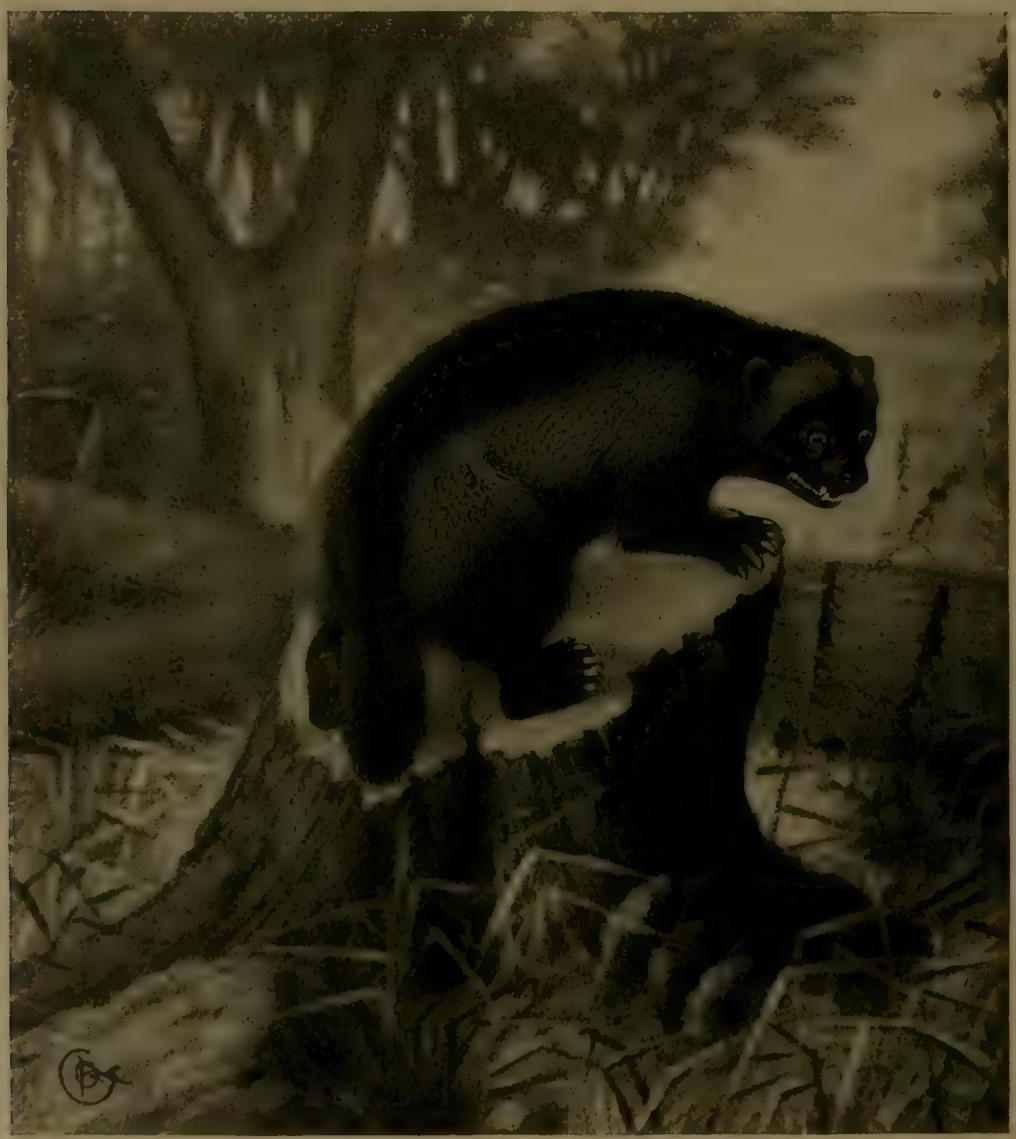

Fastern Canada Full Furred.

THE WOLVERENE

From Original Painting Property of Andersch Bros.

huts of the Laplander and to carry away frying pans, ammunition and similar articles, which it buries, and in consequence thereof is a dreaded animal, being detested by the hunter and trapper as well as the inhabitants of the extreme north. Is known to prey upon beaver and otter. Historians greatly exaggerate the con- 
sumption of food as well as the tricks and mischief which are laid at its door.

The following story from Mr. Lockhart may be very interesting :- "The winter I passed at Fort Simpson," writes Mr. Lockhart, "I had a line of marten and fox traps, and lynx snares, extending as far as Lac de Brochet. Visiting them on one occasion I found a lynx alive in one of my snares; and being indisposed to carry it so far home, determined to kill and skin it before it should freeze. But how to cache the skin until my return? This was a serious question, for carcajou were numerous. Placing the carcass as a decoy in a clump of willows at one side of the path, I went some distance on the opposite, dug a hole with my snow shoe about three feet deep in the snow, packing the snow hard down after packing the skin in the smallest compass and putting it in the bottom of the hole which I filled up again very carefully, and then strewing loose snow over the surface till the spot looked as if it had never been disturbed. I also strewed blood and entrails in the path and around the willows. Returning next morning I found that the carcass was gone, as I expected, but that the place where the skin was cached was apparently undisturbed. 'Ah, you rascal,' said I, addressing aloud the absent carcajou, 'I have outwitted you for once.' I lighted my pipe and proceeded leisurely to dig up the skin to place in my muskimoot. I went clear down to the ground, on this side and on that, but no lynx skin was there. The carcajou had been before me, and had carried it off along with the carcass; but he had taken the pains to fill up the hole again and make everything as smooth as before."

Mr. Lockhart also relates that the wolverene habitually sits on his haunches and shades his eyes with one of his fore paws, just as a human being would do in scrutinizing a dim or distant object. On one occasion he was drifting down stream in a canoe, and came within a short distance of one of the animals on the bank; it stopped on perceiving him, squatted on its haunches, and peered earnestly at the advancing boat, holding one fore paw over its eyes in the manner above described. Not seeming to take alarm, it proceeded on a few paces, and then stopped to repeat the performance, when Mr. Lockhart, now sufficiently near, fired and killed the beast.

At times the wolverene displays more boldness than this in the presence of man. It has been known to seize upon the carcass of a deer, and suffer itself to be shot rather than relinquish possession, though the hunter had approached within twenty yards of his game. When pressed by the pangs of hunger, still bolder 
exploits are sometimes performed, as in the instance narrated by Capt. J. C. Ross. In the dead of an Arctic winter, his ship's company were surprised by a visit from a wolverene, which clambered over the snow wall surrounding the vessel, and came boldly on deck among the men. Forgetful of its safety in the extremity of its need for food, the animal seized a canister of meat, and suffered himself to be noosed while eating.

The animal is of great strength, but lacks activity of body, being heavily and clumsily supported on thick-set, rather low legs and rests upon large feet. The animal resembles that of a small bear. The palms and soles are generally furred, but the digits are naked. The back is high and arched, the figure in general, drooping both before and behind, the head and tail being carried low while in locomotion, similar to a bear. The head is broad and rounded on every side, with a rather short, stubby nose, low ears, and eyes sunk rather deeply into the skull.

On the body the fur is of a blackish, deep dusky brown color. The length of the fibers beginning at the extremities where they are very short, gradually increase to $31 / 2$ to 4 inches on the sides and hips, thus giving the well-known shaggy appearance of the animal. There is a light grey patch between the ears and eyes which is extended from the shoulders on both sides and forms the ruff or shaggy aspect heretofore noted. The two broad bands on the animal's sides are occasioned by the variation in color, being of a chestnut or yellowish brown, or even fading to a dingy brownish white, starting at the shoulders and running along the sides and turning up, meeting its fellow on the rump near the base of the tail and forming a rather indistinct lyre-like connection. The claws are sharp, strong, much curved, and about an inch long. The tail resembles more that of the badger, excepting that it is twice as long; the hairs on this member are from five to seven inches long, rather coarse, and the entire member is of a brushy instead of a plume-like appearance.

The fur is used for various purposes and owing to its scarcity brings fairly high prices, but the principal use is for robe or mat purposes. The total number of skins annually collected and marketed rarely exceed 3,000 , one-half of which are marketed by the Hudson Bay Company, at London. The price varies considerably as the darker skins bring much better prices, generally from $\$ 3.00$ to $\$ 10.00$. 
Andersch Bros.' Hunters and Trappers Guide.

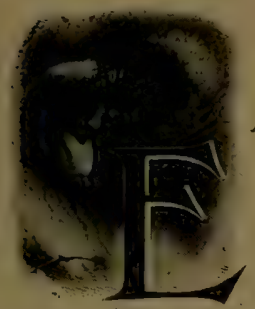

\section{THE SKUNK.}

ARLY historians, naturalists and travelers, pointed to the American skunk as the most detested animal on the face of the globe, and many are even to this day so deeply impressed with the distant horrible experiences that he or she will refuse to wear a manufactured garment made out of skunk skins, and the manufacturer is obliged to call the skins from which the garment is made "Black Mlarten." Thirty and forty years ago the animal was detested by the hunter, trapper and farmer, and it is surprising to note the change in conditions, due largely to the enlightenment of the rural population as to the benefits of the skunk, also to the rapid increase and value of their pelts. Many skunk farms are in existence, the owners making a business of raising these animals for their pelts. While this may be a queer business, nevertheless it is perfectly legitimate, and as far as known, profitable. A ready sale of the pelt is to be had, and the skins from these domesticated animals generally bring higher average prices, being well handled and killed at a time when the fur is at its best.

The skunk is by no means confined to North America, as the animal is also found in southeastern Europe, South America and in Africa. In these countries he is known under Stinktiere, Surilho, Cape Zorillo, in fact his nomenclature covers a wide range and is still greater confused by naturalists disagreeing on certain species. Mr. Gabriel Sagard-Theodat, the prominent French writer, in his history of Canada, ( $\left.{ }^{6} 6_{3} 6\right)$, designates the animal "enfan du diable" which apparently was the recognized Canadian French name for this animal; others mention the "devil's own beast." The Cree Indian knew the animal under Seecawk. Sometimes he is erroneously called polecat, fitch and chinche. He belongs to the weasel or marten family.

The skunk is found in nearly all the states and territories of the Union and climatic and geographical conditions are responsible for the great variation in size and color of its pelage. There are very few fur-bearing animals as plentiful, and especially so in the civilized sections, that bring such a handsome income to the trapper as does the skunk. As noted, the chief difference in character, besides the size of the animal itself, lies in the color of its fur, and the animal from the outward appearance is closely described in the following pages.

The body is 16 to 22 inches long, its tail from root to farthest 


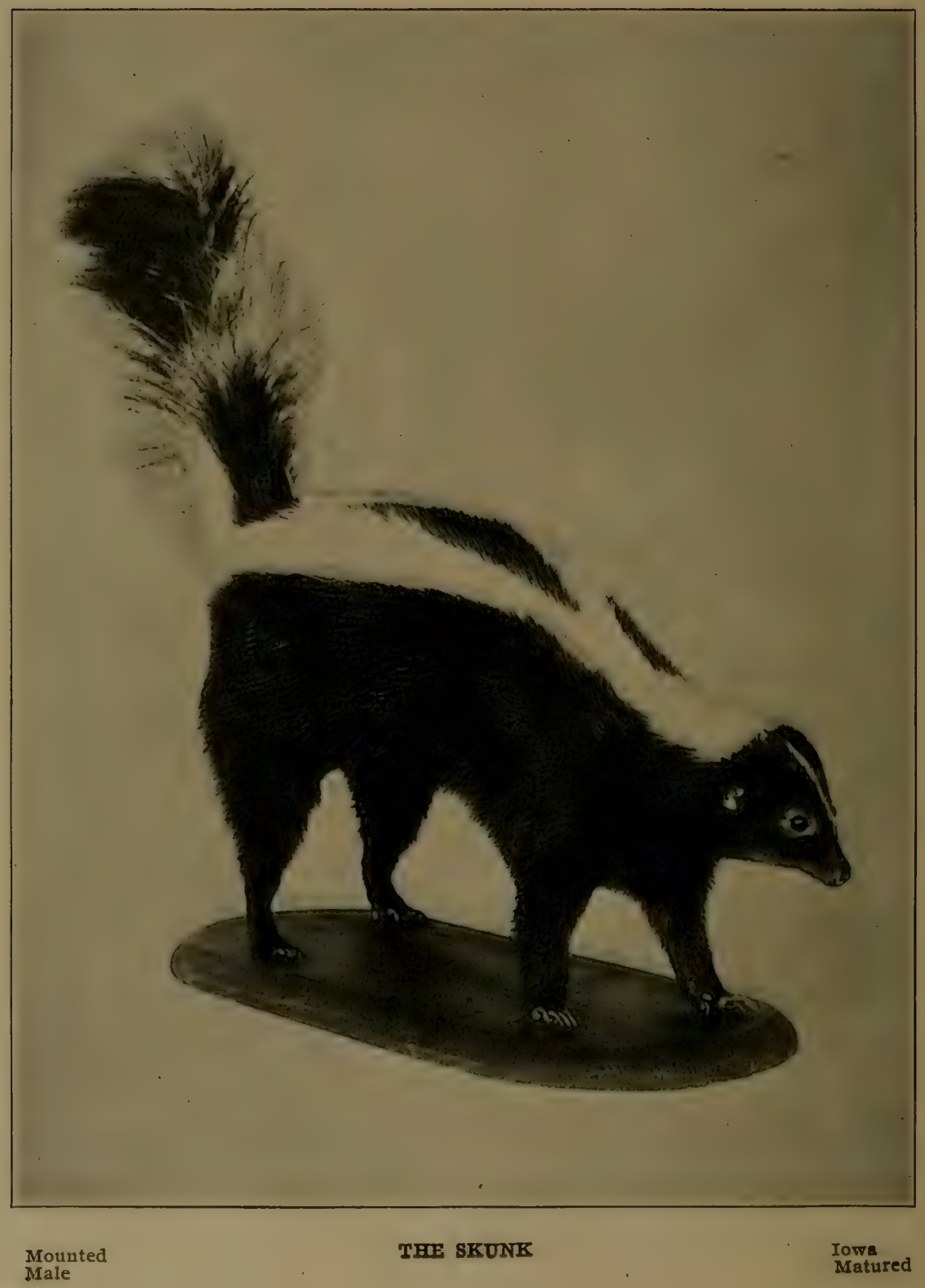


point of fur, I2 to 16 inches, the latter being covered with hair, the color of which varies, depending upon the color of the fur on the body. For instance, the fur on the tail of a black or short striped skunk is black or nearly all black, while that of the broad or narrow striped skunk is interspersed with black and white hairs. While the skin of the animal is very valuable, the tail is rarely used, though manufacturers of late years have consumed the hair in the manufacture of brushes and similar purposes. The legs are short and close to the body, the paw is naked, and the five toes on each foot are closely grown together like that of the badger. The foot is well adapted to digging. The toes are not webbed; the head is small, with short, rounded ears and rather long, projecting nose, with two small piercing eyes. Audubon describes the animal in the following words: "The skunk, although armed with claws and teeth strong enough to capture his prey, is slow on foot, apparently timid, and would be unable to escape from many of his enemies if he were not possessed of a power by which he often causes the most ferocious to make a rapid retreat, run the nose into the earth, or roll and tumble on the ground as if in convulsions; and not infrequently even the bravest of our boasting race is by this little animal compelled suddenly to break off his train of thought, hold his nose and run as if a lion were at his heels."

The skunk in general appearance is always neat and clean, and in walking seemingly takes special pride, as when promenading, its tail is erect and its back peculiarly curved. Very few animals are as harmless as this creature and were it not for the peculiar odor which it distributes when in danger, it would be more hunted and probably eradicated in sections. Its principal weapon, as heretofore noted, is a peculiar secretion and fluid possessing a very disagreeable odor. This fluid is of a palt yellow color and is discharged by the animal when in danger, in thin-like streams and with such accuracy and aim as to strike any object within 6 to 12 feet. The fluid is secreted in two anul glands from which by the contraction of the sub-caudal muscles and by uplifting of the tail it is discharged in the form as above stated. Trappers who are familiar with this secretion state that the discharge of this perfume looks like a puff of steam or white smoke. Dogs and other animals are adverse to attacking a skunk and only inexperienced or so-called "tenderfeet" will view this animal from the rear unless at a great distance.

The animal is carnivorous, nocturnal, not entirely terrestrial, as occasionally he is known to climb trees, perhaps not of choice but rather compulsion, being forced to this fancied secure posi- 
tion by the hunter or his dog. Consequently his arboreal, like his amphibious habits, are rather undeserved credentials. The theory that the animal climbs trees in search of food and birds, is discredited. The animal is beneficial in many ways to the farmer, and his eradication from any farming community should be prevented, and laws prohibiting the wanton destruction encouraged.

The contrast in size of the animal and the important variation in the color of its pelage, due to climatic and geographical differences, cannot be denied. The breeding and inter-breeding of the different colored furred species is the principal explanation why the young of a litter are so much unlike in color. A Michigan trapper recently sent my firm eleven skunk skins, two larger than the others, presumably one from the male or father, the other from the female or mother; the balance were from the offspring and were all much smaller. All were dug out from under an old granary. The skins graded as follows:

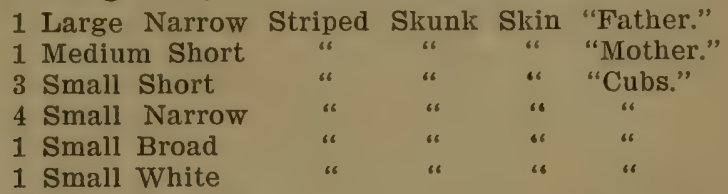

The largest of the skunk species are probably found in Manitoba, where a few years ago four animals were killed and weighed by me; the average weight of the male was I 5 pounds and that of the female II $1 / 8$ pounds. All of the animals had two long white, furred, rather narrow stripes extending from neck, over body, terminating at the tail. The average weight of the northwestern male skunk is from 6 to Io pounds, that of the eastern or southwestern animal 4 to 6 pounds.

The predominating color of the fur of all species is black and white with the exception of the Texas skunk, which due to a peculiar soil, is of reddish cast. Some of the animals have a clear coat of fur, others are all black excepting a small white star, but the majority have two stripes, some terminating at the center of body, on others the stripe continuing from the forehead over the body, terminating at the tail. The stripes on many are so wide that very little black fur is left, and quite a number of skins are annually-received that have practically no black fur at all. The white fur is usually of clear color, but occasionally skins are received that have a yellowish cast.

Habits. This carnivorous and nocturnal animal is unlike most every other animal possessing these habits. He can be seen in the early morning returning to his haunts, and once in 
a while in the middle of the day; at no time is he in a hurry, or will he discommode himself by getting out of your sight or especially away from your path and it is not to be wondered at that the farmer, as well as the hunter, will give the animal the right of way. His mode of locomotion is slow, and rarely will he be found away from his haunt a greater distance than one or two miles. His abode is usually in a hollow log, under some old barn or granary, or in a hole on the sunny side of some hill. He enjoys a sun bath, probably more than does the bear or the badger. His meal is made up by free consumption of worms, bugs, grasshoppers, mice, birds and eggs. In some sections he is known to be quite a vegetarian, consuming as he does, roots, berries, vegetables, and fruits. Occasionally frequents the henroost, not only for eggs, but for the hen as well.

In enemies he has to contend with the hunter and trapper, the fox and the wolf; but the latter two must be in an extreme state of hunger before they will disregard the pungent fluid and devour his body. Dogs are rather skeptical in attacking the skunk unless it is their first experience. In this respect they are no different than the hunter.

The animal passes the winter season in a state of incomplete hibernation, and at regular intervals he will arise, come out of his abode and expose his body to the sun, and judging from the effluvium, empty its distended pouches, but the stench thus caused, soon ceases, which is not the case when it is spurted under irritation or in self-defense. Dr. Coues states "that the animal uses this secretion in the relation of its perpetuation of the species, though overshadowed by its exaggeration into a powerfully effective means of preservation of the individual, is evidently the same as in other species of Mustelidx, each one of which has its own emanation to bring the sexes together, not only by simply indicating their whereabouts, but by serving as a positive attraction. In the case of the skunk, it would seem that the strong scent has actually tended to result in a more gregarious mode of life than is usual in this family of mammals; and it is certain, at any rate, that the occupancy by one animal of a permanent winter abode serves to attract others to the same retreat. Burrows are sometimes found to contain as many as a dozen individuals, not members of one family, but various adult animals drawn together. One other effect of the possession of such unique powers is seen not so much in mode of life as in the actual disposition of the creature. Its heedless familiarity, its temerity in pushing into places which other animals instinctively avoid as dangerous, and its indisposition to seek safety by hasty retreat, are evi- 
dent results of its confidence in the extraordinary means of defense with which it is provided. In speculating upon the development of this anal armature to a degree which renders it subservient to purposes for which the glands of other Mustelidæ, though of similar character, are manifestly inadequate, and it may not be amiss to recall how defenseless the skunk would otherwise be in comparison with its allies. A tardy, terrestrial animal of no great strength or spirit, lacking the sagacity and prowess of the wolverene, the scansorial ability of the marten, the agility, ss... I size, and tenuity of body of the weasel, the swimming and, ving powers of the otter, and even much of the eminent fossorial capacity of its nearest relations, the badgerlacking all these qualities, which in their several exhibitions conduce to the safety of the respective species, it is evident that additional means of self-protection were required; while the abundance of the animal in most parts of the country, and its audacity in the face of danger, show that its confidence in the singular means of defense it possesses is not misplaced."

The White The animal that has a clear, white-furred pelt is very sparingly found, in fact so seldom, that Skunk. many consider it a freak of nature and not a distinct species. It is common to receive skins which are commercially called "white skunk skins," but these have some black fur, either on the shoulders, neck or legs, and occasionally a few black hairs or an extremely narrow stripe of black fur in center of the skin, beginning about the shoulders and terminating at the tail. In length, quality and texture, the fur compares favorably with the other species. The skins have little value. The range of prices depends somewhat upon the size of the skin, primeness, density, quality and texture of the fur fibers. A choice, perfect, clear white-furred skin (in its natural state), suitable for manufacturing purposes or for specimen purposes, is worth $75 \mathrm{c}$ to $\$ 2.00$. Those that are partly stained or of a yellowish cast, are in little demand and their price ranges from $20 \mathrm{c}$ to $50 \mathrm{c}$, which is also the price of skins that have more or less black hairs or fur, in connection with the predominating white fur.

The white skunk is found in common with the black, short striped and narrow striped species, chiefly in the localities where the black and short striped species are more plentiful. Are unknown in the locality that the large, narrow and long striped skunk inhabits. Are found in the eastern, Atlantic, middle and western states, but the percentage of white furred skunk skins, including those also commercially called "white skunk skins," 
is small. Trappers dislike this species, and are aggravated to find a white skunk instead of a black or short striped animal in their trap.

The Black

skunk.

The animal that has a black coat of fur is found in many states, those of New York, New Jersey, Pennsylvania, Michigan, Wisconsin, and eastern Canada, are better furred, and in consequence command better prices than those coming from the central states. The black skunk is also found in Illinois, Indiana, Kentucky, Arkansas, Virginia, North Carolina and South Carolina, in fact in every locality excepting in the northwestern states, also northwestern parts of Canada. The animal cohabits with the other species, and there is no apparent rule governing the breeding and interbreeding and the probable coloration of the offspring. Somewhat disregarding the color of the parents, the litter contains black, white, short, narrow and broad striped youngsters. The fur of the black skunk, especially the eastern variety, is soft, wavy, and of a deep lustrous black. Those animals that have only a small white furred star at the forehead are commercially called "black skunk." The tail of such a skin is invariably covered with long, black hairs. The animal that inhabits the southern and southwestern states is rather small and the fur inferior, consequently the skins command a lower price as compared with those found in the middle or eastern states.

Short Striped skunk.
This animal inhabits the same section as the black skunk, the only difference between them is that the small white star of the former develops into prongs or two distinct white-furred stripes, starting at the forehead and terminating at or about the shoulders or center of body. Quite often the forehead is entirely covered with white fur, and immediately beginning at the top of head the white hair continues in two prongs, each varying in width from three-eighths to three-fourths of an inch. Should the white stripes continue clear across the body and terminate at the tail, such skins cannot be classed as short striped but are known as long, narrow or broad stripe.

Short striped skins are second in value, the price being about one-third less than that of the black skins. The white stripes are of no value to the manufacturer, these are cut out by him, and for that reason the skin that has the greatest amount of black fur is worth more and the value lessened by the increase of the white stripe. The fur of the tail is black with intermingled white hairs. The disagreeable odor is removed by the dresser (tanner) and by the time the skin reaches the manufacturer, it 
is cleansed from all impurities and ready to be made into garments.

Narrow Striped Skunk.

This animal inhabits nearly every state and, territory of the Union and greater part of Canada, and is the true American skunk, the one that is so much detested by the traveler and the early historians. His coat of fur is black, excepting two white stripes beginning at the forehead and terminating at the tail. The width of these stripes varies somewhat, depending upon the size of the animal, usually three-eighths to three-fourths of an inch. There is always a goodly portion of black fur between these stripes. The white stripe is of no particular value, and after the skin comes back from the dresser, the manufacturer removes the white stripe and sews the balance of the skin together. The white stripes are narrow and close together, but widen apart at center of back, and again narrowing when close to the root of tail. The largest animals of the skunk family come under the long or narrow striped species. Some of these animals are as large as the badger and raccoon. The smallest skins come from Texas and other southern states; the fur is rather coarse and such skins have little value.

\section{Broad Striped} skunk.

This animal is found in common with the previous species, and its difference is only in the width of the white stripe which is wider, and the quantity of black fur on the skin is lessened, thereby diminishing the value of the skin. This species is found more plentiful in the southern and southwestern states, is quite numerous in the Atlantic, western and northwestern states. On some specimens the white stripe is so broad that very little black fur is left. Perhaps this is more true of the smaller skins received from Texas and other southern states, and, of course, these have little value. There is no apparent iron-clad rule, or a dividing line between, or just where and when a skin should be called broad stripe and not a narrow striped skin. This naturally must be left largely to the judgment and discretion of the buyer or the manufacturer, who, in grading, seeks an average more than any particular dividing line. The tail is covered with white hairs with occasional interspersed black hairs.

One Striped skunk.

This animal has a long, horizontal white stripe extending from forchead, continuing over the body, terminating at root of the tail; the latter is covered with white fur and is probably more bushy in proportion to its size, than the other northwestern species. He is found only in the lower tiers of states bordering Mexico, probably more numerous in California than any other portion of this country. The 
skin is of no great value. The fur is rather coarse and the skins undesirable

From the above description it will be noted that the value of the pelt lies principally in the quantity of black fur, diminishes by the increase and increasing by the lessening of the white fur. The clear black and most glossy furred skins bring the best prices; the skins of the eastern animal are more desirable as compared with those from the middle states. Manufacturers desire the extreme large, long striped skins obtained in some of the northwestern states, including Manitoba and other parts of Canada, for the reason that the fur is long and lustrous and the skin very large.

Of late years the white stripes that are cut out of the skins are being used in the manufacture of spurious tails which are dyed to imitate the natural tail of mink, marten, etc. At other times these white pieces are sold in connection with other fur scraps or cuttings to hat manufacturers at a price of 2 to 3 cents per pound.

Only those skins that are prime in leather and full furred, command good prices. Skins that are unprime are habitually poorly furred and the leather possesses insufficient strength, also the principal guard hairs protrude through the leather. The average price of skins, and the quantity annually marketed for a period of years, will be noted elsewhere. These tables are very interesting and should be perused by the reader to obtain a closer conception of the magnitude and the probable future resources of this animal.

A story related by one of the perpetrators of a joke upon a young Russian deserter located in North Dakota, is very interesting. In company with three others, he was taken on a hunting expedition in quest of foxes and coyotes, the latter for the bounty, and the former for his pelt, which was worth $\$ 4.00$ to $\$ 5.00$. He was impressed with the great value of silver or black fox skins and their color, etc. During the forenoon each of the three succeeded in killing one or more foxes and wolves, but the young Russian was rather unfortunate and depressed in spirits, he not having had any success. A little later on he perceived a large stone pile, and upon nearing it some black furred animal entered therein. Apparently this movement was also noted by the others, but the Russian became excited, thinking that he had seen a black or silver fox enter the stone-pile. The others, however. knew that the animal he had seen was a skunk. It was agreed that whatever the animal might be, the Russian was entitled to its capture. The others gradually withdrew, but before departing, cautioned him, also intimated that the probable capture of 
the black looking animal might place hundreds of dollars in his pocket, especially if it happened to be a well furred black fox, and if he could be captured without injuring the skin. The companions in withdrawing chuckled to themselves and left the "tenderfoot" to his wits and at the mercy of the skunk.

The ambition of the Russian was to capture the fox alive and immediately rolled a large stone at the opening so as to prevent sudden egress. Stone after stone was now rolled and thrown aside, he working like a Trojan for about 20 minutes, before he reached what he thought was the den. There was no fox in sight, and more stones were removed, and while so occupied a skunk came out from one of the excavations; turning his tail to the enemy, who at that moment perceived the supposed fox and started to grab him, but in return received one or more charges from the concealed battery. Perhaps this was too sudden for both, at least indications pointed that both were surprised, but as neither party gave quarters in the battle that followed, as may be expected the Russian became the victor, but much to his sorrow immediately thereafter. Holding the skunk by the neck with both hands he begged assistance, claiming he could not see and had difficulty in breathing. He finally dropped the skunk, which decamped back to the stone pile, while he reached for his handkerchief, wiped his face and eyes, spat, and acted as if demented. His face, hands and clothing were full of perfume, which became unbearable to him, and upon being told that the animal was a skunk and not a fox, he cussed the skunk, stone pile, country and his companions, but all to no avail. The hunt ended right there and then, and they all departed for home. Upon arriving home his clothes were removed and burned. His style of action in battle was criticised and the probable result is that when he again enters into a fight of this nature, he will attack the enemy "face to face."

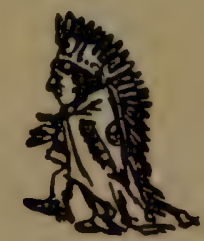




\title{
THE CIVET CAT.
}

\author{
Little Striped Skunk. Lat. Mephitis (Spilogale) Putorius.
}

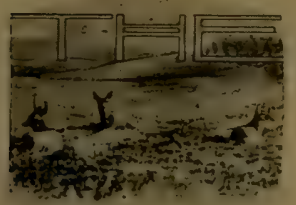

AMERICAN civet cat must not be confused with the animal inhabiting Africa or Southern Asia known as the African civet from whose pouch a perfume, commercially known as "Civet" is extracted. This little four-striped skunk, under which name it is also known, belonging to the skunk family, possesses carniverous and nocturnal habits. The animal is found in nearly all southern, central and Pacific states; is scarcely found in the states bordering Canada, and is unknown in the latter country. The animal is quite numerous in the central states, and especially so in Iowa, Missouri. Kansas, Indiana, Illinois and N'ebraska. A large number of skins are annually received from the southwestern and western states, also from Florida and Texas. The animal measures from 23 to 28 inches from end of nose to tip of tail and stands four to five inches high from the heel to top of shoulder. The construction of the animal's body is such enabling it to be quick in action and the boly proper weighs three, not exceeding four pounds.

The fantastic, harlequin-like coloring is seldom duplicated in any two species, and in fact, no two skins in a lot of three to five hundred can be found alike-due to change and number of spots and the peculiar formation of the stripes. The animal possesses a coat of soft, black fur, having a white star in the center of the forehead, and four parallel and almost equi-distant stripes, beginning on the uppermost portion of the head between the ears, and ending at or about the center of the body. Another stripe-like formation on each side of the stripes heretofore mentioned being curved in harp or lyre-like sliape, encircling and ending about the center of the body. This concludes the stripes and the remainder of the black fur is intermingled with 6 to 8 other small white spots. The tail possesses a growth of hair usually 4 to 5 inches in length, while that of the tailhone proper seldom exceeds 7 inches, usually 5 to 6 inches, a total length of Io to 15 inches, (four-fifths of bodr). Dr. Cones, in describing the stripes and the fur, notes as follows:

"The notorious inconstancy of the white markings of skunks, even of those in which the pattern is normally simplest, finds room for exaggeration in the highest degree in this case where the normal markings are numerous and complicated. In some 


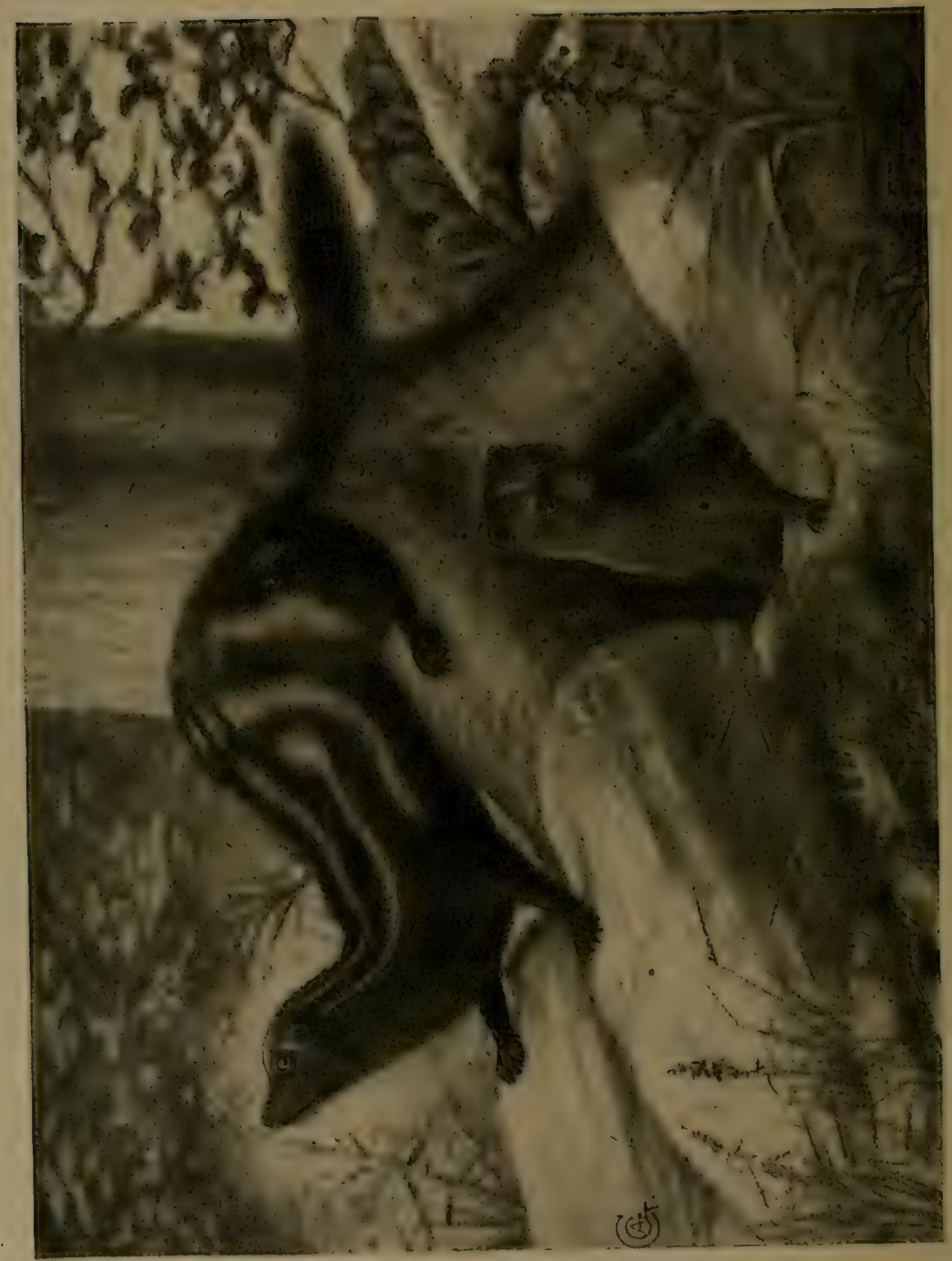

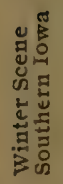

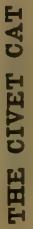

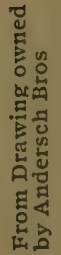


cases, owing to interruption of the usual stripes, I have counted no less than eighteen separate white marks, exclusive of tailtip and the vague chin-spots. The three head spots and the four parallel dorsal stripes on the anterior part of the body are the most constant, and may, so far as I have seen, be always traced, though the medium pair of stripes are liable to slight interruption. The lateral pair are the firmest of all the markings. There is special liability to a break in these stripes where they begin to curve downward on the side. Complete break here, fusion of the solitary pair of dorsal spots with the transverse flank stripe, and lengthening into a stripe of the hip-spot result in three vertical, crescentic stripes succeeding each other behind the end of the main lateral stripe, that runs from the ear over the shoulder. Interruption of these transverse crescents may give a set of numerous spots, without traceable stripes, on the hinder part of the body; indeed, the markings of this part of the body are wholly indefinite. The lateral spots at the root of the tail often fuse into one. The tail is ordinarily black with definite white tip, but may have white hairs mixed with the black throughout, or be all black or all white. The shoulder stripe sometimes sends short spurs around toward the throat and breast. The chin and upper throat may be perfectly black, or streaked throughout with white. The part of the ear corresponding with the white markings about it is commonly light colored; the rest of the ear is black. The naked muffle is dark colored. The claws are horn colored."

The animal's wide geographical distribution most naturally results in marked differences in size of the animal, and color of its pelage. The habits, however, are the same. The black fur is quite pure and glossy with the exception of animals from certain parts of Texas where the soil has a tendency to give the fur a reddish hue. The skin from animals above denoted Dossess four to six white stripes with numerous white spots, and its tail is covered with long, black and white hairs. The skins are used natural or dyed black, and chiefly for lining purposes. The price of skins varies considerably, usually $15 \mathrm{c}$ to $35 \mathrm{c}$. The fur is not as staple as that of mink, skunk or muskrat.

Habits. In respect to habits the animal closely resembles that of the skunk. It is nocturnal and carnivorous, better adapted to climbing trees and more readily covers distances than does the skunk. His favorable abode is under some old building, shack, crib, etc., at other times in some hollow log or burrow made by other animals. Such is generally on the side of a hill facing the morning sun. His principal food is worms, bugs, 
grasshoppers, frogs, mice, birds and rats. In some sections it is claimed the animal is a great vegetarian.

By the two anul glands from which by the contraction of the subcaudal muscles and by the uplifting of the tail, a fluid ranking in odor to that of the skunk, is discharged. The animal can discharge this obnoxious fluid at its pleasure.

\section{THE BADGER.}

\section{(Ger. Dachs, Lat. Ta.ridea Americana.)}

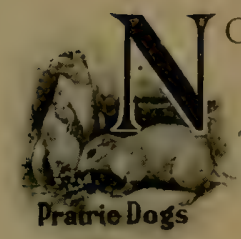

TABLE differences between the American and the European badger has caused naturalists to distinguish and divide these into separate species, where they rightfully belong. The four members or sub-family of the Melinae are found in Europe, Asia and America. The animal found on this continent is again sub-divided and the offspring known as the Mexican badger is sparingly found in Texas and the bordering states along the Mexican frontier to California, but principally confined to Mexico.

The American badger ( $T$. Americana) makes his home largely in open or prairie sections and is quite abundant west of the Mississippi River, though sparingly found in nearly every other state and territory in the United States; also in parts of Canada, but in the latter country his existence is cloubted northward of latitude 60 degrees north. Inquiry among traders operating north of the Great Slave Lake would indicate that the badger is unknown in that region. The badger is quite plentiful in the southern states, but the animal is smaller, his pelage somewhat differently colored, which is also coarser and the general character of the southern typical badger gradually melts into the Mexican sub-species berlandieri.

The body is stout, broad and flat, rather depressed and clumsy, about 24 to 32 inches long with a stubby tail measuring 4 to 6 inches. Its legs are short but heavy, being stoutly built, and its feet resemble those of the bear, long and large with five toes into which an equal number of long, curved claws are firmly set; those of the front feet measure $13 / 4$ to $2 \frac{1}{4}$ inches on outside curvature, while the rear claws are rather stubby and oniy onehalf to two-thirds as long, also the toes and feet are only proportionately as large as are the front feet. The head is rather small, and like the body, flat, especially very broad across the 
forehead. Its snout is pointed but not necessarily long. The dental formation consists of 34 teeth. In the animal's natural erect position the belly portion is scarcely more than 3 to $3^{1 / 2}$ inches from the ground, while to the top at center of back a total elevation of 12 to 13 inches may be attained.

A large, full-grown northern male badger when at its best will weigh about 40 pounds; that of the middle or western states 25 to 30 pounds, and the sout: ern species not much over 20 pounds. The female or the two-year-old male is only two-thirds, probably three-fourths as large and as heavy. The fur of the badger varies greatly in color and texture as a fortutious matter of age, season, natural surroundings and conditions, besides the usual climatic and geographical differences that form a conspicuous part in noting the differences in species, and become the nucleus in the naturalists' opinion when sub-dividing or rearranging the order of mammalia. Nature does not provide a like coat of fur for animals inhabiting different climates, and a contrast is even noticeable between animals possessing, as does the badger, hibernating habits, where one is exposed to the elements and the other remains for one or more winter months in his or her cave or burrow. Manufacturers, fur buyers, traders and trappers, in fact almost everyone connected with the raw fur business, are puzzled in the contrast of quality, quantity, length and texture of the fur fibers that exists between badgers from the same locality, of equal age and size, and like period of the season. Both skins may be prime from the flesh side, while one may possess a soft, long, mellow, and in fact perfect coat of fur, the other is unprime, harsh, shallow, coarse and flat, and entirely unsuited for manufacturing purposes.

The pelage of the mounted speciman accompaying this article, measures $I \frac{I}{2}$ to 2 inches on the upper part of body, while at its side the outer guard hairs are three-fourths to $I$ inch longer. (2I/4 to 3 inches.) The belly portion is covered with a short, coarse growth of fur three-eighths to one-half inch in length. In color the main fur fibers are divided by the outer points, being gray and of a silver tipped nature, and beginning at the middle, gradually turn into a light yellow, somewhat dirty looking, color. The fur on or about the tail is considerably coarser and a peculiar yellowish cast predominates. The fur about the upper portion of its legs, also about the neck, is short and black. The male generally possesses a darker coat of fur and is also more conspicuous in size than the female, the latter being one-third to one-fourth smaller and the body more flattened. 


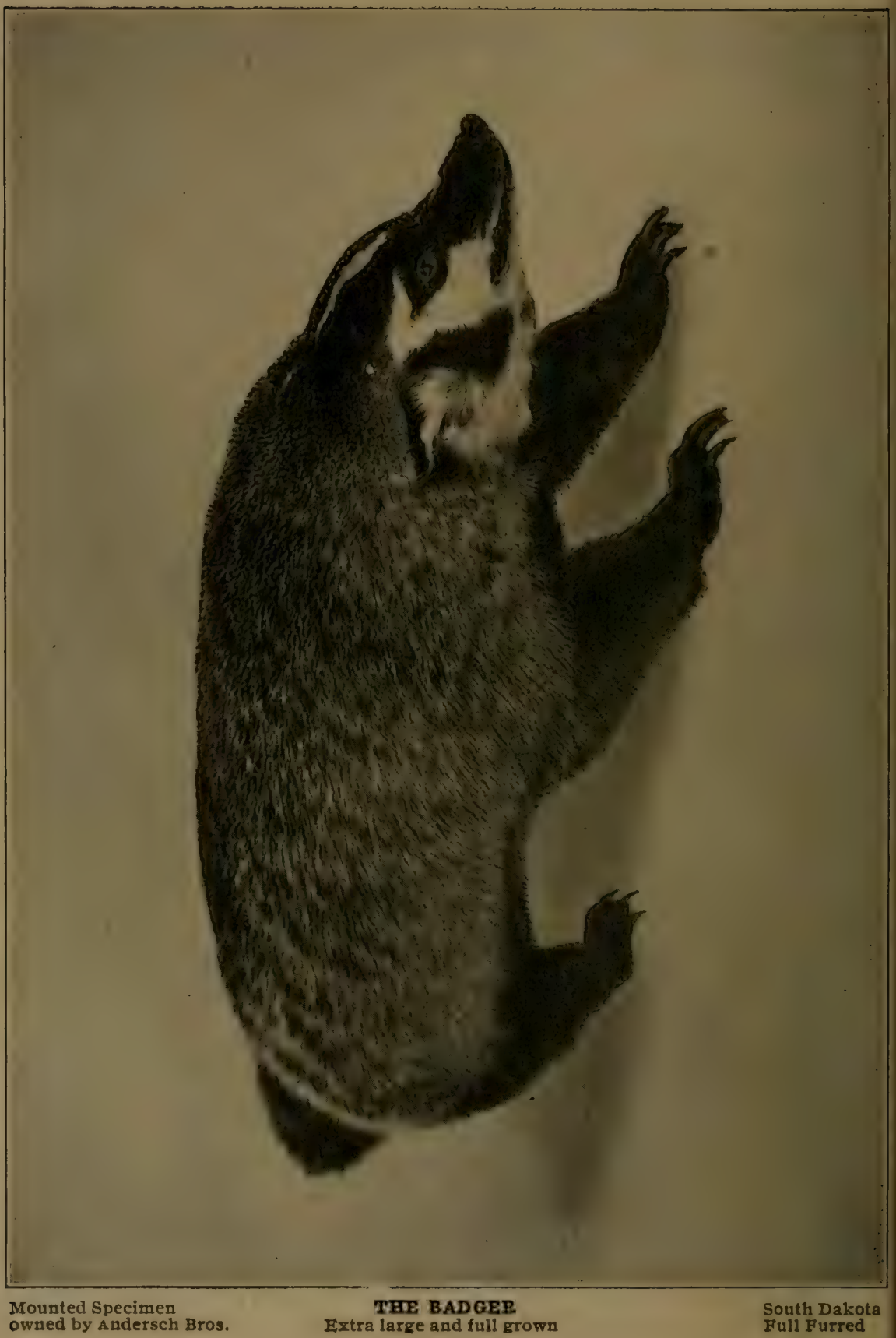


Habits. The animal's feet and claws are especially adapted for digging, and it is no wonder at all that the badger, if observed within a reasonable distance, can make a burrow of sufficient depth to bury himself before the intruder reaches the spot. In sandy soil, the badger will make a burrow of sufficient depth to bury himself in the remarkably short space of two minutes, and the hunter on approaching the spot where the animal was seen, finds only the traces of his fresh work; by disturbing the ground he will find the animal on his back ready to assume the attack. The badger above all other animals is noted for its flatness; even when running it looks broad and flat, and its body seems to sweep the ground during its rather slow, heavy and awkward progress. Seen when crouching in fancied security, or hoping to escape observation (and it will sometimes remain long motionless in this posture, permitting near approach), the animal might easily be mistaken for a stone or clod of earth. The very hairs lie flat, as if parted in middle, and form a fringe along either side, projecting, as one writer has remarked, "like the shell of a turtle or the eaves of a house."

The food consists of roots, bugs, worms, eggs, birds, mice, rabbits, and frogs; also seeks the nest of bees, and, seemingly, the tough hide is impervious to the stings of the native bee as well as the bumblebee. The abode of the badger is in some hole, quite often on the sunny side of some hill. He has from three to five subterraneous passages leading to his living room. The latter is well supplied with food and padded out with vegetation such as straw, grass, leaves, etc. Usually one passage is used for entering and egress, the others being built for air purposes; also in case of danger to have free access or exit. Quite often the animal will expose himself to the rays of the sun, and when ill-disposed will walk about the opening of the exit, up and down, making a quick turn at each end and view the surroundings with a Jemeanor indicating nervousness.

The breeding season begins early in the spring and during the month of Nay the mother brings forth a litter of three to five, which are born in her den. After suckling them for a period of 60 to 75 days, she trains them to catch, kill and devour mice, bugs and worms. Shortly thereafter the mother loses her affection for her young and they are placed upon their own resources, but continue to inhabit the same abode until the beginning of fall. The father cares little for the comfort of the children or that of the mother during the entire period. The young mature in 24 months, and the animal attains an age of Io to I2 years. As a rule the male badger will inhabit a certain abode all by himself, and only during the breeding time will he 
assume the companionship of the female. It happens quite often that a red fox will inhabit part of the den with the badger, and, seemingly, the two animals get along nicely, neither one disturbing or observing the other. In the fall the badger will carry leaves and other soft material into his den with which to pad and upholster, also to absorb the dampness of the ground in his quarters, thus making ready for a severe winter. Just before winter sets in, the badger will carry a moderate supply of food to his den or permit same to remain in some of the passages heretofore occasionally used. When about to begin his winter sleep, the animal will place his head between his two front feet, lie on his belly and sometimes slumber along for weeks and even months at a time. During warm spells or thawy nights the animal is likely to proceed somewhat beyond the outer opening, and after a stay of one to five hours will return and resume his sleeping posture.

This animal should be killed for its fur only in the winter, and even then quite a number of the skins received indicate that the animal was not sufficiently exposed to the elements, or at any rate the fur is unprime, regardless of the fact that the skin on the flesh side indicates primeness. Only such skins that have a long soft-furred coat are of any value; flat, unprime badger skin s should not be marketed.

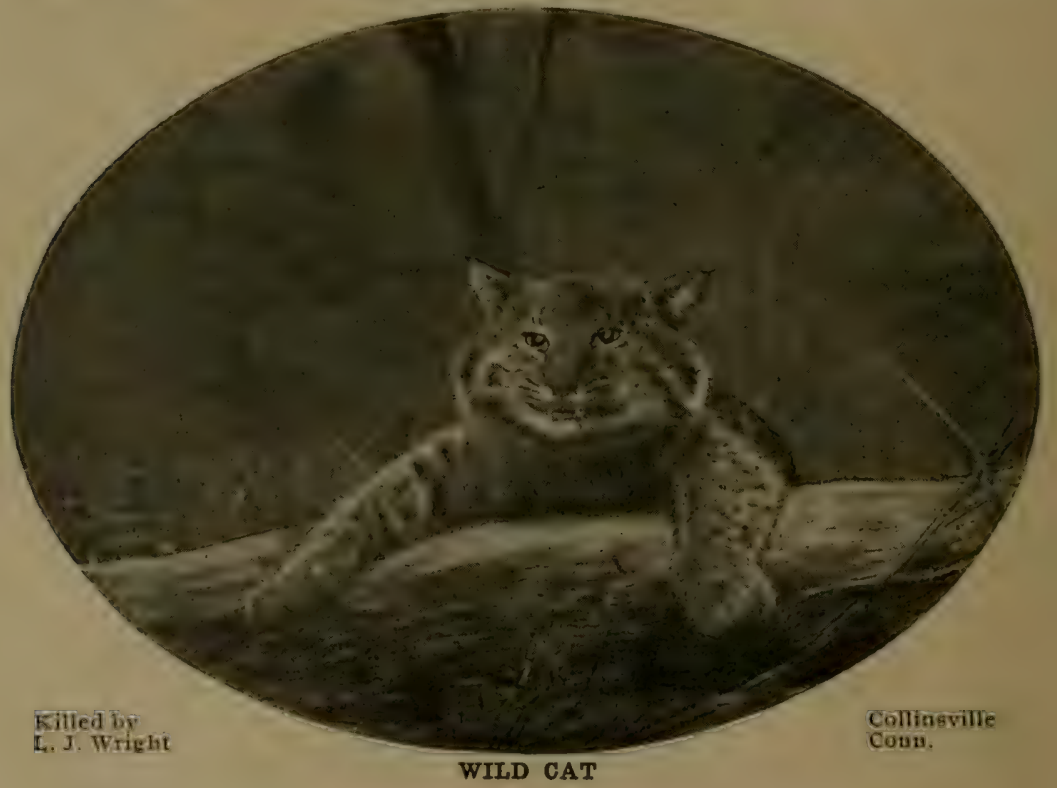




\title{
THE WILD CAT.
}

\author{
(Ger. Wildkatze, Lat. Lynx. Rufus.)
}

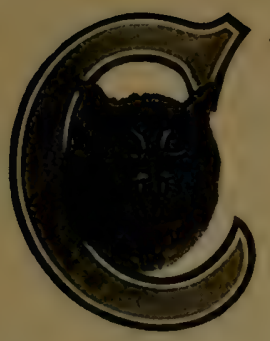
shows marked variation, and unusual differences in size and color exist. The animal is known under different names: bob cat, bay lynx, red lynx, etc. The species certainly resembles the true lynx much more than it does the house cat, and any of the latter names would be more appropriate. Some of the northern species resemble the Canadian lynx so closely in size and color and markings of fur, also in its tail, that, unless closely observed, one would believe that they are the same species; this however is not true of the beasts found in other parts of North America.

A full-grown northern wild cat will measure 32 to 36 inches from nose to root of tail. The latter is about 5 inches long. rather slender, and the fur of that member closely resembles that of the body, excepting the tip, which has a semi-circle of black fur on the end. Such a cat will weigh from 30 to 36 pounds, but individual male beasts have been known to weigh as much as 40 pounds. The legs are stout, but incomparable with those of the Canadian lynx. They seem rather long and slender and are well furred. The feet are proportionately as large, and sharp and re-tractable claws, well curved, enables the beast to climb trees with remarkable ease. The pelage of the northern species during the winter months consists of a rather dense coat of fur, fairly soft, resembling somewhat the color of the true Canadian lynx, being light brown with whitish tufts here and there, and the back portion has rather a reddish cast. Occasionally the fur of the northern wild cat is of a silver grey color. The belly part is covered with a less dense growth of fur with whitish colored interspersed tufts of black hair. There are two apparent dorsal stripes of clarker hair beginning at the forehead, continuing over the body, but at times these stripes 
are indistinct, and give way to tufts of fur that are two or three shades darker.

The ruffious formation or whiskers as they are sometimes called, that make the Canadian lynx so conspicuous, is also noticeable on the wild cat. The fur on the tail is notable in its intermingled, alternating, ring formation, ending as it does with a black tip of a semi-circle form. The fur on the southern and western species is rather short, harsh and of a reddish cast, and the black spots or tufts that scarcely appear only on the belly of the northern species, are more numerous and nearly all over the animal's body. Fully as large, if not larger, beasts inhabit

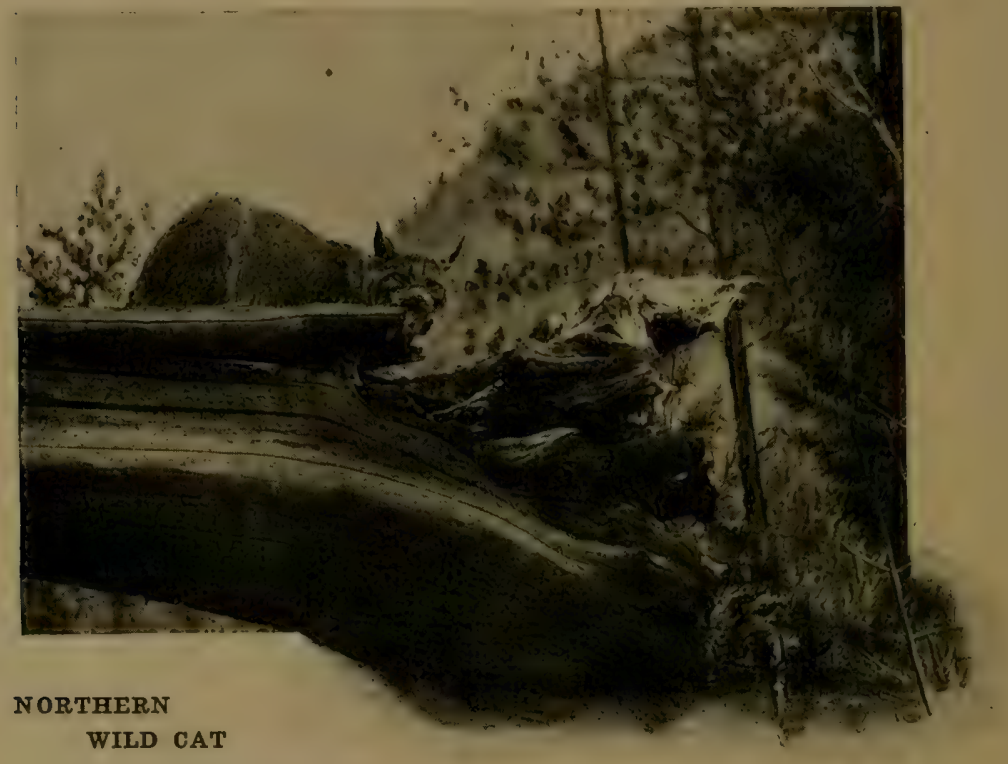

some of the western and southwestern states. Individual skins received from Colorado and other mountainous sections, measure 42 to 44 incles from nose to root of tail. The latter member, from sections, attains a total length of 7 to $71 / 2$ inches. The animal that inhabits the southeastern and middle states is comparatively smaller, invariably weighing 18 to 22 pounds.

In the fur trade that species commonly known as the red lynx, which is found in the western, also Pacific states, is graded as "wild cat," the skin resembling that of the latter. In quality the fur is inferior, while the average weight of these animals is 
from 20 to 30 pounds; some species weigh considerably more. The value of wild cat skins varies considerably, those of the northern being worth from $\$ 1.00$ to $\$ 2.00$; those of the middle and northwestern states, $65 \mathrm{c}$ to $\$ \mathrm{I} .5 \mathrm{O}$ and those of the southern $25 \mathrm{c}$ to $\$ 1.00$. During the summer months the fur is extremely short and of a reddish cast; especially is this true of the southern species and such skins are of little value.

Habits. The animal possesses great strength, and when pursued, hard pressed or cornered, will, with daring and ferocity of extraordinary degree, go for the intruder, be it dog,

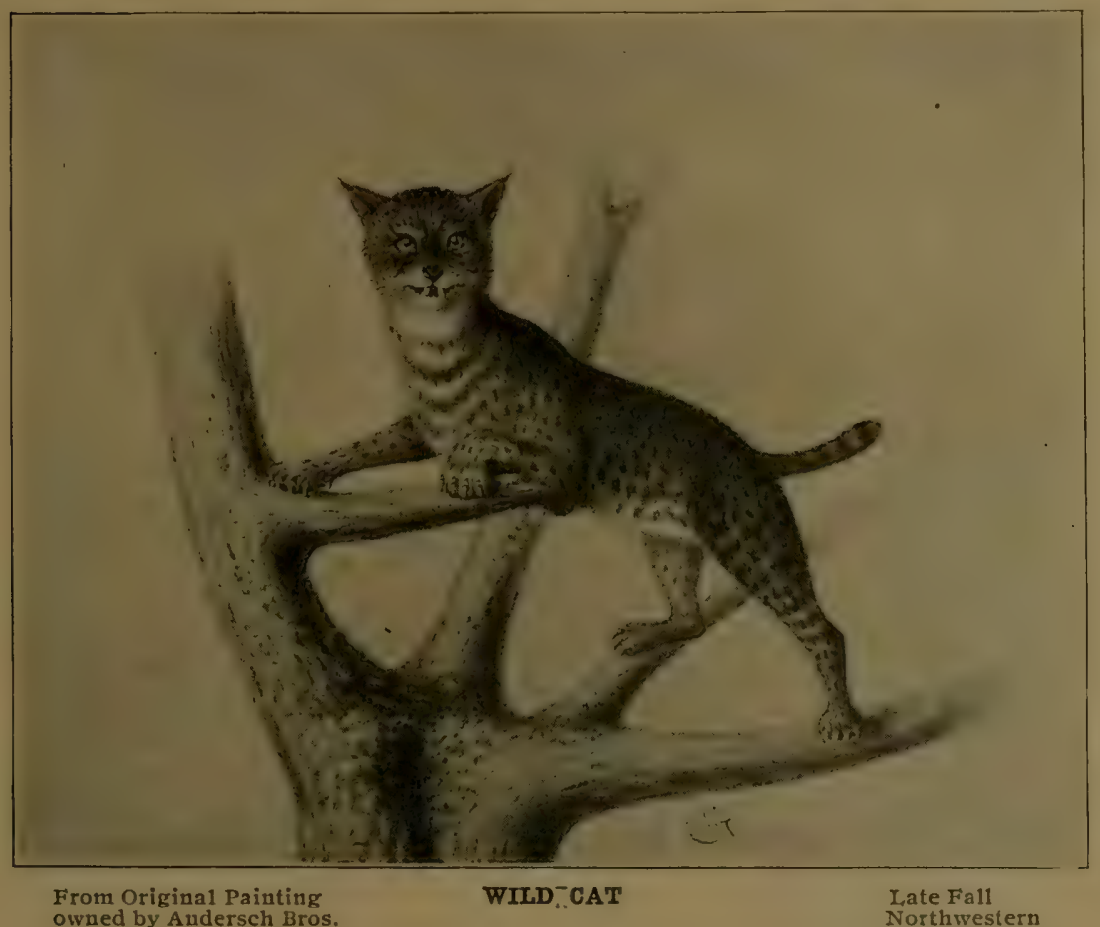

beast, or member of the human family. Otherwise the cat is of a cowardly disposition and will seldom attack anything out of the ordinary run. He much prefers dense timber where his food is more easily obtained. His meals consist chiefly of birds, rabbits, mice, rats, weasels, squirrels, muskrats and occasionally his nocturnal habits bring him to the barnyard in quest of 
chickens, geese and ducks; nor will he object to carrying away a small suckling pig or small lamb.

Their home is made either in a hollow tree, in some cliff under rocks, or other obscure locality, where they are entirely or partly protected from the elements. The mother brings forth a litter of four to seven young, which she protects and nourishes until they are able to procure their own food. The playful disposition of the kittens resembles that of the domestic cat family.

The animal's lair is occasionally 20 to 30 feet above the ground in some lofty tree; in all cases the abode is quite comfortable, being padded with moss, dried leaves, etc., and especially is this true if the abode or lair is in a cavity below the roots of some huge tree. The animal is detrimental and a nuisance, and his eradication is much desired on the part of hunters, due to his large consumption of wild bircls and game. In cat fashion he stealthily steals, winds, crawls, nearing his victim, in the most noiseless fashion until within distance, when he will suddenly dart out or pounce upon his victim from some elevation.

\section{THE CANADA LYNX.}

\section{(Ger. Luchs, Lat. Lynx Borealis or Lynx Canadenis.)}

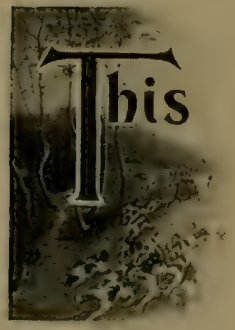

CARNIVORANT is much larger than the wild cat. Is chiefly found in Canada. Was formerly in large numbers in the heavilytimbered sections of the northern part of this country, and is now sparingly found in the tier of states extending from Maine to Washington. One or more of these species are found in nearly every country; has been one of Europe's most hated and eagerly sought after in the animal kingdom; is now

rarely found in civilized sections, although still abounding in Norway, Sweden and Russia, and especially in Siberia and other northern latitudes. Its peculiar howls during the night cause great uneasiness to the unprotected traveller or miner. He inhabits a mountainous section and is rarely found in the open, but principally in thickets, dense woods and forests, and alway's away from civilization.

An average full-grown Canadian lynx measures from nose to tip of tail 35 to 40 inches. The latter member is ahout 5 inches long, and the animal will weigh from 25 to 40 pounds. Occasionally a much larger and heavier animal is captured, but it 
is safe to state that the average length from nose to root of tail is 30 to 35 inches. The largest shin coming to my notice during the past few years, measured 43 inches from nose to root of tail, and the latter member, including the black furred tip, was $61 / 8$ inches long. The estinnated weight of this brute was certainly in the vicinity of 50 pounds. Tlie body is robust, thick and heavy, and apparently the animal is far less fleet than its congener, the bay lynx. The thighs are extremely long and the legs thick, massive and clumsy. The large paws are also massive, the toes thick and so completely concealed by the fur that the tracks made in the snow by this animal are indistinct. The ears are somewhat larger than those of the wild cat, well pointed and furred on both sides, with a bunch of long, soft, black pencil-like hairs extending from the extreme portion of the ear from $\mathrm{I} / 2$ to $\mathrm{I} 3 / 4$ inches in length. Naturalists claim that this bunch of hair acts to the animal's sense of hearing as do the long hairs on each side of the cat's mouth to its sense of smell. The tail, which is 5 to 6 inches long, is covered with fur resembling that of the body, excepting that at the end a heavy plume-like tip of a lustrous black color is very prominent. Peculiar long hairs, of a ruffious formation, often called whiskers, grow on each side of the neck just below the ears and terminate underneath the throat

The animal's pelage during the winter months is of a rich, soft, mellow character, varying in color from a light brown to a silver grey. The belly portion is of a whitish nature and the fur one-fourth to one-half inch longer as compared with that of the back; the latter is one and one-fourth to one and three-fourths inches in length, and always of darker color. The black furred spots that are so conspicuous on the belly portion of the wild cat, are entirely absent in the lynx. The skin las become very valuable during the past years, and consequently the animal is eagerly sought after by the hunter and trapper and is becoming scarcer every year. Miost skins that are received find their way to the market from Canada, and from the northwestern states, from Michigan to Washington. The Hudson Bay Co. probably market as many lynx skins as all others combined. The skins are used largely in the manufacture of ladies' wearing apparel, such as boas, scarfs, and for trimming purposes.

Habits. The lynx possesses carnivorous and nocturnal habits and his clumsy construction seems of no apparent detriment to his swiftness and precision on foot, also when in the trees. He is an excellent climber and frequently pounces from a cliff or tree upon his prey, while at other times he will follow stealthily until within springing distance and surprise the victim by pouncing upon him. He is sometimes seen in the loftiest of 


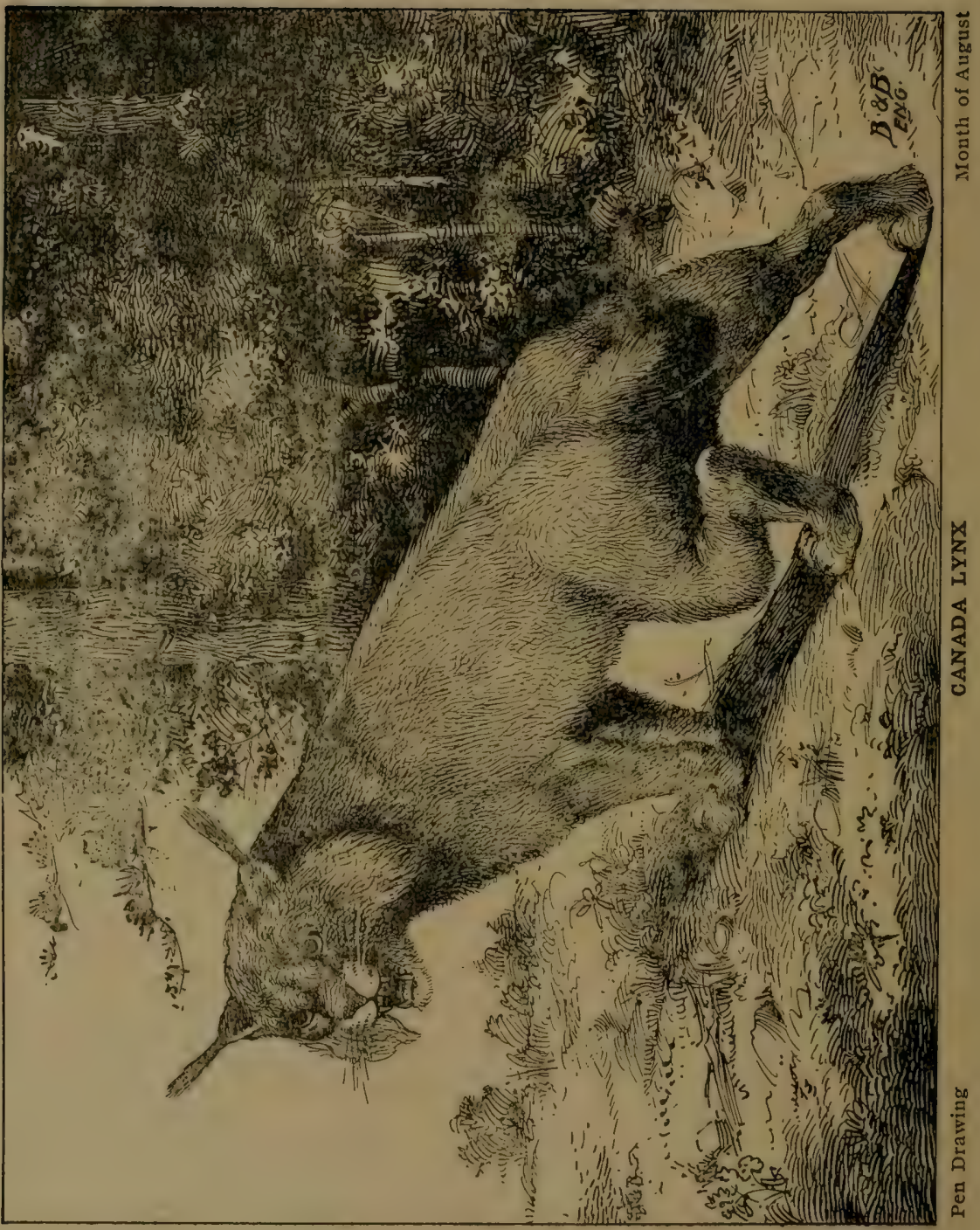


trees in search of birds or in the chase of small quadrupeds. $\mathrm{He}$ is known to cross rivers in his chase of animals, also when pursued by the hunter. The animal is a night prowler and is seldon seen during the day, which time he generally spends in a semisound slumber. The lynx is more retired in his habits than our common wild cat and keeps away from habitation, being usually found in the depth of the wilderness. He confines himself strictly to a meat diet, probably more so than any other carnivorant. In this respect he is fastidious, preferring fresh meat to that of stale or putrid. He has no particular love for fish, yet is known to devour them; but whether the brute is able to capture them in the water is unknown to us. When alarmed or pursued, he leaps, or bounds, rapidly, almost in a straight line, from danger, and if hard pressed he readily takes to a tree. He is able to leap from a considerable height to the ground without feeling the jar, alighting as he does on all four feet, and instantly de. parting, beginning the battle if dogs attempt to stop him. That the animal is able to capture a young deer, is not disputed, but to do this he must have a favorable location so that he can pounce upon the victim's neck. He will often follow the trail of cattle, cleer, moose, bear and even that of the hunter or trapper. He is known to disturb traps set for mink, marten and other animals and at other times (probably from experience), refuses to touch or go near a setting, but rather crouches down or elevates himself to some lofty position, where he awaits the anticipated visitor to the trap, upon which he pounces. A half-breed, who has trapped for years in British Columbia, relates an experience probably seldom witnessed by man:

While inspecting a line of traps set for mink, marten, and occasionally one for a fox, he came across a partly devoured rabbit that had evidently sprung a marten trap and had been found by a lynx, which was in the act of devouring the rabbit when disturbed by the approach of the trapper. Knowing the habits of the lynx, and feeling assured that the animal would return to finish his meal, the trapper set two of the largest steel traps he had with him, "No. 2I/2," about the remaining portion of the rabbit, and departed for the other side of the creek. While crossing the creek, he noticed, at a distance, two wolves evidently following his trail. He felt somewhat aggrieved at not having attached the chains to a drag to detain the wolves in case one or both should spring the traps. Apparently the lynx was in the neighborhood all this time, as only fifteen minutes expired before Mr. Lynx came back to the rabbit. He sniffed around and acted as if something was wrong. Apparently he was desirous of finishing his meal, but was afraid to approach too close, $\mathrm{He}$ 


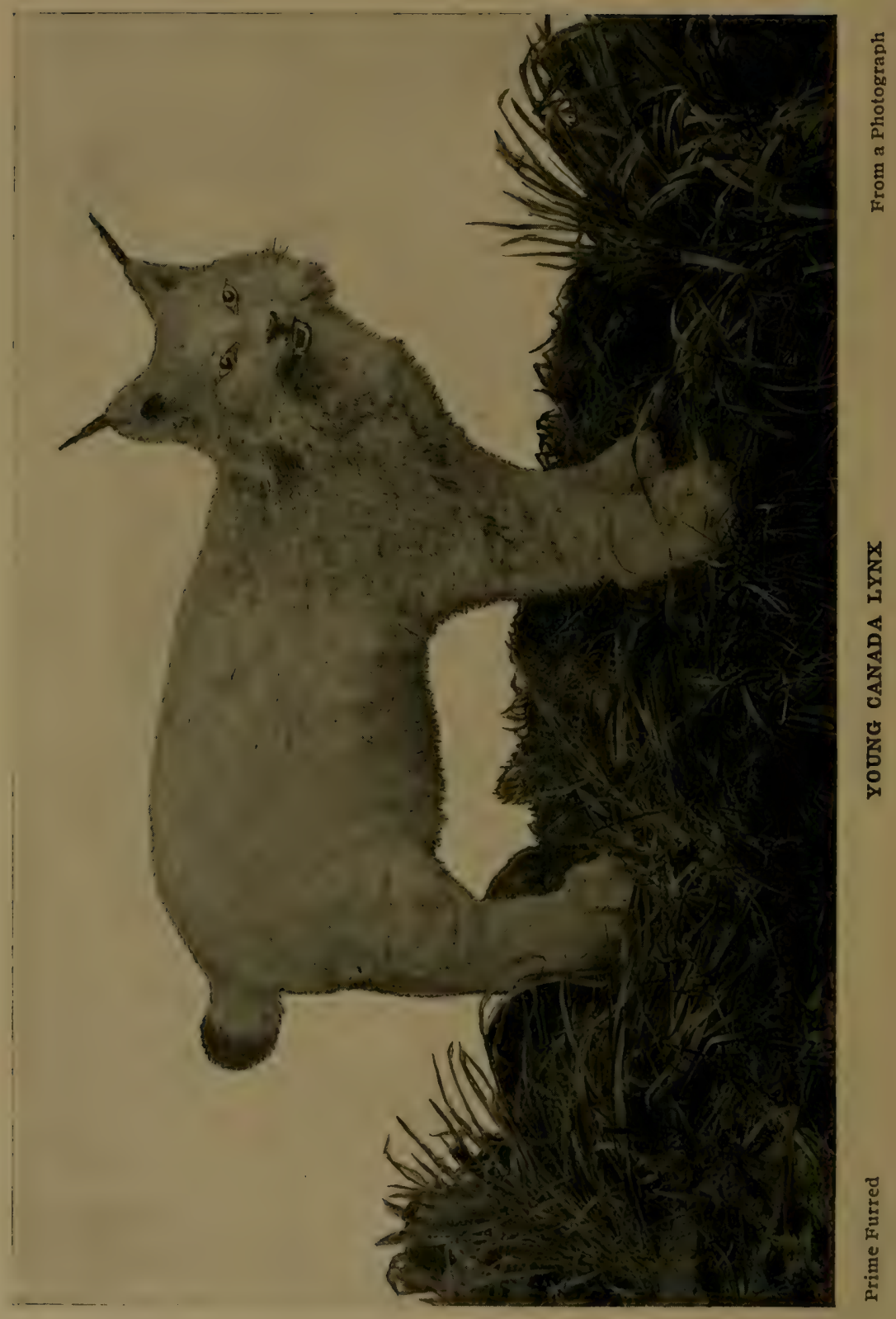


crouched and lay motionless on his belly, then he would ascend near-by trees, only to leap at once to the ground, acting in a very frenzied manner, indicating to the observing trapper that he wanted the rabbit very badly and was endeavoring to discover some way of obtaining it without delay, and without being obliged to venture too close to the spot where it lay. After the lapse of nearly ten minutes, he suddenly leaped from a tree, ran to the place where he had left the rabbit half an hour before, grabbed it, and turned about and off he went. But, alas! His forefoot sprung one of the traps. He yelped, dropped the rabbit from his mouth, took hold of the chain, and twisted it and whined. His hasty action, disregarding his usual trait of caution and alertness, was prompted by his eagerness to obtain the food that he thought belonged to him, rather than to let the approaching wolf have it. Having viewed all this from a tree, the trapper slowly desceniled, crossed the creek and taking his rifle, first killed one of the wolves and then the lynx. The bodies were skinned and about $t \mathrm{~cm}$ three Newhouse traps were set; the next day a wolf (prohably the other) had sprung the trap, and a rifle ball ended his nisery.

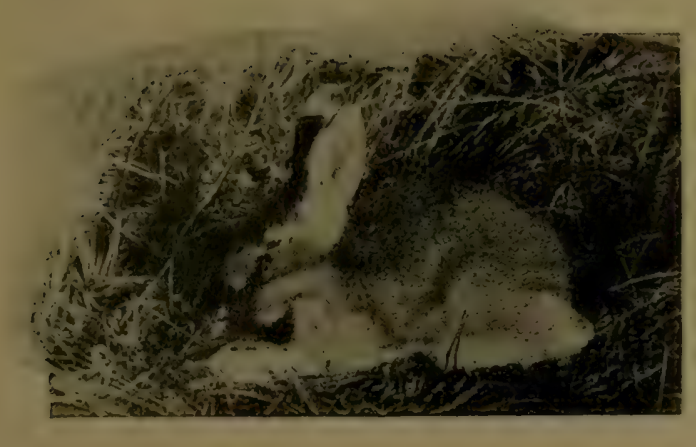




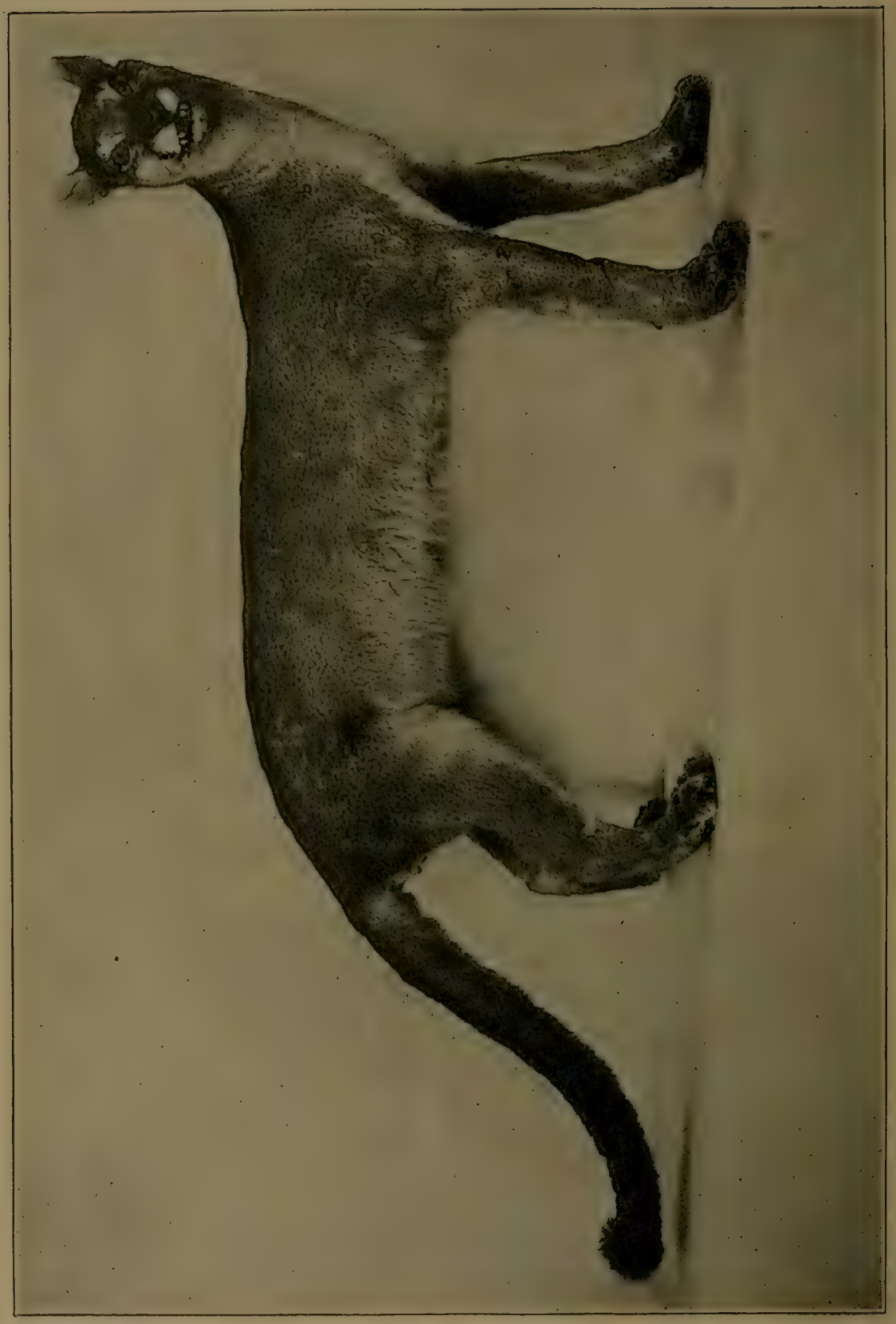

ป气

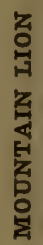

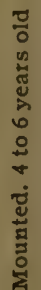




\title{
THE MOUNTAIN LION.
}

\author{
(Puma, Congar, An. Panther, Catamount.)
}

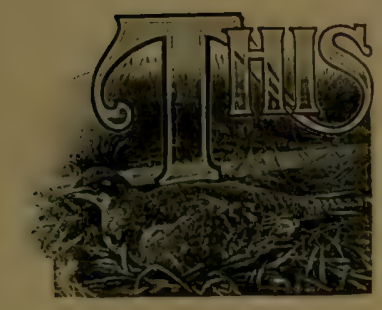

ANIMAL, known under the various names above, also American Tiger, is found principally in the western part of the United States along the Rocky Mountains from Mexico to Klondike in Alaska; also along the Sierra Nevadas and Cascade Mountains and probably in other portions of Canada, especially in the mountainous regions of Athabasca. The illustration accompanying this arficle indicates that the brute is 59 inches from nose to root of tail, the latter 33 inches long, and he stands 28 inches high from the ground to top of front shoulder. The animal possesses a uniform color, the southern species being of a few shades lighter than that of the northern, the latter being of a beautiful tan or golden brown color. The fur on the southern species is rather short and harsh, and evenly distributed about the body and tail. In color the belly portion is always a few sharles lighter. The animal has a white furred spot below the eyes, and quite often the fur on the neck and chest is of a whitish color. The fur of the northern species is about one inch long, not quite so harsh, but by no means soft or silky, and as aforesaid, of a golden brown color. Individual skins coming from the Klondike regions measure nearly six feet from nose to root of tail, and the latter is 36 inches long; but this skin was probably from an unusually large brute. The animal is eagerly hunted but is far from being exterminated. Undoubtedly it is great sport to bring this monstrous brute to bay. Mr. Theodore Roosevelt, now President of the United States, has killed many of these lions in the mountains of Colorado. There is no great danger in hunting this brute if one is cautious, but no one should attempt it unless he is a good shot, for if cornered or wounded the brute it likely to revert the tables. The animal is armed with sharp teeth, long and heavy claws, and his sneaking and pouncing attitude is only too well known.

The animal possesses carnivorous, nocturnal habits, and being of a bloodthirsty disposition, he awaits the coming of game from the trees, ridges, or upon some cliff, from which points he is able to pounce upon the victim. Their peculiar howls are distinguished from other animals and their lion-like roar sends chills through the inexperienced hunter or miner. Regardless of his bloodthirsty and ferocious nature, the animal will give wide 
range to man, and even if wounded he will seek to escape, but if closely pursued has been known to pounce upon the hunter, and if taken unawares, the latter is doomed. They are good climbers and readily take to trees when pursued by dogs, from which position, the hunter, if a good shot, can bring the brute lifeless to the earth.

His food consists chiefly of animals, both domestic and wild. and very few of the small mammals are excepted by him; all fall prey to this monster. He is able to carry away sheep, young calves and has been known to kill heifers, also colts. That a large number of deer fall prey to this monster, cannot be denied.

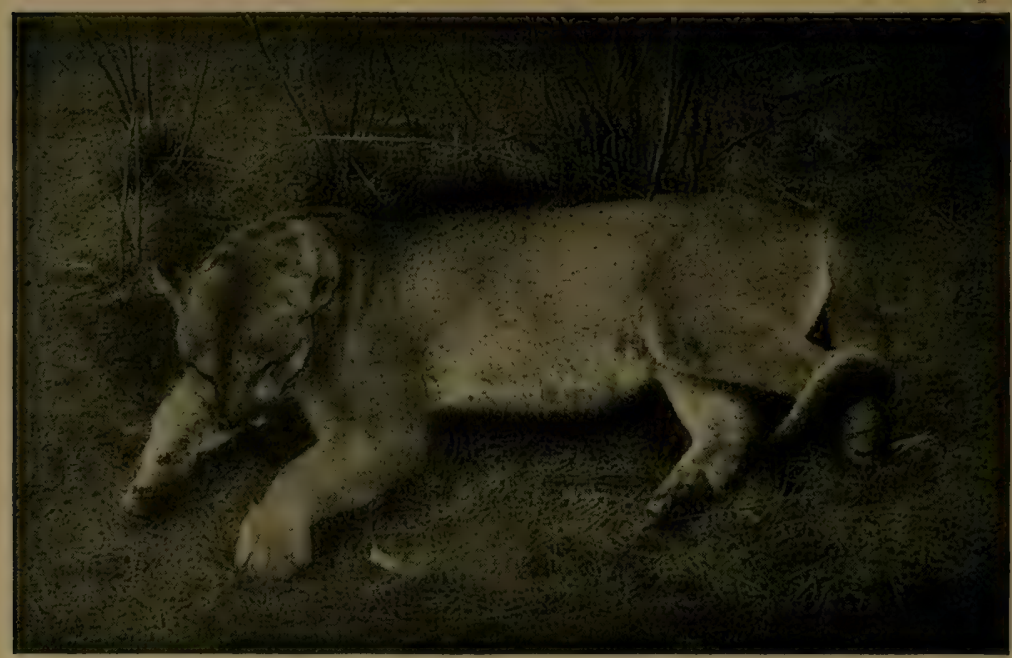

Photographed Springtime YOUNG MOUNTAIN IION

Courtesy of Along N. P. Ry. in Mont.

N. P. Ry. Co.

When the lion has seized a victim, he tears open its neck and laps the blood before he begins to eat. Small animals are devoured entirely, but the larger ones he eats only in parts, usually the neck and shoulders. The other parts are sometimes covered up with leaves, branches, grass, etc. His sense of smelling and of hearing is acute. His skin is used chiefly for rug, robe or mounting purposes, and unless head, feet and tail are perfect and attached, the skin becomes undesirable. Any hunter who is fortunate in bringing down this monster and desires the skin mounted should not fail to obtain the skull and leg bones. 


\title{
THE JAGUAR.
}

\author{
(Ger. Unze, Lat: Felix Onza.)
}

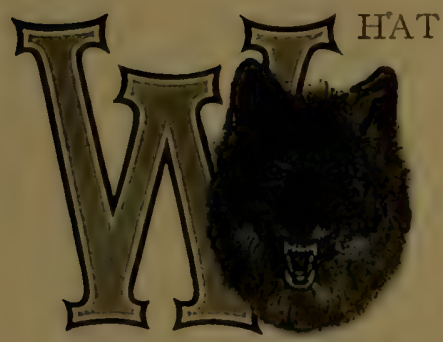

is true relative to ferocity, habits, etc., of the Puma, is also true of this animal, the largest of the cat species found on this contirent. Although its home is chiefly in South America, it was formerly found in large numbers in the southern states, especially in Louisiana and Texas, and it is still numerous in Mexico. It is safe to say that this cat has been driven away or captured, and that very few, if any, exist at the present time in the United States.

A full-grown jaguar will measure 55 to 60 inches from nose to root of tail, the latter being 25 to 30 inclies in length. The fur is soft and spotted similarly to that of the leopard, although the coat of the animal varies considerable in color, from a light brown and reddish hue to a dark, almost black appearance, all having peculiar spots upon the body and portions of the tail. The end of the tail however, possesses a dark plume-like tip followe:l by seven or eight ring formations similar to that of the raccoon, alternating black and brown and corresponding in color with that of the body.

Its favorite haunts are in swamps and jungles, bordering close to sections of timber and dense brush, and it is a frequent visitor in pastures, often lying concealed for hours near a path or trail where cattle, horses, mules or wild beasts are known to travel. He becomes master in a remarkably short period, rarely exceeding fifteen minutes, of the largest steer, cow or mule, ancl it is safe to say that whenever his teeth and sharp claws are imbedded in the animal's back and neck the monster has the prey at his mercy and every effort and the strength of the victim to remove the jaguar is of little avail. Small animals are downed with one of his paws-the animal possessing unusual and enormous strength-and often his victim is torn asunder by one stroke.

The jaguar will follow animals into the water, but seldom climbs trees after animals or bircls, though is able to climb and remain on trees and their branches for an indefinite period. Is known to swim a long distance and to go on board of anchored boats seeking food. Drelim relates having seen a jaguar near a stream in a crouching position looking into the water and succeeding in catching fish by a sudden movement of the paw, 
similar to our domestic or other species of the cat family, in that respect.

Rengger relates that the male, also the female, jaguar live alone during the greater portion of the year, and only during the months of August and September do the two sexes seek each other's companionship. A litter of two or three cubs is brotight fourth in the den or pit, the latter being protected from the sun or rain to a greater or less extent, generally in a thicket or forest.

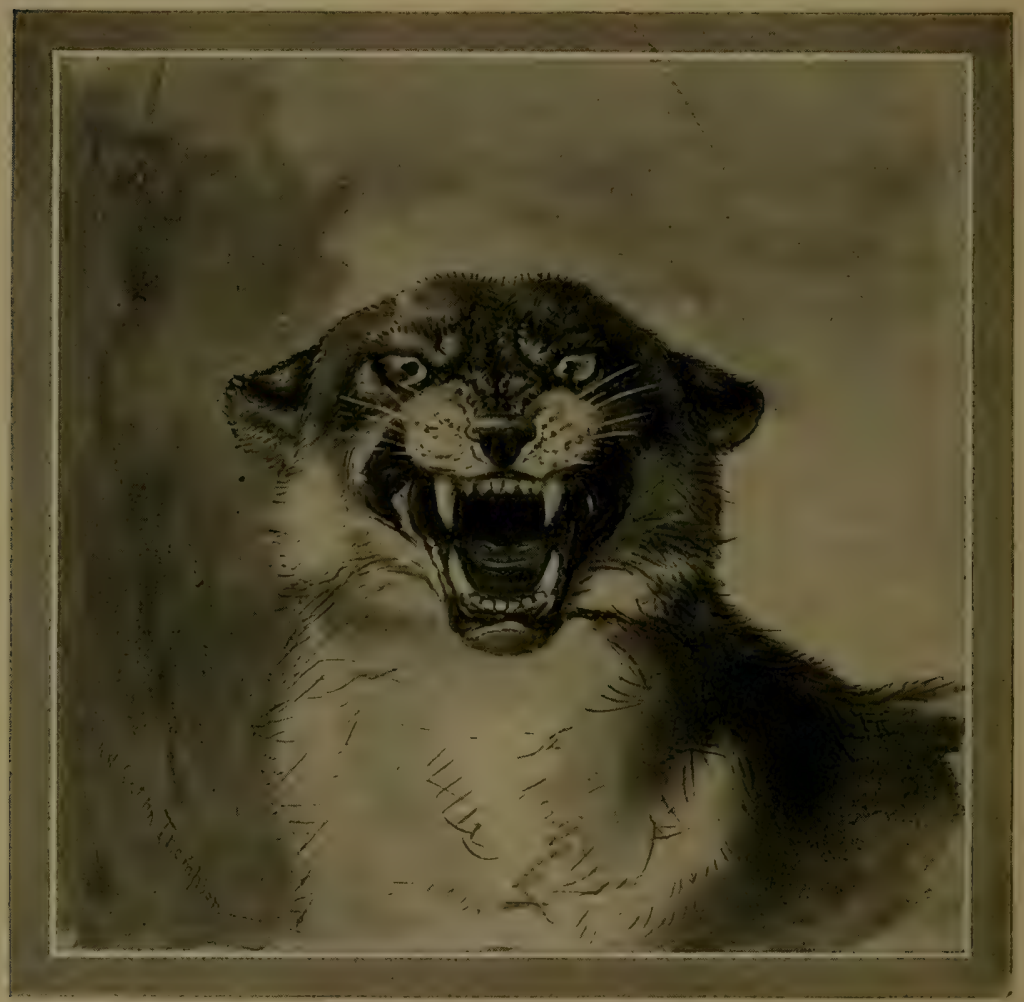

Erawn by
Thompson Seton $\quad$ ROCKY MOUNTAIN $\underset{\text { (FoUGAR }}{\text { Corllustration of Jaguar see page 8) }}$

The skins are used largely for rug purposes and have little or no value unless the head, claws and tail are perfect. Many mounted specimens can be seen in this country, also in Europe. Prominent southern planters and hunters possess skins as well as mounted specimens, the former made into rugs, the latter decorate their dining rooms or libraries. 


\section{THE WOLF.}

The Timber, The Brush or Buffalo, The Prairie or Coyote, The Black, The White, The Texas.

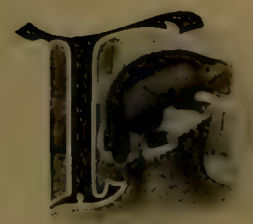

HIS animal is found in nearly all sections of the globe. Particularly so in North America, Asia and certain parts of Europe. Although varying in size, color, and apparently of different species, they all belong to the dog family, but we shall confine ourselves to the species that are known in this country.

There are very few farmers in the western states that have not at one time or another come in contact with one of these brutes. What the fox is to the poultry yard, the wolf, especially the larger species, is to sheep and calves. The wolf, like all other animals, fears man, but when in large numbers, especially if man is fearsome and the wolves hungry, the latter are rather aggravating, and at times victor over man himself.

\section{The Timber Wolf.}

A hunter in giving chase, or in his attempt to capture this brute, which like all others of its species belong to the dog family, has to contend with an animal of almost human intelligence. Few, if any, have superior sagacity and the art of dodging, and are at the same time more dangerous if cornered, than this carnivorant. He is large, robust, periodically lean, swift of foot, and has highly developed sense of smell, hearing and sight. His appetite is almost constant, and not of a fastidious order. Singlehanded he is a coward, but his appetite may revert to his ferocious nature at any opportune moment.

$\mathrm{He}$ is found in northern, western and northwestern states, also in Canada. He must not be confused with the smaller order elsewhere described under brush or buffalo, neither with the still smaller variety of prairie or coyote. Is also known under the name of giant wolf and grey wolf. The pelage of the northern variety during the winter is of a whitish to a greyish color, with one or two indistinct dorsal lines of black tipped hairs on the animal's back, extending from its neck to the tail. The fur part on the belly is of a dull, white color, and its legs are covered with a short fur ranging from a whitish to a slight yellowish cast. 


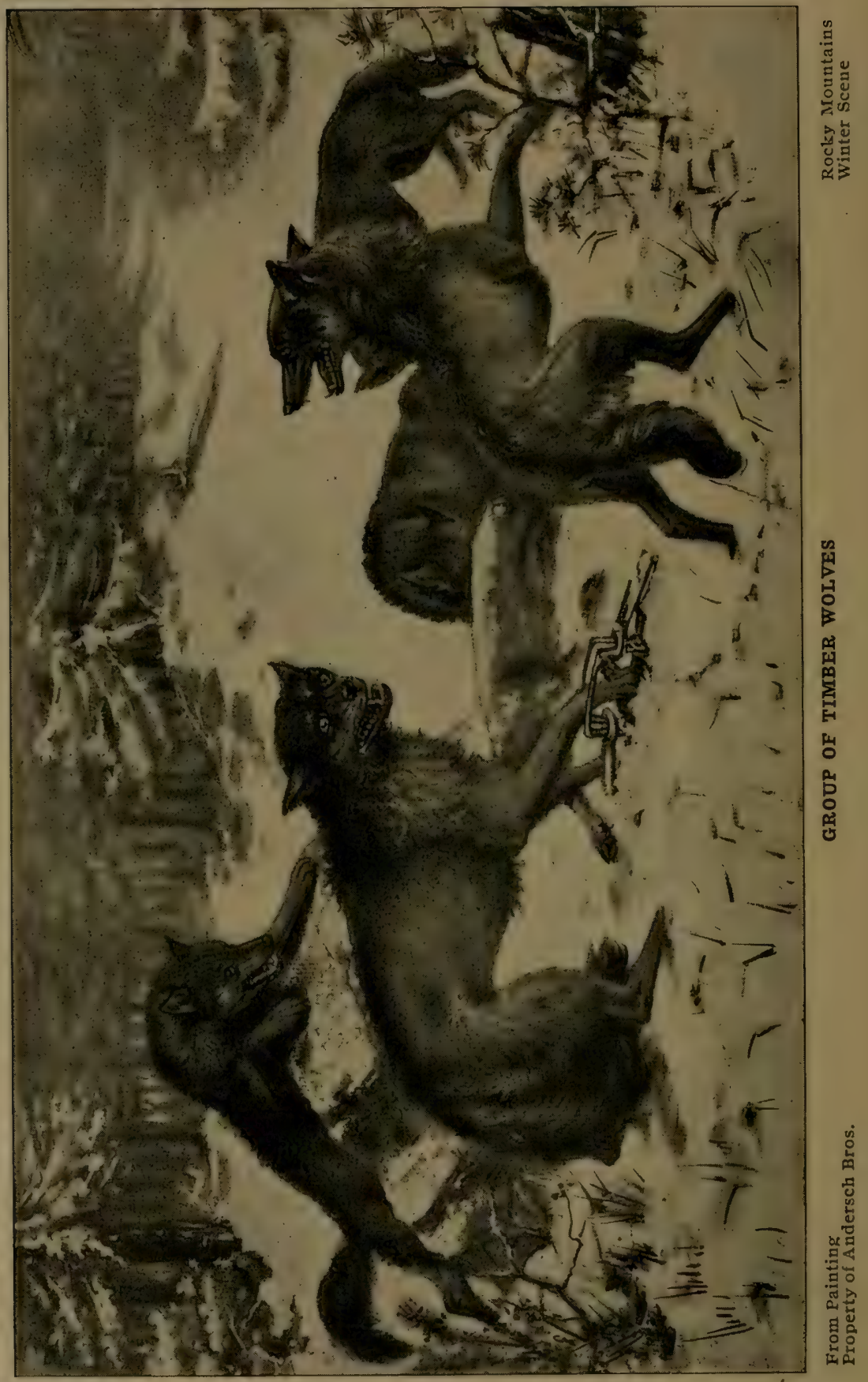


The latter color is almost absent on the northern species and becomes more distinct the farther soutl we go. The fur in general is coarse, and apparently the older and larger the animal, the coarser its fur. Such skins have a shaggy appearance, are of small value, and their use is confined to the making of rugs, robes, sleeping bags, etc.

Recently there was shipped to us from Canada what was considered by the shipper and his friends, to be a good speciman of a large timber wolf. The animal was killed by a Mr. Johnson in the vicinity of Galgary and shipped in a frozen state, reaching us in a well-preserved condition. The dimensions are judged to be as follows when the animal was alive:

Length from root of tail to extremity of nose....6 $1 / 2$ inches

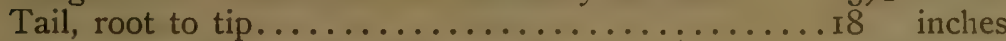
Height from floor to top of shoulders......... Circumference of body estimated.................. inches

Skins from other sections, and in particular one from northern Minnesota, measured 56 inches from nose to root of tail, the latter measuring $183 / 4$ inches over all, or its vertebræe 15 inches. The predominating color of the latter was steel grey, intermingled with dorsal of black-tipped hairs, and about the neck, shoulders and outer portion of limbs, a yellowish cast was noticeable. The belly portion was white. The body, especially round the chest, shoulders and the top portion of the front of the animal, was more densely furred; also the outer guard hairs longer as compared with the pelage on the other part of the body. The interspersed black-tipped guard hairs that appeared so noticeably on the animal's back, especially about the shoulders, terminated only near the tip of the tail.

\section{The Brush Wolf.}

This is also a northern species, somewhat smaller than the timber or grey wolf. Naturalists very often class this northern animal with the timber or grey variety, but in doing so they largely rely upon the exploits of the early explorers who failed to note the distinction, and those who did were impressed with the close similarity of the color of its pelage, construction and habits, and noted the comparative difference in size, but they inadvertently labored under the impression that they had a young grey wolf before them.

This animal is found in northern sections, usually about timber, along the bank of creeks, rivers and lakes; his favorite haunt is in brush, thickets, interpersed with open sections. He periodically inhabits prairie states, and of late years numerous skins 
have been received from the bordering states and particularly so from Canada. In size he is about one-half between that of the small prairie and the big timber species. The male is about onefifth to one-fourth larger than the female. The former attains a weight of 60 to 80 lbs. One fair-sized specimen that came to my notice, and which was killed in northern Wisconsin by being poisoned, weighed $7 \mathrm{I}$ pounds. As noted elsewhere, its pelage resembles that of the big timber wolf, but instead of its coat being coarse and shaggy, the fur on this one was unusually soft and dense. It does not compare in texture with that of the red fox. The predominating color ranged from a dirty white to a light grey, with a yellowish cast about the legs and hips, also with black outer hairs indiscriminately interspersed on its back.

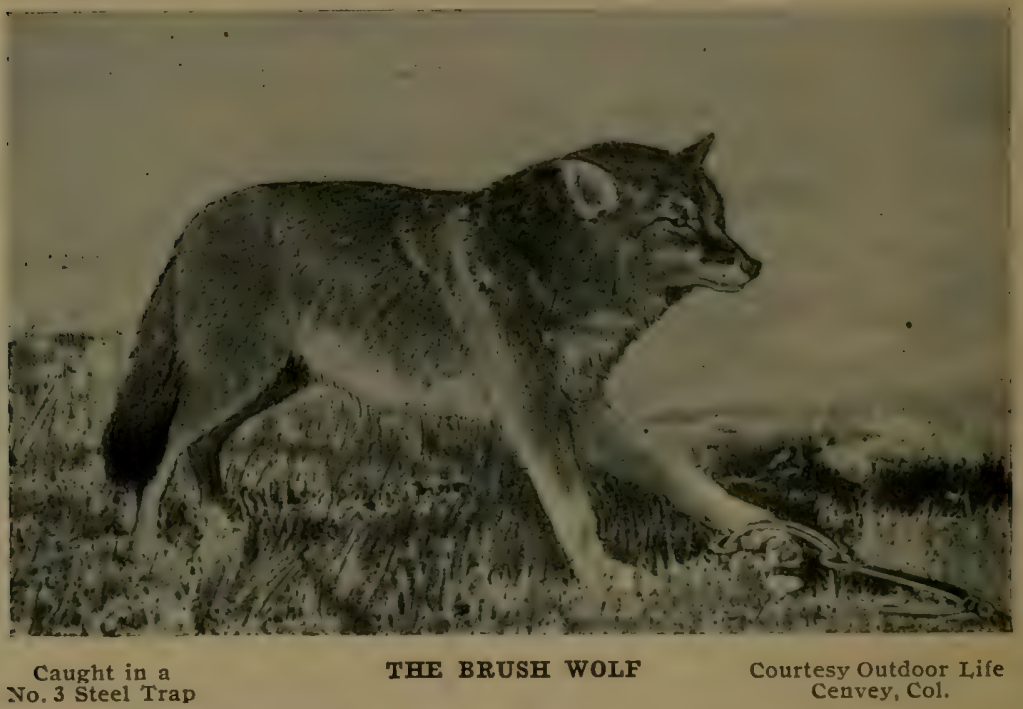

The skin of the animal during the winter time, if not otherwise damaged, is suitable for various purposes, and of late years the manufacturer has purchased the better grade of such skins, which are converted into the spurious tails so extensively used by the furrier in the making of ladies' neckwear, boas, etc.

\section{The Black Wolf.}

This dusky brute is now sparingly found on this hemisphere. Audubon and Bachman and other prominent naturalists claim that the black wolf, 40 to 60 years ago, was numerous in the 
southern states and in fact all over the United States. But what was true then is certainly not true today. The black wolf is b; no means extinct in this hemisphere, but is exceedingly scarce, and probably extinct in most states. During the last I 5 years, no less than 100,000 wolf skins of the various species came to my notice, and out of this number no more than twelve or fifteen were of the black variety.

The animal seldom attains a greater size than that of the brush wolf, although a larger specimen came to my notice two years ago. The animal from which the skin was taken must have weighed 85 to 90 pounds and resembled the timber variety more than the other species. Its pelage is comparatively finer than that of the timber or brush variety, being soft and mellow, also denser.

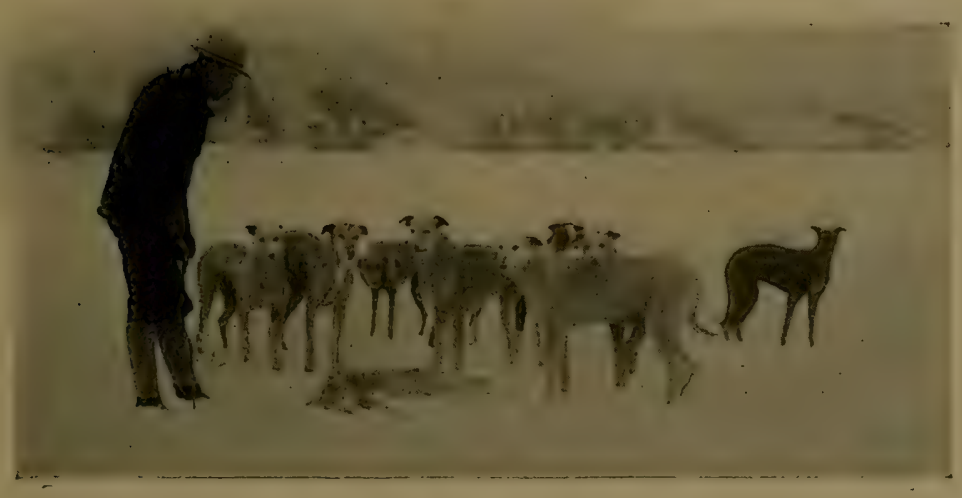

THE END OF A COYOTE HUNT

As its name signifies, the color of its pelt is black with steel grey hairs promiscuously interspersed with the large, lustrous guard hairs that bring the beauty to the skin. The fur is not kinky, curly or wavy, but the fibers are straight, smooth and of a mellow character. At times a white spot is noticed on the animal's chest, and again on the animal's tail. The black wolf resembles so closely a large, straight-furred black dog, that if the animal was tame and would follow a person in the street, he would pass unnoticed, unless for his remarkable size and beauty.

The following extracts from Audubon are interesting:

"About 70 or 80 years ago two young negroes residing near the banks of the Ohio in the lower part of Kentucky, habitually 
visited their sweethearts who were employed on a plantation some four miles distant. As to the lover every moment is precious, they usually took the shortest route which led through the cane brake. Winter had set in and the night was cold, dark and gloomy, when these two negroes, each with an axe on his shoulder, walked briskly along the narrow path, each having in mind only the damsel of his choice. Some transient glimpses of light now and then met their eyes in the more open spaces between the trees, or when the heavy drifting clouds, parting at times, allowed a star to peep forth upon the desolate scene. Fearfully a long and frightful howl burst upon them, and they were instantly aware that it proceeded from a troop of hungry and perhaps desperate wolves. Pausing for a moment, a dismal silence succeeded. All was dark save a short space of the snow-covered ground before them. Restmining their pace hastily, but with axes in their hands prepared for the attack, suddenly the foremost man was assailed by several wolves which seized on him, and inflicted terrible wounds with their fangs on his legs and arms, and as they were followed by many others as ravenous as themselves, several sprang at the breast of his companion, and dragged him to the ground. Both struggled manfully against their foes, but in a few moments one of the negroes had ceased to move. The other reduced in strength threw down his axe and sprang onto the branch of a tree and gained a place of safety among the boughs. Here he passed a miserable night; next morning the bones of his friend lay scattered around on the snow which was stained with blood. Three dead wolves lay near, but the rest of the pack had disappeared."

Superstition prevailed, not only in the southern states, but also continues among certain Indians and others in Canada as to killing this niggardly brute. A certain trapper and Indian trader informed me some years ago that this black brute is shunned by the white man as well as the Indian, that all believe that the fortunes of the individuals are affected by the killing of a black wolf.

\section{The White Wolf.}

In former years the white wolf was found to be quite numer ous in Montana, Idaho, Washington, Wyoming and Oregon, but of recent years has become almost extinct, at least such are the reports from that section, which are confirmed by the exceedingly small number of white wolf skins received in this and other principal markets of the United States. They are still quite numerous in Alaska and British North America. 
The skins are of no great value, being that the pelage is coarse, shaggy, and quite often the fur is of a yellowish cast, at other times interspersed with grey outer hairs which reduce the value of the skin, from the manufacturer's standpoint. The brute in size resembles more the buffalo or brush wolf than it does the big timber variety. Trappers observed, and Indians labored under the impression that a white furred wolf is a freak of nature, but their theory is apparently incorrect. Audubon says that the white pelage is the result of severe cold. Regnard informs us that in Lapland, wolves are almost all of whitish grey color; there are some of them white. In Siberia wolves assurne the same color. The Alps, on the other hand, by their relation may be compared to the region of the Rocky Mountains in America. In both countries the wolves become white. When Audubon compared specimens from the northern states with those of the Alpine regions, he found that both bore strong resemblance to each other in form, size, color of their pelage, and labored under the impression that there is no good reason why the older school of naturalists found distinctive character and separated the wolves into clifferent species. Certain tribes of Indians were opposed to killing the white wolf, believing as they did that by so doing they would incur the ill-will of tlieir gods, etc.

\section{The Prairie Wolf or Coyote.}

This brute is known the world over and resembles the European more than any of the other species. In the size and color of its pelage notable differences are to be recorded as between the animals inhabiting the northern states as compared with those of Texas or other southern range states. The former has a darker colored fur, and the yellowish cast is less prominent. The coat of the latter is coarse, short, somewhat light grey on the back and its yellowish cast predominates all over the body excepting the back.

Dr. Coues describes the prairie or barking wolf (Canis latrans) as by far the most abundant carnivorous animal in the western states and the coyote is commonly known as a thorough nuisance. The following words are borrowed from his works:

"The coyote theoretically compels a certain degree of admiration, viewing his irrepressible positivity of character and his versatile nature. If his genius has nothing essentially noble or lofty about it, it is undeniable that few animals possess so many and so various attributes, or act them out with such dogged perseverance. Ever on the alert, and keenly alive to a sense 


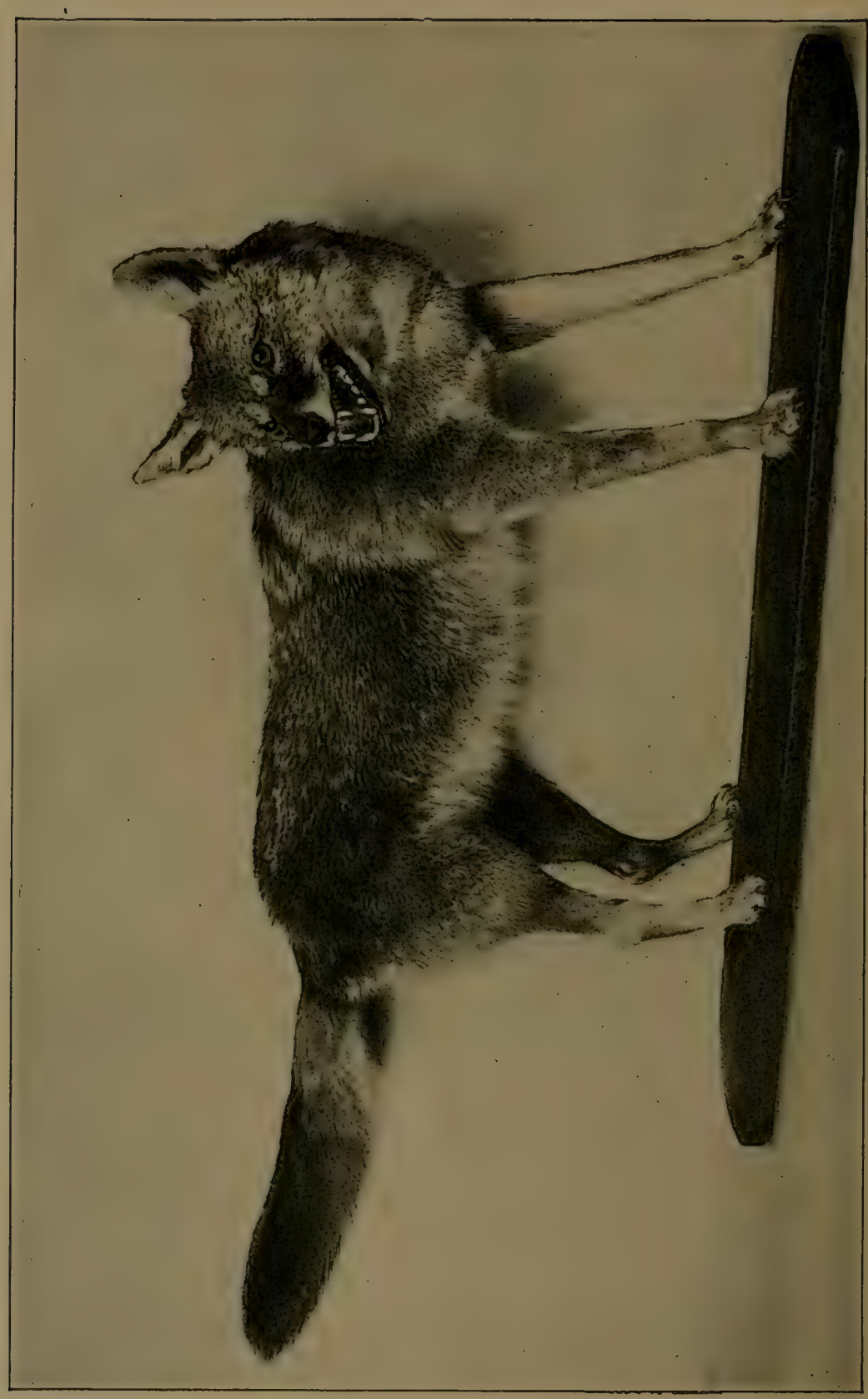

몀



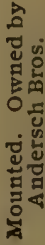


of danger, he yet exhibits the coolest effrontery when his path crosses ours. The main object of his life seems to be the satisfying of a hunger that is alway's craving; and to this aim all his cunning impudence and audacity are mainly directed.

"Much has been written concerning the famous polyglor serenades of the coyote, by those who have been unwilling listeners, but it is difficult to convey an adequate idea in words of the noisy confusion. One must have spent an hour or two vainly trying to sleep before he is in a condition to appreciate the full force of the annoyance. It is a singular fact tinat the now1ing of two or three wolves gives an impression that a score are engaged, so many, so long-drawn are the notes, and so uninterrupteclly are they continued by one individual after another. A slort, sharp bark is sounded, followed by several more in quick succession, the time growing faster and the pitch higher, till they run together in a long-drawn, lugubrious howl in the highest possible key. The same strain is taken up again and again by different members of the pack, while from a greater clistance the deep melancholy baying of the more wary lobo breaks in, to add to the discord, till the very leaves on the trees seem to be quivering to the inharmonious sounds. It is not true, as asserted by some, that the coyote howls only just after clark and at daylight. Though they may be noisiest at these times, when the pack is gathering together for a night's foraging, or dispersing again to their diurnal retreats, I know that they give tongue at any time during the night. They are rarely, if ever, heard in the daytime, though frequently to be seen, at least in secluded regions. Ordinarily however, they spend the day in quiet, out-of-the-iway places, among rocks, in thick copses, etc., and seek their prey mainly at night, collecting for this purpose into packs, as already noticed.

"The coyote, although a carnivore, is a very indiscriminate feeder, and nothing seems to come amiss which is capable of being chewed and swallowed. From the nature of the region which it inhabits, it is often hard-pressed for food, particularly in the winter season. Besides such live game as it can surprise and kill, or overpower by persevering pursuit, and force of numbers, it feeds greedily upon all sorts of dead animal matter. To procure this, it resorts in great numbers to the vicinity of settlements, where offal is sure to be found, and surrounds the hunter's camp at night. It is well-known to follow for days in the trail of a traveling-party, and each morning just after camp is broken, it rushes in to claim whatever eatable refuse may have been left behind. But it cannot always find a sufficiency of animal food, and is thus made frugiferous and herbivorous. Particularly 
in the fall, it feeds extensively upon 'tunas,' which are the juicy, soft, scarlet fruit of various species of prickly pear (Opuntia); and in the winter upon berries of various sorts, particularly those of the juniper (Juniperus pachyderma), and others.

"Coyotes are so annoying that a variety of means are used to destroy them. They may le shot of course, but to hunt them in the daytime is uncertain and hardly worth the trouble, while night shooting is still more laborious and unsatisfactory. Their cunning, inquiring disposition is ordinarily more than a match for man's ingenuity in the way of traps. The most certain, as well as the easiest methods of obtaining them is by poisoning the carcass of a dead animal or butcher's offal with strychnine. There is no doubt, also, that the odor of asafotida is attractive to them, and a little of this drug rubbed into the poisoned meat greatly heightens the cliances of their eating it. Since, after eating the poison, they suffer greatly from thirst, it is well to place a tub of water conveniently at hand, which generally keeps them from making off for water, and so being lost. There is considerable difference in the fur, both as to quality and color, according to the season. In the winter it is fuller, thicker and softer than in the summer, and has much less tawny or rufous about it, being almost black and grizzled, grayish white.

"Except under certain circumstances, there is a chronic feud between our domestic dogs and these dog-wolves. A good-sized dog will easily whip a coyote, though he may not come off unscathed from the sharp teeth and quick snaps of the latter. I have known a smallish terrier even to kill a coyote, of which he caught a throat-hold, enabling him by vigorous shakes to beat the wolf's skull against some boulders between which the conflict took place. Notwithstanding, there is abundant evidence that the coyote will cross, and bear fertile offspring with the domestic dog; and I believe that the female of either will take the male of the other. During the season of heat, which is in the spring, I have known dogs to disappear for several days, and return in such a dilapidated condition as to leave no doubt that they had been decoyed away by some female coyote and received hard treatment from her or her relatives. The hybrid is said to possess the bad qualities of both parents, and the good ones of neither, as usual with bastards, and to remain snappish and intractable, in spite of severity or kindness. The gestation of the species, as is well-known, does not differ materially from that of its allies. It brings forth in May or June, in secluded places, usually under or among rocks. Five or six puppies are ordinarily produced at a birth.

"A variety of absurcl stories regarding its re-production pass 
current even among the best-informed backwoodsmen; many affirming that the pups are born shapeless, inchoate masses, to be afterwards licked into proper shape by the mother."

The mating season occurs during the spring months, varying somewhat upon the altitude and climate. After 60 to 65 days the mother bears four to eight young. The birthplace is usually in a hollow log, cave or burrow, and sometimes in dense brushes. The young are born blind and remain in this state for a period of twenty-one days. Their growth seems retarded until they reach the age of forty-five to sixty days, when they develop by astounding degrees. The mother attends to them carefully, and her love does not cease until late in the fall when the young drift away and begin life upon their own resources. In their playful mood they resemble the actions of a litter of pups. They bark, bite, and amuse each other in dog fashion.

The average age of the prairie wolf or coyote is from eight to twelve years, though individuals have lived as long as fifteen and twenty years. As a rule the large northern timber wolf attains its enormous size only after three years and continues, and probably not earlier than Io years does his age begin to show in mis tactics, and shortly thereafter he is left behind if he finds himself in a chase with younger brutes.

The female is invariably smaller than the male, and her depredations are more noticeable during the season when with her young. At times she takes very desperate chances, apparently disregarding her usual cautiousness in her endeavor to procure food for her young.

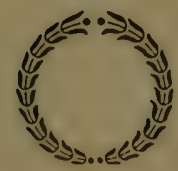




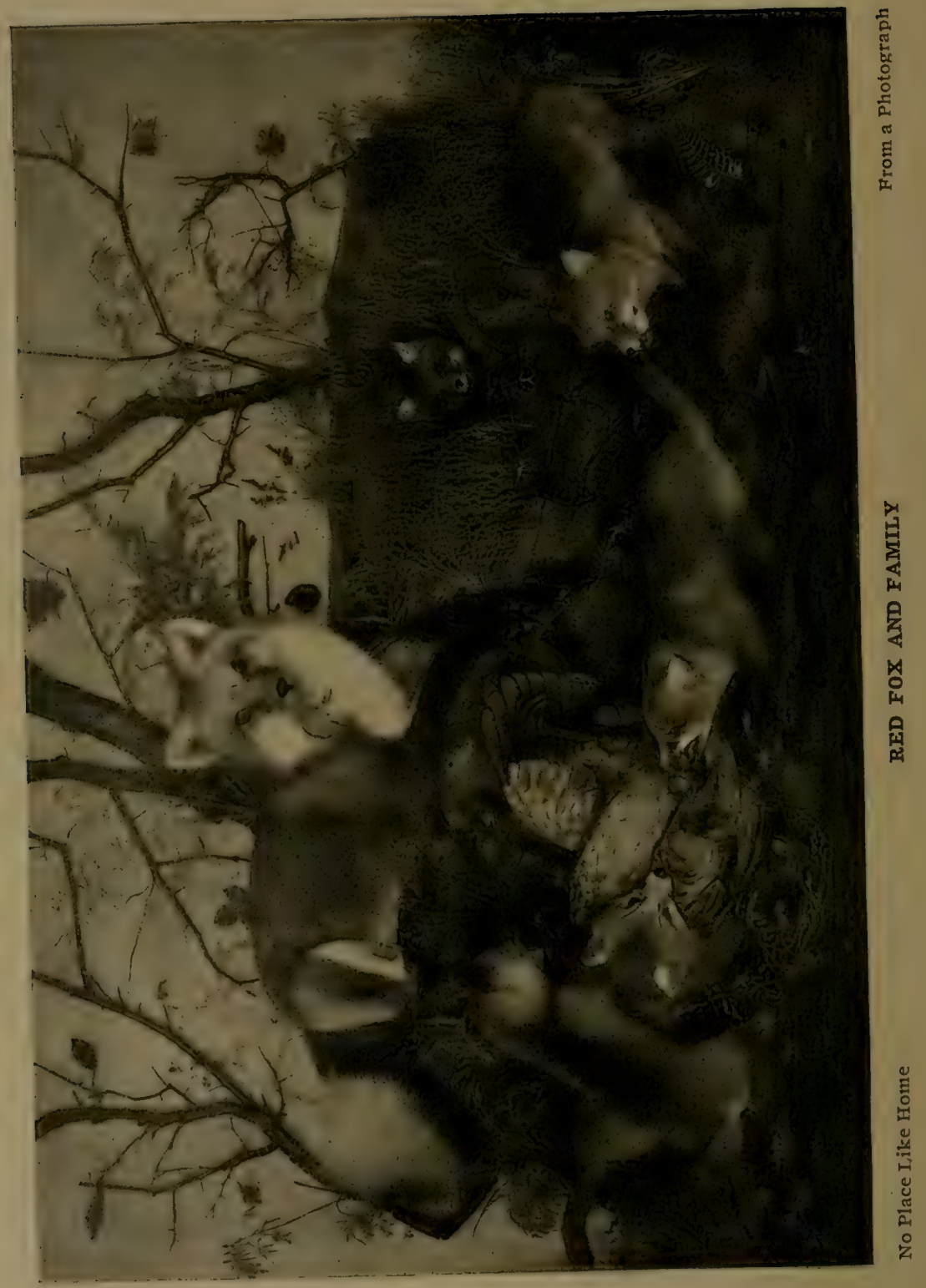




\title{
THE FOX FAMILY.
}

\author{
The Swift or Kitt Fox, The Red. Fox, The Grey Fox, The Cross, \\ The Silver Grey, The Black Fox, The White or \\ Arctic Fox, The Blue Fox.
}

\section{THE RED FOX.}

(Gcr. Rot Fuchs, Lat. Vulpes fulvus.)

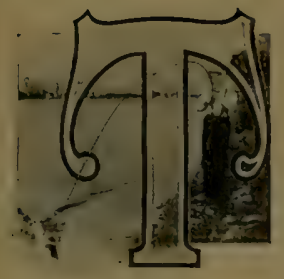

HE American red fox bears close resemblance to the European, but one who compares the two together will readily note many. distinct differences, notably the American has a larger body, longer and softer fur, and finer and larger tail, and the value of the skin is much greater than that of the European specimen. They all belong to the dog or wolf family.

In size tl:e American red fox varies unusually much in the different sections; so does its color and length of fur, and the value of its skin diminishes; or increases, as the case may be. The smallest animal is found in the eastern states, while the largest makes its home in northern Minnesota, Dakota, in Manitoba, parts of Assiniboia, Alberta and Saskatchewan. The latter are not only larger in size, but the fur is much longer, finer, and in color ustally two or three shades lighter than that of its eastern brethren.

Probably the largest and best furred skins come from the Turtle Mountain regions. The marked variation in color and quality of fur on the red fox is entirely due to climatic conditions. The average red fox will measure 25 to 30 inches in length, and its tail, which is bushy, has a white furred tip. The weight of a northern fox is from 25 to 35 pounds. An eastern fox will scarcely weigh more than 20 to 25 pounds. The color of its pelage ranges from a deep red to nearly white, with a yellowish tint. Audubon's description of the animal, is as follows:

"Point of nose, outer extremity of ears, and outer surfaces of legs below the knees, hlack: foreheid, neck, flanks, and back, bright reddish, and a little deeper tint on the back and fore- 
氮.

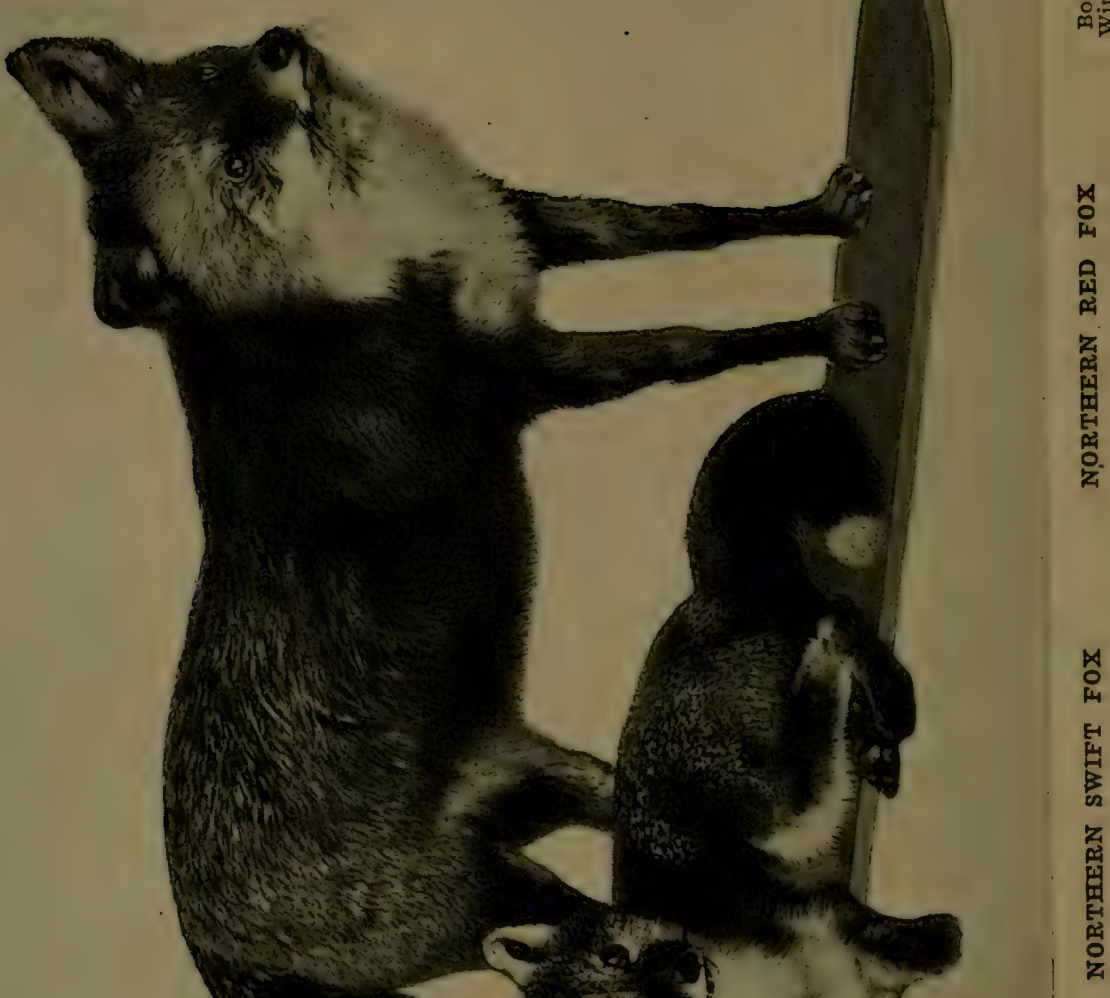

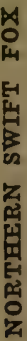

के 
shoulders; around the nostrils, margins of the upper jaw, and chin, pure white; throat, breast and a narrow space on the upper surface, dingy white; extreme end of brush slightly tipped with white; inner surface of ears, and base of the outer surface, yellowish. The hair on body is of two sorts; long hairs interspersed among a dense coat of softer, brighter, and more yellowish fur; on the tail the longer interspersed hairs are more numerous, and many of them are quite black, giving the tail a more dusky appearance than rest of the body."

Dimensions red fox killèd in central Minnesota, January, I905.

Length, point of nose to root of tail.......30 inches.

Length of tail (vertebræ) ............. in

Length of tail over all...............

Circumference of borly (fur natural) .....24 inches.

Circumference of tail (fur natural) ......... inches.

Height at shoulders.............. inches.

Habits. Notwithstanding the great diversity in the color of the animal's fur and other differences in the various sections of the United States and Canada, they can all be safely included in this species of the red fox. There is probably no other animal that is as daring, more cunning, at the same time always on the alert, quick of action and keen of smell, as Mr. Reynard.

Being carnivorous and possessing nocturnal habits, he becomes a robber of the first magnitude. Like the wolf, when the ground is covered with snow, he has difficulty in obtaining sufficient food and becomes quite desperate. His food consists of rabbits, nice, squirrels and other small quadrupeds. He certainly does not neglect grouse, chickens and other birds. The fox is also known to frequent ponds and rivers in search of fish and crabs, which are rapidly devoured with greatest appetite. Owing to their fondness for eggs and poultry, the farmer's barn-yard and coops are often frequented. In this respect he is known to be a greater robber than the mink, or weasel, and probably more harmful than the two just mentioned, or the wolf. If hunger is severe decomposed meat, fish and poultry are relished by him.

Its mode of capturing prey, is numerous, and due to his cunning, extreme fine sense of smell and hearing, is able to approach and capture his victim, by creeping stealthily within springing distances, and like a cat, spring upon it unawares. Should the victim be a small animal, such as the mouse, the fox will tantalize, tease, maltreat and handle the victim in a playish mood, similar to a house cat handling a recently captured mouse. 


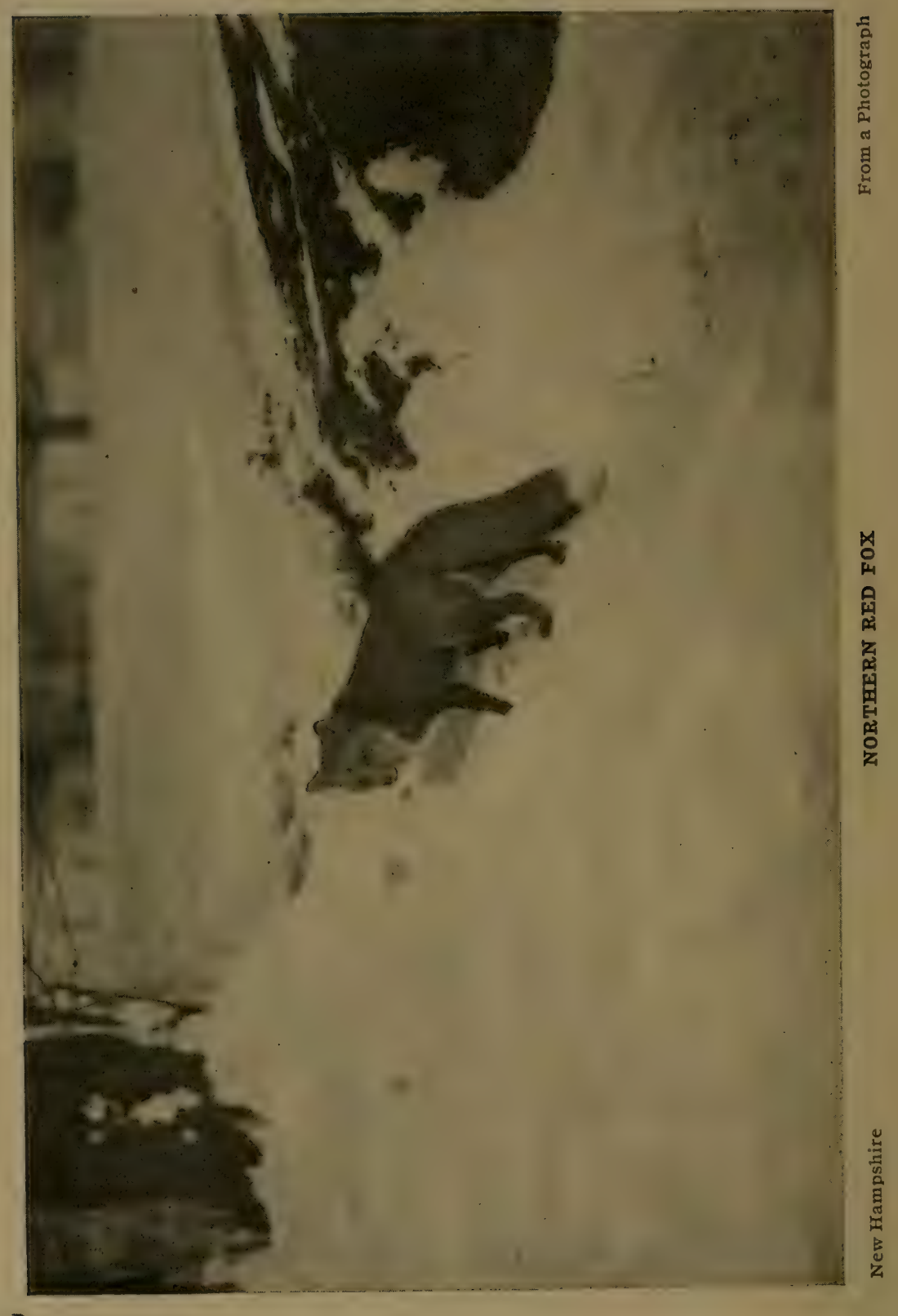


The mating season starts in the early spring, and after an expiration of two months, the female brings forth a litter of from four to ten young, which are born blincl. The mother remains steadily with her new-born babes two or three days before seeking nourishment. She is extremely fond of her young, and protects them against all enemies. Is known to carry her young atway from their birthplace upon approach or danger. The den is generally well concealed, usually in holes dug in the earth, or in rocks and sometimes in hollow trees, at other times the birthplace is in dens made by other animals, especially the badger, with whom she readily attains grcat friendship.

In about 25 to 35 days the young will begin to assume grit and expose themselves in the sun and play in a frolicsome mood, but usually the mother is ciose at hand, and gives her young the advice and protection sine affords. Later on the mother will take the young for a short stroll, teaching them the art of thievery, manner of preying, and when they become five to six months old, she leaves them to shift for themselves.

It is seldom a person is able to approach a fox den, but some years ago while in MIontana, I was attracted by a peculiar noise, and upon investigation found six to eight young, evidently awaiting the return of their mother. It is pleasing indeed to watch them from a distance, and especially when their mother appears with insufficient food for them all. It is to be noted that. both the mother and father provide food for the young, especially will the latter attend himself to the wants of his offspring in severe weather.

The fox has enemies in the wolf and bear, besides man. It has not come under my observation that our eagles are of sufficient boldness to pounce upon a red fox, much less their ability to lift a full grown fox with them into the air. The following however, is interesting and undoubtedly true.

Mr. Tschudlie, as related by Breim, states that he personally saw a large eagle grab a fox and fly away; a few minutes thereafter, the eagle with its prey descended on a ridge, and for curiosity's sake was followed by Mr. Tschudie, and, much to his surprise, on his approach the same fox ran past him, and on nearing the place of descent found the eagle bleeding furiously and unable to alight. The fox had evidently turned the tables by twisting, while in the air, and got hold of the eagle by the throat, and on the approach of Mrr. Tschudie the fox was disturbed from devouring its former antoganist. 


\section{THE GRAY (GREY) FOX.}

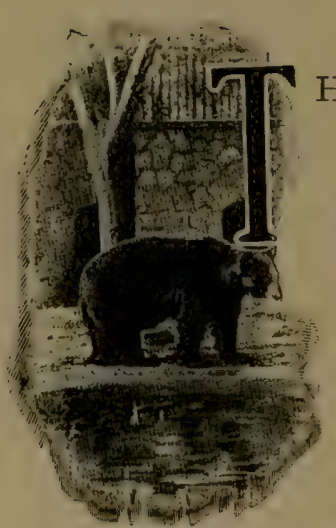

\section{(Vulpes Virginiamus.)}

$\mathrm{HE}$ gray, like the red-fox, is carnivorous, nocturnal, more shy and of rather a cowardly disposition, is found in all southern, middle, western and Atlantic states, scarcely seen in the northern states and almost unknown in Canada. Although timid and suspicious to a greater degree, his cunning and voracity place him in a prominent rank among the animals that prey upon weaker species than themselves. The gray fox, in the eyes of the southern planter, is what the red fox is to the northern farmer. Judging from personal observation and contact with these two species, and from the best information obtainable coming as it does directly from farmers, hunters and trappers, it appears that the red fox is far more to be dreaded than the gray; the latter is a pilfering thief, the former a more daring and cunning plunderer.

In size the gray and red fox are almost identical but variation in general construction and in color of pelage covering its body, head, legs and tail exists. The chief comparative characteristics in color, is that the pelage of the gray fox is gray, feet, ears and legs red, and while lower portion of the tail is red, the upper is invariably black, terminating in a black tip. The belly portion is always of a reddish cast, intermingled with three or four white blotches, usually one at lower lip and extending to neck, another at the animal's chest or between its fore legs and the last about the rear flanks. The pelage as a whole is much coarser and especially is this true of extreme southern species as compared with the red fox. The guard or outer hairs of the southern gray fox are harsher, coarser and occasionally bristlelike, resembling somewhat in texture and color the outer garment of a two-year-old silver tip bear. The gray fox is also known under Woods' gray fox.

Habits. In its habits the gray fox resembles its northern brethHabits. ren. It lacks boldness, is easily scared and refrains from visiting the barnyard to as great an extent as Reynard of the north. Inhabiting a more civilized section, and having no severe winter to contend with, his food is more easily attainable in the open or wooded sections, consequently his depredations and nocturnal visits are less frequent and costly to the inhabitants. His 


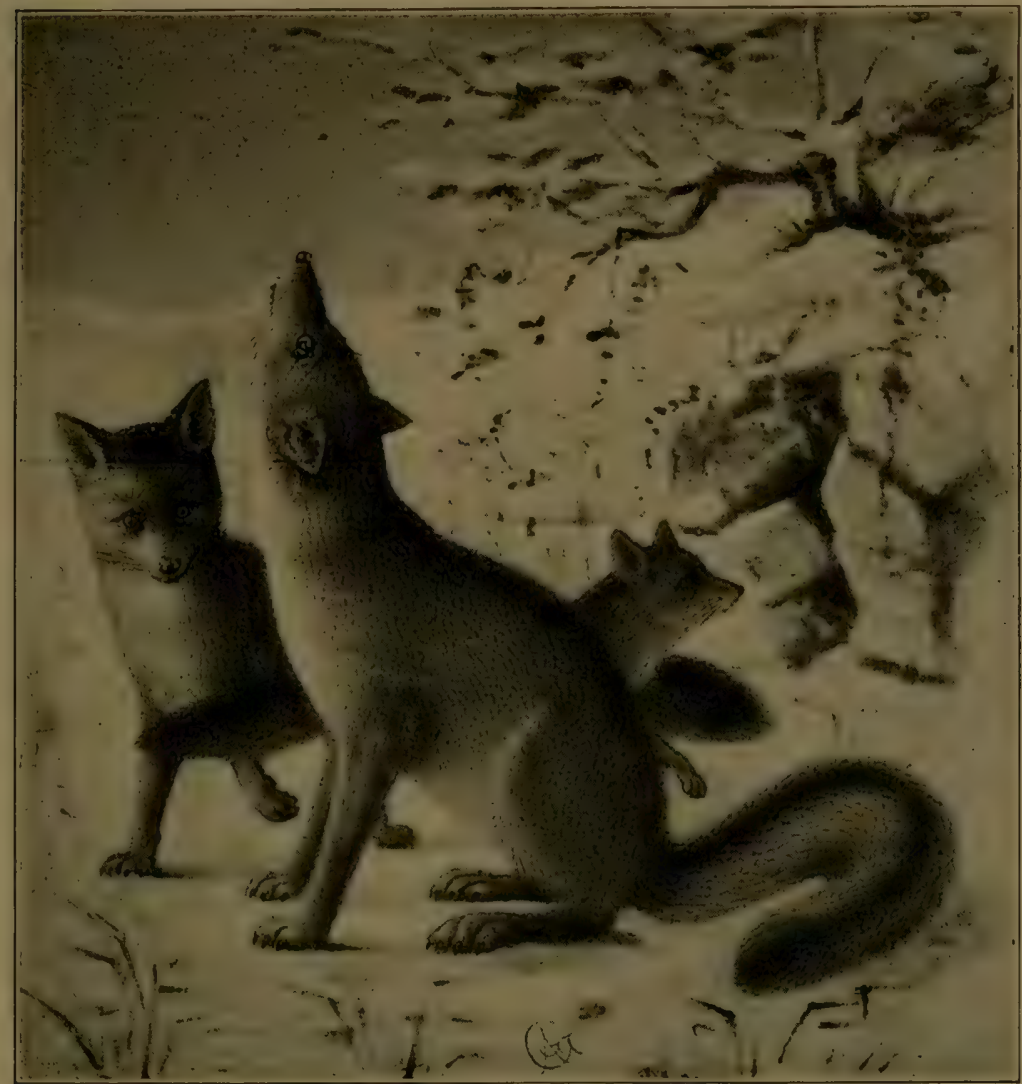

Winter Scene

THE GREY FOX

S. W. States

favorite place of abode is along thickets, or in large tufts of broom corn.

$\mathrm{He}$ is forced to seek safety frequently in the limbs of trees, when hotly pursued by hounds or the hunter. Thus his arboreal habits are not natural. Lacking the retractable claws, he necessarily gains his higher altitude by jumping, catching or pulling himself from one limb to another until he has attained a suitable position on some obscure limb. Not having personally seen the animal climb, I naturally investigated twenty or thirty reports from hunters and trappers, and invariably found that the animal will not climb trees of its own accord, and only occasionally if 
chased, will he seek a place of refuge by the unnatural trait of climbing.

The gray fox produces three to five young at a time, and these are invariably born during the month of April. Their usual abode is in caves, burrows and occasionally in hollow logs.

\section{THE SWIFT FOX.}

\section{(Kitt Fox, Lat. Vulpes velox.)}

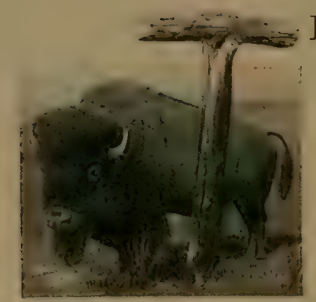

HE sivift fox is the smallest of all the foxes, and strictly a northern species. Judging from the number of skins received, the animal must be quite numerous in Montana, Idaho, Oregon, Washington, and in that part of Canada embracing British Columbia, Alberta, Assiniboia, Saskatchewan, and probably extending to the Great Slave Lake.

In size he is only one-third to one-half that of the red fox. A good comparison can be had by viewing the stuffed specimen in connection with a red fox, as illustrated elsewhere in this volume. The animal is certainly swift of foot, hard to shoot or trap, exceedingly cunning, more so than the red, gray, or southern prairie fox. Its pelage is more of a woolly nature, topped with gray pointed guard hairs that extend over the fur fibers one-quarter of an inch. The belly portion, beginning with the under lip and extending to the rear flank, is covered with a thin, but long white fur. Its legs are partly covered with white and reddish colored fur, the tail, which is eight to ten inches long, is less bushy and terminates with black hairs. The animal is very cute, neat, and of a pleasing appearance, but when cornered, shows his teeth as do the other species.

Habits. Like the other species, the swift fox possesses carnivorous and nocturnal habits, but being of small size is obliged to confine his depredations to small animals or birds Mr. Twamley advises me from Lethbridge that the swift fox is fully as hard, if not harder to trap, than the red, cross or silver fox. He further states that many are annually killed with poisoned bait. The same gentleman tells me that he is a match in swiftness, cunning, sense of sight and smell to the red fox. He is certainly sly, and the color of his pelage and smallness of body are advantageous in his pursuit of game.

An interesting narrative of an encounter between a swift fox and a large Canadian goose is related by him and is here appended. 
"One morning in the early fall, I chanced to observe a very interesting battle between a swift fox and a large Canadian goose, in which the former, as luck happened, at first won, but later paid the penalty. Coming slowly over a hill to a lake known to me as a stopping or resting place in the southern flights of our large Canadian geese, I perchanced to see a flock of them at the extreme edge of the water. Wishing to get closer, I crawled upon all fours to a more advantageous position, when to my surprise a swift fox jumped from its place of concealment, slightly elevated, and landed square upon the back of a large gander. My first impulse was to fire immediately, but upon second thought resolved to await developments. The fox, as noted, jumped upon its back, but failed to secure better than a wing hold, and being of light weight, the goose had little difficulty in its fluttering and attempted flight, to literally ilraz; the fox several feet further into the water. As luck would have it, the tussel took place in very shallow water. After a continued struggle and fluttering, the fox finally secured its desired hold, and the matter, so far as the goose was concerned, was a thing of the past. Upon being sure that the goose was unable to escape, the fox jumped and waded to shore, shook himself, and then again made for the goose and slowly dragged it to the shore. At that point I interfered by discharging the rifle, killing the fox instantly. This gave me the fox to skin and a goose to eat."

The skin is of small value, seldom exceeding $\$ 1.00$ in price for the best. The average price for years past ranged from $35 \mathrm{c}$. to $75 \mathrm{c}$. The season for propogation is in conformity with that of other species inhabiting that locality. The abode of the parents at that period is in caves, burrows, under rocks, seldom in hollow trees, and always in some isolated localit.v. 


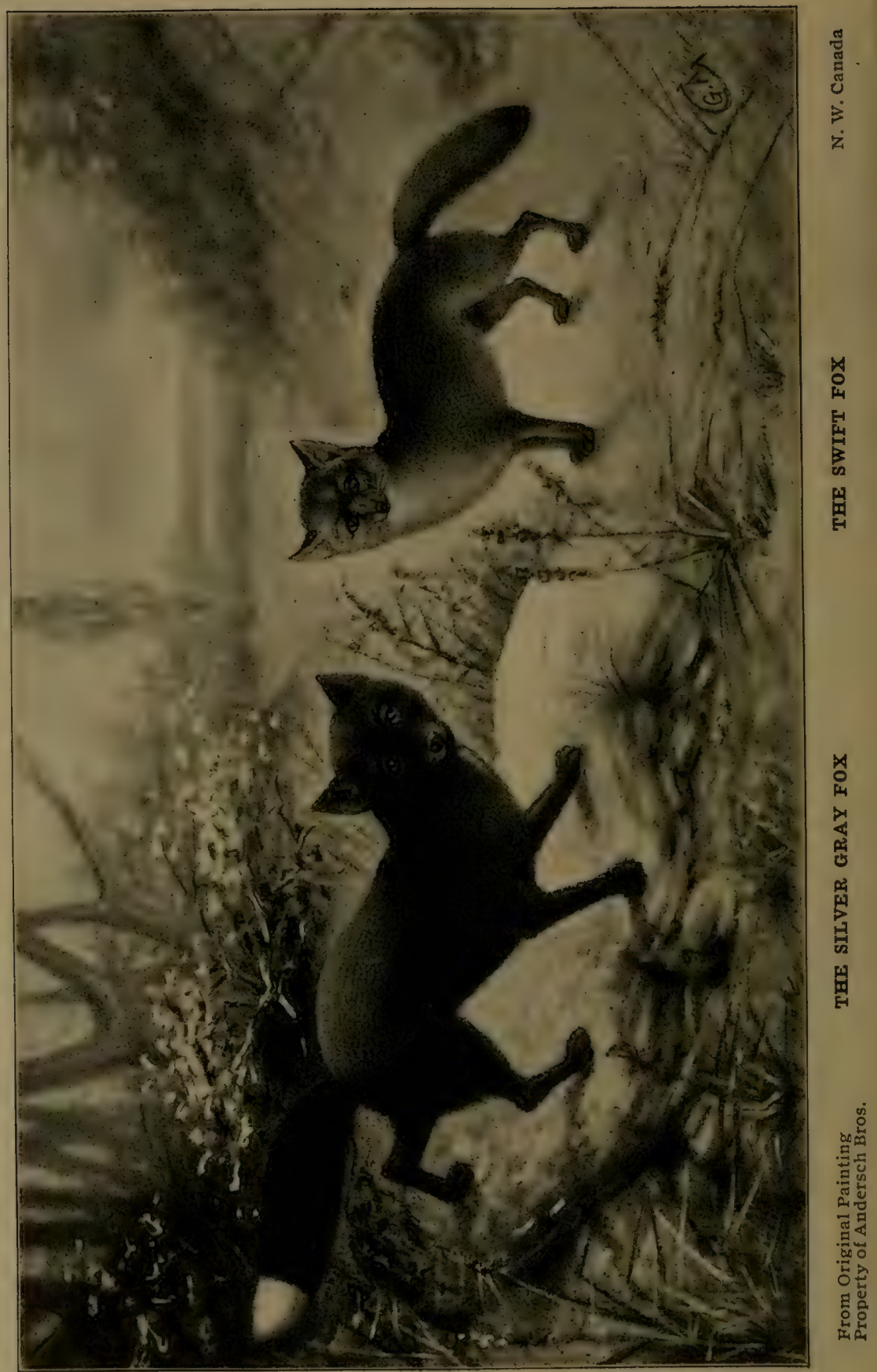




\section{THE CROSS FOX.}

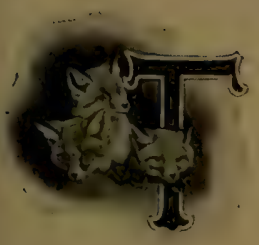

HAT such a fox should be different from what the name signifies, would be like calling a half-blood an Indian, or an Indian a Caucasian, or vice versa. No satisfactory explanation has been given why it is that the northern species will interbreed, and not the southern. Of course we all know that the cross fox is the probable result of inter-breeding between a red and black, or a red and silver. Historians fail to state the beginning of this inter-breeding, neither are we assured just what were the original breeds or species. Perhaps at one time there were only black, red and swift foxes; these three seem to possess distinct features. To advance the theory that the northern cross fox is closely related to the southern gray fox and that the present differences are entirely due to climatic conditions covering a period of perihaps 800 to $\mathrm{I}, 000$ years, is in line with the modified changes noted even in our own time. What old trapper or keen observer has not noted the changes in our climate as compared with fifty years ago, likewise changes in the color, habits and numerosity of wild animals?

The writer has personally observed the close relation between the cross and silver fox captured recently, and as much as twentyfive years ago in the state of Iowa, northern Minnesota, and one specimen in particular claimed to have been captured in central Illinois. Such an animal or its skin, if placed at a distance of ten feet from the observer and not permitting closer examination, one who is qualified will be in doubt as to whether the animal or skin is a northern silver or a southern gray fox. Close observation, however, will convince that the species is just between the two. The size and color are identical. The fur, of course, is coarser, and probably not as deep.

As will be noted, a cross fox is not a distinct species, and that in size he resembles the gray, black or silver fox. The pelage indicates variable changes, some leaning more towards the red, others toward the silver fox. The lower portion of the back, the belly and the hips, are usually covered with black fur. In the northern latitudes it is to be noted that the cross fox species will breed more together than inter-breed with the black, silver, or red. fox. The habits are all about the same. 


\section{THE SILVER GRAY FOX.}

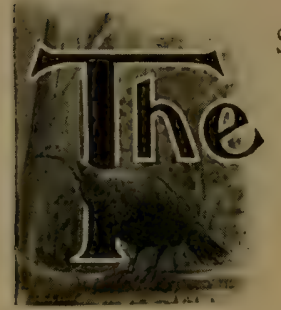

SILVER gray fox is a northern species, scarcely found in the northern states of our Union, more numerous in Canada and Alaska, also in other cold sections of the globe, notably in Siberia. In size, habits, mode of propagation, etc., it resembles the cross and red fox; is slightly larger than the blue or white fox. Its pelage consists of a beautiful coat of silver gray to black fur, that in beauty is only next to that of the scarce black fox. The price of the skin is graduated by its size, perfectness, primeness and general appearance, varying upon the quality, texture and color of its black fur. The darker furred skin is worth more than a lighter. The animal's tail is covered with a dense coat of jet black fur. The guard hairs are jet black, lustrous, all pointing away from the body and all toward the whitefurred tip.

As noted elsewhere, this species, also that of the cross fox, is the result of habitual inter-breeding between the red, black or white fox. An instance is cited where a silver fox, with young, was captured and placed in confinement. The young were born fifteen days thereafter. The old, as well as the young, were retained in captivity for years. The following winter after the capture, one of the pups had a nice silver pelage, the others resembled more that of a red fox than anything else. The mother was now confined eight morths, and the owner deemed it advisnble to procure a male, in which he finally succeeded. Upon the latter's arrival he was placed in an enclosure adjoining that of tine female. For a week or so their demeanor was anything but friendly to each other. In ten days an opening was made in the nartition, through which one could visit the other at their pleasure. The visits failed to materialize, at least none were observed. The fact that both of the animals were aware of the existing opening and that one or the other put his or her head through the opening, gave us the assurance of their knowledge. Their manner while at the opening, however, indicated that entrance was forbicklen, or that one or the other expected trouble. After three weeks to a month the two became rather friendly at times. Later the partition was entirely removed, but even then one would avoid the other's company to a greater or lesser extent. But presumably during the night or at other times unobserved, they finally became friends and enjoved each other's company. The following May there were born four young, three of which grew up to nice silver foxes, while the fourth was a specimen of a cross fox. 
The fox, as well as all other carnivorous animals can be domesticated, but this takes time, money and patience, and unless given a wide range of freedom, the skins are of little value, even if taken off at the right time.

\section{THE BLACK FOX.}

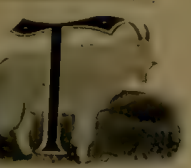

HIS, one of the Arctic species, is found only in extreme northern latitudes, Northern Canada, Alas$\mathrm{ka}$, Siberia and in some of the Islands of the Aleutian Group. Few perfect skins are annually marketed. In general appearance the animal resembles the silver fox, excepting that its pelage instead of being of a silvery nature is lustrous black, especially that portion about the shoulders. The tail is long, bushy, and all black furred, excepting the tip, which is white. Its pelage is soft, silvery, seldom wavy or linky. Living as they do in isolated places, man does not have the opportunity to study their habits, but what little is known of them indicates that their chief food is mice, snow birds and lemmings. In his persistent pursuit of food, if occasion necessitates, crosses rivers and other large bodies of water. Not being fastidious in his appetite, he is content with any form of flesh food, be it animals, birds or fish. He scarcely ever seeks sleelter unless pursued by his enemies or on approach of severe weather.

Nothing can be said about his habits that is notably untrue of the other Arctic species. All naturalists who have given the subject some attention, join in the belief that the black fox is a natural species, and not the result of intermediate breeding, as is the silver, cross, also the southern gray fox. Hudson Bay fur traders, also Indians, as late as I888, observed large droves or packs of black, white, blue and silver foxes, probably the restult of being chased by wolves, or in quest of food, or other times seeking mates, which all seems plausible.

The animal's abode is ustally under some cliff, rocks and in burrows. He is stccessfully raised for the pelt at various places, particularly so on some of the small islands forming the Aleutian Group. Favorable results are obtained when the animal is permitted his freedom, and as Elliot, one of the early explorers of the Behring Islands informs us "other less valuable fox cannot reach this remote island, for not even the ice furnishes them with a bridge, and besides this the inhabitants guard against the deterioration of their foxes, consequently no detrimental cross-breeding can take place, and the beauty of the furs, of which the inhabi- 


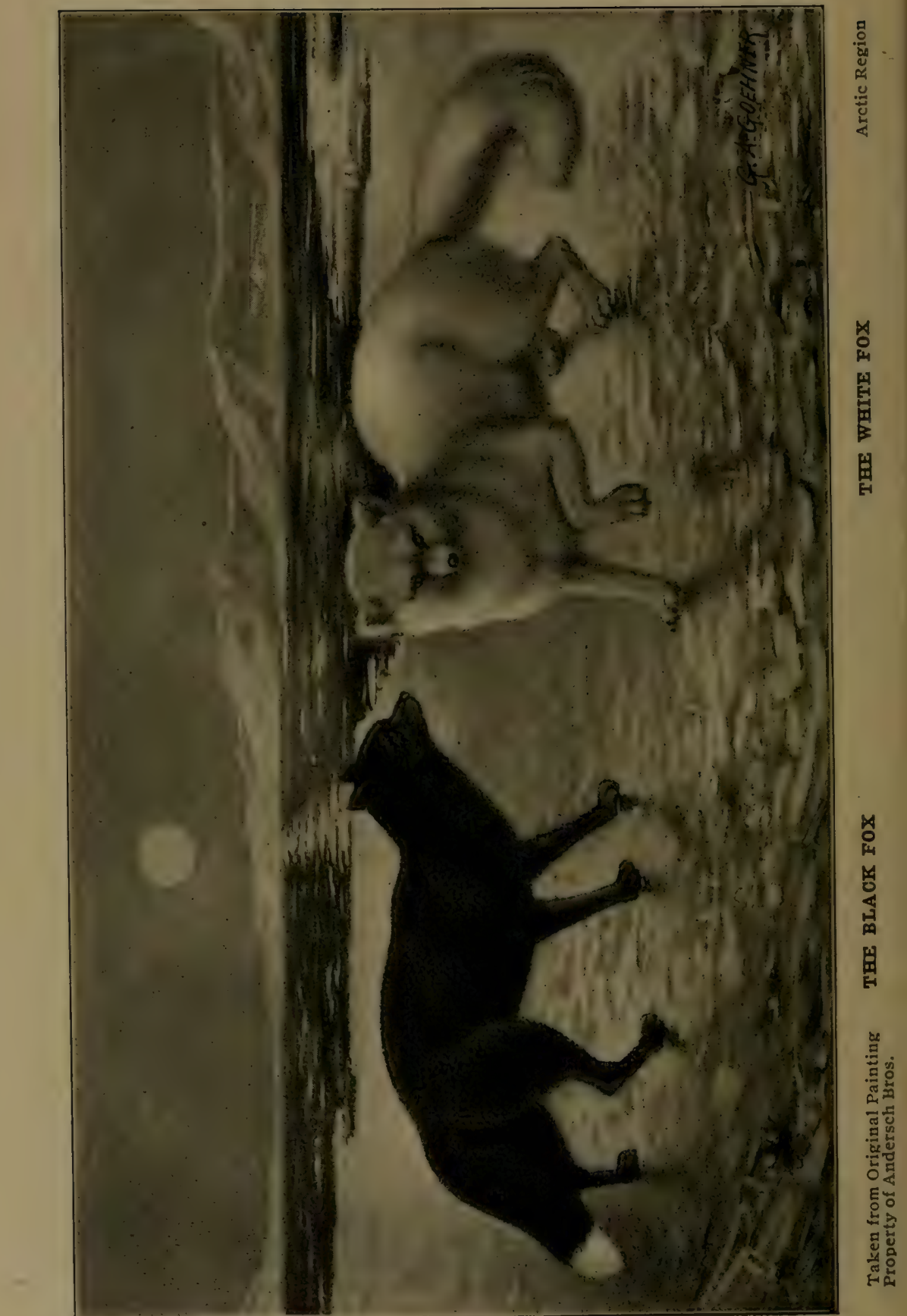


tants sell 200 to 300 annually, is beyond reproach and is universally acknowledged."

The breeding season of the Arctic fox begins with April, sometimes as late as May, and in about sixty days the female gives birtl to a large litter of cubs, in some cavern, crevice of a rock or burrow. As many as ten to twelve young are born annually. Her lair is preferably made by her in a mountain side, or at the edge of some woody region, which enables the mother to guard against approaching danger. Being over-zealous in the care of her young, she at times inadvertantly leads the trapper right to her abode, by yelping and barking at a distance, undoubtedly with the impression of scaring the intruder from the locality. Much to the detriment of the mother, as well as the young, these tactics are known by the inhabitants, who eagerly search for the place of confinement.

\section{THE BLUE FOX.}

This is strictly an Arctic species, and is found in the same sec t:ons as the white and black for, apparently distinct from them, but resembling them in size and habits. The animal is eagerly sought after, as its fur is quite valuable. The notable difference is entirely in the color of its pelage, being of rather indistinct or bluish hue. There are no blue foxes in the United States.

\section{THE WHITE FOX.}

The white fox is also an Arctic species and inhabits the polar regions. It is somewhat smaller than the red fox, also smaller than the average silver or black fox and is entirely distinct from either of them, but experienced hunters and trappers state that this species is sometimes known to live in the same burrow with some of the other Arctic foxes.

Their pelage is of a clcar white color, rather compact and of a woolly nature. The animal is quite numerous in the extreme northern portion: At numerous times individuals and pairs, were removed from the extreme north and placed in confinement, but the result has been unfavorable, as the fox, like most of the other species, long for their freedom.

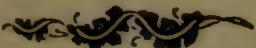




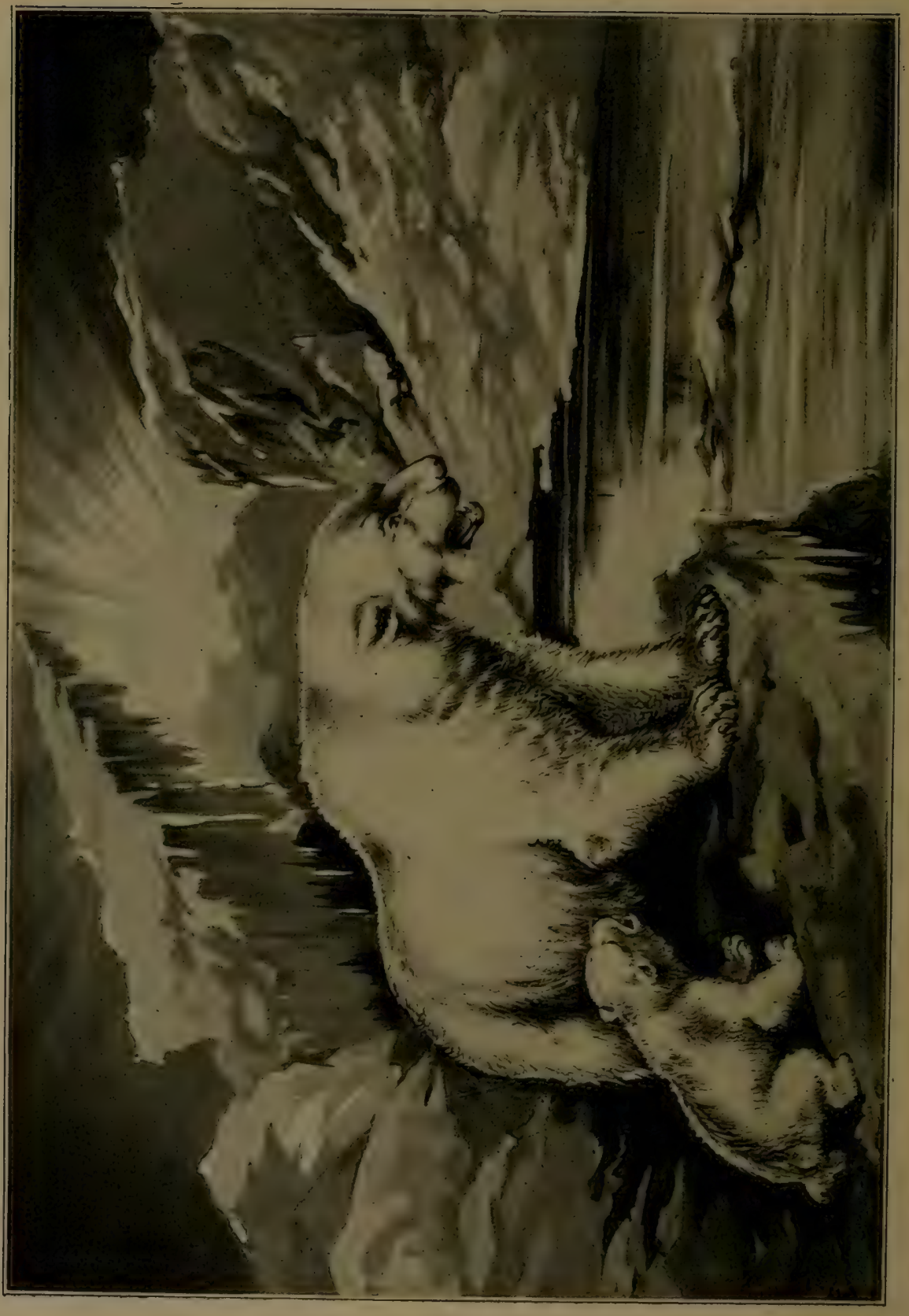




\section{THE BEAR FAMILY.}

The Black Bear, The Brown Bcar, The Cinnamon Bear, The Grizzly Bear, The Polar Bear.

\section{THE BLACK BEAR.}

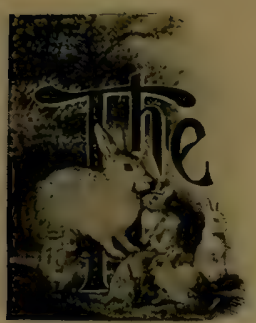

BLACK bear is the best known species, due to its numerosity and wide geographical distribution, inhabiting as it does all sections of the globe, excepting Australia. It is known by naturalists as the Baribal, Muskiva and the Ursus Americanus. On this continent the black bear is found from the Gulf of Mexico to the Arctic regions and from the Atlantic to the Pacific ocean, differing somewhat in size, habits, quality and color of its pelage, which variations are entirely traceable to climatic conditions. He resembles the European bear very much and the animal's nomenclature is extensive and diversified, as the knowledge of his existence has reached every tribe and nation. Much has been written about the black bear that has made him very popular, his ferocious habits have at times been ignored and at other times largely exaggerated.

The black bear of the north is much larger, stronger, ferocious to a greater degree, and his pelage, especially during the winter months, is much more valuable as compared with his southern brethren. A full-grown northern black bear will weigh 500 to 650 pounds, while the large yearling or two-year-old will compare favorably in size and weight with a full grown southern species, ranging from 250 to 400 pounds. Hunters relate that during the '60's, also early '7o's of the past century, black bears were killed that weighed as high as 750 pounds in the dense pine forests of Minnesota, Wisconsin and Michigan. The average rearling black bear of the north would measure forty to forty-five inches, when two years old, fifty to sixty inches, and when fullgrown six to seven feet long from tip of nose to root of tail. The ears are small and well rounded, being covered with a short, black fur, the eyes are exceedingly small, while the snout is short and in general the head is smaller in proportion to that of the brown or grizzly bear. Its legs are strong, while its feet are large, the latter possessing each, five long, but dull and almost immovable and unretractable claws. Thirty-five to thirty-seven monstrous looking teeth are firmly set in its jaws and the animal's power in its mouth is tremendous. Its lustrous black fur is from three to five inches 
in length, the undergrowth about two-thirds of the latter size. The latter quite often is wavy and instead of being glossy has a dull appearance ranging from a deep brown to a jet black. The fur is evenly distributed over the skin, but gradually tapers as the body terminates into legs, head and tail. Oftentimes the guard hairs about the hips become rubbed and the fur matted. The latter then becomes of a woolly appearance.

Habits. That the animal posiesses carnivorous as well as omnivorous habits, cannct be denied, feeding as he does indiscriminately upon vegetation, such as grass, fruits, leaves, and when opportunity presents upon poultry, sheep, veal, rabbits and cleer. Occasionally when his ferocious nature is aroused will capture and kill other live stock and miny instances can be recited

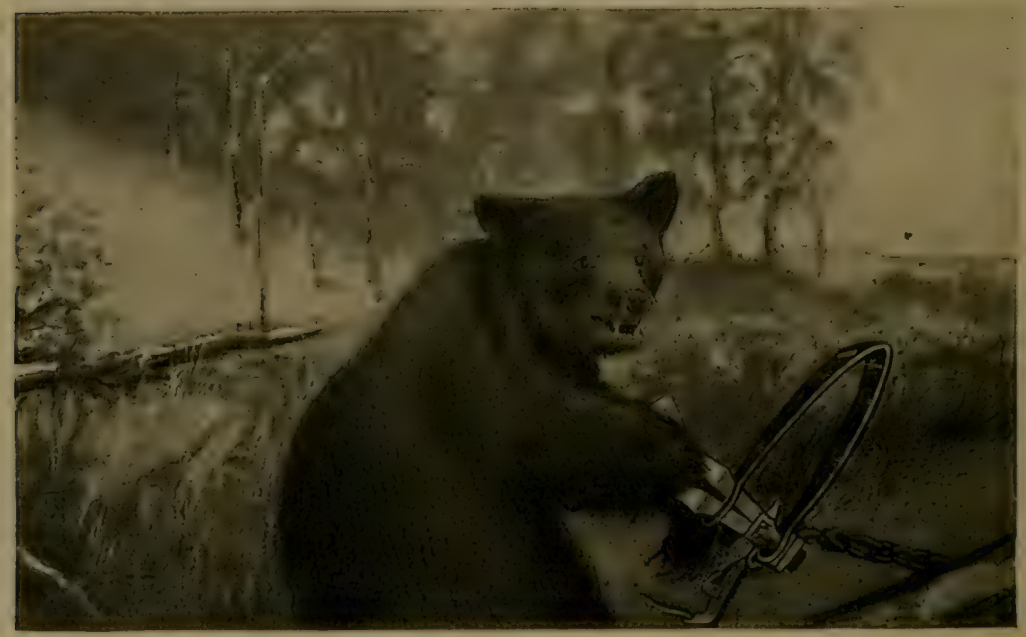

M̄ichigan

EIACK BEAR

From a Photo

In a No. 5 Newhouse Steel Trap

where the brute turned to cannibalism, although this action on the part of the animal is rare. Honey is eagerly sought by all of these species, and probably nothing is more pleasing to them than to discover a beelive. His sitting, sliding, scratching, hugging, tumbling habits, and the brute's aptitude of walking erect on his rear legs when approaching man, also his peculiar way of swinging his head when leisurely strolling, are his chief characteristics and of conrse these are well known to those who have come in contact with the black bear. His habitual sitting up on his rear haunches, invariably destroys the value of the skin for robe and rug purposes, also for the taxiclermist. The fur about the hips 
becomes badly rubbed, matted, and of a woolly appearance. During the winter months the animal is conspicuous by its absence. being in some den partaking of the winter sleep. The extent, duration and period of this hibernating habit depends largely upon the weather, surroundings, food supply, and tupon the animal himself; sometimes lasting three to four weeks, at other times as many months. Quite often during mild and thawy weather, the bear will awake from his winter slumbers and seek food and drink. When his appetite and thirst are satisfied he may re-enter his den and remain there for weeks, at other times l:e refuses to re-enter and immediately begins looking for prey, and being emaciated and run down, his requirements are large in that respect.

Bears held in captivity, unless exposeil to the elements and in some large, roomy locality, with all the natural surroundings, will lose their hibernating habit. Occasionally in his wild state and in his natural home, he will neglect to partake of this periodical winter sleep. This brute is an expert swimmer, fairly good at climbing, and it takes a good man to run away from him if the animal becomes enraged. While the cubs and young bears habituallv climb trees, the old ones very rarely climb them unless in search of food and then they quite often t:mble to the earth on account of the claws being dull. Nature has provicled him with all the facilities for escape that man has, being equal to the average man in running, climbing and swimming, lience if pursued the chances of escape are somewhat dubious unless backed with lots of nerve and good weapons.

The female brings forth a litter of two, three or four, ocsasionally five, and rarely one cub. The cave or den, where the mother raises her children, is generally warm, being padded with dry leaves, grass or other vegetation and is usually on the sunny side of some hill or mountain. The den is generally in some inscrutable place with inpervious surroundings, which obstacles the hunter readily overconnes by manifold methods. In such cases the female will carry the young away to another obscure lozality, sometimes a distance of three or four miles. While so engaged, should she meet the intruder, and cannot readily proceed in her wishes, she will turn upon the hunter, showing fight, especially if previously molested. Regardless of their clumsy construction they can outrun the pursuer, and it is not an easy matter to escape from this animal after he or she is enraged and turns upon the pursuer.

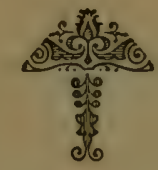




\section{THE BROWN BEAR.}

This brute is about extinct in the Appalachian chain of mountains and is now sparingly found east of the Rockies, more numerous in some of the western states, about the Sierra Nevadas, Cascade mountains and along the Rocky mountains extending from New Mexico to Alaska. Idaho, WVashington, Oregon and Montana have lately furnished most of the skins, but the animal is probably more numerous in British Columbia than anywhere else on this continent. This species is more or less confused with the cinnamon bear, which it closely resembles. Great variation in size, strength, ferocity and color of its pelage exists, due to the vast territory and the marked changes in climatic conditions. The northern animals are by all means the strongest, heaviest and probably more ferocious than their southern brethren. As compared with the black bear the brown bear is about his equal in size, but in certain localities, especially in British Columbia, the brown bear attains an enormous size exceeding in that respect the black bear by 100 to 250 pounds.

The fur of the southern brute is coarse, uneven, shaggy, harsh, less dense, and in color ranges from a dirty yellow to a light brown, and such skins are of little value, even when prime. The pelt of the northern brute is quite valuable, especially that from the two-year-old or three-year-old animal. The older the animal the coarser the fur, and consequently the skin is of less value unless it is extremely large and suitable for specimen purposes. The fur of the three-year-old animal is from three to five inches long, quite often of a wavy appearance, soft, mellow, and in color ranging from a light brown to a deep, rich, dark brown. Two beautiful colored and furred skins, coming probably from two-year-old animals, are before me now. In length the fur is seven to seven one fourth inches, in color light brown, with the inner fur two or three shades still lighter. The fur fibers are wavy, silky, mellow, and in general the skins are very beautiful. The animals from which they were taken were killed in the Caribou mountains of Athabasca, Canada. As to their habits, there is no distinct difference between this species and the black bear.

\section{THE CINNAMON BEAR.}

The cinnamon bear (Ursus Cinnamoneous) is found rather sparingly on this side of the Canadian line, although quite a number are annually dispatched in the mountainous regions along the Rocky and Cascade mountains in the states of Montana, Wyoming, Washington, Idaho and Oregon. The brute is more numerous on the Canadian side following the Rocky Mountain chain clear up 
to Alaska. This is not an Arctic species as some suppose, neither is the animal found as far south as the brown bear. Being more of a northern species it is quite natural that the animal is large, strong, robust and ferocious, and it is not surprising at all that the Indians consider it a feat second in importance when a brave succeeds in killing a large cinnamon brute to that of the famous grizzly. The cinnamon bear is more or less confused with the brown bear. As will be observed he is of larger stature, and instances are recorded where the animal attained the enormous size comparatively with the grizzly bear.

Its pelage, as its name implies, is of a dark brown, resembling the color of cinnamon bark. The fur of a medium aged animal is soft, mellow and three and one half to four inches long. The body is well and evenly covered with rather a dense coat which becomes shorter as the body terminates into the head, legs and tail. Occasionally skins are received where the fur is much longer, on the other hand the fur of the older animals is short, harsh and rather uneven.

A certain Mr. McDonald, a member of the mounted police in Canada, witnessed a fierce combat between a cinnamon and a black bear. The former became the victor only after four to six hours of the fiercest combat probably ever witnessed by man. Being so evenly matched, no apparent advantage was gained by either one over the other, until the black bear was unfortunate in being rolled into a rapidly-flowing creek, and being fairly exhausted and held down by the weight of the brown bear, it required comparatively only a few minutes until the black bear was drowned. In describing the fight he states that it resembled that between two huge dogs, biting, growling, scratching, hugging, rolling, etc. The noise these brutes made while so engaged was indescribable. In habits, the animals differ slightly, if any, from the black, brown and grizzly bear.

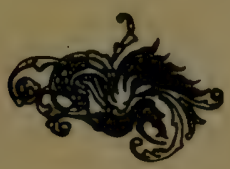




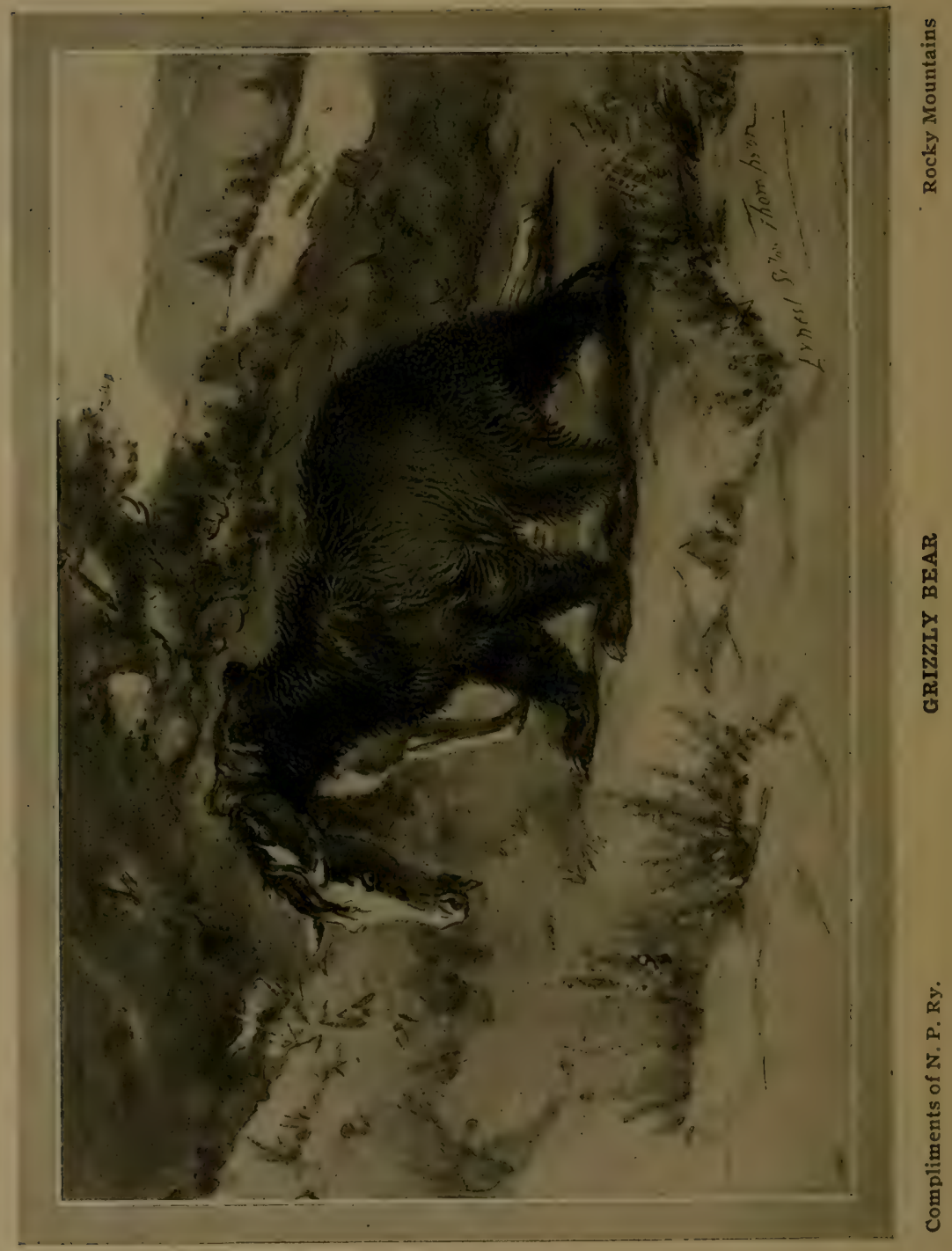




\section{THE GRIZZLY BEAR.}

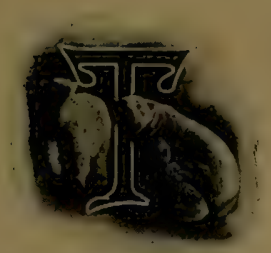

HIS monster inhabits strictly mountainous regions and is now sparingly found in the United States. W as formerly in large numbers in Montana, Wyoming, Oregon, Washington and sout'invard along the Rocky and Cascade mountains. He is numerously found in British Columbiz where a large specimen was recently captured weighing 2,800 to 3,000 po:tncls. $\mathrm{He}$ is also found in the extreme northern parts of Canada, and in Alaska. The largest skin that came to my notice measured eleven feet, three inches in length and average width of seven feet a:xd $s^{\circ} x$ incles. The fur on this skin was poor, he being killed during the early fall months when the skin and the fur were umprime.

The pelage of the grizzly bear varies greatly in color, so much so indeed that naturalists as well as the fur trade divide the species into two grades, the grizzly and silver tip. The outer ga:ment of the former is dark grey to black, with interspersed grey or silver hairs. The fur is shaggy, harsh, uneven, and especially is this true of the older animals, while the fur of the younger brites is even, somewhat fine, rather dense, and tivo and a half to three and a half, possibly four inches long. The fur of the silver tipped bear skin is more even, and tends toward a grevish color with white silvery tipped hairs, rather evenly dispersed and prominently predominating, making the skin rather beatutiful as well as serviceable. Occasionally the fur on the latter is of a dark, steel grey, with interspersed white tipped hairs. Only the skins that are prime are of any value, as summer skins are unfit to be tanned and can only be used for specimen purposes. This brute is sometimes confused with the cinnamon, also the brown bear, of which he is their master. The animal has enormous strength in his legs and jaws, and with apparent ease is able to drag a horse or cow for miles. His collossal weight and size enables him to subdue any and all wild animals which inhabit this globe and in a probable encounter with the African lion or the huge elephant he. would come off the victor.

The fur on this monster carnivorous brute is of a shaggy appearance. The word "grizzly" is justified in describing the condition of the fur of the old species, probably more so than the two to four-year-old brutes. The color of its pelage varies, not only in the different sections but also in the animal's age. The older the brute the more shaggy, grizzly and faded the fur. 


\section{THE POLAR BEAR.}

The polar bear ranks second, if not first in size of all the var. ious species of the bear family. He inhabits the extreme polar regions where ice prevails the year round. By no means does he alone belong to the Western hemisphere, as he is found on three continents. On this continent the polar bear is found about the eastern coast along the Baffin Bay, north of Hudson Bay Strait and across the continent to Alaska.

Its pelage consists of a coarse coat of yellowish white fur of various length; but that of the body is usually three to four inches long. The ears are short, neck rather long, body long in propor. tion to its height and has unusually long feet. The claws are heavy and not so stubby as those of the land species. In his habits he varies somewhat from the other strictly land species, being that he is confined to the extreme northern regions the year round, living as he does amongst ice, often obliged to procure his only food from the deep seas. This bear like all others is carnivorous, also possesses omnivorous habits, and devours with voracity the carcasses of whales that drift ashore; in fact devours all dead animals that the waves hurl against the icy shores of the Arctic region.

Capt. Lyons describes the polar bear at full speed, "as a kind of shuffle as quick as the sharp gallop of a horse." Quite often the animal swims off to floating ice or to icebergs and is carried with them hundreds of miles in the direction that the wind happens to be blowing. Capt. Peary reports that the Esquimaux on the coast of Mellville Peninsula attain part of their subsistence from the flesh of the female bear, which they dig out from the snow. Mr. Graham states that the female retires to her winter quarters in November, where she lives without food until she brings forth usually two cubs about Christmas time. The cubs in size resemble those of a shepherd dog. The offspring, especially if tired, ascends the animal's back, where they ride securely, either in water or shore. The following report from Capt. Lyons is interesting:

"At the commencement of winter the pregnant bears are very fat, and always solitary. When a heavy fall of snow sets in, the animal seeks some hollow place in which she can lie down and remain quiet, while the snow covers her. Sometimes she will wait until a quantity of snow has fallen, and then digs herself a cave; at all events it seems necessary that she should be covered by, and lie amongst, the snow. She now goes to sleep, and does not wake until the spring sun is pretty high, when she brings forth two cubs. The cave by this time has become much larger 
by the effect of the animal's warmth and breath, so that the cubs have room to move, and they acquire considerable strength by continually sucking. The dam at length becomes so thin and weak that it is with great difficulty she extricates herself, when the sun is powerful enough to throw a strong glare through the snow which roofs the den. The Esquimaux affirms that during this long confinement the bear has no evacuations, and is herself the means of preventing them by stopping all the natural passages with moss, grass, or earth. The natives find and kill the bears during their confinement by means of dogs, which scent them through the snow, and begin scratching and howling very eagerly. As it would be unsafe to make a large opening, a long trench is cut of sufficient width to enable a man to look down and see where the bear's head lies, and he then selects a mortal part, into which he thrusts his spear. The old one being killed, the hole is broken open, and the young cubs may be taken out by the hand, as, having tasted no blood, and never having been at liberty, they are then very harmless and quiet. Females, which are not pregnant, roam throughout the whole winter in the same manner as the males.

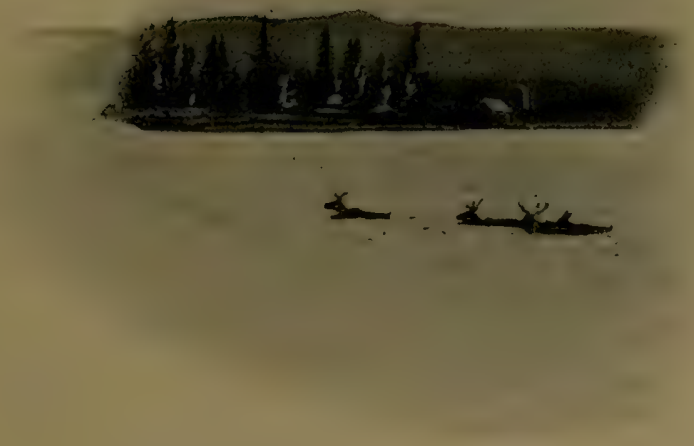




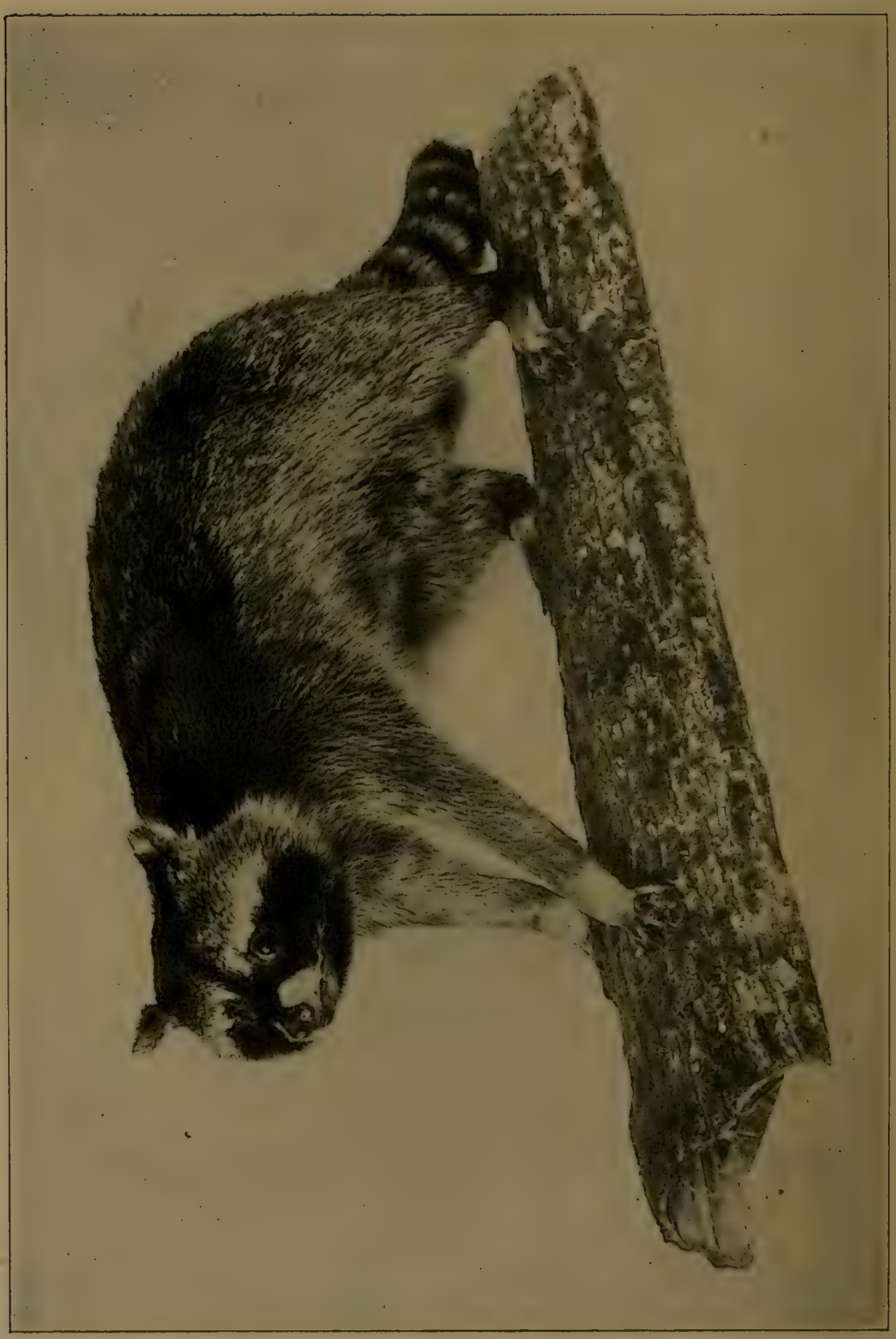

莒

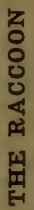

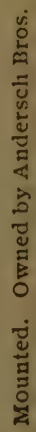


THE RACCOON.

\author{
(Ger. Waschbar, Lat. Procyon loter.)
}

HE raccoon is a native of North America, belongs to the bear family, and is somewhat related to the South America species better known as the crabeating raccoon. This animal has all the good, and nearly all the bad habits: that any other fur-bearing animal possesses. $\mathrm{He}$ is an expert climber, very good at swimming, a fairly swift rummer and expert fighter, and his nocturnal and omnivorous habits are only too well known to the hunter and trapper. He is found in almost every state and territory of the union. Probably more so in the southern states than in the western or northern. He is scarcely found in Canada, although he cloes exist in the sontherni portion thereof. Under no circumstances is he an Arctic species and is not found in that region at all; in fact, he does not inhabit any section in which the polar bear is found.

The bo:ly of the raccoon is thick, plump and resembles that of the badger, although beirg shorter and differently furred, and his body is elevated four or five inches higher than that of the badger. Climatic conditions are responsible for the marked variations of the animal as compared with those inhabiting the northern, western, eastern and southein parts of the United States. While a full-grown northern raccoon will weigh tiventy-five to thirty-five pounds and the body measures from twenty-two to twenty-eight inclies in length, to which a tail of five to seven inches is attached. the extreme southern species will rarely exceed twenty pounds in weight, its body only measuring sixteen to twenty inches in length. While the former possess a coat of dark, dense, and rather fine fur, the latter has a thin, coarse and light-colored pelage. The tail is covered with dense fur of the ring formation. The rings clange in color, alternating with the predominating color of its body.

The fur of the first above species as noted, is very dark, long, comparatively fine and the inner coat resembles that of the beaver, being dark brown, wavy and very dense. The outer guard hairs are black to dark brown in color, and extend on an average of onehalf inch above the fur fibers. The prime northern skins can be used for various purposes, the principal use being in the manufacture of fur coats. The best skins are probably picked out, plucked, dyed, or used natural, to imitate beaver. The pelage of the southern species is lighter in color, often of a brown leaning towards a 


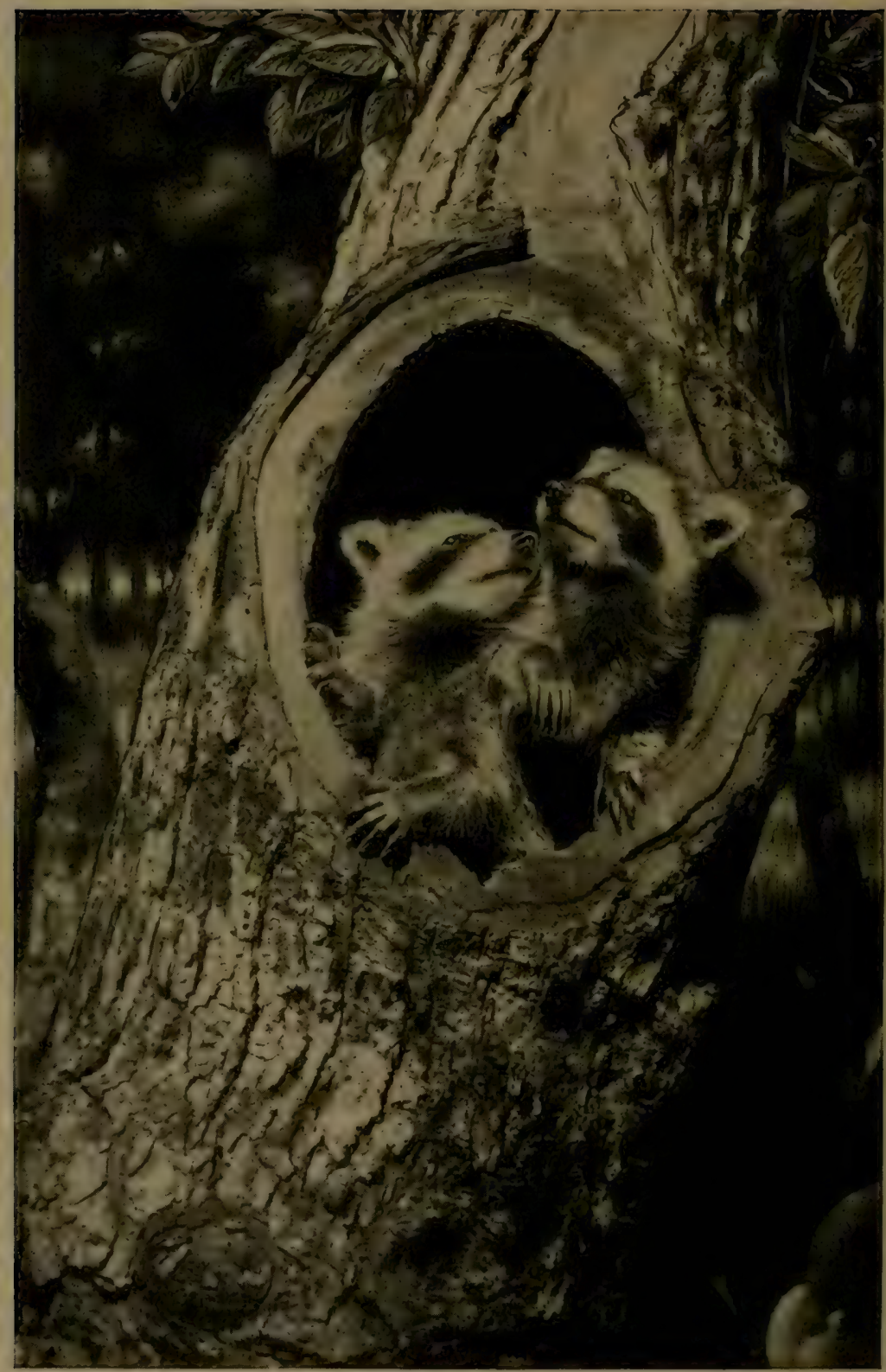

Northern states 
reddish hue, and the fur is more thinly distributed as compared with that of the northern species. The skins of the southern, middle and western states are chiefly used for gentlemen's overcoats.

The best skins for this purpose come from a section of Missouri, where particular attention is paid to the handling of them and are commercially known as "New Madrid Skins." These skins are handled largely by negroes who are specially educated in taking the skins off the animals and the stretching and drying of same to the best possible advantage for themselves and the manufacturer. As the animal is found in all states and territories of the union, with the exception of Alaska, an exceedingly large number of skins are annually marketed and consumed. It is variously estimated that $3,000,000$ to $4,000,000$ skins are annually marketed. The city of St. Louis is the leading market for the southern raccoon skins, while Minneapolis and St. Paul are the leading markets for the northern raccoon skins.

Habits. The animal possesses nocturnal and omnivorous habits, is an excellent swimmer and climber, and if chased will cover a considerable space in a remarkably short time, and when opportunity presents will seek shelter in a tree or in a hollow $\log$, and with swiftness and precision will jump from one tree to another, and if occasion demands from the extreme height of the tree immediately to the ground, alighting on its feet, and catlike fashion attempt to decamp to a place of safety unless detained by the dogs or hunter.

His food consists chiefly of nuts, grapes, fruit, vegetables and eggs. "He can be seen in the evening rambling about marshes and streams in search of frogs, fish and turtles, and at night will chase mice, rats, birds, as well as rabbits. Besides these he readily consumes vast quantities of vermin, bugs, crabs, etc. The poultry yard is often visited, and nothing is more pleasing to him than some domesticated animal, such as the pigeon, chicken, duck, and the large goose is not objected to by him. Not only is he fond of the meat, but considers eggs a greater dainty and repast. The egg is artistically held in his long paws, is broken with his month and the contents gradually sucked out. He possesses the peculiar habit of dipping his foot into the water and then rubbing it between his fore paws to wash it. This is one of his playing attitudes. He is auite often seen about streams and water where the chief part of his food is found. He takes especial delight in reaching out his paw for shining objects or articles in the water, such as a tin can, piece of glass, broken mirror, etc. If the article is unprocurable with his paws, he readily dives for it. The old as well as the young are of a playful disposition resemb- 


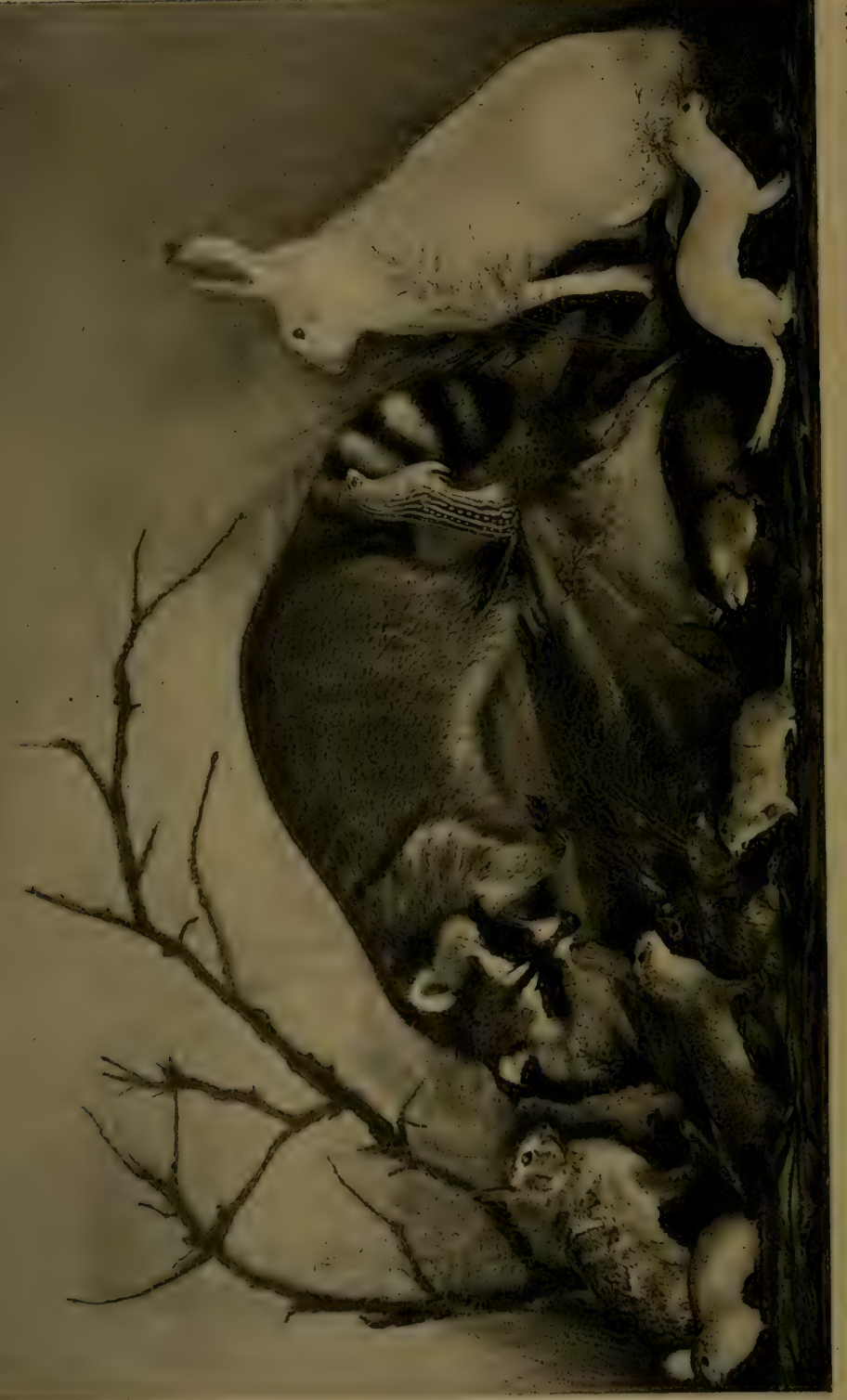

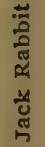

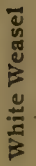

苟

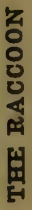

$=$

ปัँ 
ling somewhat the fox or the bear. He is a keen observer, and it is a pleasure to watch him when he is playfully inclined.

$\mathrm{He}$ is a cheerful, handsome and lively fellow. His bear-like gait with his head swinging one way and then another and with his high arched back and drooped tail, makes a pleasing picture; but upon the slightest disturbance or the discovery of some scent, his interest immediately is aroused and especially if he perceives some harmless animal. He at once pricks up his ears, listens, sometimes stands erect on his legs, and swiftly darts after the object, while if fooled, he may revert his disposition to a playful mood and dart upon some tree with an agility for which one would hardly have given him credit. Frequently one can see him running on a horizontal branch like a sloth or a monkey, with body hanging downward. He is fond of playing tricks and is very often inclined towards an inquisitive and mischievous nature. The animal can be tamed if captured young, and if successful the effort is rewarded by his constant cheerful disposition and ever giving enjoyment to the children. He enjoys being petted, and becomes much attached to persons. Of the qualities of the raccoon, Mr. Beckman has the following to say:

"An animal of unlimited inquisitive intrigue and obstinacy, with a tendency to search all nooks and corners. In sharp contrast to these qualities he also possesses coolness, self restraint, and marked sense of humor. His contending obstinacy often naturally brings about the queerest results as he realizes the impossibility of attaining any special object he has been striving for; the fiercest ferocity gives place to an apathetic indifference, and obstinate perseverance changes into resignation. On the other hand he often passes quite unexpectedly from a lazy sulkiness, into the best of spirits by turning a somersault, and in spite of all self-restraint and sagacity, commits the most serious blunders when once his desires have been attained."

The raccoon not only furnishes a skin that is valuable, but his flesh is also eaten by many southern people. During the latter part of April or May the mother will bring forth a litter from four to six young. The home is in some hollow tree or fallen log. The young attain their majority not earlier than two years, but are largely placed upon their own resources as soon as they are able to depart from their place of birth; although the mother will assist them more or less until the beginning of fall when they are able to care for themselves without her assistance. It is very amusing to see the mother followed by her offspring in search of food, and especially if the mother is fortunate in obtaining some live animal, and under her supervision the animal is teased, maltreated and finally devoured by the young. 


\title{
THE RING TAIL CAT.
}

\author{
(Lat. Lemur.)
}

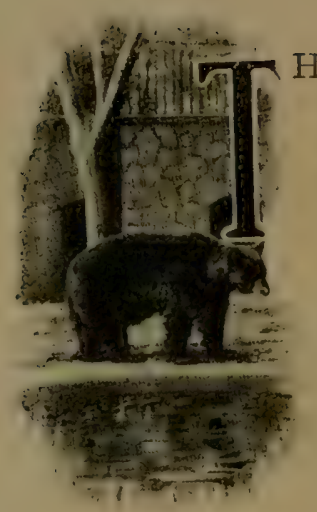

HIS species belongs to the monkey family and is the only one in the United States whose fur skin has a market value and that is commercially used by the fur trade. The animal inhabits the extreme southern parts: of the United States, Texas, southern part of New Mexico, Arizona and parts of California, but principally in Texas and Mexico. From these sections the skins are distributed throughout the remaining states and territories, being marketed in the principal fur-centers of the United States, vast numbers reaching Minneapolis and many finding their way to London where large numbers of skins are annually offered at the auction sales.

Its feet raise the body, which is twelve to fourteen inches long, about three inches from the ground. The tail, in alternate rings of black and white, is the most prominent feature, not only because of its particular markings, but by reason of its length and peculiarly bushy appearance; also that the length corresponds, or nearly so, with that of the body. Its hands resemble those of the common monkey with almost perfect fingers. The color of the body is of a grey to dirty yellow intermingled with darker guard hairs. The belly portion is always lighter, and the fur is soft and absorbs dye very readily.

Years ago there was no demand for these skins, but during the past five years manufacturers who experimented with them, found many places where the skins could be advantageously used, and at present the hunter or trapper receives a fair remuneration, ranging from $\mathrm{I} 5 \mathrm{C}$ to $4 \mathrm{OC}$ per skin. A full-grown ring tail cat will weigh three to four pounds.

Habits. Its general characteristics and habits are like those of the monkey, and is closely related to the lemur tribe of Madagascar and similar species in the West Indies. Natural. ists claim that this lemuroid is the connecting link between the monkey and Marsupialia family (pouch animal), imagining them to be the successors of a genus of unknown animal of the same family as the opossum. Their large eyes are especially adapted for use at night and their well-developed ears and soft, thick, 
woolly fur, characterize the lemuroids extremely as nocturnal animals. Their chief food is insects, frogs, mice, also certain vegetables. Apparently the animal prefers the impenetrable virgin wood, which is rich in fruits and insects to that of the ordinary timber section or open land.

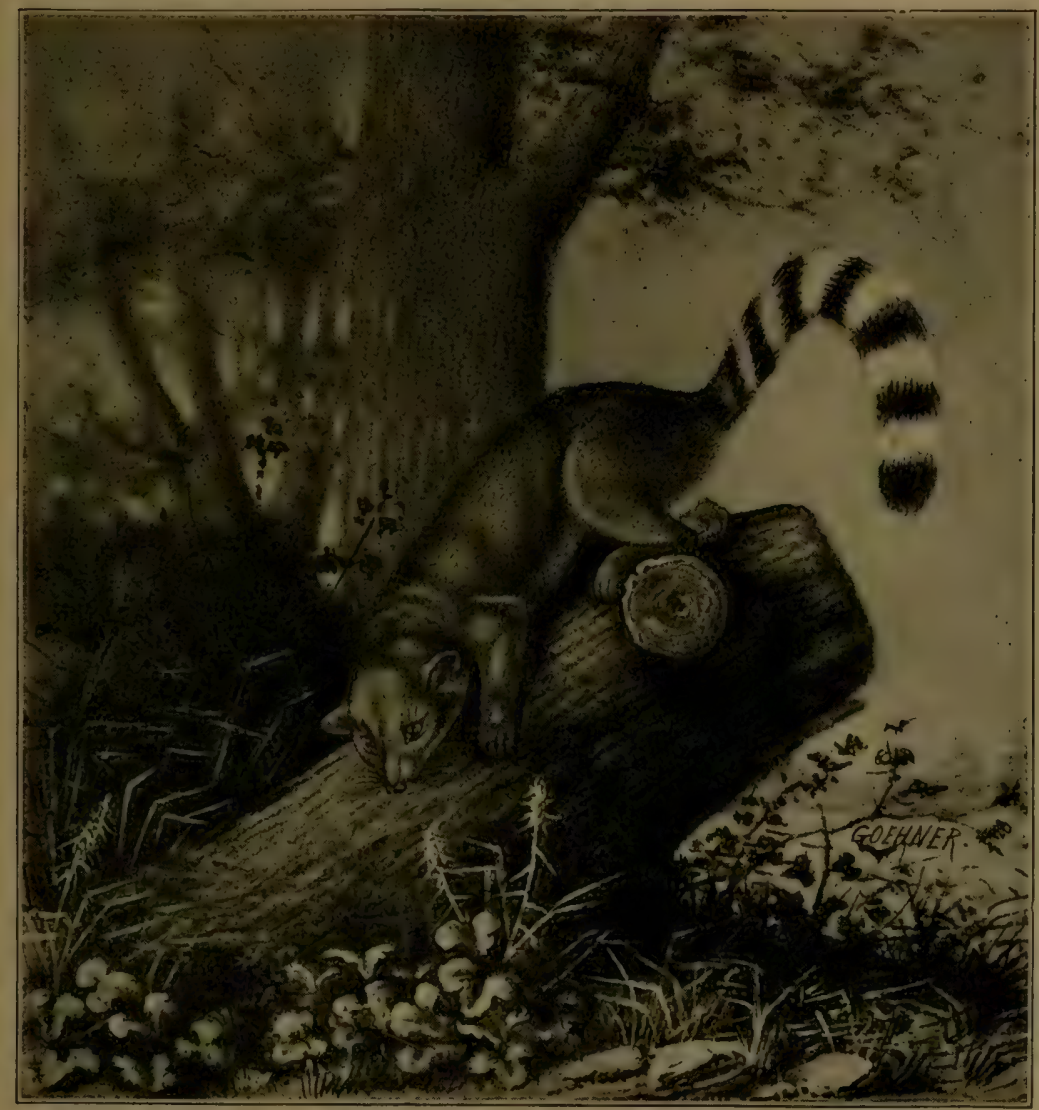

From Original Drawing
THE RING TAIL CAT
Owned by Audersch Bros. 


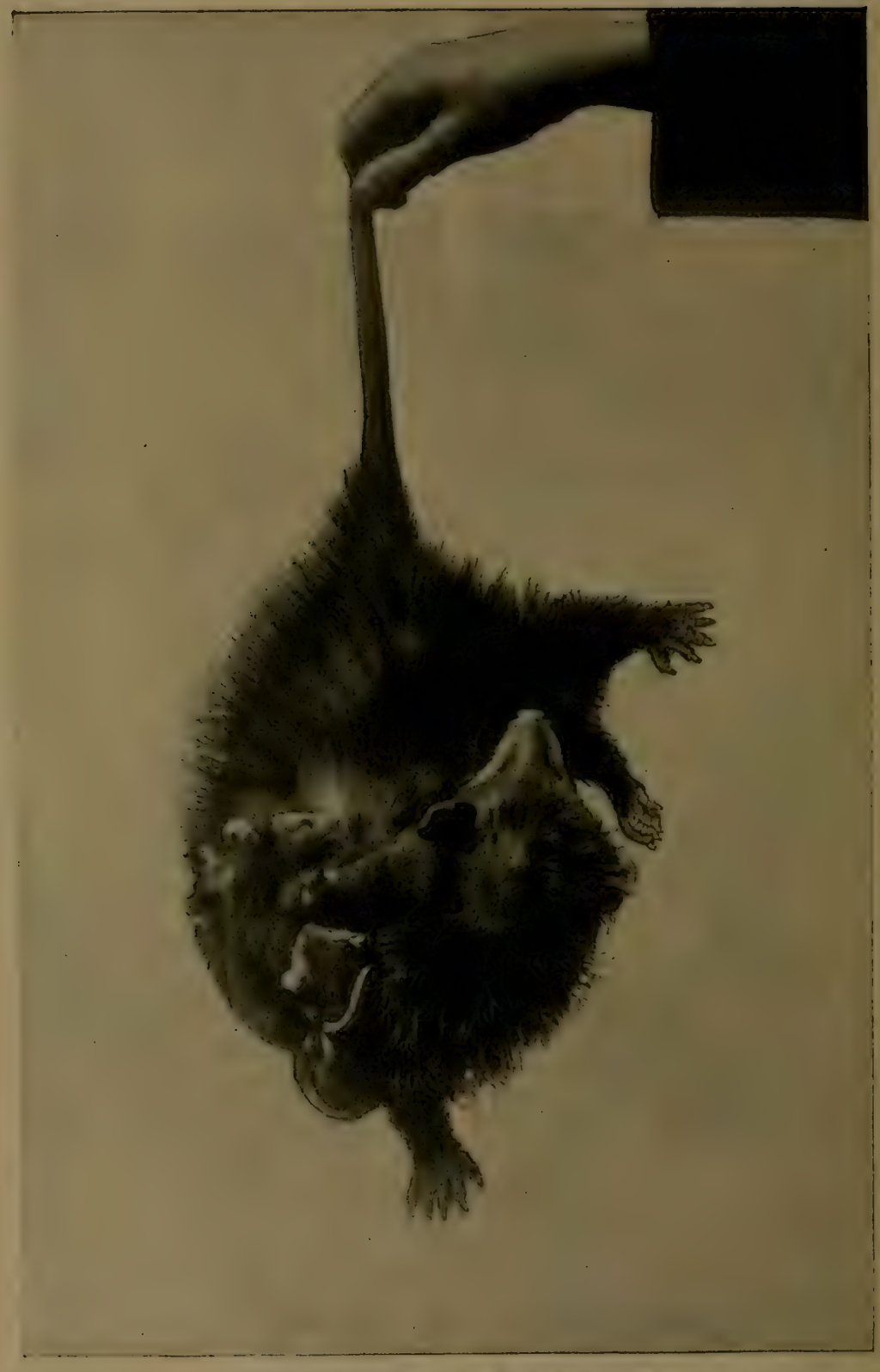

THE OPOSSUM AND HER, FAMIL, F From a Photograph 


\section{THE OPOSSUM.}

\section{(Virginian Opossum. Lat. Didelply's marsupialis.)}

This omnivorous animal has also carnivorous and arboreal habits and belongs to the marsupial family, and in form resembles a rat, some say a pig. His head is long, rather conical, snout long and pointed. The body is stout, clumsy, and especially so during the early winter months. The saying that "a person is as fat as an oppossum," is a true reflection to the opossum, as the animal is abundantly possessed with surplus fat during the winter months.

The body measures sixteen to twenty inches in length, with a tail denuded of fur almost of equal length. The tail is eminently prehensile, covered with scales, and that portion nearest the body with a slight growth of intermingled hairs. The following description is taken from Audubon:

"Nails of moderate length, curved; inner toe on the posterior extremities destitute of a nail and opposable to the other toes, thus forming a kind of hand. Tail, which may be considered a useful appendage to the legs in aiding the motions of the animal, prehensile and very strong, but capable of involution only on the under side, long, round and scaly, covered with a few coarse hairs for a few inches from the base, and the remainder with here and there a hair scattered between. Soles of the hind feet, covered with large tubercles. The female is furnished with a pouch containing thirteen mammæ arranged in a circle, with one in the center."

The animal's winter pelage consists of a coat of fur resembling in color somewhat that of the badger, being of a mixed character, consisting of an undergrowth of fine, close, woolly texture of whitish color, from which protrudes a less dense series of long, distinct, thick, harsh, rather brittle-like hairs; the latter always a few shades darker and sometimes black tipped. The fur fibers are white next to the skin, but gradually become darkek and in sections the tips are black; in other sections of a brownish or reddish cast. The young differ somewhat in color from tho old, are more uniformly lighter in color, but the fur becomes darker and assumes its natural state in the lapse of six to nine months. The meat is consumed by many trappers, especially so by the colored people, who prefer a fat, plump, roasted opossum to any other meat; the animal is hunted by this race to a great extent, not only for the meat, which they consider delicious, but also for the skin, which, if prime, commands a ready market. 


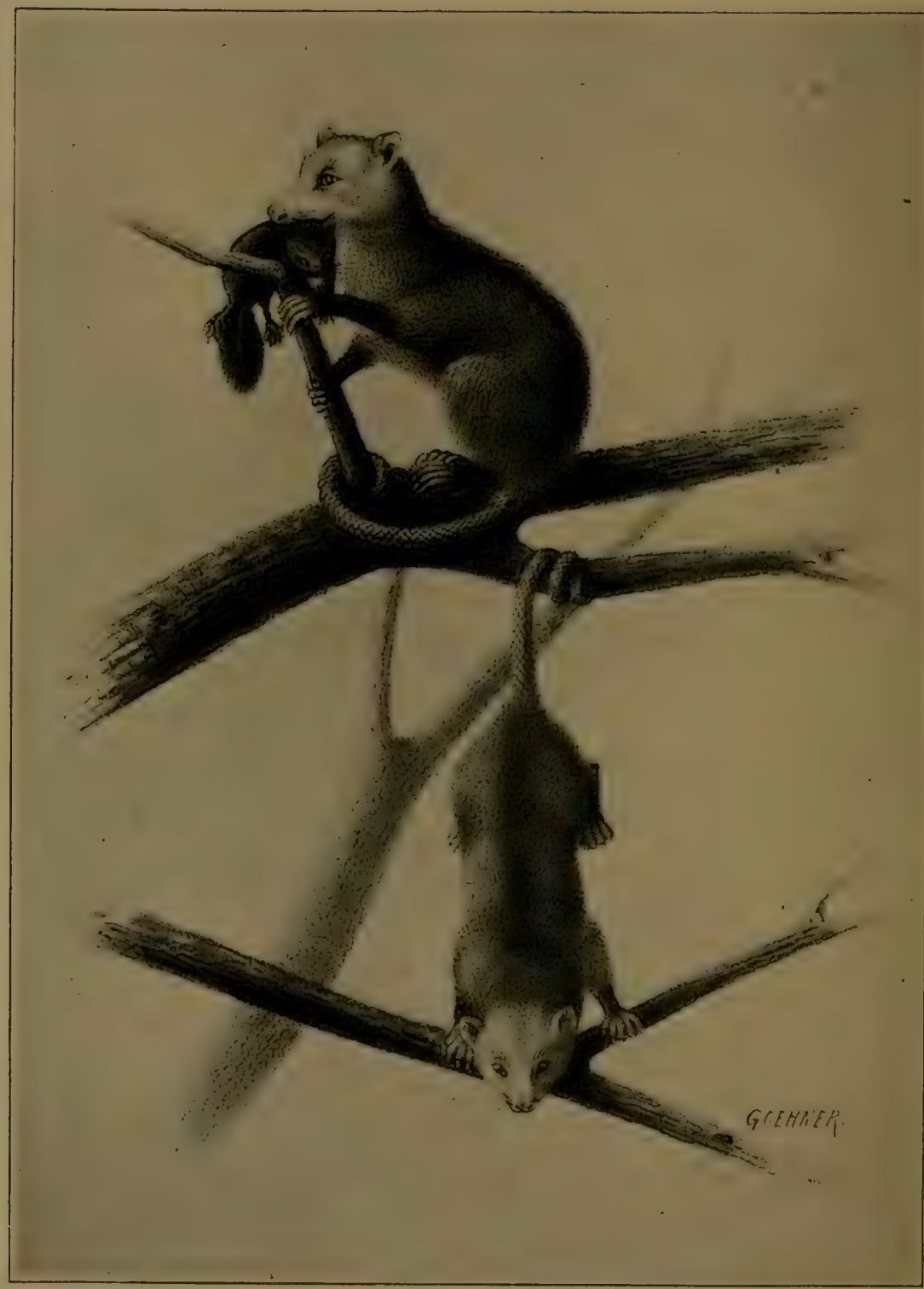

From Original Painting 
Habits. The animal is detested by the agriculturist, the fruithe is able to hold his weight by encircling the limb with his tail and springing from one branch to another in monkey fashion. $\mathrm{He}$ is slightly awkward on the ground, his movements apparently lazy, his walk plantigrade, and at times the running gait re. sembles a series of ambling leaps. His great toes and hind paws enable him to grasp and hold firmly to the limbs of trees, while his prehensile tail assists the animal to secure a desired position and immunity from falls. $\mathrm{He}$ is able to suspend himself by means of his tail for hours at a time. His constant, fastidious appetite is not confined entirely to flesh, as the animal will devour quantities of fruit, vegetables and other vegetation. His favorite passages are along fences and creeks, where the frogs afford him a tolerable repast.

$\mathrm{He}$ is very tenacious of life, and resorts to simulation when very hard pressed. At times he will roll up like a ball, at other times lie silently, feigning death. Many a farmer in capturing the thief in his poultry yard, gives the animal one or more sharp raps on the head or body, knocking it down, in which position with open jaws, extended tongue and dimmed eyes, he will feign death; the farmer in many instances carries the apparently dead opossum in the house, shows it to the family and lays it aside with the intention of skinning, and probably eating his meat, only to find later that he has regained his liberty. Apparently the animal prefers darkness to light. He sleeps through the day in the holes in the earth or hollow trees and lives with his mate only during the pairing time, leading a solitary life during the rest of the year. It has no fixed habitation, but uses any cranny which it descries in the morning after completing its nocturnal wanderings. In the early morning the opossum is especially in quest of some burrow inhabited by some weaker rodent, thus obtaining food and a day's rest without great effort, and is free of all concern until the approach of another night. 


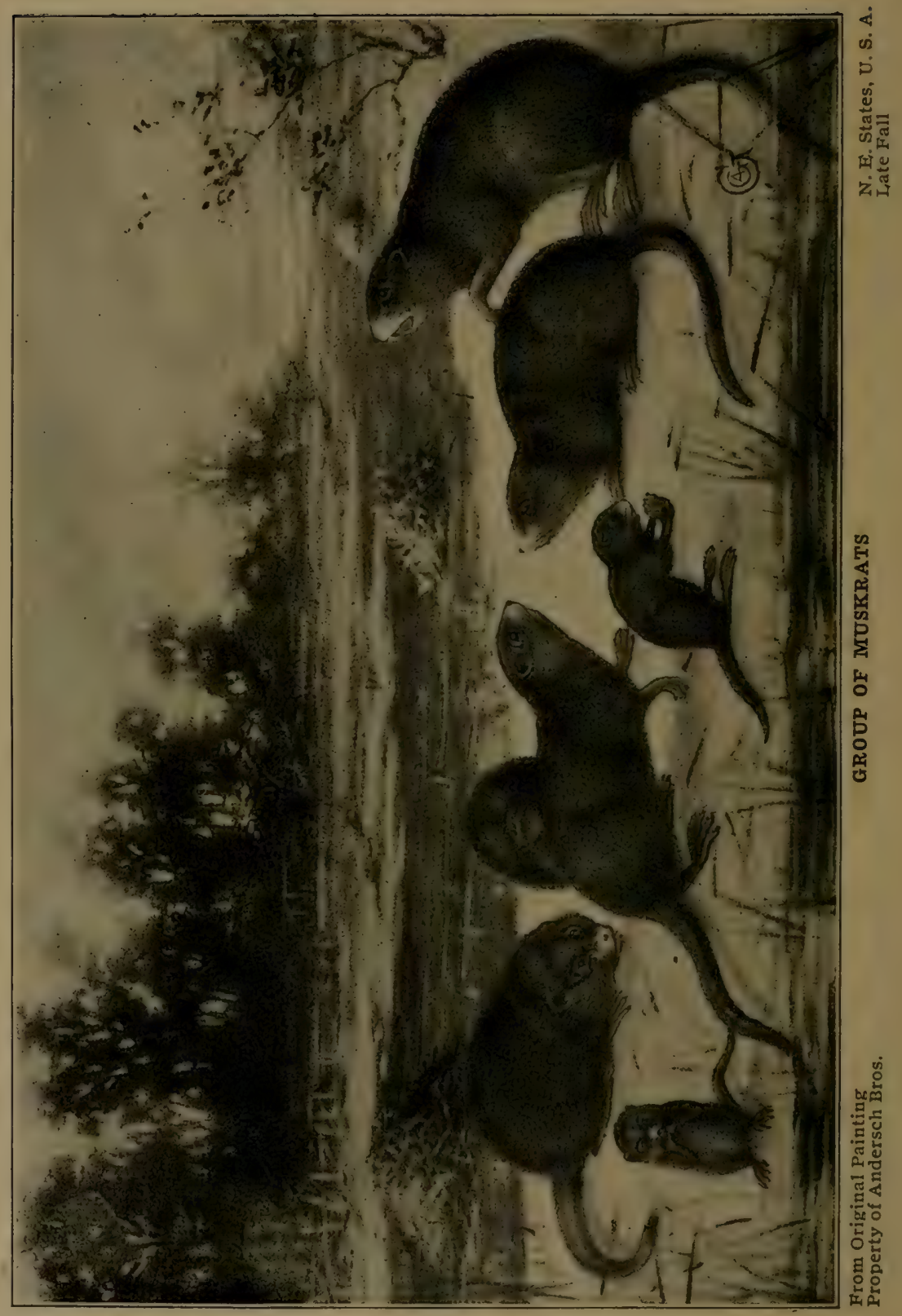


THE MUSKRAT.

(Ger. Bisamratte. Lat. Fiber zibethicus.)

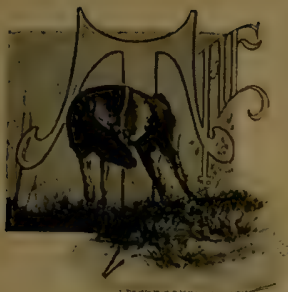

EARLY historians bethought a muskrat to be an overgrown water-rat, but such is not the case, although the above animal belongs to the same family. In their habits they bear close relation to the beaver, and certain Indian tribes always considered the beaver to belong to the muskrat fanily, but being older and somewhat overgrown. The head and body is twelve to sixteen inches long, and covered with rich, brown, soft fur, which becomes more dense on the belly but assumes a much lighter color on that portion of the body. In appearance the fur is very similar to that of the beaver, but lacking in fineness, wavy appearance, also in length. The guard hairs are a few shades darker and one-quarter to three-eighths of an inch longer than the undergrowth or fur fibers proper. Marked differences in size and quality of the fur, due to climatic and geographical variations, are notable characteristics. The muskrats inhabiting Wisconsin, Michigan and eastern states, also eastern Canada, are superior in size, and the fur is much richer than those inhabiting Minnesota, Dakota, Iowa, Montana and the western portion of Canada. Besides differences due to climatic conditions above enumerated, the color of the fur varies from a light brown to an extreme black, also in fineness and density. The black-furred musquash (or better known as muskrat) inhabits a section along the Atlantic ocean, ranging rrom Virginia to Connecticut.

The body is plump and rather cylindrical in form, the small head is attached to an extremely short and rather indistinct neck; only the hind feet are webbed and turn obliquely inwards. By observing them in action one is reminded of the foot of a duck or goose when swimming. The tail is eight to ten inches long, rather two-edged and rudder-shaped, and is covered with scales intermingled with hair, the edges being rather heavily fringed. The tail has no commercial value, and in that respect differs entirely from that of the mink, fisher, otter and other fur-bearing animals, excepting the beaver. The hind feet are webbed and used in swimming, the tail, when not used as a rudder, lies motionless below the level of the water. The musikrat is an excellent swimmer and diver and their endurance in water is especially notable. 
The muskrat is at home in North America and covers a vast territory from the Atlantic to the Pacific ocean, from the Gulf of Mexico to the Arctic regions, probably excepting the alluvial lands of Florida, Alabama, Georgia, and, perhaps certain parts of Carolina. In winter time they live in houses built by themselves in the fall months. The home is dome-shaped and is built from weeds, plants, and sticks, that are firmly held in place by being interwoven and puttied together with mud, or a peculiar sort of gluey substance. The entrance is below the water surface, thus the animals are protected against rough weather and the cold. The houses vary considerably in size and height; while some are only six inches above the water, others protrude three to four feet above the level. The large houses are four to five feet in diameter. The muskrat will usually build his house in shallow water, fifty to one hundred yards from the shore, often in marshes and ponds. In some places the houses are built on land, and occasionally their abode is in hollow trees and in holes made in the earth close to the shore; in most cases the entrance into such abodes is below the water level.

Habits. The habits of the muskrat are strictly amphibious and nocturnal, although it at times becomes visible during the daytime, feeding, playing or swimming from one place to another. His food consists chiefly of grass, roots, clams, mussels, flesh, garden vegetables and fruit, especially apples. The muskrat is very prolific, bringing forth five to ten young at a birth, and as often as three times a year. It seems that this species mature quickly as the female of the first litter becomes pregnant and bears young before the expiration of ten months, although the latter perish in large numbers, perhaps more so should the winter be severe from the start and the food supply short; also due to their youth and lack of judgment in getting away from the depredations of the mink and other animals. Their chief enemies are the mink, otter, beaver; but what wild animal pursuing carnivorous habits will not consume the flesh of the muskrat, and most of them relish the meat admirably.

The animal provides himself with a large food supply, which is gathered by all the members of a family during the fall months and carried by them into their abode. This food is stored on special shelves provided for this purpose; other shelves are provided in their dome-shaped houses upon which the animal rests, sleeps, or spends his time while in the abode. Many believe that the animal remains in the water constantly, but this is not true. Should their home be disturbed, be the intruder an animal or trapper, the muskrat will immediately plunge into the water from its resting place on the shelf and depart into one 
of the openings below the water level and swim rapidly away to some known destination, or simply try to escape.

In the event that the water on the outside is frozen, artificial breathing is resorted to; this mode of breathing is very interesting and particularly so to those not acquainted with this habit. Under normal conditions, should the animal desire to depart from its abode, it makes a special effort to supply itself with a quantity of fresh air, and immediately plunges into the water, swimming rapidly below the ice as far as the supply of air permits. He will then place his mouth and nose very close to the ice, lie perfectly motionless, expelling the air from his lungs, which immediately forms bubbles. The air thus assumes a fresh supply of oxygen, and the animal will swim from one bubble to another, inhaling the fresh supply of air, and when the bubbles are all gone, depart for its destination. This operation is repeated every two or three minutes. Should the animal be disturbed while in the act of breathing and be separated from the supply of fresh air, he will drown. Hunters and trappers acquainted with this artificial breathing on the part of the muskrat, will often rob the animal of his air. The operation is as follows:

When the ice is of sufficient thickness, the trapper with a cane will slowly walk to one of these dome-shaped abodes, and with his stick, give it one or more sharp raps. If the house is inhabited, he will hear a splash when the animal plunges from the shelf into the water. With his eye he will follow the course of the animal, and just as soon as the muskrat is in want of a fresh supply of air, he will permit it to rise next to the ice, when he will separate the animal from the air by disturbing it while in the operation of breathing. The muskrat, of course, will depart immediately, but only for a short distance, when he again seeks to obtain air; the trapper follows, repeating his operation and probably by the third attempt, the muskrat, deprived of air, will drown. All this takes place in a few moments. The drowned muskrat will of course float next to the ice, when the trapper makes a hole and removes the body.

Their houses are so constructed that this method of artificial breathing is not resorted to, as a sufficient supply of fresh air prevails the year round. The abode must be very warm as the water therein does not become frozen. Presumably the animal has some way of keeping the water from freezing in the abode; otherwise they would be prisoners since the only openings are below the water level. 


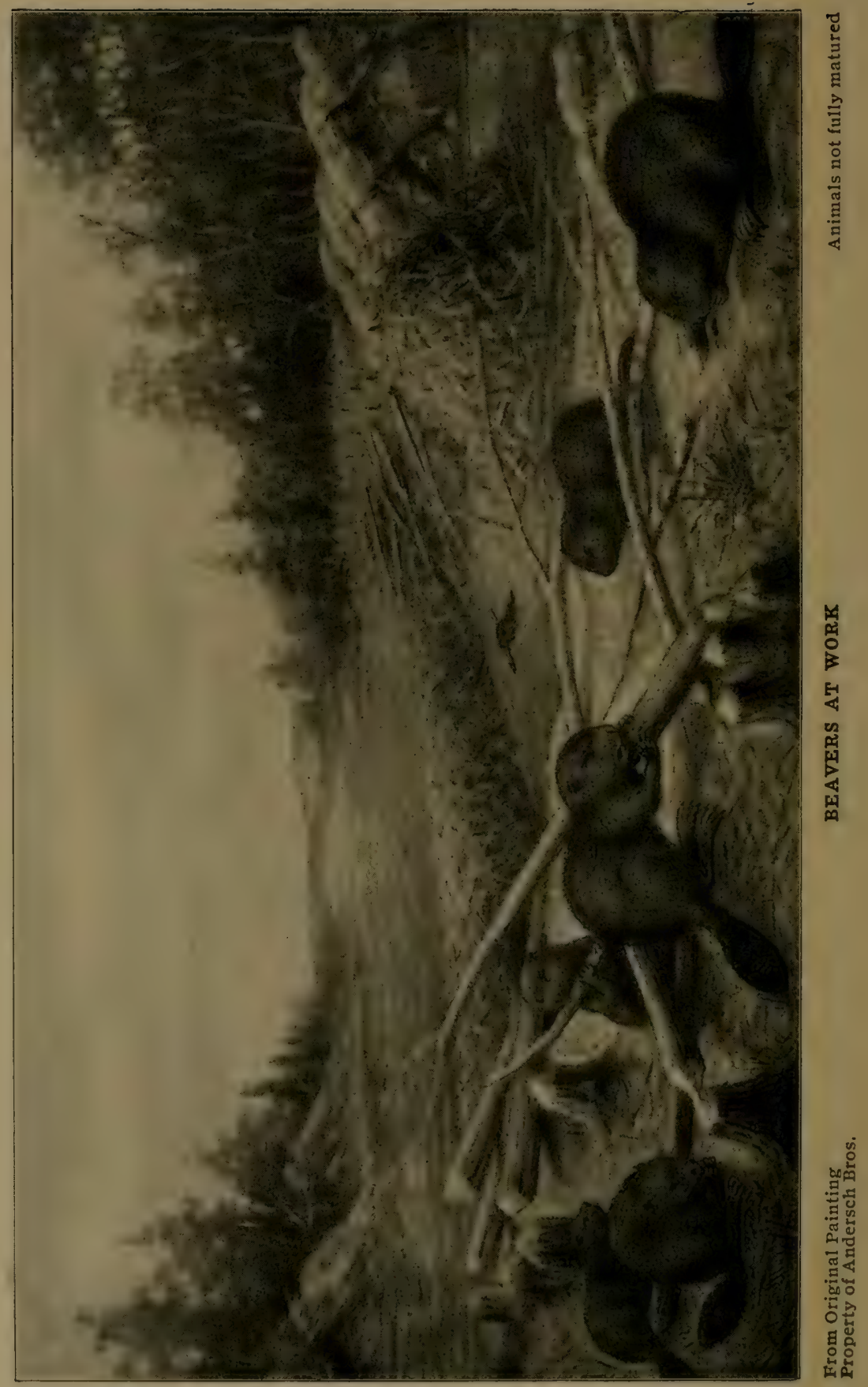




\section{THE BEAVER.}

\section{(Ger. Biber, Lat. Castor fiber.)}

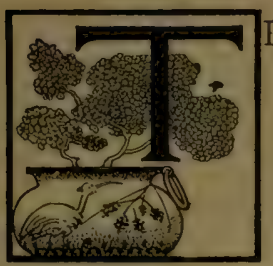

$\mathrm{HE}$ beaver in duration of his instinctive type, is one of the oldest animals, and seemingly his coarse substistence, rugged strength, aquatic habits and prolific nature, eminently fitted him for just such a career upon this earth. He is of notable interest to the human family, and besides furnishing us with his pelt and his peculiar secretion known as castoreum, we admire his constant, energetic and intelligent skill in the pursuit of his daily occupation and highly developed architectural ability in the construction of his home and the "beaver dam."

The American and European beaver are closely related, also to that found in Asia. In comparing the American with the European species, no marked outward differences are discernible. Scientists who have devoted much time and energy to this subject, after anatomical dissection, state that there are differences, that the contrast is principally in the skull and castor sacs, and not in the general construction and size of body, head, feet and tail. The general belief that these differences, slight as they are, were due entirely to climatic and geographical conditions, is apparently punctured by the aforesaid statement of the scientists.

The beaver is a rodent, possesses gregarious, amphibious and nocturnal habits, and by nature is a burrowing animal. Appended is summary given by Mr. Morgan in his "American Beaver," of three beavers captured in I866, during the months of February, March and April, near Lake Superior.

Male Female Female Weight ......................32 lbs. 291/2 lbs. $36 \mathrm{lbs}$. Length from tip of nose to end of tail ...42.25 $42.25 \quad 42$. Length of scaly portion of tail........ 9.75 Circumference of head before ears....... 14 .

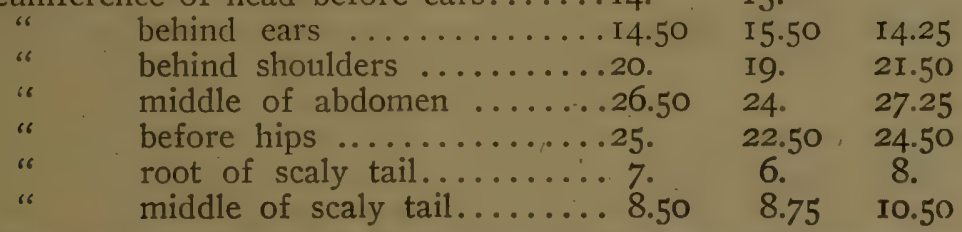

The principal food of this animal is the bark of deciduous trees, also the wood itself; at times consumes coarse grass, pond 


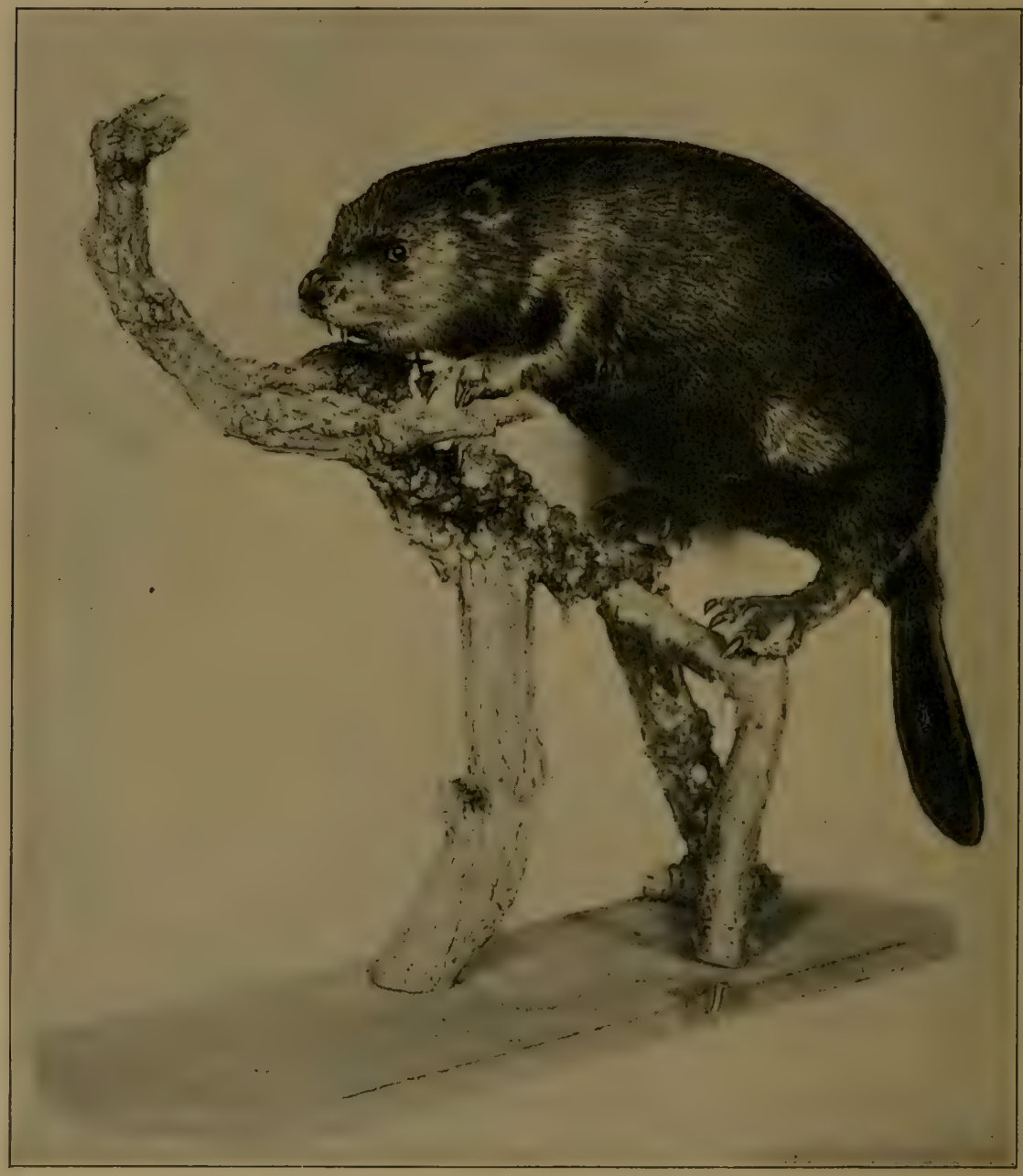

Mounted. Owned

by Andersch Bros.
TEE BEAVER

Full-grown. Feb. or Early March 
lillies, etc. The male attains a greater size than the female, and to determine the sex of the beaver from the outward appearance is difficult, as they are monotrematous and there is nothing from their outward appearance to indicate the difference in sex. It will be observed from the above table that the average weight of the beaver is from thirty to forty pounds, the length of the body from thirty-two to thirty-eight inches, and the tail, which has a scaly appearance, from nine to eleven inches long. Much larger specimens have been received from the western states, also parts of Canada, and one male beaver in particular coming fron Montana weighed fifty-eight pounds and the measurement of the body was proportionately larger.

The four incisors are extremely long, and are conspicuously used by the animal in severing roots, when burrowing below the earth, also in cutting trees, as will be observed by the illustration of Beaver Cuttings in connection with this article. The eyes are very small, and their small ears adhere closely to the body and are almost indiscernible. His sense of hearing and smell is acute, while that of sight is of short range. The animal does not rely much upon his sight unless the objects are at close range.

The body bears close resemblance to that of the muskrat, only on a larger scale. It is thick and clumsy, gradually enlarging from the head, and is largest around center of abdomen, from which point the body gradually tapers in both directions, probably more forward, and the rear is somewhat abruptly rounded off at the root of the tail. The fore feet are rather slender with toes that are well separated and flexible, and in appearance resemble hands. The claws or nails in the front feet are sharp, strong, compressed and channelled beneath. The middle toe is longest, and those on each side a little shorter. The under and inner ones are the shortest. The hind feet bear close resemblance to those of the goose, being webbed beyond the roots of the nails and have hard calloused soles, which are especially adapted for the required aquatic habits and give the animal excellent propelling power. While swimming the fore feet are closely pressed back against the abdomen and are of no use in its swimming operation. These feet or hands are capable of very considerable rotary movements and are made of especial use by the animal in holding sticks, limbs and trees, and in and with them, carries stones, mud, sod, etc., from one place to another, but in this operation the mouth is of great necessary assistance.

The most noteworthy part of the beaver is the tail, though of no commercial value. The tail, spade or trowel, is of oval 
shape, flattened on upper and lower sides, and is from nine to eleven inches long and attains a width of five to six inches at its greatest breadth. It leaves the body in a cylindrical form, perhaps one and one-half inches in diameter, although immediately upon its descent becomes flattened. The tip or extreme end is of a semi-circular shape and the entire edges are hard permitting the animal to use this member rather roughly without endangering the inner or flesh part. The entire tail is covered with a sort of six-cornered scale, intermingled with a slight hairy growth. These scales, which are such in appearance only, cover the entire surface both above and below, and are arranged in respect to length in the so-called quincunx form, diminishing in size towards the end. Their numbers are nineteen to twenty and twenty to twenty-one on the under surface, of the extreme wider portion. The skin of this member is tough, and upon being tanned one finds that these scaly substances are nothing more than longitudinal divisions, merely dips or depressions, and not scales, as that term is understood, having in mind the scales of a fish. The tail is of no great value to the animal out of water, but while swimming acts as a rudder or propeller and tends to direct the movements of the body and assist the animal while diving, or to elevate or depress the head while swimming. It is also used to give signals of alarm to its mate, and the violence of the blow in the water is shown by the spray that is thrown up two or three feet:

The nose is small and within it there is a skin having a gatelike appearance which prevents the beaver from inhaling or partaking water. The pelage of the beaver resembles that of the muskrat in color, but the fur fibers are much finer, denser, wavy, longer and of greater strength. The outer, or guard hairs are coarse and their length predominates one-half to threequarters of an inch above the fur fibers. The former, instead of beautifying the fur pelt as they do on the otter, mink, fox and even the muskrat, tends to decrease and diminish their value and appearance; therefore the tanner or dresser removes these hairs by a process called plucking, which leaves a fairly light brown or dark surface resembling somewhat the color of the otter. The contrast in the color of its outward fur during the winter months is discernable between animals inhabiting the various sections. Those in the southwestern states along the Rocky mountains, Colorado and Wyoming are of a reddish cast, especially is this color prominent about the legs and belly portion. The color of the fur of animals inhabiting Montana, western Dakota and parts of Idaho, is pale. This pale, or silvery color prevails not only on the under guard hairs, but also on the fur 
fibers. The further north one goes the darker is the fur of the beaver. Have seen skins from the northern part of Canada that are as dark as the darkest of otters. In texture the fur of the dark beaver is finer but not quite so dense, as in the case of animals inhabiting Montana.

Formerly the beaver was found in most of the states and territories, but of late years he has become so scarce, notwithstanding the rigid laws, that it is safe to say that only a question of a few years remain until the animal will be totally extinct in this country. His home is naturally in the forests, about lakes or streams and his habit of making dams and retaining the supply. of water is elsewhere explained.

Brehm relates that beaver cultivation was already in progress as early as I773, and that the animal's life is prolonged to the remarkable limit of fifty years. There are numerous beaver farms in this country but the cultivation and increase is slow and tiresome. If the place is suitable the business is a profitable one.

Habits. During the fall, winter and spring months the beaver can be found about the rivers, also lakes, especially at or near some inlet or outlet. During the month of September the beaver, like the bees during the gathering season, are busybodies. A popular saying, "work like a beaver," is only too true of this animal, for in the making of their homes, laying in roots, herbs, bark and wood, also in the building and repairing of dams he is kept busy almost the entire time and up until the approach of severe winter. The huts, or beaver houses, as commonly known, are dome-shaped, being made out of sticks, brushes or weeds, and cemented together with mud, dirt, slime and other similar materials. Their houses are similarly constructed and in appearance resemble the home of the muskrat, although much larger, and sometimes the dome or upper part protrudes out of the water three to four feet. The houses are usually roomy, and of sufficient size to hold anywhere from four to sixteen animals. Some trappers, also naturalists, claim as many as thirty beavers occupy one house, but the author believes that this is exaggerated or was caused by unusual conditions, and that at the present time seldom more than eight to twelve inhabitants are found to occupy one of these huts during the daytime. The entrance to these homes is on the bottom and always below the water level. Some years the home is built in deeper water than in other years, and trappers believe that such location has more or less to do in the forecasting of the coming summer, as to whether the season will be a dry or a wet one. This may be superstition, but the probable forecast seems true. Some beavers (bank beavers) neglect to build 
houses, but make their homes by digging holes into the banks of rivers or lakes. Such entrances are always below the level of the water.

The building of beaver dams is not only remarkable, but the construction and manipulation is such that human hands with like material could scarcely improve. These dams are usually: built where insufficient water prevails and are of apparent necessity to the welfare of the beaver. The increased and steady supply of water that these dams afford, gives to them the required playground, protection against the severeness of winter

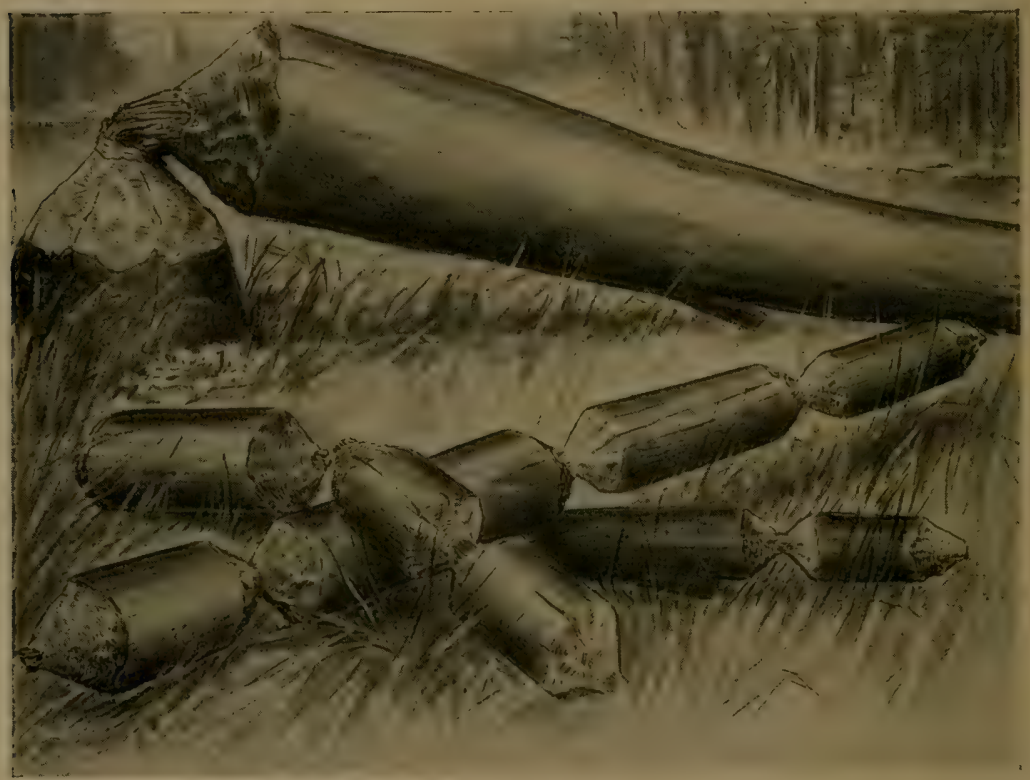

Beaver Cuttings

and protects their food supply; also materially assists them in their occupation. That this species requires a reasonable deptl and area of water, is well known, and scemingly will not do well in localities where the water is shallow. Shallow water retards the animal in the swimming, and diving habit: also offers obstacles to their method of carrying logs, branches, roots, etc., either for the construction of their home, repairing of dams or for their food supply. Besides this the forethought that shallow water may freeze to the ground, in which case the animal would be caught and unable to escape. The dams naturally stretch 
from one side of the river to another, and are often one hundred to two hundred yards in length, being from two to twelve feet high, four to six feet thick on the bottom, and ranging to a width of two to three feet on top. The latter is leveled off very nicely causing an even overflow. The length, thickness, height and manner of construction depends upon natural conditions, as some dams are only five yards long and should the water flow slowly, are only two feet thick at the bottom and about six inches on top. Some dams are built straight across, others have a convex curve leading up stream. The latter is usually constructed where the current is swift. Other dams, besicles crossing the stream, are continued on land and constructed in a semi-circular shape, and the end reaches the river on a higher elevatio: ; the result is the formation of a bay and the backing of water, and as one travels through the country he will often notice aliuvial meadows caused by these dams. At times the beaver will cut down one or more trees in such a manner that the trunk will fall directly in the place where the dam is desired, and this trunk forms the nucleus in the building operation.

Often numerous dams are to be found in one vicinity. This is clue to one or the other səx of the offspring bringing his or her mate to its former home, where a new dam either below or above the original one is built. When the young attain an age of three years they depart from their parents and after they have mated build a dam for themselves and their expected fanily. Trappers and naturalists state that in this operation the parents are of great assistance to their youthful and probably inexperienced offspring. This again is denied by careful observers. The dams are constructed out of short logs, brush, stones, grass, clirt, etc. Entire trees eight to twelve incles in diameter are rapidly felled, the beaver cutting same clown with his teeth, generally in such manner that the tree will fall towards the river. After a tree is felled, it is cut into small piezes from four to six fect long, the length depending somewhat upon the thickness and weight of the piece and the purpose for which it is intended: these are conveyed to the river, exch animal taking its own burden. Some will take logs, others brushes, sticks, weeds, stones, dirt, etc., while some are kept busy by intermingling, binding and fastening the materials together. The female is the most active builder and is usually consigned to the job of constructing, while the males will bring the material to the desired location.

Although not exclusively rocturnal in his habits, the beaver performs the principal part of his work at night. That he is of shy and timid disposition cannot be denied, and if disturbed 


\section{Castoreum and Generative Organs of Male and Female Beavers}

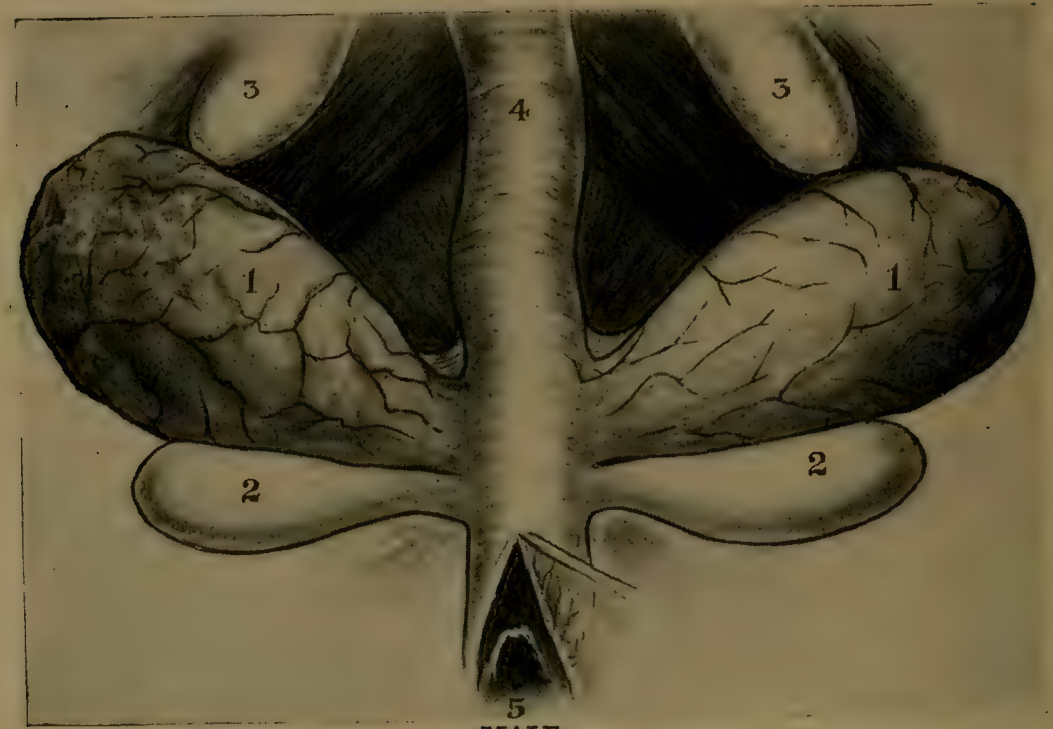

1 Castor Sacks or Bark Stones

IMALE

2 Oil Sacks or Oil Stones

3 Testicles

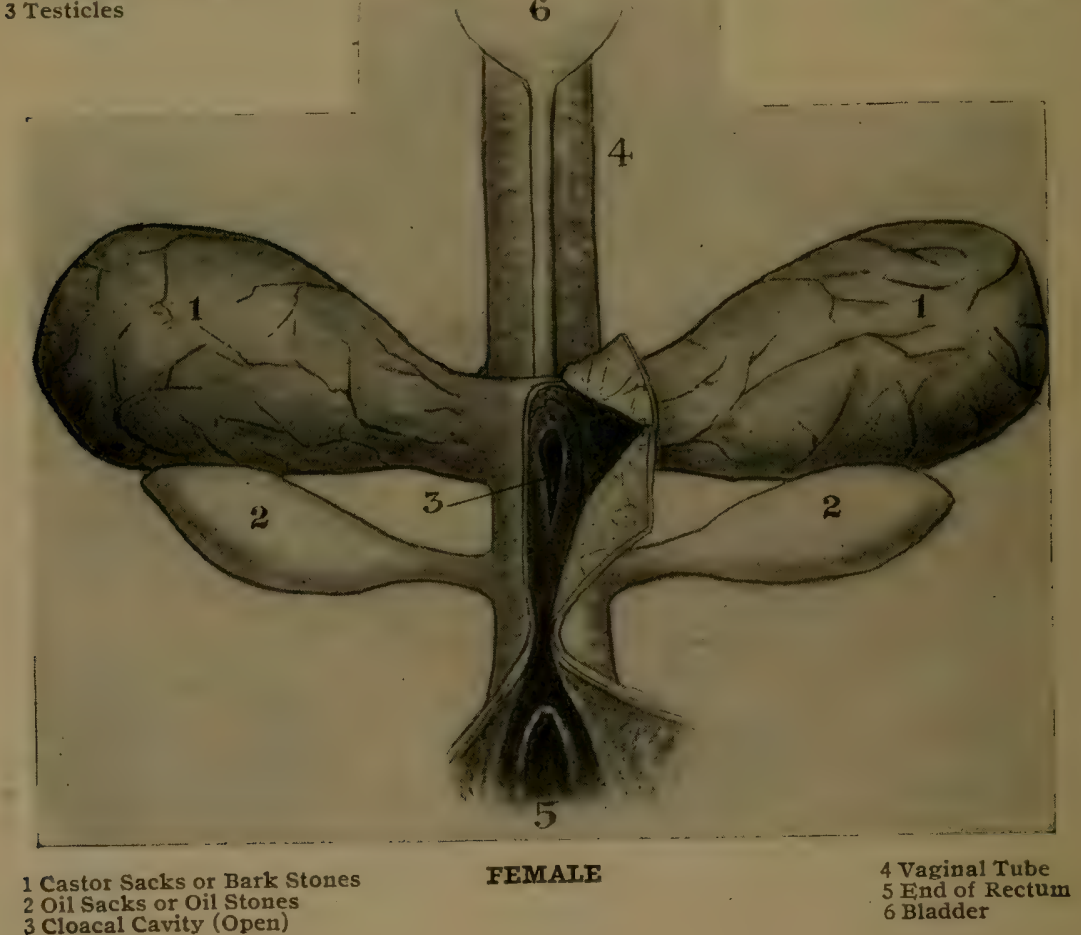


will soon decamp from his location. He is socially inclined and this disposition is manifested in their strongly developed propensities to dwell and live in the family relation. This is also corroborated by the numerous inhabitants of a given locality, and the many assistants in the building of their lodges, burrows and dams; also in the providing of their winter supply of food.

i) $(-n)$ ?

The breeding or mating season begins as early as March in the southern states and as late as May in the extreme northern climates. The female brings forth from two to five young during the month of May, June and as late as the fore part of July in the extreme northern climates. A beaver family consists of a male and female, and their offspring of the first and second years. The mother will nourish the young for a few weeks, after which time the latter take to bark. The animal is full-grown in about three years, and their life in the wild state is prolonged from ten to twenty years.

The experience of a trapper as related by Mr. Morgan pertaining to the peculiar cry of the young beaver, which resembles that of a child of a few days old, is repeated: He was going to his traps when he heard a cry which he was sure was that of a child; and fearing the presence of an Indian camp, he crept in cautiously through the cotton-wood to the bank of the stream, where he discovered two young beavers upon a low bank of earth near the water, crying for their mother, whom he afterwards found in one of his traps. Mr. Morgan's own experience is as follows: "On one occasion I was similarly deceived in an Indian lodge at the mouth of the Yellowstone River, where a young beaver was lapping milk from a saucer while an Indian baby was pulling its fur. It was not until after several repetitions that I noticed that it was the cry of the beaver instead of the child."

That the beaver, after they attain a mature age are sensitive, in that respect resembling the human family, is expressed by many trappers and believed by them as well as the Indians. Should the father or mother die, or be captured, the grief of the remaining one at times is so great that he or she will refuse to pair, and begins a solitary life which is continued until death. The animal migrates from place to place, especially when one district becomes too thickly settled; at other times his migration is forced upon him by the country becoming populated.

The animal can swim under water a distance not exceeding one-fourth of a mile when its supply of air becomes exhausted. There is quite a difference in the opinion of trappers 


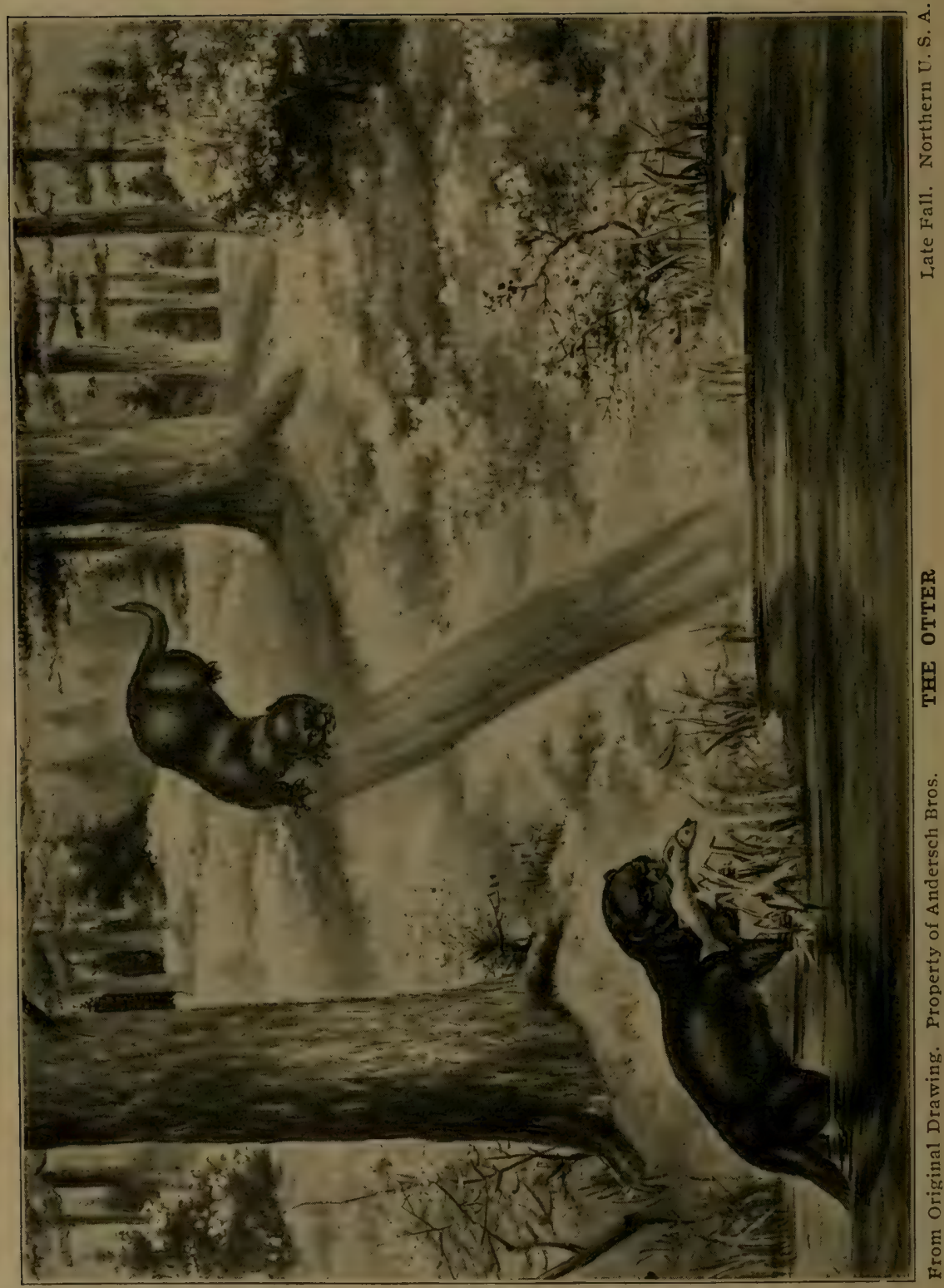


as to the durability and length of time the animal can remain below water without a supply of fresh air. Observation woulrl indicate that two to three minutes is the average time. An incident is recited where a trapper held a captured beaver below the water for ten minutes, feeling assured in that time the animal's life would be cxtingtished, but such was not the case.

One should observe and study the accompanying illustrations of this article, especially the ones pertaining to the beaver cuttings and the location of the castorium and oil bags, probably better known as bark and oil stones.

The value of the pelt differs, depending upon the locality, size of the skin, time of year, and upon the demand and fashion. Tables containing prices for a period of years will be noted elsewhere. The castor bags, when properly dried, bring $\$ 6.00$ to $\$ 9.50$ per pound. The contents are used for medicinal as well as perfume purposes, and are bought by the fur dealer, who in turn disposes of same to the manufacturer. The pelt, after it is tanned and plucked, is used for ladies as well as for gentlemen's wearing apparel. Its high cost prevents its common use, also tends to bring forth low priced imitations, such as nutra, raccoon and at times coneys. The latter are shorn and blended so as to resemble the beaver. The small pieces or offals of beaver trimmings are disposed of to hat manufacturers.

\section{THE OTTER.}

\section{(Ger. Land or Fisch Otter, Lat. Lutra canadensis.)}

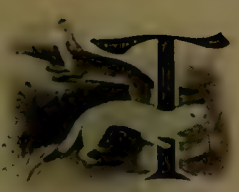

HE land otter on this continent like all fur bearing animals that are indiscriminately distributed amongst the states and territories, also Canada, as is the otter, cannot but show a marked contrast in the size of the animal and color of its furred pelt. Naturalists claim as many as twenty different species, but all resemble each other very

closely. On this continent we have only one species, but the fur trade sub-divides the otter into three geographical types-the northern otter, the southern otter and the Pacific coast otter. The former is found in the northern parts of the United States, in Canada and Alaska. The southern otter, as the name implies, inhabits the southern states, particularly Florida, Georgia, Alabama and the Carolinas, and portions of Texas. The Pacific coast otter is found along the Pacific coast from-Mexico extending along California, Oregon and sometimes those captured along 
the coast of British Columbia are classed and marketed as Pacific coast otters. The Alaska otter differs somewhat from the other species, but those inhabiting the numerous islands, resemble the Pacific coast otter very much, while those of the inland are classed as northern otters.

The otter is generally distributed over North America apparently nowhere in great abundance, but years ago was absolutely wanting in few, if any, localities adapted to its habits. Due to the high price of the skin the otter is zealously hunted and has become extinct in many localities. It is safe to say that the otter is gradually disappearing, and like the beaver will become extinct, notwithstanding the laws that give the animal protection.

The otter is peculiar in its construction, resembling somewhat the mink and the marten, only in magnified appearance. The ears are small, well rounded and almost hidden from view by the long and glossy fur. The head is broad anc flat on top, consequently the ears are wide apart. The nose is stubby, rather broad, well rounded and remarkably well developed. The small eyes are rather forward, nearer to the muzzle than to the ear and deeply set in the skull. The body is plump, thick, and long, and during the winter covered with short, dense, silky and glossy fur. The undergrowth resembles that of the beaver, but is more silky, equally as wavy, and adheres to the skin in a more dense form and is perhaps somewhat lighter in color, especially on prime skins from the extreme northern regions, which in outward appearances are extremely dark, while the fur fibres next to the skin are very light, almost of whitish color. The guard hairs are rather coarse in sections, glossy, varying in color from a brown to an extreme dark or blacks These coarse hairs are by no means harsh, on the other hand are soft, pliable, dense and evenly distributed all over the body. There is probably no better wearing fur than the otter, especially in its natural state. Only poorly furred skins, or those coming from the southern states are plucked. The others are left in their natural state as plucking would diminish their beauty and value.

The short fore limb is succeeded by a stout wrist and broad flat hand. The fingers are very short and when divaricated, their tips describe merely a semi-circle around the center of the palm. The toes are almost completely webbed by membranes reaching well within the center of the palm. The upper part of the hand or foot is covered with a hairy or fur formation while the lower part of the foot is naked. As above stated the feet are stout and short and closely attached to the extreme 
sides of the body, thus the walking on land is more of a hardship than pleasure and its travel awkivard, being of waddly appearance. If in danger the otter is likely to increase his speed of locomotion on land to a remarkably rapid gait, and the pursuer is obliged to run in order to keep up with him. The claws are similar on both hind and fore feet, being short, stout and somewhat arched. Perhaps those of the fore feet are somewhat larger and sharper and more curved than those of the rear feet.

The tail, which is two to three inches in diameter at the root, is quite well rounded, but becomes flattened as it tapers gradually to a true point in its descent. It attains a total length of fourteen to eighteen inches; depending somewhat upon the size of the animal. The member is completely furred with fibers resembling those of the body. The fur is very dense and diminishes in length as it nears the tip. The upper portion possesses a coat of very dense fur and is always two or three shades darker than that of the body.

The body is extremely slender and few animals vary more in stature than does the otter. The average size of the northern otter is from thirty-four to forty inches from nose to root of tail. Much larger specimens are occasionally captured, and one in particular that was received from British Columbia measured fifty-one inches, its tail nineteen inches, or a total of seventy inches. The animal from which this skin came must certainly have weighed forty-five pounds or more. The usual weight of matured northern otters is from thirty-five to forty pounds; that of the southern or middle states, twenty-five to thirty pounds. The usual difference in size between the male and female exist; the latter is one-fifth to one-fourth smaller. The following measurements by Dr. Coues, taken from the government records, is corroborative, especially since his measurements are taken from eastern or probably middle state species:

"Some individuals are, in round terms, twice as large and heavy as others apparently equally mature, and, at any rate, capable of reproduction. An average total length of full-grown individuals is four to four and one-half feet; some specimens however touching five feet, while others fall short of the firstnamed dimensions. The species appear to grow several years after puberty. Nose to root of tail three feet; tail one and onehalf feet; nose to eye, one and three-quarters to two inches; nose to ear three and one-half to four inches; ear less than an inch high, and about as broad; fore foot from wrist three and onehalf inches; hind foot four inches; girth of body about one and one-half feet; stature a foot or less; weight ordinarily twenty to twenty-five pounds. I have recognized no particular sexual 
differences, though the female may, as usual in this family, average smaller than the male."

Habits. It is not often that the hunter or trapper is able to observe the otter, consequently his habits are not thoroughly known. The Almighty Creator willed it that the animal become an excellent swimmer and diver and to confine himself largely to the water. The construction of its body, limbs, dense fur and long tail, gives the animal the desired facilities to remain in the water for a long period. He is known to swim miles under water, also to dive in deep or shallow water from high distances. His home is in various sized rivers and other bodies of fresh water. Its swiftness enables it to catch fish with remarkable ease, and at times is known to wantonly kill large numbers for the simple pleasure it gives him. Their principal food is confined to fish; if these are unobtainable, the otter will devour the flesh of muskrats and other procurable meats. Instances are recited where the animal captured wild ducks which were taken into his abode and there devoured. Audubon relates that he had one or more otters in confinement and when no fish could be procured, were fed upon beef which they always preferred boiled. "During the last winter we aszertained that the collection of feathers of a wild duck were taken from the banks of a rice field reserve-dam. It was conjectured that the duck had either been killed or wounded by the hunter and was in this state seized by the otter."

Their fondness for speckled and brook trout causes them to frequent clear water and rapid-flowing streams. The animal is also known to travel on land for long distances in search of lakes or streams or to habitually migrate from one lake or stream to that of another. Quite often in these travels they become victims, being killed by hunters, farmers, or are captured and devoured by such animal as the wolf. Mr. Richardson, one of the earliest authors, in writing about the Canadian otter, states as follows:

"In the winter season it frequents rapids and falls, to have the advantage of open water; and when its usual haunts are frozen over it will travel to a great distance over the snow in search of a rapid that has resisted the severity of the weather. If seen, and pursued by hunters on these journeys, it will throw itself forward on its belly and slide through the snow for several yards, leaving a deep furrow behind it. This movement is repeated with so much rapidity that even a swift runner on snowshoes has much trouble in overtaking it. It also doubles on its track with much cunning and dives under the snow to 
elude its pursuers. Wl:en closely pressed it will turn and defend itself with great obstinacy."

Its numerous slides are seen on banks of rivers, and, in some cases, on lakes, and it formerly afforded great pleasure to the Indians and the carly hunters to watch the otter sliding down these embankments, diving and swimming sometimes a short distance while at other times a long distance, only to regain the shore and the uppermost portion of the slide to repeat the operation.

Some naturalists claim that the breeding season is not specific or timely. Others claim positively that the mother brings forth her young during the month of April or May. By close observation and inquiry it is found that the season varies considerably, especially in the different climates, but seldom is beyond the Ioth of May and likewise before March I5th.

\section{THE SEA OTTER.}

(Ger. Sec-Otter, Lat. Enllydris lutris.)

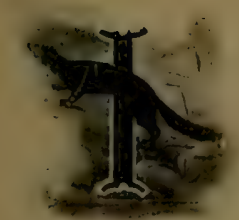

$\mathrm{N}$ all the-many years I have devoted to "Fur Bearing Animals and their Skins," I have not laid eyes upon a living sea otter and to speak or write from personal observation or experience is denied me; the information following is second-hand, excepting that individual skins were viewed, and that the contrast between such was observed and noted.

The sea otier is found in northern latitudes along the const of Alaska, the Aleutian Islands, then across to Kamchatka, following the coast line of the latter peninsula up to Cape Olutorsk, thein along the coast to Cape Navaria. In some of the above sections they are known under the name of "Kalan." The animal's existence was brought to light by Steller in I75I, but was known to the natives inhabiting the extreme northern shores of the Pacific ocean and its islands, who used the skin for wearing apparel, etc., at the time Steller made his observations. Probably no skin from any other animal of the entire animal kingdom has more merits of true value than that of the sea otter. The choicest skins of the black fox may command more money at times, but its relative value and merit is surpassed by the skin of the sea otter. In value the seal skin is far surpassed by that of the sea otter.

During the colder part of the year they dwell along the coast, and are seen on large barren rocks, evidently preparatory to 
taking plunges into the deep sea. During the warm season they migrate fifty to one hundred miles from the shore and live entirely in and on the deep sea. There is a marked difference between the sea otter and that of the land otter. The latter presents a special modification of the limbs, more particularly of the hind limbs, which are developed into flipper-like organs, not very dissimilar to those of some seals.

The body is cylindrical in form, abrupt behind, tapering before to a small globose head without noticeable constriction of neck. The limbs are short and there is a remarkable disparity in shape between the fore and hind feet. The tail is short, cylindrical, gradually tapering and ending abruptly. In no respect does the tail of the sea otter resemble that of the land otter. The fore feet are remarkably small and the rear ones are notable for their expansion and flattened effective oars. The eyes are of moderate size and set rather high up into the skull. The ears are situated remarkably low down-far below the eyes, and in fact little below the commissure of the mouth. "The whiskers are short, extremely stout and stiff. In life the skin is remarkably loose (rolling); the pelt of an individual four feet long readily stretches to six feet; and when the animal is lifted up by the skin a foot or so of "slack" gathers.

The pelage is notable for the preponderance of the woolly under-fur, the longer, stouter hairs being very scanty. It is of the same general character all over the body, but the head, feet and tail are covered with a finer fur with little or no admixture of bristly hairs. The only naked parts are the muffle and palms. The animal attains a size of four to six feet, which includes a tail of eight to ten inches in length. The average weight is eighty to one hundred and ten pounds.

Habits. From one of the Government Reports, and as noted by Coues, the following is extracted: "The sea otter mother sleeps in the water on her back, with her young clasped between her fore-paws. The pup cannot live without its mother, though frequent attempts have been made by the natives to raise them, as they often capture them alive, but, like some other species of wild animals, it seems to be so deeply imbued with fear of man that it invariably dies from self-imposed starvation.

"Their food, as might be inferred from the flat molars of dentition, is almost entirely composed of clams, mussels, and seaurchins, of which they are very fond, and which they break by striking the shells together, held in each fore-paw, sucking out the contents as they are fractured by these efforts; they also undoubtedly eat crabs, and the juicy, tender fronds of kelp or seaweed, and fish. 
"They are not polygamous, and more than an individual is seldom seen at a time when out at sea. The flesh is very unpalatable, highly charged with a rank smell and flavor.

"They are playful, it would seem, for I am assured by several old hunters that they have watched the sea otter for half an hour as it lay upon its back in the water and tossed a piece of seaweed up in the air from paw to paw, apparently taking great delight in catching it before it could fall into the water. It will also play with its young for hours.

"The quick hearing and acute smell possessed by the sea otter are not equalled by any other creatures in the territory. They will take alarm and leave from the effects of a small fire four or five miles to the windward of them; and the footstep of man must be washed by many tides before its trace ceases to alarm the animal and drive it from landing there should it approach for that purpose."

It is positively related that unlike other animals, the young, when born, possess excellent sight and sharp teeth. The mother soon takes them to sea, holding them in her mouth while she swims on her back. The usual position of the young is for them to lie on her breast between the fore-legs, she protecting one or both of them in this manner. Like the motlier of the human family she kisses her young over and over again and readily risks her life to save the young from harm.

Steller relates that the sea otter can be tamed and be placed in lakes or rivers similar to seals, although the roomy salt water is very dear to them.

The number of sea otters is rapidly diminishing, while certain vessels containing hunters and explorers as early as 1794 captured, in a season, two to five thousand otters, and later, in I80o, a few American and English vessels came into Sitka Sound, anchoring off the small Russian settlement there and traded with the natives for thousands of skins, giving in exchange firearms, powder and balls, etc. With the use of these arms the natives soon opened a systematic warfare leading towards extermination. In the year I804 a Russian and American company marketed fifteen thousand sea otter skins and realized over one million dollars therefor. For mode of capturing, which is very interesting, see article under "Trapping." The value of the skins varies considerably and is generally between $\$ 200$ to $\$ 500$ each. 


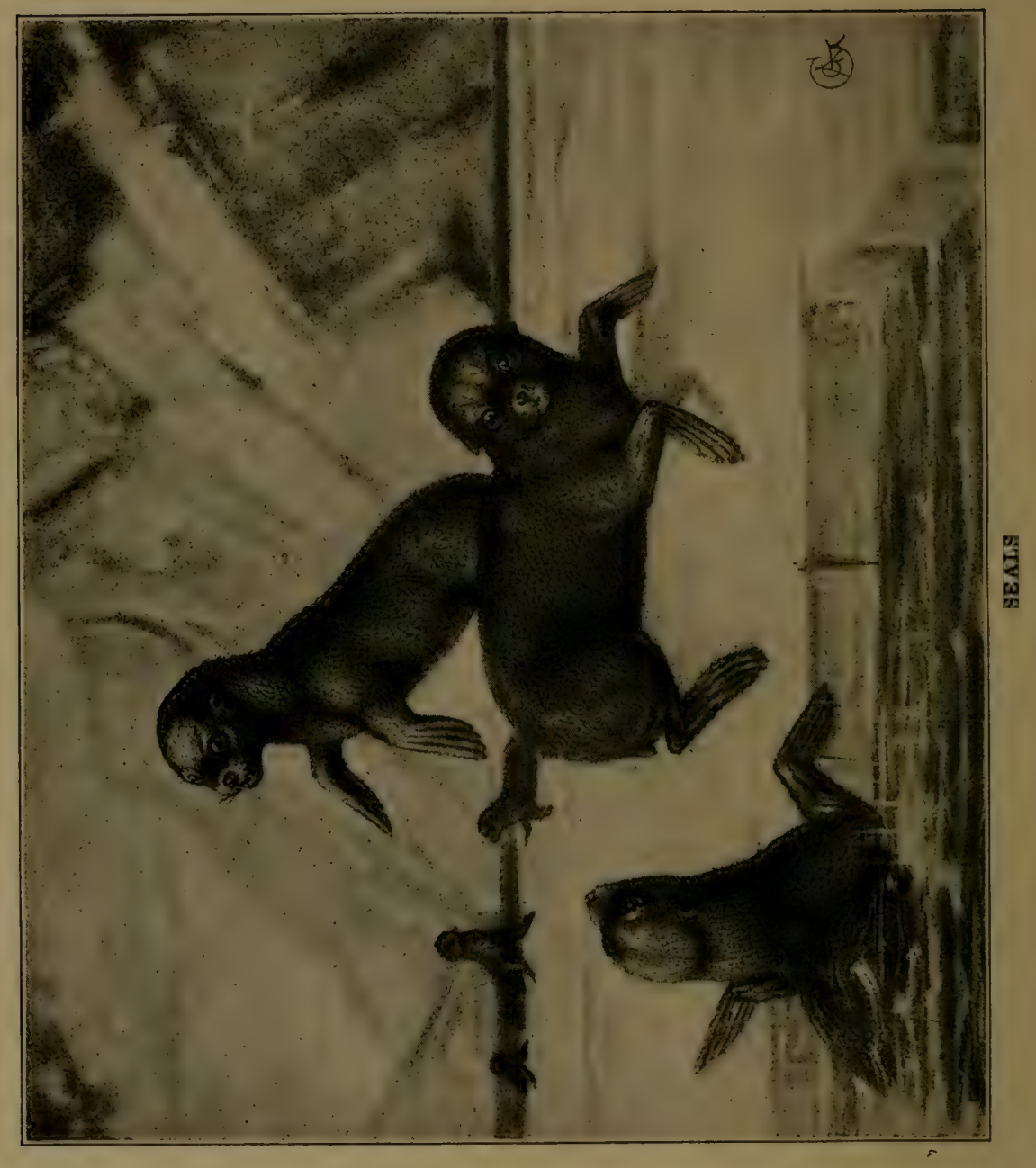




\section{THE SEAL.}

(Ger. Robben oder Flossenfuser, Lat. Pinnepedia.)

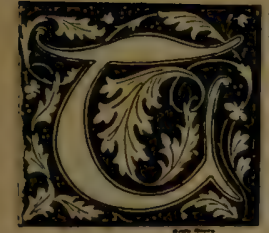

HE seals, sea lions, harp seals, hooded seals, sea bears, saddleback seals, and other species, as well as the various kinds of walruses belong to the fin footed variety and are distinguished from other mammalia by the peculiar construction of their body, habits, actions, etc.

They are able to swim and dive with the greatest ease, often remaining ten to twenty minutes below the surface of the water, and, Cuvier says, as long as one hour. Their arteries are filled with warm blood, and the animal possesses nocturnal and gregarious habits, with a highly-developed sense of sight, hearing, smell, and inhabits all oceans of the world.

All species of the seal family frequent resorts of sandy beaches, rocks and floes, for the purpose of sleeping or basking in the sun, and for breeding. The body is adlapted for continued water residence, being cylindrical and tapering gradually from centre backwards toward tail and tapering frontwards, terminating in an otter-like head, the latter being small and well rounded. The ears on certain species are well developed, while those of the Alaska fur seal are sparingly distinguished and exceedingly small, and when the animal is in the water, same are closed by a valve, which terminates the inward flow of water, but does not retard the animal's sense of hearing. It is remarkable that the seal is able to detect slight surface noises while at a depth of ten to twenty feet below the water level. Their nostrils are completely closed when under water, and the eyes are large, and pleasingly set off the animal, as well as their intelligent nature. The mammac (teats) are on the lower rear portion of the belly, and their feet are as indicated on the illustration.

From a commercial standpoint seals are divided into two groups-hair seals and fur seals. The latter produces a skin that is worn by thousands of ladies in this country and Europe, also a quantity of oil. The hair seal is caught for the value of the nil and skin-the latter is largely converted into leather. The latter species of seal inhabits Newfoundland, Labrador, Gulf of St. Lawrence, and portions of the White Sea, Arctic, Caspian and North and South Pacific oceans.

The Alaska fur seal inhabits the ocean along the coast of Alaska, and the rookeries which they frequent are situated on the islands of St. Paul and St. George, known as the Pribilof islands.

The body of the Alaska fur seal is covered with a layer of 
coarse outer hair, while the inner coat consists of dense, soft, silky fur fibres. The roots of the outside guard hairs penetrate deep into the skin, while the fur fibres are imbedded and terminate immediately beneath the grain formation of the skin. In the process of tanning, the coarse hairs are easily loosened in the operation of "fleshing," without disturbing the adherence of the tur fibres.

A full-grown Alaska bull seal measures about seven feet, and is about equal that number of feet in circumference, and will weigh about five hundred to six hundred pounds. He attains his maturity at the age of about six years. The females attain their maturity at the age of about four years, and are about twothirds the size of the male, but in weight they rarely exceed one hundred fifty pounds, usually about one hundred pounds. Their longevity varies considerably usually from sixteen to twenty years for a bull and ten to tivelve years for a female. The mother brings forth a pup usually at the age of four years, and in rare cases at the age of three years.

The Alaska seal, as aforesaid, is largely captured on the Pribilof islands, the bull seals arriving from a southward direction on the rookeries as early as May and by the first of June hundreds and thousands locate themselves in advantageous position, awaiting the reception of the females, which usually come two to three weeks later.

It is extremely hazardous and requires an unusual amount of grit for the individual bull seal to maintain and defend his position. Hundreds are annually killed in combat, especially those on the water line. The fighting is done entirely with the mouth, one seizing the other by the teeth, inflicting deep wounds, their sharp incisors tearing deep gutters in the skin and at various times shredding the flippers into ribbon strips.

The skins taken from the Pribilof islands principally constitute the Alaska seal skins though numerous animals are captured along the coast of Alaska, British Columbia, along the Aleutian islands, and others when the animals return from the Pribilof islands by the pelagic sealers.

The seals are remarkably tenacious of life, but are easily killed by a bullet piercing the brain, or by a sharp rap over the head.

The seal has other enemies besides man. The monster killer whale, the polar bear, and also certain species of large fishes, which usually overtake the young, but seldom attack the fullgrown seal.

The killing of seals is carefully regulated by law on the Pribilof islands and within a radius of sixty miles thereof. 
The Commercial Company, which has the contract from this government, is only permitted to kill a certain number of young bachelor seals. The killing of females is entirely prohibited. The female brings forth one pup, in rare cases two pups, which are born three to six days after reaching the rookeries. Strange as it may seem, the new companion of the mother takes kindly to the pup. The bull seal usually gathers about him a number of females, sometimes as high as eight, but usually two to five. These, with the offspring of the female and her previous companion are protected by him, the father of her next.pup, which is born in about a year.

The skins taken from seals inhabiting the oceans about the Shetland islands are superior in fur qualities to that of the Alaska seal, while the latter is superior to others, especially those coming from the Copper islands, Japanese, Lobos, Cape of Good Hope and other sections.

The elephant seal that is found at various portions of the globe, and formerly along the coast of California are monsters, and historians state that the elephant seal is the largest species of the seal family, single bull seals of the above species weighing between two thousand and two thousand five hundred pounds.

Many believe that the sea lions inhabiting the rocks just off the Cliff House in San Francisco are animals that produce the fur seal skins. Such is not the case. 


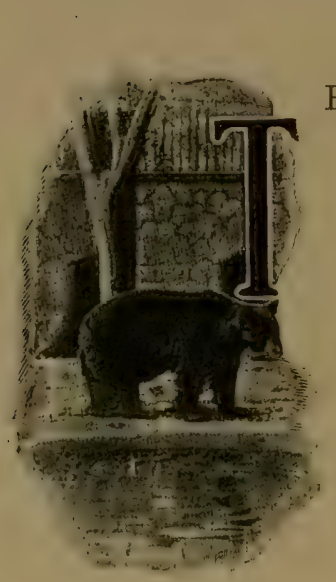

ALASKA FUR SEALS.

$\mathrm{HE}$ islands of St. Paul and St. George, forming the Pribilof islands, which are the chief seal hunting grounds, are inhabited principally by natives. Upon the former there are one hundred and sixty-eight inhabitants, nine of them being white people from this country, who are employed by the government. Upon the island of St. George there are eighty-eight native persons, representing twenty-two families.

According to contract, the North American Commercial Company gives employment to natives on both of these islands, attends to their personal wants, such as clothing, food, fuel, education, etc. The following are extracts from the governor's report to the Secretary of the Interior in 1902:

"Nineteen thousand animals (seals) were killed upon St. Paul and 3,304 upon St. George, making a total of 23,304. This number, at the contract price of $\$ 9.62 \mathrm{1} / 2$ per skin, together with the annual rental of $\$ 60,000.00$, amounts to $\$ 274,676.05$. The expense is the fuel account of one revenue cutter, the Manning, and the salaries and expense accounts of the treasury agents. Any person who visits the islands and studies these animals upon tlie rookeries can hardly bring himself to advocate their wholesale destruction. WVe undoubtedly have a property interest in them, and should stontly maintain our right by straightforward diplomacy. By what little branding that has been done we have proved that these animals migrate along the coast in the winter and early spring. Have we a right to protect them from the pelagic hunter? What is known as the sixty-mile limit, which was imposed by the court of arbitration, gives some protection, but not enough. The nursing females are killed more than two hundred miles from their rookeries. The English and Americans who were parties to the arbitration are restricted to the sixtymile limit and hunt with spears only. We refuse to clear our own vessels for hunting seals. Eighteen vessels are said to have cleared from Japanese ports this season to engage in pelagic sealing. These are armed with guns, Some of the crews of these vessels are mixed-made up of Japs, Canadians and others. These people will assert that they are not restrained by the rules of any court of arbitration in which they were not represented. It would be to the interest of the United 
States to have the whole sealing question opened up anew and to have Russia, Japan, England and the United States agree upon a plan for giving these animals adequate protection.

"They have an enemy in the thrasher or whale killer. These animals are the dread of the whole seal family. When the ser lion or hair seal scents them he knows that their only safety is to make for land; but the fur seal is not so wise. If he do'dges at the first onset he becomes curious to learn what is going on instead of trying to escape. The thrasher knows these habits to his advantage. He is armed with rows of tecth that conne together with tremendous energy. These animals in great numbers guard the passage well and no doubt consume great numbers of young seals. The agents upon the islands report that they frequently chase the seals at the rookeries, but when they discharge a rifle at them they put to sea at once. It would be well for Congress to authorize the Secretary of the Treasury to offer an ample bounty for the heads of these sea beasts of prey. It should be sufficient to induce hunters to outfit vessels for capturing them."

According to the contract between the United States and the North American Commercial Company, entered upon and between these parties on the I2th day of March, I890, said company has the sole monopoly of the seal industry on these islands, (St. George and St. Paul), and must exercise its power under rules and regulations of the Interior Department. They are restricted to capture a certain number of seals a year and are obliged to pay an annual rental of $\$ 60,000.00$. In addition thereto a revenue tax of $\$ 2.00$ is laid upon each fur seal skin taken and shipped by said company from the islands of St. Paul and St. George, ancl are also obliged to pay the United States an additional $\$ 7.62 \mathrm{I} / 2$ per skin and 50 cents per gallon of oil shipped from said islands.

They are obliged to furnish the natives with sufficient and proper food, fuel, comfortable dwellings, schoolhouses, competent teachers, places of worship, care for the aged and infirm, and give the inhabitants sufficient and proper employment, medical attenciance, etc.

The above contract is for twenty years and subject to nullifiention upon eviclence of violation or at the pleasure of the Government, and the company is subject to all present and future laws pending the seal fisheries.

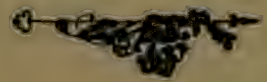




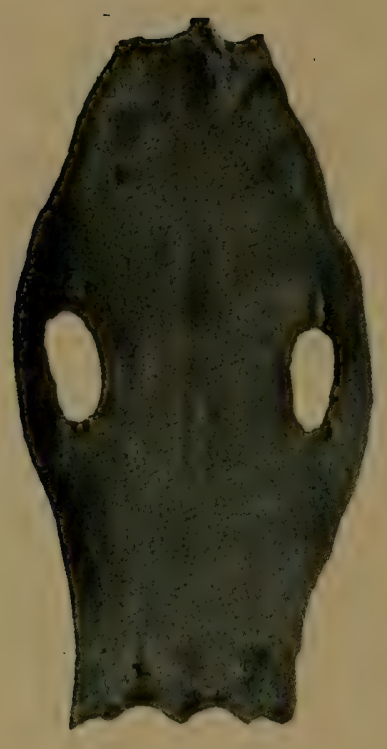

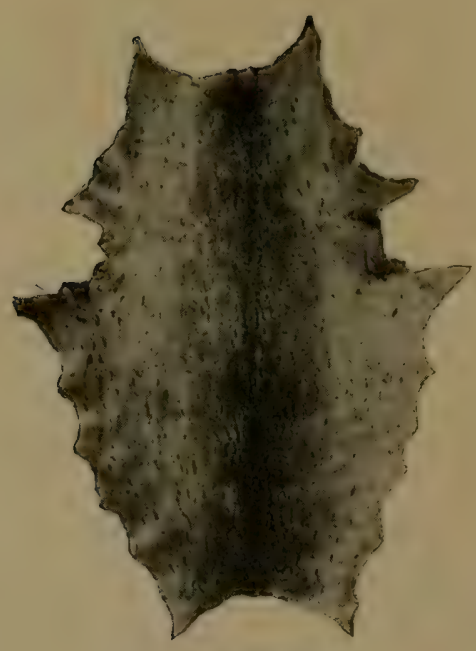

Upper, Fur Seal Skin Lower, Marbled Seal Skin

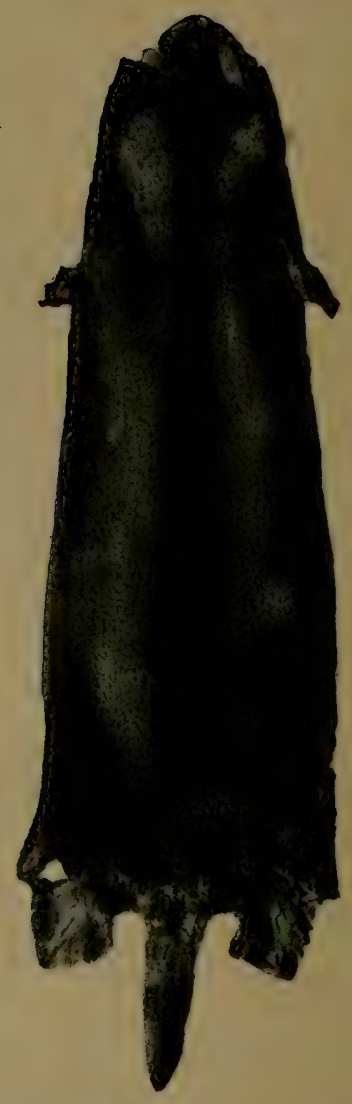

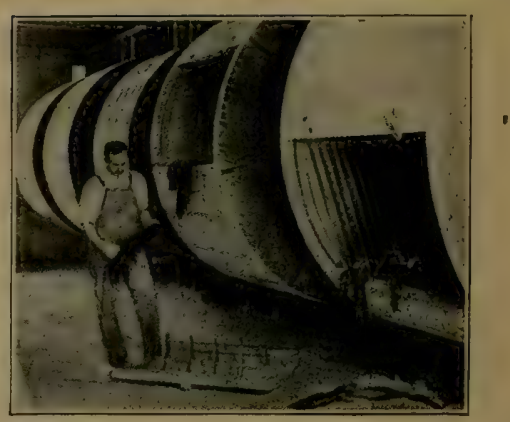

Upper, Sea Otter Skin Lower, Cleaning Drums 


\section{ALASKA FUR BEARING ANIMALS.}

\section{(E.tracts from Government Reports of Sial and Salmon Fish- eries and General Resources of Alaska, I898.)}

The Fur Seal (Callorhinus ursinus). The only hauling or breeding grounds of the fur seal known in Alaska are on the Islands of St. Paul and St. George, with the addition perhaps of the adjoining Otter Island, where these animals occasionally haul up but do not breed. From early spring tintil late in the autumn fur seals are met with in all portions of the North Pacific inclosed by the Alaska coast, from latitude $54^{\circ} 40^{\prime}$ to Mount St. Elias, and thence westward along Prince William Sound, the east side of Kenai Peninsula, and along the Aliaska Peninsula and its continuation, the Aleutian chain of islands. In Behring sea the animal has not been observed to the northward of latitude $58^{\circ}$. In the spring of the year only fur seals are found in large numbers in the vicinity of the Strait of Fuca and along the coast of Vancouver and Queen Charlotte Islands. During the time of the general migration to and from the breeding grounds several of the passes through the Aleutian chain are crowded with adults in the spring and with young seals and yearlings in the late summer and autumn. The presence of large numbers of these animals in these secluded waters and those of Prince William Sound late in the season (in June and July) has often given rise to the supposition that some breeding grounds must exist in those localities, but the most mintute and persistent search has failed to sustain the supposition.

About fifty miles south of the Aleutian chain large numbers of seals are frequently seen during the summer, and for half a century rumors of the existence of breeding grounds in that neighborhood were launched from time to time.

The Russian-American company fitted out numerous exploring expeditions, but these were always-unsuccessful. The last enterprise of the kind was undertaken by a former emplove of the Russian company, under the auspices of the present lessees of the seal islands, on the sclooner "John Bright," in 1873 , being the third expedition of the kind fitted out by the Alaska Commercial Company in two years. On this occasion indications of land, such as are accepted by all navigators, were not wanting in the waters included in the search. After a season of fruitless search the captain finally abandoned his undertaking, coming to the conclusion, however, that within a short distance southward from the Aleutian Islands there existed banks sufficiently shallow to serve as feeding grounds for the seals, which possibly visit them 
for that purpose even during the breeding season, as a journey of 300 miles is but a brief excursion for these rapid sivimmers in search of food.

All other expeditions in search of the supposed "winter home" of these seals have met with the same lack of success. The Pacific ocean and the Antarctic have been scoured by the sealers and by emissaries of trading firms, but at the present day the fact seems to be established that the fur seals, after leaving their confined breeding places, scatter over the broad Pacific to localities where extensive elevations of the bottom of the sea enable them to subsist upon fish until the instinct of reproduction calls them again from all directions to one common goal.

The Sea 0tter (Enhydra marina). The sea otter seems to exist, chiefly on a line parallel with the Japanese current, from the coast of Japan along the Kurile islands to the coast of Kamchatka, and thence westward along the Aleutian chain, the southern side of the Aliaska Peninsula, the estuaries of Cook Inlet and Prince William sound, and thence eastward and southward along the Alaskan coast, the Alexander archipelago, British Columbia, Washington Territory and Oregon.

At the beginning of the present century large numbers of these animals were also found on the coast of California, from which they have now disappeared altogether; and on the coast of Oregon, Washington Territory, and British Columbia they have decreased to such a degree that only at long intervals is the patient hunter rewarded with the prize of one of these valuable skins. On the west coast of Vancouver island, in the vicinity of Nootka Sound, where Meares, Portlock, Dixon, and others of the earliest English northwest traders found thousands of seaotter skins in the possession of chiefs, the animal has been almost exterminated, and there can be no doubt that, had it not been for the protection afforded under the Russian monopoly for nearly three-fourths of a century, this animal would be extinct today in Alaskan waters. The Innuit tribes alone entered understandingly into the measures of protection introduced by Russians. The Thlinket, on the other hand, a fierce and savage people, opposed to system and order or control of any kind, were the most active agents in the extermination of the animal. From the time they began to understand the value of sea-otter skins from the eagerness with which the early English visitors purchased all they had, even mere scraps and rags, the Thlinket all along the coast, from the mouth of Copper River southward, hunted and slaughtered the sea-otter indiscriminately and in the most clumsy manner, frightened away as many as they killed. Had these tribes joined to their recklessness the same skill and patient per- 
sistence observed among the Eskimo and Aleut, there would be no sea-otters on that coast todlay ; but in their wooden canoes they can only hunt in fine weather, and at such times the sea-otter retires from the coast to a distance to which no Thlinket would venture.

In the Russian possession about the Kurile Islands and the coast of Kamchatka but a few hundred sea-otters are now killed annually. At three different times during the existence of the Russian-American Company their agents on the Kurile islands and Kamchatka reported the sea-otter as extinct, and each time the animals appeared again after they had not been hunted for a few years. Along the Aleutian chain the sea-otters frequently: change from one feeding ground to another; for instance, for a long series of years the island of Attoo and several smaller surrounding islands furnished many hundreds of sea-ntter skins every year, but for some unexplained reason a migration eastward took place, and at the present time from fourteen to twenty skins are all that the poverty-stricken inhabitants sell to the traders. The numerous islands between Attoo and Atkha are each visited in turn by the hunters about once in three years, and under such management the numbers of the animals appear to remain the same. The outlying reefs of Atkha, which once furnished the most abundant supply of these valuable skins, are now entirely deserted, and the inhabitants undertake long hunting voyages to the westward under convoy of schooners belonging to the trading firms.

From the island of Oumnak eastward the sea-otter becomes more frequent, until we find it in its greatest abundance in the district of Sannakh and Belkovsky. Here, within a radius of not more than fifty miles, over 2,000 sea-otters are secured every year by the fortunate hunters without any apparent decline in numbers. From this point in a northeasterly direction the coast of the Aliaska Peninsula is lined with hundreds of islands and reefs, affording ample facilities for shelter and refuge to the persecuted animal, and though it is hunted here recklessly by white and native hunters, alike, using firearms in violation of existing regulations, no alarming decrease can be ascertined from statistics at hand. Still further northward, in the waters of the Kadiak archipelago and the sonthern half of Cnok Inlet. and thence eastward to Prince William sound, sea-otters are found in less number than in the district described above, but still in comparative abundance, the annual yield being between I,000 and $\mathrm{r}, 500$ skins.

As far as it is possible for us to know, the only enemy of the sea-otter is man, with the exception perhaps of the so-called "kil- 
ler-whale." We have reports of natives only in support of the last statement, but as this whale is known to make sad havoc among fur seals there is no reason to doubt that they occasionally attack the somewhat larger sea-otter. Skins have come under my observation marked with scars produced evidently by the tecth of some large marine mammal.

The distribution of the sea-otter along the coast of Alaska, as indicated in the accompanying map, has not essentially changed within historic times. Certain localities have been abandoned by the animal altogether, other temporarily; but where Behring, Chirikof, and Steller and subsequently the Russian promyshleniks found the sea-otter more than a century ago, we find it now, and the supply of such skins in the fur market of the world is certainly as great now as at any time since the first indiscriminate slaughter prior to the establishment of the Russian monopoly: in fact it is apparently much greater.

The Land 0tter (Lutra canadcusis). The land otter is one of the most widely distributed fur-bearing animals in Alaska, ranking in this respect next to the common cross fox. The skin, however, is much more valuable, since of late it has been utilized for the manufacture of an imitation of seal skin. The skin has always met with ready sale in Russia, where it is used extensively for collars and cuffs of the uniforms of army officers of the line, who cannot afford the more expensive sea-otter trimmings. The demand for it in former times was so great that the Russian-American Company in leasing a strip of land to the Hudson Bay Company was not only willing, but anxious to accept payment in land-otter skins. The Chinese also have a liking for this fur.

The land otter is found on the whole coast of Alaska, from the southern boundary to the northern shore of Norton Sound. It also occurs on all the islands inside of these limits as far as Unimak in the west and Nunivak in the north. Within the Arctic Circle the land otter is confined to the upper courses of rivers emptying into Kotzebue Sound and the Arctic Ocean, such as the Colville, the Kok, the Inland, and Selawik. It is found also along the whole course of the Yukon as far as known, along the Kuskokvim, and all over the delta lying between the mouths of these rivers, in the valleys of the Togiak and the Nushegak, and in nearly all parts of the Aliaska peninsula and Unimak islands, as well as on the Kadiak archipelago, the shores of Cook Inlet, on the Kinik and Sushetno rivers emptying into the same, on Prince William Sound, and on the Copper River. The traders report the land otter also along the whole coast from Mount St. Elias to the southern boundary, with the exception of the smaller islands. 
The Beaver (Castor fiber). The beaver was once one of the most important among the fur-bearing animals of continental Alaska, but both in supply and demand a great decline has taken place during the last half century. It would seem that the smaller demand would cause an increase in the supply, but this has not been the case. Throughout the whole interior region north of Cook Inlet and south of Yukon river the beavers have frequently suffered from excessive and prolonged cold during the winter, the ice in rivers and ponds forming so rapidly and to such thickness that the animals found it impossible to keep open the approaches to their dwellings under water, and they died from starvation before the thaws of spring opened their prisons. The Indians of the Kinik and Tennanah rivers state that after an extraordinarily cold winter they have frequently found the putrefying carcasses of hundreds of beavers in their so-called lodges. Thousands of old beaver dams all over the continental portion of Alaska also testify to the former abundance of the animal, which now is thinly scattered over the same ground. At nearly every trading post throughout Alaska where beaver skins are at all secured hundreds are purchased now where thousands appear on former records.

The northern limit of the beaver seems to be but little to the southward of that of the land otter, considerably above the Arctic circle being identical with the limit of trees. Skins are obtained from the natives living on the northern tributaries of the Yukon River, which have passed into the hands of the latter from the headwaters of the Colville and other rivers emptying into the Arctic.

All the streams emptying into Kotzebue Sound are still inhabited by the beaver, and it is found on the east shore of Norton Sound, along the whole course of the Yukon and its tributaries, among all the lakes and streams of the Yukon and Kuskokvim deltas, in the lake and river systems of the Togiak and Nushegak, about Lake Ilyamna and the lakes and rivers of the Aliaska Peninsula down to a line identical with that forming the northern boundary of the Aleutian tribe. On the shores of Cook Inlet and the rivers emptying into the same the beaver is still comparatively plentiful, especially in the vicinity of the large lakes occupying the central portion of the Kenai Peninsula. Beaver skins are also obtained from the natives occupying the headwaters of Copper river and the series of lakes connecting the river with the Kinik and the Sushetno rivers.

In the southeastern section of Alaska, west of Mount St. Elias, traders report the existence of the beaver on streams and rivers of the mainland, but it is probable that most of the skins 
obtained in that vicinity come really from the British possession, whence all these rivers flow.

In the past, when the Hudson Bay company reigned supreme throughout the beaver country of northwestern America, the skins of these animals represented in trade the value of an English shilling each, and were used and accepted as common currency. Within the Russian possessions the value was always somewhat higher, and at the present time the price of a beaver skin of average size in Alaska is from \$1.50 to \$2.00, according to weight.

The Indians of the interior and a few of the Eskimo tribes look upon the meat of the beaver as a great delicacy; it is a clish that is always set before honored guests, and is much used during festivities. The long incisors of the beaver form an important item in the domestic economy of the natives who hunt this animal, the extraordinary hardness of these teeth making it possible to use them in the manufacture of chisels, small adzes, and other tools used in the working of wood and bone. Lnder the rule of the Russian-American Company the exportation of castoreum was quite extensive, but now that article meets with no demand outsicle of the Chinese market, the Celestials still looking upon it as a valuable part of their materia medica.

The Brown Bear (Ursus richardsonii). The brown bear of Alaska, a huge, shaggy animal, varying in length from 6 to I 2 feet, is distributed over nearly every section of Alaska, but scenns to prefer an open, swampy country to the timber. The northern limit of this animal is about latitude $67^{\circ}$ north where it is found on the headwaters of the rivers emptying into the Arctic and occasionally on the streams emptying into Kotzebue Sound. and in the interior of the Kotzebue Peninsula. Being an expert fisher, the brown bear frequents during the salmon season all rivers emptying into Bering Sea and the North Pacific and their tributaries as far as the fish will go and at the end of the annual run of fish the animal retreats in the recesses of hills and tundra where berries and small game are most plentiful. The banks of all the streams are lined on either side with the well-trodden trails of these huge animals offering better facilities for the progress of the traveller than do the paths of men. The brown bear is the great road-maker of Alaska, and not only are the swampy plains intersected with paths made by him in all directions, leading generally to the easiest fording places of streams and rivers, but the hills and ridges of mountains to the very top show the traces of this ommipresent traveler. He shows great judgment and local knowledge, for his road up the mountain is as safe to follow as is the most practicable route. In greatest numbers this animal is found in the region between the lower Kuskokvim, the Togiak and the 
Nushegak rivers and also on the Aliaska Peninsula and the island of Unimak. The island of Kadiak is full of this species of bear, but the largest specimens are shipped from the coast of Cook Inlet. The skin of a bear that had been killed in the vicinity of the Kienai mission during last summer, which I measured, was fourteen feet two inclies in length. On the steep sides of the volcanic range of mountains, on the west side of Cook Inlet, brown bears can be seen in herds of twenty or thirty. Their skins are not very valuable, and, owing to this fact and to the fierce disposition of the animals, they are not commonly lumted. All natives of Alaska respect them and it is the universal custom of hunters to address a few complimentary remarks to the intended victims before attempting to kill them. Perhaps the skins of fully one-half of the brown bears killed throughout Alaska are retained by the natives for bedding and to hang before the entrances of houses in place of doors. The smaller skins are tanned and cut up into straps and lines and the natives of the interior utilize them for manufacturing sledge fastenings and the network bottoms of snowshoes, because this leather does not stretch when exposed to moisture, as moose and deer skins do.

The Black Bear (Ursus americanus). The black hear of Alaska is widely distributed over thie continental portion of the territory, but is generally confined to regions of timber and mountains; as far as known, it exists only on a few islands in Prince William Sound and on Kadiak Island. The northern limit of the black bear extends, according to observations made by MIr. E. WV. Nelson, even beyond that of his brown consin. It is said to exist farther down the rivers emptying into the Aretic, and to be quite plentiful thence southward to the valley of the Yukon. The western limit of the region where the black bear is found is perhaps a line drawn from the Selawik River southeastward to Nulato, thence across to the Kuskokvim River in the vicinity of Kalmakovsky. From the upper Nushegak many skins are obtained, and one trader reports black bear even west of tilis line, on the lower left bank of the Kuskokvim and the Togiak Peninsula, but as that region is not timbered the statement appears doubtful. From Bristol Bay eastward the black bear is confined to the timbered regions about Lake Ilyamna, but is more plentiful on the coast of Cook Inlet and in the interior of the Kenai Peninsula. From the headwaters of the Yrukon, Tennanah, Sushetno, Kinik, and Copper rivers many black bear skins are brought down to the seacoast,and from Prince William Sound and eastward the mountains and forests harbor large number of these animals. These skins command high prices and are still increasing in value, but the animals are shy, and to hunt them re- 
quires much time and patience. The natives do not fear them in the least, and, in fact, it is considered the work of boys to kill them. Owing to its value, probably, the natives never use the black bear skin for bedding. The glossiest and largest of these skins come from the St. Elias alpine range and the vicinity of Prince William Sound; but the black bear never attains the size of the brown variety.

The Red Fox (Vulpes fulvuls). The only fur-bearing animal found in every section of Alaska is the red fox. From Point Barrow to the southern boundary, and from the British line to the island of Attu, this animal is ever present. It varies in size and quality of its fur from the finest Nushegak variety, equal to the high-priced Siberian fire fox down to the diminutive, yellowtinged specimen that rambles furtively over the rocky islands of the Aleutian chain. Its color gives variety among the uniform snow-white robes of its polar cousin along the Arctic shore, and with the unwelcome persistency of the poor relation it mingles with the aristocratic black and silver foxes, always managing to deteriorate in course of time the blood and coating of the "first families." Mountain or valley, forest or swampy plain, all seem to be the same to him. The red fox seems perfectly indifferent these animals. These skins command high prices and are still in regard to his diet, fish, flesh and fowl being equally to his taste, with such little entremets as shellfish, mussels, and eggs of aquatic birds. He has an advantage over his fellows in the fact that his skin is cheap, and the natives do not eat his flesh except as a last resort in times of a famine. They hunt or trap the red fox only when nothing else can be obtained: the interior tribes, however, make winter garments of their skins.

Being an inveterate and intrepid traveller, the red fox is not above making an occasional sea voyage on the ice, which explains his presence on all the islands of the Aleutian chain, the Shumagin group, and even on St. Lawrence and the Pribilof islands, over a hundred miles from any other land. It is common practice among both Innuit and Indian tribes in the north to make household pets of young foxes whenever they can be secured alive. The average price of red-fox skins throughout the country is about \$r.oo.

The Black or Silver Fox (Vulpes fulvus, var. argentatus) and The Cross Fox (Vulpes fulvus, var. decussatus). The king among the various tribes of the "vulpes" family is the black or silver fox. He is found in his prime in the mountain fastnesses of the interior and on the headwaters of the larger rivers. Here he appears of large size with long, soft, silky fur, varying in color from a silver tint to a jet-black, the latter being the 
most rare and highly valued. These two qualities are found principally in the mountains on the boundary between southeastern Alaska and British Columbia, in the country of the Chilkhats and the Takoos, on the upper Copper River, the Kenai Peninsula, and on the Sushetno and Kinik, the upper Yukon, Tennanah, and Kuskokvim rivers. In the last-named regions the traders pay from \$10.00 to \$15.00 for each skin, but in southeastern Alaska, where competition is more fierce, as much as $\$ 40.00$ or $\$ 50.00$ in coin are frequently paid for a single skin. Along the Yukon and its northern tributaries the black fox of an inferior quality is found almost on the seacoast and on the shores of Norton Sound and in the interior of the Kotzebue Peninsula. The animal is also reported to exist on the headwaters of the Colville River up to the sixty-eighth degree of latitude. Black foxes are quite rlentiful on Kadiak Island, and they occur on the Shumagin group, Onimak Island, and on most of the Aleutian Islands as far as Atkha, but to many of these points they have been imported through the agency of man. On the timberless highlands of the Far West the fur of these animals seems to deteriorate in quality.

Another species of the fox family is generally found with the silver fox, forming, in fact, the connecting link between the red plebeian and the black aristocrat. This is the cross fox, partaking of the distinguishing qualities of both red and black, evidently the result of unrestrained intermixture. The quality and 'the color of the fur of the cross fox come much nearer those of the red, and the skin of the former exceeds that of the latter but little in value-from $\$ 2.00$ to $\$ 3.00$ being paid for the best of them. While the distribution of the cross fox is naturally almost identical with that of the silver varietv, the animal is found farther westward on the Aleutian Islands, and is more frequent on the Aliaska Peninsula, though on the islands of Prince William Sound and on Kadiak Island both the black and the cross varieties exist.

The skins of silver foxes form the most important element in the trade of the whole Yukon Basin, being almost the only highpriced skins found in that vicinity, but they are by no means numerous. The only section of Alaska where these animals are of the best quality and in large numbers at the same time, is in the mountins about the Chilkhat and Takoo rivers, and there the reckless competition leaves but little margin for profit.

The Arctic Fox (Vulpes lagopus-blue and white). Of the Arctic fox we find in Alaska two varieties-one white and the other a bluish oray, commonly called "blue fox" by the traders. The white fox is found along the coast of continental Alaska 
from the mouth of the Kuskokvim northward to Point Barrow and the eastern boundary. Its fur is of a snowy white, especially in the young, and both soft and long: but, owing to the lack of durability, it does not command a high price in the market.

The animal is very numerous northward of Norton Sound, and not at all shy: Natives and travellers alike report instances of the fearlessness with which these foxes enter their camps, and even divellings in search of food or out of mere curiosity. $A^{\prime}$ large portion of the skins secured by Eskimo and other natives are used by themselves for trimming their garments, and tle remainder falls chiefly into the hands of whalers and whisky smugglers, so that it is impossible to obtain accurate figures as to the ammal catch. They may be called omnivorous, and they refuse nothing that will fill their stomachs. I observed one sleek and apparently well-fed specimen which devoured nearly the whole of a large salmon, and afterwards worried down with considerable difficulty a thick leather strap with a heavy buckle attached to it. In the depth of winter the natives find it unsafe to leave any article of clothing, $\log$ harness, or boat material within their reach.

The blue fox exists now on several of the Aleutian Islands. where it was found by the first discoverers in I74I. The animal is also found on the Pribilof Islands, and here, where it has been possible to protect the species against intermixture with other and inferior foxes, the skins are of the finest quality, commanding a high price in the market. Traders report the existence of the blue fox to a linited extent in the vicinity of Oogashik, on the - Dliaska I'eninsula and also on the lower Kuskokvin, and it oscurs also on the clelta between the mouths of the Yukon and Kuskokvim. Captain Hooper, of the revenue marine, who commanded the Lnited States steamer "Corwin" during two successive cruises in the Arctic, reports that he saw blue foxes at Cape Espenberg. Elephant Point, Hotham Inlet, Point Hope, Point belcher, and I'oint Barrow. The same gentleman also states that he "found the blue fox much more plentiful on the Siberian than on th: . Imerican coast, and that all of the blue foxes in the far north are so inferior to those on the islands of Bering Sea as to suggest the possibility of their being a different speries." Even on the Arctic coast Captain Hooper saw blue foxes, taken at the same time and place, differing very much in the color and quality of the fur. On the Pribilof islands, from $I, 000$ to 1,500 of the hest quality of blue-fnx skins are annually shipped, and several hundrerl of a little inferior quality from tttoo and Atkha islands, but it is impossible to acertain the quantity obtained along the Arctic coast by whalers and illicit traders. 
The Mink (Putorius z'ison). The Alaska mink is distibuted almost as widely as the red fox, but does not extend to the islands. It is most plentiful in the vast tunclras or mossy marshes of the lower Yukon, Kuskokvim, Togiak and Nusliegak basins. The skin is of very little value; the Russian-Americas Company did not purchase it at all, and even now the trade in this article is confined chiefly to the natives, who manufacture it into garments or use it for trimming. No more than 10,000 or I5,000 of these small skins are exported annually: The northern limit of the mink is but little south of the Arctic coast, and from thence southward it is found everywhere thronshout the continent until its southern and western limits are reached on the Aliaska Peninsula on a line between Cape Stroganof and Stitkhum Island. The only islands on which minks are foutind to exist are those in Prince William Sound and perhaps some of those in the Alexander Archipelago. No skins of this kind shipped from any portion of Alaska equal in quality or value those of British Columbia, Washington, and Oregon, the traclers simply buying them for the sake of accomodating their customers. The region about Togiak River and lakes, which furnishes scarcely any other fur than mink, has for that reason been entirely neglested by traders. Lntil a year ago no white man had penetrated into the recesses of the tundras, and the inlabitants, having no intercourse with civilized men, are still in their primitive conclition of barbarism. The natives living on the Yukon and Kuskokvim deltas are called "mink people" in derision by their neighbors-a term e:fuivalent to beggar.

The Marten (Mustcla americanus). The limits within which the marten is found throughout Alaska are almost identical with those of standing timber. The animal is found occasionally as far north as latitude $68^{\circ}$ and inhabits the vallers of the Yukon, Kukokvim, and Nushegak rivers from the headwaters clown as far as timber exists, on the wooded mountain ranges of Cook Inlet and the Kenai Peninsula. On the Chugatch alps, the Copper River range, and the St. Elias alps martens are plentiful and of the finest quality. Very fine skirs of this kind are also purchased by the traders in southeastern Alaska, a po:tion of these probably being obtained from the British possessio:ıs. The Alaskan marten or sable is inferior to the Siberian fur of that name ("sable" is simply a corruption of the Russian word for marten "sobol," and is by no means a distinct animal). The RussianAmerican Company considered the Alaska sable of so little value that they did not export it at all from the colonies, but sold the whole catch to officers and employes of the company. The price set upon these skins under those circumstances was small 
indeed, being only io cents each. After the transfer of the Territory a demand for them arose, and in a few years of competition raised the price to $\$ 4, \$ 5$, and even $\$ 6$, much to the delight of the astonished natives, but the inferiority of the article soon made itself felt, and reaction set in until at the present day the price of marten skins in northwestern Alaska does not exceed $\$ 1.50$, though in the southeastern section excessive competition still keeps up a higher figure.

A few more fur-bearing animals existing in Alaska may be mentioned, but they are not of sufficient importance to deserve more than a passing notice. The polar bear is found on the Arctic coast, where ice in large bodies exists, and with the moving ice fields he enters and leaves the waters of Bering Sea. The number of skins annually secured forms but a very small item in the bulk of trade.

The Lynx. The lynx is found only in the wood mountains of the interior on the Kenai peninsula and the St. Elias range of mountains, the skins being used chiefly for carriage robes and trimming, but the fur is not durable.

Wolves, both gray and white, are found, but rarely killed.

Muskrats exist all over Alaska, but the skins are at most valueless, and but few are shipped away.

Rabbits and marmots are killed only for their flesh, and occasionally the natives use the skins of the latter for the garments of the poor.

Wolverines are rarely exported, as they find a ready market among the inhabitants of the coast region of the Yukon and Kuskokvim divisions, who prefer this shaggy piebald fur to any other trimming for their garments.

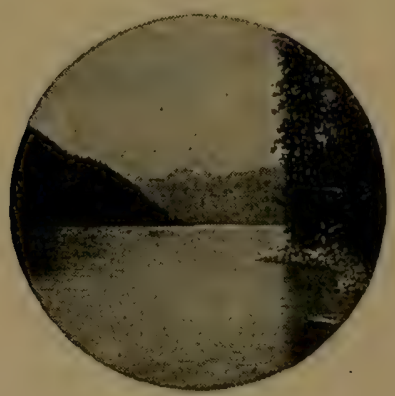




\title{
PART TWO \\ Encyclopedia
}

of

Hunting and Trapping The Fur Bearing Animals

\author{
NORTH AMERICA \\ Especially Pertaining to \\ T R A P P I N G
}

How to Skin Animals, Manner of Stretching Skins, Trappers Secrets, Preparing Decoys and Poison; How to Make Dead Falls,

Box, Barrel and other Traps, Sliding, Spring Poles,

Snares, Kind of Traps to Use and Manner of Setting Them.

\section{Illustrating All RAW FUR SKINS}

Steel Traps, Dead Falls, Box Traps, Dug Outs, Pit. Falls, Etc.

\section{TRAPPING THE ERMINE OR WEASEL.}

The weasel and ermine kill indiscriminately for food and pleasure such birds and animals as it can master; chief amongst them are mice, rats, rabbits, ground and chirping squirrels and nearly all birds and fowls, both wild and domestic. Both of these diminutive monsters, in their ceaseless quest for food and to satisfy their individual irresistible craving for blood, dart from one opening into another, whether that be a hollow log, burrow, stone pile or crevice of a rock. Upon exploration, should the abode be unoccupied, the animal's stay is a momentary one, and it will immediately decamp, taking the shortest route to the next opening; if inhabited, a general tumult follows. The weasel and ermine are more beneficial than detrimental in farming communities and should only be killed when continued losses of poultry occur. The animal's favorite hold is upon the neck, and it quenches its insatiable vampire-like thirst by lapping the blood from its victim.

If the animal's capture is desired, it can be accomplished by steel traps placed in their run-ways, holes, crevices, burrows, etc. In most cases, the animal is taken in traps originally set for mink and marten. The same methods as are applied to mink and marten should be followed in the capture of these two animals. A good place to set the steel trap is in a hollow tree, hollow $\log$, abandoned hole or abode of other animals, and in the front or rear of small openings through which the animal enters. Wire traps can be used advantageously, so can tree traps; the latter can be utilized in various places. Bait is unnecessary when the traps 


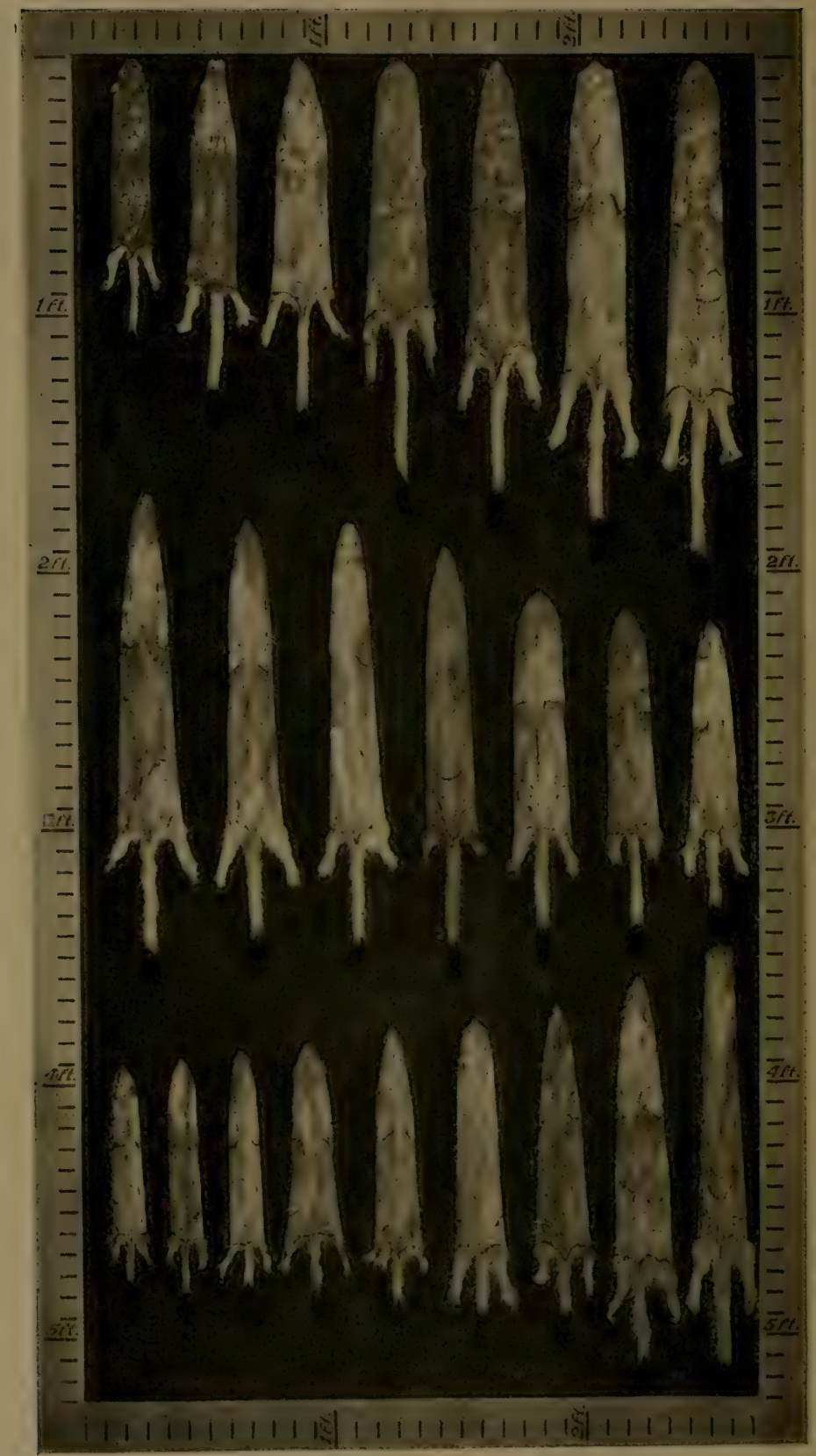

WEASEL AND ERMINE SKINS "Raw"

All Sizess. Scale Shows Inchẹs and Feet. 
are set in their habitual run-ways; at other places a piece of meat hung over the trap, or head of a chicken or rabbit, placed within the abode, will answer admirably.

The skins should be handled similarly to mink or marten skins; the fur part can be on the out or inside. A three-piece stretcher is recommended; the skin is very tender, and great care must be exercised in stretching and removing the skin from the stretcher not to tear or burst it. Only white-furred skins should be marketed as the brown skins have no commercial value, but should one of the latter species be captured, it is a useless waste of time to skin the animal and stretch the skin.

Traps can be baited with bits of meat, hung over the trap. A good place to set the trap is in a hollow tree, hollow log, abandoned holes or abodes of other animals. Bait should be used.

\section{TRAPPING THE MINK.}

These animals are. caught in various ways, depending upon the location, time of year, on land or in water. Some trappers consider the capturing of this animal an easy task; others contend that the animal is equally as sly and as cute as the red fox. The mink certainly and readily scents the hunter, trapper or works of man, and will shy on his approach and from things made by him, especially on or about his usual paths.

The animal is captured by the use of snares, steel traps, deadfalls, box, barrel and other home-made traps; also the ritle is sometimes resorted to, but the trapper who makes trapping a business, is contented with the former three methols of capturing the mink.

Snares are resorted to by all classes of trappers, even to the present day, not only in this country, but also in Europe. The snares are made out of strong linen or silk thread, silk lines, linen lines, copper or brass wires; also horsehairs. The proper way and place to set these snares is about the paths or in front of the holes which the animal frequents. Some make an artificial abode and place bait therein, and as the mink enters becomes caught. Spring poles or other methods should be adapted or attached to the snares, which takes the animal off the ground, otherwise the victim is likely to be carried away or the fur badly damaged by such animals as the fox, fisher, wolf and wolverene, or manage to escape.

The use of the rifle is advised, though the skins becomes more or less damaged. The shot-gun is detrimental to the skin, and the practice of killing the animal with this instrument should be avoided whenever possible. 


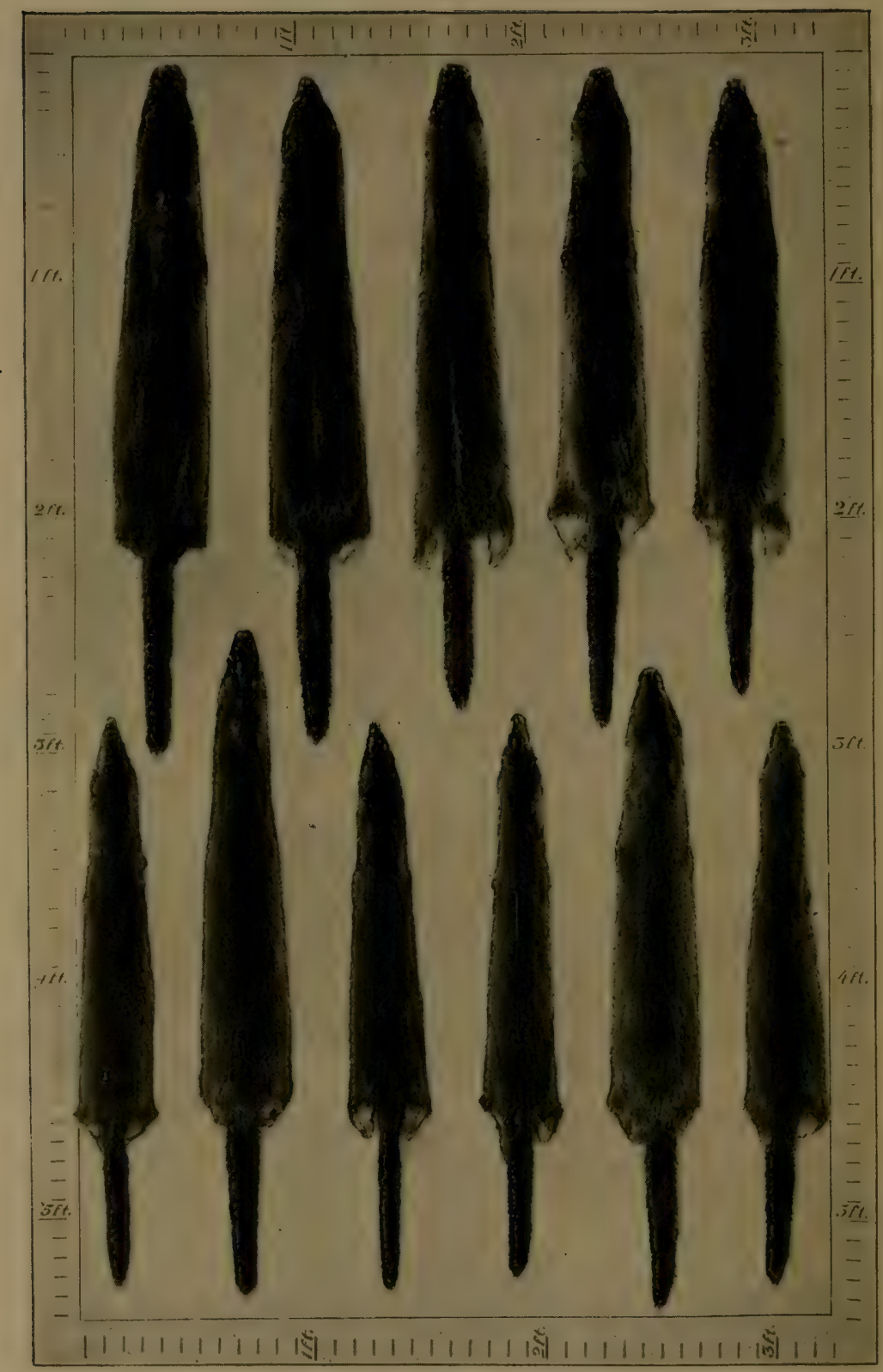

MINK SKINS. "Dressed"

All Sizes. Northern and Northwest. Scale Shows Inches and Feet. 
The reader is directed to carefully peruse the article under marten, fox, muskrat; also to study the art of making and setting of the various kinds of traps, the illustrations of which can be found on other pages. As this animal can be captured in so many different ways, almost any of the styles can be successfully adapted in the capture of the mink as well as the marten. It is not an easy matter to kill minks, as trappers say the mink has seven lives, and naturally the animal dies hard; therefore, in hunting the animal with the rifle or shot-gun, the wound, in order to become effective, must be a severe one, as a mere flesh wound will only retard the animal momentarily.

The use of steel traps is preferred, but when inconvenient or the supply becomes exhausted, other home-made traps can be resorted to; but regardless of the kind of traps used, the chief aim and ambition of the trapper should be to use such traps that will securely hold the animal and retain the value of the pelt, also to cause a speedy death. Steel traps should be set along river banks, and generally where one creek empties into another, upon paths, about holes, stumps or trees and hollow logs. If the trapper cannot find a convenient place to set his traps it sometimes behooves him to dig a hole or to make an artificial abode. If the latter is attempted, care and judgment in retaining the natural surroundings of the former conditions is essential, and the use of a good bait is recommended.

The author has set steel traps, No. I $1 / 2$ and No. 2, also has seen experienced trappers set such traps in barricaded places using an old tree, stones, ground, sod, etc., to make the abode. The making of such an abode is simple, effective and successful, although the trapper is sometimes obliged to wait for days or weeks for a victim. The traps should be set at a convenient place about the opening, somewhat below the level of the earth, and covered with fine bits of loose earth or leaves; a little cotton or leaves should be placed under the pan. Bits of rotten wood or feathers, whenever the latter are handy, should be strewn about the trap and within the abode. Great care should be taken that the animal is obliged to enter the opening left, and not to force an entrance in some other vital or detrimental part of the abode.

If bait is used, the latter should be placed six to eight inches beyond the trap in the abode. The proper bait to use is birds, fish, pieces of muskrat, or fish oil. If meat is used, same should be smoked. Some trappers burn a piece of paper or some dry leaves in the abode after the meat bait is set, thus eradicating human scent, and at the same time smoking the meat. A spring or sliding pole should be used whenever possible, as the former 


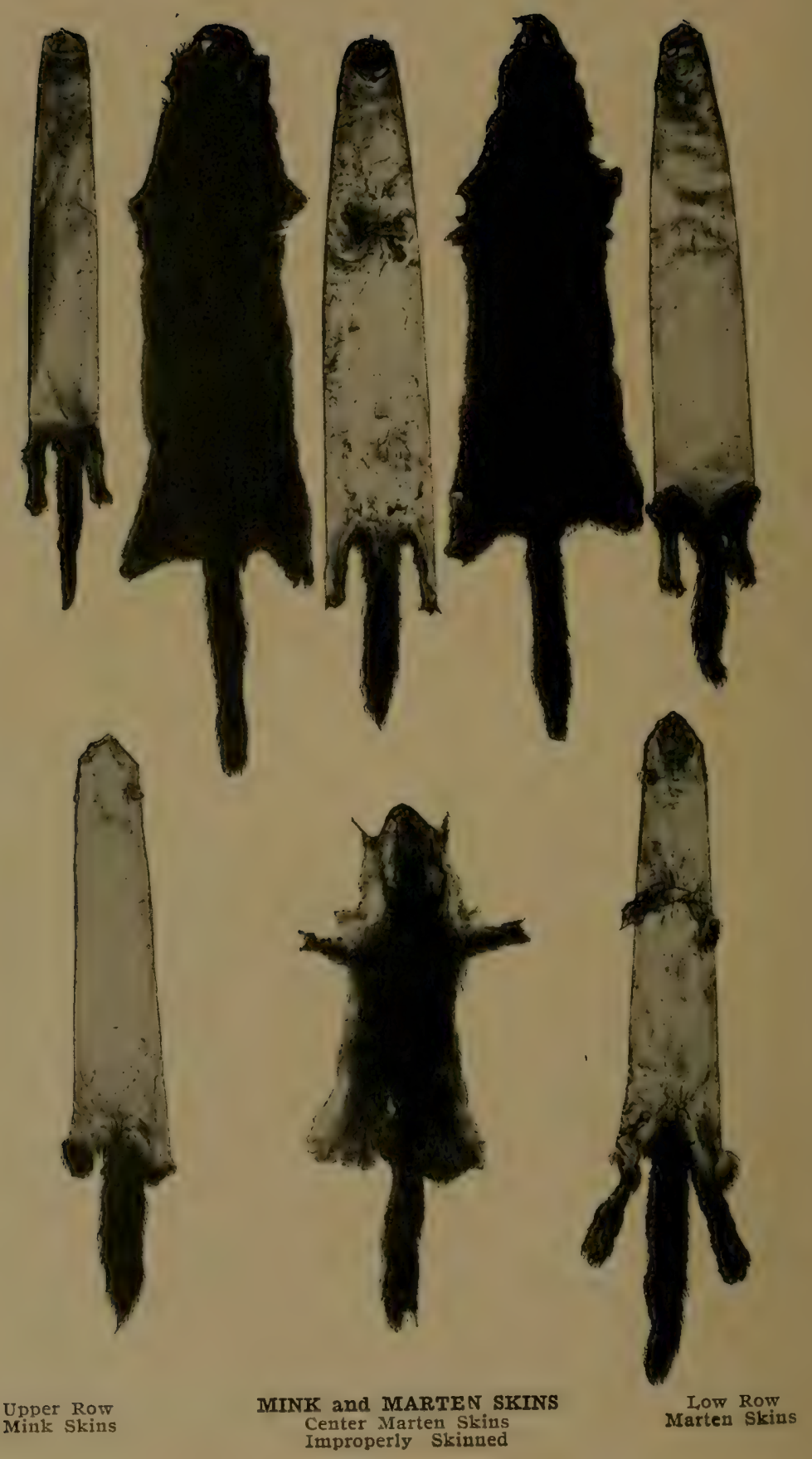


will lift the animal in the air, the other carry the victim into deep water to drown.

Deadfalls or other homemade traps working on this principle, are often used, especially by trappers in the far interior, who find plenty of time to make them. A good way to make a trap is to procure a two-inch plank, about one to two feet long, six to eight inches wide, into which a two-inch hole should be bored, and sharpened nails driven into the plank about the hole, in such a manner that if the mink places his head into the hole after bait, it cannot be withdrawn, as the nails will prevent the withdrawal, and naturally the animal is in a helpless condition. The nails must not be driven too close nor too far, and the opening must be sufficient to permit the animal to place his head through. Care must be taken that the animal will not escape by sliding clear through. See illustration for particulars.

The mink as well as the marten can be successfully lured to the place where traps are set. Nany decoys are good; the most common and easiest to procure is fish oil. Elsewhere in this book will be found methods of making these decoys, manner in which they are used, etc. Some trappers smear some of this decoy on their boots; others drag scented bait along the paths.

Wire traps can be successfully used; many trappers prefer them when they have an opportunity to set a trap in front of a hole, as a matter of fact they all recommend them in such cases. They are conveniently carried, easy to set and cost less than steel traps. Use the No. 2.

A new trap called the "Tree Trap" is being used and while some claim this trap cannot be set except on trunks of trees, others use them at different locations with good success. There are now so many makes of traps that what one trapper likes another would not have, but the majority, especially the successful trappers, stick to the Newhouse.

\section{TRAPPING THE MARTEN.}

These animals are as difficult to capture as minks, and as they largely inhalit extremely cold regions, the weather forces increased hardships upon the hunter or trapper. Martens are captured in traps similar to minks, but the traps are set more in the woods about bushes, hollow logs and sometimes in holes in the ground.

It is seldom that a rifle can be used effectively; however, woodsmen and expert hunters find little difficulty in bringing down this valuable fur-bearing animal. The many skins that are received by fur dealers show signs that death was caused by a penetrating bullet. The bait is usually birds, fish, wild fowl and 


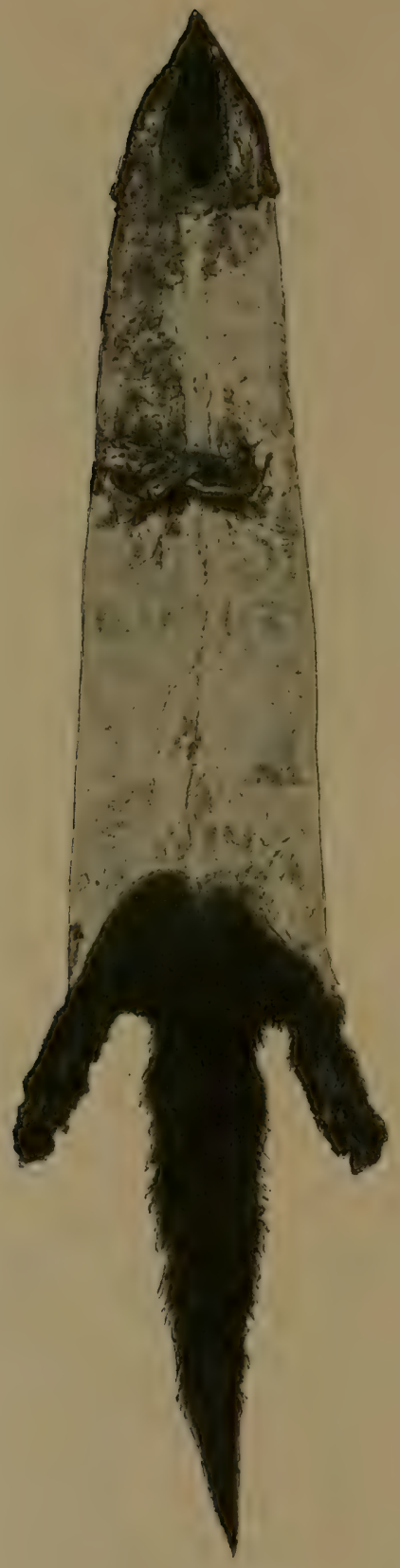

No. 2, Partly Prime

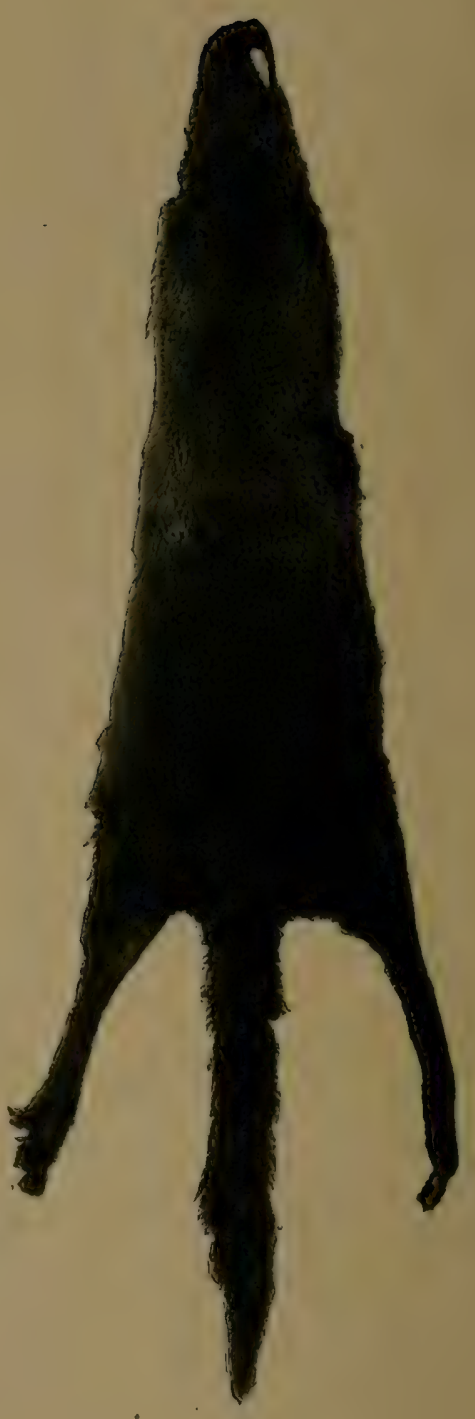

Skins of
FISHERS
No. 3, Unprime

Michigan 
pieces of meat. It must be remembered that the bait need not be large; on the other hand small pieces only are required. Heads of various species of fish, geese, ducks and legs of rabbits are sufficient and suitable.

The average trapper prefers the Newhouse steel traps, and the hunter his trusty rifle. It should be noted that many times mink, instead of marten, become the victim; therefore the same tactics should be used for both animals, especially if the traps are set upon land and in a timber country.

In former years the marten was ordinarily captured in wooden traps of very simple construction, made by the inhabitants in the vicinity in which the animal was captured. (See illustration.) These figure-four arrangements are usually enclosed in a line of stakes driven into the ground in the form of a $\mathrm{V}$ or $\mathrm{U}$. The marten is forced to enter an opening especially left for him, and in seeking the bait, steps upon the trigger. At other times the bait is attached to the trigger itself, and when the animal disturbs same the $\log$ falls upon his head, smashing the skull. Lines of such traps extend many miles. The bait used by Indians, halfbreeds and the early trappers, was a piece of squirrel, fish, bird or rabbit.

One of the greatest obstacles that the early marten trapper had to contend with in most parts of Canada, was the persistent destruction of these traps by the wolverene and fisher. These animals, especially the former, displayed great cunning and perseverence, and intentionally followed these lines of traps, not for the purpose of obtaining the bait but to destroy the traps and seemingly to make the marten hunters' life miserable.

The marten is also captured by snares; he being an expert climber, the snares can be arranged between the forks of trees through which the animal passes in his upward flight; at other times in openings of hollow trees. These home-made traps and contrivances have been replaced by the steel trap. As many as two hundred traps are attended to by a single trapper. These traps like the old figure four arrangement, are set in abodes and left there during the entire season. A Hudson Bay Trapper informed the author that these abodes are not specifically made to draw the animal into, but more so to protect the setting from bad weather, also to keep rabbits and birds from springing the traps.

Wire traps can be used, also the new Tree Traps, but from best information obtainable neither of these take well with the old and experienced marten trappers. Set guns are now prohibited in most states and parts of Canada, and their use should be discontinued. 


\section{TRAPPING THE FISHER.}

This animal is caught in steel traps similar to mink, marten, and often the trapper, much to his surprise, finds a fisher instead of the smaller animal; also traps set for foxes and wolves are sprung by the fisher. The fisher is exceedingly strong, and a powerful animal for its size, therefore the use of No. $2 \frac{1}{2}$ and No. 3 traps are better adapted than the smaller mink or marten traps. His food consists chiefly of small animals, such as rabbits, squirrels, mice, rats, birds, and he consumes large quantities of fish, although the former are preferred by him. He lives, the greater part of the time, in bushes and timber country, in close vicinity to water; but is known to lie on shore, especially on a $\log$ that lays across a river or creek, for hours, watching the opportunity to capture the slick pickerel or trout.

If the animal is to be lured to the trap by the use of decoy, the trap should be barricaded by and with logs, stumps, stones, earth, weeds, etc., leaving one place of access. It is advisable to have the trap set at least six inches within the abode, and the bait placed eighteen to twenty inches beyond the trap. The opening should be six to cight inches in diameter. Some trappers prefer to make a slight excavation before covering and barricading the trap.

While in Winnipeg I spoke to an old Hudson Bay trapper in regard to trapping fisher, and was informed that spring poles should be used in preference to any other appliances in connection with steel traps; but the author believes equally as good results can be obtained by having traps attached to more modern appliances for lifting the animal from the ground and beyond harm of the wolf and other animals. For bait the author suggests the use of fish, rabbit, or a decapitated bird, and if the fisher is to be lured or attracted to the trap, beaver decoy mixed with fish oil and a little oil of anise, should be smeared in vicinity of the trap. Some trappers place this preparation on the sole of their shoes or boots and walk to the traps, while others place the decoy in a buckskin bag which contains some cotton, the latter absorbs the decoy, and as the bag is drawn over the earth, the smell protrudes through the small openings which have been previously made in the bag. The bag should be drawn towards the trap, not away from the trap. The trapper will sometimes find a trap sprung by a fox, mink, or a marten, and in some instances by a wolverene, but the latter are usually caught by following a line of traps and while in the act of devouring a previous victim. The mink trap will hardly 
hold fisher or wolverene, unless the trap is attached to a strong spring pole, and then it is cloubtful, as the weight of the animal will cause its leg to slide through the jaws of the trap. Deadfall traps are very practical and are continually used by hundreds of trappers, especially by Canadian Indians and half-breeds. Both snares and deadfalls should be set in places where the animal frequents. The same bait and decoy used with steel traps can be advantageously applied to snares, deadfalls and other homemade traps. It is necessary that the steel traps be buried in the usual manner; spring poles or other appliances should be used, in preference to drag or clog, yet some trappers prefer a clog or drag fastened to a long chain or to a stationary object. Sliding poles can be adapted in some places, while sunken barrels or box traps can be used to advantage in certain localities. The latter must be strongly built, otherwise the fisher will escape unless so arranged that if captured he will drown in short order.

\section{TRAPPING THE WOLVERENE.}

This great michievous animal inhabits timber sections and plays havoc with lines of traps set for mink and marten. They are troublesome to the hunter, otherwise, by devouring provisions, stealing clothing, cooking utensils, etc., from the trapper's cabin. They can be captured in steel traps, snares, deadfalls, etc. but owing to their cuteness, great strength, peculiar habits and training, they will seldom fall a victim.

A Canadian half-breed trapper relates that after a single wolverene had destroyed hundreds of dollars worth of his furs, following and releasing traps for a period of three months and practically the entire season, he was fortunate enough to capture him. He set a No. $1 / 2$ steel trap in the usual way for mink and marten, and surrounding this trap he placed three No. 3 steel traps properly arranged with spring poles. The wolverene visited the scene many times, and on two occasions the trapper found signs of his usual depredations, but the third or fourth time the wolverene sprung one of the traps and was lifted high from the ground.

The wolverene is detested by professional trappers, who spend weeks following this horrid creature at the expense of other work.

An aged hunter and trapper, upon his return from the civil war in $186_{5}$, settled in the upper part of Michigan, where he continued his vocation. On one occasion he relates that he captured this marauder after a fruitless effort of three weeks' continued watching, and at one time this wolverene led Mr. Graham for thirty miles, who, upon return to the cabin in three days, 
found fresh tracks of the animal, and upon setting six nests, (three steel traps to each nest), placed at intervals, baiting with pieces of beaver, otter, muskrats, parts of fur scented with castoreum, finally captured a large wolverene.

$\mathrm{He}$ invariably used deadfalls and No. 3 steel traps attached to spring poles, and "Of all voracious animals," says Mr. Graham, "the wolverene is the hardest to trap, but by running him down and skillfully manipulating the traps for his reception, by no means become discouraged, and you will triumph and bring the evil-doer to the end of his rope."

Poison can be successfully applied if placed within a carcass of a marten, mink, bird or muskrat; also small pieces strewn about.

The following is borrowed from Mr. Lockhart: "At Peel's River, on one occasion, a very old wolverene discovered my marten road, on which I had nearly a hundred and fifty traps. I was in the habit of visiting the line about once a fortnight; but the beast fell into the way of coming oftener than I did, to my great annoyance and vexation. I determined to put a stop to his thieving and his life together, cost what it might. So I made six strong traps at as many different points, and also set three steel traps. For three weeks I tried my best to catch the beast, without success; and my worst enemy would allow that I am no green hand in these matters. The animal carefully avoided the traps set for his own benefit, and seemed to be taking more delight than ever in demolishing my marten traps and eating the martens, scattering the poles in every direction, and caching what baits or martens he did not devour on the spot. As we had no poison in those days, I next set a gun on the bank of a little lake. The gun was concealed in some low bushes, but the bait was so placed that the wolverene must see it on his way up the bank. I blockaded my path to the gun with a small pine tree which completely hid it. On my first visit afterward I found that the beast had gone up to the bait and smelled it, but had left it untouched. $\mathrm{He}$ had next pulled up the pine tree that blocked the path and gone around the gun and cut the line which connected the bait with the trigger, just behind the muzzle.

Then he had gone back and pulled the bait away and carried it out on the lake, where he laid down and devoured it at his leisure. There I found my string. I could scarcely believe that all this had been done designedly, for it seemed that faculties fully on a par with human reason would be required for such an exploit, if done intentionally. I therefore rearranged things, tying the string where it had been bitten. But the result was exactly the same for three successive occasions, as I could plainly 
see by the footprints; and what is most singular of all, each time the brute was careful to cut the line a little back of where it had been tied before, as if actually reasoning with himself that even the knots might be some new device of mine, and therefore a source of hidden danger he would prudently avoid. I came to the conclusion that that wolverene ought to live, as he must be something at least human, if not worse. I gave it up and abandoned the road for a period.

"On another occasion a wolverene amused himself, much as usual, by tracking my line from one end to the other and demolishing my traps as fast as I could set them. I put a large steel trap in the middle of a path that branched off among some willows, spreading no bait, but risking the chance that the animal would 'put his foot in it' on his way to break a trap at the end of the path. On my next visit I found that the trap was gone, but I noticed the blood and entrails of a hare that had evidently been caught in the trap and devoured by the wolverene on the spot. Examining his footprints I was satisfied that he had not been caught, and I took up his trail. Proceeding about a mile through the woods I came to a small lake, on the banks of which I recognized traces of the trap, which the beast had laid down in order to go a few steps to one side to make water on a stump. He had then returned and picked up the trap, which he had carried across the lake, with many a twist and turn on the hard crust of snow to mislead his expected pursucr, and then again entered the woods. I followed for about half a mile farthex and then came to a large hole dug in the snow. This place, however, seemed not to have suited him, for there was nothing there. A few yards farther on, however, I found a neatly built mound of snow on which the animal had made water and left his dirt; this I knew was his cache. Using one of my snowshoes for a spade, I dug into the hillock and down to the ground, the snow being abot:t four feet deep; and there I found my trap, with the toes of a rabbit still in the jaws. Could it have been the animal's instinctive impulse to hide prey that made him carry my trap so far merely for the morsel of meat still held in it? Or did his cunning nature prompt him to hide the trap for fear that on some future unlucky occasion he might put his own toes in it and share the rabbit's fate?"

The skin should be cased similar to mink, marten and fisher. Retain its size and do not over-stretch. If skins are to be stretched flat or open, cut open upon the belly in process of skinning and stretch in a frame or upon some smooth, flat surface and dry in a shady place away from the sun and artificial heat. Fasten skin in frame with withes or laces. All fat must be removed. 


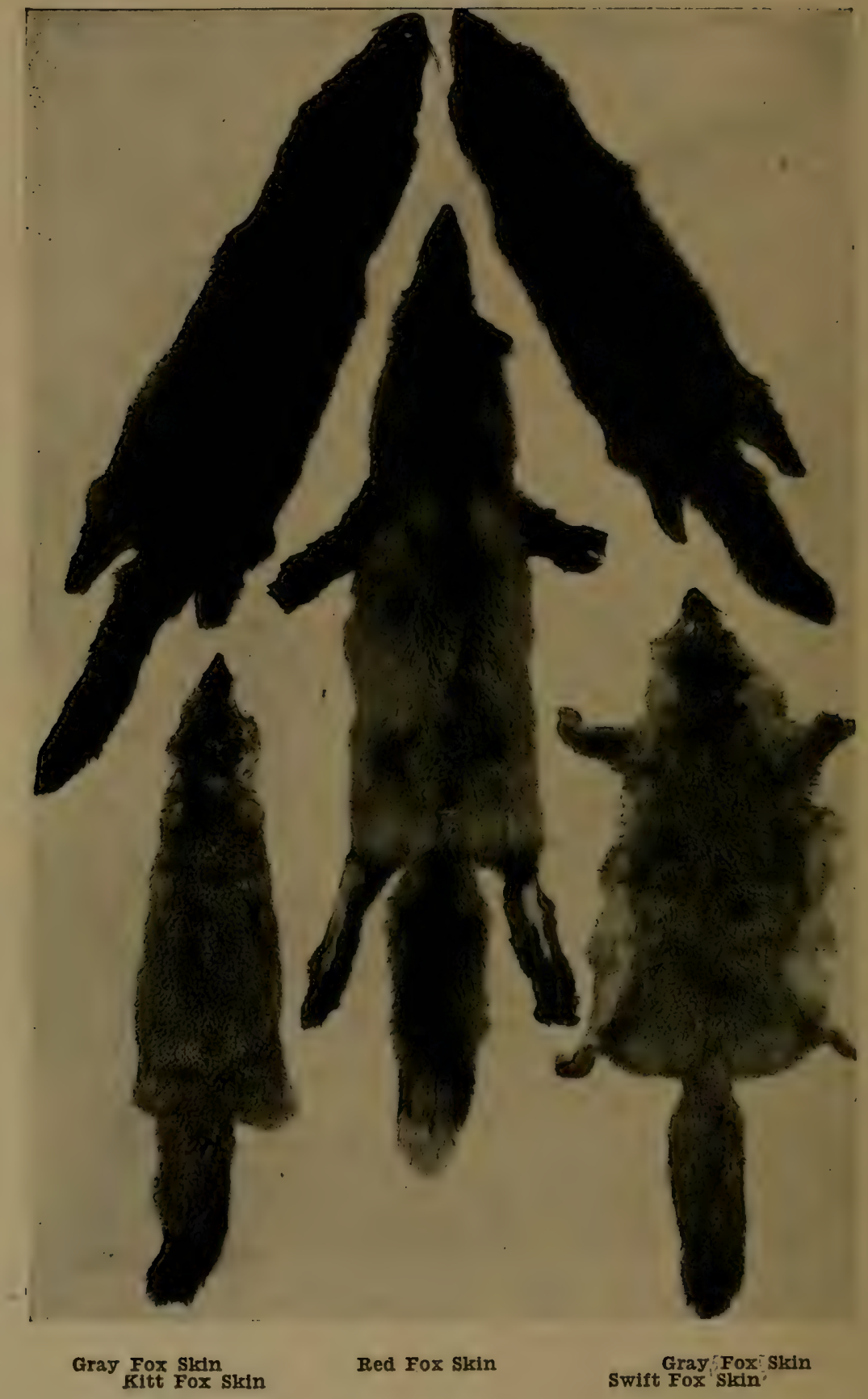




\section{TRAPPING THE FOX.}

This animal, like the wolf, is hard to capture or trap. It belongs to the dog or wolf fanily, and is carnivorous in its habits. The different variations number as high as twenty-one, but in this country eight species are commonly known to the hunter and general public, though naturalists claim as many as thirteen varieties on the western continent. As they resemble each other closely in appearance, habits, kind of food, and all possess tunusually fine sense of smell, sight, hearing, and are rapid in locomotion, we shall not endeavor to place the different species when it comes to capturing the animal for the pelt or to kill for otler reasons, under various headings, but under one common a:ud generally applicable rule.

The fox can be caught in various ways, and with many different traps and ingenious appliances, common to the hunter and trapper, especially of the frontier days.

Steel traps are now commonly used; the No. 2 trap is preferable and sufficiently strong to hold any full-grown animal, though in localities where such game as lynx, wild cat and wolf exist, larger traps shotld be set. It is advisable in all cases, to smear the trap and chain with blood, beeswax, lard, etc., to prevent the smell of iron from alarming the animals. The chain should be attached to a clog weighing about eight to ten pounds, and be buried the usual depth. Loose bits of earth, or what is still better, wood ashes, should be strewn over the excavated portion uncler which the traps are buried. The smell of the ashes, especially if wet, often is sufficiently strong to overcome the smell of iron.

Traps should be nested by having three to five traps to one bait. It is advisable to set the traps on an elevation; some knoll or high ground will answer admirably.

Birds, skinned muskrats, or other small, freshly skinned or bleeding animals, will answer for bait; the latter should be fastened so as to detain the fox, and should he endeavor to pull at the bait or walk around it, the chances of his springing a trap is greatly increased. Occasionally two traps are sprung in his frantic endeavors to free himself. It is advisable to set a trap slightly in or just before a hole or excavation to or from which tracks lead; should the animal be absent, most likely he will return the following night. Bury the trap and clog in the usual manner, and smear a little of the musk or matrix from the female fox above or beyond the trap, but not on the trap, chain or clog.

An experienced trapper informed me that he was very successful in catching foxes by tying a live bird or mouse in the center of a nest of four No. 3 traps. The mice were caught in 


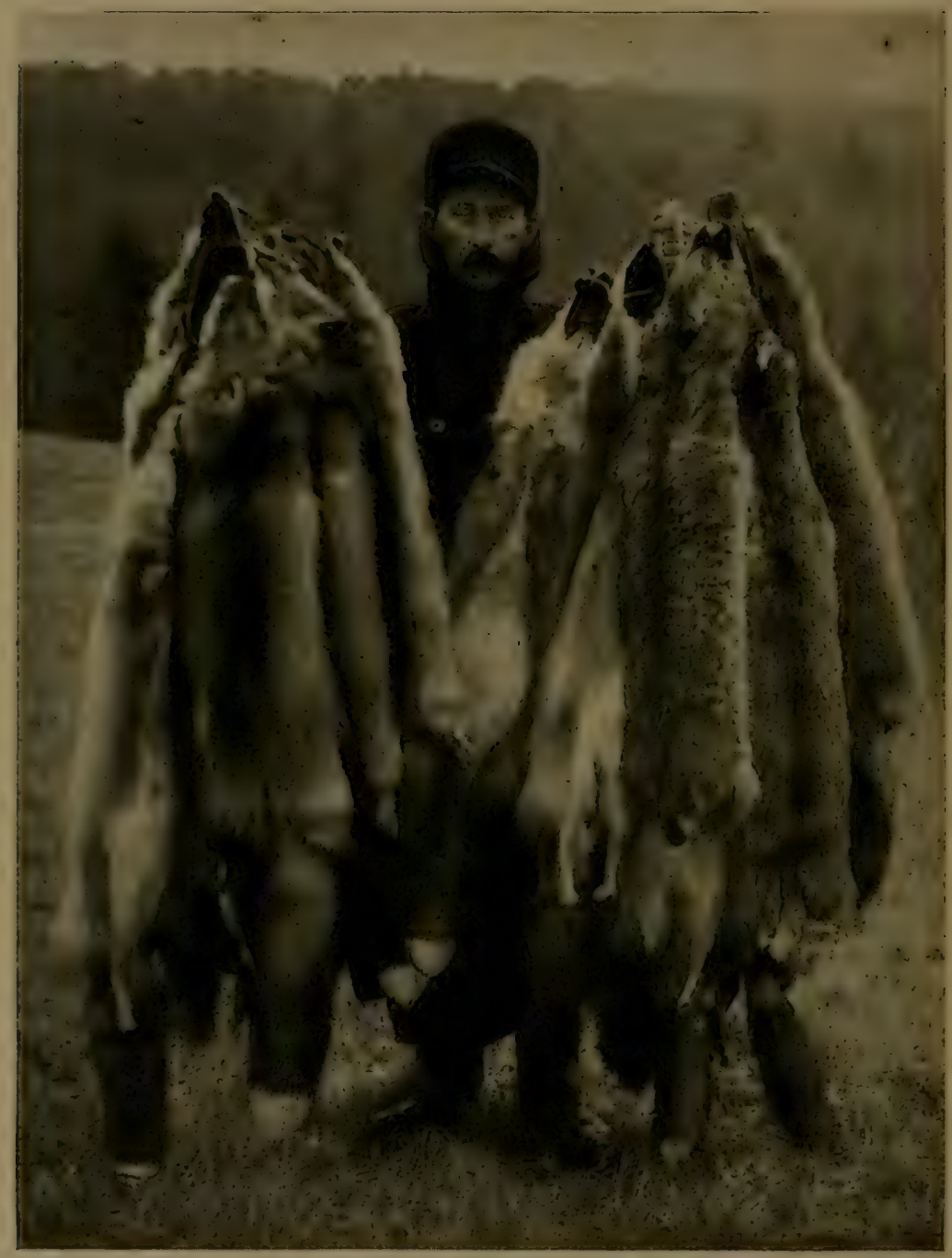

RED FOX AND WILD CAT SKINS 
small wire traps, and then a light brass or aluminum chain was tied with linen thread to one of their feet, likewise to the bird's, one or both fastened in center of nested traps and left to the mercy of the game. Sufficient nourishment was left with the mouse or bird, to prevent starvation. It is wise to try this plan, but in our judgment, a chicken or a duck would be more acceptable, especially, if the fox has frequented the roost, and the farmer or trapper desires to risk another fowl in order for the thief to become the victim.

Wool, moss, leaves, deer hair, cotton and the like, should be placed beneath the pan and around the jaws. A horse's tail or piece of sheep pelt should be used to brush away loose bits of earth from the excavation, also in visiting traps, especially when the trap was accidentally sprung, it is advisable to attach a piece of sheep skin or other fur to the boots and approach the traps in this manner. In handling traps or working about them, and in the act of setting, always wear gloves; some trappers smear their gloves with blood or decoy.

If meat be placed about the traps in small chunks, it is preferable that same is fried. Honey bait about the trap answers well, and is sometimes more successful than meat bait. Some trappers drag a piece of fresh meat or poultry about the trap with the intention of leading game to it. The bait is often placed on a stick about two feet above the traps. A European Jager (licensed hunter) placed a steel trap near to a flowing spring in about two inches of water, the surroundings were cleared of moss, stones, etc., and the bait arranged so that the fox would naturally step with his front feet on the pan, which was covered with moss, to keep from wetting his feet, thus springing the trap and becoming the victim.

A spring pole can be used advantageously, especially if the traps cannot be visited every twenty-four hours. Some of the northwestern farmers are unusually lucky in ridding their ranch or farm of wolves and foxes, also making a little spending money during the dull winter months, by setting traps and capturing these animals. The traps are set in various places, and both steel and deadfalls are used. The former is buried in the usual manner, and instead of being covered with earth, leaves and the like, the excavations are covered with manure taken from hen coop, which is strewn about, while the musk of the female fox, wolf or dog, taken during the mating season, is smeared about the deadfall trap.

Many farmers and trappers use the deadfall very advantageously while others prefer to snare such game in the old 


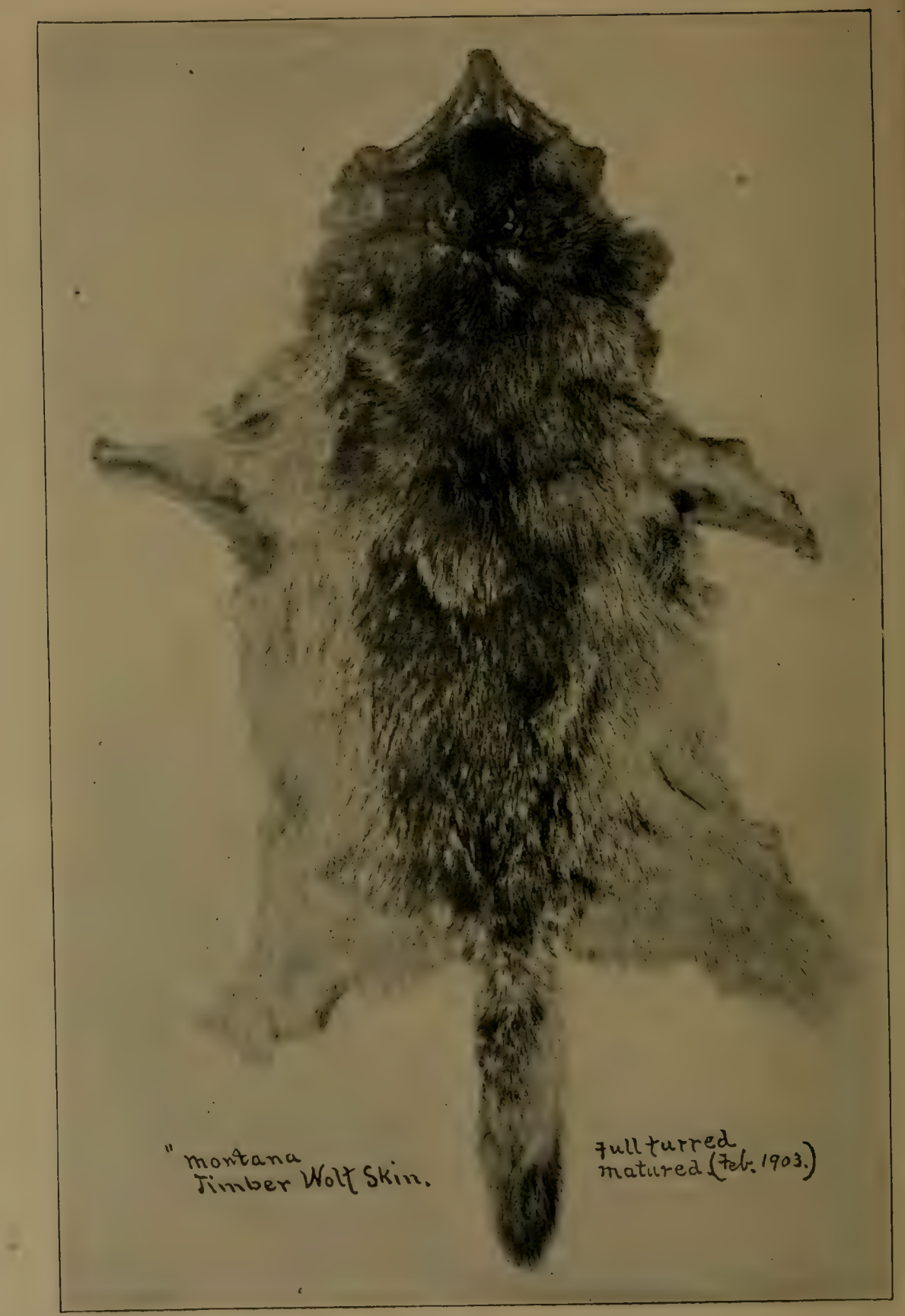


fashion. If snares are to be used it is advisable to attach same to spring poles.

Whenever opportunity presents the fox can be killed with a rifle, as the pelt is not damaged extensively, and seldom grades as damaged with the fur dealer.

This animal can also be poisoned with strychnine, but as a rule shuns such bait, unless exceedingly hungry. The author has known poisoned bait to lie for twenty to thirty days undisturbed, although the fox has frequented and even watered in the vicinity without disturbing same, but shortly thereafter a heavy snow storm set in, and as food was scarce, the fox scratchel for the bait, which he easily located, ate same, and his corpse was found within twenty-five yards. The poison should be mixed with a little honey or lard and a dose inserted in a piece of meat ; five to ten such pieces should be strewn about. If you have reason to believe that one of these pieces was devoured, look carefully in the vicinity and you are sure to find the corpse.

\section{TRAPPING THE WOLF.}

This animal is difficult to capture, being swift, cute and outwits humanity in chase. In most cases they are captured by the use of steel traps, snares, rifle, poison, and with other domestic paraphernalia. The same tactics used in hunting fores can be applied to wolves; but one must reason and allow for the great strength, cuteness and habits. For trapping wolves No. 4 steel traps are recommended, which shouli be set in conspicuous places, usually in cattle runs, cattle trails, watering places, near corrals or wagon roads, foot paths, also in woods, brushes, about dead animals, etc. It largely depends upon the kind of wolf and the locality, also time of the year.

Some set the traps right in the cattle trails, trusting to the wolf to walk in them, others between two trees or dead $\log$ and tree, also in path between and under bushes. The use of a grab hook (iron 4-prong hook) attached to a fifteen to thirty pound $\log$ ( see cut) should be invariably attached to the steel trap. The former will make a trail that can easily be followed by the trapper to the location of the captured wolf, who generally drags the clog fifty to two hundred yards, sometimes a mile away. The hook will detain the wolf and increase the hardship of his travel and often, when the animal roams frantically about, will be detained by the hook becoming caught in bushes or the ground. Never attach two traps to one clog, neither is it advisable to attach the chain to a stationary object, as the victim is likely to tear loose, break, chew or twist his leg out of the trap. 


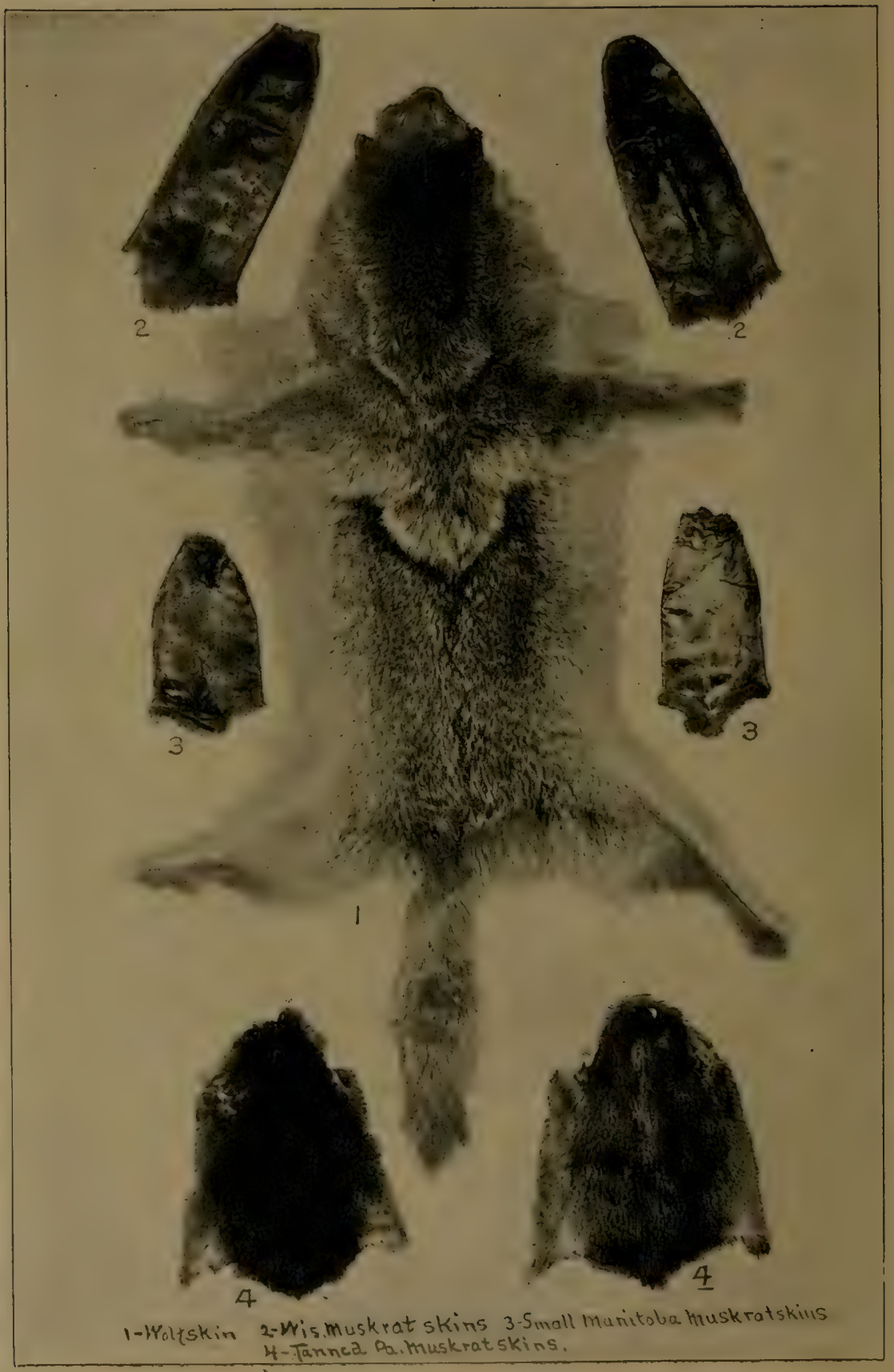


In setting steel traps, on cattle trails the traps should be set three to six inches apart, and the clog as well as the traps buried. One should avoid tle deeply worn spots and choose a place near weeds or bushes. Spread a blanket or large open wool sack near place of excavation on which throw all loose dirt, also stand on same while working as much as possible. When the holes are ready, bury clogs, chains and traps and carefully cover with dirt or sod. One of the chief objects to be attained is to see that the pan does not rest upon the earth; if any danger of filling in under pan, place a quantity of loose cotton underneath. To obtain good and prompt results, arrange the surroundings to the former natural condition. One should avoid artificial arrangements of appearance and remove all loose soil.

The best arrangements or order of setting four traps on a cattle trail is to bury two clogs on each side and only excavate a few inches deep where the trap is to be set, which should be so arranged that the inner jaw of the trap is about one inch away from centre of path. (See illustration.)

Traps should not be handled with bare hands, but with gloves smeared with fresh blood or smoked; the former is preferable. The traps themselves should be held over smoke or dipped in fresh blood. Tie a piece of sheep pelt or other kind of furred skin on bottom of shoes when visiting traps or setting them. Sprinkle blood about the places where traps are set, and it is also advisable to scatter bits of meat in vicinity thereof. Some smear traps with decoy oils, others claim the decoy and oil is a detriment to success. The author suggests, in this style of setting, not to use any artificial oils, whatever, but if any decoy is used preference should be given to the fluid from the female wolf or dog taken during mating season, which should be smeared on bushes or on a stick placed about the traps, if consistent, one or two feet above the trap. The latter is sure to be a drawing card, and wolves will be attracted from long distances.

Traps set about a dead carcass is a splendid idea, but one should note that wolves will not eat old or diseased meat, unless possessed with extreme hunger. However it is seldom indeed when this animal does not possess a good appetite, therefore, part of the dead carcass is consumed or carried away.

When a wolf lacks appetite and crosses scent of food, he naturally follows it up until the article or body is reached. Should the article be small he will grab, shake and carry it away to his hiding place or bury same; if large or ill-suited, he will turn and water upon it.

It is common for wolf hunters to have seventy-five to one 
hundred twenty-five traps scattered, and probably in as high as fifty settings, but as the traps should be visited at least once a day, and naturally so many traps or settings cover a large district, it will be noted that little time will be left to skin the victims and handle the pelt, therefore the latter should be left for others who can care for the skin properly as well as promptly.

In visiting traps set for wolves, one should ride horseback or in a wagon dragging a freshly killed animal behind, which should be attached to a rope, and the latter to the horn of a saddle or axle.

A good place to set traps is (if one is fortunate to find a place) where wolves recently devoured some animal and especially if parts thereof remain. Mr. Wolf is sure to come again. Western ranchers attach the chain of the trap to a beef head which answers for bait as well as a clog.

A certain western rancher set his traps in two rows, probably four to six feet apart, carefully burying the clogs and traps. and in three or four days thereafter would ricle horseback dragging a freshly skinned and bleeding sheep or calf for miles and ride between the traps and drop the carcass there. Sufficient time had elapsed for the eradication of all human scent from the time traps were set to the time the bait was dropped. This latter method is a secret, and well worth the time and expense, as one is likely to rid the ranch of these howling devastators. The rancher sometimes got a wolf in each trap every night, and the traps were set in the same position for some weeks and less costly bait or none thereafter was used.

Another method to catch wolves or other animals, or even bears is to dig a hole six to ten feet square and five to six feet deep and set traps along the outside of the hole about twelve to fifteen inches from the edge. The chains can either be secured to some stake driven within the pitfall or attached to some weight suspended upon temporary brackets. By the latter method, the victim is usually caught by one of the fore feet and in its endeavor to free itself, or to decamp, the weight to which the chain is attached and which hangs suspended within the pitfall, descends and pulls the animal within the pit; thus making him a chained prisoner.

As far as bait is concerned, a bleating calf or a squealing pig lowered in the pit is probably the best. If the former are unobtainable, some dead animal dragged behind a wagon, or attached by means of a rope, to the horn of a saddle, and, thrown into the pit, makes an excellent bait. The wolf or the fox will readily pick up the scent, follow it to the pit, and become a victim. The idea is to bring the wolf to the pit and then in smelling around 
in close proximity to the pit, should spring one of the concealed steel traps and be drawn or thrown within the hole. A dead dog (preferably female) also the carcass of a wolf or fox, if dragged in various directions to this pit, will surely be followed should any of the animals of the dog family cross the trail.

The noise of the captured wolf and the bait therein will attract other wolves who come to ascertain the trouble, and if they are curious or close observers, they naturally will attempt to get very close to the excavation and be caught. If this method is adopted the traps should be set about two feet apart and carefully concealed. (See illustration)

There are a great many other ways of setting steel traps but the foregoing will give anyone with fair intelligence, and those who possess the genuine trapper's sagacity, to comprehend the art of setting these traps for wolves at various places. It should be observed that the surroundings be the least possible disturbed, and all the loose earth removed. A blanket or open wool sack should be used, on which loose earth is to be thrown, and whatever is not used must be carried away for some distance.

Snares can be advantageously used in brush or timber country, especially for gray wolves. These snares should be strong and so arranged that the animals are caught by the neck, as, if caught by the foot, Mr. Wolf may get away, notwithstanding the use of a spring pole. The spring pole must lift the animal entirely off the ground, otherwise the victim will escape. It is the author's opinion, that snares can be successfully adopted when wolves are known to enter corrals through openings, and in such cases the snares should be conveniently placed above the same path that the wolf is accustomed to frequent.

An Iowa farmer informed the author that he used snares with great success. Seemingly he had a controversy with his neighbor, and claimed that his dogs were in the habit of digging holes under the fence, get into the enclosure, bite and run the sheep for hours, and of course, as a natural result, some of them died and others were more or less chewed up. A dispute arose and he told the neighbor that he would ascertain the trespasser in a short time, and if the dogs were caught in the enclosure or thereabouts he would hold their owner responsible for all the damage done heretofore, and, in case some other dogs or wolves were in the habit of getting into the enclosure, he would grant his neighbor a certain right of way over a strip of land, which the latter desired, and highly prized. This was agreed upon between the two farmers. The informant tore or knocked two boards from the fence and braided four small fish 


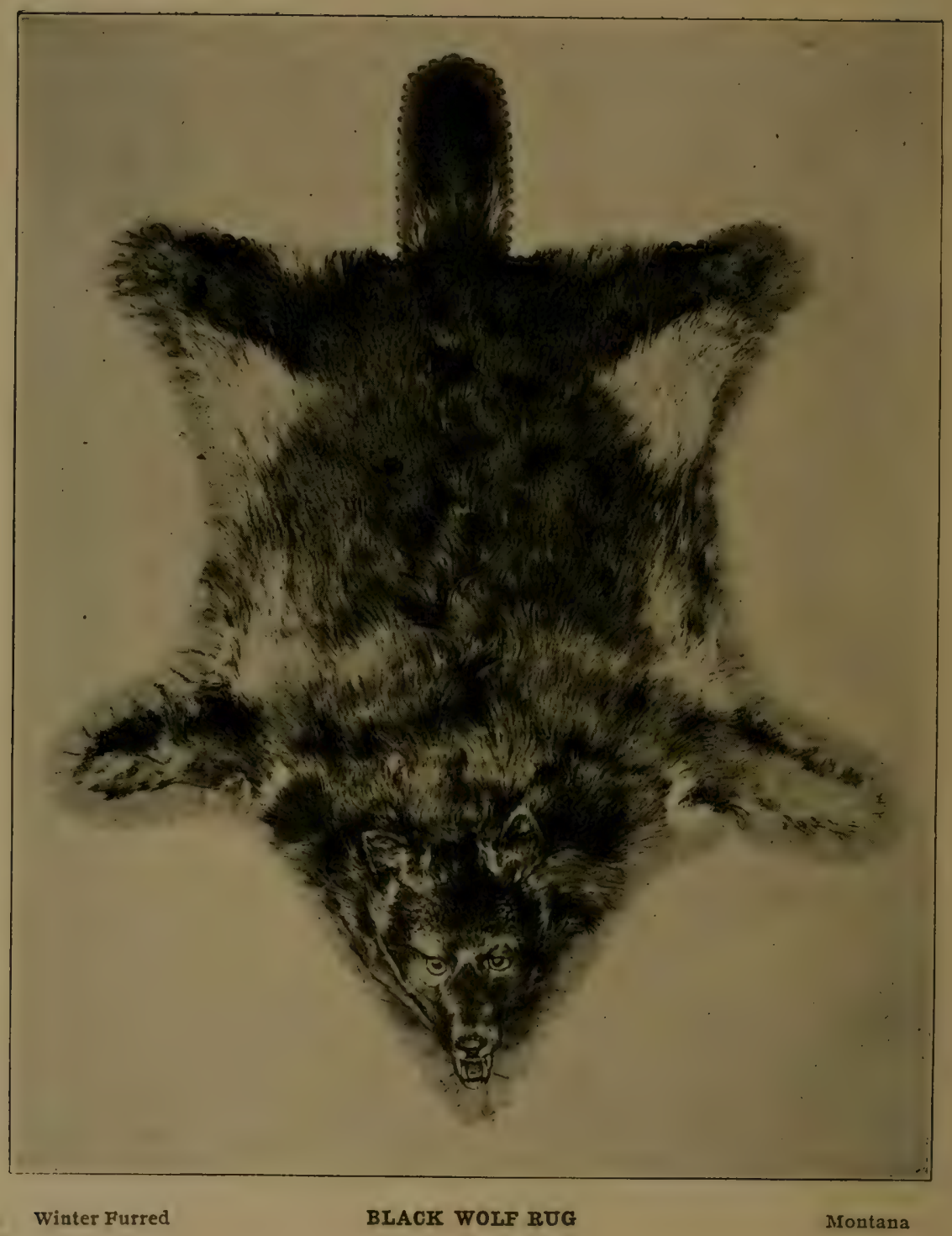


lines into one good strong line and arranged same into a snare, placed the latter at the opening made by the boards that he previously knocked off. The end of the snare was attached to a rope and the latter to a cattle hoist, which was so arranged that if a certain stick was pulled out the wheel would turn and hoist the victim high in the air. The power was obtained by having another rope wound around the centre shaft in opposite direction, on which was tied a sack of stones weighing approximately one hundred pounds. The sack was raised twelve feet in the air and the hoist wheel was fastened in such a way that when a stick was removed the wheel would turn by the descending weight. An additional line from the snare to the stick was placed, thus if the animal was caught the stick would be pulled out and the weight descend while the victim would be rapidly hoisted into the air.

The first night nothing came, at least, the snare was unmolested; but the second night Mr. Wolf came and was strangled to death; on the third night the neighbor's dog was caught in the same manner, to the admiration of both the farmer and the owner of the dog. They jointly agreed that neither was to receive any compensation. This method is certainly a very good one, both the wolf and the dog can be made to stretch hemp; thus farmers can get rid of sheep-killing dogs as well as the devastating wolf.

The rifle should not fail to achieve credit and assist the eradication of these animals as much as possible, but it is to be regretted that opportunity is seldom presented for an average hunter to obtain a satisfactory aim; hence, killing wolves by the use of the rifle, much less the shot gun, is not extensive. We urge hunters to kill wolves in or out of season, and to loot the homes of the young whenever possible.

The bounty question is too often taken for deliberation, and the sum too often drawn by men who should feel ashamed to ask the county or state to pay them for something that they should feel it's their duty to perform. The true hunter as well as the farmer should cease scrambling about bounty; the former will be rewarded by increase of other game, and the latter from loss of stock. All should unite and effect as near as possible the capture and eradication of the timber, brush and prairie wolf.

Wolves can be lured to death by the legitimate and proper use of poison, but to be successful one should distribute the poison at such a time when food is scarce and the animal roams frantically around in searcl of food to satisfy its hunger. During the winter time when the snow is deep the wolf will overcome the usual fondness for fresh and wholesome meat, and will devour 
suspicious looking bits of meat in which poison has been placed, and naturally the corpse will be found in close vicinity.

Strychnine mixed with lard and inserted in small pieces of meat often tempts the animal and, to the surprise of the farmer as well as to the wolf, the poison will be prompt in action, and the victim found with upturned toes.

Another method is to mix strychnine with fresh blood and dissolved lard. Run this mixture into little holes previously made in the frozen earth. Others make balls of this mixture which are thrown in conspicuous places. As a rule wolves will not eat or chew poisoned meat; hence, small pieces are preferred, which the animal can swallow. Extreme hunger, however, on the part of the wolves, causes them to tackle a poisoned carcass, but seemingly, are extremely cautious, nevertheless some parts are devoured. To the detriment of the trapper or hunter, often insufficient poison is consumed by the wolf, and occasionally, the poison is improverly injected, or too old.

Don't give up hunting for the dead wolves should you find that some of the pieces of bait were consumed, neither feel downhearted if you find that the bait remains undisturbed for two or three weeks. The author has known baits to lie undisturbed for a month regardless of the fact that wolf tracks about the bait were numerous. Generally after a severe storm or spell of cold weather, or a blizzard with a large quantity of snow, wolves go in search of food and look tup the places where they. have buried same heretofore, and consume the bait that they previously neglected to devour. At such times the wolves will devour the bait and naturally suffer the penalty of death. The poison acts promptly and generally within ten minutes. The author has seen a wolf snatch the bait off sticks and shortly thereafter, much to his detriment, drag and twist himself in all shapes, suffering great agony and pain. Sometimes the pain is so extensive and prompt that they are unable to run away, other times the dead body of the wolf will be found a distance of a mile. The proper place to put such bait is on small hills, which this animal, as well as the fox, frequent, to enable them to view the surroundings. Therefore bait placed on some slight hill is preferable. In a prairie country it is an easy matter to see the carcass for a long distance.

Some trappers fasten poisoned bait on sticks which are driven into the ground, but no more than eight or less than four baits should be used at one place. The chief trouble and failure of success is the use of old or insufficient poison. We advise hunters, trappers or farmers to procure fresh poison from reputable drug-stores. 
It takes a large and swift dog to tussle with an average fullgrown prairie wolf. Often more than one dog gets torn up before a wolf is finally captured. For one or two dogs to attempt to capture a large timber wolf is almost like sending them against a bear, mountain lion, or lynx. If a dog is fortumate to come up to a large, full-grown timber wolf, and a fight ensues, the dog will soon be disengaged and only when two or three others arrive to the rescue do dogs have a show of killing their enemy, and even then it's only after the large and heavy dogs arrive that the wolf finds his position reversed.

A Russian nobleman relates that in a chase four to six dogs to the value of $I, 500$ rubles, became engaged with a large native wolf. The latter killed three and were it not for the timely arrival of the horseman the wolf would have escaped almost unharmed.

Wolves, foxes, as well as mink, skunk, and similar animals can be caught by using a live rooster or other domestic fowl, rabbit, etc., and by placing same within an enclosure made of wire netting. Ordinarily small mesh wire netting answers the purpose, and if set for large animals such as wolf, the strength of the netting can be increased by inserting thicker wire and fastening it above as well as below. A suitable top out of wire netting must also be made.

Place the fowl or rabbit within the enclosure, provide it with sufficient food for the required number of days and secure the enclosure to the ground. Place your traps about the enclosure,

A suitable trap for above named animals is also made by driving stakes in a snake-like circle and placing the fowl or rabbit within a small enclosure at center part. Adjust a proper sized snare at the opening and place one or two steel traps further therein. The wolf or fox may listen to the peculiar sound of the fowl for hours without attempting to go near, but as no other disturbances are discernable he becomes accustomed to the surroundings, and will finally venture for the prey, only to become nabbed. and cover them in the usual way with vegetation, ashes, etc.

It is known that wolves are about as sly as the fox, and if not too hungry will shy at most anything that a trapper usually prepares for Mr. Wolf's reception. It is related by an experienced Massachusetts trapper and traveler that if one is fortunate to obtain from a female dog the fluid or matrix that predominates during the period of coition, and can use this liquid before it becomes too old and odorless, he is sure of attracting Mr. Wolf from long distances and lead him to the traps, deadfalls, or even the socalled bait set gun.

It is known that wolves have been successfully crossed with 
dogs, and as they belong to the same family it is only natural that the male wolf would be attracted by the liquid from the female dog when in heat.

Mr. Snyder, a well known sportsman, relates that he captured two young wolves, raised them up, and successfully hunted wild wolves with their assistance. He was fortunate to view a fierce fight between his dog Snapmouth and a large wild brush wolf. The fight was much fiercer than that of two bull-dogs or of any other fight that he had seen, but as his wolf-dog was well nourished and protected by a steel collar around the neck, he had the advantage, notwithstanding his enemy outweighed Snapmouth. After a fierce fight of about one-half an hour or so the wild brute gave way and Snapmouth was the victor. On examination the wolf was badly torn and chewed up, especially around the neck. The same writer also relates that he crossed and bred his brindle dog Nero (half bull and English mastiff) to his female wolf very successfully.

Bed traps, that is a number of traps set in a line parallel with the path or trail are successfully used by western trappers where the coyote or wolf abounds. First select a suitable location upon some paths, or some other place where digging is easy. Keep away from sod as much as possible.

Take four No. 3 , No. 4 or No. $4 \frac{1}{2}$ traps, first having prepared a suitable stake and place said stake through the rings of the traps and drive into the ground so that the upper part is about two inches below the surface. Now dig out a bed for each trap about two feet away from stake. Place dirt on canvas or sack. Set so that each trap will be about one-half inch below the level of the surrounding ground when covered with earth. Place enough wool underneath pan to keep dirt out, also to prevent birds or other small animals from springing. Leave surroundings in natural condition.

Wolves can be killed by various home-made traps, deadfalls, bear traps or in pitfalls and dugouts, the latter covered up with fresh grass, etc. If interested, see description of these traps on other pages of this book. 


\section{HOW TO HUNT AND TRAP THE BEAR.}

The bear is a coward and will not molest man, even if disturbed, many times he will seek to escape the intruder and only in rare instances will he turn upon man without due provocation. To throw a stone at him, whether the stone falls short or not, is sometimes sufficient for Bruin to turn about, other times if shot and wounded he will scamper away, perhaps the latter occurs selclom, as he is known to go for the hunter, who must be prepared for his reception.

One who cannot await his time for the bear to approach within twenty-five yards has no business to go on a bear hunt. Only those shots that hit count; perhaps tlie statement made by President Roosevelt when speaking of our navy "In time of war and in battle only those shots that hit, and hit well, count" is also true when on a bear hunt.

"One of the best hunters that I ever saw was scarcely five feet ta!l, weighed about one hundred and fifteen pounds, and a tailor by trade," says Mr. Huntington, an experienced hunter and trapper, formerly a western guide, and at one time connected with the Alaska Commercial Company. "This little fellow with one or two guides would go for weeks hunting in the most lonesome forests. At one time we struck a family of grizzlies. and do you suppose he would give me a shot at them? No sir! We followed them for some time and when within shot he bacle me stay behind while he went forward. When within thirty to forty yards he darted behind a tree, rested his rifle on the side of the tree, took careful aim, and fired. The first shot hit this monster bear high on the head and glanced off ; the bear turned in a circle, like if demented, stopped for a moment, and made for the little fellow who had stepped aside the tree. The bear had gone about five yards when this tailor took aim but reserved his fire until the bear raised himself on his hind legs. A sharp report, a fall, and Mr. Bruin was done for. I rapidly ran to the scene and was requested not to approach the dead bear until our rifles were first in complete order and allowing sufficient time for the bear to pass through his death struggles. While I skinned the monster and prepared to camp for the night in the vicinity, the tailor went after the female bear but not being able to locate her returned to camp. The next morning, much to our surprise we corralled the mother and two yearlings which were promptly dispatched."

On one occasion two Wyoming cowboys chased a black matured bear from his ustual abode out into the open where he was roped about the neck, each man keeping the rope or lasso stretched 


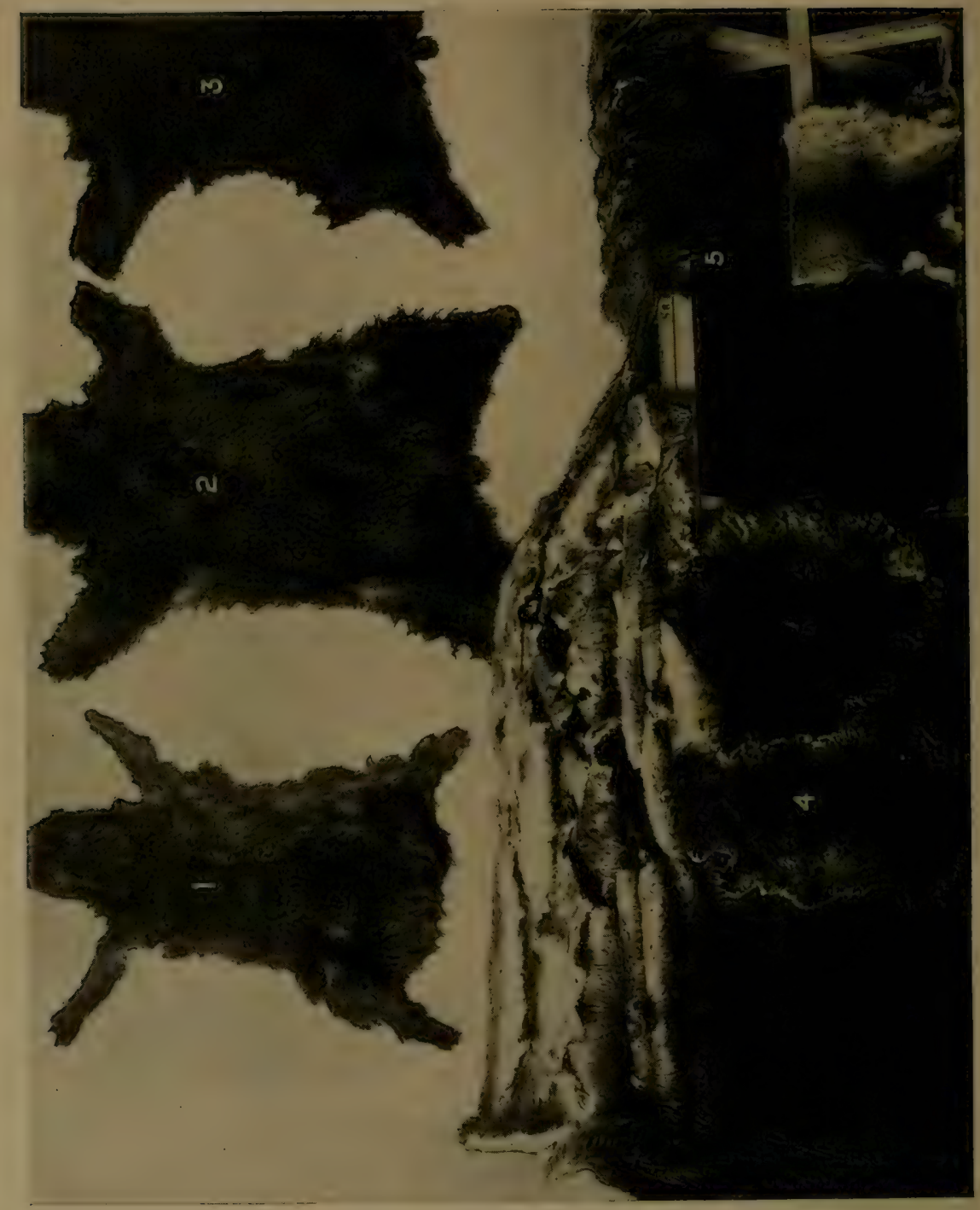

(1) Brown Bear Skin

(2) Grizzly Bear Skin

(3) Black Bear Skin (4) Pile of Beaver Skins

(5) Pile of Marten Skins 
and bruin in the middle away from any possible harm to the horses or riders. In this manner and position he was partly pulled, dragged and run into town where the folks viewed the prisoner with unusual admiration. Towards evening a mock jury conclemned the prisoner "to be shot in the head until dead."

Some years ago the government sent a special party to capture alive some of the monster grizzlies still found in the Rocky Mountain regions in Canacla. This party was successful in capturing two large specimens weighing over two thousand pounds each. From their report it would seem that the grizzlies were captured in pitfalls into which cages were lowered, and the animals being partly starved were driven into the cages and then hoisted and placed aboard a ship, and brought to the United States at an expense of about $\$ 10,000.00$. Of course, no trapper or hunter would care to spend such a sum fitting out an expedition.

Deadfalls, log nouse traps, snares, pitfalls, set guns and Newhouse steel traps are commonly used for capturing these monsters. The large No. 6 Newhouse steel trap is guaranteed by the manufacturers to be of sufficient strength to hold a two thousand five hundred pound grizzly or polar bear. If steel traps are used the clog must be twentv-five to fifty pounds for an ordinary bear, and seventy-five to ore humclred pounds for the grizzly or polar bear. These large traps should be set with clamps, and no one man should attempt to set these powerful devices without assistance. For bait large chunks of meat or carcasses of small animals are commonly used. These should be fastened. Honey bait prepared in various ways bring excellent results. How to make this bait is noted elsewhere in this book.

If you have reason to know that Mr. Bruin is in a certain locality and you possess a large trap and are desirous of getting the skin and meat-the latter leing very delicious and highly prized during the winter months, not only by trappers and woodsmen but also city people (especially in large cities where steaks often retail from twenty-five to thirty-five cents per pound), you should first select a proper place to set the trap. A good location is next to a fallen log. The latter will answer for one part of the " $V$." Drive a sufficient number of 3 -incl thick stakes, twelve to twenty inches into the ground; the stakes should protrude about three feet above the ground more or less as the surroundings warrant or require. Have stakes close together. The row of stakes should be about five fect long and the mouth of the "V" should be three feet wide. When this is done excavate immediately within the mouth of the " $V$ " shaped enclosure-in which excavation place the trap. Arrange the trap when covered with leaves and dirt so as to be even with the surrounding ground. Be sure 
and place wool or similar materials underneath the pan to prevent dirt from getting under or the trap being sprung by small animals. After this is completed place bait in the narrowest part of the "V" enclosure. Chain should be attached to a clog, never to a stake or other stationary object.

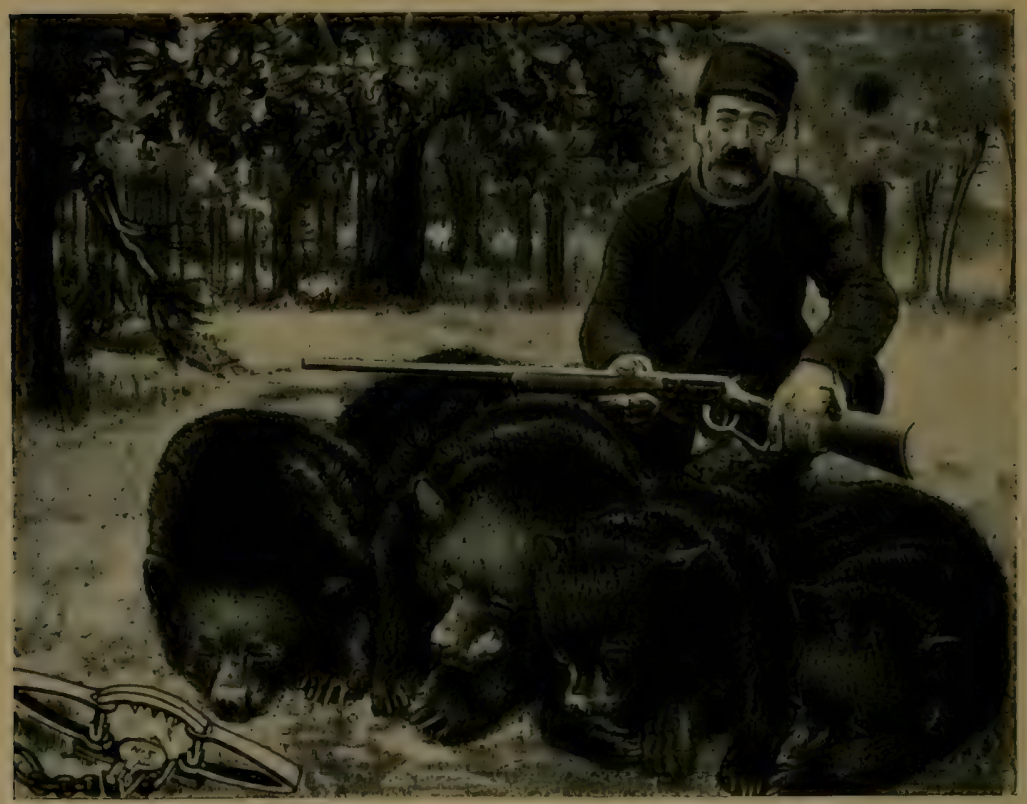

WHAT DO YOU TEINK OF TEAT? From a Photograph

An experienced hunter from the "Great Black Forest" in Europe relates that he caught a monstrous bear in an American steel trap set at the widest part of a " $V$ " enclosure, and used a small squealing pig as a bait; the latter was fastened in the narrowest part of the $\mathrm{V}$-shaped pen. The trap, (supposed to have been a Newhonse No. 6) was set in an excavation between the widest part of the enclosure and covered with earth, leaves, etc. The springs of the trap nearly touched the respective opposite stakes of the pen.

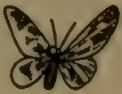




\section{HOW TO HUNT AND TRAP THE RACCOON.}

The animal is caught in traps of various kinds and often hunted by dogs and chased from tree to tree, and out of hollow logs or trees.

Steel traps should be set at the entrance of the animal's abode or in their paths. Snares and deadfalls can also be advantageously used. The bait can be vegetables or meat such as chicken, rabbits, and fish, which should be roasted in order to extend an inviting smell and give the animal an appetizing relish.

Favorable results are obtained in the late fall and early spring or before the water is frozen, by setting a steel trap in shallow water, ten to fifteen inches from the shore, with some shining object placed upon the pan, or the latter polished so that when the sun shines, its brightness is reflected to the observing coon when passing. The raccoon, in observing the shining object, becomes curious and will examine it. He will slowly step into the water, sniff and smell about, place his paw on the trap and if he does not succeed in removing the object, will go a little further into the water, the nearer he goes the more weight will be placed upon his foot, thus springing the trap and capturing the coon.

At other times the trap is set the same distance away from the shore on some especially prepared island. The bait which is put on a stick is stuck into the ground six to twelve inches beyond the island. The coon will smell about upon discovering the bait, jump upon the covered trap and become a victim. The trap thus set should be staked and can also be attached to a spring pole; a sliding pole may answer the purpose, but trappers as a rule dislike the idea of skinning a drowned coon.

A good idea is to put upon the stick a shining tin can especially polished for Mr. Coon, which will also attract him. Other times a bright, shining tin can in the water will cause the coon to leave the shore, wade to the can and with his paw, slowly roll it towards the shore or abandon it if it rolls into too deep water. A steel, trap set between the shore and the curious object will do the trick; no bait necessary.

Wire traps, as well as the new tree trap, have been successfully used in trapping the raccoon. The former is set at the entrance of some hole or cave, and the latter is securely fastened on some sloping tree. Both traps are very humane, killing or choking the animal in the space of a few moments.

It is great sport to hunt the raccoon with the aid of dogs and to chase him out of hollow logs and see the animal dart out of same, get on a tree, etc., only to be brought down with the trusty rifle or be captured by the dogs themselves. 
Hunting this animal by moonlight is great sport. Usually two or three hunters, one with a rifle, the other with shotgun and the third with an ax, accompanied by two good dogs constitute the outfit and party. The dogs will usually tree the coon or discover him in a hollow log; then the fun begins. Of course the coon won't come down nor will he get out. If on a tree a fire is usually built so that the smoke reaches his nostrils when he will jump down and a fight with the dogs results. Many times the coon es-

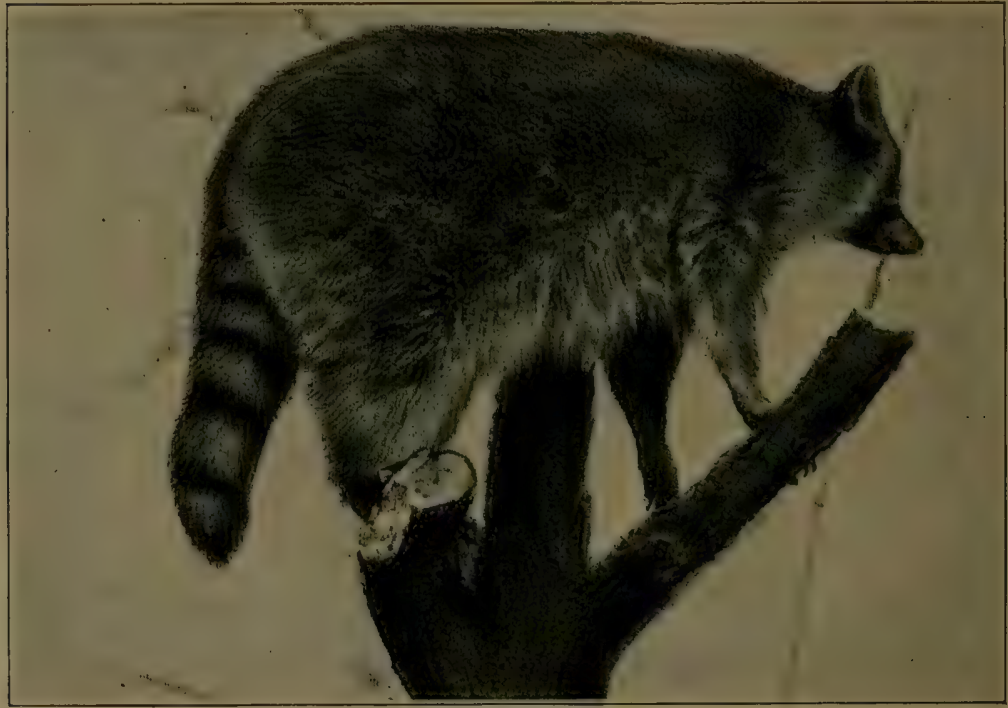

capes only to be treed again, other times he is killed by the dogs or hunters. A long pole is used to poke him out of a hollow $\log$; other times the log is cut down or into pieces.

If the night is dark and your dogs have treed a coon and you are unable to see the animal, stand with your back against the moon and face tree, or build a fire close to the tree and stand off a ways and the fire will no doubt illuminate the surroundings sufficiently so when standing at a distance overlooking the fire towards tree you will see the coon crouched on some limb or between some fork or crotch. Take good aim, fire, and down he will fall. 


\section{TRAPPING THE SKUNK.}

This animal belongs to the weasel family, and is nocturnal in its habits, but unlike other fur-bearing animals of the weasel family, lacks alertness. It is unable to climb trees, is exceedingly slow in locomotion as compared with other animals, and naturally falls an easy prey to the average hunter or trapper.

The only drawback and reason why this animal was not extensively hunted or trapped and the skin marketed twenty or thirty years ago, was the danger of being sprayed with their peculiar essence, which is its only weapon and upon that the animal relies to distract the hunter, trapper or poacher and, naturally, the strong odor becomes speedily effective and answers the purpose only too well.

The fur is fine and eagerly sought after, especially the black furred skins, which bring high prices. As many as 500,000 skunk skins are marketed in a year, and if the demand is good, the skins bring 75 cents to $\$ 3.00$ each, depending on size and quality of fur.

The skins are generally divided into four or five distinct grades, and each grade is then assorted accordingly to quality and size. The black, short or half-striped, narrow or long striped, broad striped and white, are the common grades, but the skins vary considerably in value. The fur of the former is all black, the second, or half-striped are such skins as have two short, white stripes descending from the nose over the head and reach to about the center of body, while the stripes on the third class extend clear along the body and run well into the tail. The broad striped, or fourth order, as above enumerated, is similar to the third order, excepting the white stripes are broader, thus lessening the value of the skin considerably, as the white part is not used by manufacturers. The fifth order, or white skunks, have little value, as the back, in fact, nearly all portions of the skin is covered with white fur, and such skins are only used after the fur is dyed, for cheap garments or trimmings.

Skunks should not be killed for the pelt out of season, but this is true of all animals, where the furred skin has a market value. The open season for Minnesota, Dakotas, Iowa, Wisconsin, Montana and northern sections, is from November ist to February I 5 th, varying somewhat upon the weather. South or middle states the season opens somewhat earlier, and naturally closes on approach of warm weather. The fur of the skunk is the first of all fur-bearing animals to become prime, and is also first to suffer the loss of its lustre and primeness.

There are many ways and methods in common use for cap- 


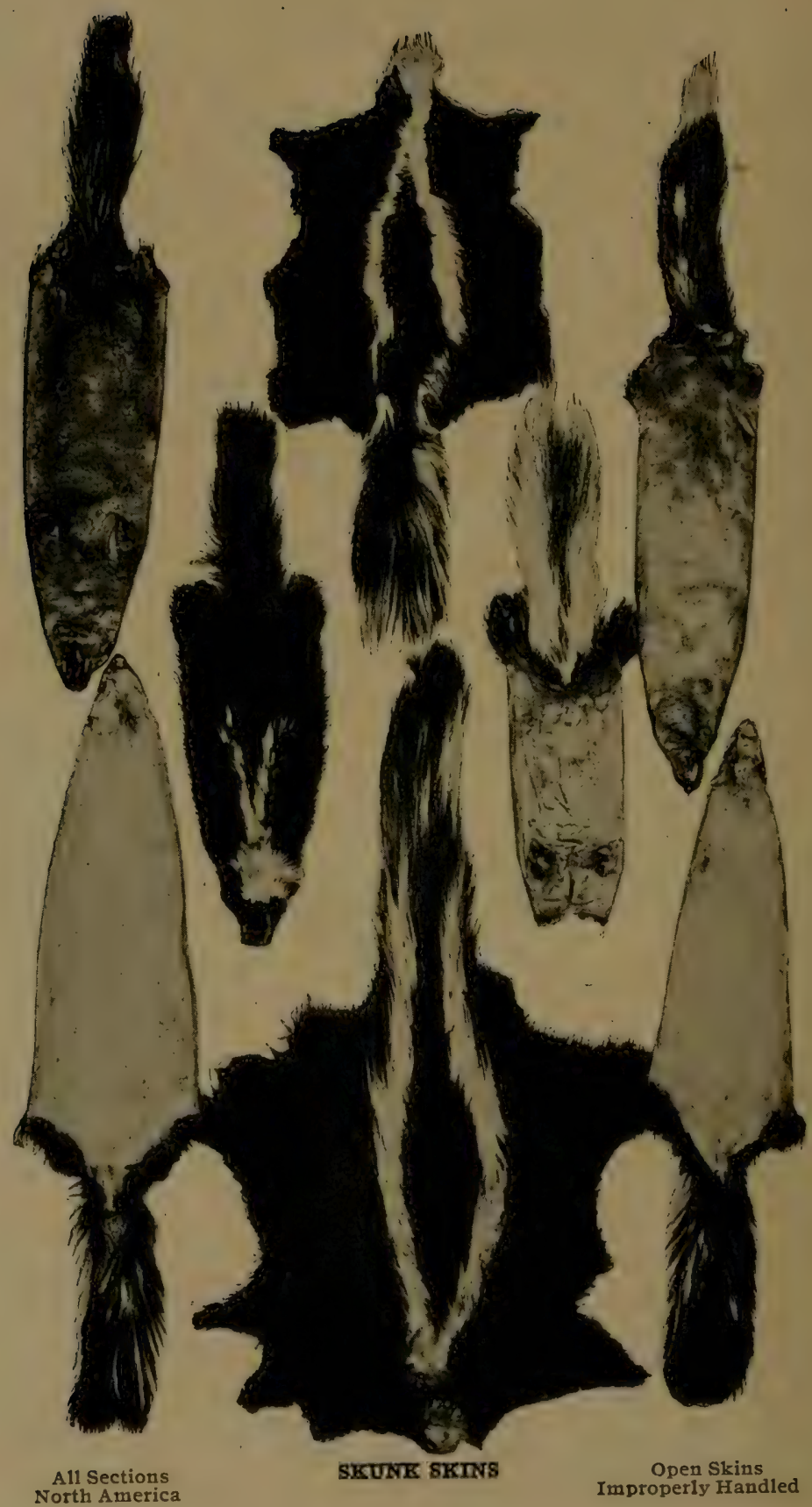


turing and killing this animal, but probably the best is the use of steel traps, though a long stick is equally as good, providing the one who holds it comprehends his business and uses same advantageously. The author has known two lads to kill and skin forty skunks in a day. Of course, great care must be exercised to kill the animal without receiving a discharge of the perfume. A six to eight foot long stick, one and a half to two inches in diameter is the proper weapon and instrument to use in killing skunks. A smart blow on the back about one to two inches beyond the tail will readily fell the animal. This blow will paralyze and benumb the muscles and nerves employed by the animal to distribute its obnoxious fluid. An additional blow is necessary, and the latter should be given on top of head.

Steel traps are used with good effect. They should be set just before the hole and be covered with loose bits of dirt, leaves or other vegetation. Some prefer to use bait, the latter can be a beef head, a chicken, or, in fact, any chunk of old meat or carcass. Drag same in various ways and drop in a conspicuous place or in center of a nest of traps. The trap should be attached to a clog, or loose bushes, never attach two traps to the same article. Skunks often spring traps set for mink, wolf and other animals, but seldom devour or even touch a victim should they come upon same while making their nocturnal visits.

The usual bait for skunk is birds, bits of meat, pieces of chicken and rabbit, whether old or fresh. A good method and trap is to bury a large dry goods box; see that the top is even with the surface of the earth, place light brushes, leaves, hay or straw across the opening, upon which sprinkle a little loose earth. Some prefer to make an artificial opening in top of box after same is buried, into which the skunk will descend, rather fall in, but cannot get out. Some strong smelling bait should be placed in the box, which is to attract the animal from a distance. As many as eight skikuks have been caught during one night by the use of this style of box trap.

Another method is the so-called barrel trap. A sugar, vinegar or whiskey barrel will answer. Remove the head and securely fasten the bait on inside bottom of barrel. Place the barrel in a slanting position, open part toward the earth, and arrange by balancing the barrel in such a way that when the skunk enters by crawling up in barrel, being attracted there by the bait, the barrel with the skunk will tip over and Mr. Skunk fall on his nose inside of the barrel and be a captive. This is a good and cheap trap and the victim cannot get out, though only one animal can be caught at one time. Some trappers dig the skunk out, others dig until they reach the cavity in which they usually lave their 


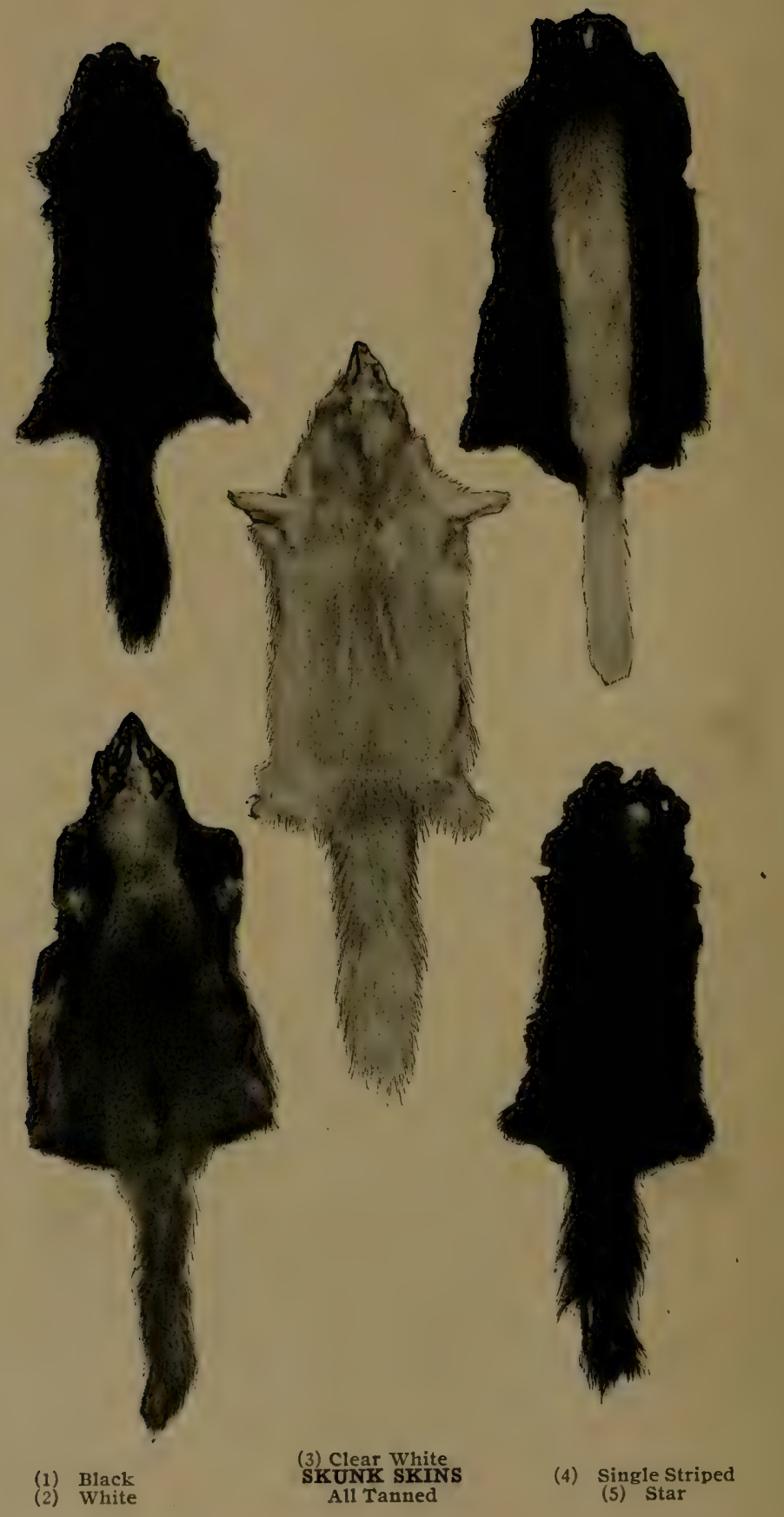


nests and are found huddled up together in a bunch. If found in such a position it is an easy matter to suffocate them, thus obliterating all possible chances of the animals distributing their obnoxious perfume. All that is necessary after one sees the animals is to cover them up with soft dirt, which should be lightly tamped every two inches of filling and continued until about fifteen to eighteen inches is securely tamped. In about fifteen to twenty minutes the trapper can uncover the den by removing the earth, and he will find the animals suffocated.

It is unnecessary, but we recommend for the trapper, (new beginners) or hunters, to remove the perfume containers (glands) before skinning, as one is likely to cut into the bags and distribute the perfume, but if removed all danger of coming in contact with the liquid weapon is of the past.

Skunks, when located in holes, can be smoked out or suffocated, either with common smoke or vapors arising from burning sulphur. To locate the distance of digging, insert a long switch or telegraph wire into the hole. The author has personally seen trappers dig down for a short distance and then reach after the animals with their hands, and sure enough they succeed in bringin the animals, one by one, from their den. Strange as it seems no perfume was discharged. This is probably due to the fact that the other trapper assisted by knocking them senseless immediately after their heads appeared through the hole. A piece of $3 / 4$-inch round iron, about twelve inches in length, was used. Trappers relate and claim that it is a positive fact that the skunk will refrain from biting or discharging their perfume while in their holes.

Deadfalls, figure four and other home-made traps can be employed, though the animal must be skinned promptly, and often the fur becomes damaged from the instrument itself or by long delay and exposure to the weather. There are many other methods and ways to capture and kill this animal, but by the foregoing anyone contemplating to trap or hunt will have the essential knowledge.

The rifle can be used whenever possible, but the use of the shotgun is detrimental to the skin, and its use should be prevented when the question of its fur is taken into consideration. The animal should not be entirely eradicated from any particular locality, as the skunk is more beneficial than harmful to the farms, and again, the killing of skunks out of season is entirely absurd and uncalled for, the animal being harmless. The meat while not generally consumed, can be used, though when fried, it is dry and tough, resembling bull meat in that respect. The fat is used for medicinal purposes, though of recent years, substitutes are 


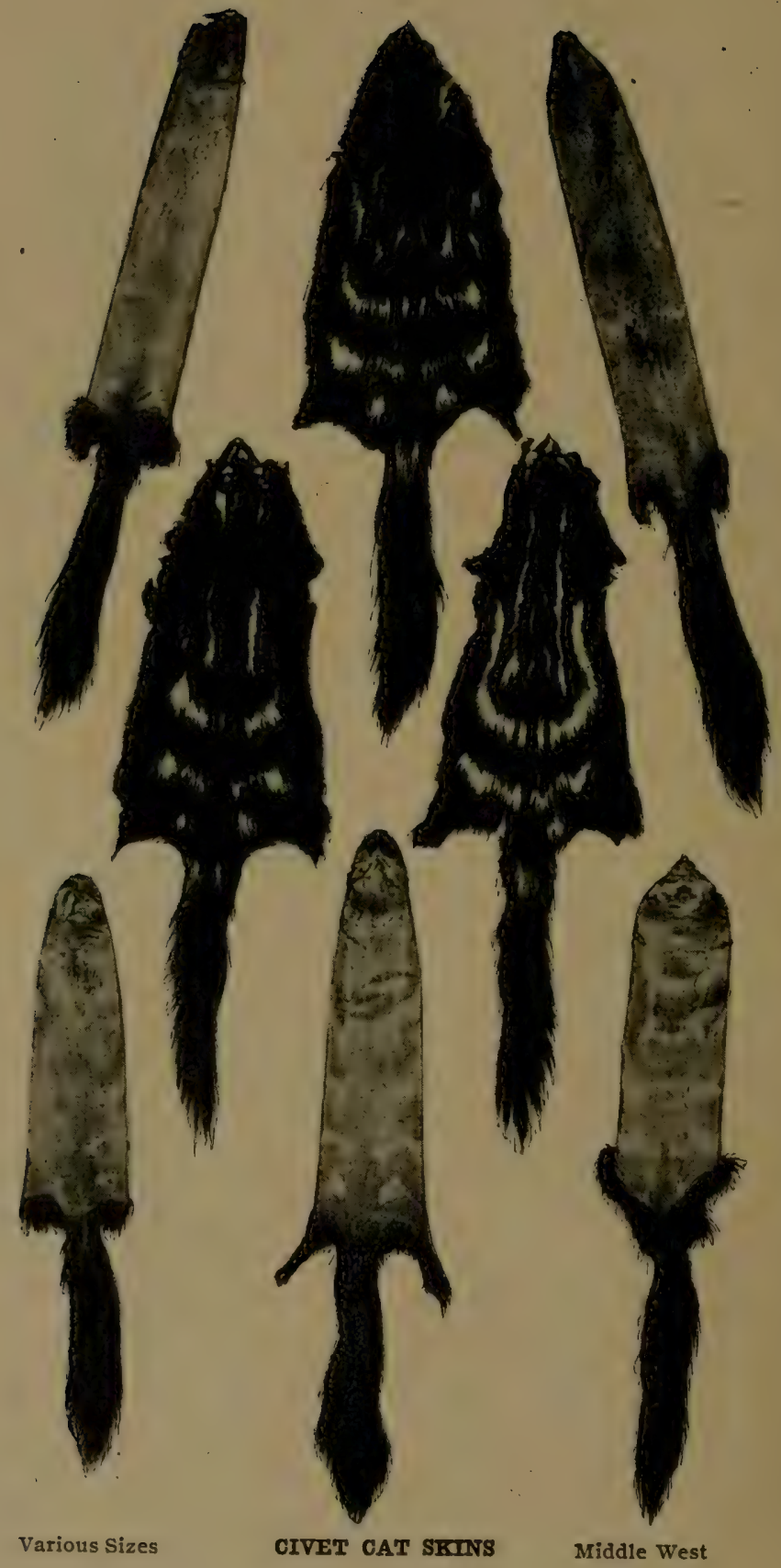


placed before the public and the demand consequently somewhat lessened.

The druggist who formerly handled refined skunk oil, will now satisfy the purchaser with adulterants or cheap imitations. Skunk oil is highly recommended for sore throat, croup, etc.

\section{TRAPPING THE CIVET CAT.}

The civet cat, like the skunk, is an easy animal to trap. The same methods are employed in trapping the civet cat as are used for skunk. Use same size traps, if anything, smaller, and set same as for skunk. Traps are set at openings of dens; at other times make artificial enclosure for the trap, so as to cover the bait from the weather. Wire traps are also very good. In fact, I prefer the wire trap to the steel trap every time when the former can be set in front of some abode.

In skinning one must be careful not to cut the scent bags. One would hardly believe that two civet cats could be caught in the same trap, but such has been the case. Presumably both came across the bait at the same time and in their eagerness to take hold, stepped on the pan. As far as bait is concerned any old piece of meat will do. No bait is necessary when traps are set in front of their dens or over their holes.

\section{TRAPPING THE OPOSSUM.}

The opossum is an easy animal to trap, being of a lazy disposition and does not suspect danger as does the mink, fox or wolf, in this respect he resembles the skunk very much. Almost the identical methods used in the capture of the skunk can be applied to the opossum.

The best manner to trap them is with steel traps, No. I, No. $\mathrm{I} / 2$, not larger than No. 2. He can also be taken with deadfalls, box traps, snares and by the use of poison. In seeking to capture the opossum one need only study his habits, ascertain his whereabouts and then by placing bait along his path which usually is beside fences, he is easily taken.

It will be remembered that the opossum feigns death and the trapper should make sure of his victim; otherwise he may trouble himself carrying the supposed dead opossum home, only to find that "the dead arise" and leave in quick order. A smart rap or blow on the forehead is sufficient. Many instances have been reported to us where the opossum, after being released from the trap, he having feigned death, scampered away.

Many prefer to smoke the opossum out if located in some 


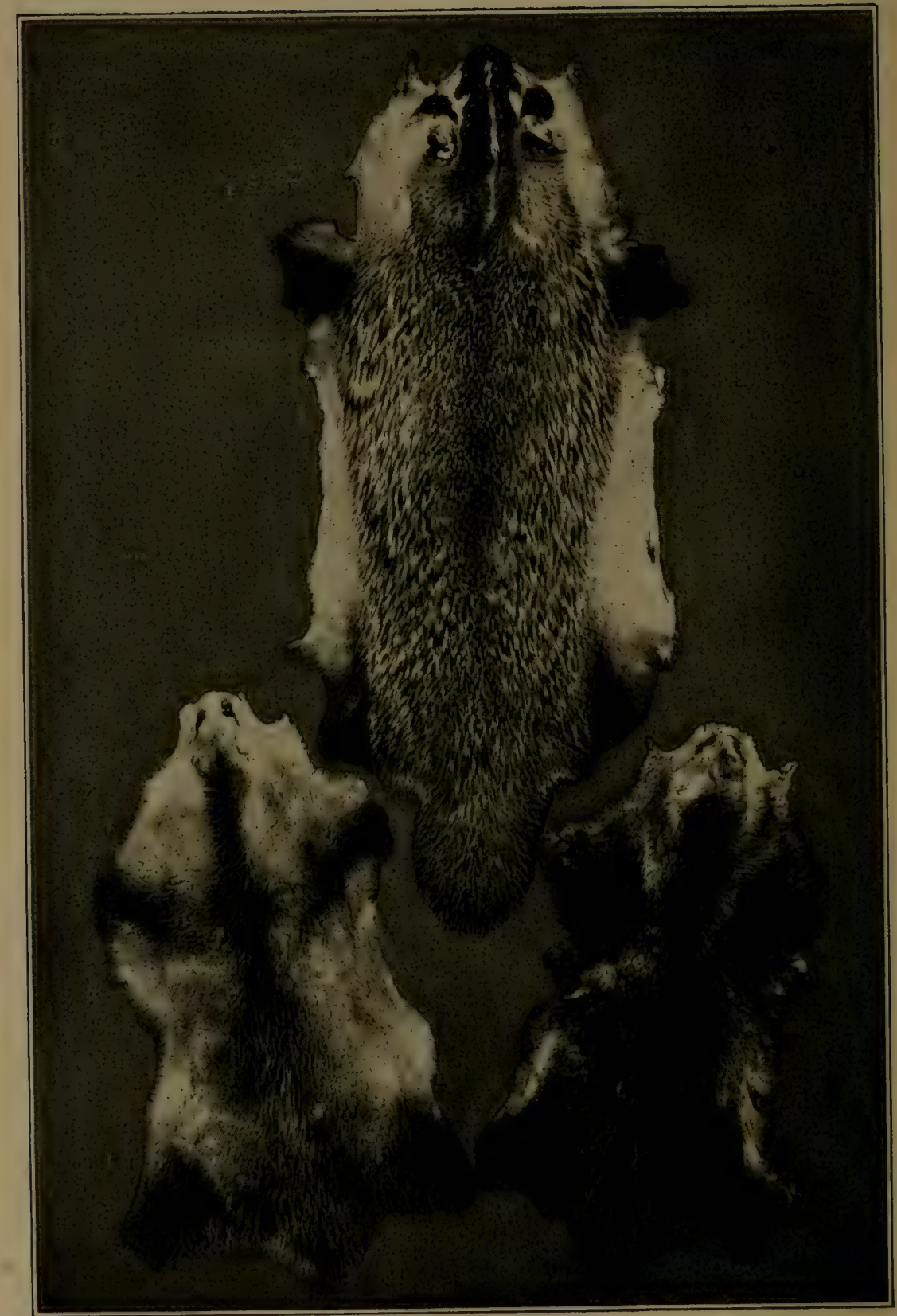


den or in a hollow tree. Take cotton waste, rags, or if in a hollow tree make a fire below, and you will soon have him on the limb, if such is possible for the animal to reach.

For bait use any old piece of meat as he is not very fastidions and cares little whether it is fresh or putrid. The skin should be handled similar to that of the skunk, never cut open on the belly but leave it cased; preferably to have the flesh side out. The tail should be severed from the boly and all fat removed from the skin. The skin is very tender and the party in charge must exercise due judgment in skinning, scraping and stretching, especially if in the latter process one-piece stretchers are used. We recommend the three-piece stretchers every time. The skin of the opossum has no value out of season and low, thrashy skins should not be marketed.

\section{TRAPPING THE BADGER.}

There are no particular secrets or methods in trapping this animal. The steel trap is invariably used (No. 2 and No. 3 traps recommended), and a great many badgers, owing to their size and slow locomotion, are dispatched by the use of the rifle in the hands of hunters and trappers.

Snares cannot be used effectively, though if attached to a spring pole of sufficient strength to hoist the animal off the ground, a strong line or wire may be arranged for his capture.

Deadfalls and other home-made appliances can be used, but the animal must be immediately killed. It would be a foolish hunter to use box trap or pitfall for a badger, as in the course of no time the animal will free himself.

Steel traps should be placed slightly within the abode or den and if the latter cannot be found, the traps can be placed in his paths. As the badger has many holes it is quite necessary that all excepting one be closed up, within which a No. 2 or No. 3 trap should be set. Bait is unnecessary though if desired, can be used.

There is probably no animal that is as easily captured as the badger, since he can be approached without danger, and any one having any courage at all, can knock him on the head with a five or six foot stick. Quite often he is dug out the same as skunk, but this a tedious job, especially during the winter. Digging them out is not recommended, as badgers are likely to have many passages and quite often the skins are poorly furred, due to their hibernating habit. The skins of the badger are only good during the winter time and only from those that have exposed themselves to the severe weather a good share of the time. 

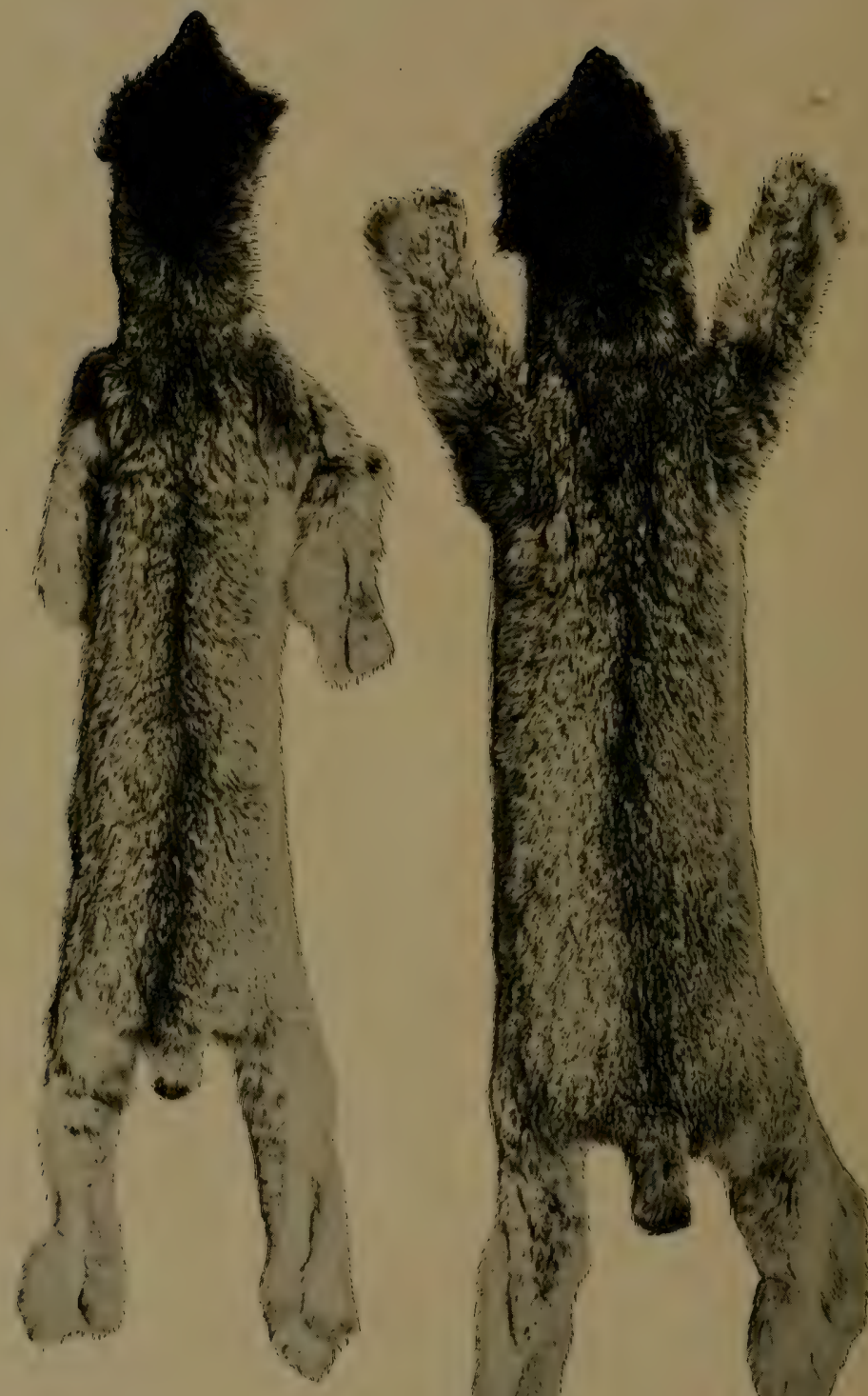

r.
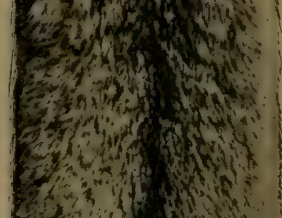

Lon

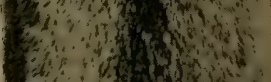

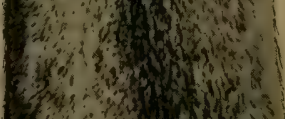

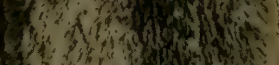

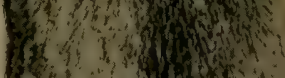

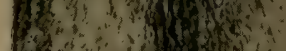
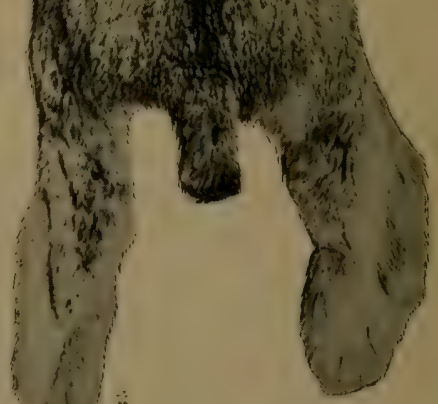

LYNX SKINS 


\section{TRAPPING THE LYNX.}

The lynx, like the mountain lion, can be caught in traps, but whenever opportunity presents he should be killed with the rifle. Steel traps and deadfalls are responsible for most deaths, and it is to be regretted that the animal is not as easy to trap as one mav imagine.

He is not numerous in any parts of the United States, but formerly was found quite plentiful in the western mountainous states and in the timbered sections from Minnesota down along the Canadian border as far south as the Alleghany mountains and northward into Canada. As aforesaid, deadfalls and steel traps are chiefly used in killing this carnivorous cat. When using steel traps nothing smaller than No. 2I, 2 will securely hold the Canadian lynx, but instances are recorded where this animal sprung a No. I trap and the jaw held the brute by one of his toes until the hunter released him from his misery. The Newhouse traps are much preferred over any other steel traps-No. 3 or $3^{\mathrm{T} / 2}$ probably best adapted. The former is a double spring trap, the other a single spring with four prongs. Either of them will hold Mr. Lynx. By all means fasten the chain securely to some spring pole and if this cannot be done to some limb which he is able to drag a short distance.

As the lynx is found principally in dense forests, it is quite natural that the traps must be set in some place that the animal frequent; quite often in a trail or open place; if the latter, choose a good-sized tree against which make an artificial abode. The lynx is known to follow lines of marten traps, and follow the trapper from one place to another, anticipating a carcass, bait, etc., and occasionally steals the bait placed by the trapper for mink and marten. The traps should be covered in the usual way. Steel traps can also be set underneath the snow, but a sufficient quantity of wool, leaves or other material must be placed beneath the pan. He has also been caught in traps set for wolves and foxes. Is known to favor the smell of castoreum and many a trapper lures the lynx to his death by the use of this decoy. His presence is made known to the trapper during the night-time by the peculiar yell that he gives from time to time.

The deadfall has been successfully used probably for at least Ioo years. In fact, the early Canadian trapper confined himself almost exclusively to this variety of trap. These were set in conspictous places and the bait so arranged that the lynx, in touching the trigger, caused the upper log to fall upon his head, killing him instantly. The snare can be advantageously used if the paths of the animal lead through brush. The ends of the wire or line should be fastened to some spring pole. One shrewd trapper 


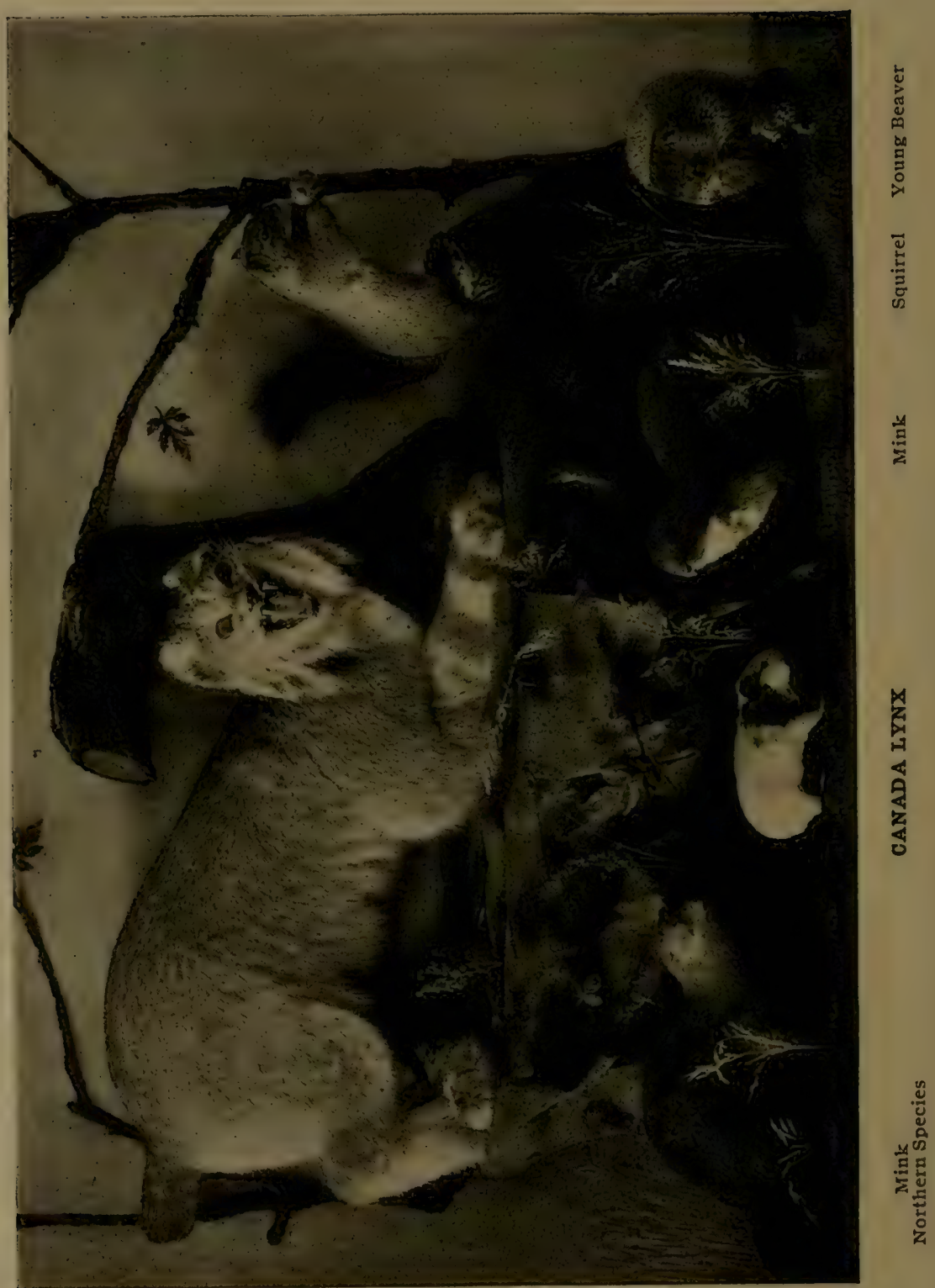


was accustomed to set his traps in his own path, especially when the ground was covered with snow. He took pains that the path should be fairly smooth and placed a small, dry piece of a limb between the traps over which the animal was expected to step, and in so doing step upon the pan and spring the trap, thus becoming a victim. The chain was invariably attached to some limb. or permanently to some near-by brush. He managed to trap many lynx in this way. At other times he made an artificial abode against a tree and set his trap at the entrance. To prevent rabbits, squirrels and similar animals from springing these traps, it is advisable to place some dry brush in front of the opening over which the the small animals will hardly climb; the lynx, on the other hand, will shove this aside: so will the wolverene and fisher.

A full-grown Canadian lynx is equal to two or three average dogs and in a fight, should any of the latter escape, they are usually so badly wounded that they die thereafter; other times are killed by the owner to stop their painful sufferings. The lynx, on the other hand, often escapes.

\section{HOW TO HUNT AND TRAP THE WILD CAT.}

This animal, like the lynx, can be caught in traps but is generally tracked by dogs and is brought to bay with the rifle. Traps can be set about the shores of rivers and lakes, or in paths. If a place is found where the cat has lately devoured its victim and lett a few remnants, one or two traps should be set about the location. Traps should be covered up in the usual manner. Any of the baits used for lynx will answer the purpose. Bait placed within hollow logs and the traps concealed in the usual manner will often result in his capture. One or two dogs are seldom equal to a cat and generally are put into misery and the cat escapes. Many traps set for coon or mink are sprung by the wild cat and, if strong enough, detain the animal.

Quite often steel traps are set on each side of a log, or edges thereof over or along which the animal is known to travel. If a good, strong trap is placed at the entrance of a $\mathrm{V}$ or $\mathrm{U}$ shaped enclosure and a piece of rabbit is thrown further into the den, the result quite often is favorable to the trapper. If one is successful in locating their habitual paths, traps should be set thereon. Exercise great care in leaving the surroundings natural and always cover traps so that nothing of the human work is visible.

Another good place to set traps is where the animal has previously enjoyed a former meal, and especially if some leavings remain. Place three or four traps in the immediate vicinity. The cat will return to this place the same day, or in a few days, and in so doing is very likely to spring a trap. 


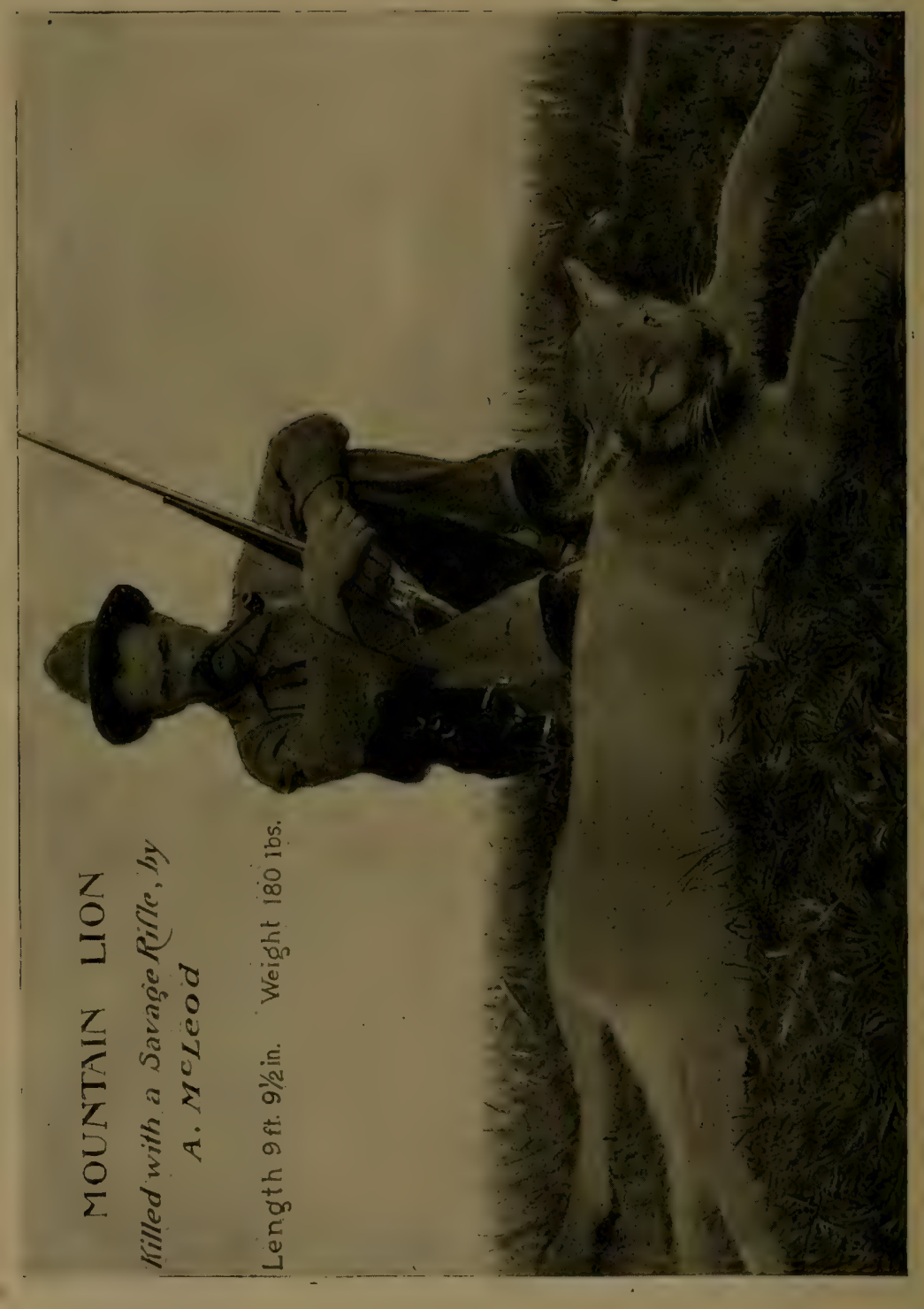




\section{HOW TO HUNT THE JAGUAR, MOUNTAIN LION AND COUGAR.}

Either of the above brutes can be captured with steel traps, but the scarcity, peculiar habits and great strength, are obstacles to the ordinary trapper, who like the hunter, prefers the trusty rifle in going against this monster cat. Should one be fortunate to locate a place where one of these brutes recently enjoyed a meal and some remnants remain, at such a place, set two or three No. $4 \frac{1}{2}$, No. 50 or No. 150 Newhouse Steel Traps. The traps should be buried and covered up with loose earth, leaves, rotten wood, etc., suitable to the surroundings. A clog or drag must be attached to either of the latter traps, which must also be buried. Traps set in front of their dens or in paths, brings result. Snares can also be arranged, but one should take care not to under estimate the strength of these ferocious beasts. Dead-falls have been and are still used in remote timber sections, not only in Canada and Alaska, but also in the Western States.

A certain Mr. Saunders, formerly of the Black Hills in Dakota, where he gained much experience in mining and some in hunting and trapping, relates that he killed many a Mountain Lion with a Savage rifle, and captured both the male and female brutes in steel traps. A few years ago he moved to the Klondike and from there sent us many skins. He was quite successful in capturing this brute in dead-falls, but most of the skins received from him indicated that the brutes were killed with the rifle.

A Wyoming trapper relates that he succeeded in chasing one of these monsters into a cave, and not wishing to wait until the brute came out, he partly closed the opening, arranged a snare out of a galvanized wash line and securely fastened the other end to a spring pole. The next morning he visited the den and found the Lion in the snare, partly off the ground, but very much alive. A bullet in the chest sent the brute to eternity.

Many difficulties are encountered in bringing this brute to bay. Rarely is he seen by the hunter, for he manages to see the hunter and makes good his escape before he himself is seen. Dogs are used to track and locate him, and at times sett-guns are conveniently placed so as to kill the monster on his next passage.

The skins have no great value and are chiefly used for ornamental purposes. If one is fortunate to kill or capture this brute and desires the animal mounted, he should preserve the leg bones and be very careful in skinning, especially about the eyes, ears, nose and lips; paws, of course, should be left attached. 


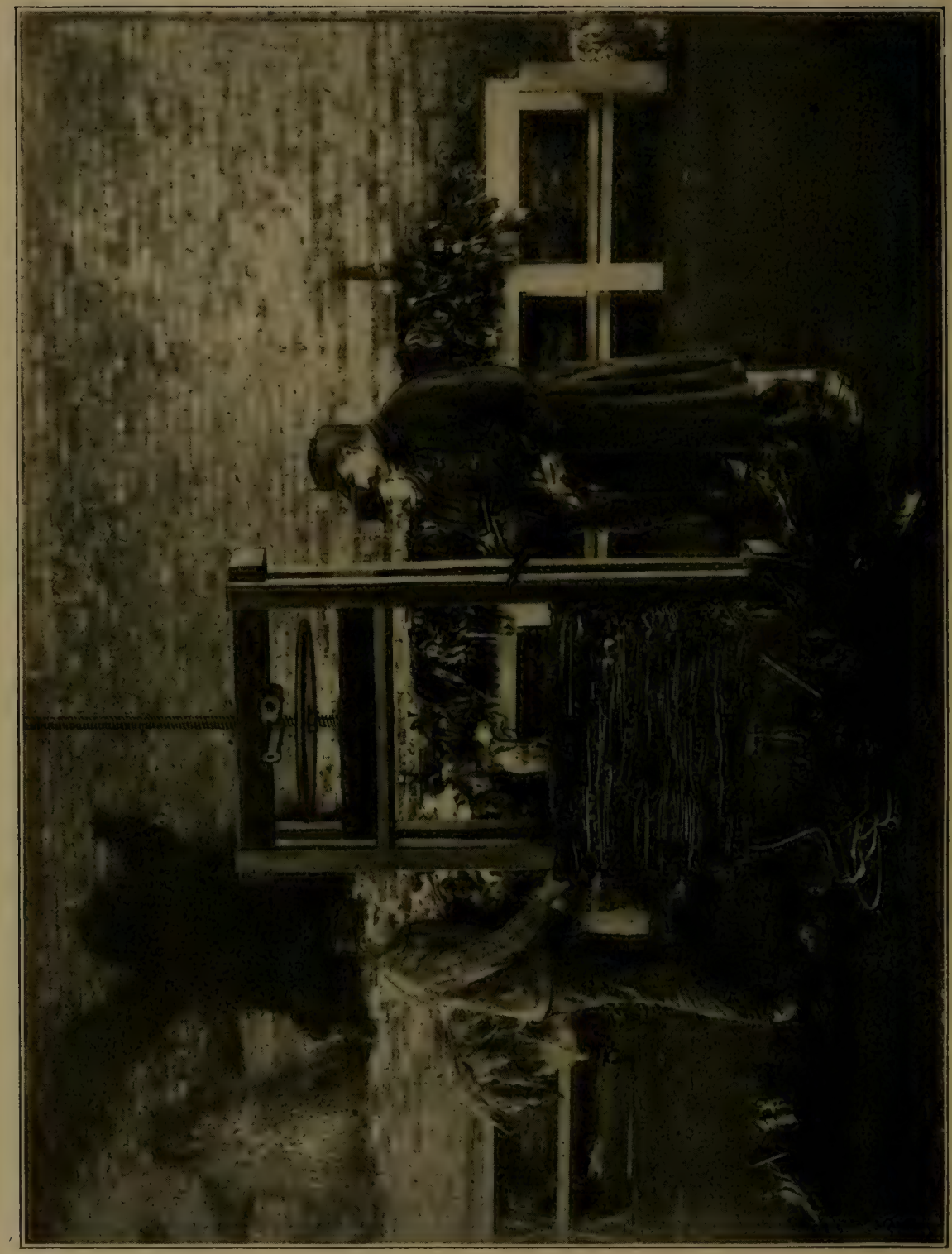

Andersch Bros.

BALING RAW FURE

For Export

Scene in Fur Rootn 


\section{TRAPPING THE MUSKRAT.}

The muskrat is found in marshes, lakes and rivers, and their abode is principally in dome-shaped houses made by them during the fall months. At times, and in certain sections, the muskrat makes his abode in banks, other times in hollow trees, but always if not in the water, in close proximity thereto.

The niuskrat is captured in many ways and it does not require long experience to enable one to capture them. At the sime time an experienced trapper will be much more successful than one who has had no previous experience and who is unacquainted with the many metlods, kind of traps, and other arrangements in use by the more experienced trapper. Where one trapper may get ten or fifteen rats, the other may get twenty-five or more in the same space of time, and probably with less exertion.

The muskrat is chiefly caught in steel traps, although many are shot, suffocated, speared, drowned, killed in deadfalls, wire traps, snares and other home-made appliances; but probably two-thirds of the muskrats captured whose skins are marketed, were caught in steel traps.

The use of a spear for capturing muskrats is slowly dying out, as the pelts become more or less damneed, and as a rule fur dealers class them as damaged, although if the skins are not badly pierced and only about the head or neck, they will generally pass as No. I, unless otherwise clamaged or umprime. Some use regu$\ln r$ fish spears, others single prong spears with the usual projecting hooks. These spears can be made by any village blacksmith or can be purchased at hardware stores. The handle with the spear is from eight to twelve feet long.

Nany thousands of muskrats are annually killed by the rifle, in and out of scason, that are never skinned. Have known trappers to give up steel traps and entirely depend upon their small 22 calibre rifle. The skin is not damaged to any great extent, especially if the bullet should strike the head or neck. Such skins are much pieferred over those that are speared, and no great, if any, distinction is made between skins killed by such a small calibre rifle and those that are trapped. It is to be regretted that many trappers, especially the inexperienced ones, resort to killing the muskrat with birdshot or shells intended for fowls. The skins, showing so many holes, are always rejected and bring a very small price, consequently the use of the shot gun is detrimental to the hunter's interest, and we recommend trappers to refrain from killing this, or any other fur bearing animal, with the shot gun.

A great many muskrats are annually captured bv robbing the 
animal of its breath. The operation is simple, and to many amusing. In this operation the trapper takes a stick, axe or hatchet and walks out upon the ice to their houses, and strikes a sharp blow upon the house. If the house is inlabited he will immediately see the muskrat depart. By following one of them, say a distance of thirty to forty feet, he will see the animal come next to the ice, place his nose against it, expel his breath which immediately forms into bubbles, and after a few moments begins to inhale the purified air. If the trapper intends to rob the animal of his breath, all that is necessary is to disturb him before he inhales the air that is contained in the bubbles. On being disturbed the muskrat swims a distance of ten to thirty feet and endeavors to repeat the operation. It must again be disturbed, and if successful, the muskrat will be unable to swim much farther and for lack of air, will shortly drown. The proper time to drive them away from their breath is when the air is expelled from their lungs. The trapper will know this by the many bubbles next to the ice. He must immediately drive him away, follow his course and repeat the operation. Having succeeded in separating the muskrat from his breath, the drov'ned body will lie next to the ice, when the trapper takes his hatchet or axe, chops a hole and takes the body out. In about ten minutes or so the operation can be repeated, as by this time many of the other muskrats have returned to their house: if not, other houses should be looked up.

Deadfalls have been used, but as the value of the skin is so small, it hardly pays a trapper to resort to this method, as they cannot be moved from one place to another advantageously and then again the labor and time expended is too great for the possible remuneration. These are more adapted to places where the muskrat makes his home in banks rather than in houses out in the marshes or lakes.

What is true of the deadfall is also true of the snare. They do not seem to pay, since steel traps are too popular and reasonably cheap. Furthermore snares cannot be successfully arranged due to the habits, especially at times when the skin is prime.

As heretofore stated, two-thirds of the skins marketed, comes from animals captured in steel traps. Steel traps are set in numerous ways, and especially can good results be obtained in the spring months immediately after the ice becomes melted. No. I and No. $1 / 2$ steel traps are set below the ice in front of the openings into their houses, or what is still better on their paths leading up the bank. Some trappers prefer to set steel traps in and about their usual feeding grounds, others at a point where the animal passes from the shore into deep water. If a hole is made in the dome-shaped house and a trap is set, either upon the shelf 
or next to the hole, through which they pass into and from deep water, one is quite assured of having it sprung by a muskrat and once in a while by a mink. The hole made into the house must be closed to prevent the water from becoming frozen, which would make the house uninhabitable.

Many trappers prefer to set a line of traps upon some plank or railroad tie, which is later shoved out into the lake near muskrat houses. The chains are fastened to the log or plank, and when the muskrat springs a trap he immediately jumps into the water and drowns. (See illustration). At times traps are lowered into the water and set in their paths. Such traps must be covered and the chains fastened either to a stake or to a wire. It is of utmost importance that all traps set in or about the water should be so fastened or arranged that the animal will jump into deep water and drown, thus preventing the gnawing or twisting off of his leg and thus escaping.

Bait is unnecessary in most sets, excepting if traps are set away from their paths or feeding grounds, in which case carrots, parsnips, or a piece of their own meat may be used. Decoy is likewise unnecessary, but if its use should facilitate matters, suggest that a few drops of musk from the female muskrat be sprinkled about the trap; this musk can be procured by any trapper. All that is necessary is to capture the female muskrat and squeeze the contents of the bag that is near the vagina, into a bottle. Bait should be fastened to a stick and placed 6 to Io inches above the trap. As elsewhere stated, arrange the setting so that the animal cannot regain the surface, or obtain air, and without air it must drown.

Barrel and box traps are used by many trappers with great success. Sink a water-tight barrel so that two or three inches protrude above the level, and arrange a top or cover to swing on two pegs. Weight it in such a way that when the muskrat crawls or jumps upon the cover, he will be dumped into the barrel. The barrel should be weighted down in its place with stones and be filled about half full of water. The muskrat not being able to get out, will drown very shortly. (See illustration). Bait should be used. This is fastened on the cover. Carrots, flesh, apples, etc., will answer the purpose.

The muskrat is also captured in boxes or troughs similarly arranged as the barrel trap, excepting that they may be floated from one place to another. At other times platforms are sunk beneath the ice or water level, upon which traps are arranged. The platform is held secure by being fastened to some scantling or pole driven into the ground. At other times small platforms are nailed to a scantling or stake, upon which a 
steel trap is set. Then the entire stake is driven into the ground. Bait is placed five to six inches above the platform and when the animal tries to get at the bait quite natırally steps upon the platform, thus springing the trap and becomes a victim. A double platform can be arranged, but it is not advisable to place more than two traps to any stake. Such stakes should be driven at or near the muskrat house, and if possible in the path.

Elsewhere in this book will be found many illustrations suitable for trapping muskrats; one interested should read the different methods successfully used by trappers.

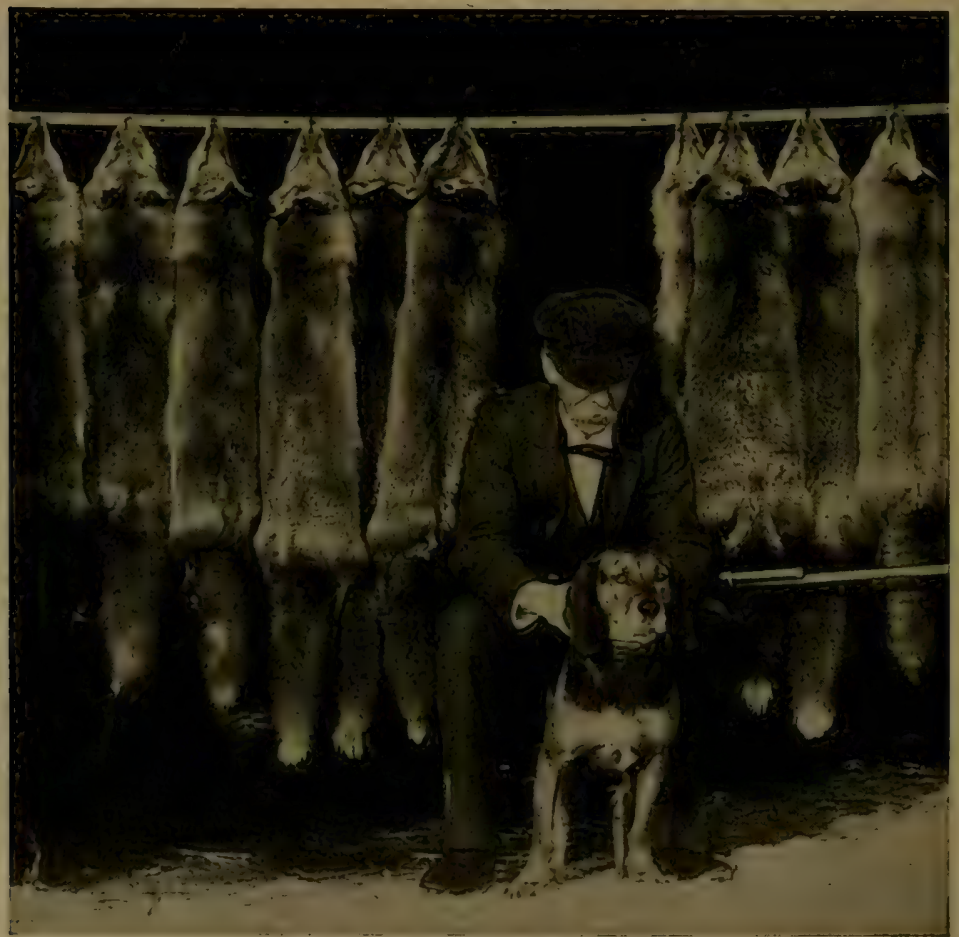

WELL HANDLED RED FOX SKINS 


\section{TRAPPING THE BEAVER.}

It was common for fur dealers to receive hundreds and thousands of beaver skins annually ten or more years ago, but of recent years the receipts are light, due to the rapid. decrease of the beaver in the states. Nothwithstanding the rigid laws and their prompt enforcement, the beaver will soon become extinct and the supply be drawn chiefly from Canada. WVe do not want to be unclerstood as saying there are no beavers left, as such is untrue. In some states beavers have increased during the past few years due to the rigid enforcement of the law. The killing of beavers is prohibited in most states throughout the season. However, it is only a question of time when civilization will force the beaver to scek others quarters, and as the animal is not inclined to migrate, quite often prevented, due to natural conditions, at other times killed by the hunter, trapper or farmer, the former for curiosity's sake, the latter to prevent the cutting of timLe: and to faciliate the natural flow of water, he will shortly become unlinown, especially in sections where the woodsman's axe tminovers the natural haunt of the beaver.

There are many ways to capture and kill this animal. The steel trap is preferred by trappers, while hinters use the deadly rifle to eradlicate the beaver and often without receiving any remumeration. Deadfalls, snares and other home-made cont:ivances are sparingly used in Canada.

To locate the beaver the trapper or hunter must look for him about streams, in timber that is rarely visited by man. Beaver dams and their houses are the true signs, and if the trapper has struck such a place and found dams and houses intact, he can feel assured that the animal is close by. He should appronch such a place with care, especially if in the winter or spring months. Trappers who have come in contact with the animal for years, state that at certain periods of the year when the beaver is repairing the dam, building houses or playing, pickets are put on guard who immediately notify the remainder in case of danger or the approach of man. The signals given by these pickets are well understood by the remaining family. Such a signal consists of the animals giving a peculiar sound from their mouth, a sharp splash with their tail and fect, and immediate cleparture for their abode. On hearing such a signal all others will instantly take to the water and disappear. Those that happen to be on land will leave everything and make for the water into which they dive and swim rapidly to their respective abodes. In a few moments thereafter everything is still, and one not familiar with such signals, would be astonished to find no sigr. of life. 


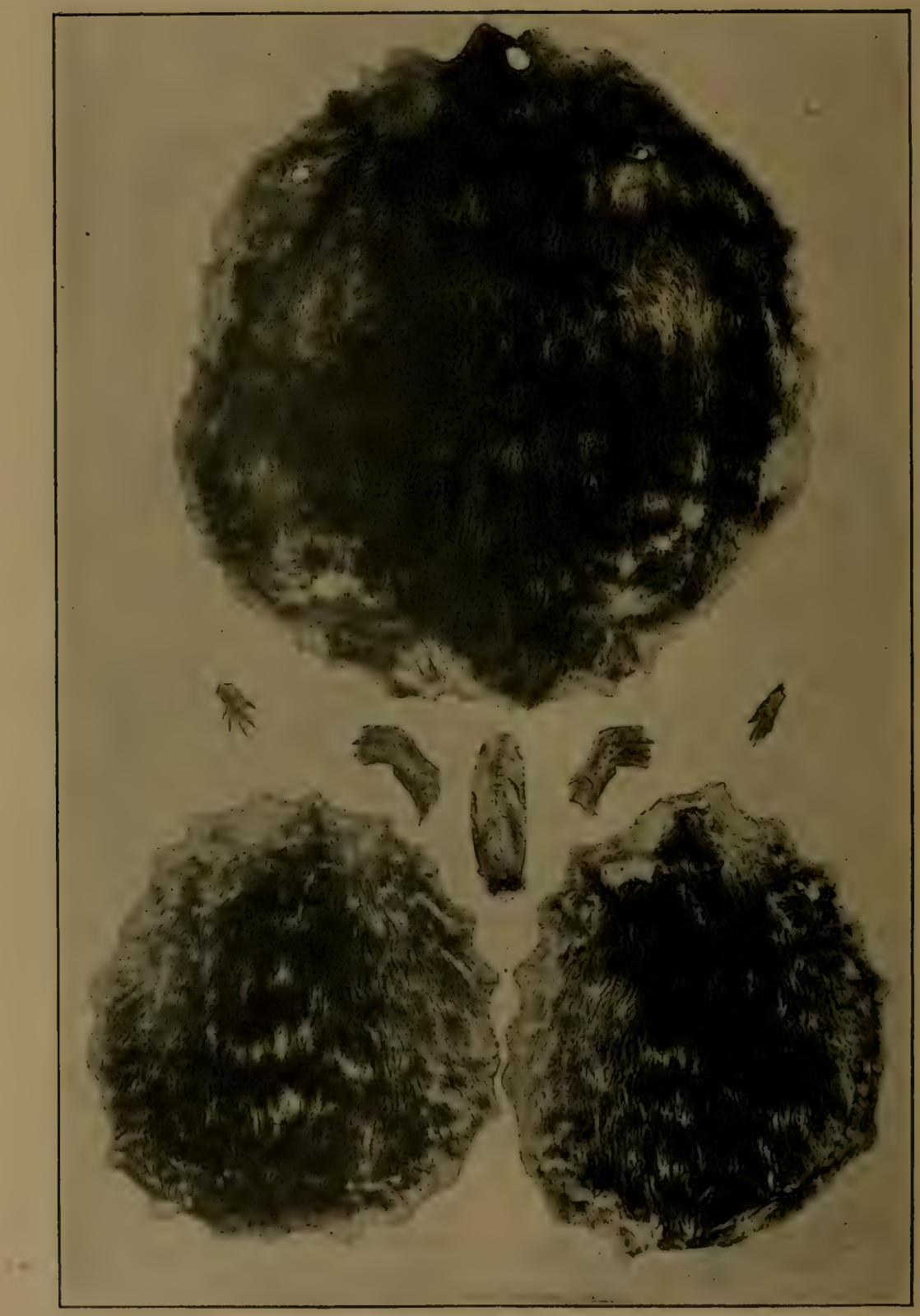

BEAVER SKINS 
Some trappers have been in the habit of spearing beavers while in their home. Others cautiously set steel traps at such points where the beaver is known to come from the water. The usual method is to set the steel trap in three to four inches of water at such places where the beaver comes out or enters the river. Cotton or other soft material should be placed below the pan and the entire trap be covered with sand or earth. The trapper must not leave any footprints, either upon the land or in the water, and to obliterate them a quantity of brush is tied together and such places where the prints appear are brushed over. After this operation the trapper usually takes his hat or cap and throws a quantity of water along the shore, so as to thoroughly drench the surroundings, which has a tendency to eradicate the human tracks as well as to eliminate the scent or odor of the trapper.

Elsewhere in this book will be found original articles from trappers, which are very interesting and should be digested by those interested in hunting or trapping the beaver. The castoriums should be saved, as they are adapted not only for attracting the beaver, but in fact, nearly all other animals like the smell of castorium or beaver medicine as some call it. The manner of making this medicine will be found under "Decoy and Trappers' Secrets."

Sliding poles should be used, unless one can make good use of a limb from a nearby tree or a young tree itself as a spring pole. The sliding pole, however, is the best, as the animal will drown in a short time, and be kept away from land animals. If a sliding pole is used, the pole should be dry, not green, and the bark should be first removed, otherwise the beaver is likely to carry the pole away for food purposes.

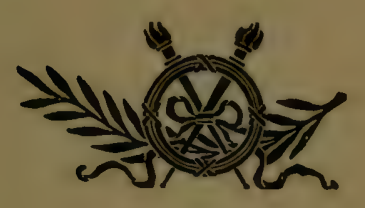




$$
11
$$




\section{TRAPPING THE OTTER.}

This aquatic animal is probably more hunted than any land or aquatic animal, due to the high price paid for their skins. The otter is found in many states and prefers rivers to lakes. Their homes are made along river banks and the animal makes a practice of migrating from one stream to another. As the mother retains the young for a period of two to three years, it is common for trappers to see as many as 8 or to otters in one vicinity. Their rambling and gregarious habits are especially noteworthy when migrating from one stream to another, one following the other in a path, and sometimes a line of march covers many miles, one following the other at a distance of 5 to 20 yards. It is remarkable that the otter is able to choose the shortest line in his travels.

About their playgrounds, if the banks are 8 to I2 feet high, one will see the so-called otter-slides, and it is generally about these places that the trapper sets his traps; the latter should be attached to sliding or spring-poles. These slides are usually between some trees or bushes giving protection from the sun. The practice of otters is never to walk on or near these slicles when ascending the shores, but usually choose a place where the bank has a gradual elevation on which to ascend, and thus walk to the slicle. The otter will usually rest a few minutes before descending, and many trappers place their steel traps on the highest elevation of these slides, and as the otter gets into position. becomes the victim. Such traps should be attached to strong spring-poles. The otter will usually slide down into the water with all available force and swim under water for a considerable distance, only to regain the shore and repeat the former operntion of descending the slide for another plunge.

Trappers should not be disappointed in case otters do not make their daily appearance about the slides, for possibly they have migrated to other streams and will return in the course of five to ten days. These excursions are made quite often, both during the summer and winter.

There are many ways to trap or capture them, and as they have subterranean passages, the entrance usually being 15 to 20 inches below the water level, traps should be set there. Many trappers use claw-traps, which are set in center of slides, but the most experienced trappers will set their traps at places where the otter usually starts out of the water and makes for the slide. The usual method is to set steel traps, one on each side of the path, not in the center: thus the otter, in passing upwards, will most likely be caught by the right or left foot, and sometimes with both. Traps placed on the bottom, where the otter comes 


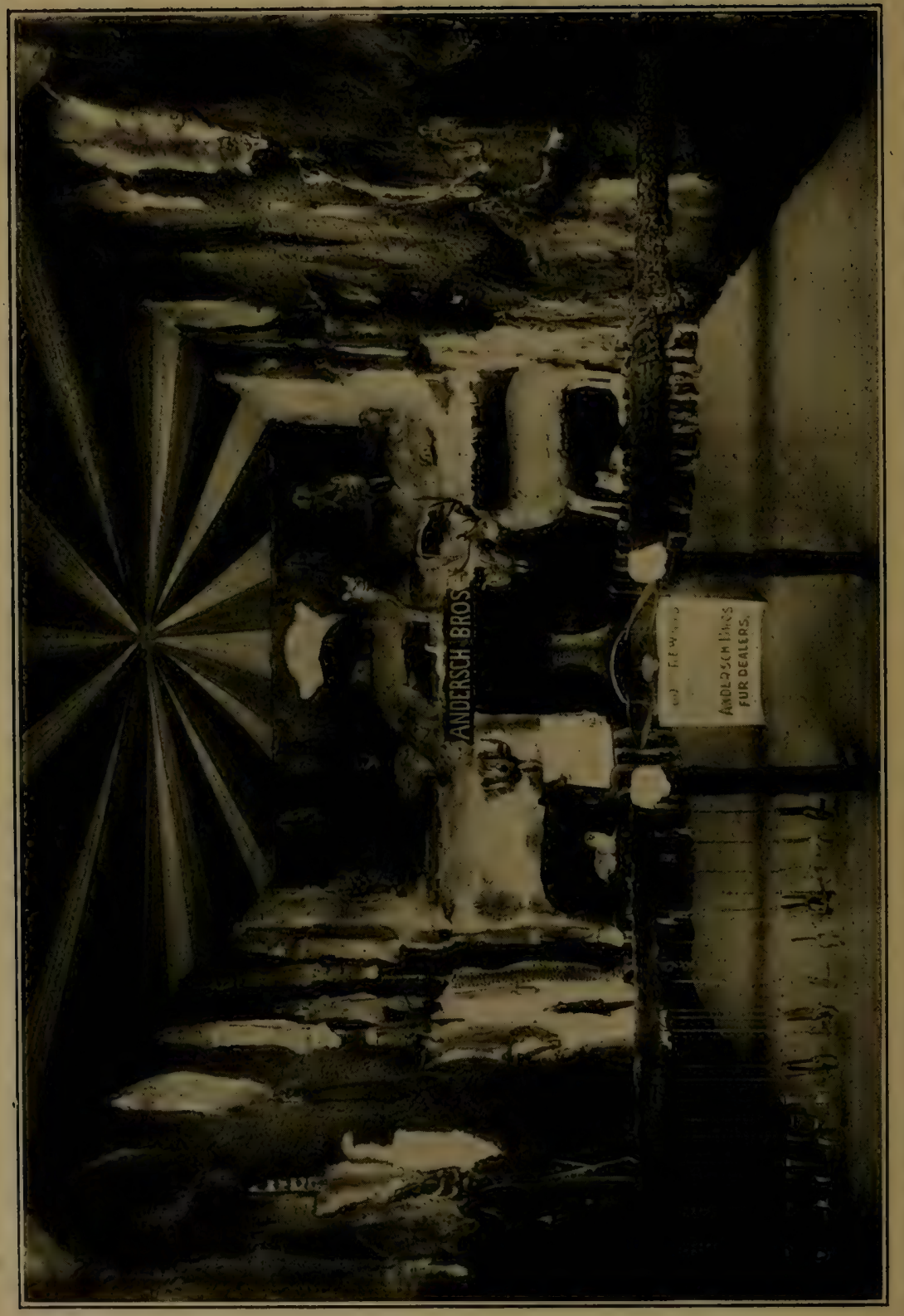

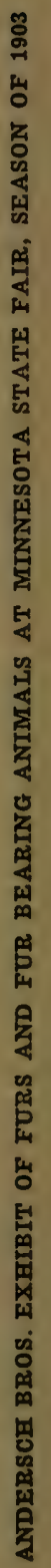


out of water, should be attached to sliding poles, as the animal should be drowned in the quickest. possible time. No. $21 / 2,3$ and $3^{1} / 2$ Newhouse traps, or other makes similar in size, are commonly used for otters. All traps should be buried in the usual manner, some cotton, leaves or similar substance should be placed under the pan.

It is more difficult to set traps beneath the ice, but by following closely this method one should be successful. If the trap is to be set about or in airholes, attach the chain to a long pole, which should necessarily stick out three or four feet over the ice, have one end securely driven in on the bottom. The chain can be attached by wire or by inserting the pole through the ring before it is driven into the ground. To prevent the chain from slipping off from either end, one should drive a wooden pin through the pole, the chain should traverse the entire length of the pole loosely. A suitable platform should be made on which trap is to be set, and covered over with evergreens; this shelf or platform should be securely fastened to the pole so that the trap when set is 6 to Io inches below the ice. Some trappers wind the entire jaws of the traps with evergreens, also the springs; thus, when the otter comes to the hole to obtain a fresh supply of air, its front feet will rest on the trap, and if the latter is placed correctly, the animal will become a victim. The otter, after struggling under water for a reasonable length of time, will drown.

The pole should naturally be driven very securely into the ground, and it is a good policy to attach the outer end of the pole to a rope or wire; thus, should the pole become disengaged from the bottom, the trapper will be able to pull up the pole by the string, and naturally the victim will come along.

As this animal possesses an unusually fine sense of smell, it is seldom indeed that a trapper is able to observe the otter at play or even see it plunge into the water, but if one is fortunate to gain the desired location, he will naturally see the otter come out of the water, ascend the bank, pass to the slide, and then with all its might and force plunge into the water, and while under water will swim considerable distances, its route being noticed by the air-bubbles.

Steel traps should be set under water or under the ice near the shore where the depth does not exceed two feet. The usual custom is to set the traps in a nest of three to four. It is always a good policy to set traps below the airholes, providing the depth of water under the ice is from one to three feet; in either case, the traps should be covered with evergreens and attached to a sliding pole. 


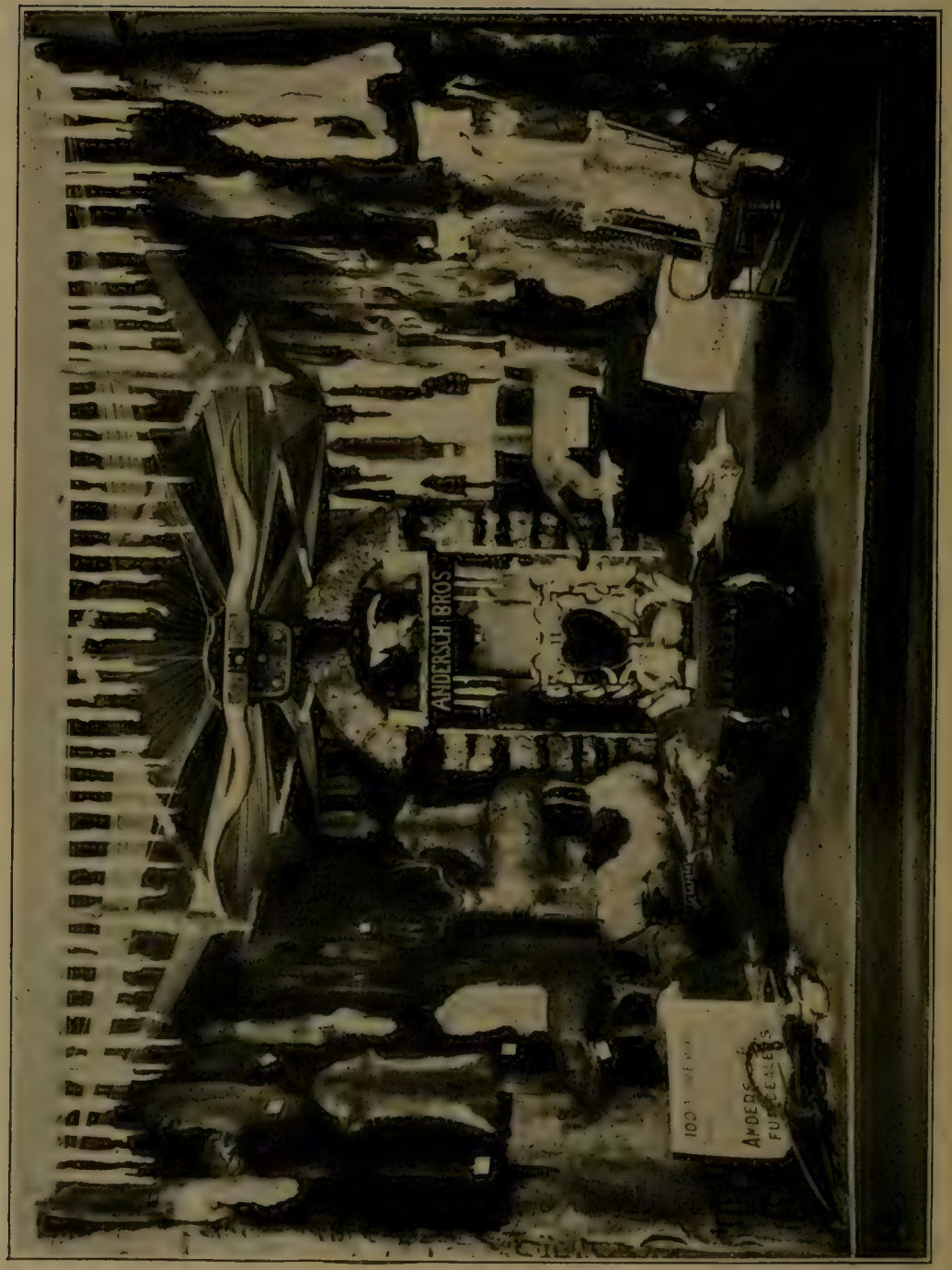

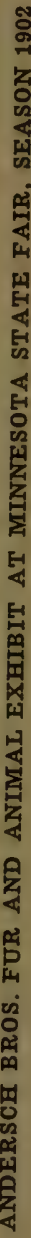


A certain Wisconsin trapper, during the '7o's, was very successful in catching otters by nesting his traps about the airholes, he attached a stone weighing 6 to 8 pounds to each trap, also a I $5 \mathrm{ft}$. long wire to some stationary object upon the ice. The otter having sprung a trap, would drag trap and stone away from the air-hole as far as wire permitted, and shortly drown. The other traps would remain intact. The trapper, upon finding a trap disarranged, would pull that particular wire, thus bringing the trap, stone and otter to the surface. By the use of this method he caught as many as three otters in one day.

Hudson Bay trappers prefer to set their traps under water, and visit them in a boat.

A certain half-breed informed the writer that he caught many otters with snares. The latter were set about the inner edges of the air-hole, just one to two inches below the ice, being held in place by thin cords weighted down, also by sticks driven in the ice. Such snares should be attached to a stone, probably weighing eight to twelve pounds, and sufficient to hold and drown the animal. In case the water is too shallow, a spring pole should be used. If one is unable to secure a proper spring poie suggest the use of a weighted pole; see illustration elsewhere. Heavy copper or brass wire should be used in all instances, as otters have been known to become caught in such snares about the body, just below the forefeet, therefore it takes a strong wire and proper weight to prevent escape.

In tl:e springtime, when the ice is gone, otters can be chaserl with dogs, especially where more than one otter is seen. The usual custom is to place heavy seines across the stream preventing escape from ascending or descending the river, and when the otter rises to obtain air about the seine, they should be killed by using a rifle.

Mr. Richter relates that in Schottland dogs were used to drive otters for long distances. A seine is similarly stretched across the river, and when the dogs bring otters, up or down stream, as the case may be, another seine is stretched to prevent escape, thus hemming the animals with the dogs between two seines. Men with spears or rifles dispatch the otter 3 in quick succession. The dead bodies cannot escape by floating, but usually the dors are trained to dive and bring the bodies out should they fail to appear on top the water.

During the winter time, if the paths of otters are discovered, it is advisable to set a bunch of traps on the paths, as the probabilities are the otters will come back the same way, and if the traps are properly set-that is, the pan about two inches from center of paths, most likely one or two animals will be secured. Spring or weighted poles should be used. 


\section{HOW THE SEA OTTER IS CAPTURED.}

Peculiar methods are adapted to capturing this animal, and in the attempt many hunters lost their lives, but seemingly others are ready to assume the unfinished work of the former.

Capturing this otter in mid-sea is out ji the question, and as they possess gregarious and rambling habits, hunters usually await the opportune time, when the ramblers are about one or two miles from the shore, as many as I 5 to 20 boats, each containing two or three men, one being provided with a rifle, the other with a spear or harpoon, and the third generally managing the boat. The boats usually go out in rows, following one after another, stretched out as long as a mile. If any one sees an otter the proper signal is given and a circle about the animal is formed; naturally the otter will disappear, but on its next arise the riflemen will discharge their rifles, so the bullets will strike to to 25 feet from the animal, thus preventing the latter from obtaining fresh supply of air. On its second descent one or two of the boats leave the circle, these generally contain the best harpoonists. All are still awaiting the next arise of the animal when he is promptly disturbed and prevented from breathing in a fresh supply of air, either by the discharge of the rifles or by splashes of the oars. If not too far, the harpoonists will attempt to spear, but if unsuccessful the former method of preventing the animal from obtaining air will finally triumph. If not killed by the harpoonists the otter will drown, due to lack of fresh air. It often requires two to three hours to capture one animal.

It is very seldom, in fact, extremely so, when anyone can approach this animal in a boat while the latter is on the shore and a target for the hunter. Their sense of smell, sight and hearing is very fine.

During stormy weather hunters attempt to capture the otter on the windward side of the ocean, as the animal, during such storms, generally seeks shelter on the shore, and sometimes travels quite a distance from the water. The hunter is able to approach the otter unusually close, as the noise of the wind and the restless waves deafen all possible sound of their approach, or even the discharge of the rifle, should the aim be poor, is unheard or unnoticed.

On the Asian coast, as related by Steller, as many as 75 otters were killed on one occasion. The otters, in this instance, reached shelter during a furious storm by landing on the shore. A number of hunters provided with clubs chased them further inland, and when escape was made less possible a number of them preceded and clubbed the otters to death, the remaining 
guarding the outward passage. While the otter is generally considered dangerous, these men dispatched them with remarkable ease; a single, stout blow on the forehead caused the otter to place the two forepaws over the head, and another soon puts them out of misery.

The use of steel traps is little resorted to, as the sections of the coast which the otters frequent is generally uninhabited, therefore would be unprofitable, especially as the landing of the animals is an uncertainty, both as to time and place.

Mr. Anderson, an experienced seal hunter, states that the reason such a small number of sea otters are killed is because their habits, as to time and place of landing is uncertain, also the number of the animals is insignificant as compared with the seals.

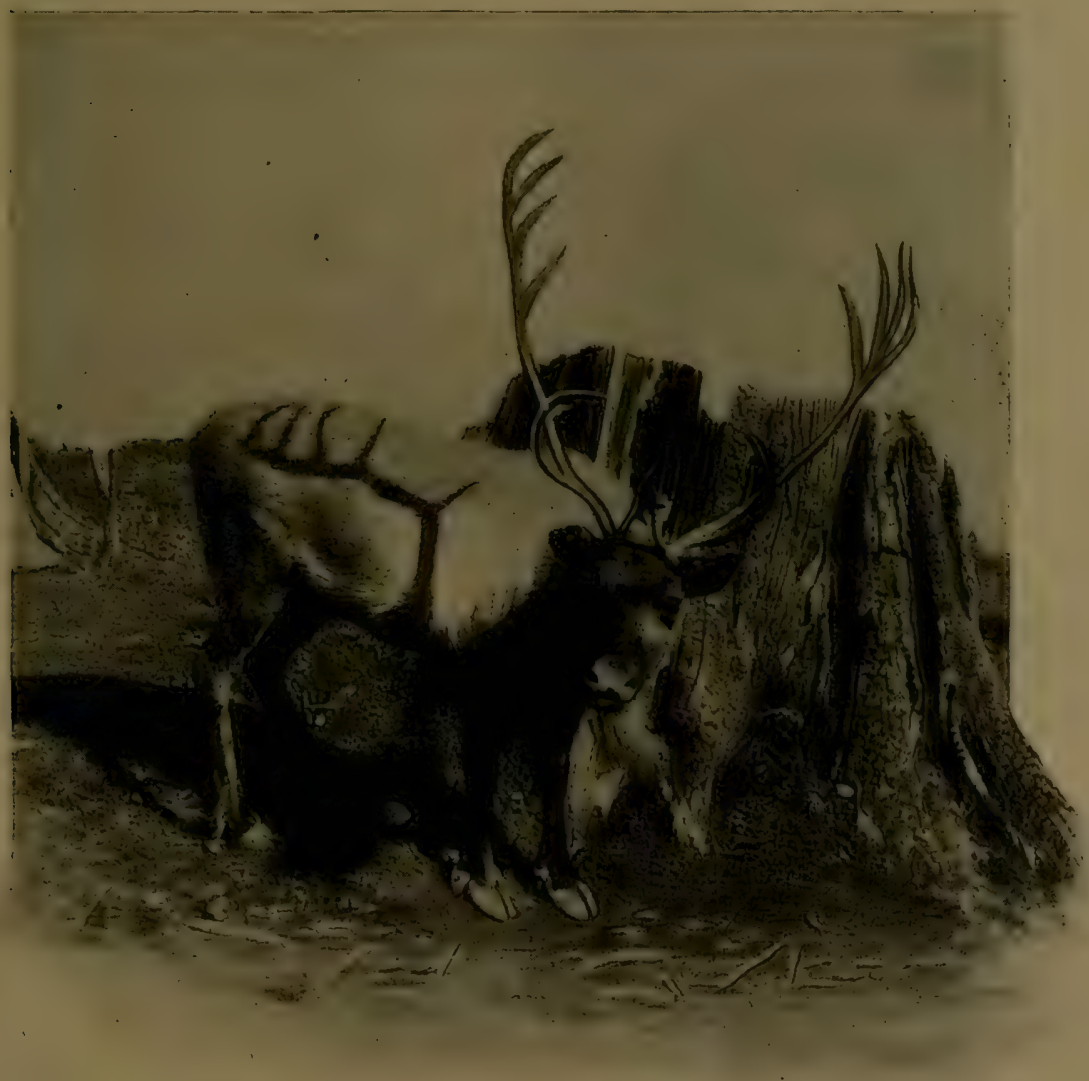




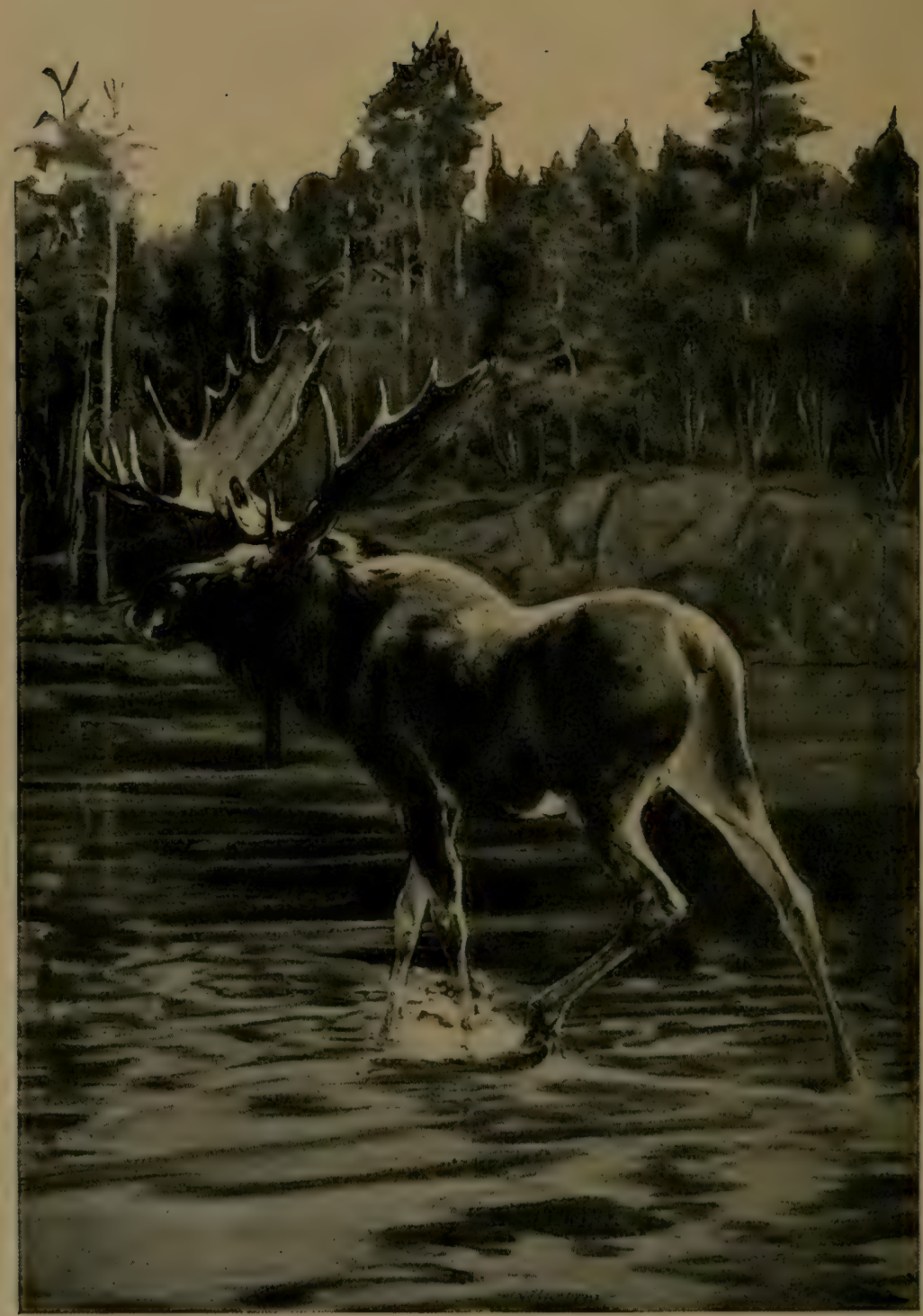




\section{TRAPPERS' SECRETS.}

\section{How to Prepare and Use Decoys, Poison, Bait, Scent, Lure, Etc.}

\section{NOTES ABOUT TRAPPING.}

The trapper or hunter who has made a study of the habits of fur-bearing animals is the one who will succeed. He knows their habits, their run-ways, distinguishes their tracks, knows where to look for mink, marten, raccoon, wolves, foxes, otter and other animals, and naturally places the right-sized trap, the proper spring or sliding pole, the proper size clog or drag, the necessary weight for deadfalls, and last but not least, knows the right time to capture the animals.

Keep your eyes peeled, ears open, make least possible noise, be always prepared to use your rifle at a moment's notice, keep cool, don't get excited, examine where you go, note surroundings, act promptly but not without deliberation, provide yourself with necessary clothing and food, don't get in too much of a hurry, and remember above all that your health is better than your wealth, and treat your brother hunter or trapper as you would have him treat you.

$\mathrm{Be}$ on the lookout for signs of game, ascertain cause of flight of birds, note sudden noise or disturbances, and when you follow animals do so against the wind if possible.

Ascertain where game frequents, follow tracks, as they are likely to lead to some den or watering place, and note carefully signs of a previous struggle or feeding place. By all means convince yourself what animal you are following. This you can do in many ways; size of tracks and their nature, length of steps, object of animal, location of its travels, size and quantity of its manure, size of den, whether it can climb trees, also if dens are visited look for hairs on sides. After you have established the kind of animal and know its habits, it is an easy matter to set your traps. Keep in mind that certain animals seldom go over the same route unless something is there to attract them. Feeding places are visited tens and hundreds of times, if not by the same, by other animals possessing carnivorous habits. If many tracks are visible and you are unable to set your traps at a suitable location, make some artificial abode, or set in one of the paths, drag bait or previously captured game in various directions leading to concealed traps, and invariably leave bait close to traps. By all means leave the surroundings in a natural state and visit your traps as often as possible, and if unmolested do not approach them. 
SOME RULES AND REGULATIONS ON TRAPPING.

Prepare traps, decoys, stretchers, and pick out trapping grounds one to three months in advance.

Start to trap when the weather is real cold-never before November-better wait until $\underset{*}{\text { December. }}$

Stop trapping in the spring as soon as the skins begin to get red, and the fur thin, pale and shedding. The skin is generally thick when the fur is thin.

Remove the skin promptly from the animal unless the carcass is found in a frozen state.

If time permits educate fur-bearing animals to visit places where you intend to place your traps. ${ }_{*}{ }_{*} *_{*}$

Post yourself thoroughly in manner of skinning, and how skins should be $\underset{*}{\text { prepared to bring }} \underset{*}{*}$ best $_{*}^{\text {prices. }}{ }_{*}$

Don't try to fool buyers by overstretching a skin. They know their business and are not blind, besides overstretching hurts the skin.

Keep furs away from artificial heat and from the sun. Rapid drying by the stove or sun is not desirable, and tends to curl tips. Hang furs in a cool and shady place.

Do not cut off ears, nose, or mutilate the skin, and if accidentally cut, sew portions together before drying in Indian style.

Skunk, opossum, raccoon, mink, and similar animals can be smoked out of their abode by the use of sulphur or brimstone.

Never dry skins by the fire or close to artificial heat, neither expose them to the sun.

Never make a practice of handling traps with the bare hands, especially when about to set them.

Scrape all fat and meat off the skin before drying. Skins should be stretched shortly after being scraped and while yet very green. Give the skins as much as possible their natural size and do not overstretch any particular part. 
Do not attempt to set large traps without two clamps; it can be done but is a foolish piece of business for a trapper to attempt, especially if alone.

$$
* \quad * \quad * \quad * \quad * \quad *
$$

Never go it alone, especially if you expect to be away one or more weeks. Share your luck and experience with a good trapper. A good dog is the next best companion.

* $\quad * \quad * \quad * \quad * \quad *$

Furs caught in season, properly handled, and marketed during the months of December, January, February and March will command best prices.

\section{DECOYS AND POISONS.}

\section{(Trappers' Secrets.)}

The list below gives names. of various oils-natural and artificial — used by hunters and trappers. Elsewhere in this book will be found how the oil is used, when and where applied.

\section{Artificial 0ils.}

Oil of Fenugreek.

Oil of Asafetida.

Oil of Valerian.

Oil of Anise.
Oil of Amber.

Oil of Lavender.

Oil of Rhodium.

Oil of Cumin.

\section{Natural Musk.}

Oil of Beaver from Beaver. Oil of Mink from Mink. Oil of Otter from Otter. Oil of Musk from Muskrats.

\section{Fish 0il.}

This preparation is made by cutting up various sizes and kinds of fish into small pieces, placing into a bottle and exposing same to the sun, loosely corked. In about 3 to 4 weeks of continued exposure the contents should be pressed through a sieve, separating the oil, which should be run into a bottle having a small neck. The smaller the fishes the better the oil.

If fish oil is unobtainable and the trapper should run out of this preparation, purchase sardines and use them as bait, or make oil therefrom. A small ten cent box will go quite a ways. Salmon is also very good. 


\section{Matrix and Urine from Animals.}

Matrix and urine from the female fox, wolf and dog during period of coition makes an excellent bait for wild animals of the dog family. This preparation in order to retain the odor should be tightly corked up and used similarly to other artificial and natural oils.

Matrix from the female mink or marten taken from the animal during the copulative period is probably the best attraction for the male species. Capture one or more females, dip or hold rear parts into sweet oil or alcohol, later kill the animal, cut out the sexual parts, place all into a bottle which cork tightly. Smear beyond or about the traps.

\section{Poison.}

Sugar of Lead.

Strychnine.

Arsenic.

\section{Poisoned Eggs.}

To kill animals that frequent the henroost to devour eggs, also those that rob the nests of wild birds, as well as for baiting traps, snares, etc., procure one or more eggs and bore a small hole with a wire or gimlet in one end, into which insert strychnine, and paste hole over with sticking plaster, paper or egg shell.

Some animals refuse poisoned meat and vegetables, neither can they be caught as promptly as desired with traps, snares and other contrivances, and their suspicion is seldom aroused if these prepared eggs are laid in some conspicuous place, in a nest-natural or artificial-or in their paths, under bushes, outhouses, barns, and, in fact, any place where these animals frequent. Trappers often place these poisoned eggs under a dead chicken, other times in nests of wild birds. Farmers who are desirous of catching their neighbor's dog in their chicken coop can apply this method of stopping the thief and prevent a revisit.

\section{Capsules.}

Equal parts of the following poisons in 2 to 3 grain capsules for skunk, mink and small animals, and 4 to 5 grain capsules for wolf, fox and similar sized beasts are used with success by leading trappers. Insert poison into meat, also vegetables:

One-half of powdered arsenic. One-half of carbolic crystals. 


\section{Decoy.}

Dung of any species, also their urine will attract like kind.

Place urine and dung in a bottle, cork tightly and use small quantity at each setting. This decoy is especially good during the rutting season.

\section{Fox and Wolf Decoy.}

3 oz. Urine of a dog, fox or wolf (female preferred).

I oz. Oil of valerian.

Mix well, use 5 to Io drops on stake, stump of tree or protruding rock. Fox, wolf, in fact all animals of the dog kind, are attracted by this decoy and will urinate. Set traps 12 to I4 inches from trunk of tree. Bury and cover traps in the usual way.

\section{Mink Decoy.}

$1 / 4$ Musk of Mink.

$1 / 4$ Matrix of Mink.

I/4 Musk of Muskrat.

$1 / 4$ Oil of Cumin.

Mix well. If too thick add urine of the female mink or alcohol. Keep corked. Use few drops.

\section{Coyote or Fox Bait.}

I oz. oil of cumin;

I oz. oil of rhodium;

$1 / 2$ oz. asafetida (grated) :

Wart of horse, size of hickory nut (grated).

Alcohol to cut and make compound to consistency of dough. Place in wide necked bottle, $6 \mathrm{oz}$. or larger; keep corked. Use in two or three weeks. Smear small quantity close to traps on some stick or bush.

\section{To Overcome Smell of Iron.}

To overcome the smell of iron as well as human scent, nothing is better than a mixture or compound made out of catnip. Mink, fox and nearly all other animals are familiar with the peculiar catnip odor; and if this compound is smeared over the traps and hands, all strange odors are overcome. The animals, being familiar with the odor are not suspicious.

Procure a quantity of catnip and mash it between stones or in some old mill and add enough liquid to make a thick paste. Place this into a screw top can or bottle, use when you want it.

\section{Mink Scent.}

$1 / 2$ oz. essence of peppermint.

2 oz. fish oil.

2 oz. honey. 


\section{Mink Bait.}

$1 / 4$ part musk of muskrat, $1 / 4$ part musk of mink, $1 / 2$ part alcohol. Keep corked up in warm place ten days before using.

Fox Musk.

Musk taken from the glandal sac of the fox is excellent for attracting like species. Use this musk as you would the musk of beaver, muskrat and other natural decoys. It is an undisputed secret held sacred by old trappers that natural musk will attract its own kind of animals quicker and from a greater distance than any other preparation. It is also necessary to use the utmost care in trapping for sly Mr. Fox.

\section{Oil of Otter (Musk).}

This is obtained from the animal by extracting the substance from the two small glands on the belly of both sexes, often called oil stones. This natural oil is used by experienced trappers with splendid results in attracting these species.

\section{Manure or Dung Bait.}

Obtain manure or urine of the animal that you seck to capture and if this is unobtainable, procure the droppings of the domestic dog, but what is still better, from tame foxes or wolves. Droppings from the sheep are also handy and of good avail.

\section{Musk of Beaver or Beaver Medicine.}

(The following four formulas are natural baits and will fool the oldest beaver and other animals.) Make cold and preserve in a large-neck bottle.

(I) Castors of one beaver, 20 drops oil of cinnamon, Io drops oil of anise,

Urine of beaver sufficient to make the consistency of mush.

(2) Castors of one beaver,

7 drops oil of sassafras,

7 drops oil of anise,

Io drops oil from the oil stone.

(3) Castors of one beaver, ro drops Jamaica rum,

5 drops oil of anise,

5 drops oil of cloves,

5 drops oil of sassafras,

5 drops oil of rhodium,

(4) Castors of one beaver, Io drops oil from oil stone, 
Urine of beaver sufficient to make all the consistency of mush.

\section{Mink Scent.}

A Pennsylvania trapper writes as follows: "Take two or three scent bags found at the root of the mink's tail and place them in a 3 or 4 -ounce large-necked bottle, over which pour $\mathrm{I} / 2 \mathrm{oz}$. of oil of anise; fill remainder with water. Now take sharp knife or chisel and cut bag into as many pieces as possible. Cork up and leave stand in warm place. Do not permit it to freeze. This is a good scent for capturing mink and similar animals. Have had best of luck and can recommend it to any trapper, and I feel confident that he will be successful in attracting mink.

\section{Mink Decoy.}

"This bait is especially adapted for the mink during their running season. It is prepared as follows:

"During the fall months, or in fact any time that I have occasion to capture a mink, I remove the animal's scent bags, which are placed within a 2 oz. bottle into which I pour I oz. of alcohol and Io drops of oil of anise. Cork and let stand in a warm place. Two scent bags to I oz. alcohol and Io drops of anise is correct; larger quantities in same proportion can be made."

\section{Secret Method.}

"My method and secret of success is to wrap the jaws, springs, pan and every portion of the steel trap except the trigger, with withes (hemlock preferred). Even the wire traps are wound around with these withes by me. On the ends and edges to hold withes from coming off. I tie with waxed thread. This method removes the smell of iron and I do not have to cover up sets so heavily with earth, as the traps already resemble the surroundings very much. Of course, I remove the newness of my work with damp dirt which is rubbed or smeared into the covering. Probably if smeared with wax tallow and a little castorium, the setting would require no bait or other decoy, but I have never tried it.

Jess McArthur.

\section{Natural Mink Scent or Lure.}

If one is successful in capturing a female mink when the animal is in heat, do not injure or kill her, especially if the animal's scent to attract the male to the trap is desired. Obtain a pint of pure sweet oil, and dip her hind parts into the oil and hold her therein for Io or I5 minutes. Immediately thereafter 
place the oil in a bottle which cork tightly. A few drops sprinkled on the twigs or in the vicinty of traps, or place four or five drops on a leaf and place it in abode beyond the trap or in a hollow log.

The trapper who favored us with the above claims to have had success, and gives good reason for believing that this natural scent is much stronger than that obtained from the dead mink. No alcohol is to be added and if the preparation is to be kept over the summer months, it should be placed in an ice house and kept there, otherwise in the lowest possible temperature.

Perhaps after obtaining the natural scent from the animal in the above method, it would be advisable to kill the mink and by removing that portion of the animal and placing it in a bottle in connection with alcohol, one would be able to ascertain more positively, especially if used in connection with the first named preparation, as to which is the best. If the latter preparation is to be made place parts into a wide-necked bottle, holding three to four ounces, and fill with alcohol.

FRED O'FLYNN.

\section{My Favorite Fox Scent and Bait.}

"I prefer skunk, woodchuck or muskrat for bait. These I cut into small pieces about as large as an egg. This preparation is made during the summer months, placed in a clean screw-top can and exposed to the sun so as to become tainted. The scent that $I$ use is made out of pure skunk glands, pure strained honey (not sugar-fed honey, but clover and flower honey.). This scent is especially good for the fall months. During the winter months I obtain the matrix from a female fox taken during the animal's running season, and in addition to this I take the musk of two or three muskrats and a small quantity of pure strained honey. Mix these well together and I assure you that same will attract the male fox and is probably the strongest scent in existence. I have also had good success in trapping foxes with scent made out of frog eggs; mix with the musk of muskrats and glands of the skunk. I wish my brother trappers best success."

G. W. O.

\section{How to Make Decoy to Capture Foxes, Wild Cats and Other Animals.}

Mr. J. H. Van Ness, a Michigan trapper, gives us the following secret and claims to have been very successful whenever the bait or decoy as stated below is used:

"Remove from the legs of horses a piece of cork. A piece the size of an ordinary hickory-nut is sufficient to make one 
pint. Cut or shave this piece of cork into small shavings and put same into a pint of lard, also place a piece of asafetida as large as a bean therein, and cook these three articles together. Let them boil for several hours over a slow fire. Stir continually and keep shavings from settling. A peculiar, strong odor will arise just as soon as boiling begins; the women folks will leave the room and the dog and cat will begin to sniff and smell. After it has boiled for two or three hours remove from the stove and permit to cool.

"Smear this preparation above or about the traps, but never upon them. The fox, wild cat, and even the domestic dog as well as cat, is likely to enter the trap. This bait will attract these animals from long distances. It is very powerful, and, as aforesaid, has always been very successful.

"I usually wear gloves in handling traps preparatory to setting them, also boil my traps or bury them for a few days in order to remove the smell of iron."

We are indebted to Mr. C. A. Beeh, an Iowa trapper, for the following decoy that he claims to have used and continues to use for trapping mink, wolf, fox, skunk and other carnivorous animals. The following formula is based on a pint of preparation:

"Take a pint fruit jar and fill one-third full with blood. Blood from domestic animals will do, especially from calf, dog or hog. Add the following: 2 teaspoonfuls or 2 fluid drahms oil of cinnamon; 2 teaspoonfuls of powdered asafetida; 2 teaspoonfuls oil of cloves; grind a nutmeg or pound it between rocks so that it is very fine, and place in the mixture; fill the remaining part of the bottle with alcohol or whiskey; mix thoroughly. Boiling is unnecessary. Keep bottle corked up for at least 5 to Io days and then run through a cloth or thin sieve. After it is strained, return the liquid in any kind of bottle and throw away the thick stuff. Before throwing away the thick stuff be sure and squeeze all the liquid therefrom.

"This preparation should be used in similar manner to other good preparations by smearing above or about the traps. Being very powerful, it will attract animals for a great distance."

\section{Honey-Bait.}

This bait is commonly used for bears. Save Mr. Bear the trouble of climbing trees and give him his heart's delight. Place this bait near the steel trap, snare or deadfall, or within and about the dugout. Take a quantity of honey, place in a vessel, add one-tenth part of beeswax and a few drops oil of anise. Place pan upon a stove and allow to come to a boil. Stir fre- 
quently to prevent burning or becoming settled. This preparation, after it is cold, can be used in various ways. Some trappers cut up a dried sponge, attaching each small piece to a wire or string and permitting the sponge to become soaked with the preparation. The object of attaching the wire or string is that the sponge may be conveniently tied to trap or thereabouts. Never smear traps with this preparation, unless you want to catch the bear by the head, and that certainly is not desired. If traps are set close to brush, smear the bait on latter, about four to five feet above the ground.

\section{How to Kill Wolves and Foxes with Poison.}

In the Dakotas, Montana, Wyoming, Colorado, Idaho, western and southwestern states in general where wolves are still in large numbers and often roam in herds, and where hundreds of cattle, sheep, colts, and other domestic as well as wild animals are annually killed by the wolf, it is the prevailing custom that an entire dead carcass be poisoned. Usually the carcass is dragged out upon the open prairie on some high knoll or hill. Thirty to fifty incisions at various places on the body are made with a knife into which pure strychnine is inserted. It takes a large amount of stychnine to poison an entire carcass, so that when wild beasts partake of a few mouthfuls of the poisoned meat sufficient poison will get into their stomachs to produce death. It is also advisable to cut off small pieces of about one inch square into which a small quantity of strychnine is placed, and the pieces strewn about the body. The bodies of the wolf and fox are usually found at a distance of 20 to 40 rods, sometimes in the immediate vicinity of the bait.

Other trappers cut the carcass into small pieces and insert strychnine in good-sized quantities therein, then distribute the poisoned bait on the open prairie where wolves and foxes are known to run.

If strychnine is inserted in chopped meat-the latter made into round forms and then permitted to freeze-and strewn about, the fox or wolf is very likely to swallow the entire bait, resulting in almost immediate death.

Trappers who are desirous of using poison to affect the death of game generally procure rabbits, birds and other small animals which they cut into small pieces. A liberal quantity of strychnine or other poison is placed in the middle portion thereof. The pieces need not be large, usually one to one and a half inches round or square. The fact that bait smells strong and rapidly decays is no great detriment, sometimes the wild beast will prefer these decayed pieces to fresh bait. While some 
trappers insert the strychnine in capsule form, others believe that strychnine will act more promptly and with better results if inserted in the old-fashioned way. As foxes, wolves and other animals are very suspicious they will often water upon the bait, other times smell it, but generally when possessed with severe hunger will partake of some-much to their detriment. Usually these animals visit some knoll, hill, or high elevation and scrutinize the surroundings with the utmost care. Therefore, if the bait cannot be strewn upon their paths, it is advisable to place same on some high elevation as above stated.

\section{Decoy for Wolves.}

If you have tried everything and cannot get the wolf to the trap, try the following: Obtain the bladder from a dog or wolf (either sex) which empty in a jug or bottle. If your traps are already prepared in the form of a cluster, take a piece of porous wood and pour the contents of the jug over it, saturating same thoroughly. A Montana trapper assured us that he has succeeded in capturing hundreds of wolves in his time. After he caught the first wolf he always saved the water from the animal and used it in his next set. This same party caught enough wolves to help him pay off the mortgage on the ranch. The bounty and the skin, not only in Montana, but in other states, amount to considerable money. This method is certainly worth trying.

\section{Fox Bait.}

A mixture made of the following has been successfully used by various trappers. Take all or part of a muskrat carcass and place within a screw-top jar, one holding two quarts preferred. Then take the fat of the skunk, also the scent bags. Procure three field mice and place entrails of same within the can. Screw lid on can, not too tight, and place in a pile of heated manure and leave for two or three weeks. This mixture should be well stirred before it is placed in the pile, but thereafter the can should be kept closed as much as possible. When one has occasion to use this preparation, take a stick and smear this within the abode or at other convenient places to which the fox or wolf is to be attracted.

\section{Mink Bait.}

Mr. O. G. Wells states that he ties a live crawfish with thread to the pan of trap. Tie thread to each arm, close to the body, but not in the joints. Then tie both threads together and fasten body to pan so that the fish will be able to move but not off. the pan. The trap should be set in shallow water 
close to the shore, and the bait should almost reach the level of the water. As the mink travels along the shore in search of food he will see the bait, and in endeavoring to remove it with his foot will spring the trap and become a victim.

\section{THE SLIDING POLE, SPRING POLE, CLOG, DRAG; HOW TO MAKE AND USE THEM. BY EXPERIENCED TRAPPERS.}

The sliding One of the best methods employed to prePole. vent aquatic animals from escaping, either by gnawing or twisting their feet off, or from being devoured by other animals, is to use a sliding chain or a knotted rope. To use either of them the water must be deep.

The sliding pole, which is made out of a green sapling, securely fastened on shore, the smaller end being in the water, is very good. The weight of the chain and trap is sufficient to drown the animal after his first struggle to free himself.

Spring A green sapling or limb of tree, to which the

Pole. chain is fastened and the end firmly held to the ground by a notched stake, is preferable to anything else for land trapping.

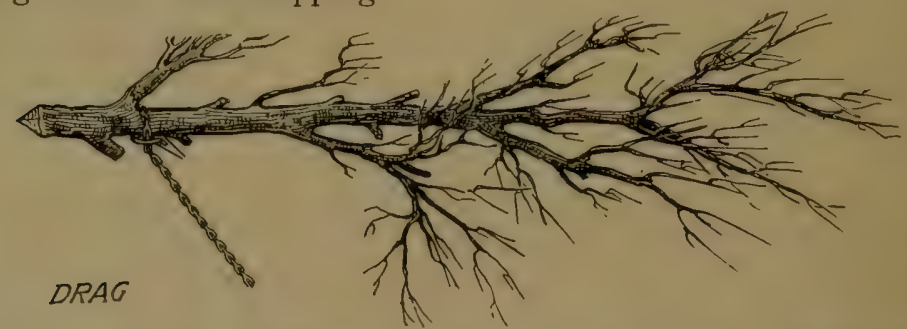

$\begin{array}{cl}\text { Clogs and } & \text { Should be used when spring pole, sliding pole } \\ \text { Drags. } & \text { or cliains are unllandy or cannot be obtained. On } \\ \text { some of the larger traps one will find a three or }\end{array}$ or four pronged hook to act as a drag, attached. The weight of drag or clog entirely depends upon the size of the animal and that of the trap. An old limb of a tree makes an excellent drag, one which can be followed very easily. Quite often the animal becomes tangled up. Stakes should not be used unless on the open prairie where wood is scarce and drags of that kind unobtainable.

Weights Attached to Traps.

A successful trapper knows the importance of drowning the animal after he has sprung the trap at the earliest possible moment. To do this is a connumdrum and many trappers pay insufficient attention to this important item. If traps are set 
on a $\log$ there is nothing easier than to attach a stone to the chain. This should be attached as near as possible to the trap, and so arranged that when the animal springs the trap and jumps into the water, the stone will follow him. At times, if the end of chain is attached to a rope or wire and placed over limb of tree, with the other end weighted so when the animal springs the trap he will jerk the rope, and by so doing the weight that rests on the fork will descend, lifting the victim up in its descent. These appliances are sometimes called gallows.

Anything to drown aquatic animals and to raise land animals off the earth, will do. The trapper who knows the different ways and can choose the best one in any given locality, is the boy that will be crowned with success.

\section{Sliding Pole, Spring Pole, Clogs, Drags, etc.}

Drag. For animals such as mink, muskrat, raccoon, badger, opossum and similar animals, a light drag, to which the trap is attached, is often preferable to having the chain fastened on some permanent object. A branch of a tree that has many sub-branches is preferable. Do not have it too heavy and see that ring is securely fastened.

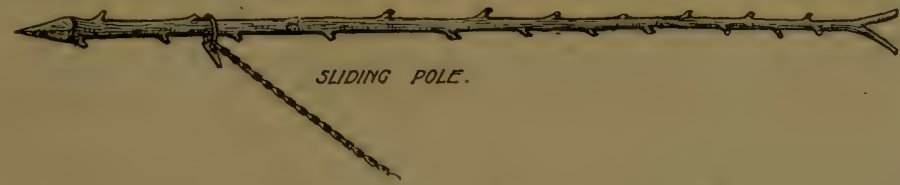

Sliding

A sliding pole in the capture of mink, muskrat, and Pole. other aquatic animals is often preferable to that of a drag, spring pole or stakes. Such a pole should be eight to ten feet long and the additional limbs trimmed so as to permit the ring of the trap to descend, but not to come back. The end, of course, should be driven into the bank or weighted down by stones so that the animal will be unable to withdraw it. The other end should be in deep water. In the animal's desire to escape he will gradually go into the water and not being able to come back will drown.

The Clog.

"Some powerful and violent animals, if caught in a trap that is staked fast, will pull their legs off or beat the trap in pieces, but if allowed to drag the trap about with a moderate weight attached will behave more gently or at least will not be able to get loose for want of purchase. The weight used in such cases is called a clog. It is usually a pole or stick of wood of sufficient size to correspond with size of animal. As the object is to encumber but not hold it fast, the 
chain should be attached to one of its ends so that it will not be liable to become fastened among the bushes for a considerable time. The usual way is to slip the ring over the large end of the pole and fasten with a wedge. The weight for a black bear should be 30 pounds, and for a grizzly bear 80 pounds."

The spring "In taking several kinds of land animals, such Pole. as the marten and fisher, it is necessary to provide against their being devoured by other animals before the trapper reaches them, also against their gnawing off their legs or breaking the chain or the trap by violence. The contrivance used for this purpose is called a spring pole and is prepared in the following manner: If a small tree can be found standing near the place where your trap is set, trim it and use it for a spring as it stands. If not, cut a pole of sufficient size and drive it firmly into the ground, bend down the top, fasten the chain ring to it, and fasten the pole in its bent position by a notch or hook on a small tree or stick driven into the ground. When the animal is caught, his struggles, pulling on the chain, unhook the pole, which flying up with a jerk, carries him into the air out of the reach of prowlers, and disables his attempts to escape by self-amputation or other violence. The size of the pole must be proportioned to the weight of the game it is expected to lift."

The sliding Pole.

"Animals of aquatic habits when caught in traps invariably plunge at once into deep water and it is the object of the trapper availing himself of this plunge, to drown his captive as soon as possible in order to stop his violence and keep him out of the reach of other animals. The weight of the trap and chain is sufficient for this purpose, in case of the muskrat. But in taking the larger amphibious animals such as the beaver, the trapper uses a sliding pole. It is prepared in the following manner: Cut a pole ten or twelve feet long, leaving branches enough on the end to prevent the ring of the chain from slipping off. Place the pole near where you set your trap in an inclined position. with its small end reaching into the deepest part of the stream and the large end secured by a hook driven into the ground. Slip the ring of the chain on to this pole and see that it is free to traverse down the whole length. When the animal is taken it plunges desperately down into the region towards which the pole leads. The ring slides down to the end of the pole at the bottom of the stream and with a short chain prevents the victim from rising to the surface again or returning to the shore," 


\section{HOW TO SKIN FUR BEARING ANIMALS, MANNER OF STRETCHING RAW FUR SKINS, HOW TO MAKE FUR STRETCHERS, MANNER OF PREPARING SKINS FOR THE MARKET, DRYING SKINS, ETC.}

\section{The Handling of Furs.}

Not only is it necessary for the trapper to possess the knowledge of setting traps, snares or other contrivances, or in what manner to poison, also the proper manipulation of the rifle or shot-gun in hunting or trappingr fur-bearing animals, but he must also comprehend and master the proper care of skins in order to realize full market value and to prevent spoiling.

To be successful a trapper should visit his traps as often as possible. Every twenty-four hours or every other day is generally sufficient. If the victim lies too long in the trap the skin is likely to slip or taint. Also other animals may damage or devour the victim. The skin should be removed just as soon as the animal is dead or the fur sufficiently dry. It is poor policy to remove skin while the body is in a frozen state. If the body is warm, it is often advisable, especially in larger animals, to start the blood by cutting, permitting the blood to flow as freely as possible.

\section{Proper Way of Skinning.}

In the skinning of animals that require the skin to be dried in a cased shape, such as mink, marten, otter, muskrat, red fox, wild cat, lynx, wolf, badger, opossum, etc., it is necessary to begin with the knife at the hind feet and slit down to and around the vent, strip the skin from the tailbone, in case of an otter cut the tail open but on other animals simply pull the skin over the bone. Then peel the skin from the body by drawing or pulling it over, leaving the fur inward. Use the knife as little as possible. One should have no difficulty if above method is used. Leave all claws attached to the skin, also care should be taken not to mutilate the skin around the mouth and eyes as some skins are used for mounting purposes. Heads must be complete.

\section{Skinning Beaver.}

Take a regular butcher's skinning knife and slit from center of lower jaw down over belly to vent. Skin out jaw and carefully remove skin from head. Do not cut legs open. Remove skin from body without further cuts in skin. Be sure and scrape all fat off. (See directions for stretching beaver skins on page 244.) 


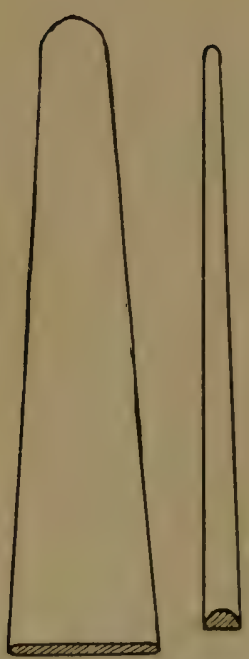

2 PIECE STRETCHER FOR

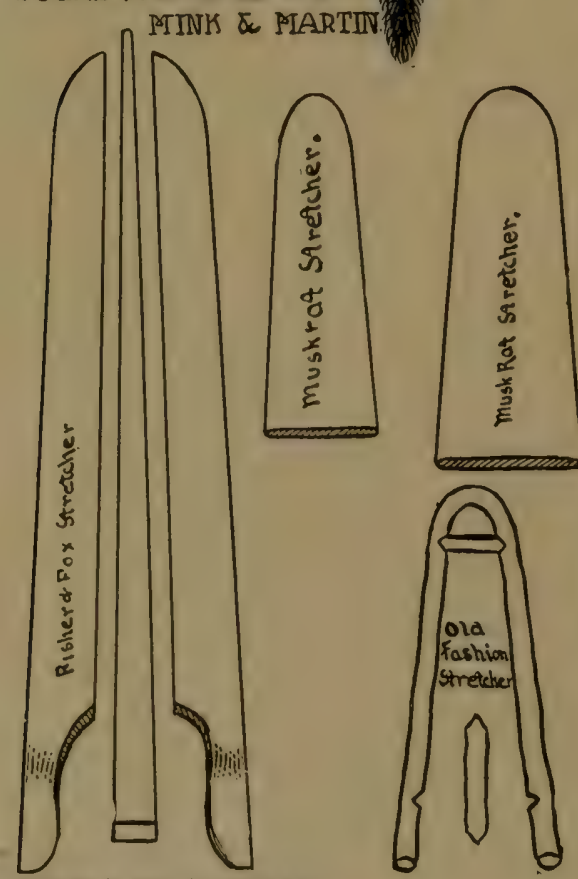

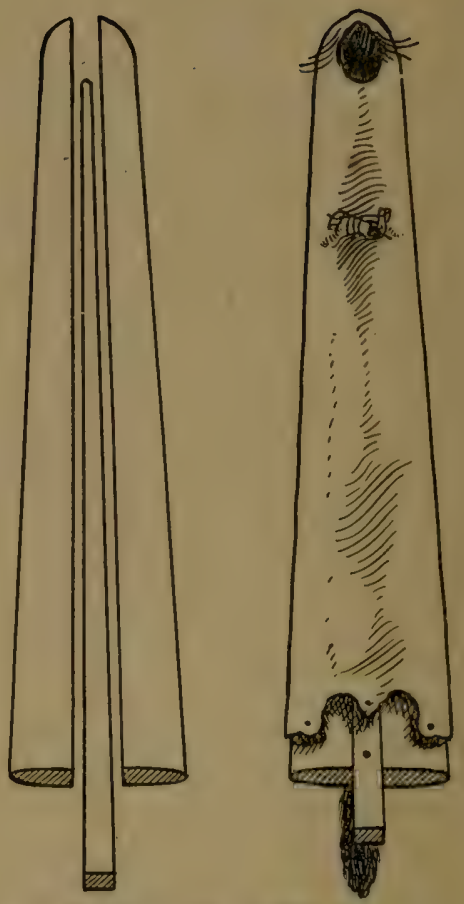

A. 3 BOARD OR WEDGE STRETCHER

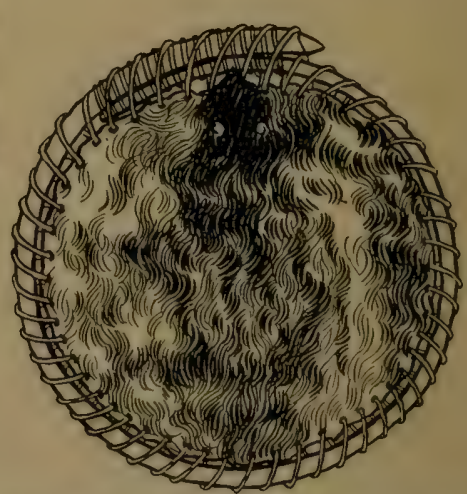

A SMALL BEAVER SKIN ON HOOP STRETCHER SEWED WITH WITHES THEREON.

PISHER \& FOX \$TRETCHER 


\section{Lightning Method for Skinning Muskrats.}

Cut off front feet and tail with a hatchet, with knife slit from hind legs to vent, skin around hind legs, attach a strong cord to both legs and pull skin over body.

\section{Skinning a Bear.}

Some trappers prefer to skin a bear similar to taking of lides from cattle. This method is O. K. For the benefit of those not familiar the following suggestions will be in time.

Take knife and slit from hind legs to vent. Then from inner part of fore legs to brisket down to center of lower jaw. Then open skin by cutting straight over the belly to vent. Remove the skin from head witl care. Leave ears, jaw, openings of 'eyes intact.

Another method resulting in Indian style handled skins, is to remove the skins similar to that of beaver, excepting the legs should be cut open so as to permit the skin to be stretched in proper shape; bear skins must not be stretched in a round shape like the beaver.

\section{Skinning Deer, Elk and Moose.}

The skin of the above animals should be removed similar to cattle, calf and horse hides. The hides should be in like shape excepting the head should never be slit open as is the practice of butchers in taking off cattle hides.

\section{Skinning a Wolf.}

To remove a wolf skin from the carcass properly, it is necessary to follow and use the same methods employed in skinning the fox, mink, or other animals whose skins should be cased and not cut open on the belly. In western states it is the practice to remove the skins by cutting clear across the belly and by following the method used in skinning bear, and removing cattle hides, though not as good as if left cased; the price for the skin is about the same.

\section{Stretching Skins in a Frame.}

The skins from such animals as the bear, beaver, raccoon, wolverine, deer and dog can be best stretched in a frame. The frame is made out of four pieces. The latter can be scantlings or one-inch boards. If these cannot be had, take saplings, which make excellent frames. The skins, however, must be green, as a part dry skin will not stretch sufficiently. After yout have made a frame of sufficient size for the skin, take a large sack needle and some strong twine and sew by making stitches every one 
or two inches, each stitch encircling that particular portion of the frame.

Do not cut off the feet or ears; that would make holes in the skin. If same are cut off, sew such openings together before putting skin on stretcher. Some remove all meat and fat before stretching, others proceed to scrape after skin is stretched upon the frame. One can suit himself, but we believe all surplus meat and fat should be removed first, and when skin is on the stretcher, finish the work with a dull knife, hardwood stick or spoon. Shape skin with your hands before sewing in frame; do not overstretch, but make allowance for the natural shrinkage in process of drying.

\section{Bow Stretchers.}

The use of the bow stretchers is dying out and it is well for trappers to discontinue stretching their skins in such a careless manner. A few Indian tribes and occasionally a trapper who has no tools for making other stretchers, use the bow stretcher, but only for muskrat. We recommend the discontinuance of its use altogether.

\section{Hoop Stretchers.}

In sections where beaver are plentiful it is well for the skins to be stretcherl on a hoop made out of a stick of hickory or other flexible wood. If a single stick is not long enough, two small ones can be spliced together; tie over-lapping ends together with withes. See that the hoop is round, and not too large in size for the skin it is intended.

In skinning rip from center of lip to vent, gradually skin, peel and fist around the lips, eyes and ears, continue until vou have reached legs. Do not rip lengthwise on legs but gradually pull them from the skin and cut so as to have smallest possible opening when skin is finally stretched. (Some prefer to sew leg holes together). When skin is off, begin at the head and fasten to hoop with twine or withes inserted about an inch apart and continue until entire skin is stretched round and as tightly as a drum-head.

Formerly bears, wolves and raccoons were stretched in this way, but of late years beavers are the only skins stretched in round shape.

\section{Skinning and Handling Raccoon Skin.}

"As I have given the main points of my experience in trapping the raccoon, I will now tell how I skin and stretch the hides. If you wish to case the skin, cut the skin around the hind legs near the heels, then slit along the back part of legs through the 


\section{Andersch Bros.' Hunters and Trappers Guide.}

anus from heel to heel. Peel the skin down the legs to the root of the tail, pull the bone out of the latter, strip the skin toward the head, cutting it loose at the fore feet, and around the mouth carefully. Be very careful in skinning the tail for if it is broken the sale is injured. Take two small, square edged sticks about four or six inches long. Place the bone of the tail between them and pull steadily. To case, get a board of length and width to suit the size of the skin, the thinner the better. It should not be too sharp at the nose nor too broad at the rear. Make it nicely rounded at the nose, slip the skin, on with fur inside, pull the nose over end of board to lap on chin, tack through both, then pull for length, and tack both hind legs and root of tail.

"To remove skin with intention to leave it flat or open, slit hind legs as described above, slit fore legs across the breast from foot to foot, then entire length of belly to chin, strip skin from hind legs and tail as above; then strip to head, leaving the ears entire on skin and cut carefully around mouth and nose. To stretch, cut holes near the edge of skin along both sides from hind leg to foreleg, across the bottom, and across the top just below the ears; then insert four sticks in the four rows of holes, the length depending upon size of hide. The hide should be square or nearly so, Place a stick across the middle with the ends swallow forked to keep it in. Place another from the root of tail to end of nose. I prefer splitting the head to the back of the ears and sewing the jaw and foreleg together. This makes a beautiful figure The holes should not be more than two or three inches apart and all particles of flesh and thin pelt should be stripped off before stretching. Hang in the shade to dry with fur to the wall. When ready to ship take out all sticks, boards or stretchers, pack the skins with two fur sides together and two flesh sides alternately, as the flesh might grease the fur and give it an oily feeling. Bale or sew up in burlap and they are ready for market.

Mink and

Opossum.

"Opossum and mink are skinned the same as raccoons. Prepare for casing, and stretch on boards as described for cased raccoon. The tail of opossum should be cut off, that of mink left on. A slit should be made in the end of tails of raccoon, mink, otter, etc., to let out any foul matter that may gather in the cavity in warm, foggy weather. A perfect skin of a raccoon when ready for market should be nearly square. If mink, otter, or opossum, it should be nicely rounded at the nose, not too sharp, nor too wide at the tail. If the ears are hard and dry it is not a perfect skin. If the tail is hard, kinked or crooked, it is not a perfect fur. If blue behind the forelegs or under the chin, it was caught too early. If it has been whitened by salt or alum, it is not a perfect fur."

O. Pullnow. 


\section{To Skin the Wild Cat and Red Fox.}

To Skin a Wild Cat.

As soon as possible after the animal is dead or killed, it should be skinned and the skin stretched. In warm weather a dead animal will turn black or blue on the belly in fourteen hours. The animal should be skinned while the warmth is in the body. All skins of animals smaller than a bear can be cased more conveniently by the trapper. As

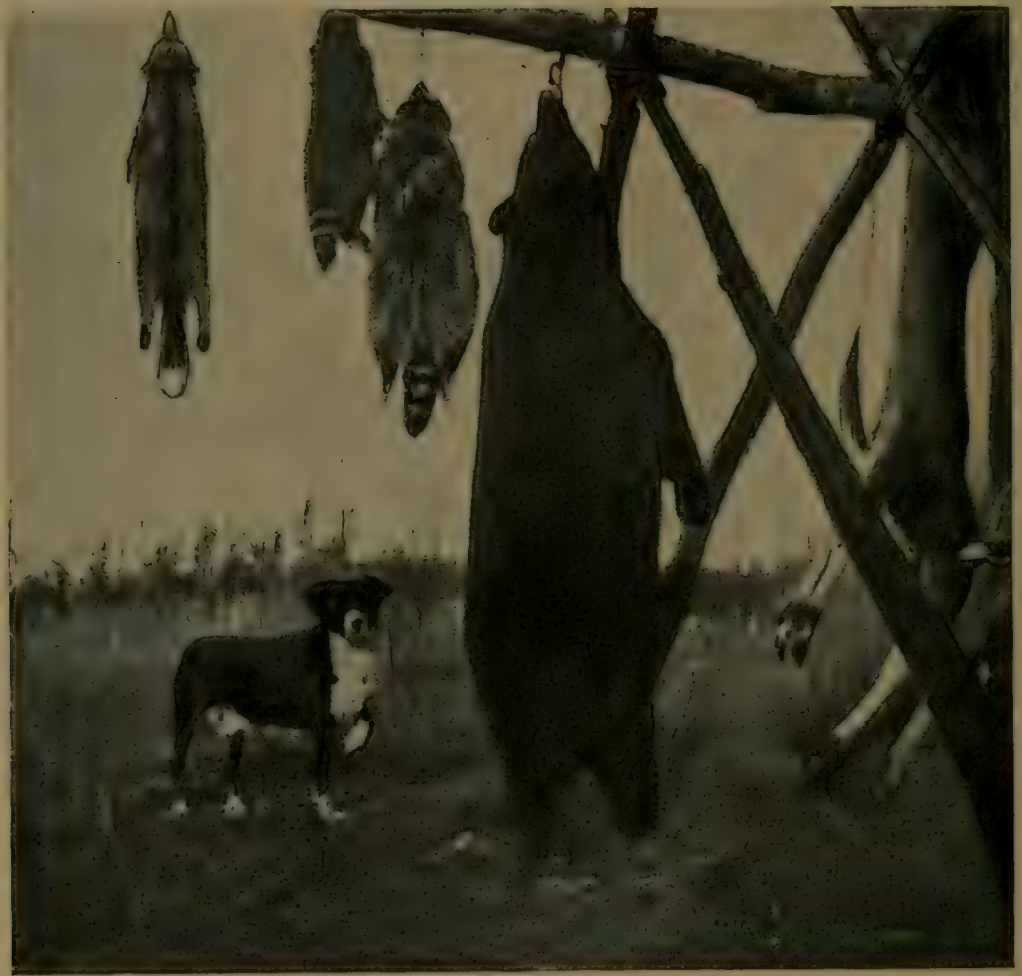

The Result of Knowing How to Hunt and Trap

to hoop stretcher and bow stretcher, I do not favor them. A bow stretcher can be made in a pinch for such as muskrat.

"Hang the animal by one leg and commence by cutting down inside the hind leg to the vent and up the other leg. Cut around the leg above the claws, (I do not leave the hind claws unless for special reasons, except the mountain lion), and make a slit up the tail a little way's, pulling tail out by the help of a split stick. (Tails are worthless on beaver and muskrat, and the tail of the 
otter should be cut open and spread out). Skin or peel down to the forelegs, break off below knee and leave paws in the skin. Cut around ears, eyes and mouth and the skin is then ready to be put on the stretcher. Always have the fur towards the stretcher and the skin part outside. The stretcher should be made in the following manner:

stretching. "Get a board one-half inch thick, three feet long, nine inches wide at the wide end, tapering to about four and one-half inches wide at small end, rounded and notched out for the head. The illustration (elsewhere in this book) will give an idea of how the stretcher will look. I don't use a singlepiece stretcher unless I have to.

"By ripping the above stretcher into three piece's and making a wedge or three-picce stretcher therefrom, the result will be nicely shaped skins which can be removed without danger of tearing. I take a rip saw and cut from center of stretcher a wedge of about one and three-quarters inch to about two inches wide at lower part to a point at head of strethcer. This forms a nice wedge, and if necessary, this wedge can be run through the mouth of the skin in case the animal is a large one, and if smaller, it need not be placed clear down. This stretcher is excellent for otter, wolf, wild cat, foxes, and if made smaller, for all other animals of the weasel or marten family. The skin is pulled over the stretcher and when fairly tight, drive four nails, two on each side, into the skin to hold same firmly, and then take wedge and slowly insert until the skin attains its proper size and becomes smooth. Then take more nails and fasten skin on rear part of stretcher and wedge.

"Always stretch belly on one side and back on other side of stretcher and see that tail is exactly in center of wedge. Before putting the skin on stretcher, take a hatchet, sharp stick or knife and scrape fat from skin; when on stretcher smooth out with the same tools and remove every bit of grease, wash and wipe thoroughly dry, and then hang skin away in a shady place for five to ten days. When firmly set, stretcher can be removed. Never take stretcher off too early as skins will crumble up and get in bad shape.

"Be careful and not get fat on fur and tail. When skins are thoroughly dry and you are ready to ship, pack in burlap and ship." by express. If skins are only partly dry, they will mildew and possibly spoil ; therefore, the skins should be thoroughly dry."

To skin "The body should not be frozen, if it is, thaw so a Fox. that the outer portion of the body is thoroughly hanging up. thawed out. The fox should be skinned while 


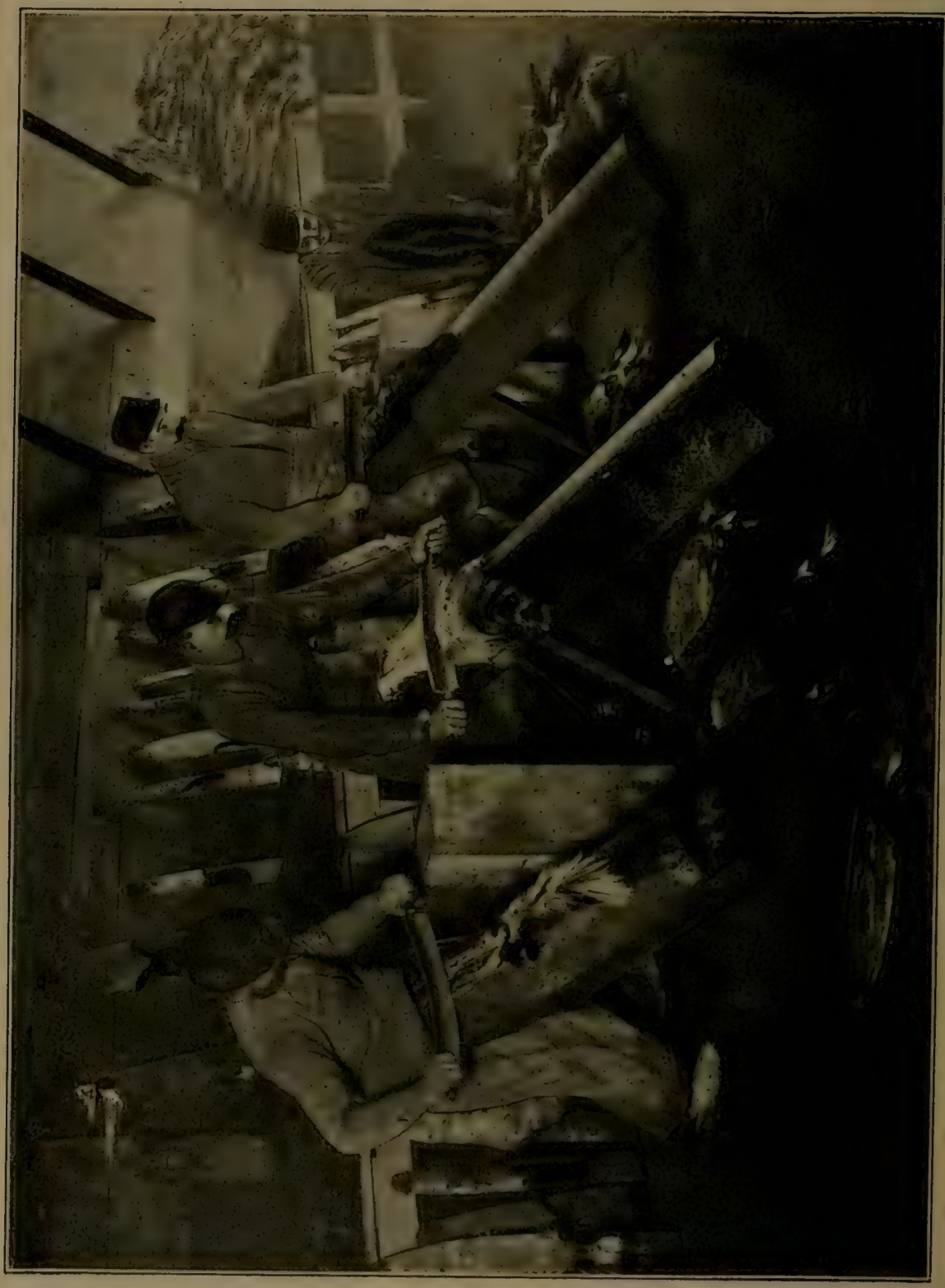

घं

वี

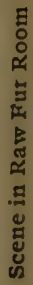


"Take a small, sharp-pointed, thin-bladed knife and a large skinning knife-both should be very sharp. Cut crosswise on inside of hoof, leaving claws attached to the skin, then open hind legs by inserting small knife between the skin and body from claws to vent, following the peculiar furred line indicating the innermost portion of leg. Now skin out the legs; use the knife to start with and pull to free the skin, in preference to cutting. Pull skin upwards so as to free the second joints of the foot before severing the skin with the claws from the leg at the joint indicated above.

"When legs are freed get spreader or gamber stick and place in position through the cords, and hang carcass up.

"Now skin on belly down about five to seven inches, then about the sides and back, leaving the tail portion unmolested until you come up from bottom.

"Now comes the most delicate job. Get an eight or ten-inch stick, three-fourth or one inch thick, split in center to about half way down. Put the body on the ground. Take split stick and place at root of naked tail, then with left hand take body and with right hand hold stick, pull steadily and you have skinned the tail.

"Now hang up again, and pull skin down over belly. Use knife as little as possible, and be very careful on belly portion as the skin is very tender and you may tear it.

"When at forelegs, take knife and open about knee and slit down to the body; but if one wants the skin of the legs left on pull skin with one hand, holding the body, and with your knife assist until you come to knee or foot, which dislodge, one leg at a time. Then pull the skin down to the head, cut ears close to the skull, pull down to the eyes-cut about same way at the nose. Always leave ears, eye part, lips and nose on skin.

stretching. "This requires little work. Get two thin pieces of boards, have them planed smoothly, thinner on one side than on the other, also taper from one-half inch to three inches. Procure wedge one-sixteenth to one-half inch wide, same thickness as other two boards and about as long or longer. Some place fur inside and others outside. A nice prime red fox looks better if fur is outside. Place skin over stretcher, then take wedge and insert, smooth out, nail skin at tail and on belly portion, and hang up in high, shady place in the barn to dry. In a few days remove stretcher, and hang skin up until perfectly dry." From G. Halvorson; Arvilla, N. D.

\section{How to Skin and Stretch Mink Skins.}

Take a small, sharp, thin, narrow-bladed knife, and slit down where the fur comes together on the inner part of the leg, from 
heel to anus. Now take thumb and forefinger and peel the hide off the legs; take knife and slit from anus to end of tail. With your thumb and fingers loosen tailbone from skin. Some only open tail one inch from anus and then take two flat, notched sticks, fitting around the tailbone, which grasp firmly in one liand and pull skin off bone with the other. Now proceed to further remove skin from rear legs, scarcely using the knife. Pull skin over body, using your thumb and hands. When at fore legs continue to use fingers and pull forelegs out. Another pull will bring you to the ears when a knife should be used in cutting them off close to the skull. A slight pull will bring the skin off body and the knife should be used for the last time in cutting off the nose and trimming around the lips.

stretching. Stretching mink skins and making them look nice and fine is more important than skinning, and, in fact, next to trapping the animal itself. Three-piece stretchers are used exclusively by me, unless in a pinch I use a one-board stretcher with a small wedge on top to take up the slack and to assist in removing the skin from the stretcher. The belly and back part of the animal should be on opposite sides and exactly even. Stretch out legs and ears, but do not tack permanently until skin is scraped.

scraping. Take a dull case knife and remove all surplus fat it cannot be stretched right. After you have removed surplus fat and meat, start to stretch the skin permanently.

Use pains in stretching out all parts of the skin, especially legs and tail. Take especial pains with the tail so that same is stretched, or use coarse, hollow straw, which insert so as to permit the tail to dry. Now take a dull case-knife and scrape off all fat. Don't let fat run on the fur. Wipe it off with a rag. If fat has a tendency to run in the grain of the skin, cut close with a sharp knife. Having removed all fat take a sponge or woolen rag, dampen with water, and proceed to work all grease out of the skin. All large filaments, which present a rough and ragged appearance should be removed. After skin is cleaned, put in a shady place to dry; never close to a stove, neither pile one skin on top of another. If you have occasion to force drying, put the skin in a warm room where there is good circulation of air.

\section{Stretching Skins, Flat and 0pen.}

$$
\text { N. C. A. }
$$

Begin at the head, nailing at the nose. Stretch lengthwise, until fairly tight and tack through the tail. Now place one nail through each leg at the foot, but not too tight. Stretch crosswise, placing nails about one inch apart. Be careful not to 
over-stretch the hicles, as it gives them a thin appearance and deducts much from their value.

FrED AвBotT,

\section{Method of Skimning Muskrat and Stretching Skin.}

A few remarks on skinning and stretching may not be amiss, as on the speed and thoroughness depends much of the trapper's success. Make two hooks from stout wire or tenpenny nails, just large enough to fit tightly over the smallest point of the muskrat's hind legs. Tie a stout cord to each of the hooks and fasten to some object far enough apart so as to have the hooks six inches apart when the muskrat is hung up. Now take your knife, which should be slim bladed and at least 4 inches long, and insert it under the skin of hind legs, letting the point of the knife come out at root of tail. Give one quick jerk and rip the hicle the whole length. Insert the knife in the other side of the tail, letting it come out at the other hind foot, and repeat the operation, but do not cut around the feet, as by so doing one is likely to cut the flesh which will come off with the hide and cause inconvenience. Take the hide between the thumb and fore-finger and pull the skin around the fect. "With some practice this can be done quickly and is better than cutting. Pull the skin over the body down to the forelegs and pull them out without cutting them. On reaching the ears, take knife and cut around eyes, ears and nose.

stretching. Make your stretcher out of thin boards about five inches wide and tapering well to the small end. Plare an:l sandpaper until you have a smooth surface. Use onepiece or three-piece stretchers. For fleshing and to remove fat and surplus meat, take a large tablespoon and use the bowl for seraping off this fat and flesh. By this method there is absolutely no danger of hurting the skin, or damaging same by cutting, as is often the case if a knife is used. The skin is also of smooth appearance. Do not let any fat get on the fur. If you do, wipe it off with clean rag or use dry hardwood sawdust.

T. Gullickson,

\section{Proper Manner of Skinning Mink and Stretching Skins.}

First cut down the back of hind legs from heel to ants. Now, with thumb and fore-finger peel the hide off the legs. Next, slit from anus towards the end of the tail one inch; loosen with fingers as before around butt of tail; then get a couple of flat sticks and notch them to fit around the tail bone. Grasp these firmly in one hand and pull the skin off the tail. Proceed with the knife to carefully remove hide from the hind-quarters. Having cut past the navel, you can, with a single pull, rip the hide past the 
shoulder. Now place your thumb between hide and fore-leg, at elbow joint, and pull fore-leg out. Another pull will bring you to the ears, where the knife comes into play again. Cut ears at the base, close to the skull and proceed to carefully skin to the end of the nose.

How to

Board being of proper length and width, proceed

Stretch. to pull hide over same, hair inside, belly on one side and back square on the other flat side of the board; not on the edge. If there be much flesh on hide, as sometimes happens with an old mink, pull hide tight, securely fasten with a few small wire nails, putting nails in the end of legs and

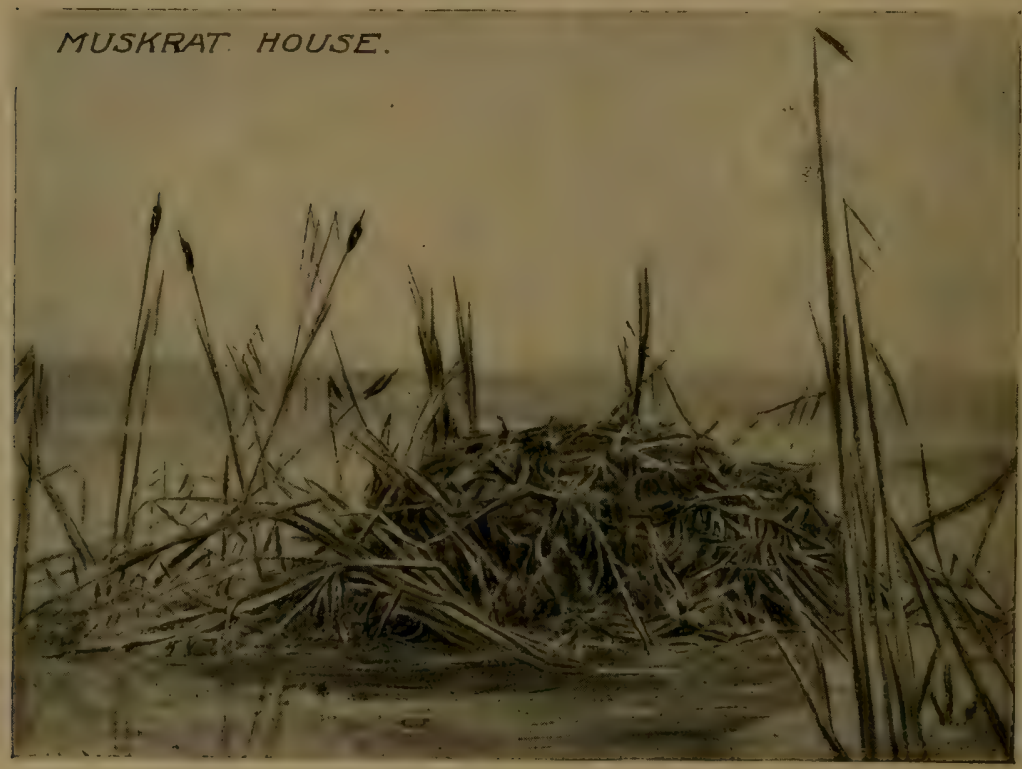

one at root of the tail. With a dull case knife scrape off the surplus flesh. This will enable you to stretch properly as a fleshy hide will not stretch well. This done, you may pull out the nails and proceed to stretch out legs, nailing at edge of board on belly side. Have both legs even. Put at least half a dozen nails in each skin, so that they will not give way when the hide dries up. On the other side, put a nail near the edge of the board, taking care to keep the back even as it looks much neater than if long ,cornered, and cuts better when it comes to making up. Always place your nails near the edge of the hide. If you use a threepiece stretcher, shove the wedge as far as it will go, but do not 
use too much force as you may split the hide and ruin it. Now, tack the belly and the back, pull the tail straight, and tack on the middle piece. In this position, it will dry nicely and not kink up as they are sure to do when not nailed.

My choice, is a flat board stretcher, with two tapering cleats, one for the belly and one for the back, the latter being long enough to allow the tail to be tacked to it. Put a nail in the belly cleat, so as to keep the hide and the cleat in place. Next, pull fore-leg up, tie with thread or twine close up to body. With a sharp knife cut about three-eighths of an inch above the string, press down with the finger, having care to turn hair out, forming a sort of rosette.

Now put away in a warm room, but not near the stove. After 8 or Io hours, or when half-dry, it is ready to clean and polish. Use a dull case knife, scrape gently, and the fat will readily come off. If any filaments have a tendency to run into the grain of the skin, cut close with a sharp knife. Having removed all fat, we are ready for the finishing touch or polish. Dampen a small sponge or woolen rag, don't soak, and rub all over the hide. This will lay low all the fleshy filaments which give such a ragged appearance to a skin, and will give it a neat and glossy appearance such as I have never been able to obtain by any other process. Now put away to dry, but keep away from the fire. Let it dry thoroughly, before taking off the board, as a partly-dried hide will shrink, consequently decreasing in value. When dry, always hang (don't pile up) in a dry, cool place, where mice cannot get at them. A good way is to hang them to the ceiling with a string. J. A. Despardins.

\section{To Stretch a Mink Skin.}

To stretch a mink skin on a three-piece or wedge stretcher, take the skin, which should be green and clean, and insert the two sword shaped pieces with the smaller ends toward the nose. To prevent nose from slipping off ends, drive a tack or small nail in each end of the board. Always have flesh part of the skin on the outside and the fur part next to the stretcher.

Now pull skin up as far as possible. Be sure tail is in center, drive two tacks, one on each side to hold skin up, then insert center piece (wedge) between the two side stretchers, shove wedge down until skin is the required shape and all parts properly stretched.

Use ordinary judgment and care and be sure not to overstretch the skin. Drive tack through tail in wedge. This completes the stretching. A medium sized northern or north-western mink skin (not including tail) stretched in this way should be twenty to twenty-two inches long, three and one-half to four 
inches wide on bottom and gradually tapering down to the nose.

\section{How to Make Mink Stretchers.}

Take two pieces of pine wood about thirty inches long, one and one-half inches wide and five-eighths to three-fourths inches thick. Taper edges from one end so as to be about three-fourths inches wide when about two inches from the other end. This again taper to one-third inch to the extreme end.

When this is done plane off from the sides so as to leave the pieces in a sword-like shape. The thickest portion when finished should be 7-16 to 9-16 of an inch on the edge while the other end about 3-16 of an inch and also tapering to a point more abruptly when about two inches from the end. Sandpaper and smooth the thin edge, also sides. Then take a piece of wood thirty inches long, the same thickness as the thickest part of the side pieces, about one and one-half inches to two inches wide and taper so as to make a wedge of about one and one-half to two inches on one end to about one-fourth or three-eights of an inch on the other end. This completes the so-called mink stretcher.

\section{HOW TO SKIN A HEAD THAT IS TO BE MOUNTED.}

Many trappers often kill horned game, also fur bearing animals which they desire mounted, but in skinning invariably spoil the skin for the purpose intended. Even when skins are not desired to be mounted by the hunter, it is well to skin animal, having in view that someone else may want the skin mounted, in consequence thereof the value of the skin is increased. This is especially true in skinning the wolverene, mountain lion and cougar, also in removing the skin from horned game, such as deer, elk, moose, antelope, mountain sheep and mountain goat. In removing the skin of the latter, it is necessary to cut from the base of one horn to that of another and from center between the horns down the back of neck to the shoulder; this forms a cut resembling a "T," and the only one necessary. Never cut the skin open from the lip running along the neck to the breast as that spoils it for taxidermist purposes, and even if it does not, no taxidermist can make a good job therefrom. Great care should be taken in skinning about the eyes, and be sure and leave on all parts of the lip; special care should be exercised about the corners of the mouth and eyes. Leave considerable of the gristle of the nose attached to skin. If you can, turn the ears inside out. All surplus fat should be removed and the skin immediately salted. If this cannot be done, hang in a shady place to dry. All parts should be stretched so as to be exposed to the air; otherwise that portion lying next to another will become tainted. 
Horns, in fact, the entire sku1l, should be saved and these, if good sized and well formed have always a commercial value.

\section{ADDITIONAL REVENUE FOR TRAPPERS.}

It is well known that the large beef and pork packers in the operation of their plants, utilize every part of the animal. There is no waste or offal that is not turned into account; even the manure in the pouch of the animal is sold; in fact, everything is utilized excepting a "stray kick" or the "squeal" of a pig. Hair, blood, ears, tail, sinews, toes, horns, intestines, hoofs, etc., all find their way to market and bring good prices. All of these articles, as well as the flesh and bodies of fur bearing animals, could be utilized, if concentrated, as is done by the packers. Alas! it is impossible. Therefore the trapper must be satisfied in saving as many parts of the body as possible, and for which he can find a market.

Intestines. It is well known amongst old trappers that the Indians used dried intestines in sewing and patching their clothing as well as in the preparation of their furs. These were also used in the manufacture of ropes, lariats and snares, and particularly in making bow strings. Of late years, intestines, after they are cleansed and partly dried are used for musical strings.

Bear Galls. These have a commercial value, bringing from $\$ 3.00^{\circ}$ to $\$ 5.00$ per. pound. Prevent leakage, by tying the ends with a string and hang up to dry in a shady place; when dry, market. We have a demand for these. If you have any, write us.

Beaver Castoriums.

These have been saved for the last 50 or 100 years. There is a commercial demand for them and of late years the demand is greater than the supply. These castors are found in both the male and the female beaver. The contents are of a deep orange color when dry. Hang up in a shady place and when dry, market. The oil bags that are immediately attached to the beaver castors have no commercial value. Trappers, however, use them in the manufacture of decoy.

The perfume out of these glands, as predic-
ted by certain naturalists and scientists, will soon have a market value. If the contents of the containers or glands, are squeezed into a bottle, there is little danger of having the fluid distributed over the operator. This should be done in the open air; keep the bottle corked up. We expect a demand for this article.

skunk Oil. Formerly there was a good demand for this oil,
but of late years manufacturers have used other 


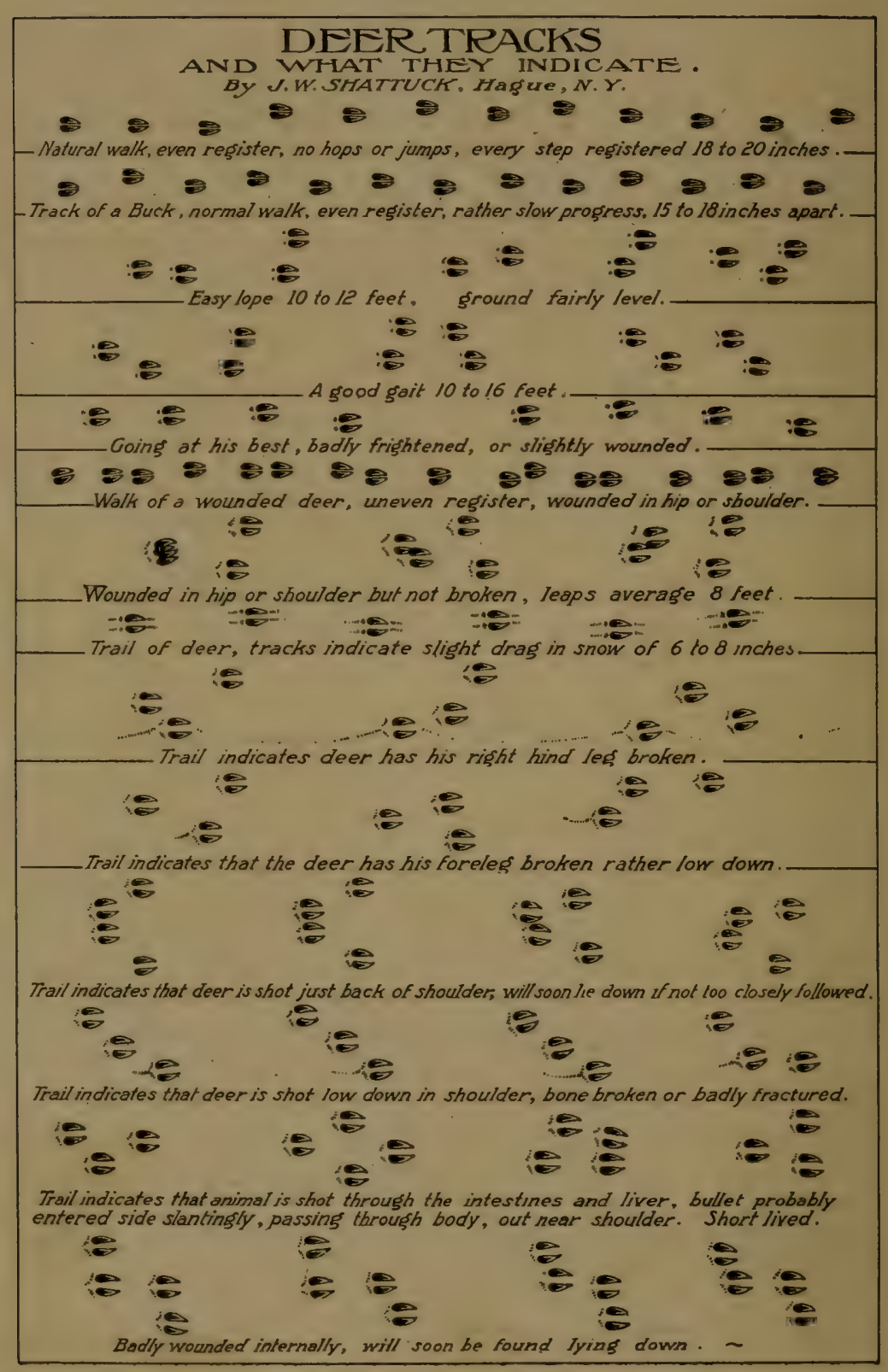


oils which are much cheaper and always obtainable, therefore the demand and use of skunk oil has become less and less every year. Of late years the surplus has been sold at prices comparing with aged lard or tallow.

Skunk Galls.

Are used for medicinal and manufacturing quantity, write us.

purposes. Save them, and when you have a

Musk Bags.

The bags obtained from muskrats are salable, some years the demand is so great that the supply is exhausted and used up before half the summer is over. Handle them the same as you would beaver castors.

Animal claws. The claws of bear, mountain lion and other ferocious animals have a market value. By no means should they be removed from the skin; if animals of this kind are killed during the summer months when the skin is of no value, they should be cut off, cleaned, and marketed.

Elk Teeth. Certain teeth of this animal are in very good them by communicating with members of the "Elk Lodge."

skulls. A ready demand for skulls exists. Trappers should save them.. If skulls are saved, remove meat by boiling head in water. All fat and meat must be eliminated. The skulls from bear, mountain lion, lynx, wild cat, cougar, and occasionally those of the smaller carnivorants are wanted by taxidermists, naturalists, and others. Skulls with horns from elk, moose, deer, mountain sheep, mountain goat and smaller animals are salable, but buyers insist that the skin should acconpany the skulls. Thousands of artificial sku1ls are annually used, while the natural ones go to decay.

\section{TO STILL HUNT OR STALK A DEER.}

An old buck is very wary, cunning or frail, as the case may be. If he is followed by one or more hounds, he runs at the first yelp making over hills and down to the brook in which he plunges and goes down stream for a mile or more, until he feels it is safe to go on shore. He listens: no dogs within hearing; he walks up on a knoll away from the brook, so he can hear better, but listening for some time. He finally decides that everything is all right, the dogs are off the trail, and he walks upon the ridge takes a bite and lies down to rest, seeking a position that may be as safe as possible. He looks up the hill, notes that the wind is blowing sideways of the mountain; he goes up wind for half a mile then tacks down wind for forty or fifty rods, then tacks back up the hill a few rods higher, then back a little higher up, then with the wind and up the hill and stops and looks all around. 
Now, if there is a hunter out looking for deer he is going along that acorn ridge, knowing they are fond of acorns, and as he comes to this track he looks it over; he knows that it is an old buck for the tracks are large and the toe is round up; the bucks do more travelling than the doe and on rocky gravel their toes become rounded. He finds where he left the ridge; he takes the trail and follows at a lively walk all the way until he finds

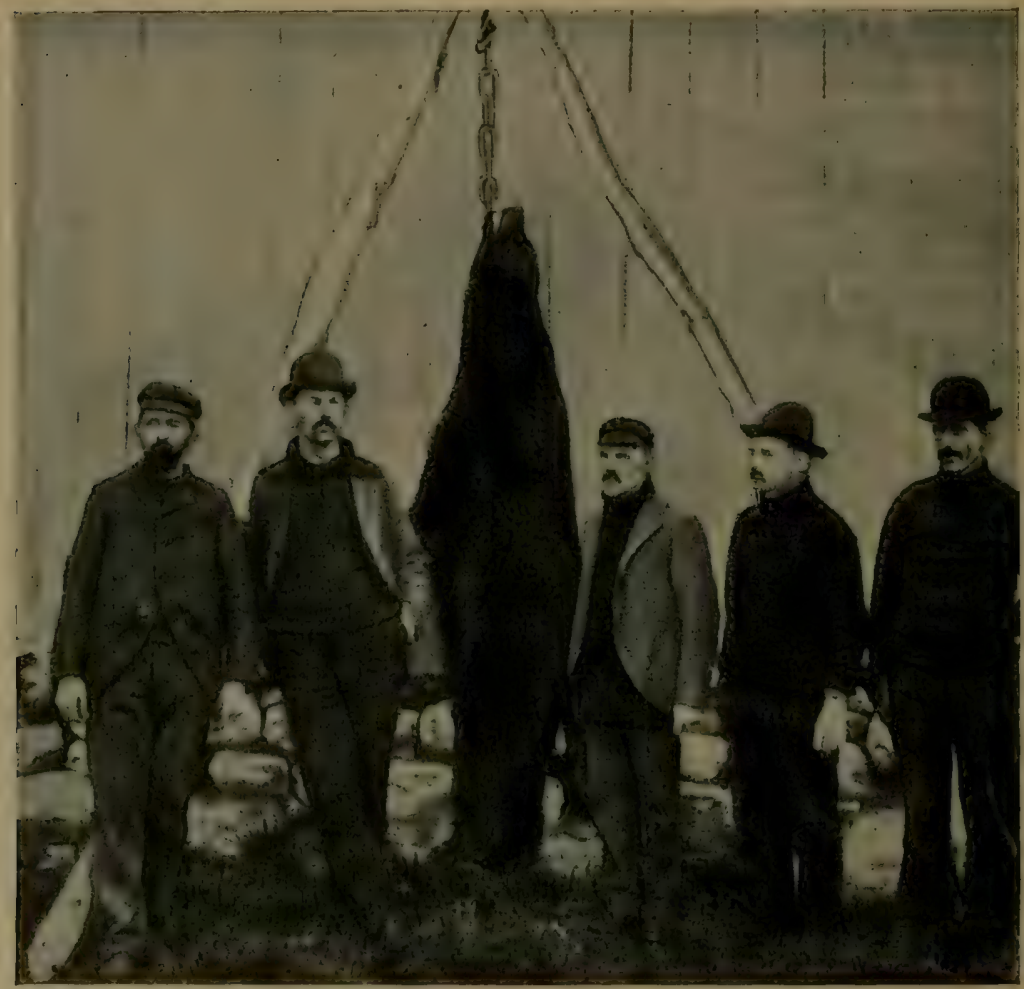

Courtesy of

We Were Seven

Nat. Sportsman

where the deer tacked; from there he goes slowly, and at the next tack slower. Finally when he goes down wind he turns off and takes a large circle up the mountain, coming down very carefully and slowly, his eyes taking in every inch of ground as fast as it comes into view; working along the edge of every ledge that affords a lookout, moving very slowly, no quick motions or noise, no breaking of sticks; if he does he stops short, looks in every direction. He knows if the deer heard the noise he would get up at once and stand till he saw something move. He goes on 
down the ravine and up the next raise to the top of ridge, coming up purposely behind a large tree standing on top of ridge, keeping as low down as possible until he reaches the tree, then raises himself up full height against the tree and very slowly looks around. After looking the ground all over he says to himself, "That buck is in that little thicket, I believe." He gives a low whistle and looks short. In an instant the old fellow comes on to his feet and looks straight at him. The hunter was prepared beforehand, his gun was in line and ready; now for the point of his shoulder just in front where all the muscles from the neck come together. The gun cracks, the buck drops but is not dead. He throws up his head, 'but is unable to get up. The hunter goes down and setting his gun against a tree takes out his hunting knife, steps one foot over his neck and front of his forelegs and with his left hand takes hold of a horn and with his right hand he drives the knife in to that little curve just above the brisket and the job is done. The deer is dead in a few moments, -now to hang him up.

He rolls the deer on to his back, and makes an opening from the point of breast bone, cutting away the mid-ribs and removing heart, liver and lungs. He now takes the liver in his hand and makes two cuts across it; from two to four live blood stickers fall out; there is no gall here to cut away. Now this is not known to all the hunters of the world, but nine out of ten cleer have them.

Now to hang up this deer; he is a big one-250 pounds. $\mathrm{He}$ cuts a pole with his axe (always carried by a good hunter). This pole is straight and I 2 feet long; he lays it along the cleer's belly between his legs. Then he cuts a stick about $2 \frac{\mathrm{I}}{2}$ feet long, $\mathrm{I} / 2$ inches in diameter, cuts a hole through and puts the stick through both legs and over the pole; he cuts a notch in pole to keep it from slipping; then he cuts two crotches about 9 feet long, he sets them up to end of pole just behind the deer and then lifts the pole and crotches up till the lower end of crotches catch; then he sets first one and then the other up a little at a time till the deer hangs as high as is desired. He then goes to the nearest water, or if not near any, snow will do, and washes his hands. He then fills his pipe, he could not smoke while after that deer, He then looks at the compass that is set in his gun stock, gets his bearings, and marks the farther side of a few trees so he can see the marks coming back and he goes home to tell the boys what a big buck hangs out on the side of old Tremble Mountain.

J. W. Shattuck. Hague, N. Y. 


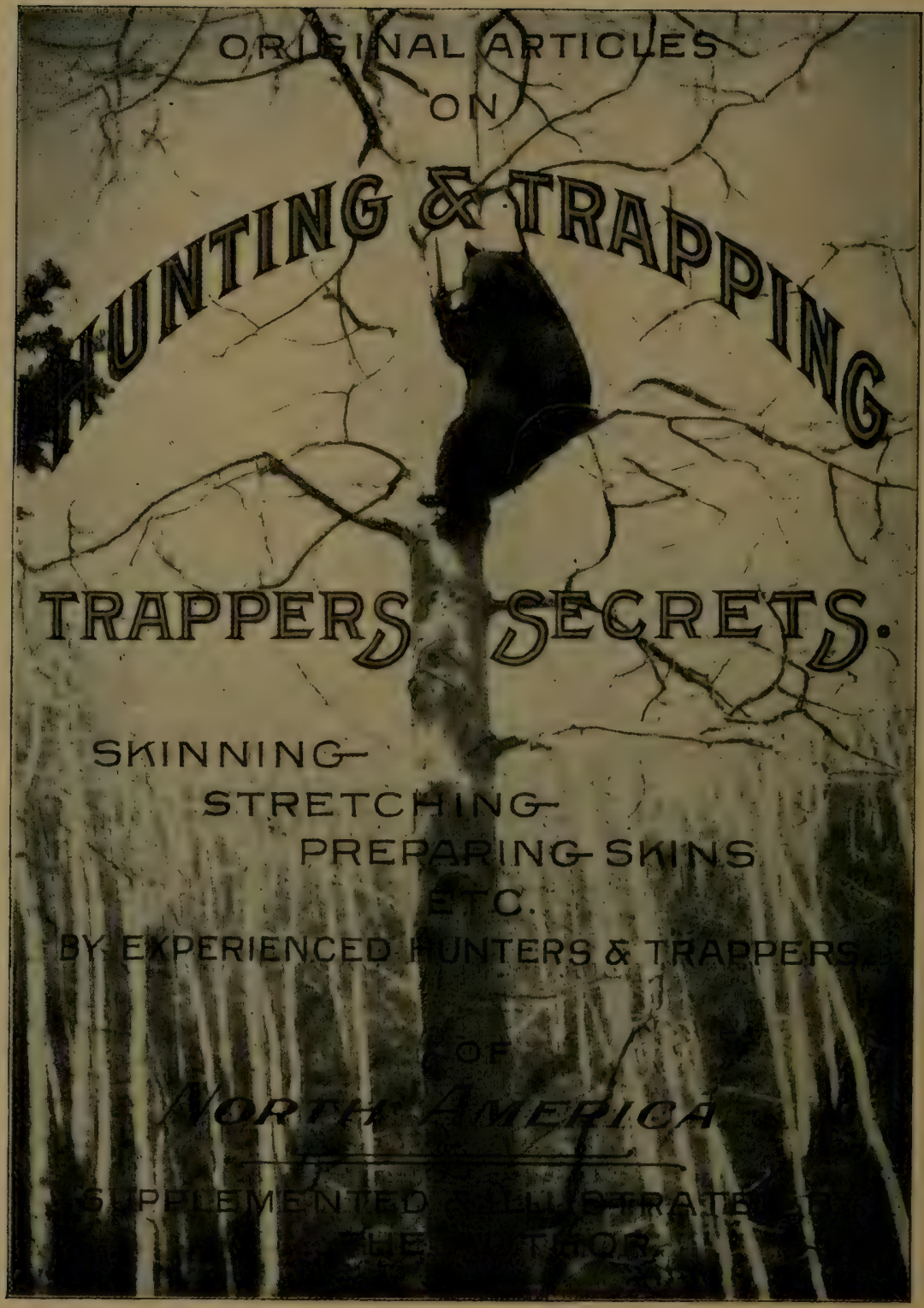




\section{TRAPPING THE WEASEL}

As soon as the snow is on the ground and the weather sufficiently cold, take as many ' $O$ ' traps as you have or can carry, and having a hatchet, go to the woods and locate the runways or some abode that the weasel frequents. If you find such abode, set one or more traps in the immediate vicinity or therein. Place cotton or wool unclerneath the pan and see that the pan works very easily. Cover trap with rotten wood, etc. If you are unable to find a hole, endeavor to kill a rabbit. If you are successful, take a knife and strike the animal in the neck so as to bleed slowly. Now walk along dragging the animal behind; when you come to a convenient locality, set your trap, permitting the rabbit's blood to drop in the vicinity; if advisable hang a small piece of the rabbit above the trap. Proceed until all the traps are used up.

\section{Trapping the Weasel.}

N. C. A.

A few years ago I never bothered to skin a white weasel, because the skin was ustually worth only five or ten cents, but of late years I have devoted as much time to weasel trapping as to mink and skunk. I use No. I traps which I set close to the trunk of a tree. On the latter I suspend my bait eight to ten inches from the ground so that the weasel will be able to reach it when standing on his hind legs. The meat is securely fastened to the tree, which forces the weasel to jump around.

One funny experience I had last winter: I saw a weasel run into a hollow tree. The opening was no more than a good sized knot hole. I thought to myself "Ah, ha, Mr. Weasel, I've got you." I immediately went to work, took my hatchet and made a large excavation and stapled the trap with the pan facing the knot hole to the tree. I was careful so as to give plenty of room for the jaws to close. The next morning when I came the trap had a firm hold of Mr. Weasel's head; in fact the bones were considerably bruised after I had taken off the skin.

\section{TRAPPING THE MINK.}

$$
\text { F. C. MARSH. }
$$

Mr. Leuhrs, an Illinois trapper, writes as follows: "To become a successful mink trapper it is absolutely necessary that one study the habits and thoroughly acquaint himself with the locality, otherwise he will not make a success. I have no particular secrets, but have been successful and have trapped from the Gulf of Mexico to the northern part of Canada. Last year I caught I2I mink from the 4 th of Nov. I905, to 20 th of Jan. I906, 
and all within thirty or forty miles of Chicago. The rules that I follow in trapping mink are as follows:

"When going over strange ground upon which I intend to trap I study the watery shores of the lakes, streams, sivamps and creeks for their natural haunts. I take special notice of their rtuns, paths, dens, feeding places and dung heaps and make it a point never to disturb them. When placing my traps always disturb as little as possible and approach the place by way of water. Then I set my traps always level with the ground and if possible a little deeper, especially if the surrounding soil permits this. I excavate an opening the size of the trap which I pad out with leaves or similar rubbish, then place the trap therein. If a water set is preferred the trap must be even with the ground about one-half to two inches below the level of the water. Some soft substance must be placed below the pan, otherwise sand will fill in and the trap will not be sprung. In water sets I prefer the sliding or spring pole or wire. When making a dry land set I cover trap with fine leaves or other material that I happen to find in the locality. Occasionally I use tip-ups. My three best mink sets are as follows:

Set No. I. Dig up nice, loose ground along the bank of a lake or running water so that it looks as though some animal had started to dig a den, the pile being large enough to hold a No. I $1 / 2$ Newhouse or No. 2 B. \& L. trap. I place cotton or wool, or the hair of rabbits under the pan; never pack it under but place loosely under the pan. Of course before setting the trap I make an opening of the required size on top of pile and then when trap is set, smooth off the pile and cover trap with earth, etc. No bait is required.

Set. No. 2. I find a spring or open running water. I place the traps so that they are covered by water about two inches. For bait I take three or four little fish (shiners or perch will do), which I fasten with wire to the pan, being careful not to kill them. At other times I use frog or crab. The mink will naturally go after the live bait and in so doing becomes a victim. Bear in mind that a raccoon, fox or otter may spring the trap, conseqently a strong trap is recommended.

Set No. 3. When the creeks are all frozen over with ice, take your hatchet or axe and chop a hole about four inches wide clear across the creek, then take some stakes, drive them about an inch apart from one side to the other. In the center leave an opening of sufficient size permitting the mink to pass through. If the water is too deep, fill up partly with grass, stones or mud. I use three traps in this set. Have often had three minks. I set one on each end and one in the middle. These stakes must 
be long enough to reach out of the ice. The bait I use is fish, birds, squirrels, rabbit, muskrat, etc. Bait however, is unnecessary. If used, I alway's place it in a natural position and always so that the animal in order to reach it must pass over the trap.

\section{Trapping the Mink.}

"I will write you my method of trapping the mink, during the rutting season, which you may use in your Trapper's Guide," writes Mr. W. Snow of Boscobel, Wis.

"During the early winter, mink should be trapped by setting the traps in their runways and holes, or by making a hole at the edge of the water where their tracks are seen. For bait nothing is better than the head and forepart of the fresh muskrat or a fresh fish. It should be fastened in the back part of the hole, by running a forked stick through, and the trap set at the entrance so the pan of trap is about one-half inch under water. If the chain is then fastened to a sliding pole the mink will be drowned and in good condition. In case their holes near water cannot be found, make an artificial abode with stones, roots of trees, bark, logs, earth, etc., on the shore. The rust and smell of iron should be removed from the traps, first by greasing, and burning off the grease in a blaze, being careful not to overheat the springs, and then boiling them in a kettle of water and hemlock or willow bark. Place bait in hole or hollow $\log$ as before, and make a place with your hatchet to set a No. I Newhouse trap so the jaws will be about level with the ground. Cover all up, being careful to put very fine material around the jaws so the trap will spring.

"Take all the musk from the mink you catch this way and save it until the last part of winter, during the rutting or mating season. The musk is found in small bags near the tail of minks. Put bag and all in a small bottle and cork tightly. Then if there is a mild spell late in January or in February, take a clean trap and tie a piece of muskrat skin or half rotten wood to the pan of trap and put on it a few drops of mink musk. Go to a marsh where there are a lot of muskrat houses. By this time of year the mink will have holes in some of their houses, or find a runway in a log or along the edge of the marsh. Dig out a little place with your hatchet to set the trap in and cover spring and chain completely. The best thing to cover with is the moss, plants and stuff from the inside of a muskrat house as they like the smell of this stuff and it covers up the smell of iron if there is much left on the trap. Place a few large leaves over the jaws and pan. If a mink comes anywhere near he is sure to smell the musk and be crazy to get at it, and while scratching away the leaves is pretty sure to 


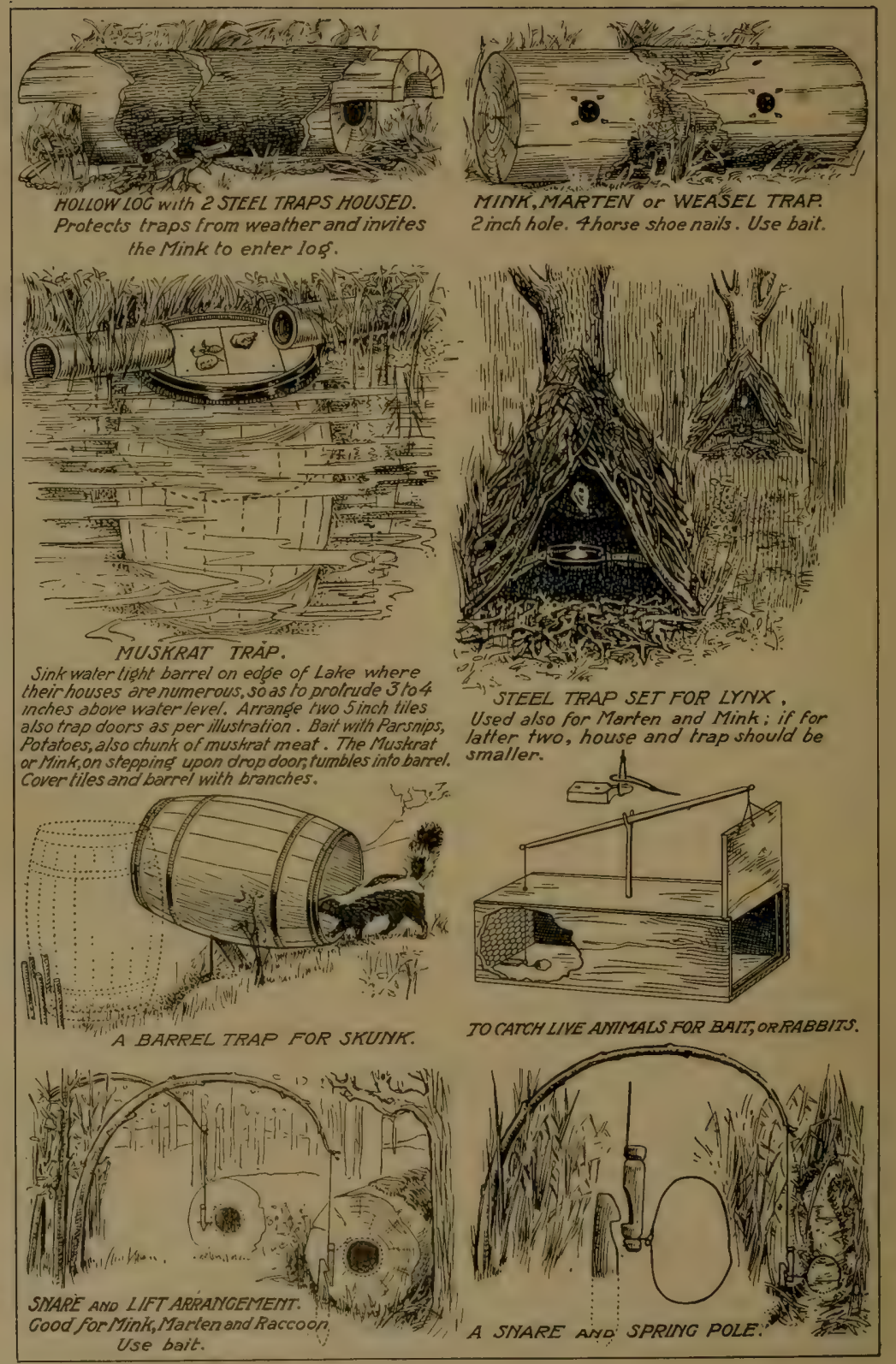


get a foot in the trap. Fasten the chain to a pole (not very heavy) about three or four feet from one end. This will prevent him from going under the ice; after he has pulled it a ways it will get tangled up in brush and he will be too weak to pull out."

\section{Trapping the Mink.}

One making mink trapping a speciality writes as follows:

"To be a successful mink trapper it is necessary to study the mink and his habits."

"I. Mink follow streams, along lake shores, are found in holes, excavations, dens, crevices, and in or about muskrat houses."

"2. Set your trap, No. I or No. 2 steel trap, in or about above mentioned abodes, and use chicken, rabbit or any other good bait, either scented or natural; place beyond the trap in the hole, also put above the trap. The animal will go in after the bait and becomes caught.

"3. Take the captured mink (be sure he is dead) and use him as a decoy. With left hand take body about upper part of hind legs, and with your right hand pull tail back and squeeze with left hand, and allow drippings to fall about trap set, also rub hind part within abode. This will make a strong scent, and other minks will readily enter hole believing that one is inside, also drag mink on ground from one trap to another.

"4. Use fine grass in covering up the trap, and always place cotton, dry leaves, and similar soft substances under the pan; cover lightly.

\section{Trapping the Mink.}

My experience in trapping dates back to 1857 . During this period I must have trapped thousands of mink and large numbers of foxes, trapped and killed bears, mountain lions, and in my time have seen plenty of buffalo and other large game. To be successful, I have always studied the habits of the animal. Steel traps in my time were not plentiful, and I was obliged to resort to home-made contrivances very often.

Some years ago, notwithstanding my long experience, I was unable to catch a certain mink. I tried all methods, set the steel trap up-side down, used snares, deadfalls, but all to no avail. I gave it up for the time being, and my son tried his hand with the same result. He finally made a box I $4 \times 16 \times 22$ with glass on two sides; into this box was placed a live chicken, and after the first slight snow, the box, chicken and all was carried to the place that the mink frequented almost every day. The traps had been set quite a number of days before, one 
securely fastened to a spring pole, the other to a drag. The box was set between the two traps and a quantity of loose brush thrown over it so as to make it look natural. The same day it snowed considerably.

One of us visited the box every day. Tracks were seen the second day, but the mink did not attempt to get the chicken or neared the concealed traps, but seemed to walk in a circle about the box. Next day, however, much to our surprise Mr. Mink was hanging five feet in the air. It was a large male mink and at one time must have been nipped in a steel trap. The skin was sold for $\$ 4.00$.

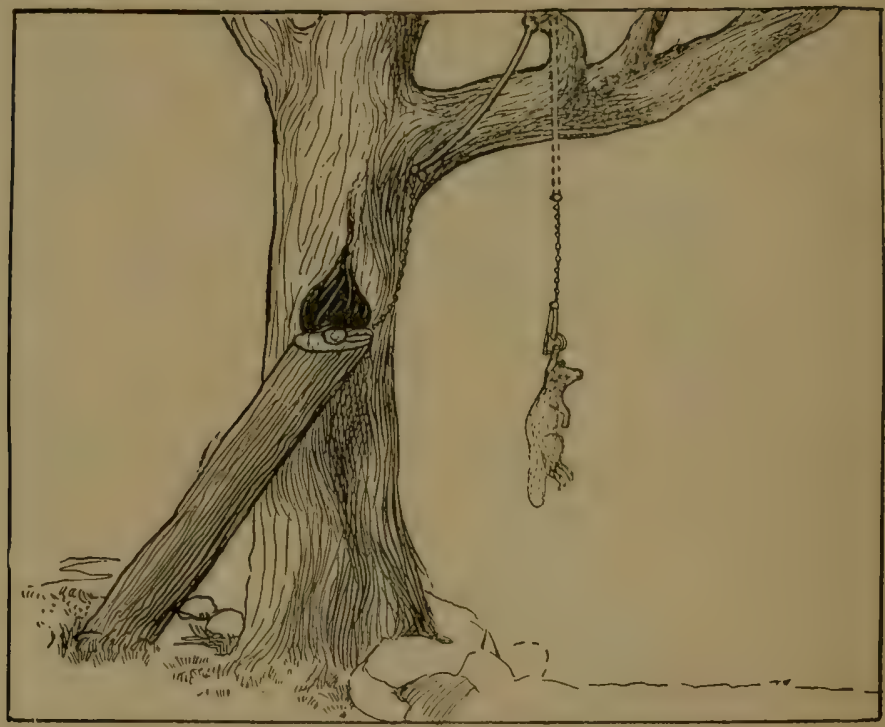

HOLLOW LOG STEEL TRAP SET.

When the trapper observes mink, marten, fisher, opossum or similar animals to frequent hollow logs, the entrance of which is two to five feet above the ground, an arrangement as above illustrated is strictly proper. The steel trap should be covered with moss, leaves or grass. Place bait at or about opening.

Supposing some trapper who has had the same kind of ill luck try this method.

\section{Trapping the Mink.}

R. B. A.

Mr. Frank Becht, of Webster, S. Dak., sends a few of his ways of catching mink.

"As I use the Stop Thief Wire Trap, I make a hole in bank of creek or stream, three or four inches leep, and place a small bird in back end of it for bait, and then put trap uver hole; but 
if trapping in common sloughs where the mink's holes can be easily found, place your trap over hole in such a way that the trigger or trip of trap will be close to the bottom of hole. Then place a bunch of feathers about four inches away from trap saturated with decoy or beaver's oil, and oil of amber for bait. If a common spring trap is used, make a stick about sixteen inches high, place a roasted chicken on top of stick, and set your trap below. The roasted chicken attracts the mink, and when there he will walk about, sniffing up towards the bait, and be sure to step in the trap."

\section{Trapping the Mink.}

My favorite way of capturing mink, writes Mr. Patrick Laughrey, West Broughton, Canada, is to drive a row of old sticks across the mouth of a small stream, leaving a small gap at center, in which gap I set my trap. I use No. I B. \& L. which I set about one inch below the level of the water. Trap should be covered in the usual way.

I have also been very successful in setting my traps along a small stream where the bank is steep. I set my trap close to the water edge on one side with a level beach on the other side. I make a little wall of stones so that the end reaches the water. The trap is placed at the edge of the wall below the level of the water and should a mink come along he will invariably pass by the edge of the wall and of course becomes a victim. I use no bait or scent. The trap is covered. Caught seventeen mink this season.

\section{Trapping the Mink.}

Have had much success in trapping mink on my farm and in its vicinity, and on one occasion caught a wolf. My method is as follows: "I take a dead chicken or any large piece of meat, whether old or fresh makes no difference. Bury this in the ground so that part of it protrudes and upon this set your trap. If you can spare more than one trap, set these about six to eight inches from the meat. The traps are to be buried and covered up. Be sure and put some wool under the pan. The animal in locating the meat will naturally become caught.

\section{Trapping the Mink.} N. C. A.

Mr. Lauersdorf, a Wisconsin trapper, writes as follows: "Take a skinned muskrat, tie a string about five feet long to it and drag it along on the ground where mink are known to run, and when you find a good place to set the trap, hang it on three stakes driven into the ground and extending six to eight inches 
above the ground; place your trap underneath. The mink, upon finding the track, will shortly follow it, and when it comes to the muskrat will spring the trap and become caught.

At other times a trap can be placed about two inches under water along shores that mink frequent. My method of making decoy is as follows: I procure small fish or minnows, which I ctit up into small pieces and place them in a wide necked bottle and with them about one-fourth to one-third angle worms. When bottle is three-quarters full, fill remainder with rain water. Cork up and expose bottle to the sun. When rancid, decoy is ready to use. Put a few drops of the above decoy on the bait or above the trap. Mink, marten, muskrat and coon are attracted by this decoy.

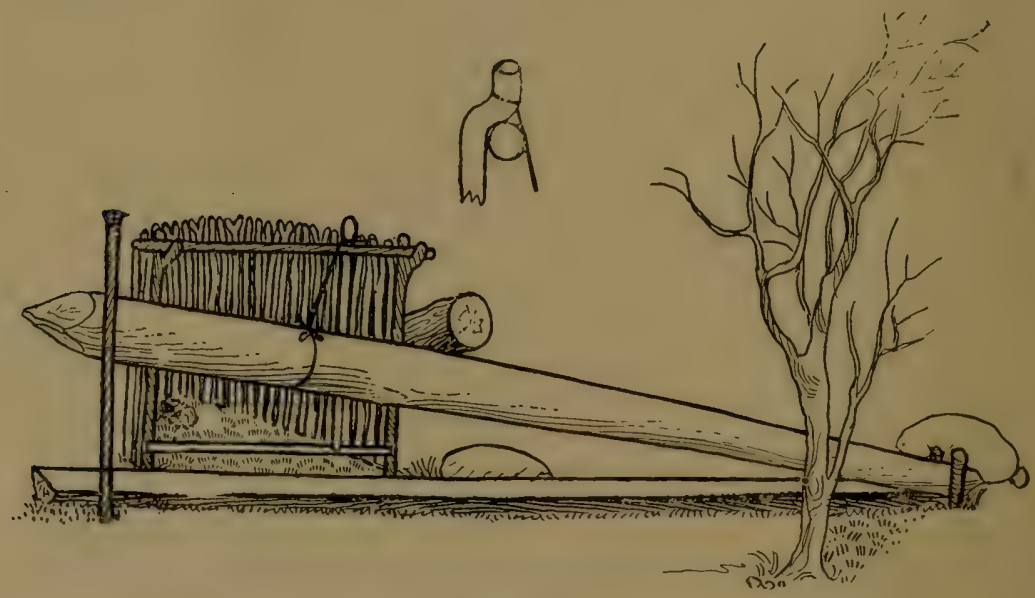

DEADFALL.

Another simple arrangement. Bait with a rabbit, dead fowl, or piece of muskrat. Bait should be fastened to the ground so as to detain the victim: To spring the trap the animal must either step on the spindle $n r$ press it down with his belly on entering the enclosure. Suitable for all classes of animals, especially the badger, skunk, wolf, fox, etc. A steel trap set in front of entrance makes the visitor's capture doubly sure.

Ascertain a den where a mink frequents and set your trap at the opening, concealing it in the usual way. A piece of muskrat or some other bait thrown carelessly in the opening ten to twelve inches, is sufficient bait. Should the animal pass that vicinity the bait will attract him, especially if he be a strange animal, and in passing into the abode to obtain the bait, will spring the trap. If the abode is inhabited, the mink in departing is likely to spring the trap, as well as the one entering." 


\section{Trapping the Mink.}

This interesting article we received from Mr. T. Wolfe, an Iowa trapper living at Tabor.

"Perhaps this most valuable little fur animal found in most sections of the U. S. and to the far north in British possessions, frequenting lakes, streams and small rivulets, has puzzled more trappers than are willing to admit because of its keen scent and extremely cautious nature. I think I can say, who should not say it, that I have been fairly successful in trapping for mink, having caught as high as $\$ 436.00$ worth in a single week, making trapping remumerative as well as a pleasure. Much has been said about the kind of bait, scent, etc., to be used. The best bait is fish, muskrat, sapsucker, prairie chicken and quail. When a mink will not pay attention to any of these it is evident that it is not hungry. Many so-called scents serve only to frighten the mink away. I once caught $\$ 436.00$ worth in a week, and they were not plentiful to speak of either, but did it by diligence and caution.

"Never set a trap for mink that has the scent of other animals on it, for that will at once arouse their suspicion. If you are trapping on a stream, it may sometimes become necessary to set in the water, although this is objectionable, for the mink in trying to release himself, is apt to cover his fur with mud and if cased in this condition is most likely to grade as damaged fur. The proper thing to do in a case of this kind is to carry the mink to camp, get a basin of warm water and thoroughly wash and dry the fur before casing.

"When minks frequent lakes, if there are rushes and rat houses, go along the borders where they are most likely to travel and select a rat house well surrounded by flags and rushes, carefully cut a place in the edge of the house for a trap, then place the bait first so the mink will have to go over the trap to reach it. Always turn the spring of the trap toward the bait or in such a manner that the mink will not be standing over the spring of the trap when it throws as the springs are apt to throw its feet out of the jaws of the trap.

"A friend of mine once trapped for a large mink, which frequented a slough, the surrounding country being flat and more or less marshy. Not being able to catch it he turned it over to me and it was with some misgiving I undertook the job as I knew him to be quite apt; but selecting a few good traps, I went up the slough one morning after a fresh fall of snow. I found the mink had been out in much evidence; following the tracks up I soon came to where the mink had struck across the bottom; still following I soon came to where he went into a hole that 
apparently went straight down. Selecting a good strong trap and carefully clearing away the frost and snow, I placed the trap upside down over the hole, taking care to have the pan of the trap exactly over the hole. Next morning I had a very valuable mink. I have caught quite a number of minks in this way.

"Minks like to follow old fence rows that border the banks of lakes and sloughs, making it easy to take them by setting a trap by a fence post and tacking the bait to the post just above the trap. This rule will hold good along the banks of wooded streams where the trap can be fastened to small saplings or trees, or to a toggle. Every sucecssful trapper should carry a good hatchet and wire staples as there is nothing better than wire staples to fasten to a toggle or other convenient things."

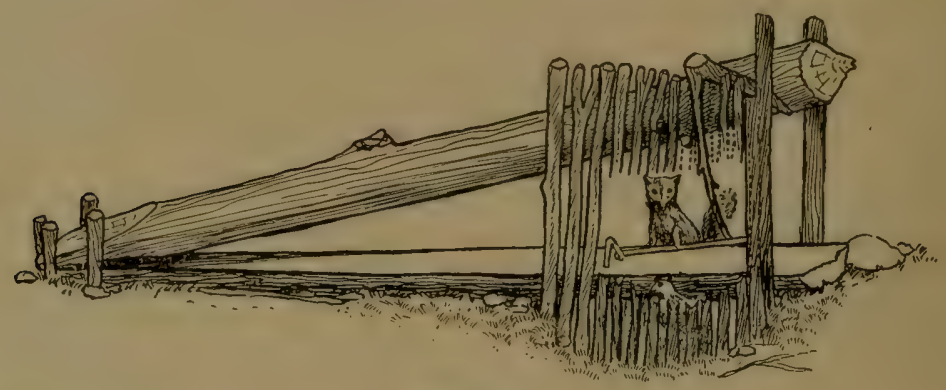

DEADFALL.

A peculiar yet successful arrangement in capturing various animalis from the little weasel to the black bear. This deadfall is continually useis by trappers, especially throughout Canada, chiefly in timber sections.

\section{Trapping the Mink.}

I find the mink a rather shy animal, but have never had any great trouble in catching him. One of my ways is to set my traps in old muskrat volts, pinning my bait down and well back in the hole with a sharp stick, using for bait rabbit, bird, and fish. Always have your bait fresh and clean. I also find the outlet of tiled drainage, which seems a splendid place to catch both mink and skunk, always making a neat, careful set close up to the tile, and if an extra large one, set well up in the tile without bait.

Another plan I find very good is to go to old field road bridges that are down low to the water and take up one of the planks. Set your trap in two inches of water. Leave a small nail in one of the stringers and hang your bait with a string directly over your trap, and six inches above it. Also you will find under the roots of large trees that have been partly washed out, a good place to set traps with bait. 
The mink is a great traveler and hunter and he frequents every nook and corner and if you keep all these places well occupied by careful, neat set traps, you will have your share of success. You will find a great many of these plans to be good and successful ones. Also you will learn some of your best plans by careful study and practical experience, the same as in all other business. You have to adapt your plans to suit the country you trap in, such as a prairie trapper, or a timber, or mountain trapper.

\section{Charles Sessions,}

Clinton, Ill.

Deadfall I give you herewith my method of making a Trigger. trigger for the deadfall. This trigger I believe to be entirely new to the outside world, although it has been in use a good many years by two old Canadian trappers

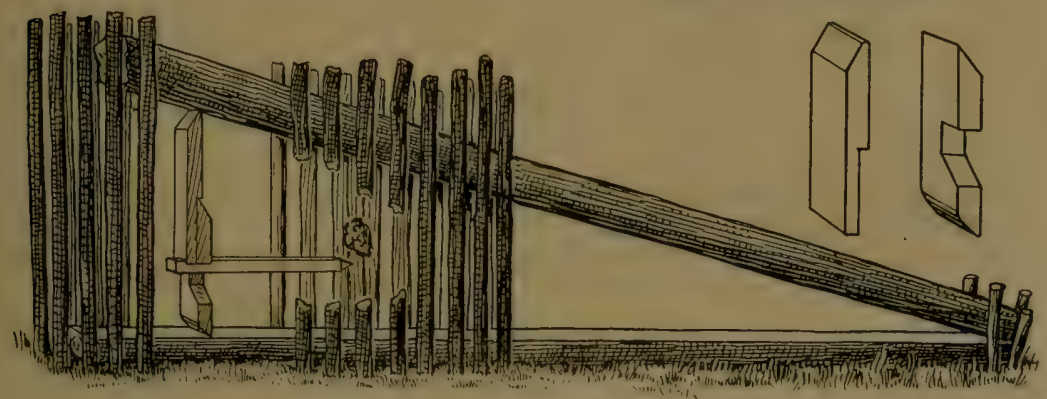

who were the originators. I got this trigger from one of the trappers and have tested it thoroughly on mink, marten, etc., and find it so far ahead of any other that I use it entirely.

Some animals go into a pen for nothing else than to smell the bait or to investigate. This trap catcles these fellows, whereas the other triggers do not. The pen of this trap wants to be short so that the animal cannot get in too far. The bait should be stuck or hung up on back of pen, say six inches high, for mink, marten, etc. The animal never fails to step or rub against trigger in reaching up to smell bait. Always keep the guides a distance from the trigger to prevent jamming, or use one set of guides. The treadle also wants to be slightly turned in pen.

\section{RaLPH Wolverton. \\ Cascade, B. C.}

Trapping the Mink.

To capture mink, I follow the banks of streams where the water nears a bank two or three feet high. I then dig a hole in 
the bank a foot wide and two feet deep. Then proceed to build a sort of wharf out of stones. Some of the dirt I place on top of the bank and when my sets are complete I take handfuls of the dirt and strew over the setting so as to eradicate the footprints and to make everything seem fresh. The bait is placed within the abode, excepting small pieces are carefully strewn close to the water which has a tendency to attract the animal. The trap is placed a few inches within the abode, the pan facing the stream. There is no harm in dragging the bait in the immediate vicinity, finally leading it into the hole. The trap should be securely covered with rotten wood and lastly with fine earth.

For scent I use fish oil made by me during the summer time from minnows, shiners and perch. If in position to obtain a female mink during the running season, the matrix of the animal is placed in a bottle, either separate or with the fish oil. Have had good success. As much as possible I use spring poles, but if the weather is mild I arrange to fix up some way to drown the animal.

\section{Trapping the Mink.}

N. C. A.

"Many years have now past but I still remember one February morning at three o'clock my father yelled-."Roll out Son, if you want to go the round with me this morning." A snow storm was in full bloom. After a hasty breakfast of corn bread, venison and black coffee, we both swung out on the trail. Father was trapping for mink and promised to take me along. This was mating season and about one mile up stream, close to a pond where a small stream emptied into the Tygart we came to a small hollow $\log$ and in this $\log$ was a female mink. On the outside father had set three Newhouse traps and two of them were sprung each holding a male mink. Farther up the trap line we came to a hollow tree. Inside this father had imprisoned another female mink. He had set five traps on the outside and three of them were sprung, each holding a large male mink; five minks in less than two miles trapping. I was small then but I learned a secret that morning that easily knocks out any method known to the trapping world. Brother Trapper you can readily understand why these minks were imprisoned. The next thing is how to catch the female mink, alive and unharmed.

Get four boards six inches wide and nail them together forming a long box. In one end make a trap door by inserting piece of board nine inches long; fasten the end of the board with leather hinges, thus you have a door that inclines toward the center of box. Take a stick the size of a pencil two inches long, and set upright. Now you have the door set. If you have already located den-which every old trapper knows is easily done by 
certain signs-insert the trap with door raised about one foot into the hole. If you cannot find such a den, make one, into which after placing the box, close up all other openings and see that box is solid. Let swing door rest on pencil. No bait is necessary. The female mink will enter in order to hide from the male and you have your mink as sure as shooting.

You will ask: "Why can't we catch the male mink by this method?" Simply because the male mink is rarely, if ever, in their home dens at this season as they are travelling and seek drifts, etc., by day.

\section{WES RAY, Trapping the Mink and Muskrat. \\ Olive Hill, Ky.}

For trapping mink in a water set, find a shallow place about one or two inches deep then take your bait (a piece of muskrat, bird or fish is good), run a stick through it and stake to the bottom so that the bait will just stick out. Set your trap alongside of it and cover trap with wet leaves or grass. Do not make any tracks on bank but wade up the creek in order not to disturb anything.

second: Find a stream about two feet wide that flows into a lake, pond or larger stream; stake it off with small
twigs or weeds, leaving a small open place in center about four inches wide in which place a No. I or $\mathrm{I} / 2$ trap. When the mink is travelling up this small stream he will go through the open place and get caught.

Third: Find a hollow log along the stream, and set your trap so it will be level with the bottom of the $\log$; cover with decayed wood from the same log so it will look natural. Mink like to run through anything hollow.

muskrat. A good way to catch muskrats is to make a box
about four feet long and one foot wide with wire

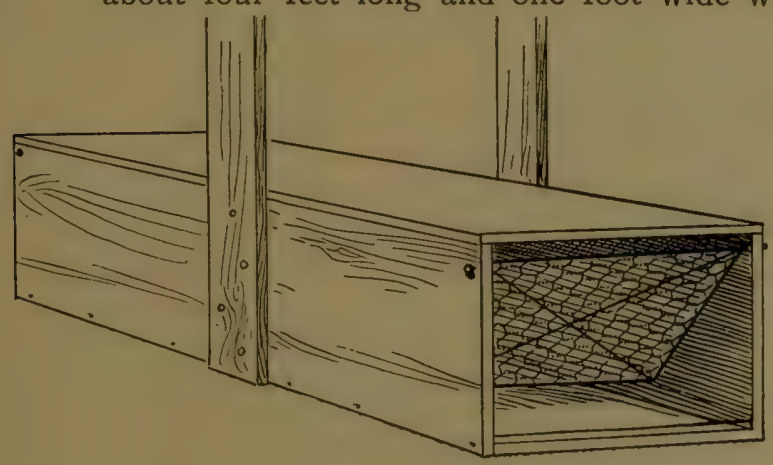


end. A roller, or mowable stick is fitted into each end and by givulet hole. wires fastened thereto large eanough to insiline at forty-five degrees as shown in illustration.

The animal lifts the irops in soing in firon citier end. but camot get out. Set this in a small strem and arrange it so he will have to go through the box to get past. This can be dona by driving stakes into the bottom along the box. I have caught as high as five in one night in this way.

\section{FRAXK B.NDER, \\ S. Williamsport, $\mathrm{Pa}$. \\ Trapping the Mink.}

I have been very successul in trapping mink; I give you herewith my method: Find a mink dent take a rabbit. for or rod suuirrel and a small bush or tree t the same kind that is near the (en or hole) and rum the stake through the gambrels of the rabbit. Drive the stake about one foot from the bole: lig out a place just large enough for the trap about midway between tlie bait and the hole: place another trap on the other sicle of your bait. Sink this trap in level with the top of the sround. put some rine grass in the bottom and place trap on the grass so it will set solid, and cover with leaves or grass. I prefer a No. I? 2 trap. Use a bush for a stake and only trim enough to lrive it in the ground.

\section{E. N. DABNET, Trapping the Mink. Bristolville, $\mathrm{O}$.}

The best and most successtul way to trap mink is to find where they have been running and track them to their den and if same canmot be found set rour trap ( No. I or I 1 ..) in the freshest of the tracks: if they are in the sand or digsab?e earth. exavate a place large enough to hold trap and chain and arrange to have pan level with the surrounding earth. Cover pan and tran with loose leaves and sprinkle fine earth over leaves so as to cover trap completely, but at the same time so that earth or leaves do not interfere when trap is sprung. Quite oiten I place the ring through a limb. which I insert in the earth to resemble a small growing tree. After this is done remove all possible traces and leave place in natural state. Bait with fish, birds or part of a muskrat. If you have reason to believe that the mink that you are trying to capture is cne that has been pinched before. you can take it as coming from an old experienced trapper, that a job is before you. and in this respect a very good location in which to set your trap is in an old muskrat house, especially if the mink is in the habit of going in or about the house. If 
there is no opening on the top of the house, make one. Pull up some of the grasses, weeds, ete., that are usually within a muskrat house and arrange your trap about the wall and cover with grasses, etc. It is preferable to place two or three traps, the more the better-and the quicker you are likely to capture the sly thief. Bait with bird or muskrat and promiscuously strew feathers about the traps and their immediate vicinity. In addition I use Oil of Anise and the scent of the female mink.

HEINRICH BRos.,

\section{Set for Minks, Coons, etc.}

Baldwin, N. Y.

Having noticed that where a tree or log has fallen or been placed across a brook or creek, any animal travelling in that vicinity will, more or less, cross upon it, led me to invent the following device:

The only tools necessary are a good sharp axe and a spade. With your tools and traps, go to the mouth of some stream or creek that empties into a lake or river. Take your axe and cut a $\log$ say eight or ten inclies in diameter and long enough to reach across the creek, allowing about six inches to extend on

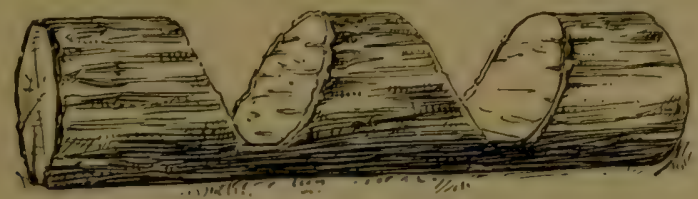

either shore. Bcfore putting log in place, take your axe and at center of $\log$ cut a notch just the size of trap and $I \frac{1}{2}$ inches deep. Cut two more notches, one on each side of the trap notch, in shape of the letter "V," six inches wide at the top and seven inches deep.

When notches are cut, lay the $\log$ across the creek near the moutl. Take the spade and dig out each bank so the log will be $\mathrm{I} / 2$ inches out of water. Set the trap in the center notch and stake trap chain to bed of the creek. It is best to set trap in good shape, taking plenty of time and concealing each trap carefully.

\section{ORRIN WICKS, Hamilton, Mich.}

\section{Trapping the Mink.}

I am 54 years old, and have been interested in hunting, trapping, fishing and woodcraft practically all my life. I give you my suggestive ideas as to trapping mink, also in another article as to fishing. not only for bait, but for food supply. The latter is very important for one away from home or civilization. 
The time for setting traps for mink depends upon the weather and locality. In the northern and eastern states, from the first to the last of October. If your first mink skin shows dark on the inside, you had better leave your bait and take up your traps for a iew days. The place to set your traps is along the banks of streams and on the shores of lakes and ponds. If possible find small spring brooks that empty into streams and lakes and at the mouth of these runs, build an enclosure with an opening in front of same, say five or six inches wide by about ten or twelve high. This end of the enclosure should stand in the water so that your trap will be about one inch under water. Now cover trap with moss or wet leaves. Never stake your trap, but use a swing or talley pole; if the first, drive a stake with crotch on, lown near the trap, and place a pole in the crotch. fasten trap chain to the small end, and hook it down to a peg driven in the ground. The butt end of pole should be heavy enough to swing mink clear of the ground. Oi the two I prefer the talley prie. from the fact that one will not lose a trap if a skunk or raccoinn is caught. For this, use a sapling with all limbs left on. wedge chain ring on and tie the top of talley pole to a near-by bush or small limb. There is give enough to this arrangement to prevent mink from pulling out. Now place the bait on a stick in the back end of enclosure. I have found no better bait than muskrat, fish is also good. Any meat will answer.

A good scent for fall trapping is fish oil (preferably trout) with three or four musk glands from the muskrat added; put fish and glanis into a bottle, crork and hang same in the sun. use a few drops of this around the enclosure, not on the bait. Save the musk glands of the female mink (bottle, hang in the sun as before) for winter and spring trapping.

Another ver: good way is to set trap in a runway. If a natural one cannict be found, make one by placing an rold log near a steep bank and place another log partly over this so that it will rest against the bank. If there is a space between logs and water drive down a iew stakes, then they will quite likely pass through the artificial runway. Use no bait in this set; use talley pole as before.

Skinning.-Rip down the back side of both hind legs to vent. be careful and not go deep enough to cut musk glands at root of tail. use a split stick to remove bone from tail. Now pull skin off over body, cut aro:and the e:es and ears and the skin is ready for stretching.

Stretching Skin.-This is best done on a three piece fur-board, which is marle as iollows: First make the board from one-half inch stock, round off end and the edges. Now saw this length- 
wise into three pieces; the middle piece should be a little tapering to form a wedge. Put the shin on the outside pieces first and stretch it as long as it will go and tack. Now insert the wedge. When the shin is dry, which is best done in a dark place, it 1 s ready for market.

$$
\begin{aligned}
& \text { F. H. BAsSET, } \\
& \text { Trapping Mink and Fox. }
\end{aligned}
$$

I have a very good way to catch mink and fox. My minchod of catching mink is this: I use a No. 3 Newhouse trap, but remove one of the springs. Thus I have a trap that catches a mink so high that he cannot gnaw or twist out. They stay right there until I take them out. I never had a mink get away yet. But a No. 2 trap gets feet and toes.

I use mink's musk and mink's matrix, muskrat's musk, and oil of cumin, well mixed, and let it stand in an air-tight bottle six months and shake well before using. Four to six drops of this scent is all I need to catch the slyest old dog mink that ever walked. I certainly can get them every time. I catch three female mink in the mating season, and get the matrix of the three and put into a half-pint bottle. Then I take the musk-bags of fifteen male mink and squeeze the musk into the bottle. I then citch enough muskrats to get four ounces of clear rat musk and from the druggist I get one ounce of oil of cumin. I put all into the bottle and cork it up air-tight. To bait the traps, I take a piece of muskrat skin and tie it on the pan of my trap and put four to six drops of this scent on it. Then I cover trap and chain so nothing is in sight but the muskrat shin on the pan. If there is a mink within one mile of my trap, and the wind blows in his direction, I know of no reason why I will not catcl him. It is the best mink scent and bait that any living man ever used.

I have used all kinds of scent and never found any that was anywheres near as good as this kind. I know from experience what I am saying. I never had a mink get away from a No. 3 trap yet. Anyone starting to make this scent need not make as mucli at one time. Make one-half or one-quarter at a time to get started. That is the way to capture the mink.

\section{ED BREHMER,}

\section{Trapping the Mink.}

Spring Valley, Minn.

In trapping the mink I have seldom used bait, although he will taste of almost anything that is, fish. flesh or fowl. The bait and trap in which I place the most reliance, is set in a hole- 
in some bank of a stream or pond; in a hollow log, among the rocks; under a root; stranded ice or overlianging bank. A mink is almost certain to poke into any hole that he comes to.

He seldom passes a hollow log or a hole in the bank without diving into it and exploring it to the bottom. If there is a $\log$ leaning from the bank into the water he will go under instead of over it and a Newhouse No. I or a "jumper" placed in the entrance and lightly covered with moss or leaves, will get him the first time he comes that way. I will say right here that I do not believe a mink cares any more for a naked trap than he does for a stick. If a trap is not covered, he will step over it or go round it because it is better footing that way. It is much better to cover a trap than not for the purpose of making easy footing, and if he is guided by sticks or stones onto the spot where the trap is, the catch is made more certain.

Male minks are great wanderers during the months of February and March. During their rustling about they are looking more intently for the female than for food; their errand being one of love, in their quest they leave no hiding place unexplored, and whatever caution they may have is forgotten at this time, and they will rush as blindly into any kind of a trap as a pig. The female remains more closely at home, seldom going far from the valley, swamp or water course that has been her home, so long as there is plenty of the favorite food.

Mink feed on the cottontail rabbit more often than on fish and I believe prefer the muskrat to either. I have caught a great many in traps set in the places where muskrats haul up aquatic plants to eat. Where rats are at all abundant (these places are common along water courses and ponds) they are frequently caught in traps set in muskrat houses in the winter.

A favorite set of mine has been to drive a number of stakes across a small stream, making a fence that is impassable except through an opening about six inches wide, in which a trap is set on a stone sunk to leave the trap about an inch under water. If placed where there is some current it is quite an effective set in cold weather.

I seldom use the sliding pole in trapping mink as they scarcely ever twist off a foot even on land, and when near deep water they usually become entangled in roots or other obstructions and drown.

Where bait is used, a good place to set your trap is at the junction of a small brook with a larger one; the trap is to be set in the water with the bait suspended over it in such a way that the animal must step on the trap to get at it. A hole dug in the 
bank and the bait placed in the back with the trap at the entrance is also very good.

For lure, the scent bags of the female preserved in glycerine has great attraction for the male, as is the case with all animals. Fish oil is good medicine-anything fishy attracts them--canned salmon, sardines, rotten shiners or other small fish, among which a few fresh ones are placed, is very attractive to them.

An old mill dam is a favorite haunt of minks and there can usually be found a well-defined trail from the stream below the dam to the pond above around one or both ends.

\section{Chalsles E. Ingalis,}

East Templeton, Mass.

\section{Trapping the Mink.}

"I will tell you how I have been very successful catching mink," writes Mr. J. Funk of Tiffin, Ohio.

"I always used the No. I Newhouse trap. I did my trapping along a small creek and I would always try to set my trap on the bank where the creek made a sharp curve, especially where the water washed under the roots of trees. If there is a log near, I set my trap along this. Now I make what I call a coop. For this I procure a piece of bark or a flat piece of wood about twenty inches long and seven inches wide. Then I cut four small stakes and drive two of these in the ground six inches from the $\log$ and one inch apart; the next two I drive about the same distance from the $\log$ and six inches from the other two. Then I slip the bark down between these stakes; get two sticks, lay one at each end from the bark to the log. Another piece of bark is needed for the roof so it will cover the coop nicely. Chopping should be avoided as much as possible. After this part is completed, I put a chunk in one end of the coop as tight as possible so the mink is compelled to enter from the other end. Then I put my bait in the back end against the chunk, and I always use chicken, rabbit, or muskrat for this. Now I set my trap. This should be set as light as possible with the spring toward the back end of the coop and cover with nice dry beach leaves. I always stake my trap for minks, by getting a stake about fourteen inches long with a branch at the top so the ring cannot slip off ,and driving it down at the side of the coop."

We have the following from Mr. Ernest Havner, of Ludlow, Montana:

"The mink eats fish, frogs and craw fish, and now and then gets into the barn and steals chickens, goslings and ducks, and crawls into the cellar and eats up the sausage meat, or whatever 
he can get his jaws on. $\mathrm{He}$ is a pilfering little animal and yet so simple and foolish that he is easily caught by a trapper that knows his habits. For the sake of something to eat, he runs up streams and crosses from one lake to another, a regular renegade. He only runs along steep banks, or under old roots and around rocks. The young are brought forth in May or June, in litters of five or six blấck looking little things.

"To catch this animal you have only to be acquainted with its habits. He follows streams of water, hunting every nook and corner for something to eat. Place your trap near the edge of the water, (No. I $1 / 2$ is the best for mink). Have it covered with about an inch of water, directly in front of a steep bank or rock, or something on which you can hang your bait about eighteen inches above the level of the trap, which must be so close to

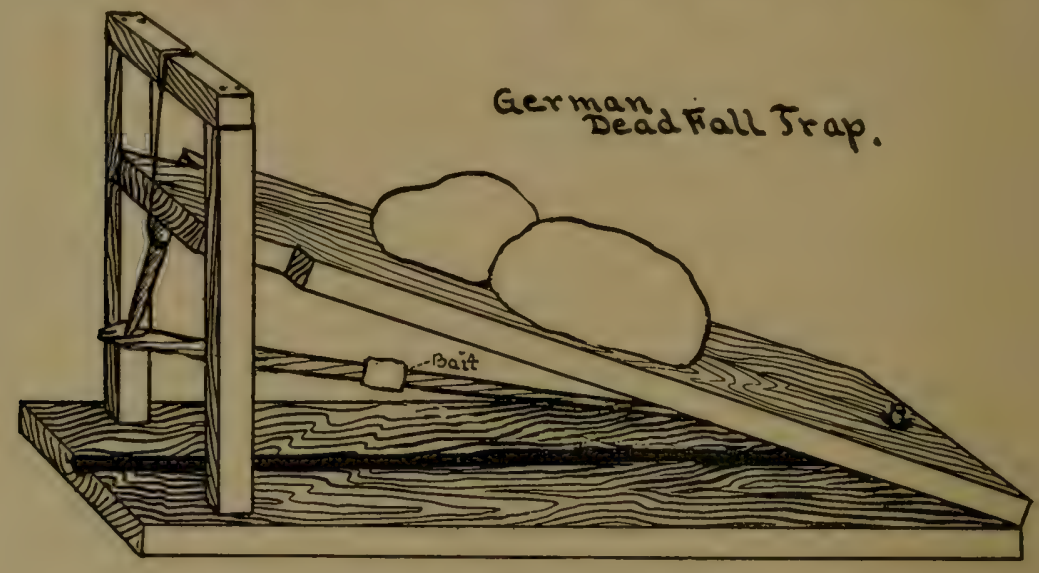

GERMAN DEADFALL TRAP.

This contrivance is chiefly used in Europe for killing mice and rats. In this country it is commonly known as the "gallow trap." Large numbers of weasels, ermines and minks are annually caught in this trap, principally in or abcut the chicken coop. If made on a larger scale the trap is suitable for killing mink, marten, fisher and foxes. The weight on top of upper board must be heavy, so as to break the bones and hold the animal fast. Spindle is tied to center pin by a thin string. Upper board should fit loosely about lower pin.

the shore that the mink cannot get to the bait without stepping on it. The bait should be fresh fish or frogs, or the head of some bird or fowl, as he is very fond of brains.

"Another plan is to set your trap on the land about ten feet from the shore, covering it with a few leaves, moss, grass or loose dirt, or anything that will not prevent the jaws from closing. Hang the bait about eighteen inches above it and scent it with a mixture made of equal parts of honey, sweet oil, and essence of 
peppermint. About a teaspoonful of this on the bait will cause . them to come a long distance.

"Another good plan in which I have had good success is to set your traps about two feet back from the water, and from forty to eighty rods apart, up or down stream. Then walk over the line drawing after you the carcass of a muskrat or a roasted crow, or almost any fresh meat, and any mink that crosses this line or trail will follow it to the trap.

"It is also a good plan to set your trap where the mink must walk over it to get at the bait. $\mathrm{He}$ is a great fellow to catch muskrats, which he loves to eat, and you may bait the trap with muskrat carcass and set it in a rat house where you will often find handfuls of little fish that the mink has brought there.

"In the winter time he travels along springy brooks, pulling out frogs, and here he may be easily caught. You may also catch them in winter at the sides of big springs or along the springy sides of ponds and swamps where they like to roam."

Gentlemen :-

\section{Poisoning Minks.}

Answering your letter relative to my ways of trapping, pormit me to say that I use poison to a greater or less extent.

The poison is put into $2,3,4$ and 5 grain capsules and I use equal parts of powdered arsenic and carbolic crystals. Tiie smaller sized capsules are for smaller animals and the others for fox and wolf.

I place these capsules sometimes into the carcass of dead animals, other times in small bits of meat, especially for the wolf, that he can swallow. Sure death is a positive result. Never known to fail.

I have known and personally caught skunk and mink, as we!l as muskrat, by placing a bait on good sized fish-hook-the latter being attached to a wire. This may seen funny but nevertheless it is a fact. It is not more cruel to catch these animals that way than it is to catch fish. Death comes just as soon as they iry to escape.

Yours truly, Frank JENSEN.

\section{Box Set For Mink.}

A British Columbia trapper, who wants his name withheld, states that he has had continued success for three years in trapping mink, and during that time shipped at least $\$ 500.00$ ivorth of raw furs, and no small part of them were mink captured in the usual way, also in his favorite Box Spring Set. 
Locate a spring or some junction point where the water of a spring enters into a creek, and at the most stiitable place birilr a box of two-inch boards, two to three feet wide, three to five feet long and as deep as necessary (twelve to twenty inches). Bore many small holes into the sides or ends, so that a fresh supply of water circulates at all times. Now place small live fish as bait therein and continue to keep this stocked from the early fall or even summer. The idea is to educate the mink, marten, otter or even the fox to habitually come after a meal. They will soon become accustomed to come every few days.

I make a small shelf on one side or end of the box about three inches below the level, upon which the mink usually stands and gets into and out of the box. I set my trap on this shelf. Trap is attached to a stone by wire, so that when the trap is sprung the mink will jump into the water and pull the nearly balanced stone with him. The weight of the trap and stone will easily drown the mink. On one occasion I set two traps, one as above described, the other on the edge of the box nearest to the shore. The latter trap had a regulation chain which I attached to a rope. This rope was passed over limb of tree that stood conveniently by. On the fork of this limb I balanced a stone weighing probably ten to fourteen pounds, so when the fisher came during the night to obtain a bite or two he sprung the trap and evidently made a side jump, and in so doing disturbed the stone. When I came I found the mink dead in the water and the young fisher swinging five feet in the air. I killed him with my revolver. When I saw him hanging I just thought it was an otter, but his long neck and firm hold with his teeth on the chain convinced me that a lead pellet would put him out of misery and enrich me by $\$ 6.00$ to $\$ 10.00$.

When nearing the set, even when re-stocking the box with fish, I made it a point to wade through the water and always from the opposite side.

\section{Unique Method of Capturing Mink and Muskrats.}

This unique way of catching mink, muskrats, even fisher and otter, is worthy of trial by anyone who finds a suitable log across a stream or reaching out in some lake.

A strong wire is attached from one end to another on stakes securely driven into the ground, the wire running parallel with the $\log$ but at a distance of twelve to sixteen inches. Fasten strong fish hooks to some linen lines capable of holding the desired animal, and attach to wire. Fasten securely so as not to slide. Bait hooks with small pieces of muskrat, which the animal is able to swallow without chewing. One-half of the hooks 
so baited should be placed on the log, the remainder just touching the water. To prevent the victim chewing off the string, use guitar wire or gut strings. If hook is attached six inches from one end of line and to the latter a stone weighing one to two pounds is placed on the log, when the animal is caught he will jump off the log into the water and the stone will have a tendency to hold the animal down and of course he will drown very quickly. Those lines which touch the water are arranged for mink, muskrats and others coming up stream and become caught without getting on the log.

A Montana trapper has used this method successfully and at one time caught an otter, on another occasion his six out of eight hooks had a victim-three minks, one marten, a weasel and a fisher. It is a very good idea to arrange a stone to pull the animal below the level of the water.

$$
\text { C. F. G. }
$$

\section{Trapping the Mink.}

After trying nearly all kinds of baits and scents with no great results, I hit upon a bait of my own three years ago, which I have used exclusively since, and will say that I have had first-rate results. While minks are scarce in my locality, if I can find where one runs or a place they travel, I have nearly always taken them, and $I$ am going to give the readers of this article the benefit of my experience.

I am not going to tell you how to set your traps, as I find nearly every trapper has his favorite sets. As for me, I use the pen or cobby, the hollow $\log$, or hole; whichever I find handiest. I take pains in setting and covering my trap. My favorite trap is the Oneida Jump trap No. 2, which I set and cover to make look as nearly natural with the surroundings as possible.

Then, for bait, I use the common canned salmon and I find, in my locality a mink will take it when nothing else will attract him. The way I use it is to take a can as it comes from the store and empty the juice and about half the fish in a largemouthed bottle with a good cork to it. After setting my trap, I dip a stick down in this bottle and place the stick back of the trap, only using what salmon adheres to the stick. This is both a scent and a bait.

I have purchased different kinds of scents, paying \$r.00 for a little bottle no bigger than my little finger, also made fish oil, angle worm, and all those things, but give me the canned salmon. It does not hurt it if it becomes a little rancid.

F. H. SHEEr, Montrose, $\mathrm{Pa}$. 
Take a box trap and line it with tin. Take a two-inch plank, bore a two or three-inch hole in it, drive sharp nails in about one inch from the top. Bore a hole a little larger than the spindle, insert spindle in it; have the plank so arranged that it cannot be shoved in any farther. Put bait behind plank and set trap. As the mink puts his head in the hole to get bait, he will pull to get out and spring the trap, and once sprung, he is yours.

Stop Thief traps are very good. I averaged one mink every day for a week by the use of these traps, which could hardly be possible with any other. Take essence of peppermint, honey and sweet oil for scent, or small fish cut in pieces and put in a bottle in the sun till oil is formed.

\section{TRAPPING THE MARTEN.}

N. C. A.

"I will tell you how I trap marten," writes Mr. C. Anderson of Cape Scott. "I go up on a hill where there is cedar and find

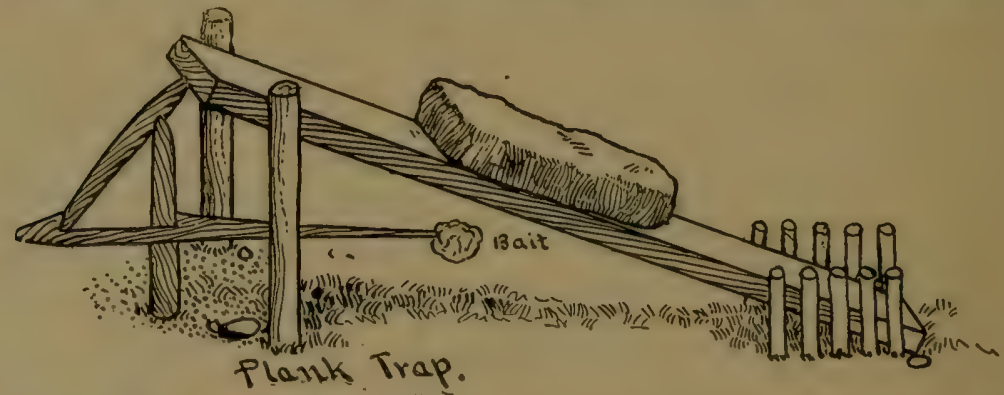

where they have been running up and scratching the bark off the trees. I then take sticks and drive in the ground to make a pen, leaving an opening where I set a No. I trap, and cover it up with feathers. Use fish and venison for bait. Throw the bait in the pen about eighteen inches from the trap. Drag bait when going from one trap to another as the marten will follow the scent."

In trapping marten one wants to set his traps the same as he does for mink, excepting he must take into consideration that the marten is at home on trees, perhaps more so than on terra firma. I prefer to set my traps mostly in pens, especially constructed with the idea of leaving them from one year to that of another. Set the traps in the den, concealing them in the usual way.

When it comes to bait, I use decomposed fish; probably nothing is better than salmon roe, especially if putrid. If this is unobtainable any other meat or fish will do. No artificial oil is used 
by me, although a brother trapper of mine has used anise oil. No. I and $I 1 / 2$ Newhouse traps are used exclusively by me. Since trapping up here, I have found that it does not pay to depend entirely upon marten, as some years the catch is so light that one would starve if he had to depend upon the returns that he received from the sale of marten skins. Therefore I spend considerable time in trapping for fox, lynx and of course mink.

There is no particular rule where marten traps are to be set. One must study the habits of the animal and during the winter time choose the place where the tracks are most numerous. $\mathrm{My}$ marten line sometimes extends three-quarters of a mile, but 50 traps is all I care to handle besides sets for other animals.

\section{Trapping the Marten.}

E. L. Turner.

Frequently marten are met with in low, swampy ground, where the timber is small and therefore there will be no hollow logs or decayed stumps. In such case the trapper will have to avail himself of the boughs of spruce or balsam-fir to make a structure to keep out snow. Selecting a place where tracks are most numerous, both old and fresh, and where there are one or more evergreens growing, he proceeds to cut down a spruce and trimming off the branches cuts it into lengths about three feet long; these he drives into the snow or mossy ground in a circle about a foot in diameter, with an opening on one side alsout four inches wide. The stakes slant outward, making the pen wider at top. The bait, which may be any kind of meat or bird, is fastened inside the pen with a peg put through it. The trap is placed in the opening and two twigs are stuck in the ground on both sides of the trap, thus insuring success. The twigs also should slant outwards; next the sides and top of the pen are covered with spruce boughs, heavily on the top and letting the ends come down so as to almost conceal the opening. This is for keeping out meat birds and other vermin. The marten will find the opening without difficulty and of course when he steps in to get the bait becomes caught.

\section{TRAPPING THE SKUNK.}

T. Gullickson.

The trapping of skunk is one of the most profitable branches of trapping, especially for the farmer and members of his family, on their own and adjoining lands, and it is only natural that the younger element should pursue these practices during the winter months.

The fur of the skunk usually becomes prime November Ist, and during that month, also December, his skin brings the trap- 


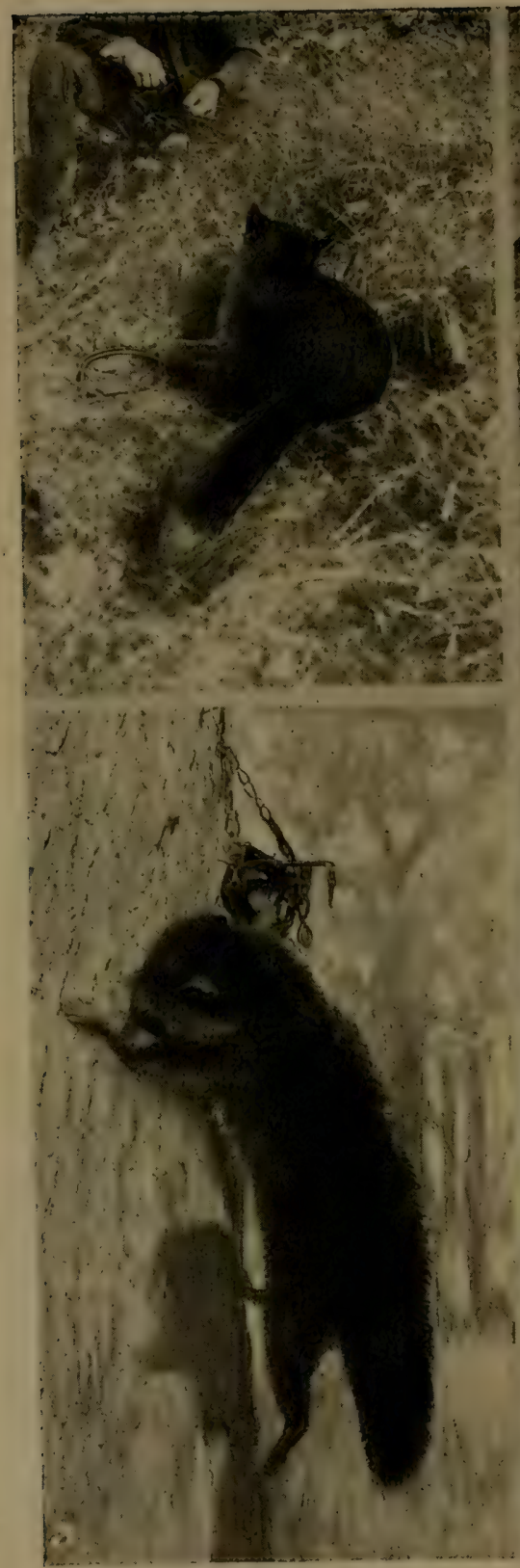

1 Red Fox in a Jump Trap

2 Young Raccoon in a New House Steel Trap

3 Raccoon in a Jump Trap

42 Skunks Caught in Steel Traps
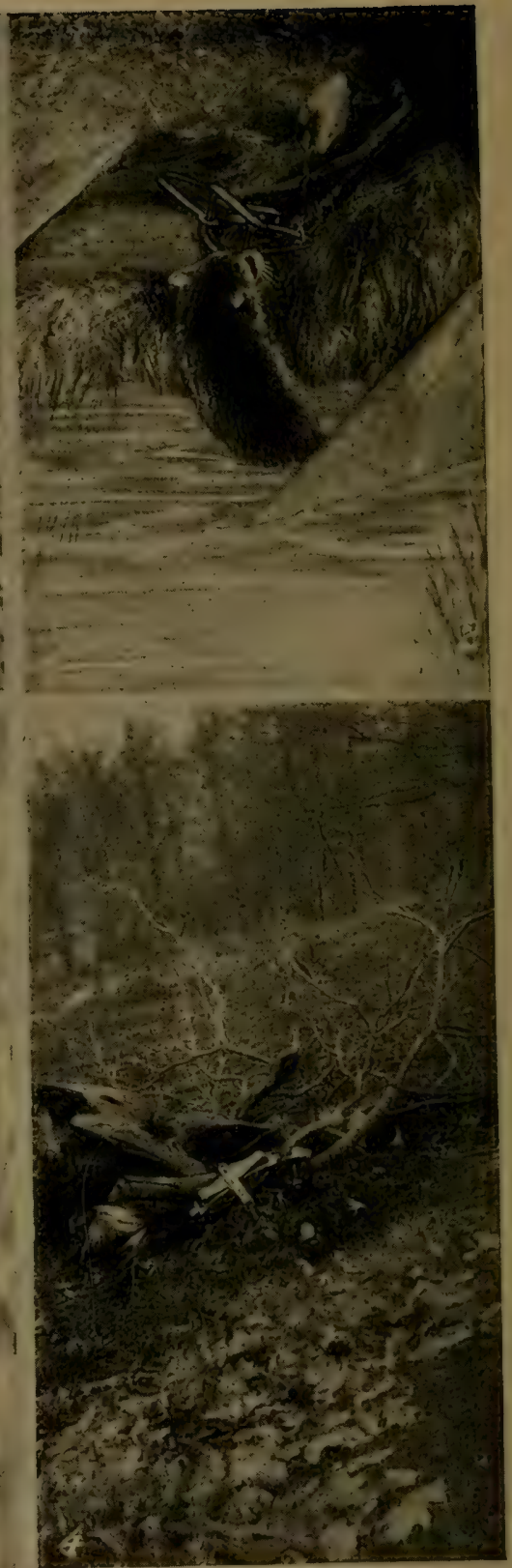

Caught and Photographed by $H . O$. Ingalls, West Haven, 
per more money and probably he is caught then with more ease than later in the year when one has to resort to digging them out. The skunk can be caught with the assistance of a good clog during the night, also by setting traps in their dens which may be in some side of a hill, under a root of a tree, in hollow logs, under old out-buildings, barns, etc. Quite often, if such places are not found, traps may be set in some small enclosures made by stakes driven in the ground. Baiting is quite essential but anything will do for the skunk.

During January skunks are somewhat harder to trap, but just as soon as the sun gets warm, which is usually the case cluring the month of February, the skunk will begin to run from one hole to that of another and their hibernating habits cease. The buck skunk will usually travel much farther, but I find that the female skunk does not confine herself to her abode as is the practice of the female mink. Should the weather be cold the running season does not begin until March. At that time, you will find skunk on the go night and day. Quite naturally the male skunk knows every den in the immediate vicinity and in his haunts visits one after another and, seemingly, he is not detained very long in any one of them, but passes on to another within a very short time. This is the time when the farmer boy should devote a week or two to trapping skunks, because soon thereafter the skins are unprime, the fur begins to shed, and the fur dealer is obliged to class same as No. 2, No. 3 , and shedding.

Place your steel traps in front of their dens. Don't confine yourself to steel traps entirely but obtain wire traps, either the Stop Thief pattern, or those made by the Oneida Community Co. Better results are sometimes obtained by using home-made traps, especially when you can get five to six skunks at one time. At this time of the year, when skunks are plenty, I never stop to dig them out; time seems to be too precious. If the weather should turn unfavorable, then I revert to digging.

Last year I caught over three hundred skunks within three weeks, besides other furs, and if any one can beat me, he will have to show me because I come from Missouri.

\section{Trapping the Skunk.} JACK MORROW.

From a trapper in Missonri we have the following article on catching skunks:

"To find the skunk's den look for a hole at the side of a hill or rise of ground, or under rock piles and rocky bluffs, and sometimes in old wells. Now examine the holes to find if black and white hairs are sticking to the entrance, which is often the case when the holes are too small. Skunks are lazy animals 
and when possible, they take possession of holes made by other animals. If they have occupied the hole long, you will find a manure pile near by.

"If their den is found in the side of a hill where digging is easy, dig them out, but never start where there are too many rocks. Their bed is usually placed above the rest of the hole in such a manner that makes it very hard to drown them out. With these points in view it is best to trap them either with steel traps or with what is commonly known as a "deadfall" which consists of a lot about twelve inches each way closed on three sides. On the fourth side lies a pole which sets upon the "triggers" and which is baited with hog-liver, if obtainable; if not, with fresh meat (preferably rabbit heads). When the skunk touches the bait the trigger rod releases the pole, and falling, it breaks the back of the animal, and consequently, when found the next morning, he is dead. These traps should be placed about five feet from the hole in the run, and baited carefully. Should you wish to use the steel traps rub them with hog-liver. Place the traps in the hole and cover all but the plate with leaves; then fasten the trap securely to some clog or stake. Take the fat from some fish and fry it out and pour into a bottle. Leave the cork out and expose it until the oil decays and becomes very strong. Place a few drops near the hole and some on the plate of the trap. Cover the trap with fine leaves, fasten securely, and visit your traps each morning. This decoy is also good in trapping other animals.

"The skinning is the next process; to do this, cut from the foot of one hind leg to the foot of the other and detach them from the flesh. Next cut from both sides to the root of the tail, carefully avoiding the "musk bag." Then after skinning the tail, put your feet on its two hind feet and pull steadily until you have detached the hide. Be very careful not to cut any holes in the fur as this slightly injures its selling value. Stretch and dry the hide in a cased shape and always have the fur next to the board or stretcher, so as to keep the flesh part exposed to the air to dry: Scrape the fat from the skunks and render just as you would lard. This makes a very good medicine for people suffering from colds. Ship your furs to a reliable company and do not sell to the home dealer as he usually pays an inferior price. Go to your traps daily and skin as fast as caught."

\section{Trapping the Skunk.}

A Pennsylvania trapper, who wishes his name withheld, writes as follows:

"My experience in catching skunk is as follows: The time 
to start out is during the fall (November or December) when there is a light fall of snow which enables me to follow the skunk by his tracks to the den or his feeding place, and at these places I set the traps. Their holes are found generally on the south side of a hill under stone piles, and when you have found such a place examine the sides of the holes and look for black and white hairs, that generally adhere to the sides. If you find these hairs you can bet that the hole is not an old one and that skunks inhabit the same.

"Another way I can always find out whether the hole is occupied or inhabited is in looking about the opening and if I find a pile of their manure which has a fresh appearance, I know that hole is inhabited, and I set my trap on the pile or thereabouts. I use a steel trap, No. I or $1 / 2$, but in front of holes often use Stop Thief traps.

"You will find all the way from two to twelve skunks in a den. They are not shrewd at all and will readily walk into uncovered steel traps. I like the Stop Thief trap better for the reason that it kills the skunk and does not leave the disagreeable odor on the pelt."

\section{Trapping The Skunk.}

I well remember the first skunk I ever caught, in fact, I shall never forget it. I had heard a lot about people catching them, and selling skins for a good price and as I wanted some money, I concluded I would catch skunks.

One warm day in January, I started out with an axe and spade on my shoulder. (Skunks are nearly always dug out in this vicinity.) I had gone about a mile and came onto a track and followed it till it went into a hole under a stump. As it was afternoon when I started, it got dark before I got Mr. Skunk. I concluded to plug the hole up and leave him till morning. I went back the next morning, but he had gotten out, so off I went on his track, following about two miles, to where he had stopped for the day. I set to work again and as it was a short shallow hole in a sheltered place, I soon came to him. I got a long stick and pounded him till he ceased to struggle. Then I got him out and he proved to be a big broad stripe. I certainly was pleased to think I had got him and came home feeling great. Everything went fine until I got home. Then the trouble began. I had to change my clothes, wash my hands good, and put my boots outdoors. You will all know why. I sold his pelt for $40 \mathrm{C}$ and that ended my first winter's skunk-hunting.

But I did better afterwards, as I got along without any smell in either killing or skinning. I will give my method for the 
benefit of those who dig skunks out. First, when you get a skunk tracked to a hole, look all about to see if there are two or more entrances. If there is only one entrance all the better. If more than one, run a stick down below the frost in all but one, so the skunk cannot get out. Then begin to dig at the mouth of the hole and follow right along. If there are branches off of the main hole, dig them out too, unless you have a good dog. If you have, he will soon show you where your game is. The most delicate part of the digging-out process is when you come to his skunkship. When you get right close to him, be careful not to disturb him, but quietly shut the hole up in front of him and dig over top and past him. Dig till there is not more than an

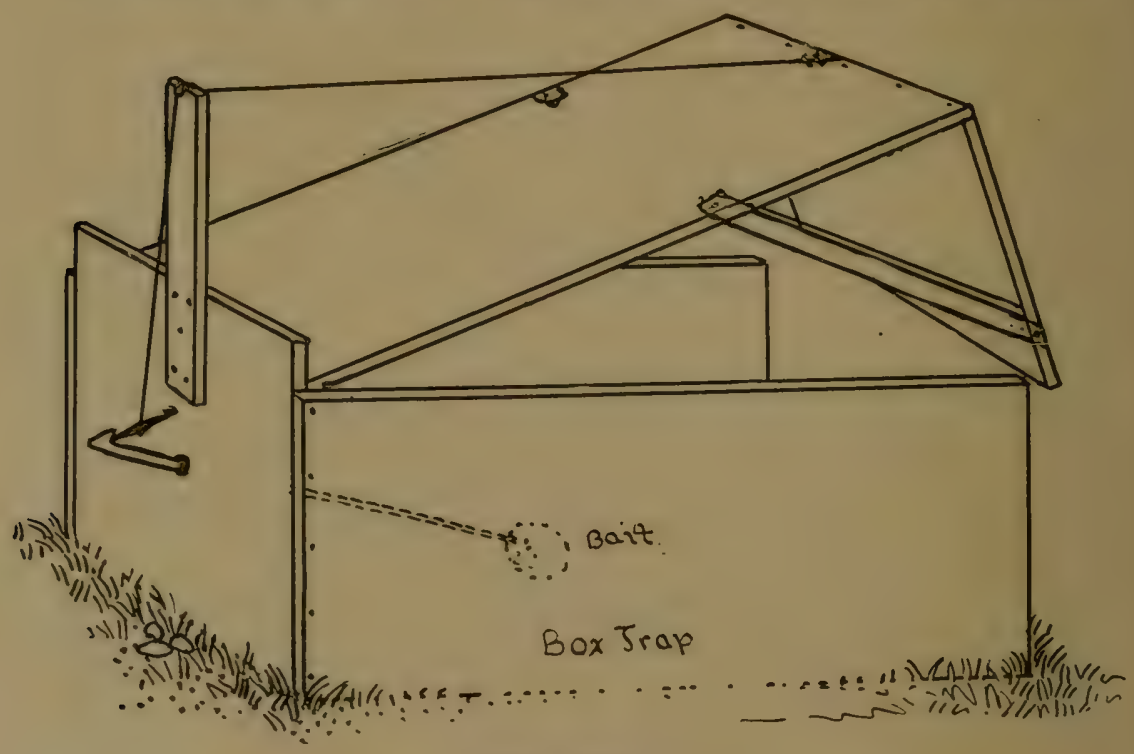

BOX TRAP.

A very simple arrangement especially adapted for capturing animals and birds alive. The cover or lid can be raised much higher if preférred. A similar contrivance was used some years ago for capturing a large African lion that was taken to England.

inch of dirt over top, then gently begin to press the dirt down on him.: After you get him nicely covered three or four inches deep, begin to tramp the dirt in solidly. Cover about eighteen or twenty inches deep and leave for fifteen or twenty minutes and he will be dead.

Skinning is the next operation. I always begin at the heels on the inside of hind legs and cut to the root of tail. It is best to use a very sharp knife for this. Loosen the skin around the 
hind legs and take tail-bone out. Sharpen a stick six or eight inches long at both ends and fit through the large cords just above the heels and hang over a limb of convenient height. Then use your hands and a somewhat duller knife to pull the pelt over his head. Be careful cutting around the eyes and not leave a big hole as it injures the pelt. Be careful around the ears also.

Stretching comes next in order. This is a very important part of handling too. I use the one piece stretcher most, although I sometimes use the three-piece, which I believe is a little better as you can stretch the skin a little more. It is hard to get the one-piece stretcher just the right size and the three-piece stretcher can be vaned a little to suit the size of the skin. There is danger of stretching the skin too hard with the three-piece stretcher, which makes the fur appear thin.

Selling our catch is important to the most of us too. Well handled skins always bring a good price and everybody likes to buy them. Poorly handled, the buyers try to buy them cheap. The trapper, as well as the buyer is displeased with his returns for poorly handled skins. Some travelling buyers pay good prices and some very poor prices, so taking everything into consideration, it is better for the trapper to ship his own catch to some reliable company.

\section{Trapping The Skunk.}

ROY ABRAY, Highgate, Ont.,

Mr. A. A. Lamb, Buchanan, Mich., states that he has been very successful in capturing skunk. "I sometimes use two or three joints of ordinary stove pipe with a swing door on one end, which the skunk is able to push inward; the other end is closed. I also fasten the pipe so that the animal cannot roll it when inside. Have taken as many as six skunks in one night. For bait I use a piece of muskrat or part of some old stinking chicken. Either of these are good. A neighbor and myself dug a trench long enough for four joints of stove pipe and covered these joints up with earth and placed an old chicken for bait therein. One of the openings was closed, and in the other end a swinging door, opening inward, through which the skunk was supposed to pass, was arranged. A dead chicken was dragged in various directions leading to the opening. On one occasion we dragged this bait for such a distance that there was very - little left of it. The next morning, however, we found thirteen skunks in the stove pipe."

\section{Trapping The Skunk.}

The skunk is not a very sly animal and with a little care can be easily caught. However, I always cover my trap well, 
first by spreading a paper over the jaws and then covering with loose dirt. I do not set my tra; at the entrance of the den, as when one is caught, the rest will sometimes leave, but place it about a rod from the entrance, bait it with mice, prairie dog. squirrel, or bits of meat, and the skunk, greedy for bait, will seldom fail to get caught.

After getting them in the trap, to kill them without getting the scent on one's person, come up, if possible, without attracting attention and give them a quick blow at the root of the tail. This paralyzes them so they cannot use their scent for some time and they can then be easily killed.

Or, if trapping along a stream, set the trap so that a weight may be placed over the water, so that when the skunk is caught he will be thrown into the water and drown; in this way no scent will remain about the hide.

Fred D. Aвbott.

Ft. Pierre, S. D.

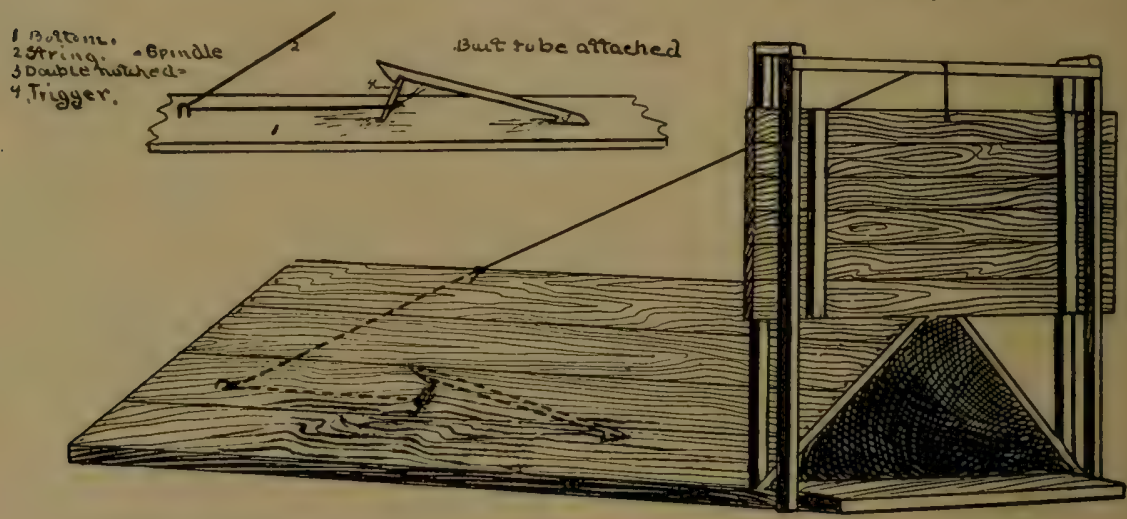

TRIANGLE BOX TRAP.

The triangle should be from 3 to 4 feet long, and for bottom take 2-inch plank 14 inches wide. Lower plank should be 3 inches longer on each end. Securely fasten wire screening or laths on one end and arrange drop door'as per illustration. Tie a string to door, pass over beam througl upper portion of triangle, then slanting to staple, and fasten to figure four arrangement by using lower plank as a part of the contrivance, The spindle should be arranged to hold upright stick to which string is attached by a notch made into the plank. Bait should be attached to spindle. T'he animal by partaking of the bait disturbs the spindle and the door drops.

\section{Trapping The Skunk.}

We have the following interesting article from Mr. William Plummer, of Rochester. Minn.

"I was once told that skunks were the most ignorant of all wild animals and the most easy to catch. Probably, that is pretty near the truth, for, as a rule, it does not require much skill and experience to catch the ordinary skunk. But like every- 
thing else, there are a few of them that get wise by experience; at least, I have found it so.

"During the winter of Igor, a neighbor's boy told me where several skunks were in the habit of frequenting. He had been trapping for then but could not catch them. They would get into his traps but always pulled out some way. He showed me his traps. They were No. o rat traps. Well, I told him I would try my hand, so I went to work with a No. II/2. The ground was bare at the time so I had to go somewhat by guess. I set at least half a dozen traps, using smoked bacon for bait. I kept this up for a week but got no skunk. Finally, one evening, there fell a light soft snow. Now, I thought, I will get my skunk. I was out early, found a track and followed it to within six feet of my trap where it turned off. I followed it further and found where some sheep had been killed by wolves. Just part of one leg and some wool was left. Mr. Skunk had feasted on that and gone on. I set two traps right there, covered them up carefully, brushed out my tracks best I could. Next morning I went to get my skunk but he was not there. He had come for another meal but having discovered danger, turned when within ten feet of the trap and left. Several others served me the same way during the week, so I gave it up. That neighbor's rat trap had educated them, but they are not all wise.

"I have caught them by turning over a nail keg, placing a steel trap in the front end, and laying a small bit of bacon at rear end. I have caught them by setting steel traps in paths uncovered; have caught them by the neck by placing a bit of meat under the pan of trap.

"Skunks will gather together in dens for the winter, a dozen or more in a den. Last winter I caught eighteen at one den with a No. 2 Newhouse trap. I kept that trap there all winter, day and night. Sometimes, though, one or two only will stay at one place. Towards spring the toms will start out on long journeys, stopping at every den they come to, and the man that undertakes to run them down must prepare for a long trip.

"One morning last winter in going over my line of traps, I noticed a track going up to a den where I had a trap set but the skunk had turned aside when he noticed the trap, so I made up my mind to run him down. A soft snow had fallen during the previous day-the brush was covered with it-but I was determined to get that skunk. He stopped at a dozen different dens, and led me through the worst thickets in the forest. Finally, about three o'clock in the afternoon he brought up at a den where skunk tracks were coming and going in all directions. I stopped right there and set a No. 2 Newhouse in 
the den and two outside, and during the next few days caught seven skunks right there-five of them females.

"I generally use No. 2 double spring steel traps. I find it pays as they sometimes pull out of smaller traps. When setting in dens, I use no bait and seldom cover the trap, but in paths away from dens, I usually cover them lightly with dried grass or leaves, and bait with smoked bacon under the pan or hang about a foot above. To kill them without scenting, I take a foot of fine brass or copper wire, make a loop of it, tie it to a twelve foot pole, slip the loop over the skunk's head, and pull him quickly off the ground. If caught just right he dies in a few minutes; if he continues to wriggle I hang the pole over a bush, stump, rock or whatever is handiest, and look after the rest of my traps; when I come back he is always dead."

\section{Trapping the Skunk.}

An Iowa trapper relates his way of killing skunk without the animal throwing its essence over him.

"Take a stick three to four feet long, and when I see a skunk

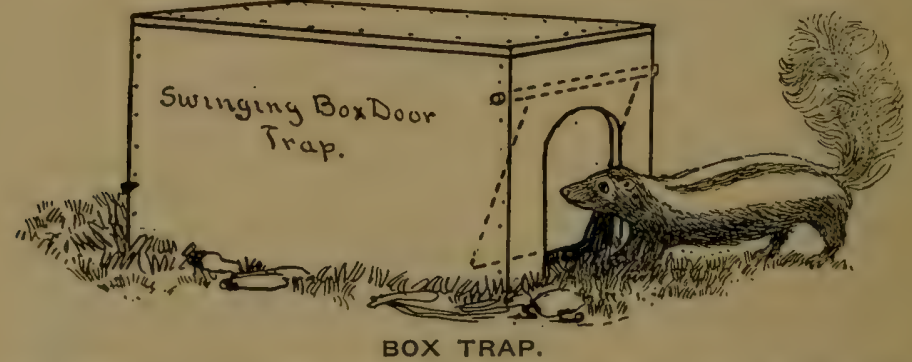

Especially adapted for capturing skunk, badger and similar animals. The box is about 18 to 20 inches long, 12 to 14 inches deep. The door is conveniently hung on a rod penetrating from one side to the other, as per illustration. This trap is recommended only when trapper desires to capture the animal alive. Bait with meat or dead birds, rabbits etc.

in the road or about his hole, I simply walk right for him, pointing the stick at his nose, and it's surprising that the animal will stand in a hypnotized manner, and when you get within reach will try to grab the stick. Then is the time to give the animal a sharp blow over the head. This will settle him. I never trap or kill skunk until about the first of December, and not later than February."

\section{Trapping the Skunk.}

"Last winter I caught sixteen skunks by setting No. I I 2 steel traps just at the opening leading to an old graveyard.

"I barricaded all other openings, excepting two, and set a 
trap a little on one side in the opening and every morning I had one or two of them caught. I killed them with my twenty-two rifle by shooting them in the head or eyes.

"My brother, who makes a business of trapping each winter, helped me to take the skins off and I will tell you how he did it. He calls it 'his lightning way,' and sure enough, it didn't take him any time to take the skins off from the first three skunks. He has had great experience trapping for the last ten or fifteen years, and selling $\$ 300.00$ to $\$ 500.00$ worth of fur every year, all being his own skins.

"When I told him to help me, he went into the barn, brought two knives, a hatchet, two knife-like pieces of wood made out of oak, a rope, a few pieces of strong cord, a small hand saw, some nails, and stretchers. This constituted his outfit for skunks.

"He tied a string to each hind foot, raised the animal off the ground, hung it against a tree in which he first drove a tenpenny nail with his hatchet, and then took the small knife and made a slit from the vent to where the strings were tied on the legs, cut around each leg just below the string, and then proceeded to skin out the legs. He then skinned as far as possible down the body, severed the tail from the body, and pulled the skin down, using the knife as little as possible. In no time he was down to the front legs. He cut the legs off just by the knee, and with one hand against the body, the other holding the skin, ireed the legs, then he pulled the skin down to the head. He cut around the ears, eyes and mouth, and the skin was off. I don't think it took him five minutes. He later removed the string and placed it on another skunk, and proceeded the same way as he did before.

"When it came to stretching, he took an ordinary single board stretcher and with his hatchet drove four nails-two on each side of the tail and two on belly portion-and proceeded with his hatchet to scrape off the surplus fat and later used the two hard-ivood knife-like pieces, and in no time had the skin freed from fat. He also split the tail open and by attaching a string to the tail-bone, pulled the bone out; at another time he simply ripped the tail open and removed the tail-bone by cutting it out. When he was through with all the skunks we took the skins home and he placed them for me on regular wedge stretchers. After the skins were thoroughly dry, I shipped them to you at Minneapolis and you allowed me from $85 \mathrm{c}$ to $\$ \mathrm{I} .30$ apiece -they being narrow striped skins-and the average price I realized after freight was deducted was nearly \$r.05 each."

PEdAR Olson. 


\section{TRAPPING THE CIVET CAT.}

This carnivorous animal, feeding on rats, mice and gophers, frequently makes a visit to the farmer's poultry yard. They are not very cunning, readily entering a trap. If you set the trap at their dens you should have the trap staked back from the hole so if one gets in he will not pull the trap back into the hole thus making it hard to kill him without getting scented. Set traps along creeks, hedges, fences, etc. Before setting traps take a piece of pork and hold it over the fire until it gets good and brown, also take along some fish oil (which can be purchased at any drug store), put a few pieces of the pork and a few drops of the fish oil around your traps and you are pretty sure of every civet cat that comes that way. I prefer a No. I trap for them, for if you get a skunk in a trap set for them he will stay there while he would be apt to pull out of a No. o. Skin them as you would a mink, taking care not to cut the scent-glands; it is best to remove them. If you take them out, commence back of them, cutting into the flesh underneath until you have them cut entirely out. Stretch your skin on a board like a mink; always flesh part outside. Leave tail attached. They are ready to take off the board in two weeks.

\section{Obrey L. Wolfe, Malvern, Iowa.}

\section{Trapping the Civet Cat.}

The civet cat, like the skunk, is an easy animal to trap. In fact, I make no distinction in setting the traps, neither in size of traps for one or the other. The traps are set at the openings of their dens; at other times I make artificial enclosures for the trap so as to cover the bait from the weather. Wire traps are also very good. In fact, I prefer the wire trap to the steel trap when in quest of civet cat.

Skinning-In skinning one must be careful not to cut their scent bags. One would hardly believe me when I state that I caught two civet cats in one trap, while living in the southern part of Indiana, but such is a fact. Presumably both came across the bait at the same time, and being eager to take hold, stepped on the pan. As far as bait is concerned, I use any old piece of meat. No bait is necessary when traps are set in front of their dens or over their holes.

F. L. RoBinson.

\section{Trapping the Civet Cat.}

Civet cat are as easy to trap as skunk. The only experience I have had in trapping civet cat especially, was some years ago on the farm, and having nothing to do one December day, I 
fixed up an old smoke stack from an engine, which was discarded, arranged a trap door at one end and the other end I pounded together. This I carried about half a mile and placed it along a fence where I had previously seen skunk and civet cat. I dragged an old hen, from which the feathers were previously burned off, along the ground in various directions and finally threw it in the stack. The next morning I took out three skunks and two civet cats and continued to catch one or two of these animals every day.

A. L. BERRENS.

\section{TRAPPING THE WILD CAT.}

We have the following on trapping the wild cat from Mr. John A. Lien, of Wisconsin:

"The wild cat (or bob cat sometimes called) finds its home in thick woods or swamps, particularly dense cedar swamps. To trap these animals no great skill is necessary as they enter a trap readily if properly covered with some soft material, such as powdered wood, fine grass, or tissue paper is all right when it is slightly sprinkled with snow under the open sky.

"This is the way I go at it: I build my camp or shanty away from any settlement in the centre of my trapping territory so that I trap four different ways. To save walking, I generally string my traps out four or five miles either way, and so that I can see them every other day. I set them about twenty to thirty rods apart and three traps at a place in the following manner: First, I cut stakes, (or logs, if more convenient) and build a kind of house or pen, one side open large enough for the cat to enter. I place three traps in the opening. Then I get balsam or spruce boughs and make a roof large enough to shield the traps from rain or snow. I clog my traps (I never stake them fast) and cover them with any material I find handy,-feathers are very well. I then put the bait in the bottom of the house or pen, and all is ready. I use very seldom any odors, but fish oil or any attraction for mink will do for the wild cat. Any kind of bait will do-rabbit is as good as any. I make my trail as close to the settings (as I call the place where I put my traps) as I can walk. The better I get my trail the surer I am of getting my cat. It is a good plan to take a proper log and drag after you to make your trail more even. Never make any sharp turns on it, as a cat will follow a trail for any length if it is fine and the snow is deep, and if once on your trail she will visit every setting until she is caught.

"A good plan is to place several traps where you see some remnants of a cat's former meal as she is most likely to return. Leaving a dead cat surrounded by traps is also good, for if there 
are any cats in the vicinity you are sure of a visit. The reason I set three traps to each setting is because there are always more or less squirrels, birds or rabbits coming into them and when you have several traps close by, you are more sure of getting your cat when she comes.

"The traps I have used are various, from a poor rat trap to a beaver trap. I caught the most of them in mink and muskrat traps. I never lost one that got in the trap, and even if only caught by one claw it generally holds her. However, I lost several traps from lack of better fastening to the clog. A Newhouse trap No. I is good enough but a No. I I/2 is the kind I prefer."

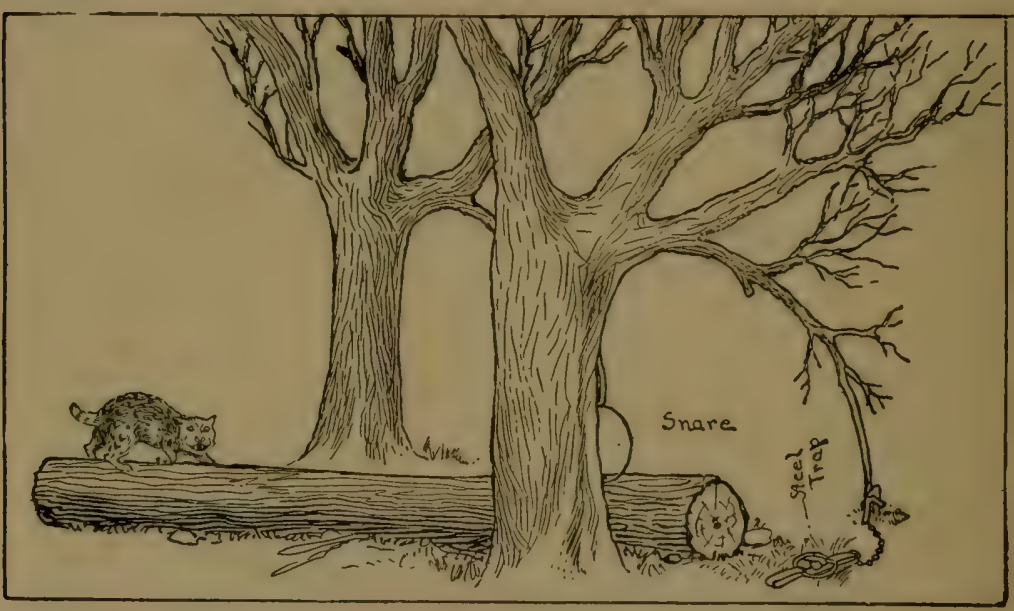

COMBINATION STEEL TRAP AND SNARE SET.

The snare should be slightly fastened to the log and side of tree and arranged to a spring pole. The steel trap must be covered with straw, leaves and similar vegetation, upon which throw a thin layer of loose earth. The above arrangement is suitable for raccoons, wild cats, lynx and similar animals.

\section{Trapping The Wild Cat.}

From a trapper residing in Utah, Mr. Wm. R. Green, Jr., by name, we have the following:

"I herewith send my experience in trapping wild cat. I first get a location in a canon or valley with a stream running through it. Then I get some sort of game meat such as rabbit, chicken or venison and drag it across the canon or valley from mountain to mountain at intervals about a mile apart. I set a No. 2 to No. 4 steel trap at intervals along these paths about two hundred yards apart. I will place the trap in a pen of a rectangular shape, the 
point of pen being made in some bush or bunch of willows or against a tree, and I then place the bait in the bush or hang it on a limb of the tree a little above and a little back of the trap and make it fast and solid with a wire or some strong cord. The trap should be made fast to a clog or stick of wood about three feet long and about three inches in diameter. This clog should be covered with leaves or dirt-whichever may be handiest. The wild cats generally travel up and down a canon or valley, and I will guarantee that I can catch nine out of every ten that crosses my path in the way above described.

"N. B. The traps should be covered with leaves or trash so that nothing is visible and so that they will not freeze down."

\section{Trapping the Wild Cat.}

W. H. Hendershot, a trapper of twenty-five years' experience, writes as follows:

"I generally hunt wild cats and lynx by using a dog to follow the tracks of the cat. I assist him very often as the cat walks logs, climbs trees, etc. But when the dog starts the animal, one must be on the lookout and ready to shoot as the cat will run here and there and all around, dodging the dog, and in order to save the dog one must shoot the cat; otherwise the dog would become useless for further hunting, should a fight ensue.

"In trapping this animal, I find, if possible, remnants of his former meal and set traps about his leavings, or place where the cat buried the remaining portion of his victim.

"The trap, of course, must be covered with leaves, bits of rotten wood, and if snow around, I cover with snow but always have leaves, etc., under pan. If any cats or lynx are around you will catch them, and sometimes a wolf or fox."

\section{Trapping the Wild Cat.}

It is quite easy to catch these animals. They have their dens in cliffs and when these are not handy, they are in holes in the ground where they have their young. As a rule, they stay near their dens the year round. Find where their tracks are quite plentiful, which usually, is near their dens. Now make an enclosure in a V-shape, or find a natural one and improve it a little, so there is only one side for the animal to get in at. For bait, take a rabbit, put him in the pen, and jerk his intestines out so it will cause an odor. This is the best bait a trapper can get out in the wilderness, with the exception of deer liver, lungs, and intestines, which is the best bait on earth for these animals. Sometimes sheep carcass is also good bait. 
Now, if the enclosure is narrow, use one trap. If it is wide, use two or three traps. Set them in front of the enclosure two feet apart, and by using three traps, set them in triangle shape. If I trap in a country where there are mountain lions, I use the set with three traps, but if there are no lions, just one trap is plenty.

A No. 2 Newhouse, or Hawley and Norton, will hold a cat, but if you trap in a country where there are lions, be sure to use No. 4 of the same make, for I have caught as many lions with this set, as I have wild cat and lynx.

WM. WEIBEL, La Porte, Colo.

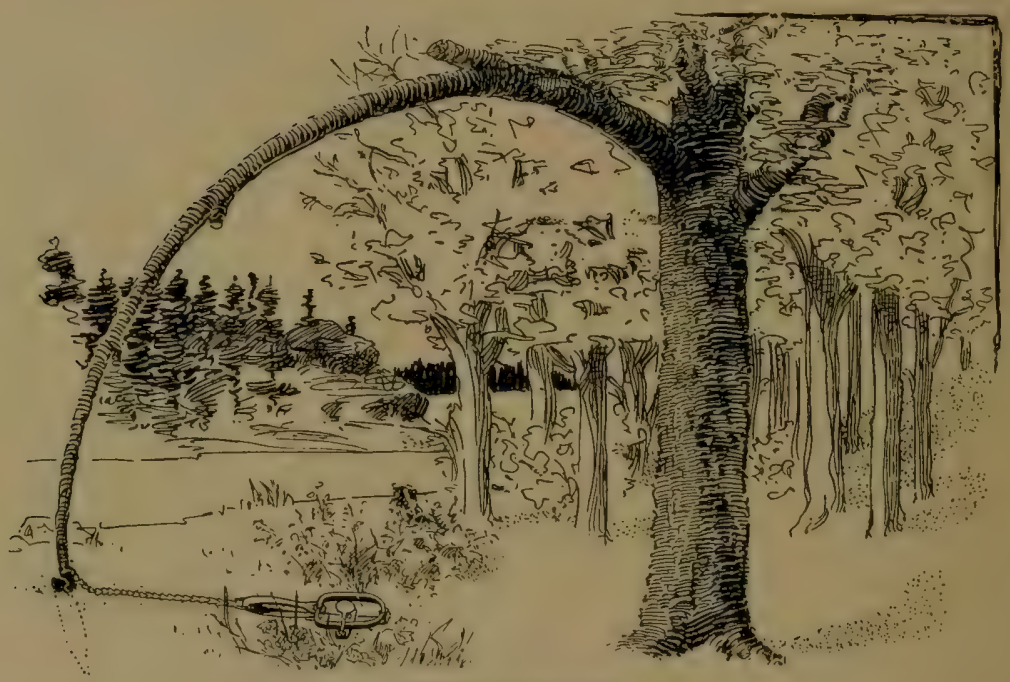

SPRING POLE.

The above is one of the best, cheapest and probably the surest way of raising the captured mink, fox, lynx, or even the wolf, from the ground. The steel trap and chain must be covered and care should be taken to have some leaves, cotton or other soft suistance beneath the pan to prevent filling under.

\section{HOW THE LYNX IS HUNTED AND TRAPPED.}

In the first place I liad one tied up by the side of my door so I could study their habits. I find by all kinds of treatment they are vicious and untamable. Will eat all kinds of game but no vegetables or bread or any kind of cooked food. Will eat sparingly of fish if starved to it. Rabbits are their general food. Where you find great numbers of rabbits you will find lynx. They will kill young deer, also young calves; will follow a trail for 
miles. Drag a small piece of deer paunch as you walk along, or if you have no paunch, get five or six pounds of beef liver, hang up behind the stove for two or three days or a week until it gets tainted and the blood begins to drop out of it. Then mash up to a jelly, put in jar and set away, where it won't freeze. If you happen to be in possession of a beaver carcass, take all fat off of it and try out in lard pail; do not scorch it. When cool, take say five or six tablespoonfuls of the beaver oil and a small teacup of the mashed liver and mix both together. Have this in a bottle to carry with you. Every half mile, on going the rounds of your traps, put a little on the soles of your shoes or moccasins; and the lynx when he comes to your trail will never leave it until he comes to your trap. If your trap is properly set, you will have the lynx. I use four or five drops of anise oil in the mixture also.

Now a lynx as a general thing is quite a genius and is also very inquisitive. Never try to make a lynx get in a trap if he has just had a good meal for he will not do it. But he will follow your trail for miles and look into each house you have got on the trail, and will keep on going until he gets hungry. In order to catch them while on these rounds, I have adopted the "gate on the trail," or the "double stick racket." I found by close study that lynx will always step in your tracks, that is, if you do not step too far. I never step over ten or twelve inches. Do not make your trail too wide; keep it as narrow as you can in the snow. I have had as many as five to seven lynx follow me for over a mile, just looking into the houses and go on to the next one. So I made a little brush fence for a couple of yards or so on each side of trail; leaving a small passageway for myself and the lynx to pass through. Then I lay two small sticks across trail, say one inch in diameter and about four inches high and seven inches apart; then set a No. 3 Newhouse trap in center of little sticks and cover up with wild grass that I find around under trees. The next lynx that comes along will step over one of the sticks and into the trap. I caught no less than six lynx in one trap this way.

I make my lynx houses out of old brush and poles. Find a good tree that sheds snow as much as possible and make a lynx house by leaning sticks about five feet long, up against it, enclosing it quite tight and leaving an opening about fifteen inches wide facing the trail. Put bait back in house and tie it fast, and set a No. 3 trap about three inches outside of entrance and a little to one side. I use for bait a small piece of rabbit with three or four drops of anise oil and some of the liver mixture mentioned before.

JOHN A. BLEEKER, 


\section{Trapping the Lynx.}

Lynx are not difficult to trap. I have had pretty good sticcess, and you probably know that as well as any one else by the number of skins I have sent you. I do not expect to stay in British Columbia much longer, therefore will give you my methods of trapping in this section.

As far as traps are concerned, I prefer the Newhouse, nothing smaller than No. $2^{I} / 2$, larger ones preferred, although $I$ have caught a lynx in a No. I. He would have escaped were it not for the fact that the jaws held him by one of his toes, and he had sense enough not to struggle.

The lynx will follow the trail of other animals as well as that of the trapper. I set my traps in my own path, as well as those made by cattle or wild beasts. A hole is made of sufficient size to hold the trap. A piece of dry limb is laid on each

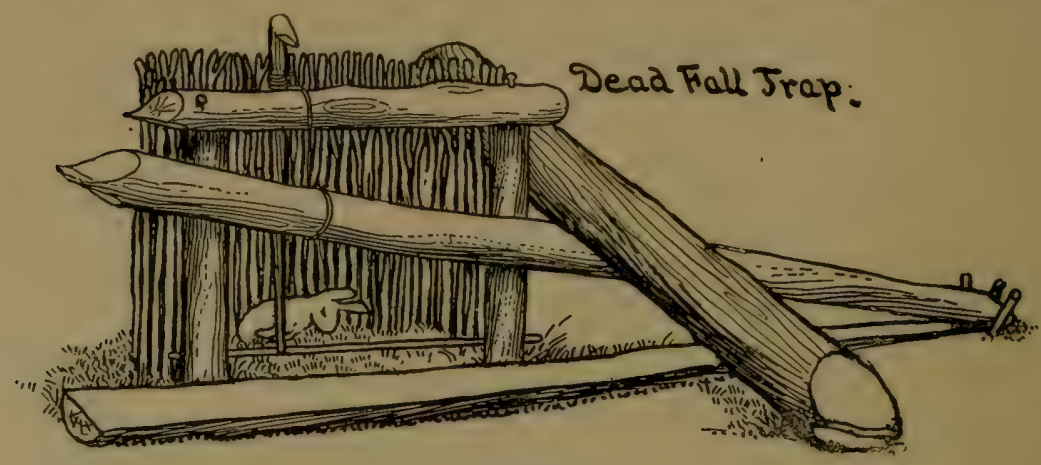

DEADFALL.

To spring trap, animal steps upon spindle or presses it down with his belly upon entering inclosure to obtain bait. Suitable for wolf, fox, lynx. wild cat, . wolverine, etc. A steel trap set in front of entrance makes the visitor's capture doubly sure.

side of the trap, so when the lynx comes along lie will prefer to step between the two pieces of wood and of course in the trap. At other times I make an artificial abode and set my trap within it. Sucli sets require bait. The lynx is not very particular as to what kind of bait it is-rabbit, grouse, duck, goose, or, in fact, any kind of bircls or animals or parts therefrom. Occasionally the traps are fastened to some drag. At other times I arrange chain to spring pole. None of these are essential, as traps fastened on a stick answer the purpose. I do not think much about decoy but have used beaver castors mixed with whiskey and asafetida. Have killed as many lynx with the rifle as with traps, and probably all due to the lynx coming pretty close 
to the cabin at night. I usually shoot from the roof of the cabin.

Snares are also very good, but the cheapest and best, next to steel traps, and probably the surest, are deadfalls. In your first edition, you had my favorite deadfall (pages 218-227). You also had a good one on page 230, but in addition I always drove stakes about the front edges of logs, thus forcing all animals to get in between the logs. Last year I caught one of the prettiest black bears I ever laid my eyes on in one of the last described traps. His head was flattened and he died almost instantly.

\section{Trapping the Lynx.}

J. H. DonnLy.

Select a large tree close to where lynx travel and fasten bait, which may be a rabbit or the skin therefrom stuffed; tie to trunk of tree about three feet from ground and set up a few dry branches or stakes on both sides forming kind of shelter for the trap and a pen so that they cannot get the bait without stepping on the trap. Set your trap about two feet in front of the tree, and if rabbits are numerous, throw a few branches outside of the trap to keep them out. Towards the latter part of February trappers should have all traps out set for lynx that they can possibly attend to, as at that time the lynx will go more readily for bait than at any other time in the year, and when one is caught its carcass should be thrown into the pen for bait.

T. Gullicikson.

\section{TRAPPING THE MOUNTAIN LION.}

"Some years ago while at home near my uncle's place in the mountains of Pennsylvania," relates Mrr. Hassinger, "a large American tiger (mountain lion) made his existence known by peculiar cries, and later, became visible not only to myself but others.

"We were often followed when returning from work by this brute, and my uncle prepared and set a thirty-four pound double spring steel trap in his path and he felt sure he would follow us some day from the mountains and get into the trap.

"Some few days later his capture was made known by the terrible yells that caused chills to overcome those that heard him. My uncle, being an expert shot, visited the scene accompanied by his two little boys - four to six years old. He took careful aim and fired, and much surprised was he in missing the animal. The bullet struck the trap, breaking it, and at the same time freeing the brute. If there ever was a time that he wished his second shot to count, the time had come and he prayed that his aim might be good and he be relieved from responsibility of taking the children with him for such a task. Before the ani- 
mal was able to use his benumbed paw, my uncle again took careful aim and fired, and his prayers were answered by the bullet striking the animal in the head and the brute reeling over to the ground.

"Careful investigation showed that after the brute was caught in the thirty-four pound trap he made various leaps in the air - the greatest of them was when he cleared thirty-two feet without touching the ground, carrying with him in the air a weight of thirty-four pounds.

"This tiger is the largest I have ever seen and adorns the back parlor of my uncle's mountain home."

\section{Trapping the Mountain Lion.}

My experience in trapping the mountain lion is limited, as I prefer to bring him down with the rifle. I came across these brutes many times while in the Yukon country. It seems to me that the brutes there are much larger than those in Colorado. They tell me that the animal is very plentiful in parts of Alaska.

While in Colorado we caught one of these animals in a wolf trap. It was either No. 4 or $4 \frac{1}{2} 2$ trap and the lion sprung it with his front paw. The trap got a good hold of him, and notwithstanding that he dragged the trap and the post to which it was attached, for miles, we finally got him, though spending the best part of the day to find him. He was a vicious brute and none of us dared to go near him. We finally had to kill him with the rifle.

One of the largest lions I ever killed in the Yukon country must have weighed 125 to I 50 pounds, and measured from nose to tip of tail at least eight and one-half or nine feet. I would take my chances any time with a bear instead of one of these brutes.

\section{TRAPPING THE FOX.}

C. J. Lоomis.

If every other method fails, the following, if properly done, will crown you with success.

In some out-of-the-way place, which foxes are known to frequent, away from the public road and from dogs, on side of small hill out of view of roads, houses and other places of habitation, drop a load of barn manure from a wagon or sled but do not step off the wagon or sled. In unloading the manure make a round pile somewhat flat on top. In a few days drive to the place again and drop from the wagon or sled the stomach and intestines from a freshly butchered hog, sheep or other animal. Place this on top of the pile and slightly cover with manure. Now take two or three fox traps and set them twelve to fourteen inches outside of bait. Before setting traps see that they are in 
good working order, and either have them soaked in blood or smoke them. Fasten chain to some drag, which may be a limb, piece of fence post or any object weighing ten to fifteen pounds, unless it be a limb, in which case it can be much lighter. Cover every part of the trap and chain with old manure, and take especial pains in covering the trap with fine grass or rotten wood, leaves or feathers, in fact, anything that is light and yielding. If one prefers a few drops of anise oil or other decoy may be used about the trap. Have known foxes to be attracted three or four miles, apparently the wind taking the smell such a distance, and where the fox or wolf once sniffs the odor he is sure to locate the bait and of course becomes caught. The manure has a tendency to overcome the human scent, and again, manure piles, such as above described, are natural signs to the animal.

\section{Trapping the Fox.}

N. C.

Mr. Patrick Laughrey, West Broughton, Canada, uses the following method in trapping foxes: To trap the fox I use a No. 4 B. \& L. trap. I usually provide a place to set these traps two or three weeks or a month before time to trap. My favorite place is to go to a small stream or spring and choose a place where there is no bank; take a hoe and dig a place in the side for trap, so that the water will be one and one-half inches deep when trap is set. Place some sod on pan so as to be level with the remaining shore. Then I procure another piece of sod that has long grass on. This I place about twelve inches from the shore in the water. The sod should protrude a little above the water. After making everything natural, I leave the place. In a few days I return and place the bait on the little island and within the tall grass. It is a good policy to sprinkle water all over the set before you leave it the firct day. Any bait will do, but I prefer that made as follows:

"Take a quart screw-top jar, into which put the carcass of a muskrat finely cut up. Also the fat of a skunk and their scent bag and the entrails of three field mice. Screw on cover, not too tight and then bury the can in a pile of manure which has heated for three weeks, and leave it for several weeks; then it is ready to use. I usually take a clean stick and smear part of this mixture on the grass or lay some of it between the grass on the sod. I assure the trappers that this is a very good bait. Caught twenty-seven foxes last season."

\section{Trapping the Fox.}

Sir Reynard has not only a very fine scent, but is an exceedingly acute observer. He notices everything that has been moved 
or laid amiss and cautiously steers clear of all objects that have the least suspicious look; yet for all this, he can be easily trapped in several different ways. By using judgment, and exercising patience, and as the object of this article is to tell how that can be done successfully, I will not dwell on his peculiar characteristics further than is necessary to tell how he can be caught.

One way to bait traps for red foxes is with live rabbits. Make a chain two and one-half or three feet long out of small wire. Put a small leather strap in one end and buckle or tie this around bunnie's neck. Drive a stake in the ground where the fox is in the habit of passing and fasten the other end of the chain to the top of the stake, which should be on a level with the ground to

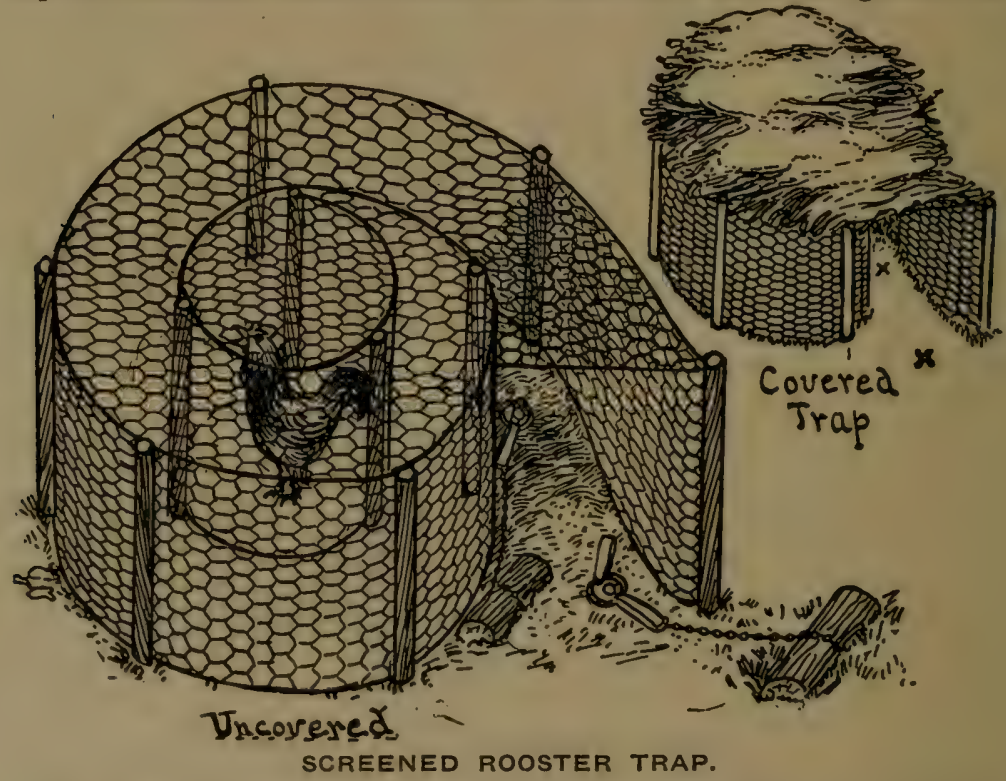

An original practical and worthy contrivance, suitable for capturing mink, fox, wolf and other similar sized animals. If this contrivance is placed where wolves, foxes and minks are very numerous, it is well to set additional traps. A snare properly placed immediately at the opening may also be effective, but should be used only in connection with the spring pole. Newhouse No. 1 to No. 2 traps are recommended.

keep the rabbit from winding the chain up. Set one-half dozen steel traps far enough from the stake that the rabbit cannot throw them. When Mr. Fox sees bunnie hopping around, he forgets all danger and makes a rush. In his effort to get the rabbit, he gets in the trap. This method has its drawbacks, as it is difficult to keep a rabbit alive after the second night, if tied by the neck. 
Another way of baiting for the red fox, is to go to some stream, where they are in the habit of travelling on the ice. Take a half rabbit, split open lengthwise, and nail or tie it to a stump, log, root, or perpendicular bank, with the lower end resting on the ice. As soon as the ice is sufficiently strong, set a steel trap on the ice in front of the rabbit. The first snow that falls, the fox will take to the ice, stop at your rabbit and get his foot in the trap. It does not matter if there is nothing left of the rabbit except the hide and bones.

Another very good method is to go to some stream where they are in the habit of travelling on the ice. Find a rock that protrudes a few inches above the surface, or a log that lays lengthwise up and down the stream, and half above the water. Set a trap at the upper and lower sides of the rock, or at the ends of the log. Then wait until it snows. Foxes almost invariably walk over the top of any object that raises above the level of the ice when it is covered with snow. A small log can be placed on the ice for this purpose, after it freezes and before it snows. The log should always point up and down the stream.

Still another very successful method is to find some den or hole where they are, or where they are likely to congregate during the running or mating season. Set your traps clear outside the hole, where he will have to walk up to look in. Then wait until it snows. Foxes examine these places especially right after a snow fall. Then if you have your traps set, you get Mr. Fox. Foxes seldom go into these dens, except the females after the mating season is over. But they all visit these places, just before, during, and just after the mating season.

When trapping for foxes, I always use a common No. I $1 / 2$ trap. I always fasten a trap that I set for a fox with wire or a grape vine, ten, twelve or fifteen feet away from the trap and two or three feet from the ground to a springy bush. Never go to a trap that is set for a fox, unless it is absolutely necessary, until you catch the fox. Pass by near enough to see if all is right. Let well enough alone. Have patience and you will be successful.

E. G. Alldredge, Russellville, Mo.

\section{Trapping the Fox.}

"I first locate their haunts, then when trapping season is about in (around December Ist), I take a little straw or hay and pile it up, say fifty or one hundred yards from their dens or passes, and burn it. Let it lay two or three days until the burnt smell is gone, then set your traps in the ash pile. as many as you like. I use No. I I $/ 2$ Newhouse traps and find they are large enough for fox and smaller game. Put ash piles about four or 
six feet square and five or six inches deep. This makes a good set in all kinds of weather. Set tliree or four traps in ashes about one or two feet apart and fasten about two traps each to a little pole or stone just big enough so they can move it a little; in this way they are not so apt to get loose. Set traps in form of circle in the ash pile and bait with chicken in centre of ashes, covering your trap lightly with ashes, also your drag or weights. Then strew some feathers around ash pile and over traps, using caution not to spit or make too many tracks around your sets, as Mr. Fox has a cute nose, in fact, he is cute all over; when set is made brush all tracks over with brush or weeds and leave very carefully for Mr. Fox's inspection. He will come when the weather gets cold and stormy, and you will get him sure; try it, boys.

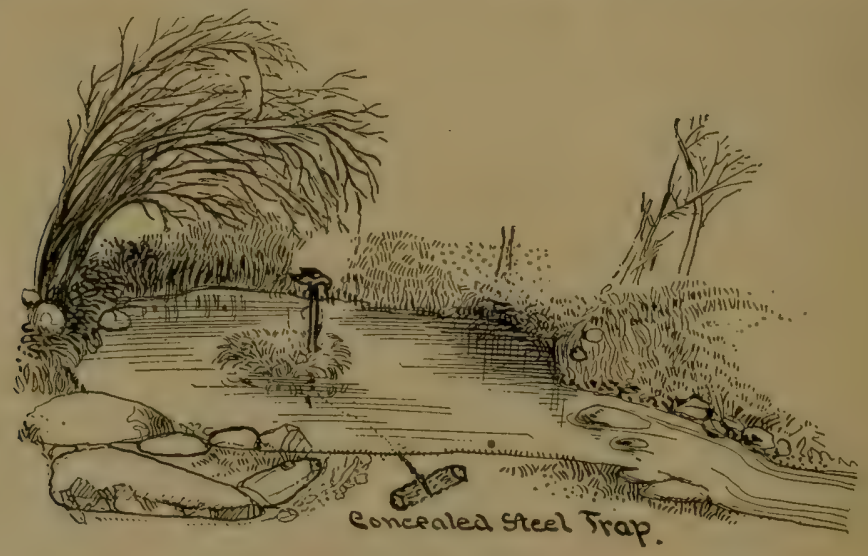

CONCEALED STEEL TRAP.

The above is an excellent set for fox, raccoon, also aquatic animals. Set one or two traps on some artificial island, 16 to 18 inches from the shore,, cover in usual manner and place bait on a stick 18 to 20 inches above the set. Attach chain to spring pole or drag. One or more steel traps can be concealed at the nearest approach to the island from which the fox usually jumps to obtain a foothold upon the island. If clog is used same must be buried.

"I have had good luck with this kind of sets, catching twenty odd each winter for the past three winters. Try it, using care in making your sets, and you will have success in catching fox on the prairies of the Northwest."

R. B. A.

\section{Trapping the Fox.}

Mr. Martin Brenner, a Minnesota trapper, favors us with the following:

"I have trapped foxes, minks, wolves, etc., in Beltrami county, 
Minnesota, and I must admit that there is no grander sport than the trapping of foxes.

"But, before continuing $17 y$ narrative, I must say a word or two about myself. I an: an old trapper and woodsman with considerable practice.

"In the fall of $1899 \mathrm{I}$ fourcl myself, together with a hunting party, in Beltrami county, and there I saw 'signs' which led me to believe that I could find no better place for my winter trapping.

"I at once sent for a supply of traps, ammunition, etc., and set to work on a cabin. It was slow work, and it was November I 5 th before it was ready. I then received a goodly supply of traps, ammunition and provisions.

"I now began cutting logs and building log traps, which, as all woodsmen know, was also very slow work. By November 25 th I had built eight log traps, seven feet square at the bottom, tapering to four feet square at the top, and five or six feet high. I did this work almost for nothing, as I caught only one fox in them all.

"But $\log$ traps were not my only resource. I had ordered two dozen mink traps, one dozen fox traps and one dozen otter traps with teetn. These latter, though the most expensive, proved also the most effective.

"I set traps around the carcasses of foxes and sprinkled thereon a few urops of oil of rhodium and oil of bergamot, mixed half and half. These oils have a wonderful attraction for foxes, wolves, minks, etc., and I once caught four foxes around a fox carcass-all within a week.

"I also caught a great many foxes by setting traps in their holes. I first smeared blood on the traps, and after setting them, sprinkled water all around.

"That winter I caught twenty-seven red foxes, nine cross foxes, nine young foxes, four wolves and seventeen minks. I shot one red fox, one mink, and a number of rabbits and other animals, which I used for food.

"By shipping the furs to the best fur establishments in Minneapolis I realized nearly twice what I could have got in towns near where I camped."

\section{Trapping the Fox.}

The following fox set has been used by me for the last three years and is original as far as I know. Am also sending you herewith two photos. Have had good success with this earth set and I recommend it to your consideration.

This set can be made in a pasture, fields or in woodland. Choose places as free from small stones as possible; when there 
are stones, they should be carefully picked out, as they are very apt to catch between the jaws of the trap and prevent them shutting close.

The sod and stones should be removed from a place eighteen inches in diameter and with a hoe, or some tool, dig, chop, and work the dirt until you have it fine, and free from all roots, sticks, etc., to a depth of six inches. The finer the dirt, the better. Have a piece of cloth of some sort three or four feet square to put sods, stones, etc., on. When the bed is finished take up the cloth by the four corners and carry away to a distance, say ten rods, and dump in some inconspicuous place.

Beds should be made several days before setting traps. In placing the trap, set it at a distance; have everything you will need with you; walk directly to bed. Dig a hole in the center deep enough to hold grapple, chain and trap. Place the creeper with one prong down on bottom of hole and press down till the other two prongs lie flat on bottom, coil chain top of creeper, put in a little dirt, and bed trap firmly in this. Put a little paper, leaves, or something over trap to keep out loose dirt, then gently level over the whole trap, about one-half inch of dirt. Smooth the whole bed level with bush or stick; drop four or five drops of decoy six or eight inches from, and on each side of trap. Now pass straight on to next trap. Do not move the feet, or step about, while making the set. Walk up, stop, and stand still while you work. All movements leave signs that are hard to efface.

Decoy: To one ounce of pure, home-made trout oil, add ten or twelve drops of skunk musk, and the scent glands of two or three muskrats (males, and must be taken in the springtine).

When tending traps, go only near enough to see that everything is all right. If trap is gone, there will be a distinct hollow in bed. The B. \& L. No. 3 or 4 is especially good for this set.

$$
\begin{aligned}
& \text { L. J. Wright, } \\
& \text { Collinsville, Conn. }
\end{aligned}
$$

\section{Trapping the Fox.}

In order to trap foxes in snow, you must first find where they travel or the places where their traces are most numerous. Look up and down old wood roads, and in and around swampy places. When you are sure you have found where they frequent most, follow along their tracks until you come to a small bush or tree twenty or thirty feet away from their path. Notice the bush and the surroundings carefully so you can find it when you come to set your traps. As soon as you feel a snow-storm coming, take three or four Blake \& Lamb traps, and a hen, or leg of a horse or cow, and cut some limbs four to six feet long 
with the branches about three inches long to fasten your trap chain to for a drag. Go to the bush and tie your bait securely about twelve inches from the ground and about ten feet away set your traps forming a circle. Dig out the snow just deep enough to set your trap in. Put large, dry leaves in the bottom of the trap hole and set the trap on top, also put leaves on top of trap and brush just enough snow over it to cover lightly. Cover the chain and lay clog or drag in the snow out of sight. Set your traps about ten feet apart, forming a circle around the tree. Now about one hundred feet away put a few drops of scent on some old dry limb, up as high or higher than your head if you can.

Take some muskrat's musk, and mix it well with foxes' musk and honey. This is a good scent.

Now, when the snow comes, it will cover your traps, and tracks, and the scent will entice the foxes in there, and when they are there, they will be attracted by the bait. If they are hungry, they will walk around and around it, coming closer each time around, and are very liable to step in one of the traps. Attend your traps about every other day and don't go any closer to the traps than you can help. The farther you keep off, the quicker you will catch foxes. Take plenty of time in fixing your traps, and use care about smoking and spitting around or near the setting.

ED. BREHMER, Spring Valley, Minn.

\section{Trapping the Fox.}

L. M. Pickens, Mooresville, Tenn., writes: "For trapping foxes around pastures and fields, the following method can be relied upon, and is familiarly known as the path method:

"Look for fox tracks in stock paths, about the fields, pastures and woods, old roads not much used, places under fences, gullies and washouts, sand-bars along the streams, and chances are you will see fox tracks going and coming. Then select narrow places and dig a pit just the size of trap to be used, having the springs laid lengthwise in the path or trail-not across it-just deep enough so the trap will be a little below the surface level when put in the pit. Cover over the springs and around the outside of jaws with soft dirt, put wool, cotton, or soft dry moss inside of jaws and under pan, or lay flat leaves, thin paper or a small piece of cloth over entire trap, then pulverize fine some dirt and sprinkle enough over the trap to entirely conceal it, always finishing to look natural as before the set was undertaken. Complete the set by laying a dead weed an inch or two from the trap so the fox will step over it and into the trap. Fasten your chain with bailing wire to the middle of a green cut limby brush, the 
size and length of a hoe handle, and conceal the chain. No bait to be used."

\section{Trapping the Fox.}

"Here is my method of catching and trapping the red fox. It may seem queer, but nevertheless it is very effective.

"Take a common house cat-whether it is your wife's pet or not, doesn't make any difference. Tie a wire around the

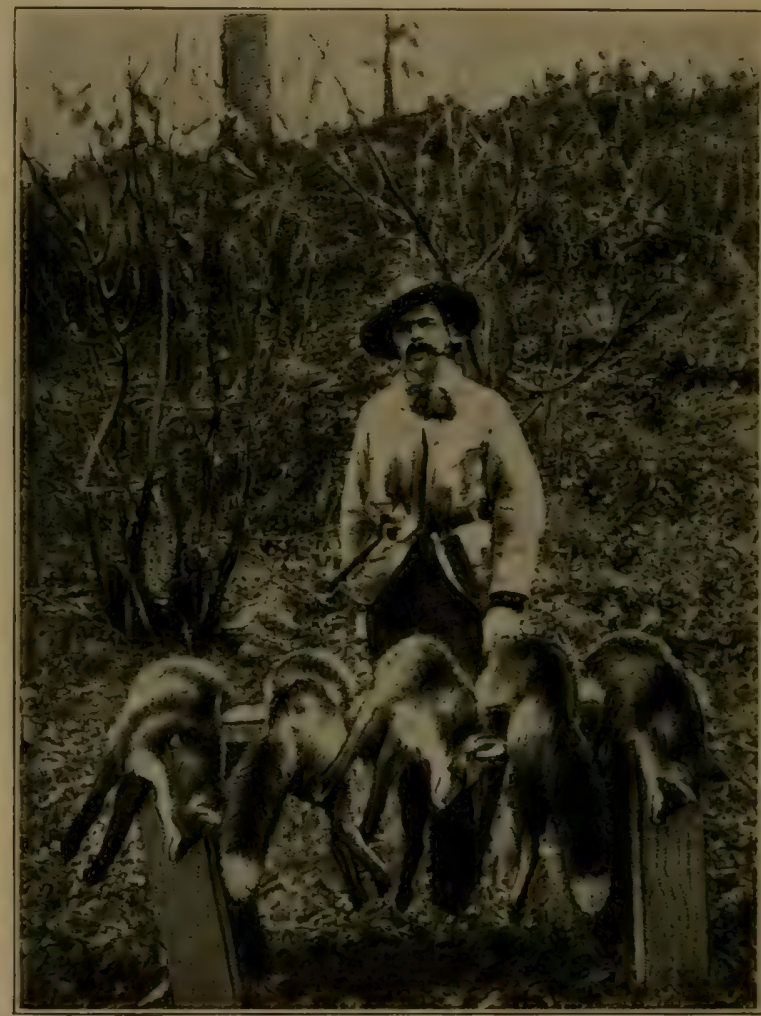

Excellent Result

5 Red Foxes

Courtesy of Nat. Sportsman

cat's neck, either before you kill it or after the cat is dead. Then roast the cat with the skin on over an outside fire until the cat is fairly roasted, being brown and juicy. Then insert in a sack and carry it until you are in the vicinity of the place that you anticipate setting your trap. Then drag the bag in various directions about the trap, and proceed to make a hole about six inches deep, into which insert the cat, leaving part outside. 
Cover portions below the surface with earth and make a small mound around the other portion, leaving an opening in the centre, so as to make the appearance similar to a gopher hole. Now take two No. 2 steel traps, fasten to a stick driven in the ground or to a clog, both covered up and made invisible. Place one trap over the hole, covering up both springs and placing a little dirt on pan. The other trap set on windward side. The fox will go at bait from that side. Remember to cover the trap up and leave the surroundings very smooth, so as to be natural. In case of snow, don't go near the trap until it is sprung unless you have reasons to believe that the setting is not proper or frozen under. The trap might not be touched for some few days, but generally the fox seeks the bait after a little snow.

"In my time I have caught over one hundred red foxesnineteen of them last year. My fifteen years' experience certainly amounts to something. Tell your friends about it, but don't use my name."

\section{Trapping the Fox.}

"I thought I would write a little of my experience in humtand trapping the fox," writes MIr. A. Carpenter, of Witoka. Minn., "as I have made it a business for several years past, and know something about their habits.

"I have made a business of still hunting without any dog, and have made good success of it in the Southeastern part in the State of Minnesota, where the foxes are very plentiful in the bluff country along the Mississippi River and Root River Valleys; both red and grey foxes are found here.

"I start in the morning after a new snow and go out over the hills until I strike a fresh fox track. Then follow it until have got on the bluffs, for no care is needed in being quiet while the fox is running on the flat. There is where he goes to hunt for mice, of which he is very fond, especially the common meadow mole or grass mole, which also makes very good bait to use in trapping. This is also a safe bait to put out with poison in, as dogs will not touch it. The right amount of poison to use is about one dram bottle to six baits, if moles are used for bait. As the mouse will freeze very hard, it takes more poison to do the work quickly, and if that amount is used he won't go over 40 rods from where he eats the bait. I killed 55 last winter this way.

"But to go on with hunting the fox. After he leaves the flat and goes on the hill or brush, then some care is needed in going still, and if you see the fox is walking you can make up your mind the fox will not go much further before he lies down; and he is almost sure to lie down in a bunch of red grass or in hazel brush, if there is any to be found, and always on the south side 
of the bluff or point. If there is neither brush nor grass, he is pretty sure to lie down behind some small stone, with his back against it so he can't be seen from the lower side of the hili and so he can watch the upper side and his back tracks. Consequently, lots of care is needed to move quietly, for they are very quick to hear and very cunning. I have known a man to walk up within two or three rods of one and then scare him up and yet never see him sneak away in almost clear ground for 20 ror's, and without the hunter knowing that he had frightened him away. If he lies down on the point, which he is quite apt to do, he will always lie down with his nose pointing down hill, and it is easier to get up to him by coming down the point on him.

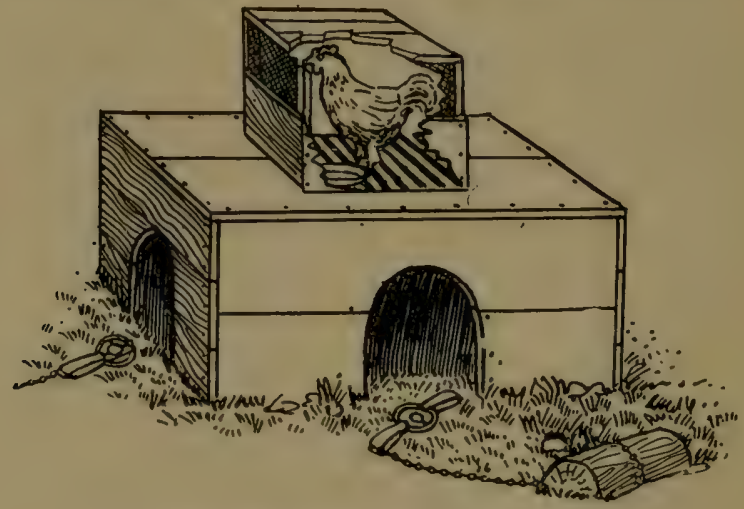

UNCOVERED STEEL TRAP SET.

An easily constructed contrivance, having a live rooster, hen, squirrel or rabbit for bait. If properly made and placed no better all-around set exists for capturing the barnyard thief, as well as raccoon, skunk, mink, and is suitable for all animals possessing carnivorous habits. The steel traps should be covered, also the clog. Use No. $1 \frac{1 / 2}{2}$ Newhouse traps. If set for wolves or foxes, a larger size trap must be used.

"In trapping them the best way is to take a sack of oat straw or chaff and throw down in their paths or where they run frequently, and after it has been there for a week or so, the foxes will be sure to come there to play and look for mice. You want to set the traps in the chaff and cover them and the clogs with chaff, and you will be sure to catch some foxes this way. Powdered fetty is a very good thing to put on the traps and around the chaff, as they like the smell of it. About the first of Jant1ary catch a female fox and cut the entire sexual part, which smells very strong and drag it along over traps and around the bait, and the male fox will be sure to follow it.

"Well, I have written about all the main points I have found out through experience in my hunting and trapping the fox for 
the last six or seven winters, and what I write here I know to be true and I hope it will prove to be of some value to my fellow friends."

\section{Trapping the Fox.}

Mr. G. Halvorson, of Arvilla, writes that he has been very successful in trapping. Read what he says below:

"Have been very successful in trapping foxes. Procure a dead horse or colt, drag it to a place where red foxes are known to roam. Leave it there for a time until you have evidence of foxes partaking therefrom. Then is the time to set your traps about the animal; attach each trap to a clog or drag (must not be too heavy). Cover with weeds, grass and snow. I'll bet my farm that a No. I imitation Newhouse trap will not hold him every time.

"Other times when setting traps, I use ashes from burnt wheat straw. I take a piece of newspaper, just enough to cover the trap, and sprinkle ashes about one inch on the paper which covers the steel trap. On top of this I take snow and just sufficient to make everything look natural.

"I've caught foxes in traps set in a pile of ashes. They come to a burnt straw stack because large numbers of mice are generally found there, and these the foxes eat with a relish."

\section{Trapping the Fox.}

Elsewhere will be found his article on skinning the $r$ d fux. Note the article below from G. Miller, of Conway, about red foxes.

"The trap should be well smeared with blood or becswax to destroy the odor of the iron. Set it in soft earth, packing noss or leaves lightly around the pan and jaws. Bait with fried meat. To make the allurement doubly sure, obtain from the female of the dog, fox or wolf the matrix in the season of coition and preserve it in alcohol, tightly corked. Leave a small portion of it on something near the trap, also when visiting the traps put some on your boots.

"Another method is to make a bed of chaff in the open fiels in a locality the fox frequents, but when it will be least likely to be visited by passing hunters. Visit it daily and stir into chaff every old scrap of meat made fine or toasted cheese, using utmost caution not to clinnge the appearance of the bed or its surroundings, and make as few tracks as possible. The materials of which the bed is composed should not be handled any more than is absolutely necessary. Too much care cannot be taken in making the beds, for if foxes are plenty and you get several to visit it, 
it will last for sometime and will afford you a great deal of amusement. As soon as you are satisfied the fox has visited the bed regularly for five or six nights, you may put in your trap. It should be fastened to a clog light enough for a fox to drag, but heavy enough so that he cannot get too far away, though if there is no snow on the ground there will be some difficulty in finding him if he goes some distance. He may be caught the first night, but more likely than not, will dig ont jour trap or show his contempt in some other way, compelling you to bring into force all your ingenuity before your efforts are successful."

\section{Trapping the Fox.}

J. Stephen, of Hart, writes the following on foxes:

"I will give you my two best methods of catching Reynard, The Fox.

"First find a place in the woods where there is a fox run-way and follow it until you come to a small knoll or where there has been a tree turned out and rotted away; then as a fox most always leaps over it, set your trap just under the snow on the opposite side, and as he jumps over he is quite likely to jump into one of your traps (it is a good plan to have about three).

"Another good method is to take about four good traps (I use Newhouse), and go where there has been something killed (the slaughter house is a good place), and soak your traps in the blood. Then take a hen (one that is dead will do), and drag it along the trail until you come to where he goes through some bushes. Then hang the hen up by a wire around her head; set your traps under the snow, or under the ground, and cover them with leaves or grass so that all looks natural. When the fox comes along he sees the hen; he lies down on the ground about five minutes and watches the hen, then jumps for her neck, which he gets, and the hunter gets the fox."

\section{Trapping the Fox.}

From Sherwood Shattuck, of Pepperell, Mass., we have the following :

"I find the senses of foxes are acute, especially those of hearing and of smell; their limbs are exceedingly pliant, and their tail is so flexible that they can roll it around their nose. They are shy, cautious, exceedingly cunning and patient.

"This is the way I catch the fox: One of the most attractive objects to the four-footed midnight marauder is a well-stocked hen-roost, and its attractiveness may be turned to good account by turning the tables on the fox, mink, skunk, or, indeed, any animal that has a constitutional predilection for poultry. The 
following ingenious but very simple arrangement will be found entirely successful in not only fully protecting the chickens, but also rendering the capture of the intruder sure. The contrivance consists of two parts, independent of the trap. The first is a box without a lid, and one of its ends taken out. This is inverted as seen in illustration, and a piece of the bottom cut away at one end, corresponding in size to the inside measurement of another similar, but smaller, box; this latter is also without lid, open at one end (see illustration), and large enough to furnish a place for a dead hen. This smaller box constitutes the second part of the affair; instead of a lid it is fitted with laths or slats across the width, the ends of the slats being secured to cleets nailed one on each side along inside of the box. To make these arrangements available, the larger box is placed on the ground inverted, with its open end against and inclosing the entrance to the hen-roost-the latter being allowed to remain invitingly open. Inside the box, and just facing the entrance, a steel trap is placed, set for effective service, and lightly covered with buckwheat shucks. Smoke trap by burning hens' feathers to prevent smell of steel, as foxes have a keen scent, as has already been said. The chain of the trap is attached firmly to the ground. A chicken is next placed inside the smaller box, and this inverted exactly over the hole which has been made in the bottom (now the top) of the larger box. Any enterprising fox, or other henroost thief, passing by will take advantage of the open entrance, survey with feelings of unmixed satisfaction the chicken overhead, take just one step nearer to secure his prey, to find his whole energies enlisted in fruitless endeavors to depart, without his anticipated feast, his captivity rendered almost unendurable by the tantalizing sight of his supper 'so near and yet so far.' I use No. 3 Newhouse traps for foxes."

\section{Trapping the Fox.}

How an Idaho trapper captures the grey fox:

"Find some trail where the fox is most apt to pass along, empty a gallon of wood ashes out in a round pile and set your trap in the centre of the pile. The fox is sure to step in the ashes for I have never seen it to fail. The only kind of bait I ever use for trapping fox is burnt meat skins; that will attract their attention for a long distance. The kind of traps used for fox are the No. $I \frac{1}{2}$ single spring Newhouse trap; if smaller than $I / 2$ trap is used don't fasten trap solid, but fasten to small stick or block of wood, so when the fox leaps it will give without pulling off his foot." 


\section{Trapping the Fox.}

"My favorite dry land set for $f \circ x$ is to find some stump or some opening $V$ shaped on the bottom, which I carefully clean out; and into which I set my trap. For bait, I generally succeed by nailing a piece of meat, such as muskrat or bird at the farthest end. Leave the surroundings in the most natural condition and always place some cotton or fleecy material beneath the pan.

My favorite water set for the fox is to find some spring, make an artificial island Io to I5 inches from the shore. This I sometimes makes as early as July or August. The reason I

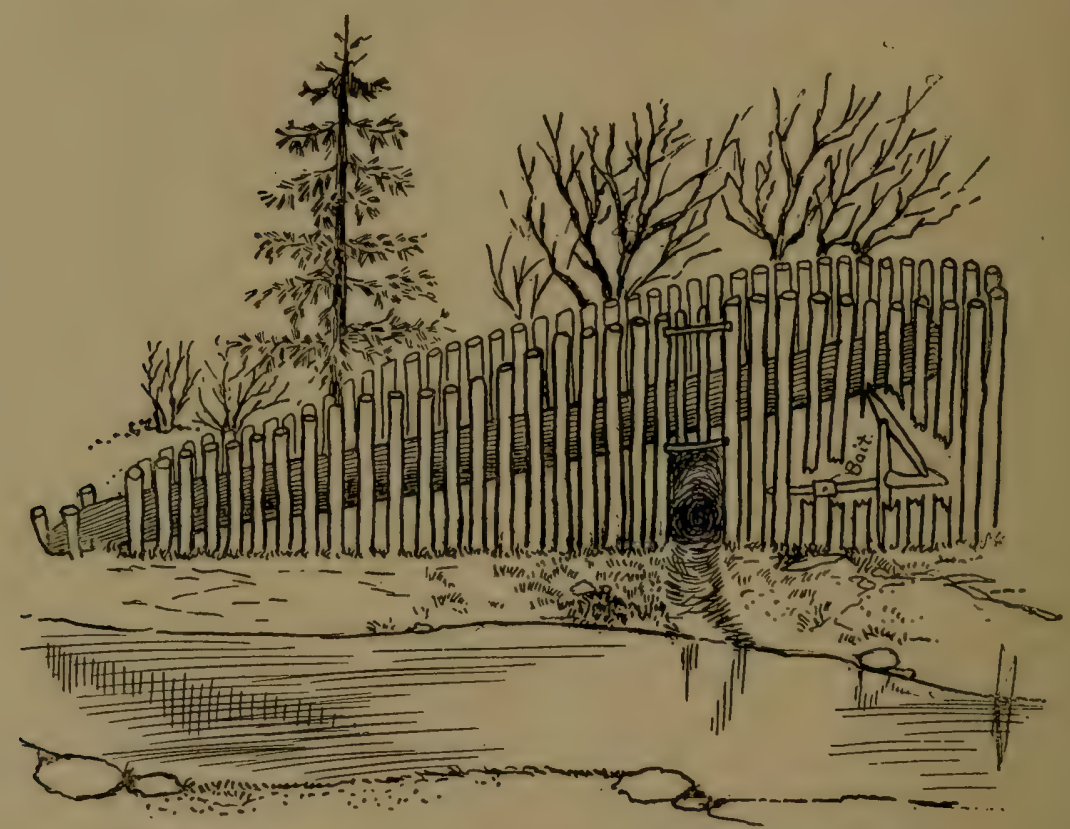

DEADFALL FOR WILDCAT, LYNX, RACCOON, FOX AND WOLF.

The above log trap is inclosed with sticks driven into the ground, with an opening of sufficient size permitting the entrance of wild cat, lynx, raccoon, fox, wolf, and, if $\log$ is of sufficient size and weight, for bear. Set figure four arrangement with care and place bait on spindle. For bait use meat, honey, and, if consistent, smear spindle with some of the preparation elsewhere noted in this Guide.

choose a spring is that the water is about the same level the year round. Trap should be set on a flat stone and on top of this stone place sod two or three inches thick, but remove sufficient to hold trap so that when the trap is covered it is just even with the upper part of the sod. Place some soft material below the 
pan, and cover trap with grass which can be weighted down with small quantity of earth. Springs can be covered with a thin layer of sod. The entire island thus formed should not be more than six to seven inches wide and everything below the water as much as possible excepting the pan. For bait I use piece of muskrat or bird, freshened up with some fish oil or natural scent of the female of the fox or dog. This I place on a stick beyond the trap so that the animal in endeavoring to get at the bait places his forefeet on the island where the trap is set.

\section{Trapping the Fox.}

J. C. O'ReILly.

Another good way to trap Mr. Reynard, especially if he is bait shy, is to set a trap near some tree or stump, if you happen to find the path of the fox and there is no tree or stump in the neighborhood, drive in a stake or a fence post a yard or two from the path. Set your trap I4 to I6 inches from the stump, tree or stake. Prefer to use two or three traps.

Now obtain from the dog a quantity of urine, which pour on the stake. The fox being of the dog kind, has the same habits as the dog, and when passing along will run up to the stake, tree or stump to urinate, and of course becomes a victim. If a tree, stump or stake is unhandy, use a boulder or flat stone; the latter should be set in the ground edgewise. After you have succeeded in capturing one fox, especially if it should be a female, after skinning, save the animal's urine, which you will find in the bladder; run it in a bottle and use same at the various places where traps are set.

E. L. S.

After you have satisfied yourself of the kind of decoy to use, take an auger ( $I / 2$ to $I$ inch), and start out to where foxes are known to run. Ascertain some old stump that has been sawed off, into which bore a hole and fill with the prepared scent or decoy. This hole is usually bored in center of stump. The fox will naturally put his front feet on the stump and endeavor to procure the decoy with his mouth or lick same with his tongue. The steel trap should be about a foot away from the stump, and he will either spring it with his front or hind feet. It is a good idea to have numerous sets in a vicinity of this kind, and if a stump cannot be found, bore a hole in some log or tree.

\section{Trapping the Fox.}

M. C. A.

Many trappers will laugh at me when I tell them that in my experience of trapping, on more than one occasion have I set my traps upside down. They may look funny, but it is true nevertheless. 
I remember distinctly 12 or I5 years ago the first time I had trouble in capturing a fox. I found his den and set a No. 3 trap in the usual way, only to find every little while the trap disturbed, either by being many feet away from the place where it was set or turned upside down, and quite a number of times the fox watered upon it. The fox on that morning had thrown the trap on one side of the hole and evidently had tried to cover it up with earth. I asked an old grey-headed trapper what to do, and he told me to set the trap upside down in the locality where I had set it previously, and sure enough the next morning the trap held the front foot of a red fox. Of course I did not see how he disturbed the trap, but I reasoned that he uprooted the trap with his nose and then pawed it away. There was no sign on the animal that he was captured before. Have heard other

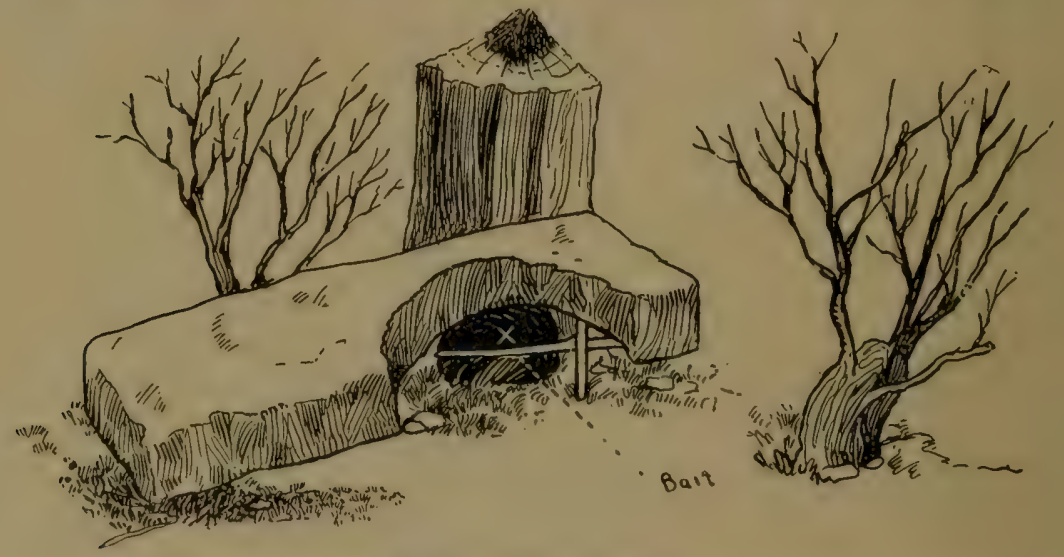

STONE DEADFALL.

This arangement was used by our forefathers, and history records its use many hundreds of years ago. It is very simple, and if properly arranged becomes one of the surest methods of killing small animals that we know of. Now sparingly used.

trappers say that occasionally they have the saine trouble with mink, and by turning the traps upside down, are able to capture them. Have set Newhouse traps over a hole with pan downwards and more than once caught mink that way. Would recommend trappers who have experienced like trouble to try this method.

WiLl Hendricks.

\section{TRAPPING THE WOLF OR COYOTE.}

"I will relate a successful way to trap the coyote," writes Mr. Lothamer, a Canadian trapper residing at Heather Brae. 
"The coyote is a very cautious animal, and is hard to trap, yet he can be caught in several different ways. The trap should be hid in a small pile of ashes or leaves, and should be smeared with lard or blood. Fasten the trap to a small clog or log, so that he can move about when caught. Obtain from the female of the dog, the matrix, in the season of coition, and preserve it in alcohol, tightly corked, when it can be had. Leave a drop here and there around the trap and put some on your shoes when visiting the traps. Take a piece of raw flesh and draw it in several directions from the trap and squeeze the blood out every little while. Leave everything as natural as possible near and around your traps.

"Here is another method. Find a place in the woods or in the brush where the coyote has made a trail and set your trap in it. Then hang a piece of meat off to one side of your trap to draw his attention avay from the trap. The reason why I hang the meat to one side is because a coyote never goes directly to the bait, but circles around it first, and in making the circle will naturally follow his old trail, at the same time keeping his eye on the meat, and walks into your trap. Use your owa judgment to advantage, and you will be successful. Use Neiv! ouse traps No. I $1 / 2$ or No. $2 . "$

\section{Trapping the Wolf or Coyote.}

We quote a trapper, H. Miller, living at Redding, Cal., who writes an article on the coyote:

The coyote is a very shy animal, and it requires considerable care and attention in setting the traps. This is one of my plans and is nearly always successful if the coyote is pretty hungry. I first find out about where he runs; then take the entrails or any part of the sheep, deer or goat (entrails from hogs will sometimes do). Select a place where there are a few brush, near a trai! nr road; fasten if you can the bait to the bottom of a tree or spreading bush; fix a pen with brush on both sides of bait and joining the tree at the end; must be old brush, make no new work that will show when brush is in shape. Then set our trap about four feet from bait and near the entrance of the pen; cover nicely. and leave no part of the trap in sight. Chain cais ise fastened to the butt end of a large limb or bush sunk in the ground so as to admit of being smoothly covered. Pen should be about a frot wide at the entrance. If work is done well and trap rightly sit, when he comes-whatever he is-and is hungry, you will catch him. No need of smoking traps to catch such animals; that is nonsense.

"I have tried all plans in my 13 years of tiapping and can safely say that I never could see that smoking or h'lindling with 
gloves did any good, as the scent on traps will go away of its own accord in a few days. This plan is the best I have found when meat for bait is used."

\section{Trapping the Wolf or Coyote.}

"In trapping for wolves," writes Mr. Chamberlain, "take entrails of a hog or beef to a place where you know wolves frequent, and throw upon an ant-hill or some mound, and set steel traps about 3 to 6 feet away on some other high elevation if possible. The wolf will go around and around the bait, sniffing and gradually reaching closer and closer, until he gets caught. Attach cliain to a 5-pound, not heavier than Io-pound clog."

\section{Trapping the Wolf or Coyote.}

The way I trap wolves is to find where they hang out. One will find them near some river, creek or lake. Horse manure or old barn yard litter will take away the scent of traps. I cover traps with manure or chaff. To attract wolves, I kill some ani-

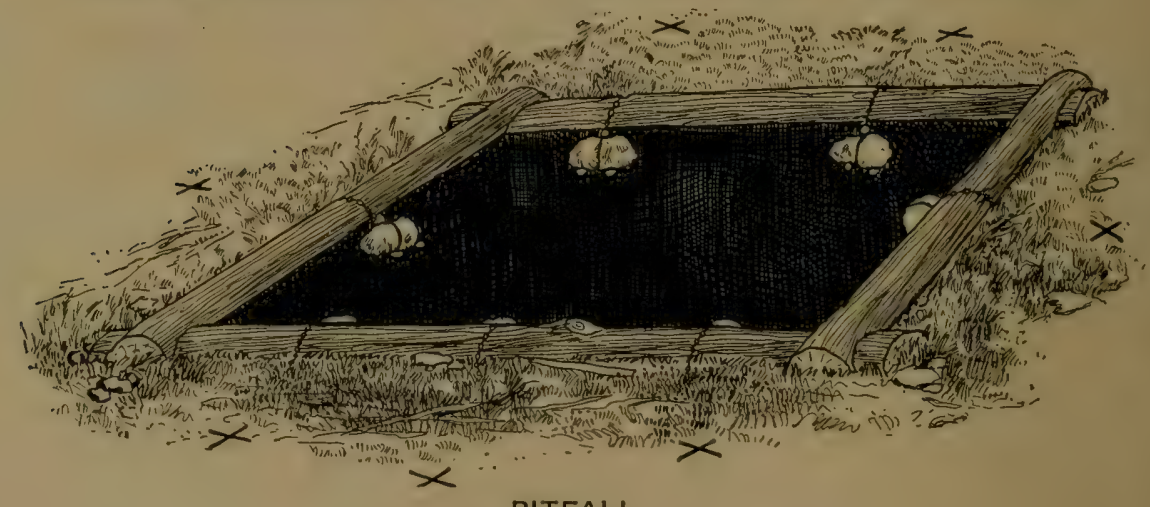

PITFALL.

Suitable for prairie wolves. Set traps 15 to 30 inches beyond pit, attach 30-pound weight to chain and arrange weight upon pegs driven into the sides of pit. Attractive live bait is preferable to dead carcasses. The victim after springing tiap will release weight which with the animals falls into pit.

mal and roast the carcass; this is done at the place where I expect to set my traps. The carcass will roast and smoulder for quite a while and the odor therefrom is smelled by the fox or wolf a. a great distance and I am sure will attract these animals for nuiles. Before starting the fire, have your traps set in the manure and hide them in the usual way. Where there are plenty of wolves I set from four to six No. $4 \frac{1}{2}$ wolf traps about the bait. My reason for using No. $4^{1} / 2$ traps is on account of the long chains and pronged drag. If a wolf springs the trap he will try to get away and in the space of time will become tangled up. The trail made by these pronged hooks is very easy to follow. 
The wolf is a cunning rascal and very suspicious when he detects any artificial arrangement. At the same time he is so inquisitive that he will shortly investigate everything and will come to the same place right along for a period of weeks. If you cannot prepare a roast for the wolf obtain fish; these even if vadly decayed are better than if fresh. The stronger the scent the greater the distance it will be carried by the wind. I never go to my traps on foot, usually look over the line on horseback. The advantage of placing such a set upon some slightly elevated place, especially during a snow storm, is to be taken into account. I prefer to place such sets close to cattle trails.

I hope the brother trapper will get many pelts and enrich his pocketbook by the bounty which the state offers.

Chas. H. Zeigler.

"In a level country it is sometimes more difficult to set traps during the winter months when snow is drifting and the wind has sufficient power to disturb even haystacks as well as piles of manure that may be hauled in the open prairie. In starting out to trap wolves, I pay particular attention to my traps. Instead of smoking them I tuse a compound made out of tallow, spruce and cedar needles. These I boil up together and then pour contents into a fruit jar. When I have located place that the wolf frequents, I drive or ride in the vicinity where I intend to set my traps and scatter a few branches smeared with this preparation. MIy favorite place is to set traps around a straw or hay stack. In a few days thereafter I take the stomach or intestines of some calf, sheep, hog or beef, and throw it close to the stack. I now take two No. 4 or $4^{T / 2}$ double spring traps and set them I2 to I4 inches on the outside of the bait. These traps are set level with the ground, and concealed with earth, rotten wood, etc. The chains are securely fastened to some old limb, or loose fencepost. The latter makes an excellent drag. If traps are skillfully set and concealed and if there are any wolves or foxes in the neighborhood, you will get them. Do not be disappointed if you are not successful the first few days, as the fox and wolf are both suspicious and sometimes will loiter in the vicinity for hours at a time and two or three days before they will approach the bait.

The funniest experience that I have had was in Manitoba along the Red River, where two of the aforementioned sets were placed on the opposite sides of a haystack. In one trap I got a large buffalo wolf and in the other a stray dog. During that same season and with the same three traps, I caught 6 wolves, 8 foxes (for one of these skins I received $\$ 85.00$ ) and one dog.

J. R. BARTON. 
Trapping the Wolf or Coyote.

A favorite set is to bury part or all of some dead carcass on an elevated mound or hill. From is to 20 inches on each side, place one or more stcel traps, which are to be buried and covered in the usual way. Occasionally I place poisoned pellets of meat in the immediate vicinity.

Just before leaving I obtain one or two armfuls of straw, which I place four or five feet away from the center of bait, start it afire, and just as soon as I am sure the fire is all out, go away. The wolf or fox will come the same or next night, and if the set is a natural one, he may go to the bait the first day. If

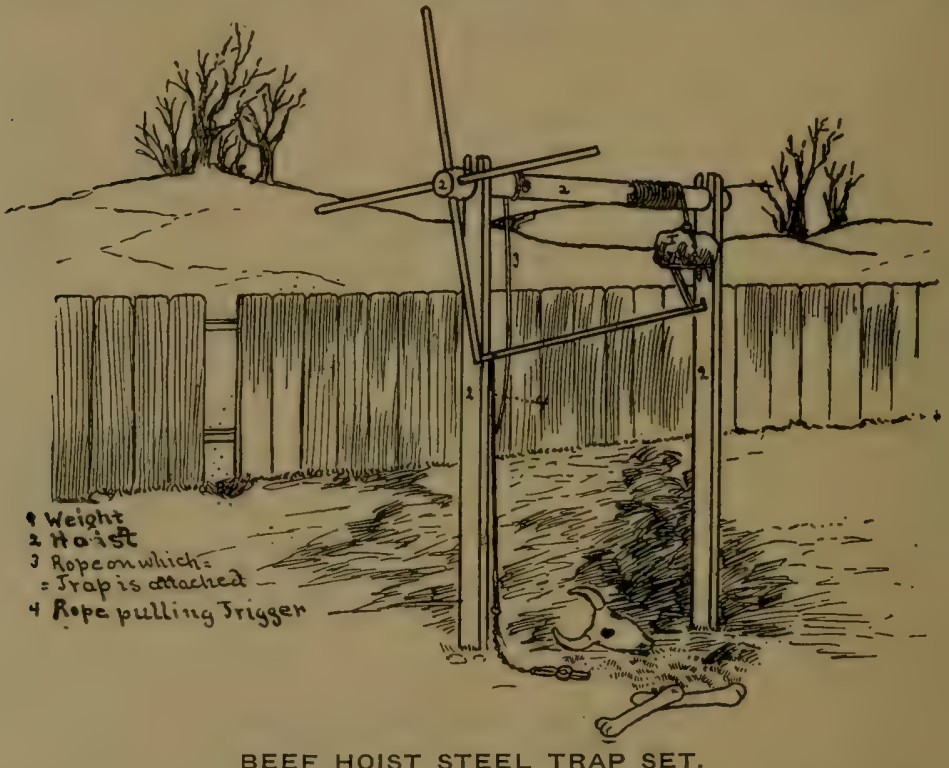

This original and unique set has been tried and proven a success. Suit able for all kinds and sizes of animals. Weight must be one-fourth to one-third heavier than the proposed victim. When trap is sprung, animai pulls trigger, releasing weight which descends and furnishes the power to hoist the victim in the trap off the ground.

not, he will go in two or thrce days. The wind has a tendency to distribute the ashes and by so doing overcomes any and all human scent that the trapper may have left. $\quad$ R. B. A.

\section{Went Fishing For Wolves.}

A Nevada youth, not having any traps, caught many wolves by promiscuously baiting three pronged trolling fish hooks with small pieces of meat attaching them to ordinary baling wire fas- 
tened on limbs of trees, so as to hang four feet from the grouncl. The wolf in jumping for the bait snaps just like a dog, and the prongs very readily find themselves imbedded in his upper and lower jaws.

\section{Trapping the Wolf or Coyote.}

Coyotes, unlike the wolf, are not very great travelers. Generally unless driven out, they remain in the vicinity where they were raised, and on their range, are as familiar as a clerk in a store. They travel on trails, wherever they lead, in the direction they are traveling. It is as natural for them to travel on a trail as it is for a cow or horse, because their feet get sore from travelling over rough ground covered with rocks.

Find a cow trail where you see coyote tracks quite often. Locate a small bush about 2 to I $_{5}$ feet from the trail. Now take three traps, No. 3 or 4 Newhouse or $H$. \& $N$. Nlways use large traps, for there is no telling what kind of an animal is going to get caught acciclentally. Have a grapple on each trap. Now put a trap on 3 sides of the bush. I'ut the grapple of each trap in the center of the bush and cover with leaves. Bury each trap down level with the ground. l'ut 2 or 3 grass stems over the jaws, then put a piece of paper over the jaws, and cover lightly: with fine, dry dirt. Treat each trap this way. Everything should look so natural that you, yourself, cannot see the slightest alteration. Now put some cracklings in the center of the bush and over all sprinkle fish oil, especially on top of the bush so the wind can carry the smell a long ways. A coyote can smell this set if the wind is blowing in his direction, for one-half mile and will then come straight for it.

Always use clean buckskin gloves when handling your trajs. Traps for coyotes should be set horse-back. Take along a piece of hide large enough to stand on. Tie a 6-foot rope on it, throw this on the ground, step off and set your traps. When through, get on your horse, and pull the hide up with the rope. If you are trapping in a country where there are deer or antelope, use their hides in place of a beef hide. This leaves no human scent on the ground and fools the smartest coyote,

The way I make my fish oil is to cut up fish and put them in a bottle, cork up and let stand in the sun for two weeks. It is then ready for use.

This is the best set I have ever used and is used by the best and most successful trapper in Wyoming, known as RattleSnake Jack. I have taken 3 corotes at one set, in one night. If this set is used in the vicinity of a dead horse or cow, a person is sure of success the first night.

WM. WEIBEL, La Porte, Colo. 


\section{Trapping the Wolf or Coyote.}

Will herein give you my experience and method in trapping the wily coyote and grey wolf, which are very troublesome to the stockmen of the country, or other stock-raising countries. The bounties paid for these friendless animals by state, county, and stockmen, pay the trappers very well for pursuing them both winter and summer. The county bounty, is $\$ 6.00$, state, $\$ 3.00$ and the bounties paid by stockmen in different parts of the state vary from $\$ 5.00$ to $\$ 20.00$ on a single wolf; so between the bounty and his skin, it is worth while looking after Mr. Wolf. But let me tell you, boys, the trapper has to deal with an animal of almost human intelligence and sometimes it seems to be more so than that of man. I have, before now, set my traps for wolf and on going back afterwards have found the trap taken up and thrown out of concealed place, not even being sprung.

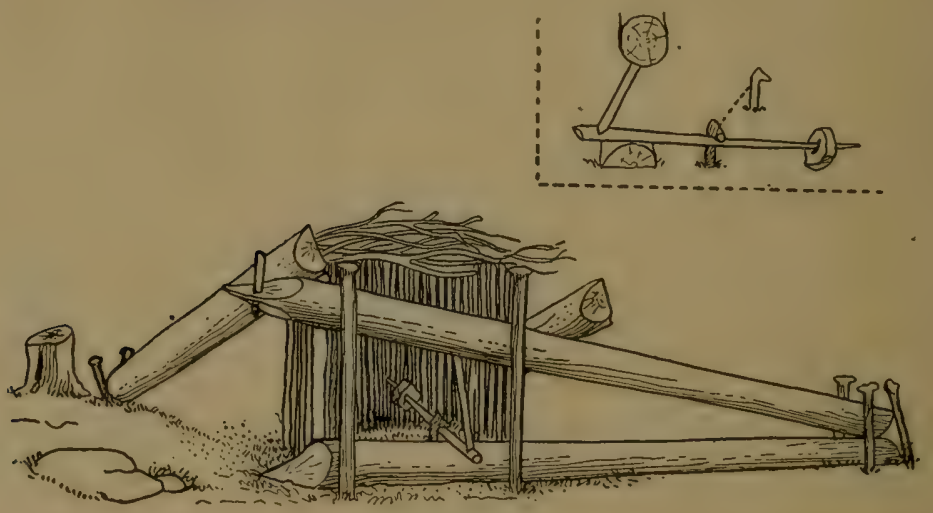

DEADFALL.

This is a very simple arrangement not much used of late years, but formerly used by frontiersmen in the capture of wolves, lynx, wild cats and other large animals, even the black bear. Bait should be securely fastened to the spindle or on the ground within the enclosure.

For trapping the wolf, always use the Newhouse No. 4 beaver trap. Instead of using a drag, I use an iron pin, 2 feet long, driven into the ground out of sight. This is not so heavy to pack and does just as well.

First, have your traps smoked over cedar boughs or feathers of any kind. This kills the odor of iron. When setting traps, always dig out a hole in the ground about two and one-half inches deep to fit a trap, with springs a little bit turned to let jaws down even. Now place your trap and cover with a piece of paper large enough to cover jaws of trap and cover all with 
fine, dry dirt one inch deep. Also cover chain and pin. See that the latter is just even with the ground. The idea in using paper is to prevent dirt getting under the pan of the trap, then when any animal steps on the pan, your trap is sure to spring. If the dirt taken out of the hole is too lumpy, have a sack or something to carry the lumps away, and bring good dirt. Leave everything looking just as it did before you came. When covering traps, never use your bare hand, always have on mittens or gloves and brush : iway your track, or you will get no wolf.

This, in my experience, is the best method for catching the foxy old wolf. When looking after traps, keep from Io to 15 rods away, unless you have something in your trap, or it is sprung.

After catching a wolf, always clean and change your traps, because you will never catch two wolves in one place in this country where there are so many cattle. I set my traps in trails where cattle go and come from water. I set them at cross trails or in forks of trails. This makes lots of work as the cattle often spring your traps. Where there are lots of rabbits, cattle and stuff for wolves to eat, no bait is necessary as this would only arouse the wolf's suspicion and cause him to walk away.

Another good way where bait is to be used: Find a place where there are a few mounds. Now, conceal your trap as before stated on each mound and throw your bait between mounds. He is certain to get upon these mounds to look around and you will get him, or the trap will.

When you think a snow storm is near at hand, don't cover the traps deep, as the snow makes a good covering with just a little dirt under it.

I think this method of concealing the traps will also answer for taking other land animals. But the trapper will have to use his own judgment in covering the traps, with regard to the size of the animal he expects to capture, as a small animal would not spring a trap with so much dirt on it. I have caught skunks and badgers in this manner.

I never use the chains that come with the traps, as they will not hold a wolf in cold weather. I remove same and make chains from chain tugs, and have same a foot long.

\section{ROBERT ROBERTS, Harding Grove, S. D.}

\section{Trapping the Wolf or Coyote.}

The wolf is the most cunning animal with which the trapper has to deal and to trap him successfully takes both care and patience, but with my method, I have good success. 
First, if the traps are rusty or stained, boil them in willow bark and water. This will remove any odor, rust or blood. When handling, use buckskin gloves. Set the traps where there are signs of wolves.

I use No. 4 Newhouse traps, and for scent I use,

I oz. Anise Oil.

$1 / 2$ oz. Skunk Scent.

I oz. Essence of the Wolf.

Mix and apply to pan and spring of traps.

Now, cover the trap first, by placing a paper over the pan and Jaws, then cover with dirt enough to remove all traces of the trap and chain.

For bait, I use squirrel, prairie dog, rabbit, or birds, and alive when possible. To fasten the bait, bury a stake in the ground and fasten the bait to it by means of a short chain attached by one end to the stake and wire the other end to the leg of the bait.

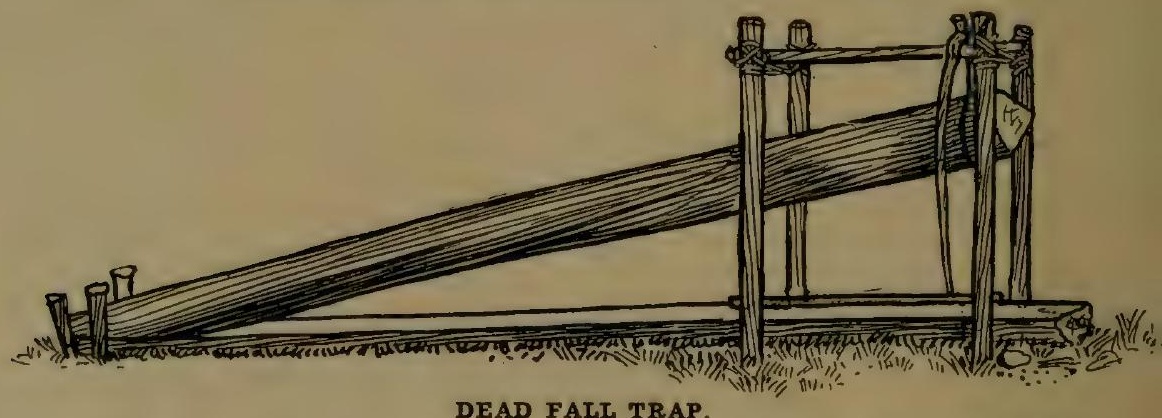

Now, set a trap on each side of the bait, and about six feet from it, and when the wolf sees that the bait is fast, he will begin to sniff and walk in a circle around it and so get caught.

I have seldom known this to fail when the wolf came near (nough to see the bait.

\section{F. Аввот, Ft. Pierre, S. D. \\ Trapping the Wolf or Coyote.}

In such states where a good bounty is offered it is more profitable to capture young wolves for the reason that they are more plentiful and easier captured. When they are three or four months old they can be seen going away quite a distance from their abode. Then is the time to bring some dead carcass In the vicinity and to place No. 2 , No. 3 or No. $3 \frac{1}{2}$ traps thereabouts. Nine times out of ten the mother will be suspicious, but she cannot prevent the cubs from nearing the bait, due to 
their over-zealous desire to satisfy their carnivorous appetites. The cubs, as they become captured, will of course make a big disturbance, and the mother will approach them timidly. Sometimes will carry them away, trap and all. On one occasion four cubs and three full grown wolves were captured at one setting, presumably the larger ones went to the assistance of the cubs or probably for pure deviltry. At other times, notwithstanding the suffering of those captured, others will come and devour parts or all of the bait.

\section{Trapping the Wolf or Coyote.}

N. C. A.

The wolf is probably the most cunning animal of the dog family. If he was as easily captured and killed as is the buffalo he would now be extinct a hundred times. It is a well-known fact that a wolf is not as cunning in a new country as he is in an old settled community, and he does not feel out of place to travel in good society in an old settlement. What methods are good in one place may not be worth the paper written on in another.

I was fortunate enough to catch one of the slyest wolves that ever lived in southern Minnesota. He was known for years as the "three legged wolf" and seemingly had had an encounter with a double spring trap years ago. Since then he baffled everything in the trap line and no one in the vicinity was able to bring him to bait. There was no use to set traps around a dead critter; for such, it was better to have kept the traps at home as it would have saved many the worry and trouble of looking after them. I took the bones of an old carcass and hauled them out in the open and left them there for some time. Mr. Wolf came and smelled round the bones for two or three days and then watered upon them. Probably the wolf had no idea that a man would be so foolish as to expect him to eat dry bones, or that one would place traps thereabouts; but nevertheless I got him.

To set your traps when going into a wolf country, drive if possible; tie a big piece of meat (lung or liver is good) behind your wagon and drag it along. Smear the drag with three parts of asafoetida, beeswax one part, and thirty drops of anise oil to one pint of mixture. If you get off the wagon smear your soles with this preparation, also your gloves. I usually take along a pail of blood which I sprinkle in the immediate vicinity in places where I set my traps. I also dip the traps in the pail before setting them. Traps should be set in some cattle trail near some bush, and if possible at some intersection of another trail or road. Traps should be covered with leaves and grass and make the setting 
look quite natural with the surroundings. Occasionally I cover my traps with rabbit fur. At other times when the weather is real cold, I dip the traps in water and-roll them in loose feathers or rabbit fur, which of course becomes immediately attached to the trap. If the weather continues cold, set this trap in the trail without any additional covering. The wolf will come along, and ninety-nine times out of a hundred, paws at it.

Young cubs are easily caught. Place traps around their feeding place and if you cannot locate the feeding place, make one by bringing some dead carcass there. The cubs are not very shrewd and in their over-zealous desire to satisfy their craving appetite, they near the bait and of course become a victim.

\section{ANDREW DAVIDSON, \\ Trapping the Wolf or Coyote. \\ Bathgate, S. D.}

A wolf is the most cautious and keen animal I ever tried to trap. A person has to go some in order to fool him. The only successful way to trap him is to use a blind set at a dead horse or cow, for he will not go near it as long as there are any live cattle on the range. A wolf travels in a large circle and manages to get around this circle once every four or five days. They generally, unless very hungry, lay around in cliffs and washouts in the daytime and when night comes, come out of their dens and prowl about all night in search of prey.

Find a place where you see his tracks in a cow trail or old deserted road. Watch the place where you have seen his tracks and see if they occur there more than once. If they do, you have found a place where he travels regularly. Now take five No. 4 Newhouse or Hawley \& Norton traps, with an eight-inch chain and a good swivel, and a twelve or fifteen-inch pin if the ground is frozen, and if not a twenty-inch pin is none too long. Use one pin for each trap. Take a calf, antelope, or deer hide, tie a six-foot rope to it. Do not touch the hide or traps with bare hands, but use very clean buckskin gloves. They will leave no human scent on traps. Now take your traps and hide and get on a horse and go where the set is to be made. When the place is reached, throw the hide down on the ground, step off on the hide. You should also have a small piece of hide, one foot square, so you can stand on it with one foot and move the other hide to a convenient spot. Under no conditions get off the hide, as you will then leave a scent. Take the traps and drive the stake of each trap so that when the traps are set they will cover about thirteen feet of the trail. The stakes should be driven so deep that they will not show. The traps must all be huried level with the ground. Put two or three straws over 
the jaws, then a piece of paper. Now cover them with fine dirt. Cover enough so the paper will not show. When you are through take fine dirt and throw it up in the air so it will light on the covered traps. Make everything so natural that it looks no different where the traps are than it does fifteen feet away from the traps in the trail.

Use no scent. Experience has taught me not to, as it will make him suspicious and he will walk around your traps and your work is all for nothing.

When all is ready, get on your horse and pull the hide up. Now the next time he walks along you have got him for it is impossible for him to walk over this set without stepping in one or more traps. This is the only successful set I have ever used or have seen used and works when all others fail.

WM. WEIBEL, La Porte, Colo.

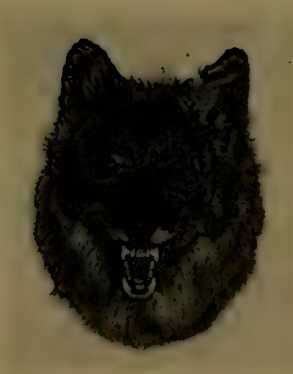




\section{HOW THE BEAR IS HUNTED OR TRAPPED.}

"A Wisconsin lumberman relates an interesting story of the capture of a three-year-old black bear without gun or trap. and without previous preparation for the capture of bruin.

The cabin that this bear visited during his nocturnal prowls was located in dense forest, near a stream, inhabited by woods. men. Being winter, the ground was covered with snow and the night of the capture or detention of the thief with his plunder, was clear and cold.

The men were accustomed to see game and carnivorous animals not only in the woods, but about the cabin, picking up scraps

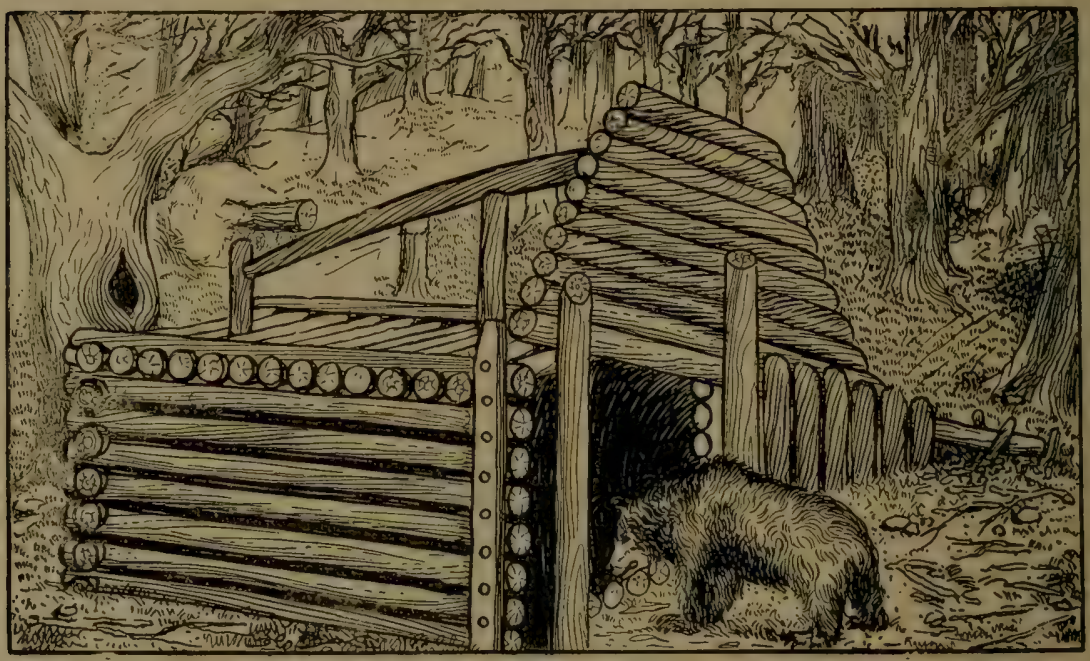

LOG PEN TRAP.

The old-fashioned log pen trap is still used by hunters and trappers, but owing to the large amount of labor required in its construction only those trappers that live far in the interior, chiefly in Canada, Alaska and in Siberia, construct them.

of food that were thrown out from day to day. A small empty pork barrel was rolled out during the day, and no one dreamed that this barrel with its many protruding nails would make the best kind of a bear trap. The bear, in seeking food, placed his head and neck far into the barrel, and being unable to get the barrel off by shaking, rolling and tearing through the dense: bushes, knocking against trees, was obliged through loss of blood and exhaustion to give way to the inevitable. When the body was found two or three days thereafter it was frozen stiff. 
and it was necessary to break the barrel to remove it from the animal. The barrel being rather small and with its many nails did the work. The bear roaming about with such a mask must have terrorized all animals in the community.

Many bears are annually dispatched by Minnesota, Wisconsin, Michigan and Canadian woodsmen by the use of an ax, and, as a matter of fact, these men much prefer to meet a full-grown bear, either in the woods or on denuded land with an ax instead of a Winchester rifle.

While this is true with bears, it is not so with lynx, wild cat or other members of the cat family, who pounce upon the victin from some lofty place (many times unknown) and in the hunter's unpreparedness a hunting knife is about the only weapon in close quarters, unless a test of brute strength becomes appa:ently necessary.

\section{How the Bear is. Hunted or Trapped.}

Bears are probably as much hunted as trapped, in fact, think more are captured with the rifle than by steel traps. There is probably nothing better than live, noisy, squealing bait to attract a bear. Personally I think a small pig would make a clandy bait, but up here in Canada the closest one comes to a pig is to get some eastern bacon, and this is a better bait for the trapper than for bruin.

If one owns one or more No. 5 or No. 6 Newhouse bear traps, he should proceed to make a $V$ or $U$ enclostre; either of these can be made out of three or four-inch stakes about five feet long: drive sharpened end into the ground about two inches apart. The opening should not exceed three feet for large bears and two and one-half feet for smaller ones. Set trap at entrance, and cover in the usual way. Bait should be put well within the enclosure, usually in the narrowest part. A little anise oil will not hurt. Whether the peculiar, or the strange odor, is the. attraction, I cannot say, but know from experience that the anis? oil does the work. Log pens with drop-doors are also being used in some parts of Canada, but up here bears are not very plentiful, not worth the time to build such strong dens.

A very good yet peculiar trap arrangement that I saw used by a friend of mine trapping in the Blue Mountains in Pritish Columbia, and useful not only for bears, but for other large game, was a pit with a trap door. The pit was about six by seven feet square and five and one-half to six feet deep. The dirt was held in place by long stakes driven into the ground. The top was covered all up; in the center he had arranged a trap door, about five feet square, hinges on the inner side. The catch was arranged to the bait, also if a lever were stepped upon, door would drop' 
and with it the victim. This pit was in the woods adjoining a spring where animals came to water. It was level with the ground and the first time that he took me there, I would readis have walked into the trap had he not pulled me back, so well was it arranged by him, that no one could perceive the arrangement. This was in the summer time, and while there one morning, an innocent deer was taken out. He claimed to have caught inve bears the preceding season.

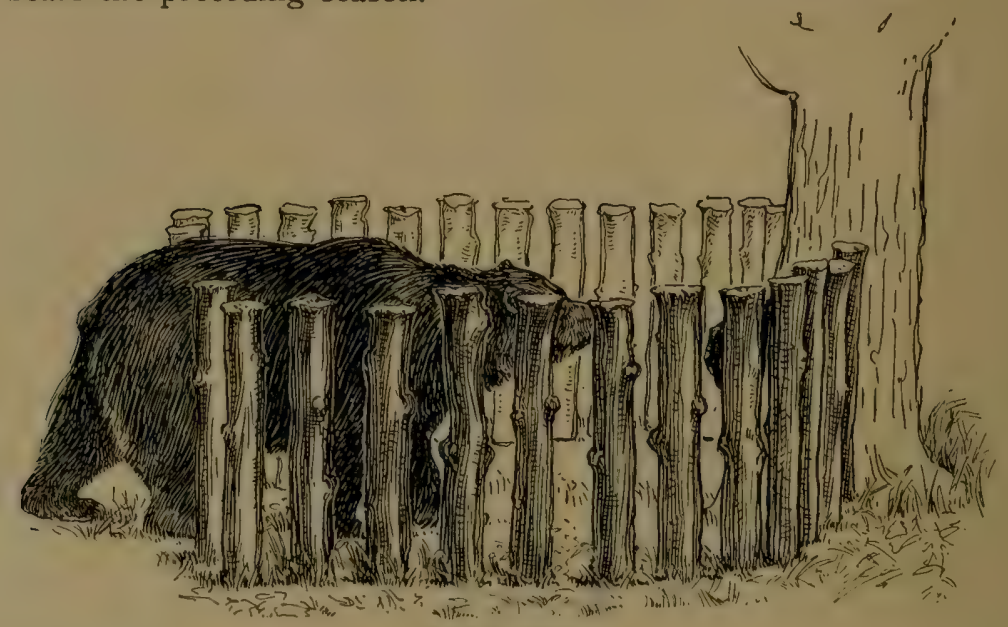

BEAR PEN.

Steel trap is to be set just within entrance. For a set gun arrangement bore a hole slantingly into trunk of tree and arrange trigger with a string to bait or some artificial treadle.

In skinning a bear, I always take particular pains not to ciit the skin and to leave everything including ears, nose, eyes and feet with claws complete, attached to hide. One thing I do, which perhaps other trappers do not, is to ship the skull of the bear along with the skin. The buyer will pay a little more for the hide, as he may have some customer who will want to make it into a rug and the natural skull is preferred over an artificial one, which I understand is made out of plaster paris.

A. R. EDwARDS.

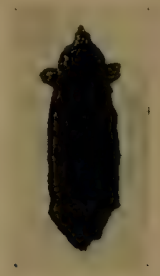




\section{TRAPPING THE RACCOON.}

Southern methods as used by R. W. Riggs in the swamps of Louisiana-The bait used and the way to set traps:

The bait: The castor sacs of a beaver put into a little alcohol to keep it. A little of this put on a stick six inches high and placed so that he will have to go over the trap to get it, is a sure coon exterminator. Next to that, something good to eat-fish, squirrel, persimmons and corn are my favorites, the first two preferred. In January and a part of February, I set many traps on logs. I look for old logs; cut in a place for my traps and cover with whatever is on the log. Then place two round sticks about one inch thick on each side of the trap. On logs I use the $2 \frac{1}{2}$ Oneida Jump trap, in most other places the No. 2 Newhouse. I make mostly water sets and think them the best in this section. I set where anything forces the coon to take to the water, at the end of a $\log$, behind a tree, by steep banks and like places. But my best set is at the clay roots of a tree that has blown down out in the water. I fasten all of my traps to a good-sized stake, driven into the ground at quite an angle. My stakes are two feet out of the water. I put mud on them to make them look old. To fasten the traps I slip the chain through the ring and put the loop over my stake. Set the trap between the stake and the bank in about two inches of water if possible. Cover well and put bait on stick eighteen inches above trap. Set around clay roots and you will get the coon.

\section{Trapping the Raccoon.}

"To catch Mr. Raccoon," writes MIr. J. Hight, of Samoth, I11., "one of the surest and best ways is to hunt at night with dogs, a gun, and if the night is dark, a lantern is needed. The success and profit in hunting with dog and gun lies in the fact that several will be put upon the same tree. I have known as many as seven to be found up an oak eating acorns before the hard frosts came. When up a tree, if the night is dark hold the lantern above your head and imitate the sound of a fighting coon or one worried by dogs, by putting the forefinger in the mouth and squealing. Zip will look down in the direction of the noise and his eyes will shine like balls of fire; then with a shotgun he can be brought down. I have made them jump out of the tree with finger in mouth where they were easily caught by the dogs. If the moon is bright you do not need a lantern, but you can "Moon" Mr. Rack by placing yourself so that the coon is between you and the moon. I have shot them on a full moon with a rifle. "In trapping, I use the Newhouse No. I I $/ 2$ trap and select a swamp or slough if I see any sign there. Place the trap 
under water three or four inches from the edgre and secure it by a stake driven through the ring in the chain or drive the wedge into something the coon cannot drag. I bait by dropping a few grains of white corn in and around the trap, or by placing a small piece of white china on the trigger plate. This latter seems to have a fatal fascination for Mr. Zip, as it seems he will investigate every one he sees. If there are logs in the swamp, I look for logs they travel on, which is indicated by their excrement, being voided on certain logs in crossing. If I set on a log above water, I chip out a place large enough to hold the set trap. I put in the bottom of this under the trap a piece of chicken or bread soaked in syrup or fish, if I can get it. I sometimes use the sexual member of the female, also asafoetida. All these are good baits, and by using different baits on different traps,

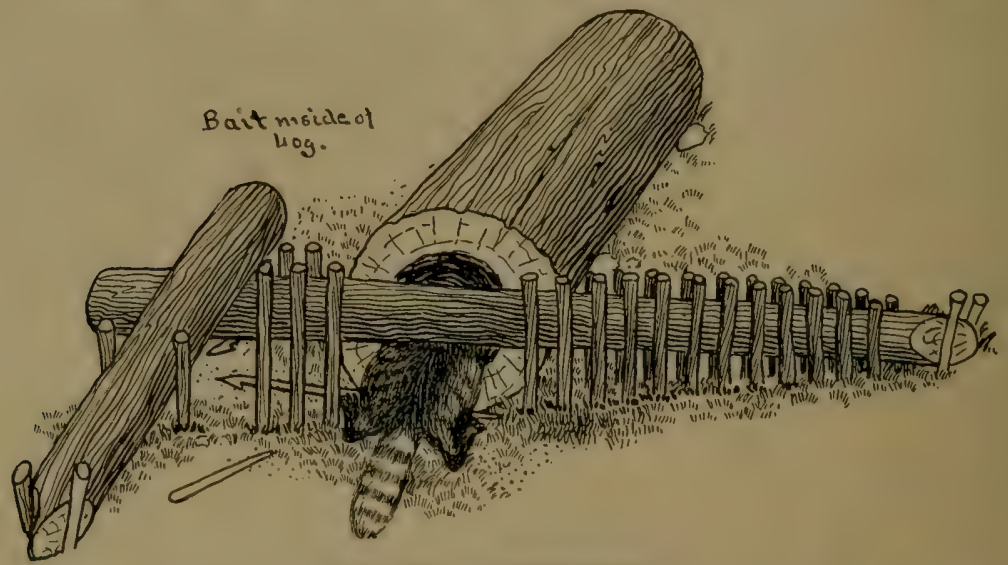

HOLLOW LOG DEADFALL.

The captured raccoon in above illustration tells the story. The bait is placed within the log. It is best to leave both ends open, permitting the animal to see through. This arrangement is also suitable for mink, marten, fox and fisher.

you can learn a great deal of Ringtail's habits. The best place I ever set a trap is on a log, some part of which goes down into the water. When he comes to the water he is sure to feel for the depth; there put your trap, log chipped as above, and you will get the coon. The coon is a Benjamite, that is, he is left-handed. Seventy-five per cent of all I or my companions ever caught were caught by the left forefoot.

"Another good way to catch Zip is with the 'deadfall.' Find, as before, the logs they cross the water on, and lay a pole four or six inches in diameter across a $\log$, fastened at the other end between two stakes withed or nailed together at the proper height. 
To make level, chip a flat place on the end across the log for the upright trigger to stand on, fasten a string to the rear end of the 'fall' pole, let it be secured to the upright trigger, being drawn tight enough that a slight push on the string will throw the trap. Use triggers similar to the figure 4 triggers, the string being the long trigger. Or I sometimes use a small switch about three feet long for a long trigger. The poles must be weighed by crossing poles above the log, which will compel cooney to go between the poles, push the string and die. Deadfalls cost no money, and there will be no gnawing the foot off or pulling out and getting away.

"Another simple device used in the swamps of Illinois is the two-inch auger hole, bored three inches deep with four horseshoe nails, driven slanting so that one-quarter of an inch of the points will be in the hole: put sugar, frog, fish or broken china in the hole, and when coon tries to withdraw his foot he is caught.

"One other thing I forgot to mention in the beginning of this article, is in hunting with dogs, if I cannot 'shine' his eyes, I build two or three bonfires under the tree, which will make it so light that the whole body of the conn can be seen, and shot. This is better than cutting timber and paying fines. This has been my experience."

\section{Trapping the Raccoon.}

Mr. Chamberlain, a South Dakota trapper, writes "that in trapping raccoons, he always sets traps at foot of a tree, and securely nails a bird or rabbit about two and one-half feet above the trap on the tree, so that the raccoon has to get upon his hind legs to get the bait. By the animal tramping about he will get into the steel trap. I use a clog of about three to five pounds, unless you can arrange to fasten trap to limb of trce, so that when trap is sprung it will lift the victim up in the air."

\section{Trapping Raccoons and Stretching.}

I herewith give you my method of trapping the raccoon and stretching the skin: First go along the sloughs and look for their tracks and set your traps in the edge of the water: cover them up with a little thin mud. Drive a stake a little distance back of your trap on top of which place a small piece of honey, and I assure you if you have a trap strong enough to hold him, he will be there when you go back.

Now for the skinning and stretching: First lay the coon on his back. Rip across back part of hind legs from one end to the other: then across from one fore-paw to the other: then rip straight through center of belly to chin and take off hide. Lav the hide on a table and stretch it both ways with your hands, until 
you get it a little longer than it is wide. Straighten out legs, then cut off hind legs even with the hide; sew up the upper edges of fore-leg along side of the skin that comes off the lower jaw.

Cut sticks about one foot longer than the hide; take darning needle (large size best) and common wrapping twine and sew in the same as a woman sews a quilt in the frames. Take dry sticks (about size of little finger) - lead hedge sprouts are good as they are stiff. Trim off thorns; when the side sticks are sewed in well, which must be stitched about one inch apart, cut your end sticks with a " $V$ " shaped notch in each end so they will not slip out. Cut long enough so as to be fairly tight, but not tight enough to make the hide wider than it is long. Place lower one just below the end of the hide, sew in same as side sticks; place top stick in just above and across the ears; sew hide to stick

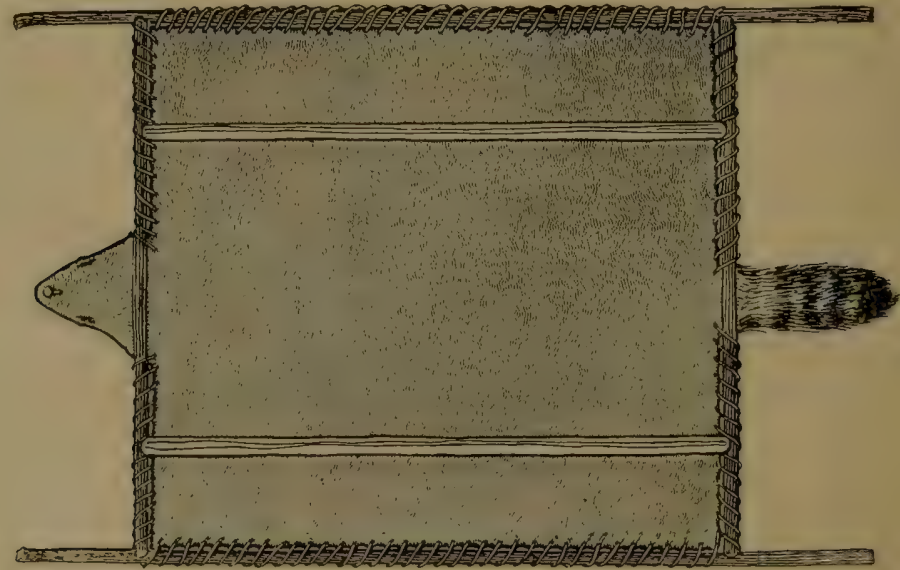

from outside toward center until you reach the neck which sew on each side alike. Now, put on the stretcher sticks, one on each side running lengthwise the hide. Split a hole in end of nose and hang up. Take a coarse comb and comb the hair down nice and straight, taking out all burrs, mud, etc. Put all sticks in on the flesh side of the hide.

\section{IRA BRADEN, Beardstown, Ill.}

\section{Trapping the Raccoon.}

An Ohio trapper gives his method of capturing raccoon in the following two paragraphs: The raccoon is not a hard animal to trap. If I have occasion to believe that a raccoon is in a given vicinity, I pass along the shores of creeks and rivers and am 
always on the lookout for signs. Should I come across a $\log$ that is partly under water and extending to the shore, I take my hatchet and chop an opening large enough in which to set a No. I, No. I $1 / 2$ or No. 2 trap. This I cover up with leaves and moss, and to keep the wind from blowing the leaves or moss off, I usually load them down with sand or dirt. If the water is of sufficient depth I arrange chain to a large stone so as to pull the raccoon into the water where he will drown. A few drops of anise on top of the moss or along the log is an attraction.

At other times I place the trap within four to five inches of water, placing a shining piece of nickel or tin on pan of trap. The raccoon seeing the reflection of the mirror-like object, will come and investigate it, and most likely when he attemps to disturb the mirror with his paw he will spring the trap and find himself a prisoner. The chain I always attach to the limb of some tree, or piece of wood, and if convenient I use the spring pole. If the trap is staked fast the raccoon is likely to twist until he gets his foot out, or have seen cases where the foot or paw is left in the trap. For that reason I prefer a large limb that the raccoon can drag away and enables me to follow the trail.

\section{Trapping the Raccoon.}

R. B. A.

We have the following article from William Plummer of Rochester, Minnesota:

"Three years ago I went to trapping on a small scale. I borrowed a few traps from my neighbor, No. I and $I \frac{1}{2}$, having located several dens in the rocks on the south side of a bluff. Coons will always go into rocky dens for winter quarters in preference to anywhere else. Well, I set my traps. Next morning several traps were sprung, coon hair was on the traps, but the raccoons were gone. They would pull and chew until th.y would get out. Finally, the one den became so covered with blood from their crippled feet that they wouldn't go in it any more, nor have I ever known a coon to go in there since. Well, something had to be done-I must have those coons. So I invested in two No. 2 Newhouse and set them in the other den. I managed to catch two small coons there during the winter.

"Last winter I made up my mind to do better at the business. So I bought half a dozen No. 3 Newhouse, and went to work at those dens. At the first den I could get nothing. They seemed to think that was a dangerous place. At the other den I did better, and caught eight cluring the winter. I used no bait, but simply placed the trap in the mouth of the den. One old fellow, however, got the best of me for a while-he would turn the left jaw of the trap over and walk by. So I placed another No. 2 to 
one side and a little behind the first one. I covered the second trap up with leaves and the next morning I had several toes, but Mr. Coon was gone. Well, that was rather disgusting, but I was bound to get him. About every other morning my traps would be sprung, and nothing there but a little fur. I got two No. 3 traps, and took the No. 2's out, putting larger ones in their place. The next morning both traps were sprung, and on the outside; Mr. Coon had got out, but left quite a chunk of

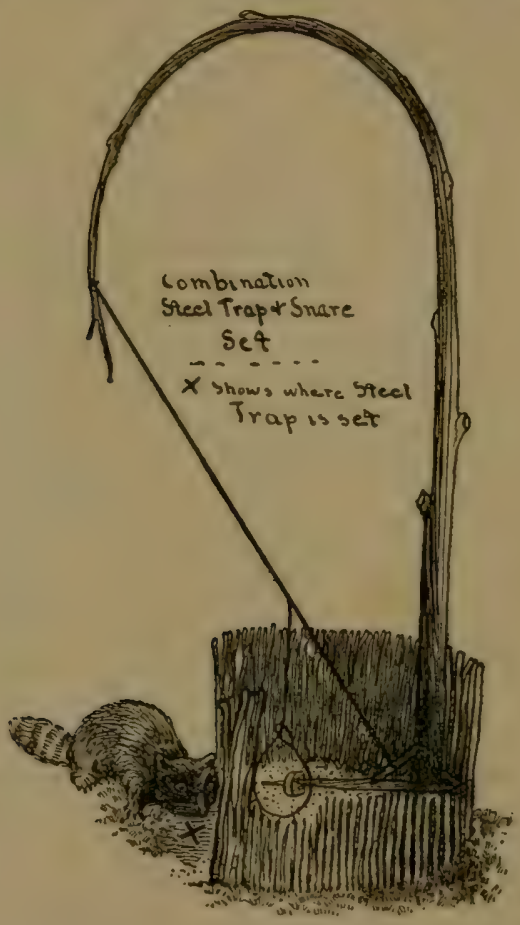

COMBINATION STEEL TRAP AND SNARE SET.

This is a very successful steel trap and snare arrangement. Bait with meat, etc. Suitable for raccoon, badger and other carnivorous animals. Bury trap, also attach chain to spring pole. $\mathrm{X}$ is where trap is to be buried.

his flank in the trap. How he got caught in the flank I am not able to tell unless he rolled over the traps to spring them. About a week afterward I found the coon in the trap and dead, but his fur was badly damaged.

"This winter I concluded to try a new scheme. I had posted myself during the summer on the different kinds of bait for coon. I read up 'Trappers' Guides' on the subject, and went to work by 
placing a No. 3 trap in each path approaching the den, covered the traps nicely with chicken feathers, placing over each trap a bit of smoked codfish and scattered a little oil of anise and rhodium around. Well, the next morning I had three of the neighlyors tomcats, but no coons; so I found that would not do. Then I went at the old plan, placing traps in the den. During the first week I caught two young ones, but no old ones. Then, again, my traps commenced to be sprung every night. Sometimes a little fur left but no coon. I placed a trap in each of three different paths within six feet of the den, covered them up with feathers and leaves. The feathers would be pulled off the traps and the traps in the den sprung. Well, I hardly knew what next to do, but thought I would try still another plan. I placed a No. 3 just at entrance to den, covered it up carefully, leaving the two traps on inside uncovered, and in five days caught one young coon and two of the largest old coons I ever saw. I have tried all kinds of bait I ever heard of, but never succeeded. WVell, with it I have caught coons in paths by placing a stone or pole on either side of trap to make them step over and covering the trap carefully; but if they become pinched a few times they become wary."

\section{Trapping the Raccoon.}

"I caught hundreds of raccoons in my time," writes Mr. Hammond, now retired and living in Albany. " $M y$ trapping grounds were along rivers, creeks, canals and close to lakes in Ohio, near Deshler, and later in Missouri, south of Jefferson City. I was always upon the alert, and while fishing one spring day and sitting among bushes on the river bank, I noticed a coon on the opposite side coming up the river, and suddenly stretched his neck in direction of square oyster can (used in those days) that was about three feet from the shore in four or five inches of water. He stayed around for about fifteen minutes, at various times reaching out after the can and even moving it from one place to another, and scrutinizing it very closely. As my cork went down, I pulled in a fish, and, naturally, the coon went skipping into the woods.

"The following winter I bought a dozen coon traps, took them to the machine shop and had two small holes drilled in each pan. Then I took from an old alarm clock the nickel case and made small round disks in size resembling that of the pan. I then riveted these nickel plates thereon and polished same with wood ashes, and sct the traps along the river banks, two to five inches under water. I also riveted gold plated disks upon the pans with equal results. On one occasion I placed a small pocket mirror fastened on a piece of wood slanting and shining towards 
the shore; and set a common steel trap just between the shore and the looking glass, but out of the water. I covered other parts of the trap with grass, leaves, etc:, so when the coon tried to examine the looking glass, he stepped upon the protruding covered trap and was caught.

"I cut the skin open on the belly and stretched same in square shape. Keep grease from the fur and always pull the tail-bone out. Nicely handled and seasonable skins bring twenty-five per cent more, and that's where the profit lies for the experienced trapper.

"Before closing my letter let me relate how I captured wild cats, coons, rabbits and other animals with snares. In tramping through the woods, I often came across tracks that I did not know

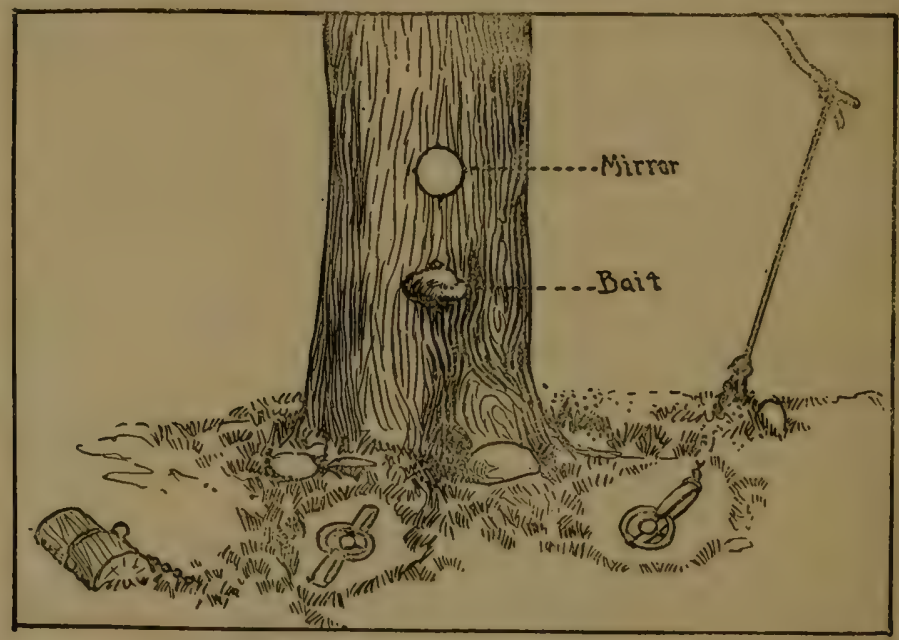

UNCOVERED STEEL TRAP SET FOR RACCOONS.

The mirror and bait form double attractions to the raccoon. A double set of this kind should be arranged near the bank of some stream or lake, or near the places the raccoon frequents. The steel trap as well as the clog should be buried.

by what animal they were marle. I set these snares, made from gut strings, wire, also cotton or linen lines, at various places, such as in front of hollow logs, passages, under brush or fence rails, and other favorable places. Arrange to lift the animal off its feet and away from harm of other animals by pulling down limbs or small trees, and if these were not conveniently situated, I often threw a long rope across a distant limb, attached a ten to twentypound stone on end and raised it high up; the other end I fastened to the snare in such a way that if pulled by the animal the fastener 
would break or pull out and the wcight descend and hang the victim before he knew what was up. The animal would sometimes get away if caught by front foot, but never if caught around the neck or hind foot."

\section{Trapping the Raccoon.}

"The raccoon is not a very difficult animal to capture. The traps should be set either in the paths in some woods that the animal frequents, or along the shores of a stream or lake. One of the most successful ways is to make a U-shaped enclosure at the edge of the water. This can be done by driving sticks in the shore; not necessary that the open part should be exposed to the water. Set trap at entrance and place some bait at the farthest end of the pen. Cover the trap with water-soaked leaves which can be held in place by a light covering of earth. I usually fasten the trap to a brush drag. The latter I throw in the water, and if light put a stone on top of it to keep it from floating away. Quite often if the raccoon springs the trap he will get tangled up in the drag; consequently you do not have to hunt him up. This set is also recommended for mink. If the water happens to be fairly deep, the chain will become tangled up in the brush and the weight of the trap will drown the mink in short order. Caugl:t thirteen raccoons and about twcnty-five minks a year ago. IVas unable to trap last year." R. B. A.

\section{TRAPPING THE OPOSSUM.}

"Below I give in a brief manner my way of trapping and taking the opossum:

"I find out where the opossum runs, then cut some sticks about one inch in diameter, about eighteen to twenty inches long, and drive them into the ground three to four inches apart, in a circle formation of a diameter of eighteen to twenty inches, leaving an opening of about six inches wide.

"Then take one or two steel traps and set at opening, using pieces of rabbit or chicken as bait which I place about twelve inches beyond opening inside of coop. I always cover the trap with leaves, bits of rotten wood and earth, having first placed loose leaves beneath pan of trap to keep dirt from falling beneath it. I also throw small bits of meat outside the enclosure.

"The best place to set this kind of trap is at the edge of a bush or thicket, bordering an old field or creek, lake or any place where the opossum comes for food or water.

"Have used snares advantageously, but always attached same to a spring pole or limb of a tree, or a young tree itself. A 
fiddle-string or horse-hair noose is better than copper wire, at least I always prefer it."

JOHN D. KNOLL.

\section{Trapping the 0 possum.}

"The opossum has a habit of going around at night, visiting henroosts, if there are any near. If not, it catches birds, or whatever it can find, until it gets fat. Then it goes into its hole which it digs or takes from other animals. There it stays until it gets hungry and poor.

"I have had success in smoking them out. I took waste cotton rags, tearing them into small strips, putting them loosely over the hole; then setting them on fire, blowing them until they burn well. Then I put my hand or something over the hole to smother the blaze and drive the smoke into the hole as far as possible.

"Then set the trap as you would to catch it without smoking, and you will have the opossum, as the smoke will clrive it out.

"The kind of a trap I use is a No. I . Victor, which always holds them if it is good working order.". R. B. A.

\section{Trapping the 0possum.}

The opossum, like the skunk, is an easy animal to trap. Having found out where he runs I set my line of traps on his path. Any kind of meat bait will do. Traps, however, should be covered up, and be sure and put some cotton under the pan to keep sand and dirt from falling beneath it. To keep him from twisting ont, I generally attach trap to a spring pole.

A good place to set your trap is where you have seen him drink water. Also in front of his hole. I never resort to snares, although I have seen a lot of negroes catching them with ordinary fish lines. On one occasion a negro brought past our house a large male opossim that he claimed to have caught with an ordinary fish hook. He suspended the bait over a fence rail and the animal in his eagerness to devour the meat, swallowed hook and all. When the time cane to go away, he found there was something tickling.

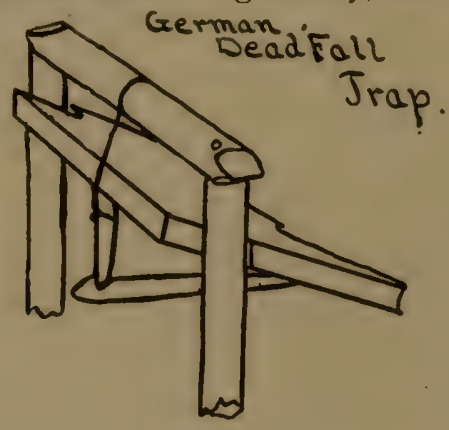

N. C. A. 


\section{TRAPPING THE MUSKRAT.}

I have trapped muskrats since I was twelve years old, and have had good success. I will give you my rule. Trapped more than $\mathrm{r}, 000$ the first month this year after the water was frozen.

Chop a small hole in the south side of the house large enough in which to set your trap. Dig away a little moss on the mound so as to set the trap under water; the grown rats are wise enough to fill the trap with moss and not get caught and you only get the small rats.

No. I Victor traps are good for rats. Select weak traps as the strong ones break the bone and they gnaw their leg or foot off and get away. Use the wet moss to line edges of the opening of hole, and bank up good enough to keep from freezing; then clean away about $2 \frac{1}{2}$ inches from the level of the water, and set trap and if the water freezes one-half inch, you get a rat anyway. If you set on the mound, you don't. First trap out the small feeding houses, then the larger one. Later in the winter, a person should get five to six rats in each house.

If you wish to spear the rats, get on the house and jump till you see one and then follow him up and spear him, when the ice is first freezing. For a spear, use steel rod, like a wagon rod, sharpened to a point, tapering three to five inches, with a heavy handle. A person may spear Ioo in a day. Baits are not necessary for muskrats.

In the spring is a good time to shoot rats. In a boat you may get in good shooting range. When they are pairing they are out all day and you can get them regularly two at a time, with good wages, for two or three weeks after the ice is broken up.

Rats can also be trapped with a barrel at the level of the water, half full of water with some shingles floating in it. The rat swimming up to the barrel sees the bait on the shingles, jumps down, and cannot get out. Many rats can be caught that way.

If you are unable to select weak traps for capturing muskrats, you may weaken them by heating them. You lose thirty out of 100 by using strong traps, but you can catch them by the hind leg by setting about three inches in the water.

AdolPH LiEN,

\section{Trapping Muskrats Under Ice.}

Olaf, Iowa.

This is my method of trapping muskrats under the ice: Take two ten-inch boards two feet long, and two six-inch boards two feet long, and make a box, using the ten-inch boards for sides and the six-inch boards for top and bottom. Now make a trap door of wire for the front end of the box, which will push in but 
will not push out; set at an angle of about forty-five degrees. Drive shingle nails about every inch or so around the back end of the trap and weare a net across it so that any mink could not get through.

This cut shows the trap finished with narrow boards nailed to the sides, which come in handy to sink in the water for trapping muskrats. Find the muskrat runway under the ice, which you can always tell by the bubbles or riley water. Put a stone on the trap and sink. I have caught four rats in a trap male like this

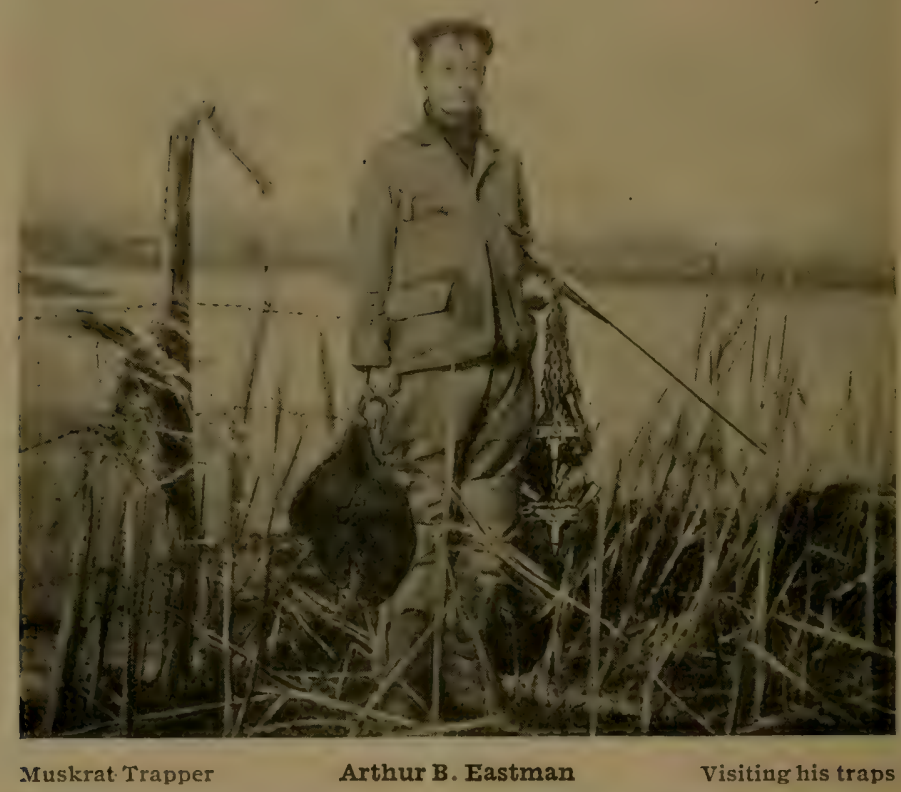

night after night, and I now seldom use any other trap for muskrats. For illustration see page 273 .

It is also a fine trap for trapping mink. Prop the door up with a short stick about $21 / 2$ inches long. Bait with rabbit or bloody chicken heads. Set under bridges or on the bank of small streams where there are stones around it, or grass overhanging sufficiently to partly cover trap.

$$
\begin{aligned}
& \text { E. J. FINEL, } \\
& \text { Waukegan, I1l. }
\end{aligned}
$$




\section{Trapping the Muskrat.}

Mr. A. S. Lamb, a Michigan trapper, writes as follows: "My method of trapping, rather capturing muskrats is as follows: Having ascertained a suitable location where muskrats are plentiful, I dig a hole in the ground into which I place a barrel halffilled with water. I place sweet apples on some laths or shingles within the barrel, and then lay a ten or twelve-inch board leading from the shore or water along to the barrel. I also place pieces of apples on the board and in the immediate vicinity on the shore, also on shingles that are fastened so as not to float away. The muskrat, on discovering the bait, will naturally go up on the board, tumble in the barrel and of course not being able to get out, will drown. So when I come along the following morning with a rake I am able to take up eight or ten drowned muskrats at a time. On one occasion I took out nineteen full-grown and three kitts.

\section{Trapping the Muskrat.}

"In trapping the muskrat on the Rush lakes of Minnesota I use a No. I steel trap. In the middle of winter when the lakes are frozen over, I proceed to business.

"I approach a rat-house and thrust the muskrat spear into it on the south or southeast side. If it is frequented by rats it will be found open and hollow inside. I next take my small hunter's ax and chop a V-shaped hole in the house on the south side. When the opening is reached, I take out all the moss, rushes, etc., which have fallen in and am careful to leave it just as the rats had it. By feeling around you will find a little shelf or slide which the rats climb upon in coming into the house. I now take the trap and set it on this shelf. If it is covered with water, which it generally is, it is not necessary to cover it otherwise; but if it is above water, I cover the trap with fine mossrubbed between the hands until so fine it will not prevent the trap holding the rat's leg. I then fill up the hole with a few rushes and moss, then cover it all with snow or moss. No bait is necessary in this kind of trapping. I visit my traps every morning and am generally rewarded by a big brown rat in each trap. I leave a trap in a house from six to ten nights, taking care to always keep it well covered so it will not freeze inside. The trap is held by a long stick stuck in the side of the house.

"In trapping the muskrat in open water in the spring I set my traps on the outside of the houses, just under the water where the rats climb upon the house. In this way I sometimes catch 5 or 6 in a single trap in one day.

"I go around to my traps in a small boat-one man can handle about 50 traps in this way. 


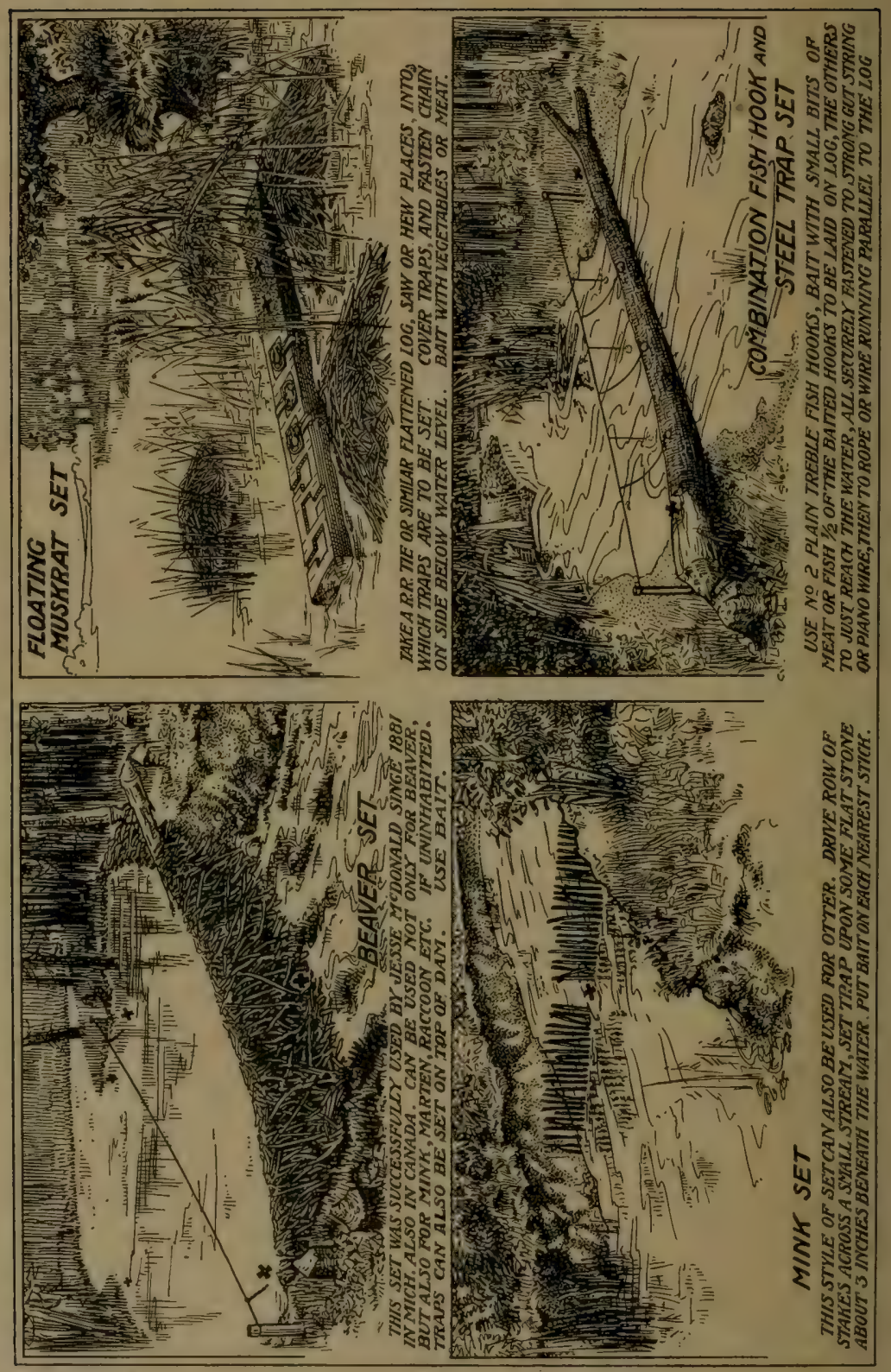


"When a rat is drowned or dies under the water, I take the hooked end of the spear and hook it into the trap, and lift my muskrat on board. If alive, take a small stick and kill them with it. Be careful not to get them too near as they will fight, and if opportunity presents impregnate their teeth in a person's limb or body. Don't give them a chance.

"I take the skin off promptly, am careful in skinning, more so in stretching, and still greater in picking out a reliable firm to ship to."

Mr. A. C. Cramblit, of Okabena.

\section{Trapping the Muskrat.}

The muskrat may be caught in winter by setting traps in their houses, by cutting a hole, preferably on the south side and setting traps on the insicle of the houses. If the opening inside is not large enough to set the trap upon, enlarge it by means of an axe or ice chisel. At any rate the trap should be set solic so that it cannot be tipped over by the muskrat climbing on the place. The opening in the house should not be made any larger than to admit the trap, and should be stopped up by wet stuff taken from the inside, after which snow may be placed on top of the house. It is very important to close the opening and make the house as warm as possible as on this depends the success of the trapper.

Another way which is very successful in the Northwest where muskrats have holes in the banks along lakes and sloughs, is to set the traps in these holes. These openings can be readily found by taking note of the riley condition of the water at their opening. The trapper now proceeds to tramp around on the bank opposite until the earth gives way beneath his feet, then cutting a hole and setting the trap in two to three inches of water; sometimes the holes are too deep for the earth to give way, when considerable digging will have to be resorted to in order to find them. Where muskrats are numerous io to ${ }_{5}$ may be caught in some individual hole.

$$
\text { J. R. S. }
$$

\section{Trapping the Muskrat.}

If the water is too shallow and the muskrat cannot be drowned in the place where traps are set, attach chain to small limb which the muskrat will drag into decp water and becoming tangled up will drown. If the water should happen to be very deep in the vicinity, attach a fish line to the drag which will enable you to pull in the muskrat, trap and lirag, on your next visit.

The laws of many states prevent the breaking of muskrat 
houses, therefore it is difficult to trap the muskrat during the winter time. My method is as follows:

Chop a hole over their run-way and lower your trap with two sticks. Now make a stick with a sharp point which drive into the bottom of the lake. On a protruding branch, tie a piece of apple, carrot, etc., and arrange bait 7 or 8 inches above trap. Ring of chain should be fastened either to a string or to a pole fastened to the bottom. Sometimes I place 3 or 4 traps in one hole; in such cases I place the bait in the center with the traps all around. The chains should be staked on the outside so that if one muskrat is caught he will not spring the other traps in his struggle to get away.

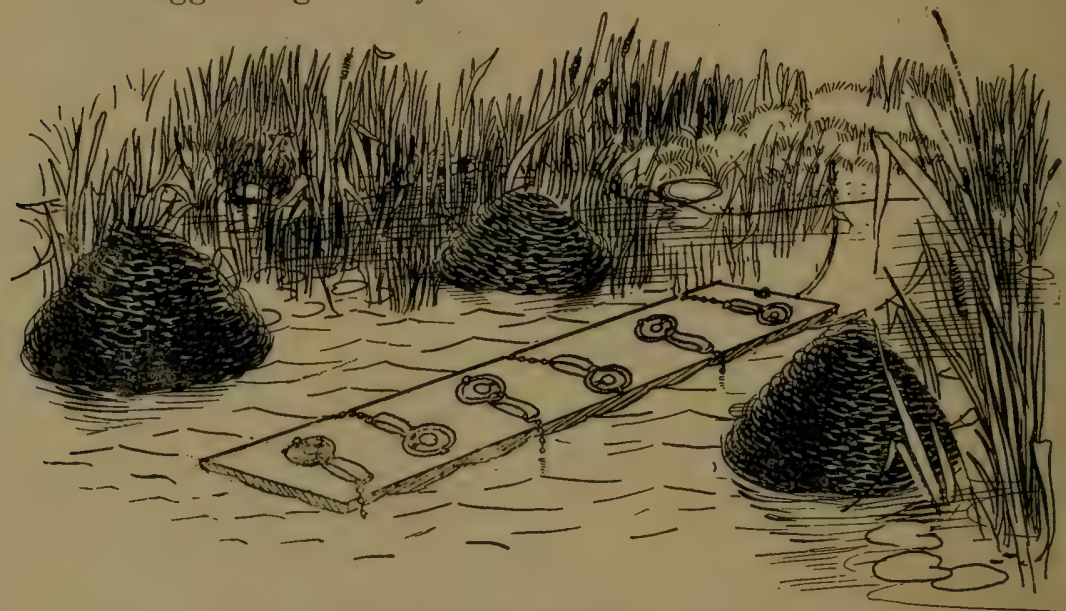

FLOATING MUSKRAT SET.

Chains should be stapled upon the bottom of plank. For kait use parsnips. beets, turnips or their own meat, which should be fastened upon plank.

In the late fall and early spring, there is as much fun in killing muskrats as there is to sit in a boat and fish. Probably more. Trapping muskrat with steel traps, wire traps, resorting to deadfalls, also to boxes and barrels, is all good enough, but when these are impracticable and to get immediate yielll during the daytime, I prefer the following:

I provide myself with a heavy club, and my partner with a hoop net attached to a 6 -foot pole. When I find an underground run-way that I think is inhabited by the muskrat, I hit the ground just above the run-way a sharp rap. If inhabited, the muskrat will immediately decamp. My partner then catches him in the net, or prevents him from coming out of the hole. If one gets away I usually get a chance to put a 22 in his head. 
If they go into another hole, I watch, and we proceed the same as before.

A box trap with a sliding door, that can be shoved right in it, or next to the hole, or placed in a run-way under the ice, is good. I have used the box trap repeatedly. If set below the ice, nail a stick to the box so that you can raise, and locate the trap. Of course, when the water is frozen one has to chop a pretty big hole, but what trapper is not accustomed to hard work as long as it is remunerative.

Probably the best way to get a great many rats is to sink a water tight barrel into the lake so that the top protrudes two to three inches. Fill barrel one-half full of water. Weight it down with stones, but first see that the barrel rests on level or a solid piece of ground; if it is not level make it so. Within the barrel fit a lid turning on two pegs. Weight one side so that lid will always close after the muskrat is dumped into the barrel. For bait I use potatoes, carrots or apples, and if these are unobtainable, a piece of their own flesh. One of my neighbors does not seem to take so much trouble in preparing this set; all he does is to fasten the bait on a string which he suspends across the top of barrel with the bait in the center. The muskrat in trying to get at the bait jumps into the barrel, from which le cannot get out.

The only time either onc of us resort to steel traps is when the weather is real cold. Chop a hole in the muskrat's house, and set one or more traps either on the shelf or on the ice within the louse. These traps are covered with grass, found in the house. Cover hole up before you go away.

To prevent muskrats from twisting their legs off or getting out of the trap otherwise, I find the best thing is to set the trap on some $\log$ or railroad tie and arrange it so that when the animal jumps into the water, he will drown. Floating sets work day and night and whether the water is high or low.

About two miles from my place there is a small lake and some years muskrats are so thick that it does not take much of a contrivance or a genius to trap them. Steel traps are too slow work for me. During the fall months, I make a box three feet wide, eight feet long, and eighteen inches deep, usually out of two-inch planks. On the outside, I nail a four-inch board clear around about three inches lower than the top of the box: this is a kind of shelf, upon which the muskrat climbs with case if some food is there to attract him. The box is filled twothirds full of water and otherwise weighted down so that the outside shelf is even with level of lake. I use apples, carrots, etc., for bait; these are securely fastened upon shelf, thus forcing the 
animals to climb upon the shelf for the food. I do this five or six times before I want to trap the muskrat. During this time, I have boards over the box so that the animal cannot get in. When the time is ripe I remove the boards and suspend the bait on a string in center of box. The muskrat, accustomed to the shelf, gets into the box, and not being able to get out, drowns.

This is a smooth water set and not good in rough weather. Trap doors can be made within the box. These are arranged so that when the muksrat steps upon the door his or her weight drops door and the muskrat. The door, of course, having unloaded its burden, goes back. $\quad$ R. B. A.

\section{TRAPPING THE BEAVER.}

Mr. Lewis D. Bergey, an old trapper, writes on trapping the beaver as follows:

"There are various modes of trapping these sagacious animals adopted by professional hunters and trappers. In the fall and spring the chief method is to make a small opening in the dam and set the No. 4 trap in such a manner that they will get caught when repairing the damage. The trap should be fastened by several feet of chain to a pole driven firmly at full length of the chain into the mud at the bottom of the lake; no marks must be left. Should the chain be slack, the beaver is almost sure to leave a toe or paw in the trap, since he has a chance of resting on the dam and by twisting and using his teeth will set himself free. It is then a labor of much ingenuity to catch him. The presence of beaver and their size are judged by the freshness of the sticks and the size of the teeth-marks on them, as well as the general appearance of the works.

"Another mode practised to catch these wiseacres is to make an opening in the dam and set the trap at some distance where he is likely to get mud and sticks for repairing the mischief. Advantage is also taken of his roads and places where he is in the habit of sitting while eating. A sort of oil called castor, used formerly for medicinal purposes, taken from the animal, is used to attract them to the trap. When setting a trap water must be splashed freely wherever the bushes or banks have been touched, as a beaver is very keen of scent, and will turn away if he suspects anything.

"The way to dress a fresh skin is to make a large hoop of birch or poplar and lace the skin tightly to it by means of holes cut all around the skin near the edge. The weight of a wellcleaned skin varies from half a pound to three pounds, according to the age and season of the year.

"Beaver are found in many places in the United States, but 
nowhere so plentiful as in Northern Canada. In the great stretch of lakes in Athabasca, and the north shore of Labrador, beaver are considered superior to those caught further west. Beaver becomes prime about the first of October and continues to improve until about the first of May, when it deteriorates. The flesh of a fat beaver is considered by many as the most delicate of any to be procured in the bush. The tail also is a delicacy when properly cooked, and when smoked and dried it has the flavor of bacon."

\section{Trapping the Beaver.}

H. Miller, of Lewistown, Mont., gives us the following article:

"The beaver is a water animal and lives in holes in the banks of streams, and in houses which it makes in the water out of mud and sticks. Its food is bark, corn, wheat, rats, grass, etc. It has its young once a year, generally in the month of April, having from two to six at a birth. They do not increase very fast, as it requires about four years to get their full growth. The beaver castor or bark sacs, and the oil stones, are found near the vent, in four sacs in both sexes. In taking them out, cut around them, and take out together with as little meat as possible. The bark sacs contain a yellow substance. To get the contents, tie a string around hole in the bark sacs and rub them between the hands until they are soft; then cut them open and squeeze the stuff into a cup. To get the oil of the oil stone, cut the end off and squeeze it. Keep separate and mix according as directed. You can put this in bottles.

"The baits for beaver are made as follows: I. Take the castor of one beaver, add twenty drops Oil of Cinnamon, ten drops Oil of Anise, and urine of the beaver to make the bait the consistency of mush. 2. Take the castor sacs of one beaver: add seven drops of Oil of Sassafras, seven drops Oil of Anise and ten drops of the oil from the Oil Stone. 3. Take the castor sacs of one beaver, ten drops Jamaica Rum, five drops Oil of Anise, five drops Oil of Cloves, five drops Oil of Sassafras and five drops Oil of Rhodium. 4. Take the castor sacs of one beaver, add ten drops of the oil from the Oil Stone, and beaver urine enough to make the bait like mush. These I call natural baits, and they will fool the oldest beaver that lives.

"Beavers cut small trees and build dams in streams and when you see fresh work you have beaver close by. You will find slides where they go into the water. Set your traps at the foot of the slides, three inches under the water, and cover with mud and leaves. Put the end of the trap towards the centes 
of the stream and fasten it to the drowning pole (described elsewhere), and leave everything as natural as possible. Take your bait and put it on the end of a stick six inches long; split one end three or four times and dip it in the bait and stick it up six or seven inches above the water in the slide. Wear gum boots in setting traps and carry a tin cup-after setting a trap use your tin cup to wash away the scent.

"Skin the beaver by starting the knife in the under lip, split skin to the tail, skin the front legs whole (some skin them all whole), stretch them as near round as possible. Use the hoop stretcher to stretch the beaver skin. Cut small holes close to the edge of the skin and use twine or bark. Stretch the skin until it is tight. Use a jutting-pole and knife to take off the grease and meat from the skin before it is stretched.

"I like the Newhouse trap best for catching nearly all kinds of animals. I have two faults to find with them, first, the pan

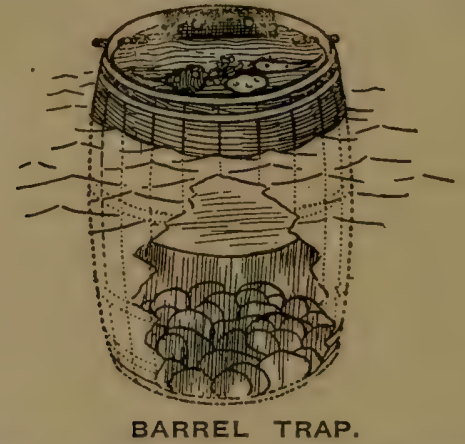

Suitable for muskrats. Sink so that top protrudes 4 or 5 inches above water. Fill barrel half full of water, weight down with stones. Bait swinging drop door as per illustration, with potatoes, apples, carrots, beets, etc.

is too small; second, the chain is too long-but they stand the weather.

"To set a trap for beaver, cut a pole eight or nine feet long (described hereafter), push the small end into the bottom of the creek where the water is deep enough to drown a beaver, put the chain ring over the big end of the pole, push the pole the length of the chain to one side of the slide, and sink the pole under the water and put your husk or stake straddle up the pole and drive it down solid; see that the ring can travel the pole when a beaver is caught. If he can get on land he will bite his feet off and go.

\section{Trapping the Beaver.}

Southern method as used in the swamps of Louisiana by $\mathrm{R}$. 
W. Riggs-The bait used and the way to set the traps:

"The bait used: First mix one-half ounce of alcohol, fifteen drops oil of sassafras. Use ten drops of this mixture with the castor sac of one large beaver.

"For a set, use two No. 4 Newhouse traps. Tie the traps together by one of the springs of each trap. This is to make more weight and also to help to tangle the beaver up when caught. Now set your traps in three to six inches of water. Set so the beaver will have to come over the loose jaw of the traps. Now whatever the distance is to deep water, tie a piece of rope to the rings of the trap chains, long enough for the beaver to get into deep water when caught. If you have a piece of iron in camp you can tie that also to the traps. The stake that the rope is fastened to should have a hook to it. Drive it down in the mud all out of sight. Coil up the rope and cover it up also with mud. Cover your traps so that nothing shows. Now take a small dead stick and stick it into your bait about an inch. Then stick it up in the water about six inches from your traps on the land side, with just the bait end sticking out of the water. I also tie the bait sticks to the traps with a string so when the beaver is caught he will take the bait stick with him. For if the bait stick was left after the beaver was caught, other beavers would come and smell of it and then that kind of bait would have no attraction for them for some time. I mix up bait from both the male and female, so that I will have a change. Set your traps away from their houses or holes. Do not disturb their dams. In setting your traps wade in on one side of the place where you are going to set your traps and do all of your work from the water side. Never walk on the ground in front of your set. When you have your set made, throw water over everything near you. If there are any bushes within five or more feet of you throw water on them. If you will use care and have a little patience you can catch every one in that colony and you need not smoke your traps or use gloves either.

\section{Trapping the Beaver.}

C. Steele, a trapper residing at Altamont, Mo., gives us the following good article on beaver:

"The beaver is a very shy and cunning animal, always on the guard against danger, thus making it hard to trap him unless one understands his ways and habits.

"My experience has been on the Pacific Coast, in the State of Washington. The beaver lives along streams or lakes; if streams, he dams them, thus forming a kind of reservoir or lake, and even at the outlet of lakes he places a dam, thus raising the 
water of the lake. After he has prepared his dam and built his home, he commences carrying food. This is chiefly branches of trees or bushes, and even smull trees themselves. He always chooses tender green ones. These he places in the bottom of the lake to use as desired, or in his lut or lodge, and should he be disturbed at any time he will stop work for several days and live off the bouglis already sunk in the bottom of the lake or lorge, thus making it impossible to trap him until he again commences work. He usually does his work among young sprouts along the bank of his lake or stream; sometimes he will go for some distance u1) a small stream and float boughs down to the main lake or dam in the stream where he has his hut.

"There are many ways to catch him, but I will only give two or three of the best ways. The first thing is the trap; the best kind is a strong steel trap, the Newhouse, or some other

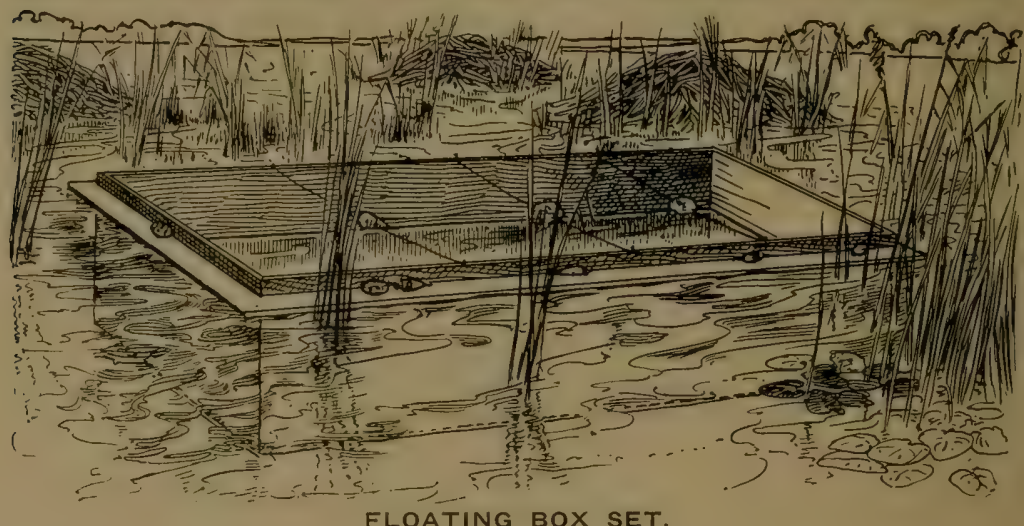

FLOATING BOX SET.

For description see page 351 .

good brand. Then the best way to trap the beaver is to procure some castoremin (which is an odorous liquid carried in a small pouch by the male beaver). Then cut some small twigs, one for each trap, and having selected the dam of the colony of beaver you wish to trap, procure a pair or rubber boots, or remove your boots and wade up the stream along the shore of the lake or stream where they have been at work upon the sprouts, but be careful and do not step out on the land where the beaver can see your tracks or scent you, for if he does he will stay in his home for several days. When you have selected a spot where the bank is steep, secure your trap by a strong stake beneath the water, then fasten a heavy rock to your trap and dig a flat place in the hank a few inches beneath water, placing your trap thereon. Then dip the end of your stick in the castoreum 
you procured and stick the opposite end in the ground, just out of the water and leaning over tl e trap. Then your trap is ready for him. He comes out as da!kness approaches and starts towards his ground where he p:ocures food, and as he swims along he smells the castorem and thinks a strange beaver has conie into his pond or lake. Hic swims up to the stake or twig to get a better scent, and as his foot touches the ground the trap is sprung. Then finding he is $\mathrm{f}$. st he springs backward into the water and displaces the rock wlich is fastened to the trap, and the heavy rock pulls him down and drowns him. This prevents him from making any noise to sc.re the rest away or from gnawing his foot off to escape, as he frequently does if left long in the trap. In this way you can sometimes catch the entire colony:

"Another way is to cut a hole or crevice in the top of the dam, and set the trap just below the surface of the water directly beneath the hole. The beaver at once starts to repair the dam and thus gets in the trap; but this method is rarely used by cxperienced trappers anless they cannot procure custoreum, and in this way they procure it, even at the expense of frightening the rest of the colony sometimes entirely away.

"Another way is to cover the trap neatly in the path of the beaver leading from the lake to his feeding ground, but this has the same disadvantage as the last plan.

"I could write you more about their ways of living, houses, etc., but think that I have told all that would be necessary to know to make a success at trapping them."

\section{Trapping the Beaver.}

To trap beaver in winter when the water is frozen: Select a place close to their houses and close to a bank where the water is not more than two feet deep under the ice. If the water is too deep, cut away part of the dam and lower the water to the right depth. Now cut a hole in the ice two or three feet across, according to thinness of ice and the size of bait. Next cut the bait, which should be the top of a poplar or birch about four inches through at the big end; shove this under the ice and fasten with a stake which has a hook on it. A trap may be placed on the bottom right below where bait is fastened by the stake, or the bait may be left without trap for one night when in the morning the bait is usually all taken away. Now set three or four traps in the following manner, and as close to the former place as possible. Cut a number of stakes (dry) and drive into bottom in half circle about fifteen inches across, put a few green sticks of poplar inside of this half-circle and clrive into bottom; set the traps on the bottom just outside of tine green sticks, resting 
firmly so that it cannot be tipped over by the beaver gnawing at the bark. The trap should be fastened to a dry stake set sloping towards the deepest part of stream. The beaver trapper should endeavor to catch as many in as short a time as possible, as the remaining beavers will soon become shy of the place.

T. Gullickson,

\section{TRAPPING THE OTTER.}

Canada.

The habits of this valuable fur bearer are less generally known than are those of the mink and others of the fur bearing animals pursued by amateur trappers. They are very shy, which fact taken with their nocturnal habits render them seldom seen, even where they are fairly common. Their sign is unmistakable after one has had his attention called to it. The excrement, consists almost wholly of the scales of fish, and when fresh a large mixture of slime. The track very much resembles that of the mink but much larger. In snow the track has been well innitated by dragging a meal bag filled with hay or sawdust and then leading a hound along the trail thus made. The otter and hound however do not walk alike. Their playful habit of rolling and plunging through the snow and sliding down steep banks into the water have been often described by other writers, but I do not remember to have ever seen in print their habit of going on land to deposit their excretia which they do in regular well defined situations, and then rolling about in much the same way that a dog rolls in carrion or other ill-smelling things. And now right there in the midst of the pile is the best place to set a trap, which should be a Newhouse No. 3 or $3 \% 2$ carefully concealed from sight and everything left as natural as possible. I have caught foxes in my otter traps set as above as they came to roll in the "fragrant" bed.

Another good place to set is where they come out of the water to go to the slide. An otter will invariably cross a point of land in a long bend of a stream when traveling, in preference to going around, and in all streams frequented by otters in their well known habit of journeying from one stream to another, a well defined path will be found across these "oxbows" and here is another good place to set a carefully concealed trap without any bait. In fact an otter will very seldom touch bait of any hind, but their bump of curiosity is highly developed, which will usually lead ther near enough to investigate through the sense of smell, any unusual object about their haunts. For instance, a dead fish placed just beyond a trap will sometimes lead to their capture although they never eat dead fish.

Otters are very regular in their wandering habit. After the 
young become large enough to follow the mother, the whole family start on the wandering life, going over again and again practically the same route, and the trapper may confidently expect them to appear at a certain slide at quite regular intervals during the fall and winter. This is kept up unitil the breeding season comes round again when the female retires to her nest in some inaccessible swamp to bring forth her young.

Sometimes the route is varied for some reason and their conspicuous trail in the deep snow is found in unexpected places, even going over elevated ridges seemingly just for the fun of wallowing through the snow. In single file they go, one after the other, resembling with the characteristic rising and falling of the arched back, a huge serpent.

The best trap in my estimation is the Newhouse No. $3^{1 / 2}-$ the teeth being a great advantage in holding him, as when caught he exerts his great strength to the utmost in his efforts to get away. Where possible a heary stone or properly constructed sliding pole should be employed to drown him as quickly as possible.

Charles E. Ingalls, East Templeton, Mass.

\section{Trapping the 0 tter.}

Mr. D. H. Smith, a man of experience in trapping otter, relates his method.

"In trapping for otter I go along banks of running streams or lakes. The otter is seldom found around ponds, as he lives principally on fish. The otter raises a litter of three to five pups every year. A successful otter trapper must study the otter and have considerable experience before he is able to set his traps and capture the animal within a reasonable length of time.

"I use No. 3 and No. 4 steel traps with a chain of four to five feet-the longer the better. As otters are travelers and run up and down streams, stopping at various places from three to six miles, a trip of that kind takes from one to two weeks. They have what trappers call 'slides,' which are found along the banks of rivers and lakes, where the bank is four to six feet high and fairly steep. They will come from the water, go up the hill, turn around, lay flat down on their belly, spread out front and rear legs, and slide rapidly into the water. This operation is repeated time and time again, and the slide becomes very sleek.

"Now, when you want to near these slides to set a trap you must go to them in a boat. I generally attach my chain of traps to poles ten to fifteen feet long and set the traps under four to six inches of water. I always turn the two springs of the traps 
towards the center and never leave them sticking out. The trap will work just as well. The end of the poles which has the chain attached is stuck into the river bed for about two or three inches to hold it securely, and the other end I attach to a willow or limb of tree. At other times I use the limb of a tree or a small tree itself, willow, etc., as a spring-pole to pull the animal out of the water if captured. The trap is securely covered up with a thin layer of dirt, and always have leaves, cotton or similar matter under the pan. If you disturb the river bottom always arrange to the natural state but never get out of the boat. In case I have no boat and am compelled to set trap this way by wading into the water, I am always careful to obliterate my tracks and

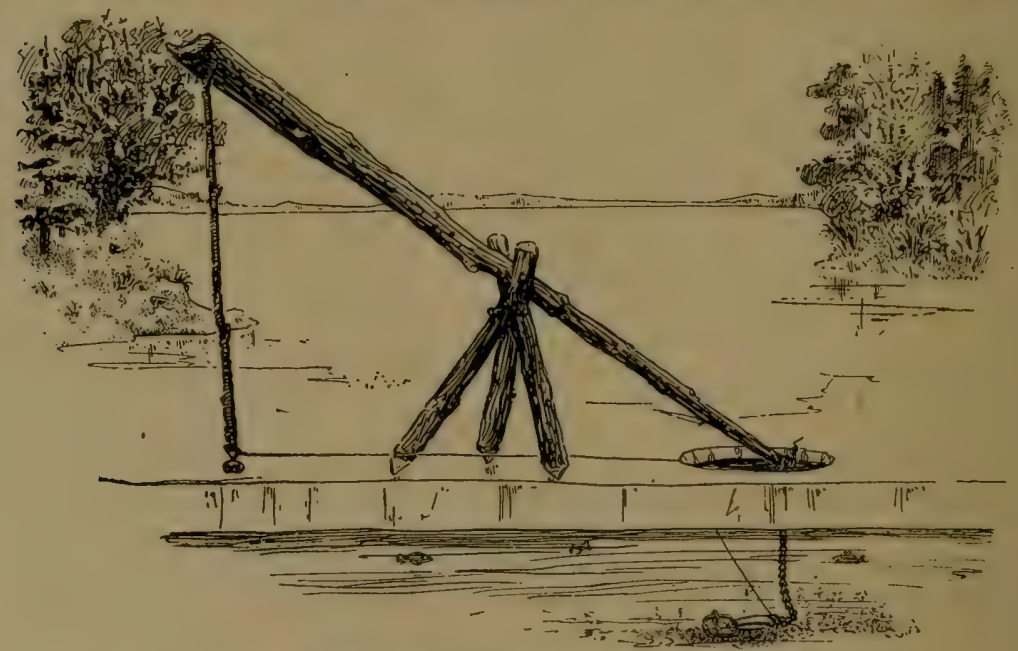

TRAPPING THROUGH THE ICE.

A well-tried arrangement for trapping through the ice. Cover trap and chain with moss, evergreens and similar light vegetation. The string or wire should be loosely wound around the chain. Experienced trappers usually have two or three traps set about the hole, all attached to the same pole. Especially good for the otter, beaver and other aquatic animals.

leave the surroundings in as natural state as possible and splash water from a distance over places that I disturb if out of the water.

"In visiting the traps never go close to them unless you want to remove them.

"If the otter caught is still alive, take a stick and with a smart blow hit across the head. One blow is generally sufficient. Never hit upon the body as it will hurt the skin. When the otter is dead take him in deep water and wash the fur so that the animal is thoroughly clean. Lay body belly upwards, and with a sharp 
knife split from point of rear foot or heel to tail, skin out the hind legs and strip the bone out of tail or cut tail open and skin out-whichever way suits me best. Then cut around forelegs and if convenient hang body four to six feet above the ground and pull skin over body. I then begin to place the skin on a proper sized stretcher, about five feet long, ten inches wide on one end to about seven inches on the other. The upper portion of the stretcher, however, is tapered to fit the head of the skin. I then take a drawing knife or steel case knife, and scrape the flesh and fat off and wash the skin with warm water and soap. The fur part must always be next to the stretcher. After the skin is thoroughly washed and free from meat and fat, I proceed to put it on the regular stretcher to dry. The latter is made out of three pieces, the middle one being a wedge. Stretch the skin as long as you possibly can, but do not overstretch it nor make it too narrow. The end and tail should be securely tacked on the board. After the hide is on the stretcher, I hang same, head portion uppermost, in some shady place to dry. Never use a single board stretcher for otter as the skin will shrink so much that you will be unable to get the board out. The following is the size of stretcher I make and how to use it.

"Take a board five to six feet long, three-quarter inch thick and eight inches wide. Both sides must be planed smooth and then shape board so that it will be six to seven inches wide on furthest point down to four inches wide on other end. Then I taper the head portion of the stretcher to about five inches to one and one-half inch or two inches. After smoothing the edges to the required thickness and slanting, I proceed to rip the board in center so that it will make two pieces of exact width. Then $I$ prepare a wedge equal length of stretcher, two by one and onehalf inches wide. I then proceed to place the first two pieces within the skin and pull the skin tightly upon it. Also fasten the skin at a few places with four-penny nails. I am very careful to have the belly portion in the center of the wedge. Then I proceed to insert the wedge and give the skin the proper shape and stretch. Pine or basswood boards are the best to use, and the time to trap is from November to the first of April. Otter, during the month of February, are the best."

\section{Trapping the 0tter.}

Earl Mooney, a trapper living in Illinois, gives us the following interesting article on how he caught his first otter:

"One day in February, about three years ago, I was going down the river in my boat. I was looking over my traps and watching for signs of game. I saw where an otter had been 
sliding down a small maple pole, which was lying partly in the water and partly out. I set a No. 3 trap where he had been coming out of the water, being very careful not to disturb anything or leave any scent behind. Three days after I had set my trap I caught my otter. I had caught him by the left hind leg, pretty well up. I killed him with a small stick, hardly big enough, I thought, to kill him, but I found out my mistake, for he was very easy to kill. I skinned him, and sold his hide for ten dollars."

\section{Trapping the 0 tter.}

The otter is a wary animal and the trap should be carefully secreted and placed on the side of the runway or otter slide at the highest point; the aim being to catch the animal by the legs which are located on the side of the animal, and are very short. A

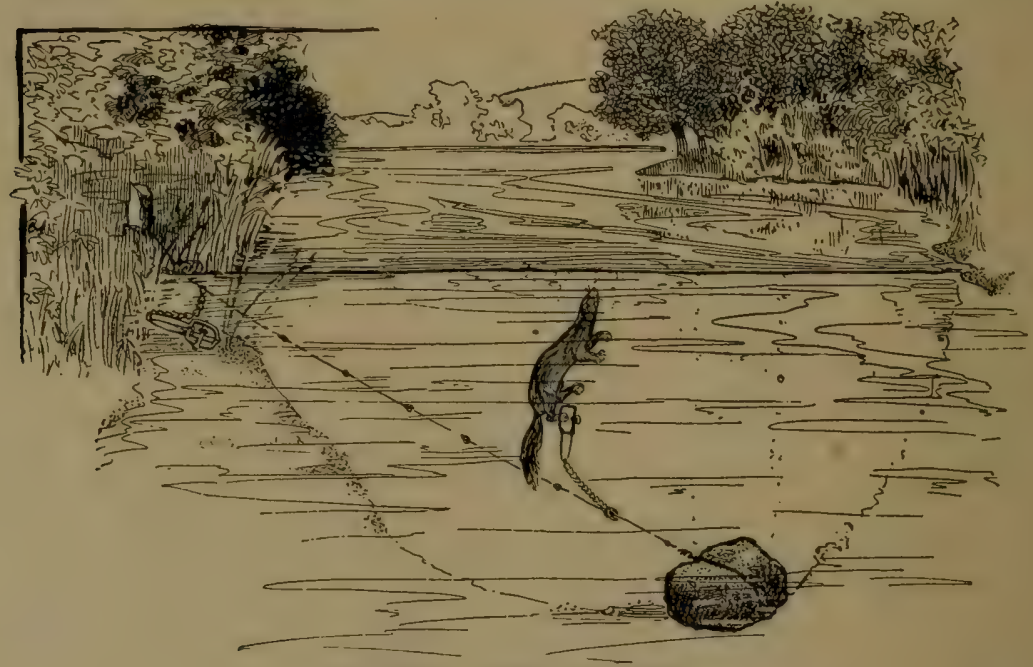

SLIDING WIRE OR ROPE.

Take a telegraph wire (some take a $3 / 8$-inch rope), fasten to some heavy object, which sink 15 to 25 feet from shore in deep water. Pass the other end through ring on trap and fasten to some tree or stake. The steel trap should be set at the edge of the shore or under water. Cover trap in the usual way. Good for otter, beaver, mink, etc.

small cavity should be made in the earth, and the trap inserted so as to be about level with the path under the pan. Around the jaws and springs make a light packing of leaves or moss; cover the trap carefully with rotten wood pulverized very fine, brush off smooth to give it a natural appearance. Cut a small tree the size of the chain ring; set upright near the path to guide the game into the trap, fastening it and securing the trap and game 
by tying the top to some other tree and the chain can be slipped on and fastened with a wedge at the other end. Then take a dry brush and drop in such a way as to turn the game towards the trap, then thoroughly drench the surroundings with water. Pour a few drops of the oil of decomposed trout or minnows on a piece of wood and drop near the trap as a draw to attract the animal. The musk of the otter may be used in conjunction, or alone, for the same purpose. Keep as far away from the trap as possible in making the rounds.

Another way: Set the trap close to the land where the otter comes out of the water to go on the slide. Place the trap about three inches under water and a little on one side of the path so that the pan is three inches from the middle of the path. Fasten the chain ring of the trap to a pole fifteen feet long, about one and one-half inches through, then fasten a stone of about ten pounds weight to the chain close to the pole for an anchor. When the animal is caught he makes for deep water, the stone drags him to the bottom and he is drowned. In case the water is not deep enough to set the right depth, dig the earth away until it is. If the water is too deep fill in under the trap. Always set the trap level. The anchor stone and pole must be sunk underneath water.

\section{Albert Rosenbush, Turtle Lake, Wis.}

\section{Trapping the 0tter.}

W. H. Smart, Crete, Nebraska, gives his ideas as to trapping otter in the following words:

"The proper place to set a steel trap is where the animal comes out of the water. They always leave a trail which any trapper with experience can locate. After setting the trap, cover with mud or leaves and leave the surroundings as natural as possible. I use the drowning pole in connection with the above set.

Another way is to find a $\log$ in the water, into which cut a deep niche and set the trap. Cover trap with mud and leaves and fine chips of wood; all stispicious articles are to be removed and the place left in its natural condition. The above setting is of course slightly under water. Before leaving the place I sprinkle a few drops of musk of skunk on the log. At times I set the trap at the bottom of the river or lake and to the pan of the trap I tie a dead fish. Make the fish look natural and so that the otter will observe it while swimming past the locality where the trap is set.

\section{Trapping the 0tter.}

Southern methods as used by $R$. W. Riggs in the swamps 
of Louisiana: The bait used and the way to set traps:

"For Bait: The muskbags of a skunk put in a little alcohol to keep it. I use the bait only where otter could or do come out on logs, with one end in the water. Cut a place in the end of the log for your trap, three inches under water. Drop some of the bait on top of the $\log$ a foot from the trap. My best set is

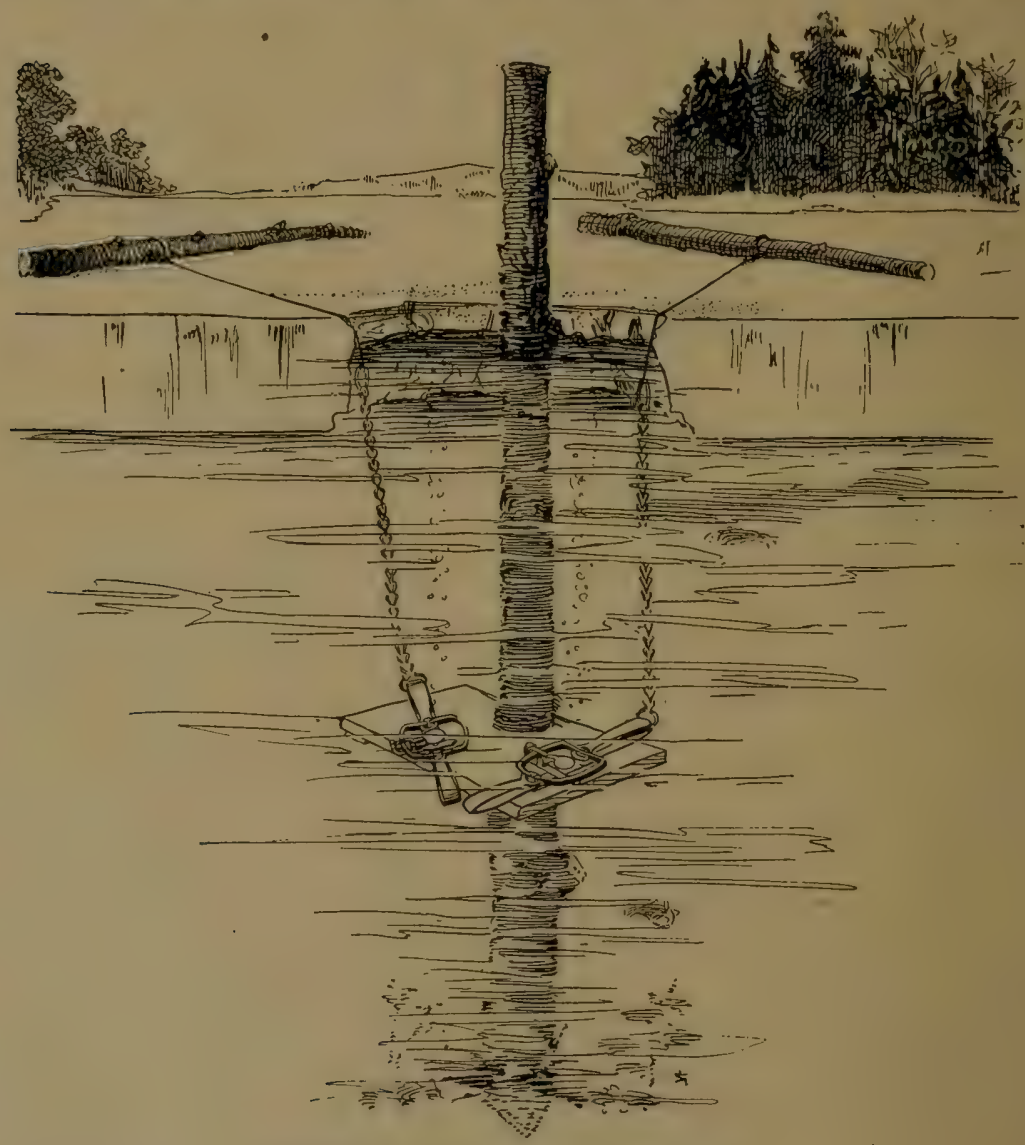

TRAPPING THROUGH THE ICE.

without bait where they come out of the water. Otters come out in many places, but they have some places they always come out at year after year. These are the places I set my traps. I never set in their slides or at the top of them. I make only a water set. I use the No. 3 Newhouse trap and use two or more to make a 
set. I want to catch them in two traps and then they never cut out with me.

"To Set the Traps: Cut a stick with a hook on it. Have the stick just large enough to go through the rings on the trap chains. Now wade in the water above or below where you are going to make the set, and do all of your work on the water side. Set your traps in three or four inches of water. If the space will take two, three or four traps, put them in. Put three traps to a stake and drive your stake into the mud out of sight. Cover traps with leaves and mud that you get from under the water. Do not put on anything that will float on top of the water. Leave everything in minder the water in front of the set, looking as it was as much as possible. Then throw water on everything near you and your set is O. K. If you do not get him in a night or two, do not get discouraged. They may be off on a trip. That in Louisiana will take them about nine days on an average to make. But keep away from in front of your sets, and you will get him and maybe two of them if the space is large enough for them to come in together and you use plenty of traps."

\section{Trapping the 0tter.}

Mr. O. G. Wells, formerly a Minnesota trapper, now located 11 Canada, writes us as follows: "The best deep water set for otter that I know of, is to take a live crawfish, tie a coarse thread to each arm close to its body but not in the joint. Tie both threads together under its body, then fasten to pan of trap, permitting the fish to move about, but not to get off the pan. Now take a forked stick or pole, slip spring of trap under fork, let cross bar of trap rest on end of fork; now lower trap to bottom of water and remove the pole. The short chain of the trap should be attached to some object of sufficient weight, either a stone or piece of iron. Wide jaw traps are the best for this purpose, as occasionally the otter is caught by the head.

"Crawfish is the favorite food for otter, raccoon and fish and quite often fish will bother the set and spring the trap. Should you find that fish disturb this set, then make another set, using the same kind of trap and place this near by. This method has been very successful, and I know positively that mink, otter and raccoon frequently visit these sets as I have seen their droppings in the immediate vicinity. When the otter is in search of food he goes to the bottom of the river and moves slowly, keeping a sharp lookout for food. Their movements are sometimes so slow and noiseless, that a school of minnows remains undisturbed. The otter can see everything around him, but while under the water is unable to smell, consequently sets of this kind are not suspicious 
and here is where the secret of success lies in my deep water set. Bait as used in the above must be kept alive.

"My other method of capturing otter in deep water is as follows: "I choose their playground and place my trap in a convenient location. Upon the pan I place a bright, mirror-like object, either of gold or silver. This glistening object attracts the otter; he will play in the immediate vicinity and will dive for the object and with one of his feet spring the trap and be captured."

\section{Trapping the 0tter.}

Undoubtedly the otter is the hardest water animal to trap that we faithful trappers have to contend with, for in addition to a sagacity and cunning second to no other animal, he is of a roving habit.

The male otter, in particular, has no fixed home except for a short time in the breeding season, but meanders aimlessly from one lake, swamp or stream to another, pausing for a short time whenever he finds comfortable quarters and ample diet, then pushing on again at his pleasure for "pastures new ;" always idle and inconsiderate of the rights of others-in a word, he is the veritable "tramp" of the fur bearing kingdom. The female is less of a wandering disposition, usually remaining with the young until the arrival of another mating season; the trapper who chances upon a domestic circle of this kind has a good thing in store if he but manages rightly. But he must be cautious, for the otter's eye is sharp and his nose surprisingly quick to catch the dreaded man scent. Its head is broad and flat, with very small ears set far apart. Its legs are hard, short with feet webbed, and are apparently set upon its side, which gives it an awkward and waddling appearance when travelling on land, which they do very little except when travelling from one water system to another. When there is a good tracking snow, these land trips afford the trapper a good opportunity to learn their crossings, and to know just which lakes or streams they are using. Watch close to see where they leave one stream and where they enter another for there is a good place for your trap. Although a great rover, an otter will seem to have a certain beat, miles in extent, which he covers with more or less regularity, returning time after time to the same spot unless trapped.

It would be useless to try to give all the successful ways of trapping the otter, for they are as many as the different circumstances under which they are met.

A good method of setting for otter, whether there be one about or a dozen, is to find an old log crosswise a narrow stream about four or five inches under water, then drive old stakes and 
brush, taken from the bottom of the stream, along beside it so as to completely barricade the stream except for a space of about six inches at the center, where a No. 3 or 4 Newhouse trap should be placed, the log having been flattened sufficiently to afford it a secure resting place. Swamp grass or moss caught among the stakes and brush and allowed to float over the trap will usually be a sufficient covering. It would be well to prepare the places several months before the trapping season. Whenever possible make your sets by deep, dark pools, and arrange by means of the sliding pole to usher your victim under water immediately. If you have left a few stubs along the pole, so that the ring cannot slip back after passing over them, and firmly secure it to the bottom or under some rock or root, he will soon drown, causing very little disturbance.

If your set is so situated that it is inconvenient to use the sliding pole, drive a good solid stake beneath the surface of the water, and loop your chain around the stake. Last, but not least, get an old water-soaked pole from the bottom of the stream, and lay across the trap chain, between the stake and trap. He will get the trap chain entangled around the pole and stake, which will be a great help in preventing him from digging or pulling out the stake.

If you have used a good heavy trap, and have plenty of water he will drown, which is always desirable, for one animal spending several hours struggling to escape from a trap will do more to create alarm among its brethren, whether it free itself or not, than will half a dozen properly disposed of. The grcat clifficulty in trapping otter arises from the fact that he is so long in body and so short in the legs, and travels by sliding much of the time, instead of walking, that he is likely to spring the trap with his body, or else slide over without springing the trap.

A very good set for the otter is where they leave the stream to go around an obstruction, such as a mill-dam or bridge, or where they leave one stream to cross over to another. A trap properly set at a place of this kind is about sure to catch, as an otter always lands feet first. In winter, they will be found around falls, rapids, airholes, and spring water where the open water affords them a chance to fish. If you know of such places to be much used, place several traps around it, just when a storm is coming up, and if the otter does not get along until they are covered with snow, you stand a good chance of getting one. A few of the young and less cunning may be taken at airholes by putting a trap in the holes, resting it on stakes driven into the bottom; but very few of the old fellows will be fooled in this way. Every one knows their habit of making slides. If you 
attempt to trap them on these, find where they leave the water. Fish is the best bait but get along without bait if possible, and in every and all cases use the utmost caution.

A good size otter will weigh twenty pounds or a little better; will be all of four feet in length from tip to tip, will stretch six inches in width at the neck and about nine at the root of the tail, and will stretch about five feet five inches in length. They are cased about the same as a mink with the exception of the tail, which is split the entire length, and is stretched out in the shape of the letter $\mathrm{V}$, being about two-thirds of the width of the body at the root of the tail, which will be a little better than a foot and a half in length when stretched.

A good prime northern otter of the above description is worth in the neighborhood of twenty dollars, so you see, brother trappers, the otter is a valuable piece of fur, but do not be in a hurry to count your money. Better wait until you have caught your game. Ever remember the word "caution" and success will crown your efforts.

H. E. Dille, Ridgeway, Ohio.

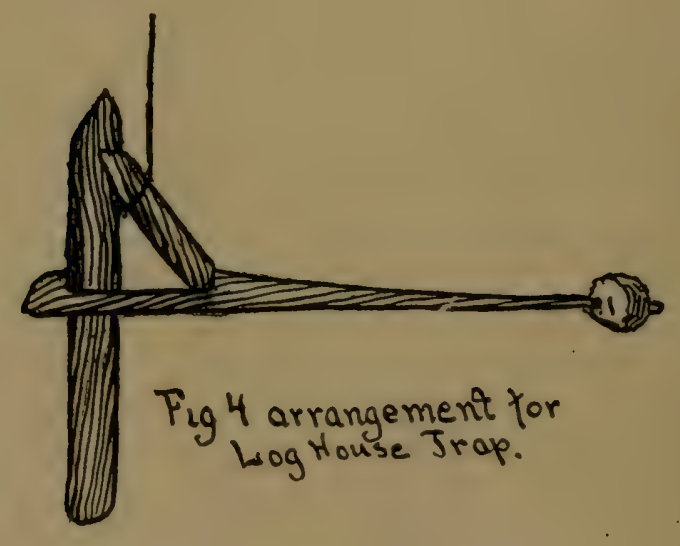




\section{Miscellaneous Articles.}

From Experienced

Hunters and Trappers.

\section{Hunting and Trapping.}

\section{WOLVES.}

Mr. Phillips, a Minnesota trapper, writes: "I set No. 3 steel traps for wolves in furrows about one and one-half foot apart, and place an eight to ten inch in diameter short log between traps, so that the wolf when stepping over the logs will step into the trap. The reason of my placing the traps in the furrow was because I found his tracks there, also that of the wild cat, repeatedly.

\section{Hunting and Trapping.}

\section{RACCOON.}

In trapping for raccoon, I find the place where he frequents and attract by tying a piece of bright shining tin upon pan of steel trap, and set two inches below clear water in some lake or stream. The coon will try to examine the shining object with his paw, and if trap is lightly set, will spring it and be captured."

\section{RACCOON.}

"For the raccoon I take a brightly polished tin can and hang it on some tree or stake about twenty inches high. On the bottom, I2 inches from the stake or tree I set my steel trap, taking particular pains to set it right, and cover every part of the trap excepting the pan, on to which I tie a small piece of bright red flannel. I also hang some kind of a bait, either rabbit or chicken, just below the can on the tree or stake. The raccoon will be attracted by the can and place his paw on the flannel and be captured. Either the tin can or the bait is not necessary, but I generally use the two and have better luck.

\section{MINK.}

"For mink, if trapping about muskrat houses, I generally cut a hole in the house and set the steel trap about four or five inches from the hole. Cover the trap up and place a piece of muskrat just at the hole. At other times I set a steel trap on the river bank and use a piece of muskrat for bait.

\section{Chas Herd, \\ Hunting and Trapping. \\ Henning, Minn.}

SKUNK.

"For skunk I use No. I I/2 steel trap, and for a sure catch place the trap within the hole or den, but on one side and not in centre, 
as some do. I find the skunk along river banks, lake shores, also in the hills where the grass and weeds are plentiful and high. Cover the trap with grass, then a thin layer of dirt. To set traps on their paths, place some soft material under the pan and a small quantity of grass above the trap, then cover slightly with snow. Drive a twenty to twenty-five inch long stick into the ground, to which attach piece of rabbit or chicken, about fifteen inches up. Attach some kind of clog or brush to end chain."

MINK.

"I have caught many minks in my experience, but in recent years have used the Stop Thief Trap entirely. I proceed to places where mink are, generally along river banks and ponds, and at or about places where the muskrat lives. In setting Stop Thief Traps for mink dig a hole in the bank eight inches, and put a piece of a fish in the hole; set the trap at the opening, and cover traps lightly with grass, so that it will look natural. I caught forty-eight minks this way in eight Stop Thief traps in one month. I consider fish the best bait and Stop Thief Traps the best for minks."

\section{Mr. GRISWOLD, . Milford, Ia. \\ Hunting and Trapping.}

MINK.

"This is the way I catch mink successfully. Set the trap at the mouth of their holes, and cover smoothly with light earth, but if the ground is frozen then cover with rotten grass. If their holes cannot be found, select a place where the mink frequents and make a barricade around your trap. Leave an entrance for the mink to pass. Put your trap in the entrance. Bait in the back so that the mink has to put his feet in before he can get at the bait.

\section{SKUNK.}

"Skunk can be taken in the same way as the mink, either by setting the trap at the mouth of their holes or by a barricade as commended for minks.

\section{MUSKRATS.}

"A funny way to trap muskrats is to take a plank, two by four, and chisel a den out, according to the size of a small trap (No. I is the proper one to use), and place the trap securely in the excavation, covering both the trap and plank with light earth. Then place the plank across the stream where the rats come. They love to run over the plank, and on being caught plunge headlong into the water and drown in a few minutes, so that they will have no time to bruise or twist their legs. 


\section{WILD CAT.}

"Wild cat are taken in the same way as raccoons, by baiting with meat and covering the trap smoothly over. The best way is to find a place where they have killed some kind of game and have left a part of the flesh for a second meal. Set your trap there and you will be sure of a visit.

\section{FISHERS.}

"Fishers are taken in traps with the same method employed in capturing mink and marten. However, the barricade around the trap should be stronger and the entrance larger, and baited as for mink.

\section{Fox.}

"One of the most successful methods of catching the fox is the following: To prevent the smell of iron from alarning the game, the trap should be smeared with blood, which can best be done by holding it under some bleeding animal and allowing it to dry. It should be set near their haunts. A hill of ashes, chaff or light earth should conceal the trap and it should be fastened to a clog of six to eight pounds. IVool, moss, leaves, or some soft substance should be slightly packed around the pan. The surface of the earth in the neighborhood should be brushed with some article, so that everything seems natural. Small pieces of meat should be scattered around and over the bed of the trap. Care should be taken to erase all footprints; so as to make allurment certain."

"Years of experience in hunting and trapping, not only in Nassachusetts, Maine and in Canacla, but elsewhere, and the fact of my realizing many thousand dollars for raw skins taken off by myself, puts me in a position to intelligently advise my brother trappers of one of the secrets of my success.

"Every trapper knows that most animals shun the smell of iron; to overcome this, traps are smoked, washed in weak solution of lye, greased, also painted with a preparation of fat and blood. This is all good, but what I consider better is that the steel or iron part should be wrapped as much as possible with withes (removed from the bark of tree: it makes no difference from what kind of tree). I use Newhouse traps. I consider then the best traps for all-around trapping. Last year I bought some Stop Thief traps; these I also wrapped abont with withes, and I was surprised at the success. Of course, the latter traps were used entirely for mink and marten, and only where the Newhouse traps could not be used advantageously.

$$
\text { "M. A. O." }
$$




\section{Hunting and Trapping.}

\section{RACCOON.}

"A good way is to take a steel trap, size No. 2 or 3 , and set it on the edge of the water about one and one-half inches below the surface. Stake the chain carefully, hang any kind of bait, such as fish, part of a bird, squirrel or rabbit over the foot plate of the trap about two feet high. When the raccoon sees the bait he will jump for it and when he comes down will invariably get his paws in the trap. The bait can be scented with a few drops of Oil of Anise, which can be procured at the drug store.

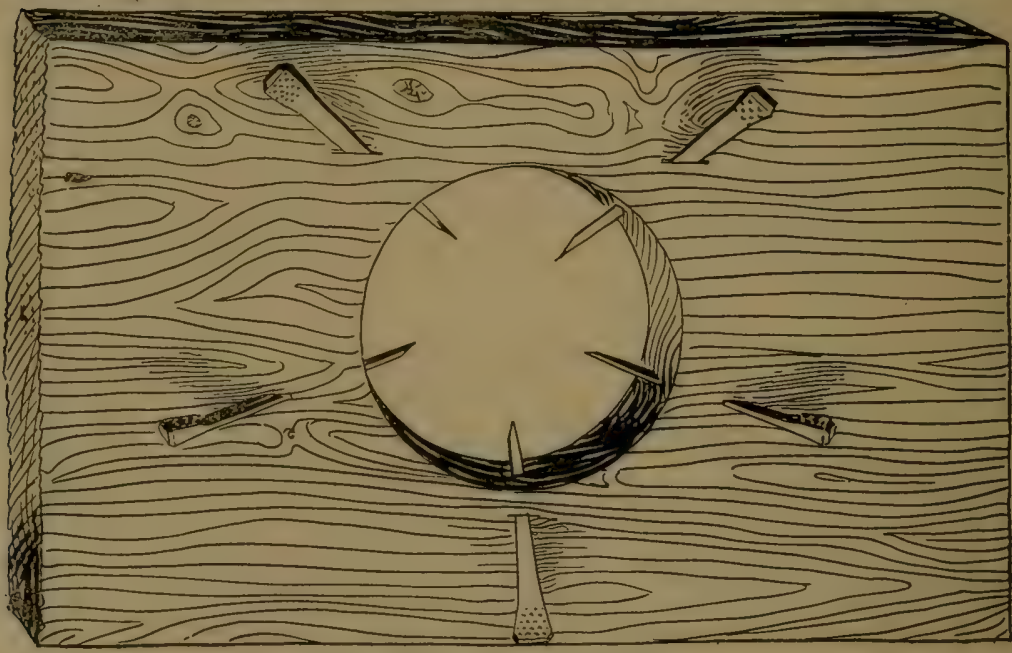

HORSESHOE NAIL TRAP.

Bore a 2 or 3 -inch hole in a thick plank and drive slantingly 3 to 5 horsehoe nails. Set in a convenient place or in front of some opening that mink, marten, weasel or similar animals are known to pass through. The animal will put his head past the nail points and not being able to pass clear through, and unable to return, becomes a victim.

MINK.

"Mink frequent the banks of streams, ponds and lakes, and can be caught in almost any appropriate trap-size No. $I^{1} / 2$ is used the most. When used in the water traps should be placed in shallow places where the water is from one to two inches deep. The bait should be a piece of bird or rabbit placed about two and one-half feet above the trap on the end of a stick, or so that the mink is compelled to stand up on its hind legs or jump upwards to get the bait. It cannot accomplish this without tread- 
ing on the pan of the trap and thereby being caught. Traps may be set at intervals along the bank of a stream and about two feet from the water, properly concealed and baited with a piece of meat, and a trail mac.e by dragging a piece of meat, or flesh of the muskrat well scented with oil of rhodium between the traps, and any mink that crosses this line or trail will follow it to one of the traps.

\section{SKUNK.}

"Skunk are not cunning and are easily caught in a steel trapsize No. I $1 / 2$ or 2 are mostly used. The box traps are not so effective on account of the stench which such traps are likely to get and retain after being used for this purpose. The steel trap, baited with a few small pieces of meat, fowl or dead mice around the pan of the trap is sure to be affective. A good way to avoid the awful smell that it throws is to approach as stealthily as possible and deal a blow upon the backbone near the tail, which will produce paralysis of the parts, and prevent the animal using his offensive powers.

Fox.

"The best way to trap fox is to make a bed about three feet in diameter of most any kind of chaff. Nake it deep enough to cover the trap, size No. 2 is mostly used, and have some under the trap to keep it off the ground or snow. Make it smooth and level; bait with a piece of fowl on the inside of jaws of trap; also place some bait around outside of bed. Bait should be scented with oil of anise and put some on pan of traps. This will induce the fox to come up to the bed, and in seeking the attractive odor he will commence to paw and will step into the trap and get caught. It is important that the trapper in setting his traps for fox should use buckskin or fur gloves so that the traps will be free from human odor. A piece of fresh meat dragged along the ground will attract the animal from a great distance.

wolves.

The wolf can be trapped in the same way as the fox, being careful to cover traps in both cases.

$$
\begin{aligned}
& \text { RAy Birdsell, } \\
& \text { Ossian, Iowa. }
\end{aligned}
$$

\section{Hunting and Trapping.}

RACCOON.

Mr. O. G. Wells, Okotoks, Canada, states that he has been very successful in capturing raccoon. He attaches a live cravfish to pan of proper sized trap so that the fish will be able to 
move on the pan, but not get off. Set the trap near the shore and if water is not deep enough, scoop out a hole into which set the trap. Arrange the crawfish so as to be partly under the water. When Mr. Raccoon is in search of food he usually travels along the shores of rivers or lakes, and in passing by one of these sets is quick to see the crawfish and as this is one of his favorite foods, he will readily reach out for it and in so doing springs the trap and becomes the victim.
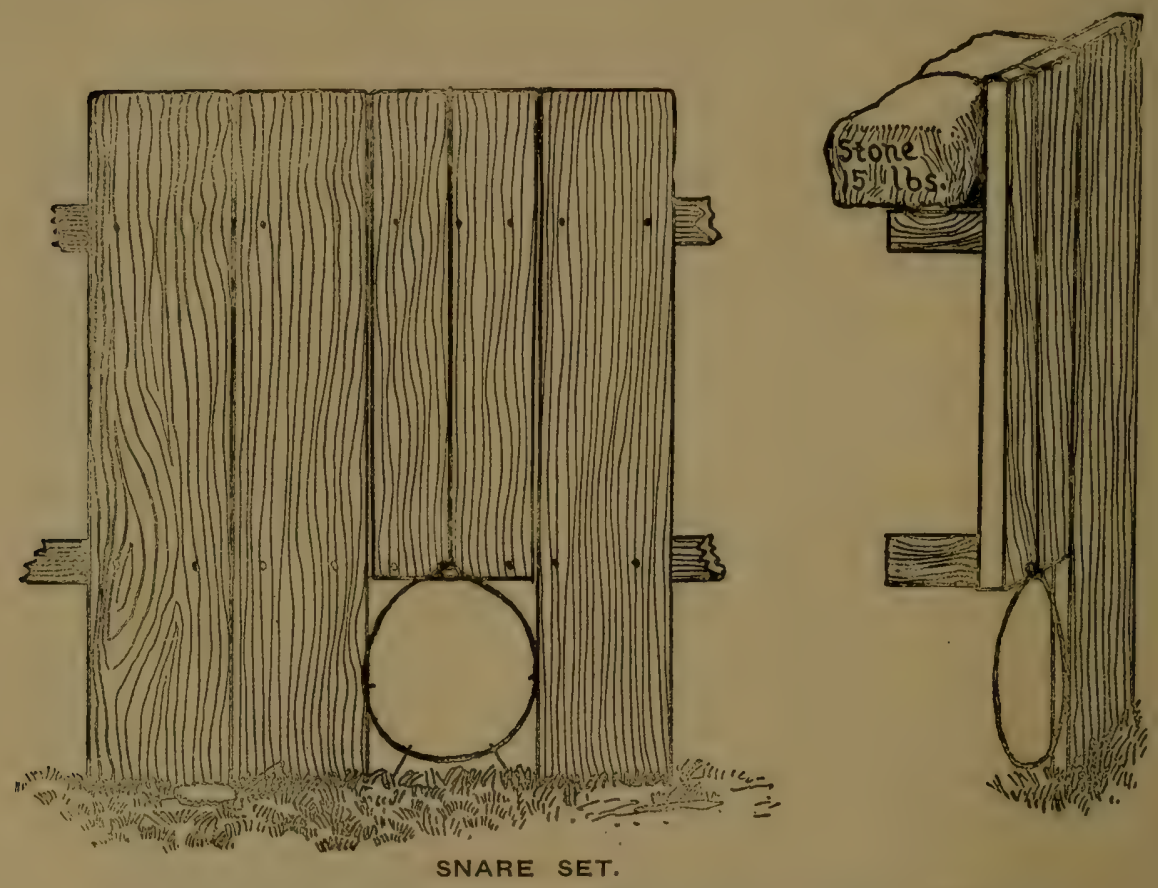

The above illustration shows a snare properly arranged. Many wolves and foxes have been captured by this arrangement. The victim will endeavor to get away, and in so doing, throw the weight off the scantling; the latter pulls him off his legs. The wire should be strong and the weight one-quarter to one-third heavier than the animal. A No. 2 Newhouse trap set at the opening may be an additional assurance of security and capture.

OTTER.

Take a tunnel set net twelve to fourteen feet long, with wings angling forward according to width of river in which net is used. The largest hoop should be I4 inches and the smallest five to six inches. The meshes at the smaller end should be one to one and one-fourth inches and those of the wings one and one-half to two 
inches. The net should be made of coarse, strong twine. Set tunnel of net in channel of stream, with wings apart, just as you would for fish. Place weight at small end of net. Keep all parts of net below the water. As the otter travels up or down stream quite regularly, should he chance to come the right way he is bound to get into the net and not being able to get out becomes a ready victim.

\section{THE FISHER.}

My method for trapping fisher is as follows: "Take a piece of fresh meat pork, beef, venison or chicken, roast it over an open fire until about half done; then smear or dip into pure honey. When cold, give it another coat of honey; tie a rope to it and drag it along the ground where you have reason to believe that fisher are likely to travel. Any fisher that comes across this path will follow it. It is preferable to have the traps set a few days before this bait is dragged. Place trap in some hollow log or stump, which has an opening at the base or make an artificial abode. Set trap at entrance and place bait within the abode. Smear honey at two or three places within the abode as the animal is very fond of this article. This is one of the best methods for trapping fisher. I discovered this in I860 when I found a fisher robbing honey from the bees in a tree.

\section{PORTABLE FLOAT FOR MUSKRATS.}

The float is a great success in trapping muskrats in early spring time. To prepare these portable floats, I cut chestnut, hemlock, pine or cedar logs that are from eight to twelve inches in diameter into pieces from three to six feet in length, according to diameter. The greater the diameter, the shorter the float may be made. I take the piece of timber to the water and immerse it. Now I carefully mark the side that lies down, as nearly all sticks seem to prefer to rest on one side more than on the other side. This bottom side is flattened a little to make it all the more steady. We now proceed to cut a notch in the top side and in the center of the float. This notch is wider on each side than in the center and is cut down within one and one-half to two inches of the bottom of the log. A steel trap is set in this notch. When Mr. Muskrat comes along looking for some place to climb upon, he spies the float. This float is housed when not in use to keep it dry. When we place them we carry them in a boat. A staple with a ring is driven in one end of the float. A stake is stuck through the ring into the bottom if the water is shallow; if not, a cord is attached to the ring and anchored with a stone to the bottom.

O. E. Bartlett. 


\section{Hunting and Trapping.}

\section{BEAR.}

"After selecting a place to set your traps, build a V shaped pen and set your trap in the opening. Never fasten the trap. Secure it with a clog. Any short piece of timber will do, for black bear the clog should weigh about forty pounds; grizzly bear from ninety to one hundred pounds. Place bait in pen beyond trap. I find the best bait to be a good sized piece of fresh meat. Drive a stake through it to prevent it being taken away without an effort, and the bear in trying to get the bait is

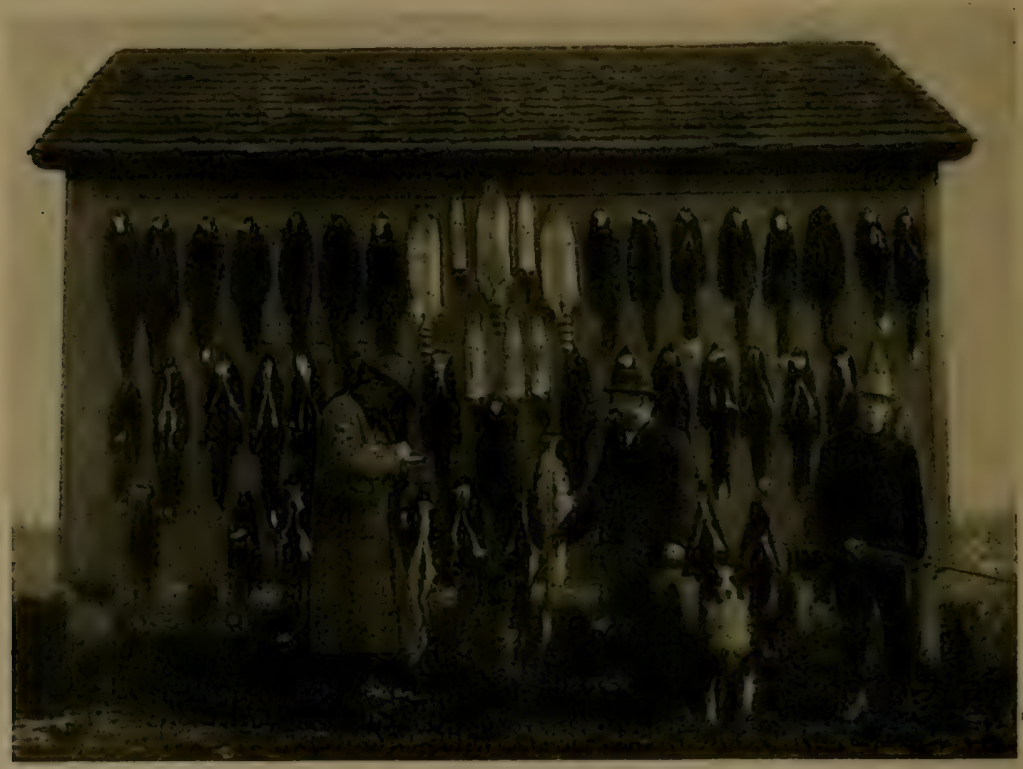

C. N. Dabney

A Nice Collection

Bristolville, 0 .

certain to get into the trap. A good plan is to smear the bait with some honey. A piece of cod fish placed near the trap is a most effective draw as the scent can be detected by the bear for a long distance. If possible, take a string of fresh fish and make a wide circle dragging them behind to as wide a radius as possible; after completing the circle place the fish in the pen; if any bear are near you are pretty certain to get them.

\section{COUGAR.}

"This animal may be trapped by the same method employed in trapping bear, by using only fresh meat as bait. But the surest 
way is to find where they have killed some animal and left a part of it uneaten. Secrete your traps near the remains and you are reasonably sure of catching your game when it returns for a second meal, as they hardly ever leave the neighborhood of a kill until the carcass is all eaten.

Albert Rosenbush.

Turtle Lake, Wis.

\section{SUFFOCATING SKUNK AND MINK.}

Have dug out many skunk, but digging them out is like working in a mine on a profit sharing plan. Hard work, long lasting hours and small results. Probably this is alright for southern climates, but up here in South Dakota where the thermometer reaches thirty to forty degrees below zero during December, January and February, the ground is frozen too hard, especially if it happens to be in clay. During the last part of November or fore part of December if the frost in the ground is not too deep, it is no trick to dig three to five holes containing all the way from one to ten skunk each, in a single day. Here are my methods :

First: Take a pick and shovel, an eight foot pole and a gunny sack. Start for the holes in the morning, but not too early as the skunk does not always get home until it is good daylight. Have seen them come from their nocturnal visitation as late as $8: 30 \mathrm{a} . \mathrm{m}$.

Arriving at the hole, I look for fresh signs, such as hairs, tracks, dung, etc. Having assured myself that the den is inhabited, I put my shovel and pick in the hole and look for other openings, as quite often there is more than one opening, especially if the skunk should happen to be in a badger hole. If there is only one opening I immediately proceed to dig until I can see the black and white hair of the skunk. Then I slowly sprinkle earth all over the skunk, pressing it closely to the animal with my hands. I continue this process until I have four or five inches of dirt over the skunk, then trample more dirt in the opening with my feet, and this process continues until I have fifteen to twenty inches of dirt over the hole. I then depart for another opening. Having found another hole and assured myself that same is inhabited, I proceed as on the first den. After the process is completed, I return to the first den, where the dirt that I trampled is removed, and with my hands I take out the dead animals.

Second: Sometimes it is easier to smoke out a skunk than to I usually take a bee-fumigator or bee-blower as it is sometimes called, and blow sulphur fumes into the holes. Quite often I am 
compelled to cover the opening up just so that the hose enters it freely. If the den is inhabited, the skunk will come out on the other end, in preference to being suffocated; but once in a while the skunks are too lazy to move and become suffocated, much to my sorrow, because then I have to go to work and dig them out.

Have suffocated many badgers, foxes and wolves by the use of the bee-blower, and on one occasion captured a live bear in the Black Hills. He was not very much alive by the time I got to him, but I immediately put a collar and chain around his neck and a pair of hobbles on his fore feet, loaded him on a buck-board and started for home. He slept in a hollow log and of course it was very easy to get the sulphur fumes to his nose. I tell you when he came to I had a time. I was about two miles from home and having only a buck-board I had great difficulty in getting him to remain with me. I finally reached home and there is where the picnic started. But that is another story.

\section{GOOD POINTERS.}

R. B. A.

TO MAKE DECOY.

Obtain from the female of the dog, wolf or fox, the matrix during the season of coition and preserve in alcolnol; keep bottle tightly corked, and when you set traps be sure and take it along, leaving a little of the liquid on something near the trap, on a bush, rock, etc.; also put some on the soles of your shoes. The animal for which you are trapping will come across this decoy and walk around and around and consequently will step into a trap before he knows it.

\section{USEFUL HINTS TO TRAPPERS.}

First: Make a trail in different directions around the traps.

Sccond: A piece of raw fish dragged about, will sometimes help to draw the animal, for the reason that if you are careful, your tracks will be covered and the animal will stop to see, as he will think that there has been some other animal around and will not fear.

Third: Be sure to leave everything as natural as possible around your traps.

Fourth: Be careful to visit your traps often enough so that the skins will not have time to get tainted.

Fiftll: As soon as the animal is dead and dry, attend to skinning and curing skin.

Si.rth: Be sure to scrape off the superflous fat on the skin, but be careful not to scrape or cut deep enough to cut the fibers of the skin, as in this way many skins are practically ruined for market purposes. 
Seventh: Never dry a skin or hide in the sun or by the fire, but in a cool, shady place, sheltered from rain or snow.

Eighth: Never wash your skins. This is a mistake made by many. Simply dry them as taken from the animal.

Ninth: Never use preparations in curing your skins; you will only ruin them. These have never been found to be any good.

Tenth: A good way in trapping animals such as the fox, lynx, etc., is to conceal your traps in a bed of ashes, leaves, chaff, etc., being careful that the trap can spring.

Eleventh: Always be sure that your trap is set so that the animal will go to it, and that it will secure him when he comes and that he shall not release himself.

Truclfth: You should always smear your traps in melted fat, blood, or beeswax, except when trapping rabbits or like animals.

Thirtecuth: In most cases it is generally best to induce the animal to come for a few nights before setting the trap.

SPRING POLE:

A good way which I have found very useful in trapping animals that are liable to be devoured by other animals, or devour a part of themselves in order to escape, is to have a spring pole as it is commonly called. First cut a pole (green so as to bend easily), then drive one end in the ground, bend it down from the top and fasten the trap to it; then fasten the pole by a notch or hook to a small tree or rock. The trapped animal in its struggles will unhook the pole and the pole will fly back lifting the animal in the air and out of the reach of other animals.

\section{HOW TO TRAP OTTERS.}

Go along a stream, look for the deepest holes where thic fish are sure to go when pursued. Look about and you will see the tracks where the otter comes out of the water and up the bank and often you will find a small tuft of grass greener than the rest. Open and examine this and you will find the dung of the otter, full of bones and scales of fishes. Then dig out a place up the bank, the form of the trap, set the trap slanting so that the otter will tread on the springs, cover over with rotten wood, leaves, etc. Set the trap level with the ground. When done, go back as far as you can and throw water on the place where the trap is set and all round to take away scent of your hands, etc. To fasten trap, cut a pole, size of chain ring and set upright and drive in ground or tie with chain to a rock or tree. Before leaving pour a few drops of fish oil over the trap.

Ralph E. Guscetti, Loyalton, Calif, 


\section{Hunting and Trapping.}

SNARES.

One of the best snares in existence is the ground snare. It is made as follows: First find a sapling about ten feet high and original thickness so that there will be enough spring in it. About four feet from it drive a piece of board about four inches wide, one inch thick and four feet long. Next make a notch in the upper end of the flat side of the board and another notch in the side of same board. Now take a stick one foot long and make it one inch square and put in the notch No. 2. Then make a notch in your stick the same as the notch in the top of the board and make your trigger holder. Beginning at the post, drive stakes into the ground pretty close together and three inches high so as to enclose a circle in front of the post a foot in diameter, taking care so the tops of the sticks lean inwards so

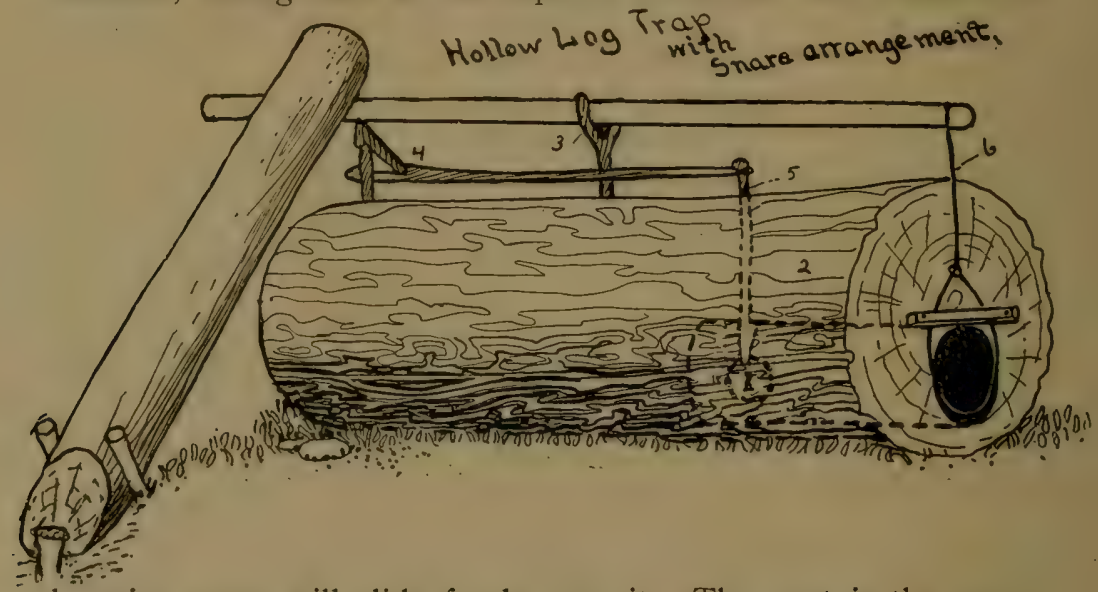

the wire noose will slide freely over it. The next is the snare. Get some strong, limber brass wire and tie securely to the top of the sloping. The wire should be about five feet long. Bend the sloping over and tie one end to the trigger holder. Now make your snare and put around the stakes and your set is ready. When the animal comes along he will have to get on his hind legs to get the bait and when he touches the bait the limb is set free and the snare catches the victim by the body and throws it up in the air; it cannot use its legs to get loose.

MINK.

Mink live along streams, rivers and lakes and feed upon fish, frogs, etc. The female mink does not run about like the male, but stays around the den and the male mink has to get the food. 
They are restless and travel almost all night in their search for food. They form regular beaten tracks by their crossing and recrossing, and a trap in such a place will nab a mink any time. A good place to set trap is under pile of drift wood in the mouth of small streams.

A good set is to find a shallow box, having a weather worn appearance and bore half inch holes in the sides so that the water coming through will cover the bottom to a depth of three inches. Drape the sides with moss and dirt and put some live fish in the box and a few traps with them. The mink are fond of taking their food alive and here you have a set that gives them a good invitation.

Another good method is to put two traps side by side and surround each by a circle of rock, the traps being in the water. Hang a bird about one and one-half feet over the traps. Make the bird look as natural as possible and you are pretty sure of getting a mink.

Another method is to find a $\log$, hollow in one end, and place in the water so that the hollow end will be about one foot from the other bank. Stake it down with stakes; put some bait in the $\log$ and stuff up the end with leaves. Put your trap right outside the log about one and one-half inches under water. When Mr. Mink comes along he stands a good show of getting caught.

Another good way is to find a place where there is a little strip of land between the land and the water, drive stakes along the water side so they come together; just outside the stakes set your trap and when the mink comes along and goes on the land the sticks will guide him directly into the trap.

A good set in water is to cut a strip across the brook (if there is ice on it) about one inch wide and drive stakes across leaving a space about four inches wide in the center. Now build up so that there will be about two inches of water above the mound. Place a trap upon the mound and then cover up everything again. This set I can recommend. Other good places is to put at holes in the ice; where you think there is a mink scrape off the snow and put a trap right by the hole, cover with rabbit fur, feathers or muskrat fur and place a rabbit under trap. When you have done this throw snow over all.

Sometimes it is preferable to use bait and sometimes not, because when a mink is hungry he will take almost any kind of bait and when he is fleeing he will take no bait. The best kinds of bait are fish, muskrats, birds, hens, rabbits and partridges. In the fall or spring it is preferable to smoke the bait as then it keeps longer. 


\section{Skinning Mink.}

In skinning a mink, rip with your knife a line from one hind leg to the other, and then rip it to the root of the tail. Skin all the skin off, even the claws, as they will then demand higher prices. Then take the tail bone out and proceed to skin down to the nose. Do not cut a ring around the leg with your knife half way or by the knee joint and then tear it off; skin all the skin off. Do not cut too many holes in the skin as the more you do this the less you get for your skin. Take plenty of time and do it right. Take off all fat and then proceed to stretch.

\section{STRETCHING SKIN.}

Get a board about four inches wide and one-quarter inch thick and three feet long. Make it narrower at one end, so it comes to a point. Make another board one inch thick and three feet long; take the small board and put on the center of the large board and then put on the skin. If you do this you will have a nice skin when it is dry:

THE SLIDING POLE.

The sliding pole is very good to use when you want to drown animals. Find a smooth pole of sufficient length so it will reach deep water, drive in the bottom of the stream and fasten to the bank with a stake. Put your trap ring around the pole and fix it so that it will slip smoothly along the pole, the pole slanting from shore to deep water, you understand. When the animal is caught it dashes for deep water and the weight of the trap keeps it from coming up again.

MoRris ThOMPSON, Blair, Wisconsin.

\section{FISHING FOR BAIT AND FOR FOOD.}

When a trapper goes many miles into an unbroken forest for a season's trapping, he is sometimes put to his wits' ends to know how to procure bait enough to supply a line of traps, especially if he has always trapped near a settlement where he could go to a near-by meat or fish market for refuse. Following is my method:

In making up my outfit for trapping, I put in five hundred or six hundred feet of cotton cord about one-eight or three- sixteen inches in diameter. This is to be used as a set line during open water in a lake or pond. Next take say fifty to seventyfive taper shank hooks that will measure about one-half to fiveeight inches across the curve. Now from a hank of linen fish line cut some leaders, four to six feet long, to be used suspender from set line, from twenty to forty feet apart. Now add one 
spool of black linen thread and a little piece of shoemakers' wax for lining the hooks, which is clone by warming the taper shanks in a lamp or candle flame and rub them on the wax, then wind the third spirally around the shank. Now lay the thread on and wind thread back over line and hook to place of beginning, then form a large loop of the thread winding one part over the other two or three turns; then take hold of loose end and pull the loop through. Wax the whole winding a little and you have a finished job, one that can be used on live bait mentioned later. All this can be done at home or in camp as preferred. It is always well to take along an extra hank of line as you may need a hobbing line to fish through the ice with later on. There are two things more needed to complete our outfit, that is a minnow net-a piece of mosquito netting will answer very well, and an ice chisel-a two inch framing chisel will answer. And by the way, it is well to fasten a cord to the end of chisel handle and loop the other end around one wrist to avoid dropping through the ice, as the writer did the first winter he was in the woods. Think of cutting holes through thirty inches of ice with an axe, and a good ice chisel only forty feet away lying at the bottom of the lake-and you will use the cord.

Now let us suppose we are in camp, many miles from civilization with outfit umpacked ready for business. We want a good mess of fish to eat, and some for trap bait. First of all we must have some fish bait; there are no fish worms to be had, so we must do the next best. We start out with axe in hand and find a dead hardwood tree, preferably a hard maple. If a portion of that tree is well decayed, cut it down and you will find in the rotten section white grubs enough to fill the immediate needs; that is to say, for enough to locate some minnows and fish enough for breakfast. Perhaps a word here about fish for food will not be out of place.

The gills and entrails should be removed soon after being caught, then lay fish in a cool place over night; that gives them time to wilt (repent as it were); then they will lay still in the frying pan and not break to pieces. Now our fish are prepared for morning, and we have located a school of minnows and we have still a little sunshine. We cut a brush from off the branches and bend it into a hoop, say four feet in diameter and fasten our net to same, put in a small stone for sinker, attach three cords to hoop and lower it in water that is from four to six feet deep, either from shore, boat or raft. The net is now ready to be baited with bread crumbs thrown on the water and allowed to settle in the net. Chew the bread well before putting it into the 
water and it will reach the net before the minnows knock it away from over the same. If bait fish are plenty, the first haul will give you all you will need for one week, as we do not propose to have many hooks robbed as you will soon see. If we have a little daylight left, we run out our set line, using our boat or raft as the case may be, fasten the line to a tree on shore and anchor other end or run it across to another tree or bush and fasten. On our way back over the line we loop on our leaders and bait the hooks. If you hook the bait through the back as most fishermen do, you will have more hooks robbed than you can keep supplied with bait. Hold the bait fish in hand with head towards you, catch point of hook in skin on one side close to tail, run the point under the skin from one-fourth to one-half inch according to size of bait. Now turn shank of hook from you and take hold of curved part and draw shank and a few inches of line through hole under skin made by hook; now catch hook in under lip and draw back slack line, and the first fish that swallows this bait is yours. If not taken by fish your bait will live from one to two weeks. When the ice freezes over, get out your ice chisel (with cord attached) and make a few holes in the ice near the shore, and use your longest set line leaders, if water is shallow; but if water is from ten to twenty feet deep you will have to use some of that extra hank we brought along with hooks fastened on as already described. Cut some bars and crotches from the bushes; the bars should be at least three feet long and three-quarters to one inch thick and lay across holes in ice; the crotches about same thickness and tapering down to one-half inch and long enough to reach a little more than through the ice, say twelve or fourteen inches. Fasten line well up on crotch and if fish are large it is well to give it a turn around the bar also. These lines are to be baited just as we baited the leaders on our set line earlier in the season. You will find fish enough in a country that is worth trapping, to supply food and bait in abundance.

In Case of Animal Bite.

F. H. BASSETT, Waterbury, Conn.

If bitten by an animal, press or bandage tightly the part above the wound until it quits bleeding; then with the mouth suck out all remaining blood. Wash the wound with carbolic acid and water. Don't stop wound from bleeding too early, a bleeding wound is safer than one that does not bleed.

\section{A TRAPPER'S OUTFIT.}

To go away Ioo to 200 miles from any railroad and from the 
next living soul, as I and my partner have done for a period of years, requires some forethought as to what to take along, especially if on the first trip. The requirements of course, depend upon the locality, season of the year, and what is necessary in one section is undesirable in another. I am thirty-two years old and my partner forty-five. Both of us have trapped and hunted in the States before coming here. The first time we started we had, or purchased what we didn't have, the following:

HARDWARE.

I Axe.

I Hatchet.

I Rifle.

I Shotgun.

I Revolver. Supply ammunition.

I Hunting knife.

$200 \mathrm{Ft}$. linen fish line. Fish hooks.

50 Ft. rope. .

I Camp stove.

3 Lengths stove pipe.

2 Spoons.

I Covered pot.

2 Plates.

I8 Pounds bacon.

I5 Pounds flour.

TO Pounds beans.

5 Pounds salt.

2 Pounds ground coffee.

$1 / 2$ Pound green tea.
I Kettle.

I Bucket.

I Frying pan.

2 Pocket match safes.

2 Pocket knives.

I Skinning knife.

I 6x8-ft. tent.

50 Steel traps.

4 Window glass, $8 \times 10-i n$.

2 Table knives.

2 Galvanized iron cups. Needles and thread.

2 Watches.

I Calendar.

\section{Groceries.}

6 Boxes matches.

3 Bars soap.

I Box pepper.

$1 / 2$ Pound can baking powder.

$1 / 2$ Pint flask alcohol.

\section{Extra Clothing EACH.}

I Suit underwear.

I Top shirt.

I Coat and pants.

I Pair shoes.
I Pair woolen blankets.

2 Pair socks.

I Pair mitts.

I Hat and cap.

Such articles as were not required on our journey were permanently packed in canvas bags suitable to be placed on the horse's back. The others were made in smaller packages, some of which were carried between us and the remainder loaded on the horse.

IVe followed a Hudson Bay Co.'s trail for many miles, then chose a river which we followed for three days. After ten days' journey we arrived at the spot which we had decided upon, 
and were both glad to get there. We pitched our tent the same afternoon and the next day started to make a permanent log house. This we had fairly completed by Oct. 2oth. The house was 12 XI $4 \mathrm{ft}$. We lacked lumber for a door, an 1 material for a window. On Oct. 25th my partner left for the R. R. station with the horse, for an additional supply of provisions, some lumber to make a suitable door, also lumber for stretchers, and 100 additional steel traps. During his absence, I kept busy laying out trapping grounds, storing vension and other meat supplies, also getting a good supply of winter fuel.

The question of food supply is an easy one in this section, especially since both of us are good shots. On November I6th he came back with provisions, traps, and a dog.

Mink and marten were what we were after in particular. We took all the lynx and fox we got hold of, but neglected wolves, wild cat, and other low priced fur bearers. Before going much farther, I want to say it is a very good idea to take along a small supply of medicines as they come in very handy.

The first part of February I took my turn to go to town with what furs that were dry, which were shipped to you at Minneapolis. When going back, I took along such provisions as flour, coffee, and a few more cooking utensils, matches, bacon, and an additional supply ammunition and traps. We did not entirely depend upon steel traps as we found them very bulky and as we had plenty of time, we made deadfalls, snares, etc.

Everything went smoothly and we had no particular trouble or hardships the first year. It may be interesting to relate that just after a severe blizzard, we were obliged to take the horse into our house to keep him from being devoured by packs of wolves that surrounded the house one night.

I would suggest and recommend all new trappers, especially those who want to locate in the upper part of Canada to choose trapping grounds pretty well in the timber, but always along some stream or lake which affords a supply of fish and better trapping on account of the easy access and habitat of fur bearing animals. Do not go it alone, but take someone with you. Neither wait until the last minute to start; on the other hand, start as early as August or September.

We have been up here now the fourth year but probably will have to change our location before next winter. The country is becoming slowly settled up. Furs are still plentiful and at these high prices a trapper can make as good wages in the four or five months as he can by working the year round in the states.

We want to suggest and recommend to all trappers who start in this country, never to go away far from the cabin unprotected, 
and when going away close and securely fasten the door. Do not wait too long in the afternoon before going home. A compass comes handy. Always pitch your tent or make your cabin close to a river or lake, and if possible near a spring so that you have fresh and wholesome drinking water.

\section{J. B. JoHNSON. MARK Steveńs.}

\section{Hunting and Trapping.}

A POINTER ON TRAPPING.

Before setting out to trap one should examine each trap. They should be smeared up with grease or other fat and just before setting start a small fire and partly burn off the lard or fat, which will leave the trap just as soon as the steel is sufficiently hot enough. Some trappers prefer to smoke the traps in preference to greasing and burning the grease off. After this is done the trap should not be handled with bare hands, and should be immediately set. Some trappers scorn the idea of smoking traps, smearing them with blood, grease, etc. By preparing traps the above way and handling them with gloves, the latter possessing odor of some musk (especially beaver or muskrat) animal's suspicion is certainly decreased, perhaps resulting twenty to thirty per cent. more strikes and victims than if traps were left natural.

\section{TRAPPING WITHOUT BAIT.}

In trapping without bait with snares, steel traps or homemade traps, it is necessary that the paths of the animals be the least possible disturbed or walked about, that the traps and snares be carefully concealed by being covered with leaves, bits of earth, rotten wood and other similar substances. The idea is to leave the place in a natural appearance. Unnecessary handling and removing dirt, excavations, etc., are to be prevented as much as possible.

\section{LEADING ANIMALS TO BAIT.}

One of the most successful and often called Indian style of trapping is to drag a fresh killed, still warm and bleeding animal about Ioo yards, in some instances, a mile, over the ground to the previously concealed trap or traps. The carcass is generally buried to a reasonable extent or fastened in one manner or another so as to detain the victim, which may be a wolf, fox bear or other similar game. Sometimes a hole is dug and the carcass (bait) thrown therein and the traps set about the hole. The Indian usually drags the bleeding bait on a rope or stick while riding a pony, thus avoiding human tracks or scent. 
SETTING TRAPS IN WINTER.

"In the winter when there is a frequent fall of snow, with occasional thawing and freezing, I have experienced some difficulty in covering traps so as to retain them in good working order. Quite often a thick, stiff crust has formed over the set and naturally small animals will not spring the trap,, and if sprung the jaws will not hold them due to obstruction. To overcome this difficulty I tried the use of white tissue paper with satisfactory results. Of course this can only be used when ground

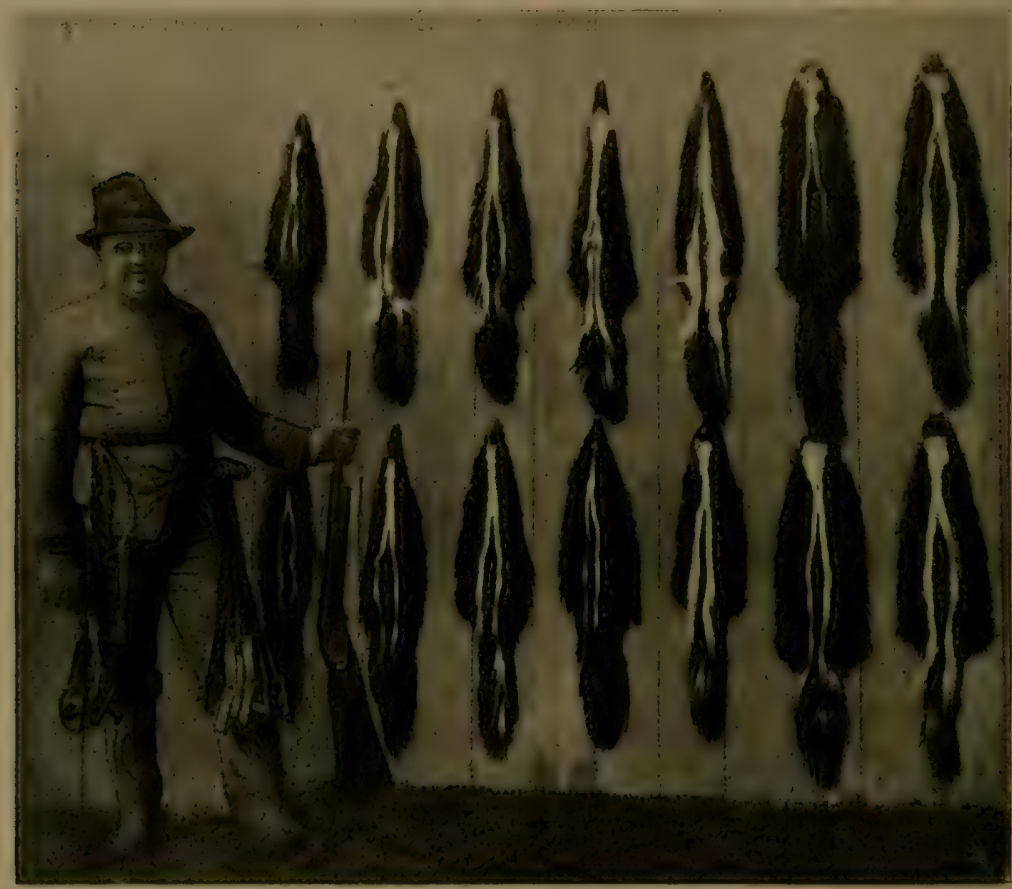

is all covered with snow and should be large enough to cover trap completely. To keep from blowing off, I usually put snow or ice on the corners. I always approach trap from same side and never approach closely unless the trap has been disturbed.

\section{Lewis Olsen,}

\section{Hunting and Trapping.}

Setting The important feature in trapping is to set the traps Traps. where the animal is most likely to come and get into it, second that the trap will hold the victim and third that the trapper get best results in skinning, stretching and drying. 
It is very necessary to have your traps free from human scent and iron odor. To overcome this smoke the traps over a fire of burning hemlock or cedar boughs, or dip traps in fresh blood, melted fat or beeswax.

An animal, such as the fox, wolf or raccoon, should be invited to cone to the same place several times before traps are set. Arrange this place with sawdust, hayseed, chaff and chicken feathers; scatter bait adlapted to the animal which you seek to catch. For the fox and wolf use the offals of chickens, bones, waste meat, fish heads, etc. For the raccoon use nubbins of corn. After leaving the ahove for a few days, and indications point to the animal having visited the place, proceed to set your traps. Scatter plenty of food, and see that traps are well fastened. Another way is to set your traps several inches under water. Then hang your bait directly above trap on a sapling or spile so as to make the animal stand directly above the trap; in trying to get at the bait he will fall into the trap. This method can be used in many places, by having the traps well covered. In the water set, have a weight or stick arranged so that the animal will drown.

Every trap should have a strong short chain attached to it, as animals will gnaw other like materials and release themselves. Traps should be so arranged that the animal cannot work around with trap and destroy its fur.

Mink Set. For mink set traps near a stream. If you cannot in the cavity. Build up the three sides with bark and stones, trap cover traps with grass and mud. In setting a trap, always have loose jaw of trap away from where the animal enters, for in many instances the loose jaw will raise up and the animal will walk over the trap. Arrange so that animal will walk into trap from the side; turn your trap in this manner wherever possible.

(For Illustration SEE PAGE 388)

J. J. STORM,

\section{Preparing Traps.}

"All new traps which I purchase, or all old ones before starting out to trap, are boiled in hemlock or spruce water. Sometimes I use hemlock bark, at other times their boughs, which I cut up in small pieces, and when the water is boiling the trap and chain are dipped therein for a few minutes and then permitted to dry. This removes the varnish and cleans the traps otherwise. If the traps are rusty I take sandpaper or a file and remove the rust before boiling traps. I have done this for years and find that the traps are not injured, as some claim that boiling has tendency to weaken the springs. J. C. Z. 


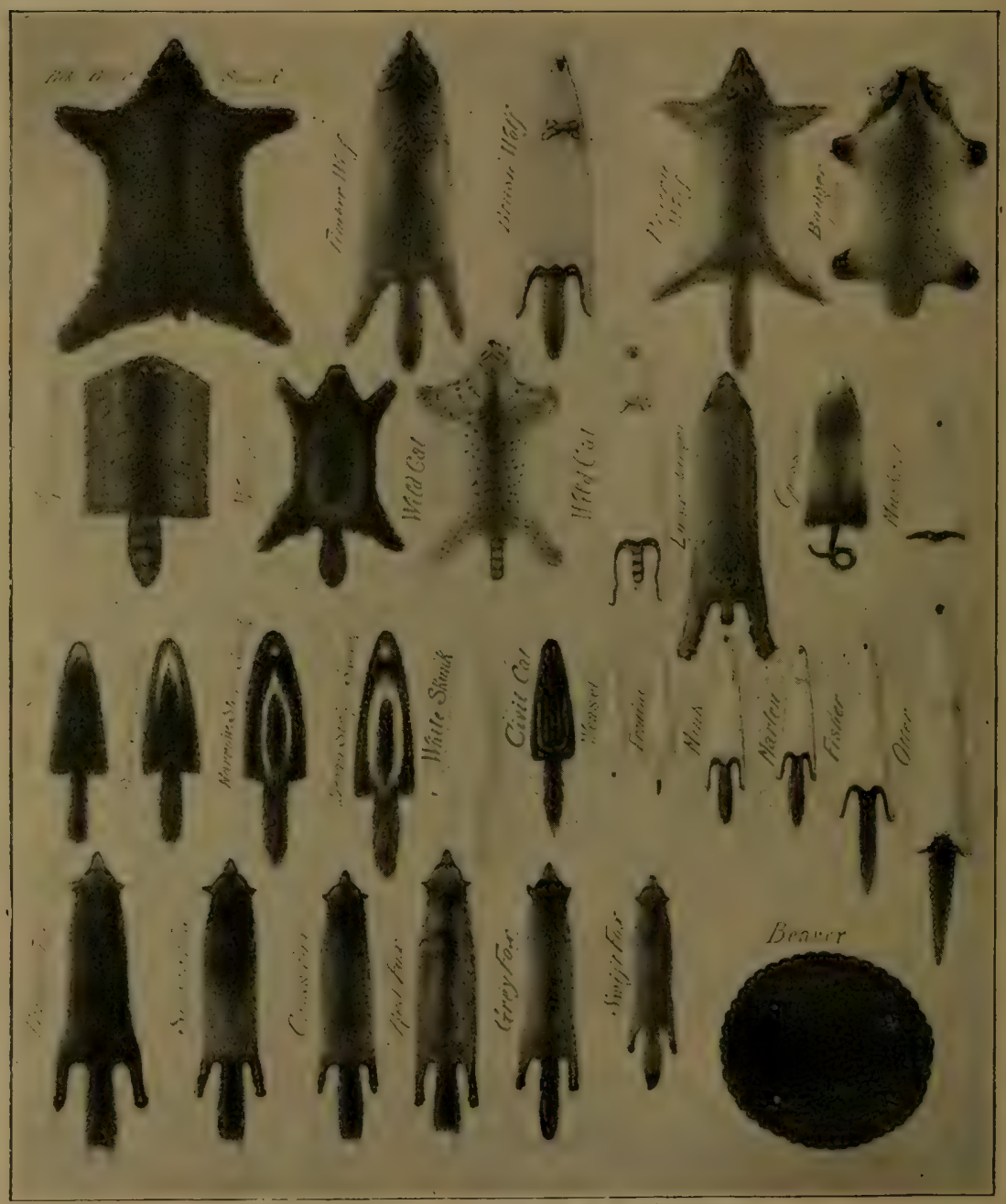

Prize Drawing of American Raw Fur Skins 


\section{TO ERADICATE THE DISAGREEABLE SKUNK ODOR FROM CLOTHING AND BODY.}

To remove the disagreeable odor from the person, clothing or skins, is quite a conundrum. Following are the best methods.

First-Hang the clothing up on a line and give garments necessary airing.

Second-Rinse clothing so affected in a bath of moist hardwood sawdust. If the sawdust is perfumed, so much the better.

Third-Rinse clothing affected by the disagreeable odor of the skunk stink and civet cat in gasoline or benzine. Immerse them numerous times, then rinse and hang out on line to dry. While doing this never smoke or permit any fire in the immediate vicinity. If you can obtain naphtha, so much the better. Obtain sufficient to cover clothing and rinse two or thrce times. Hang on the line and the naphtha will evaporate in very short order, and with it the odor.

Fourtl -Wrap affected garments up in hemlock bark or place in moist crumbs of bark. Within twenty-four hours the clothing will be ready to put on.

Fifth-Hold affected garments over fire of red cedar boughs and when they are saturated with the smoke and odor coming from the burning boughs, hang up on a line to air out. If cedar is unobtainable, use hemlock boughs or burn large quantities of pine needles.

Sixth-To eradicate this disagreeable smell from the body, especially the hands, one can use naphtha, gasoline or kerosene and finish by eradicating odor of these oils, as well as the original odor, by washing the hands or other portions of the body with tar soap. Strong soapsuds from tar soap will remove the skunk odor quite frequently alone.

At the tannery, skins are packed in moist hemlock sawdust, washed in soapsuds, or at times the odor is counteracted by the use of perfumes. If skins are not badly saturated, no attention is paid, as in the process of cleaning in the large revolving drums which contain fine, dry, hard-wood sawdust, the skins come out free from odor. These drums make about twenty revolutions per minute and the furs fall on pegs; at every revolution they are submerged in the sawdlust, which not only tends to eradicate all odor, but also cleanses the fur thoroughly. After this process the furs are freed from sawdust by shaking.

Never use chloride of lime as that destroys the clothing. Neither is it a good policy to bury the clothing in the ground, as that tends to keep the nuisance within them, unless the pieces are spread out and then covered with fine, damp earth. 


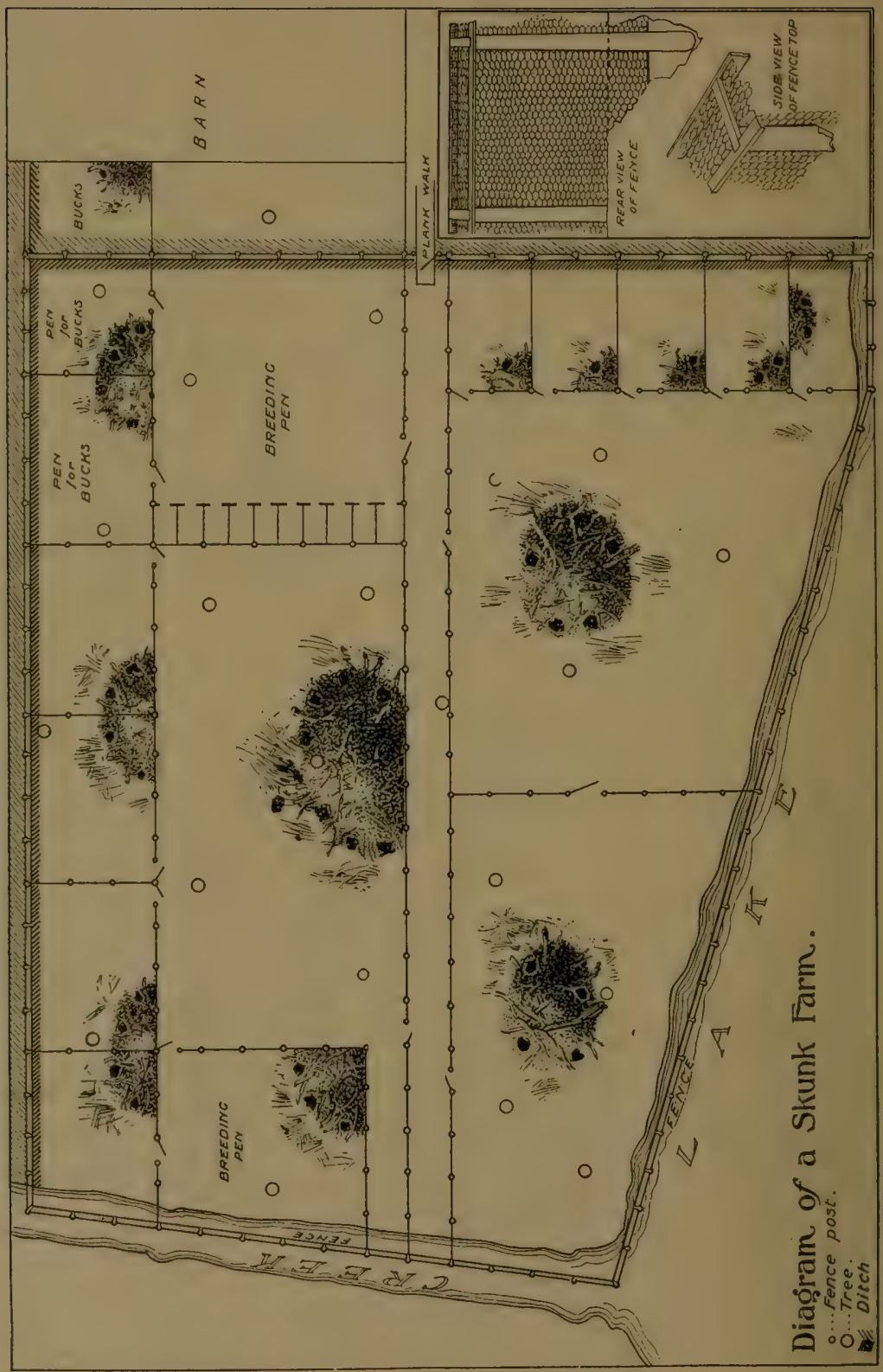




\section{SKUNK FARM.}

\section{MANNER OF STARTING A SKUNK FARM; SIZE AND LOCATION; NUIMBER WITH WHICH TO START; BREEDING; FEEDING; TIME AND KIND TO KILL; DISEASE, ETC.}

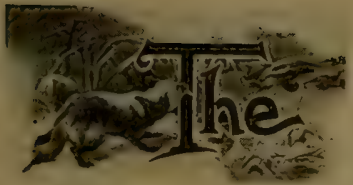

promises a fair remuneration.

BUSINESS of raising skunk for the pelt is not mutch different from the one in which any farmer is engaged when raising domestic animals, either for food or show purposes. It has been established that the raising of skunks is profitable and legitimate; and the outlook

The skins of these animals will always command a market and it is reasonable to believe that the value of a prime skin at no time will fall below fifty cents and from that up to $\$ 2.50$. A fair average price of $\$ 1.00$ can be reasonably assured, and notwithstanding other valuable by-products, the skin alone is sufficient to make the business a profitable one.

To Start No one should attempt to raise skunks unless he a Farm. has studied their habits and willingly contributes a large share of his time in caring for them; likewise must he be prepared to expend quite a sum of money in arranging a suitable location. Having accustomed and informed himself of the ways, habits and food of the animal, likewise the question of propogation and breeding, he should then look around for a location such as below described. Not to fancy the animal, to dread its existence, to get frenzied in coming in contact with their odor, and not to have patience, would naturally result in failure. The skunk needs as much attention as chickens and other domestic birds and animals. Their pens must also be cleaned, and a good supply of fresh water must be constantly before them.

Size and Location of

Farm.
Apparently this is an easy matter, but nine out of ten give this important subject insufficient attention, acting hastily, and start without due deliberation. A small island, one that is not likely to be flooded in the spring time, is the most practicable. It need not be fenced in as the only danger lies in the skunks departure during the winter time when the water is frozen, but if properly fed and provided with a reasonable sized scampering ground the skunk will not migrate; and if he does, nine times out of ten he will return to his den of his own accord. If an island cannot be secured, the next best place is a plat or location facing some lake or stream where the banks are somewhat steep in preference to a sandy shore. Endeavor to secure a location on some point where two streams, or a lake and a creek come together. 
This makes an ideal location, especially if wooded. The size of the location depends entirely upon the number of skunks that are to be raised; also somewhat upon the land, whether all parts can be utilized in making the smaller enclosures, such as breeding pens, pens where the female are to be placed while raising the young, scampering grounds in which large numbers can be placed together, etc. One not having at least an acre of ground should not attempt to start. Endeavor to have plenty of fresh water in each pen, and if consistent have the large pens in which the female are enclosed the greatest part of the time, open to flowing water,

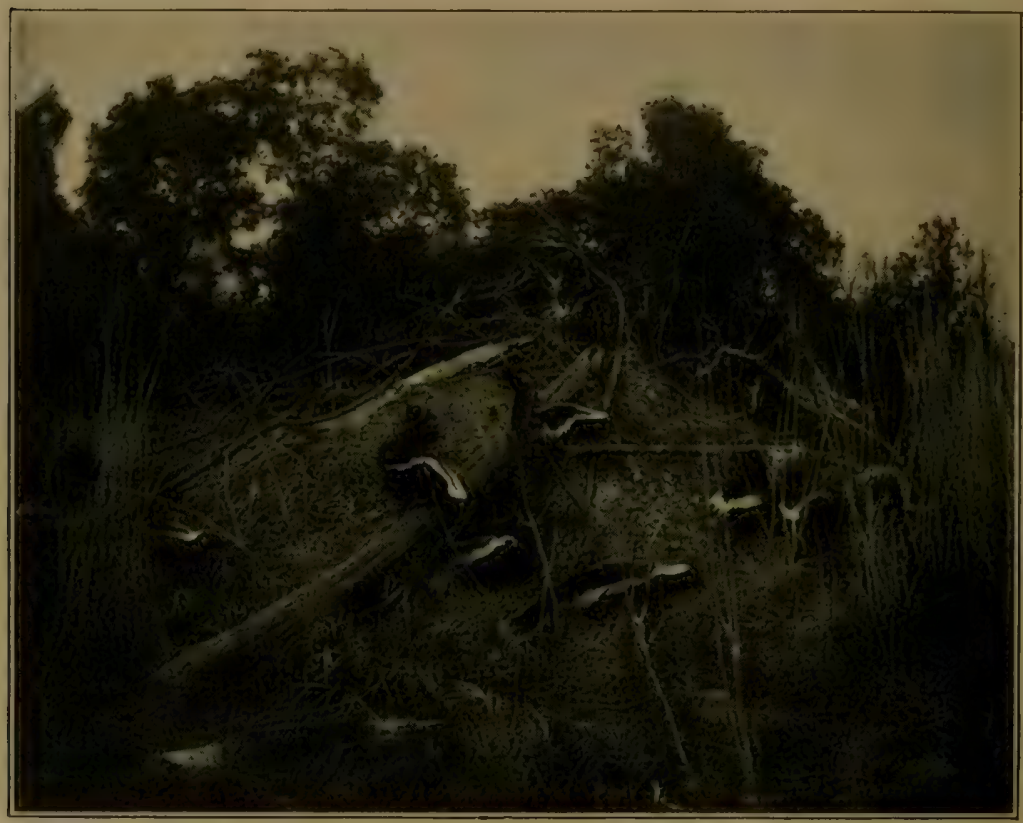

Skunks and their abode on a Skunk Farm

From a Photograph

or enclose portion of the lake front so that they may be able to obtain fresh water at any and all times.

Number with

Which to

Start.
One not having had any previous experience should start in a small way. Twenty to thirty females is sufficient. It is unnecessary to have pairs, as one buck is sufficient to serve ten females, and as the males are of no particular value excepting during the breeding season, it is unprofitable to feed a larger number than is absolutely necessary. With the exception of during the breeding season, they should be kept separate from the females. 
No more than fifty females should ever be together and we believe twenty to thirty will get along nicer and with better results to the breeder. If you have more than this number, subdivide them into separate enclosures.

It is important not to place immature males or females with the older animals; neither is it advisable to retain undesirable broad striped species, as such are unprofitable and should not be retained by any breeder. Only such as are robust, healthy, of good size, and of the black or short striped species, should be raised.

Obtain their good will and at no time punish them. Skunks will not do well in domesticity if scared of the feeder and are afraid to be in his presence.

Breeding. The breeding season starts during the month of March and seldom continues beyond April; in about nine weeks thereafter, generally during the month of May, the mother brings forth a litter of from 8 to Io which she nourishes and retains until they are able to shift for themselves. As elsewhere stated, only strong, robust, well-formed, and as near as possible, black-furred skunks should be raised. During the period of coition the females should be placed in a breeding pen 8 to Io at a time, with which put one of the bucks. If you find they are getting along nicely and not fighting, let the buck remain for two days, after which time another buck should be placed with them. After the rutting season is over the females can be placed in the large scampering pen; in about seven weeks they should be separated and placed into smaller pens, not more than two or three females to the pen, and if possible, only one. Hay, straw, grass, etc., should be given them so that they can pad their abode and make it warm. At this time they should be well fed, especially after the young are born. The female, even if penned up, alone, will not become very lonesome, being that she is able to see the others in the adjoining enclosure.

As soon as the offspring are of sufficient size where they are able to feed without the mother's assistance, they should be penned up separate. It probably makes no difference how many there are in one enclosure as long as the pen is large and roomy. Give them a chance to make holes in the earth and become accustomed to scrambling for their own food. During the fall months separate the male from the female and feed the former with meat and other well nourishing food stuff so that they will mature quickly. It is unprofitable to feed a large number of male skunks, therefore when December or January comes, or just as soon as the young males are large enough they should be killed and their skins marketed. 
It is of utmost importance never to permit any of the male offspring of your farm to cohabit with the female; on the other hand seek new bucks every year and take pains that the wild ones are not more than two years old, and that they are strong and robust, and if possible all black furred. All sickly looking male or female skunks should be removed from the others and penned up separately.

Food. There is no reason to feel any anxiety as far as food is concerned, especially when one starts in on a small scale, thus educating himself as to the quantity and kind of food necessary, also feeding time. It is very desirable that the diet be confined as much as possible to vegetables. One should reduce their carnivorous habits to the minimum; probably only once in a week give them meat and even then endeavor to have them eat it cooked or partly cooked in preference to raw. At the same time if you find a rotten chicken or a deceased animal, give them parts of it at such times as in your judgment is advisable that they should have such food. Could hardly expect anyone to cook or bother to cook such decayed flesh. It is also essential not to over-feed the animal, for by so doing they are liable to die over night; on the other hand it is of utmost importance to give them plenty of fresh water. The quantity of food is probably much more important than quality.

The skunk will eat fish, eggs, nearly all kinds of vegetables, fresh or putrid meat of any kind, also bread and milk. The latter should constitute his principal diet after they are educated and become accustomed to it.

Much of the food can be obtained for little or nothing by making arrangements with hotels in the city to keep such leavings separate, also with butcher shops, bakeries, etc. If one should make a habit of visiting such cities every other day during the summer and probably once a week during the winter time, he will be able to obtain all the food that fifty or one hundred skunks require, besides such as he should have in constant supply at home.

Skunks will eat the following articles: Fish, eggs, bugs, birds, fruit, melons, apples, sweet corn, rabbits, chickens, muskrats, decayed meats, scrapings from the table, meat and vegetables in general, and particularly milk and bread. Diseases. Have been unfortunate in satisfying ourselves of
any periodical or known diseases to which the animal is subject. The great danger is from over-feeding; the greatest danger, however, must be avoided by keeping the males away from the females, and whenever the mother is inclined to shun her offspring they must be immediately removed, otherwise 
they will be killed or starved to death. More deaths are traceable to over-feeding and to contact either by the male or female than to anything else.

Time and Manner of Killing Skunks for Market.

In captivity skunks become quite tame and the breeder is often obliged to shove them gently aside in order to pass in and out of the gates. When the weather is real cold, not before December Ist, they can be killed, but it is well to kill one as a sample and if the skin is thoroughly prime others may be picked out for slaughter.

Provide yourself with a long stick to which a wire is attached forming a snare. This should be placed over the animal's head and when the wire is at the proper place, pull it tight around the neck, lift the animal off the ground and in a few minutes he will be dead. Another plan is to take a stick about four feet long to which attach an iron knob. After you have chosen an animal for slaughter, with your stick strike the animal a sharp blow on the head; seldom more than one blow is necessary. Lifift the animal away from the others, either placing it in a sack or small wagon that should be handy for that purpose. It is needless to state the importance of skinning the animal promptly and that the skins should be properly scraped and stretched. Save the fat of the animals, which should be rendered, into clean jars or bottles. The gall and their scent bags should also be saved. The other portions of the body can be gradually fed to the other skunks.

How Farm Should be Fenced.

It is advisable, notwithstanding you have located your farm on an island, that same should be fenced in. Especially is this true if one or two sides are exposed to the water. The proper way to fence a farm of this kind is as follows:

Plow a trench three to four feet deep and four to six feet wide. Set the posts six to seven feet apart in center of trench and at least twenty inches into the ground. The wire netting should be of a close mesh and not of the chicken variety, but the stronger kind used for fencing in pigs, gardens, etc. Dig another trench along the posts which will enable you to place the bottom of the wire at least twelve inches below the level of the ground (fourteen to sixteen inches preferable). After such a fence is made, saw top of fence posts either flat or slanting, upon which nail pieces of two-by-four; under these pieces a thin mesh of chicken wire should be nailed so as to prevent the animal from climbing over the fence. To make it more compact, nail a piece of one-by-four or one-by-six un the edges of the two-by-four extensions. This makes a very durable, com1:-nt fence, over which no animal will 
climb. In making the fence along the creek or lake it is necessary that the posts should be set four or five feet from the shore in the water. The wire need not extend to the bottom, as the skunks are not in the habit of diving, therefore no opportunity is presented whereby the skunk may become liberated.

Amongst the various letters received we have quite a number who have tried skunk farming and have made it a failure. One party in particular who desires his name withheld, started in raising skunks on a large scale, paying $\$ 2.00$ to $\$ 3.00$ for the live animals regardless of sex, and invested a large sum of money

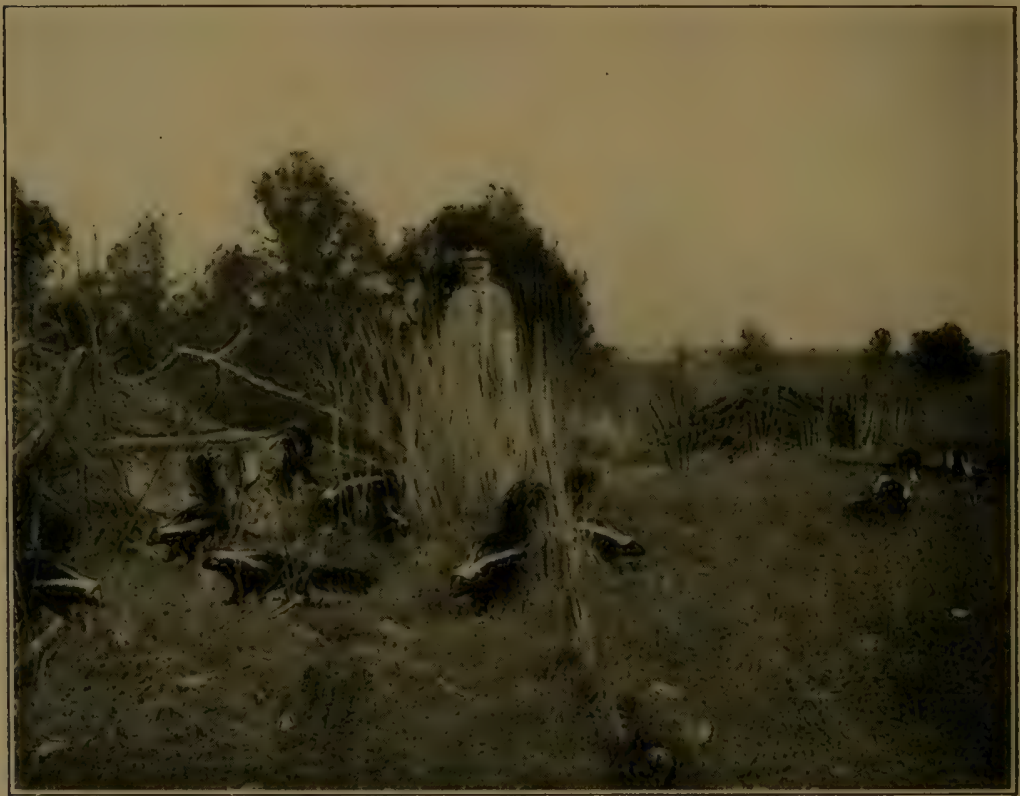

Section of a Skunk Farm

From a Phötograph

in suitable grounds, fences, etc. The chief trouble as related by him was, that skunks did not multiply fast enough and that many died without sufficient cause and some were killed by the others. This party in particular, retained the skunks in a large enclosure, paid no attention to breeding, and probably had as many males as females. The food that was supplied the animals consisted of chickens, deceased meat, principally pork, beef and mutton and at times entire carcasses of young lambs were thrown into the enclosure. This same party writes us that fish made excellent food, but that all food of any nature was cast aside for fowl, 
either chickens, turkeys, ducks, etc. This party gave the skunk plenty of water, having troughs distributed at various parts of the enclosure. He is positive that a great many of the young were killed by the male parent.

It is evident that the above mentioned party had little or no experience, and started in this without due deliberation and as stated in the first part of this article, no one should go into this business unless he likes it, and only then after he has studied the habits and ways of the skunk.

\section{SKUNK FARMING.}

I beg to acknowledge check, and here is my article on Skunk Farming; trust it will be worth the money. I have given you my experience, and hope prospective skunk farmers will be benefited by it. Have had three years' experience in raising skunk.

The first year I started with ten females and two bucks, and I thought that I found the secret of raising skunks, but in this I missed my guess, for when the young were two or three weeks old, they died, or were killed, just which I did not know at that time. All I had left of the increase was twelve young out of the possible sixty or seventy.

I felt discouraged and like giving up, but the fact that the old ones would bring $\$$ I.0O or more next fall and the skins of the young ones just as much, I decided to try again, especially since I had devoted much of my time and spent quite a little money in fencing, etc. The following morning I removed the two females that had their young left and placed them with their own legitimate offspring each in a separated enclosure. No other skunks were permitted therein, and in this way I succeeded in raising eight out of the ten. When the little ones were three months old I let them loose and they did well.

During June I increased the inhabitants of my skunk farm by twenty-six young captured by me in box traps, also got seven old ones. These I divided into four groups. Eight of the young were turned loose, the remaining eighteen were equally divided and placed into separate pens. All seemed to do well. The old ones were confined with the two bucks until such time that J could separate the males from the females. This I did a few days thereafter, and the new bucks, evidently only one year old, were held together in a pen. I was able to still further increase my inhabitants by capturing wild skunks, both young and old, by September I 5 th. During the months of July and August I lost six skunks (four old and two young ones). These evidently died through some disease.

When fall came I had sixty-five to seventy skunks; I was 
getting along nicely but felt I was devoting more time than was necessary or that the possible revenue permitted. Nevertheless, I was much interested and refused an offer to sell out for $\$ 200.00$ and $\$ 25.00$ annual rental for my ground. I turned the offer down and put more energy in the business. During the month of December I killed twenty young and old skunks. From their pelts I realized \$23.00. The skunks I killed were either broad striped or sickly looking, excepting a few of the bucks for which I had no use. The greatest part of this money was spent in wire fencing, and a little lumber.

The season for mating was soon to start. The bucks were separated, each in his pen. I then took ten females and had one buck serve them. The next day I removed the buck from the den and put in another. In this way I was sure of an offspring. The coming May I must have had 350 to 400 inhabitants, and it taxed my capacity to keep each female separate. In fact, I had to devote my entire time to the skunk farm. I had little trouble about the old killing their young. Of course I lost quite a number of young skunks during the summer months; but when fall came I realized $\$ 275.00$ out of the pelts that I sold, and in addition to that $I$ trapped outside so that my net revenue for that winter was between $\$ 425.00$ to $\$ 450.00$, and I had about I50 skunks, most of them females, left on the farm besides.

My farm consisted first of an acre of ground, which I later increased to three acres, and the third year before I quit the business, had six acres all fenced in. My location was an ideal one. I had a regular triangular piece of ground, having a lake on one side and a small creek on the other. As above stated it was all fenced. I used a five-foot small mesh wire fencing, with posts six feet apart. The posts were cut by myself from adjoining timber and were seven to eight feet long. The fence on land was set in center of a ditch, which I made by plowing about three feet deep and about five feet wide. The wire was one foot below the level of the ground and I left part of this ditch filled with water throughout the season. The posts were sawed off even on top, and on each one I nailed a strip of board, Ix6 sixteen inches long on which I fastened a twelve-inch wide wire netting, nailed flat and level with the top. On top of the fence which stood in the water I did the same, excepting that I did not run the wire clear to the ground, but managed to have the wire six to eight inches below the level. On the top the posts were sawed even and the twelve-inch strip of galvanized wire fencing was stapled on the cleats so as to keep the inhabitants from gaining their liberty if they succeeded in climbing the fence. 
As far as food is concerned, the skunk eats most anything, but it is not advisable to give them too much meat. I think animals fed on a meat diet are the ones that kill their offspring. Corn, apples, carrots, and similar vegetables were the chief diet during the summer months. There was an unusually large number of frogs in the ditch, and of course those skunks that were near the fence helped themselves. Every week I arranged to give them some meat, which I procured from the butchers and hotels in the neighboring town. From the adjoining creamery I obtained skimmed milk and I always had a good supply of old stale bread from the town, which I got for nothing. The skunk will eat fish, eggs, etc., besides the vegetables heretofore mentioned, and everything in the meat line, whether fresh or putrid; the latter, however, should be avoided as much as possible. One of the main things is not to overfeed and always have a fresh supply of water for the skunks.

The majority of the skunks were tame and no matter into what enclosure I went I had no difficulty, and only on a few occasions was I unfortunate enough to get a few sprays of their perfume. The skunks soon came to know me, even the wild ones knew me after a few weeks, and I was able to go amongst them with my pails in which I carried the food to them. If I had any occasion to go into their pens not having any pails, I always carried some bits of food, especially meat, which I cut up into one-half inch chunks. When the skunk came about me, I distributed a few of these pieces. When I did not have any pails I always carried a stick and many times was I obliged to shove them aside so as to keep them from getting into or out of the enclosures as I opened the gates. The dirt that I plowed out of the ditch was scraped into large piles in various parts of the farm and into these the skunk burrowed. In one corner of each den I placed a box with two enclosures, which I covered up with earth, probably four to five feet high. I also arranged an opening which enabled me from the outside of the fence to look into their dens direct. Many times I congregated fifty or more females together and I found, much to my surprise, that each one knew their own place of abode, which they entered in the early morning hours. However, there were exceptions; at times when large numbers were congregated, fights ensted and afterwards I never permitted as many to come together.

When fall came I paid especial attention to the feeding of the animals. I also supplied them with more meat and those that did not do well were kept separate and not permitted to mingle with the others. During the first part of December, if the weather was cold and the fur thoroughly prime, I took a small two-wheel 
wagon and four-foot stick, which had an iron on the end, and went into the pens to kill such skunks that I picked out for slaughter. When I came to a skunk that I wanted to kill, I hit it a sharp rap over the head; very seldom was I obliged to give it another rap. I then picked him up and put him in the wagon and continued this practice until the wagon was pretty well filled. I managed to take care of twenty-five skunks a day, and always skinned, scraped the fat off and stretched the skins myself. At first I did not save the glands or the fat; afterwards these were all saved including the galls, from which I obtained quite a revenue.

The question of breeding and the result of inter-breeding does not always bring forth the same species. This reminds me of one particular female skunk that only had a small white star on the forehead and was bred to a black furred skunk, but the little ones were altogether differently furred. Some were short striped, others long striped and only two skunks resembling the father or parent, were in the litter. From my experience am under the opinion that if skunks are bred right, in a period of years the individual species and kind will be perpetuated.

I also obtained bucks from a different section, and if possible larger in stature than my native skunks. New blood, coupled with strong, well-formed bodies of the desired species, and those that are very healthy, are essential, and I further believe that bucks should be changed every year. I never permitted the male offspring to serve any of the females on the farm.

When I sold out last year I had things nicely arranged and by increasing the size of the farm could have had $I, 200$ to $I, 500$ skunks at this time. If I should go into the business again, I should prefer Minnesota, Wisconsin or Michigan, and certainly not further south than Iowa, Ohio or Pennsylvania. The skunks in the north are larger, more robust, and the weather is more favorable to this business. I herewith give you a sketch of the farm as I left it, but I honestly believe the man to whom I sold will not make a success, in fact he and the skunks cannot get along. I am so situated now that I cannot take up skunk farming for a few years. Please withhold my name.

\section{OPOSSUM FARMING.}

Opossum farming is a legitimate business and a profitable one. They have been raised on a small scale as far back as 1873 and in one instance a southern financier raised these for a period of years quite extensively. In going into this business, one should study the habits of the opossum and choose a location that is quite natural and where the wild opossum does well. One not 
having any previous experience, must resist the temptation of going into the venture on a large scale, and like in all other industries, sound and good business judgment must be exercised.

Location. The place should be well situated; have running water and plenty of trees. To retain the opossum in captivity on a large scale requires a heavy expenditure. An ideal fence can be made out of six-foot galvanized wire fencing. The meshes should be close and the posts not farther than six feet apart. The fencing should be at least twelve inches below level of ground. Top of posts should be sawed off slantingly with highest part of incline towards the inside of the enclosure. Upon each post nail a two-by-four, eighteen inches long; upon the under side fasten small mesh chicken wire fencing. After you have squared the inner edges of the strips that are nailed on the posts, nail a one-by-six board clear around the fence perpendicularly so that the protruding edge looks downward. Should one find that the opossum, after climbing the fence, can still get out, a piece of tin nailed on the inner part of this board clear around the fence will prevent him gaining his liberty.

Food. The opossum will eat most any kind of fruit, vegetables, fish and frogs, but his principal diet is meat. He is not particular as to the kind of meat, whether old or fresh. As elsewhere explained, he consumes large quantities of frogs and if opportunity presents, many of the weaker rodents. In captivity he is fed with sweet corn, leavings from the table, melons and fruit and gradually becomes accustomed to a milk and bread diet. A small quantity of meat should be given him every day. This may be liver, lungs or other offals obtained from the butcher. A fresh supply of water is very essential and almost indispensable with the opossum. In addition to this one must be careful and not overfeed, especially the female. By constant feeding the opossum becomes overburdened with fat, extremely lazy, and the female seemingly inclined to shun the companionship of the male during the mating season and quite often no issue results. To du well the opossum must be active and not overly fat.

Propagation and

Breeding.

The male must be kept separate, but there is no objection in placing as. many as twenty females together. After a time they become tame and being of a playful disposition, one can amuse himself by watching their maneuvers in climbing trees, fences, etc. The opossum is very reproductive, but I cannot intelligently describe the manner in which the young are born, as they are retained for many weeks in the pouch, but after three or four weeks begin from time to time to relax their hold on the teats and now and then are occasionally seen to poke their heads outside 
the pouch. A little later on the young venture to steal from their snug retreat in the pouch and are often seen on the mother's back, securing themselves by entwining their tails around hers. In this way she moves from place to place in search of food, carrying her whole family along. It cannot be denied that the mother is much attached to her offspring. She also exhibits a considerable degree of courage, growling at the companions should they approach too closcly, and as a Louisiana gentleman, who has experimented in raising opossums for the last tivo years, states, "that it is quite essential to keep the fenlales separate as much as is possibie when the mother with her young begin to inhabit the enclosure regularly." The same gentleman states that during the period of gestation up to the time the young are able to take food independently of the mother, she should be provided with an abundance of gool, wholesome food and water; as during this period the mother becomes very lean, due to her giving sustenance to so large a family.

At this period the enclosure can be very small, as there is little danger that the female will endeavor to escape. Each female should have a separate abode. This can be a hollow log or box; if the latter it should be covered up with ground so as to be cool, and if consistent large quantities of brush should be thrown in the enclosure and about the abode so as to resemble a natural haunt. One reason for having many trees in the enclosure is for the purpose of having the animals exercise themselves.

The opossum can probably be raised more successfully in a smaller enclosure than can the skunk. It is only a question of time when the raising of skunk, opossum, mink and fox will become more extensive, and those who have the proper location and devote considerable time and patience to this industry, will be able to make it remunerative. The foundation of any business should be started on a small scale and increase gradually. The business is such that one can make a good living and in connection with such a farm, a good garden should be cultivaterl, partly for home consumption and the remainder to be marketed. One must not forget that the revenue derived from opossum farming is not alone from the pelt, but the meat is salable, especially in the larger cities.

\section{MINK FARIING.}

Mr. Schultz, a Canadian trapper, has lately tried mink raising with fairly good success. He writes as follows:

I have chosen a place in which there are four large oak trees and on the side of a small rivulet. The size of the enclosure is about 100 by 140 feet; I had this all fenced in. I was careful in making the fence; I took eight-foot poles and set them three 
feet in the ground. I then dug out a trench six inches wide between the posts and inserted twelve-inch boards on each side and filled this up with stones over which I poured cement. The cement I made out of five parts coarse sand and one part cement, well mixed. The inner board I left in the ground and upon this I nailed the lower portion of the five-foot high, thin-meshed wire fence. The posts were five feet apart, the top sawed off slantingly four feet and ten inches from the ground. On the posts I nailed boards six inches wide all along the fence. On top of these boards and immediately over the posts I nailed eighteen-inch long pieces of two-by-four, pointing inward to the enclosure. I was very careful that the inner edges of these strips were even. After this was all completed I started to nail the wire fencing on the posts, also on the board that was sticking twelve inches in the ground and as the wire was three inches wider than the length of the posts, I had sufficient for a lap which I bent and sccurely fastened on the six-inch top rail board. After this was completed I procured eighteen-inch wide, close-meshed chicken wire fencing which I nailed on the inner part of the two-by-four strip, finally finishing the enclosure by nailing a six-inch board on the edges of the two-by-four, so that the four inches clear pointed perpendicularly into the fenced field. I have not found a mink that would get out. This six-inch board keeps them from getting on top of the over-lnanging wire. The fence is so strong that no matter what kind of a wind comes along, it will withstand it. Of course the mink try to get out through the meshes and often succeed in twisting the meshes with their mouths.

I sub-divide this enclosure into smaller ones, but am not so careful in the construction of these thinner fences as I am on the outside one, with the exception of where I keep the male minks; this is made equally as good. Last spring I started with six large females, one large buck and thirty to thirty-five young cubs. One of the females disappeared and even to this day I do not know what became of her. The females were placed in two separate enclosures and the buck was fenced up all by himself. For the greatest part of the time until fall the young were put altogether, but at that period I found they were fighting considerably and I was obliged to separate the males from the females. This necessitated my putting the large females together into one pen so as to he able to have a place to receive the twelve young male minks. The season passed without any of them dying off. During the fall I was able to increase my holdings by capturing in a box trap another female.

I fed the mink almost entirely with meat and to those away from the rivulet I carried two pails of water every day and during 
the summer months four pailfuls each day. In the intermediate time I also fed them with milk, bread, fish, etc.

I dug a deep hole into which I placed a box, having one partition in the center with an opening through which the mink could travel. After setting this in the ground I made it fairly level, excepting the box which protruded about ten inches above. Over this I carried a large pile of brush, using care to leave a small opening through which the mink could get into the box if they so desired. A large part of the time was employed by the mink in climbing trees. On one occasion I fed them with live perch. These I permitted to swim in their troughs, but just as soon as I was absent the mink came eagerly to the trough, evidently smelling the fish. Watching them from a distance, it appeared to me, that they acted just as hogs do in grabbing for food. Evidently they did not use their paws but grabbed the fish with their mouths.

During the latter part of December I killed nine of the young bucks. The skins were pretty fair but not as well furred, nor were the guard hairs as perfect, as on those that $I$ caught in the wild state. However I realized the same price for them.

When mating season came, I obtained a large number of wild females, also three males, which I dug out of their dens and put into two enclosures. Knowing the habits of the animal, I prepared additional abodes for the females. I then went to work and placed a buck in each pen where the females were and left them there a few days. I changed the bucks every other day and in about ten days put the bucks in their enclosure. Not wishing to keep the old bucks for a longer period, I killed them and sold their skins and realized a fair price. The season progressed fairly well and I have had no particular trouble except once in a while a few fights. During May each female brought forth from three to five young, with the exception of one which did not become pregnant. You can readily see that I had my hands full then. I expect that these will summer through all right and when next winter comes I will have at least fifty to kill besides, retaining seventy-five or more young and old.

Had I permitted the males to remain with the females after they had their young, I am sure the latter would have been killed. Have not observed any particular disease, and as a matter of fact do not see the mink very much during the day time unless in the early morning or towards evening, when they get on the trees. Many times I observed when one or more birds had lit on the trees, especially the larger kind, one or more of the minks would sneak towards the trunk, gradually climb up and try to capture the bird. In this they are quicker than a cat and probably more successful. 
I make a habit of setting wire rat traps near the stables in which I capture house rats. Having succeeded in capturing one, the door is opened and the rat jumps into the enclosure, and in a few moments one of the minks will grab it by the neck and carry it away. Think that a large house rat stands less show of getting away from a mink than from a house cat.

In killing the mink I find that a small 22 calibre rifle is sufficient. In fact a good air gun would kill them; of course I can get within a few feet of the mink and the bullet must strike side of the head; otherwise the small $\mathrm{BB}$ shot would not penetrate the skull.

\section{Mink Farm.}

I give you my successful method of domesticating and raising the mink. Also how to capture the old and young so as to get a start.

The time to secure the young mink is in May or June when they are beginning to run with their dams. The stream along which they run must be quietly watched until you have located their trail and tracked them to their den. When you have located the den, you must be careful to capture or kill the old one first; otherwise she will carry them away. Either proceed to dig them out or capture them in box traps.

A successful breeder stated to me that he does not attempt to tame the wild animals, but only aims to supply them with such necessities as are required. The food, as we all know, consists chiefly of fish and meats, and especially the meat of the muskrat. The mating season begins the first of March and lasts about two weeks, never varying much from that date in any one locality. The female carries her young about six weeks. In the minkery, where the diet, water and conditions in general are more even, the mating season is more periodical, and in consequence the young of the different females are born the same day, or at farthest a day apart. One party who had six females stated that the young were born within twelve hours. The young are blind from four to five weeks, but very active and playful as kittens. The mother weans them from eight to ten weeks; after four weeks the mother begins to feed them meat which the young suck until they have teeth. The nest is made in some old stump or hollow $\log$ and is nicely padded out with soft materials and always in a locality where the nest will remain dry. I have seen the mother remove the young from the nest for the simple reason that the nest had become foul ; she finds another suitable place in which the young are deposited, she carrying one at a time in her mouth. The mother will care for them until they arc three and a half to four months old. There are usually four in a litter. 


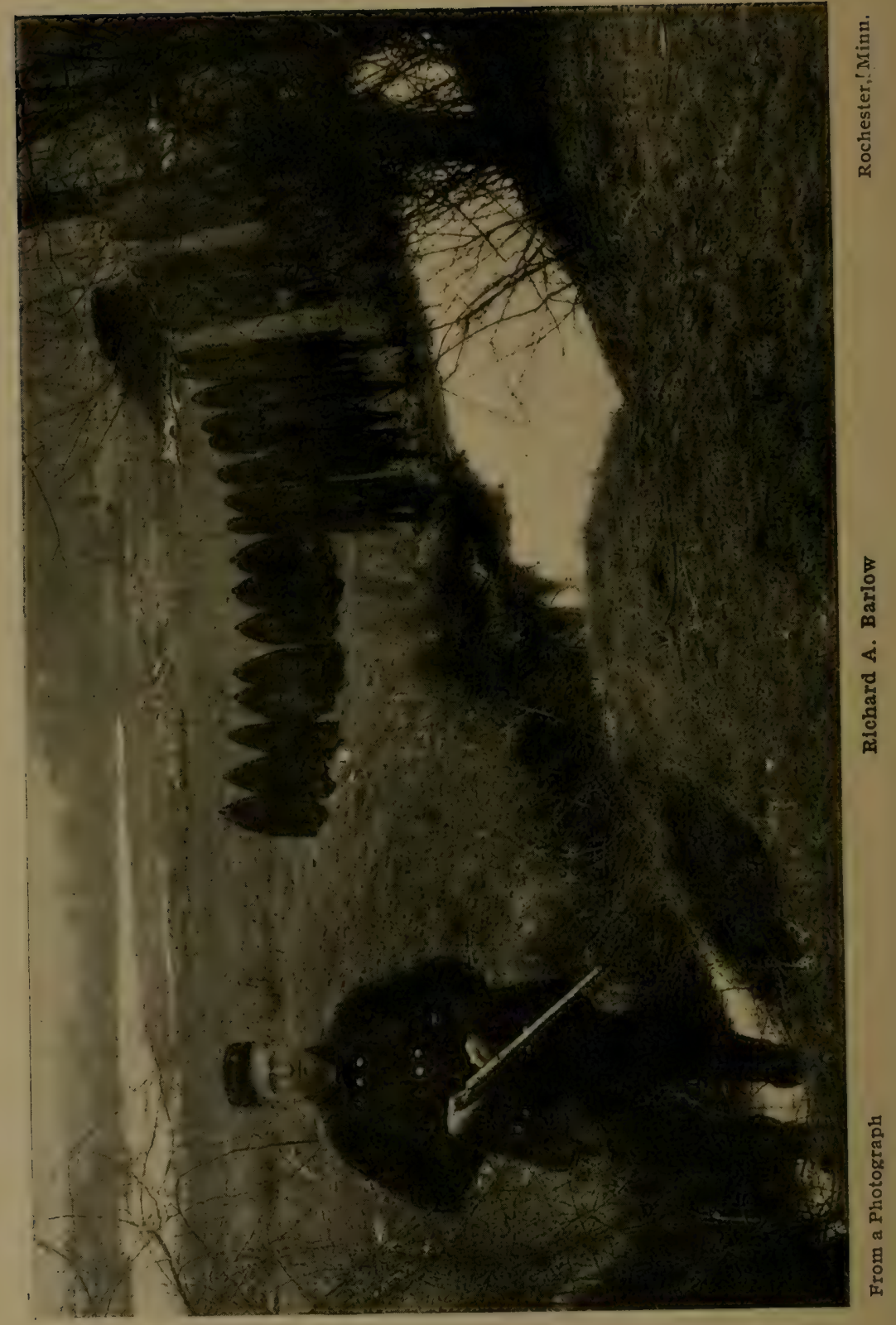


Towards fall the mother separates them into two pairs, or if the number be odd, the one is left in the nest and the other pair or pairs are placed half a mile from each other and she decamps and looks for them no more; on the other hand gets a different abode altogether.

When the young are six weeks old they should be taken from the mother and put in a pen by themselves. After a few days they become accustomed to their surroundings and begin to play. The inner she!ter should be in a box five to six feet wide and three to four feet high, somewhat raised from the ground. The box should contain at least one partition with openings through which they can enter. This box should be placed within a thin meshed, but strong enclosure. On top of the posts boards should be nailed so as to over-reach at least fifteen inches from the fence. If you find that the mink is likely to get away by getting his claws into these boards, line then with tin underneath. The pen should also contain a large trough which can be made by nailing three boards together. Have one side of the trough higher than the other so that the aninal can get into the water if it wants to. It will also enable you to draw the water off as often as desired. Each enclosure should contain a small box in which the animal can be driven and shut up during the time the pen is cleaned.

It is quite necessary to have an abundance of pure soft water, also plenty of shade. This can be obtained by bringing the enclosure below a tree or to have parts of the trunk of the tree inside the enclosure. Unless the mink has a shady enclosure the fur will be pale and not become dark.

A quart of milk once a day with some wheat bread broken fine in it, is sufficient for twelve to fifteen minks, but each mink should liave some meat besides the above mush, at least once a day. In captivity one must keepp the male away from the female most of the time, and especially after the young are born, as the buck will kill the young if he gets a chance.

June 3 , I906.

Louis SHoOK,

Sperratd, W. Va.

\section{FOX FARMING.}

The fox can be successfully raised in captivity; this has been demonstrated numerous times and with satisfactory results; no less than fifteen farms are in operation, or were during 1905 .

To obtain definite and inside information from the most successful breeders is hard to do; those that raise black, silver and cross foxes for their pelts, are close-mouthed, resulting in little information from such sources. Another reason is that the farms are located in some obscure part of the country, many in Canada, Alaska and on islands in the Pacific ocean. 
Near Edmonton there resides an old man who has devoted ten years or more to raising the silver fox. On being approached, he disliked being communicative, especially since the information was to be published. The following is the essence of his explanations:

The silver fox can be raised in northern climates, but must not be confined in any unnatural enclosure. No attempt should be made to tame the silver fox as he cannot be tamed in a period of years unless forced to live in some artificial abode when the skin would have little or no value.

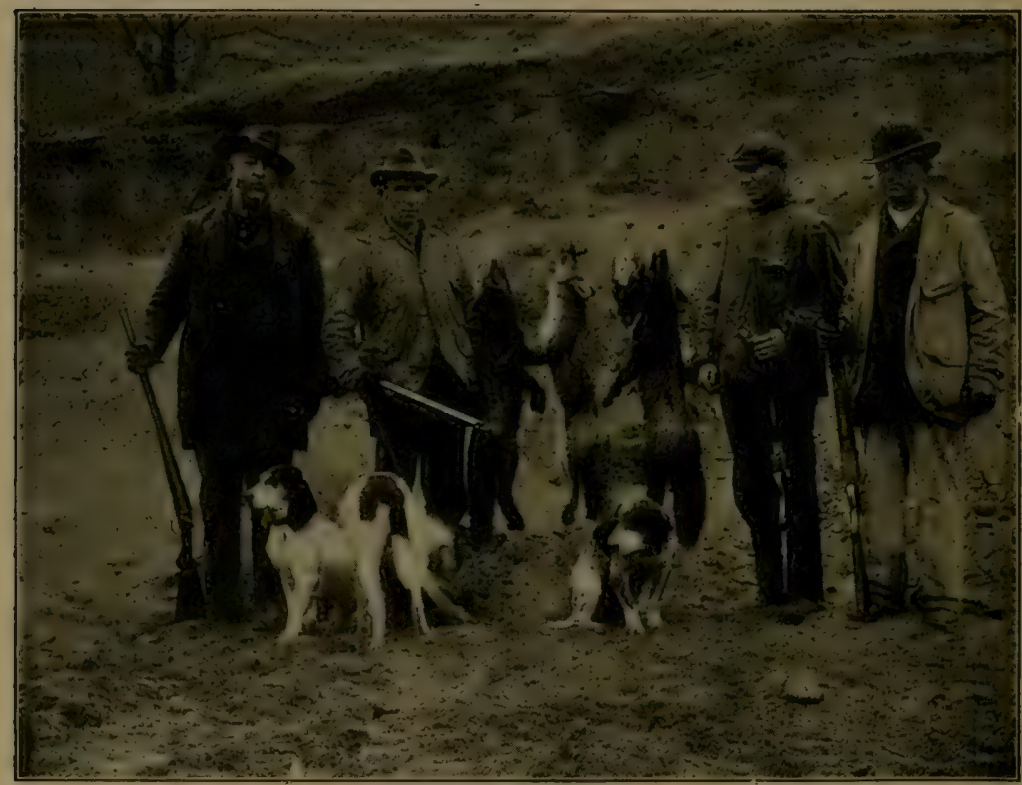

Time Well Spent

'Silver, Cross and Red Fox

From Nat'1 Sportsman

His farm was on an island of 400 to 500 acres and that was much too small in his opinion. He declined to state where his farm was, but recommended any small uninhabited island off British Columbia or Alaska, in the Pacific ocean. His reason was that the fox taken there cannot get away as the salt water does not freeze. Islands between the Slave Lake and the Great Slave Lake in the Northwest Territory are also good, but one must drive the fox, when extreme winter sets in, into some large fenced enclosure; otherwise they will escape off the island.

The fox should not be molested in the least. In fact, avoid them as much as you can. Do not let them know of your exist- 
ence. Do not hunt, or try to see how they are getting along; let them go it alone. Let them depend upon the food of the island, but if you find that game is getting short and food scarce, give them fish and meats of various sorts which place in some conspicuous part where the foxes are likely to come up to it. Fish and fat in connection with some flour boiled together, makes good food for the fox. Always have a supply of dried fish, venison and rabbits stored for them, so as to provide them with food during a severe storm.

As to raising them he had little to say. "Let them $\because$ : it alone," was his favorite reply. Nevertheless when the pelts viure prime he took pains to kill only the males. He also imported two or three male foxes from the mainland every year, which he captured in dug-outs, besides females, if they were of the right kind; otherwise he killed them for their pelts.

His ideas relative to the various species and uneven results from breeding, also manner of breeding, were different from those observed by others up to date. "Let them have their natural way; disregard as to whether there are more males than females. They will mate themselves, and if they do not, you should not be the wiser. The more you try to find out the less you will know," and other similar answers were given to questions. Never kill a fox for his pelt until he has passed a part of his second winter. Kill the off-colored ones first; do not let them breed with the black or silver.

Summing up in substance he believed that the silver fox can be domesticated but that in so doing one must give them a wide strip of territory in which to travel and not molest them in any way. He had an idea that no different or like results can be obtained in breeding so as to result in one species right along until a period of years has elapsed, when all off-colored specimens were removed and kept separate, so that no other male would have access to the female at any time of the year. He also thought that the silver and cross fox were not a true species, but the result of interbreeding between the red and black foxes.

Silver fox breeding has not been successful on an island in the upper Mississippi river, probably for the reason that the fox decamped during the winter time. Some returned, others did not.

The silver and cross fox are bred in numerous parts of islands off of Alaska and British Columbia, also on some of the islands along the Alaskian peninsula and off the mainland between Dixon sound and Cook inlet. It is claimed that silver and black foxes are domesticated on the numerous islands north of the Hudson Bay and west of Baffin Bay. 
Would not recommend anyone to try to raise silver and cross foxes even in Minnesota, unless in the extreme northern part of the state, probably in the vicinity of the Lake of the Woods, or along Rainy River, Rainy Lake and to Port Arthur. Undoubtedly the mountainous regions in the western part of Ontario are very suitable, due to the numerous lakes, and -very likely islands of sufficient size can be found where the fox undoubtedly would thrive.

Red foxes like the wolf, can be domesticated with ease, but the skins usually are of little value due to their being badly rubbed; but if the animal is not confined to a small locality but permitted to roam at will, the fur does not become matted and rubbed, consequently the skin brings a fair price.

\section{THE LETTERS BELOW REPRODUCED ARE SELF-EXPLANATORY.}

Note-Letters Were Written Five Years Ago.

Mr. M. L. Washburn, Minneapolis, Minn., May 7 th, Igor.

Manager Semidi Propagating Co., Dear Sir:Kodiak, Alaska.

We have more or less inquiry as to the manner of breeding, mode of living and the general character, behaviour, etc., of cross, silver and black foxes, and are often in the dark as to the corect answers.

We handle roo to 500 cross, silver and black fox skins every year and we draw our supply chiefly from Canada, therefore, are thoroughly conversant with the valuation of such skins and the general use same are made of both here and in Europe.

As you have had long experience and are familiar with the manner of breeding, etc., will you kindly favor us with such information to clear our minds of the uncertainty. Some of the following questions are often asked us. IVill you kindly favor us with correct and proper answers?

Can silver, cross or black fox be successfully raised in captivity?

What kind and how many foxes have you?

On what do the foxes live?

How do they retain their identity if living together, that is silver, cross and black foxes? Or are they kept apart? time?

How often do foxes bear young ones and how many at a

Do you know the respective relation of a silver fox to a black fox or are they entirely distinct species? 
Is a cross fox the result of breeding between a common red fox and silver or black fox?

For what purpose do you raise the animals?

Do you raise them for the pelts entirely or do you sell them alive, and if you do, how much do you offer them at? Any and all information that you can favor us with will be cheerfully received and we shall certainly feel under obligations to you.

Should you desire any information pertaining to the fur trade, or any other industry located in the Northwest, we shall be pleased indeed to answer any and all such questions in our power.

You will, herewith, enclosed find stamped envelope. Kindly favor us with a prompt reply. We are,

$$
\text { (Signed) "ANDERsch Bros." }
$$

\section{SEMEDI PROPAGATING CO.}

Andersch Bros.,

Minneapolis, Minn.

Kodiak, Alaska, July 29th, I90I.

Gentlemen:- We have to apologize for the delay in answering your favor of May 7 th, as the writer was absent at the time and the letter avaited. his arrival. Having been in the fox propagation for fully fourteen years, - and during that time it has assumed considerable proportions-we are still at a loss to answer many of your questions as we feel sure you would like them answered.

Question No. I. We are free to confess that with us the silver and black fox have never been successfully raised although some of the members of our company have and are successfully raising them in the east.

Question No. 2. We are now raising the blue fox exclusively on the islands of North Semedi, South Semedi, Ukamok (or Cherikoff), and Long Island, also Whale Island, and at a rough guess, after the usual precaution of marking and killing has been taken, it is safe to say we have in the vicinity of six thousand foxes.

Question No. 3. Besides the food that nature provides in the way of "beach wash" and bircls, the artificial food furnished them is of a varied sort-dried fish, salt fish, fresh fish (in localities where it can be had), corn meal, tallow, salt sea lion and whale, etc., etc.-although the best food has been found to be a sort of mush made from corn meal and tallow with dried fish for the breeding season when they can't transport the mush to the burrows for the young or the female who always stays by the young for several days, being supplied by the male fox at such times. 
Question No. 4. We have never allowed them to run together, as they are so closely allied that they would easily lose their identity, that is, they would interbreed until neither of the original bloods remained, or at least we are led to believe so from what we have observed and read.

Question No. 5. Foxes breed once each year, begininng about February Ist to mate, and bearing young in early May and June. They have been known to have as many as ten young in one litter, but three to six is the usual run.

Question No. 6. The silver fox is said to be a cross between the Arctic or white fox and the black, the cross fox tc be a cross between the black and red fox.

Question No. 7. We raise the foxes for their pelts, but are also willing to sell them alive, holding them at \$IIO.OO per pair at owner's or purchaser's risk in shipping. A better rate might be made on any number of them by writing the secretary of our company on the subject (the officers of which will be found below).

Fox raising in general has become a great industry, and while in its infancy as yet, it bids fair to become a profitable one. The islands used for the breeding of foxes are leased from the government, and prior to the passing of the homestead act for Alaska, were exempted for the sole purpose of the industry, that is, all islands leased prior to 1898 . Any further information in our power will be cheerfully given.

Signed Very truly yours, "Semedi Propagating Company. "A. C. Goss, Manager."

\section{Fox Farming in Alaska.}

The following is an extract from the Governor's report of Alaska to the Secretary of the Interior:

"This is being tried at many places. Most of those who are trying it confine their efforts to the blue fox. Those who are trying the black and silver fox have not met with much success. The habits of this animal seem to defy domesticity. The blue fox is more easily dealt with. They do fairly well upon the Pribilof Islands. This last season 232 were taken up on St. George. $\mathrm{Mr}$. Applegate, of Unalaska, has succeeded better than anyone else. The skins, which he sent to London, were the best and brought the highest price. His ranch is west of Dutch Harbor, near Umnak Island. Some of those who are experimenting in this business feed the foxes and ship in tons of meal and other food. It is quite certain that the same care and energy given to the stock raising would bring in sure and richer returns to most of those who are engaged in it." 


\section{How to Obtain a Copy of the STATE GAME AND FISH LAWS}

of the Variuus States and Territories.

STATE AND NATIONAL GAME AND FISH LAWS are subject to changes from year to year and for this and other reasons it is advisable for to hunt.

DEER, ELK, ANTELOPE and similar animals are protected in all States and can only be legally killed for a short period in each year.

FUR BEARING ANIMALS, excepting Beaver and probably a few other animals, can be be legally killed during the winter season in most all States and Territories as very few animals are protected by law, and the skins of such animals legally captured can also be shipped out of the State.

BOUNTY is paid for the capture of Bear, Lynx, Wild Cat, Wolf, Cougar, Mountain Lion and other ferocious animals in nearly every State and Territory, and sometimes by individual counties. The payment of these GEESE, regulated by law.

protected and the killing regENS, GROUSE and other feathered birds are protected and the killing regulated by law in all States. The Game Laws in to kill such birds, or having possession for the killing, capturing or intention LICENSES ar, or having possession of same out of season.

game. Fur bearing animals in nearly every State for hunting birds and high game. Fur bearing animals can be legally trapped in most all States and no license is required. The privilege of hunting can be had by residents for 25 c. to $\$ 1.00$ and up. Non-residents are usually compelled to pay $\$ 5.00$ to $\$ 25.00$, and in certain States non-residents are debarred by law from hunting. laws varying GAME OR HIDES out of the State is regulated by law-the selves before offering nearly every State-and Hunters should familiarize themselves before offering Game for. shipment. Deer skins can be legally shipped Fur skins most States during the season if accompanied by a License coupon. Fur skins can be shipped in and out of the various States though some exception is made to such skins that come from animals that are illegally
captured.

COPY OF THE GAME LAWS in pamphlet form can be had by applying to the Governor of the respective State or by addressing the State Game and Fish Warden or the State Game and Fish Commissioners at the Capitol of the State or Territory. The U. S. Government issues in pamphlet form the tional Laws. The information tates carefully tabulated, as well as the Naprehensive and complete, and contained in these bulletins is very comown State, should procure one of these bulletins. Licenses required, how Licenses are obtained, and It gives the Game Laws, can be legally shipped and other valuined, and price of same, how Game of these bulletins should write to the U. D. C., requesting the latest to the U. S. Dept of Agriculture, Washington, various States and Territories in the United States. the Game Laws of the

A Copy of the State Gatories in the United States.

The Governor, of the respective State at the had by addressnig His Excellency, addressing the following officials:

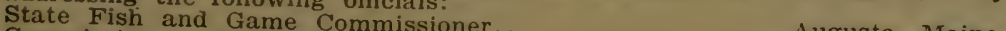

Commissioner of Fisheries and

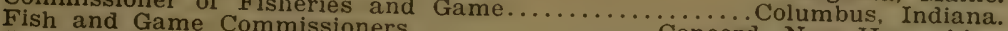

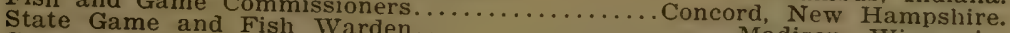
Game and Fish Wa.

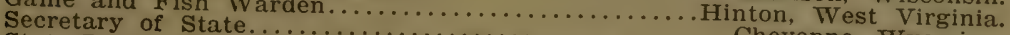

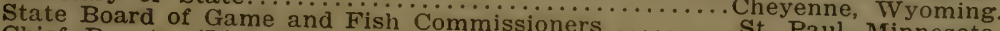
Chief Deputy (Lincoln) Fish Commissioners ............... Paul, Minnesota. State Game and Fish Commissioner. Hatcheries.... (South Bend) Nebraska.

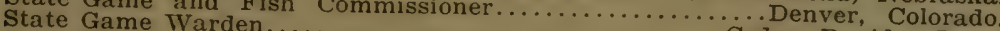

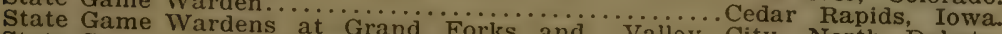
State Game and Fish Commissioners and... Valley City, North Dakota.

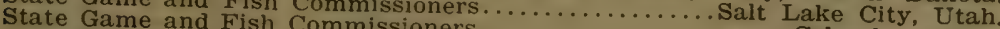

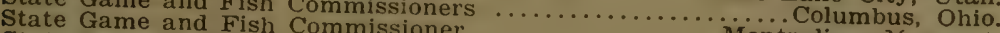
State Game Commissioner.

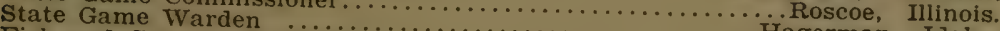

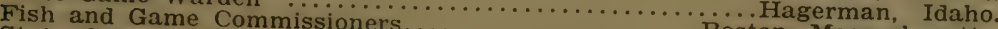

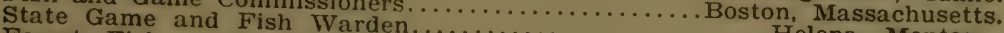

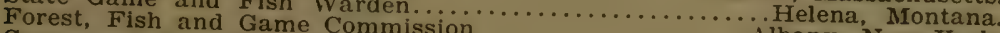

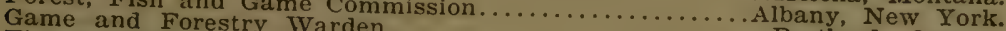

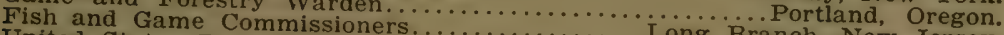
United States Department of Agriculture.......................... Branch, New Jersey. Game and Fish Warden... of Agriculture.............Washington, D. C. 


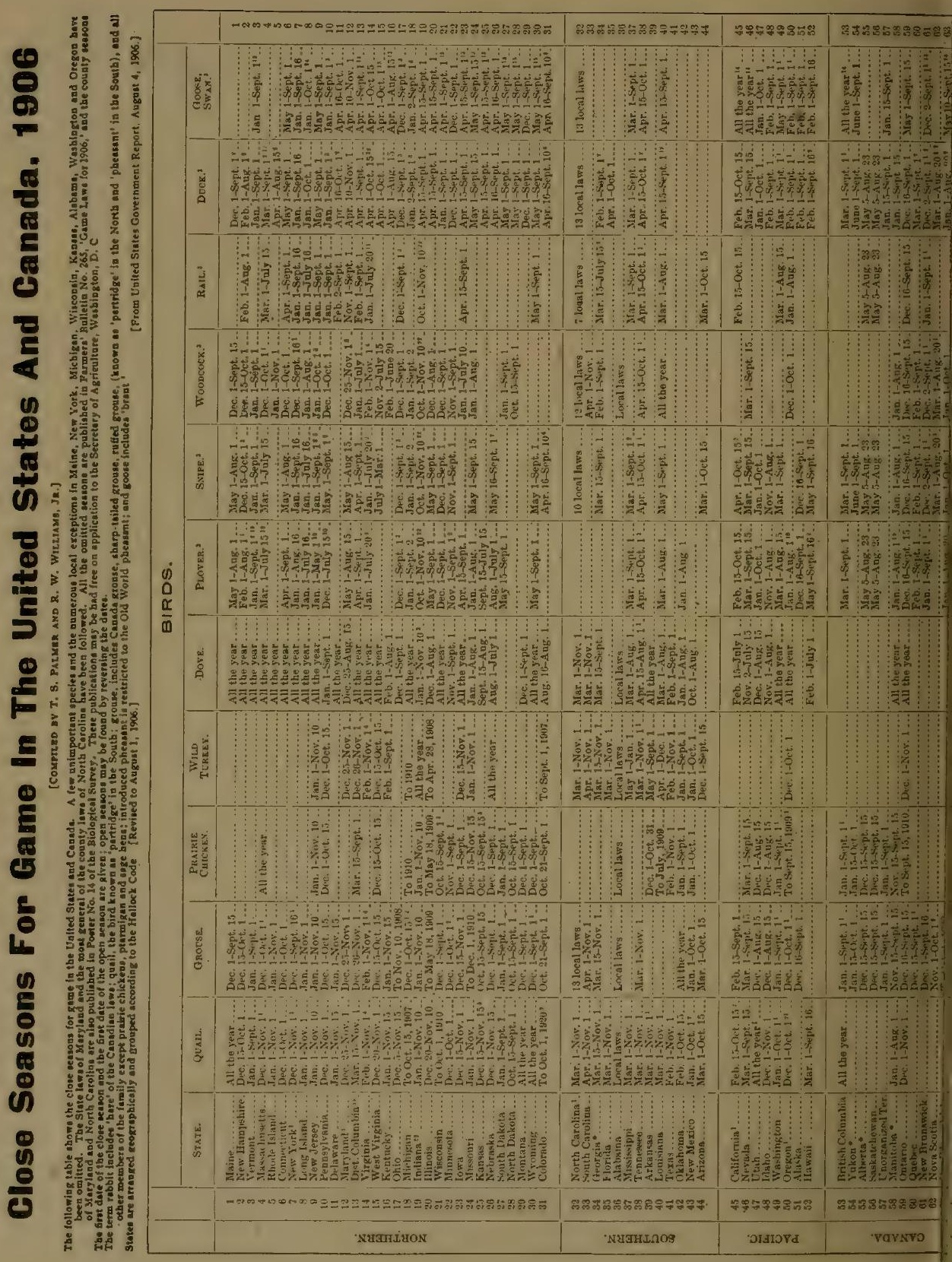




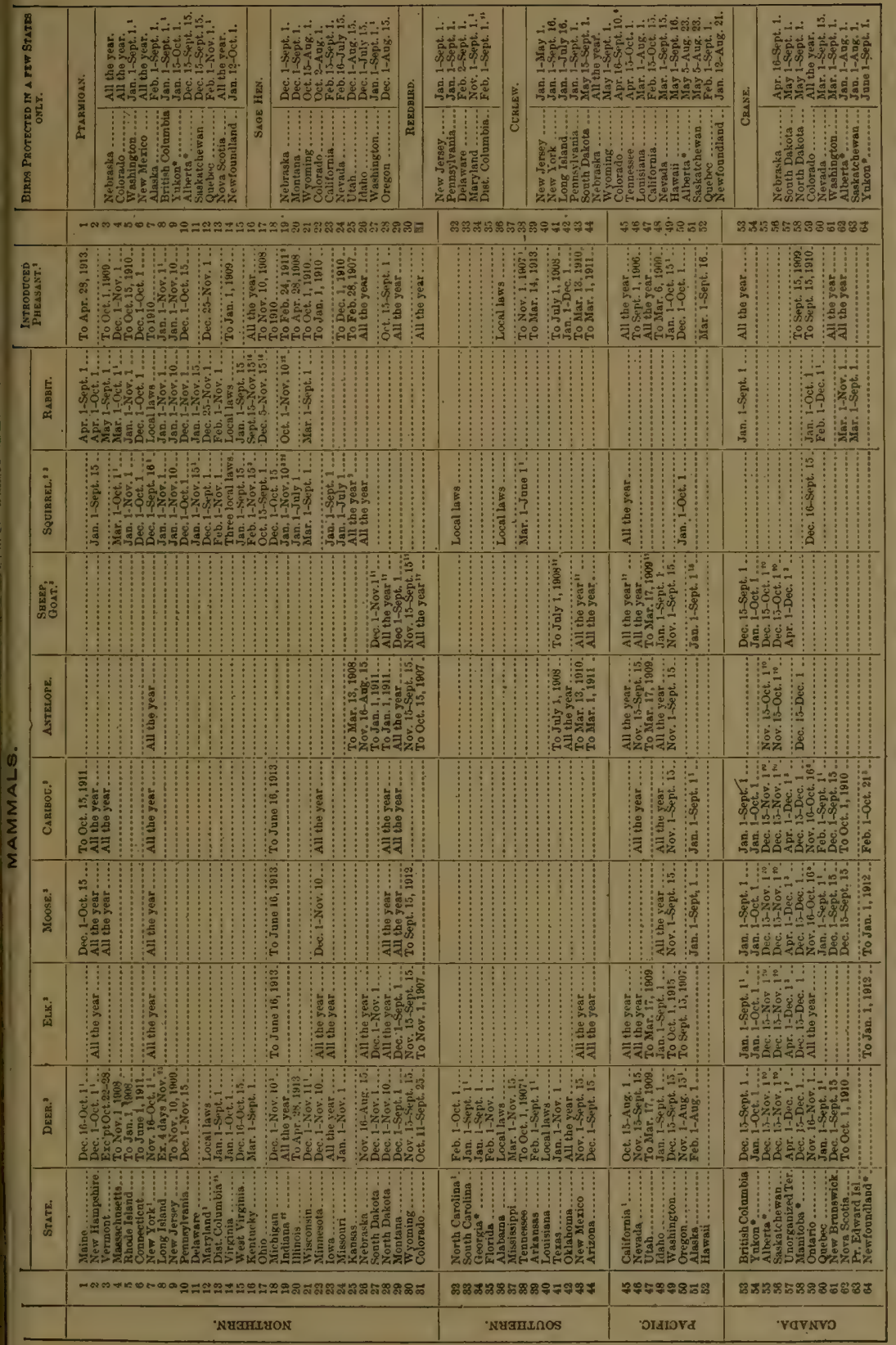

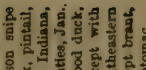

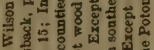
E. i.

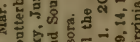

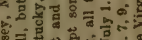

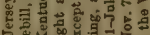

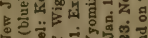
\%

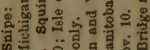
\&苛 过

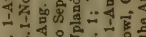

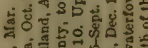

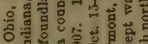

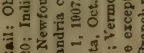

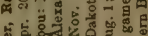

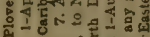

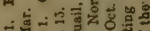

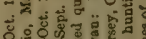

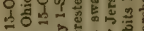
열

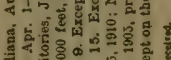

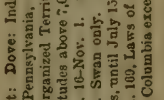

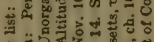

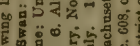

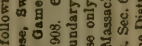

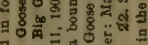

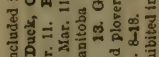

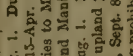

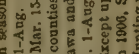

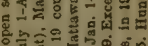

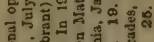

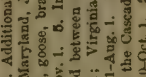
कि

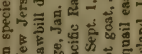

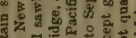

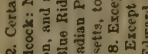

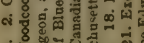

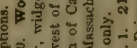

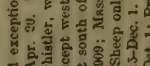

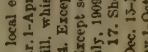

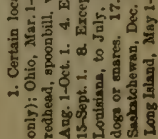




\title{
UNITED STATES GAME LAWS
}

\author{
THE LACEY ACT.
}

\author{
31 Statutes at Large, pp. 187-189.
}

CHAP. 553.-AN ACT to enlarge the nowers of the Department of Agriculture, prohibit the transportation by interstate commerce of game killed in violation of local laws, and for other purposes.

$B e$ it enacted by the Senate and House of Representatives of the United States of Amcrica in Congress assembled, That the duties and powers of the Department of Agriculture are hereby enlarged so as to include the preservation, distribution, introduction, and restoration of game birds and other wild birds. The Secretary of Agriculture is hereby authorized to adopt such measures as may be necessary to carry out the purposes of this act and to purchase such game birds and other wild birds as may be required therefor, subject, nowever, to the laws of the various States and Territories. The object and purpose of this act is to aid in the restoration of such birds in those parts of the United States adapted thereto where the same have become scarce or extinct, and also to regulate the introduction of American or foreign birds or animals in localities where they have not heretofore existed.

The Secretary of Agriculture shall from time to time collect and publish useful information as to the propagation, uses, and preservation of such birds.

And the Secretary of Agriculture shall make and publish all needful rules and regulations for carrying out the purposes of this act, and shall expend for said purposes such sums as Congress may appropriate therefor.

IMPORTATION: Sec. 2. That it shall be unlawful for any person or persons to import into the United States any foreign wild animal or bird except under special permit from the United States Department of Agriculture: provided. That nothing in this section shall restrict the importation of natural history specimens for museums or scientiflc collections, or the importation of certain cage birds, such as domesticated canaries, parrots, or such other species as the Secretary of Agriculture may designate. $a$.

PROHIBITED SPECIES: The importation of the mongoose, the socalled "flying foxes" or fruit bats, the English sparrow, the starling, or such other birds or animals as the Secretary of Agriculture may from time to time declare injurious to the interest of agriculture or horticulture is hereby prohibited, and such species upon arrival at any of the ports of the United States shall be destroyed or returned at the expense of the owner. The Secretary of the 'Treasury is hereby authorized to make regulations for carrying into effect the provisions of this section. $b$

SHIPMENT: Sec. 3. That it shall be unlawful for any person or persons to deliver to any common carrier, or for any common carrier to transport from one State or Territory to another State or Territory, or from the District of Columbia or Alaska to any State or Territory, or from any State or Territory to the District of Columbia or Alaska, any foreign animals or birds the importation of which is prohibited, or the dead bodies or parts thereof of any wild animals or birds, where such animals or birds have been killed in violation or the laws of the State, Territory, or District in which the same were kilied: Provided. That nothing herein shall prevent the transportation of any dead birds or animals killed during the season when the same may be lawfully captured, and the export of which is not prohibited by law in the State, Territory, or District in which the same are killed.

MARKING PACKAGES: Sec. 4. That all packages containing such dead animals, birds, or parts thereof, when shipped by interstate commerce, as provided in section 1 of this act, shall be plainly and clearly marked, so that the name and address of the shipper and the nature of the contents may be readily ascertained on inspection of the outside of such packages.

PENALTIES: For each invasion or violation of this act the shipper shall, upon conviction, pay a fine of not exceeding $\$ 200$; and the consignee knowingly receiving such articles so shipped and transported in violation of this act shall, upori conviction, pay a fine of not exceeding $\$ 200$ : and the carrier knowingly carrying or transporting the same shall, upon conviction, pay a tine of not exceeding $\$ 200$. 
Game Laws-Continued.

IMPORTED SPECIES SUBJECT TO LOCAL LAWS: Sec. 5 . That all dead bodies, or parts thereof, of any foreign game animals, or game or song birds, the impcrtation of which is prohibited, or the dead bodies or parts thereof, of any wild game animals, or game or song birds transported into any State or 'Territory, or remaining therein for use, consumption, sale, or storage therein, shall, upcn arrival in such State or Territory be subject to the operation and effect of the laws of such State or Territory enacted in the exercise of ils police powers, to the same extent and in the same manner as though such animals or birds had been produced in such State or Territory and shall be not exempt therefrom by reason of being introduced therein in original packages or otherwise. This act shall not prevent the importation, transportation, or sale of birds or bird plumage manufactured from the feathers of barnyard fowl. Approved May 25, 1900.

a On September 13, 1900, the Secretary of Agriculture (Circular No. 30, Biologic:al Survey) extended the list of species which can be imported without permit, as follows:

Ilammals.-Anteaters, armadillos, bears, chimpanzees, elephants, hippopotamuses, hyenas, jagaurs, kangaroos, leopards, lions, lynxes, manatees, monkeys, ocelots, crang-utans, panthers, raccoons, rhinoceroses, sea-lions, seals, sloths, tapir, tigers, or wildcats.

Birds.-Swans, wild doves, or wild pigeons of any kind.

Reptiles,-Alligators, lizards, snakes, tortoises, or other reptiles (except in Hawaii-see Circular No. 36, Biological Survey, issued May 22, 1902.) $b$ See Circular No. 101, Division of Customs, issued June 28, 1900; for regulations of the Department of Agriculture see Circultr No. 29, Biological Survey, issued July $13,1900$.

TABLE SHOWING WHAT RAW FUR SKINS ARE TO BE CUT OPEN OR LEFT CASED. WHETHER FUR OR FLESH SIDE OUT. ALSO ADDITIONAL, REMARKS INDICATING COMPLETENESS OF SKINS AS

DESIRED BY THE FUR TRADE.

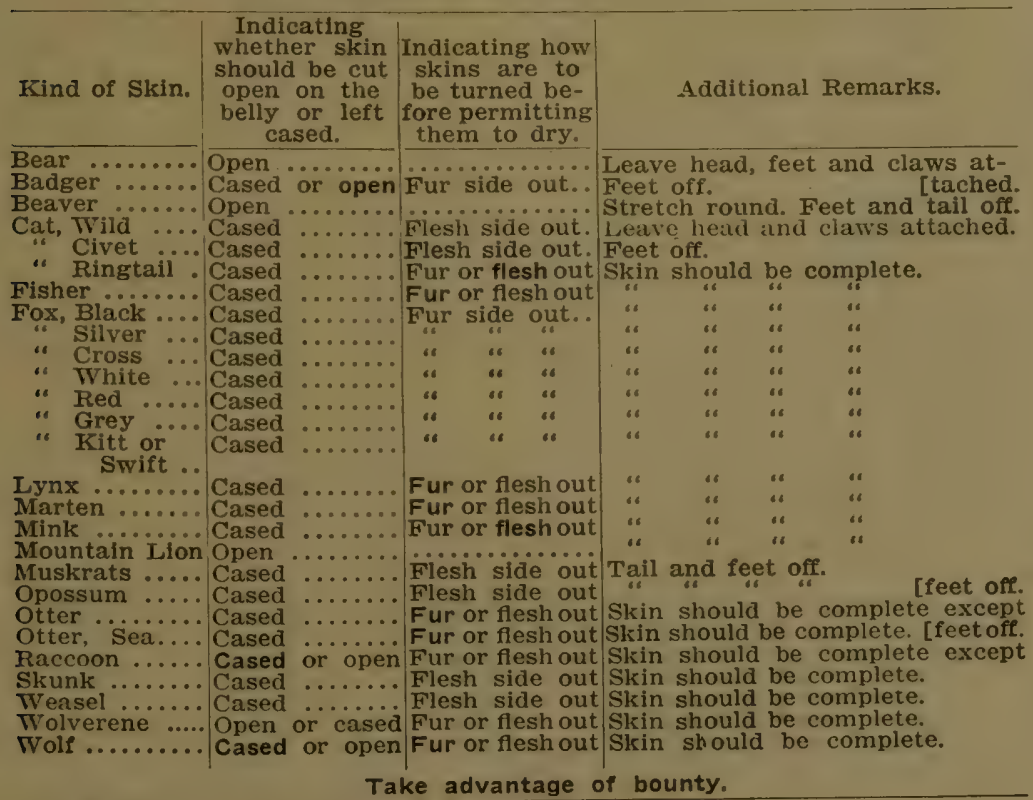

Preference, if any, denoted by heavier type. 


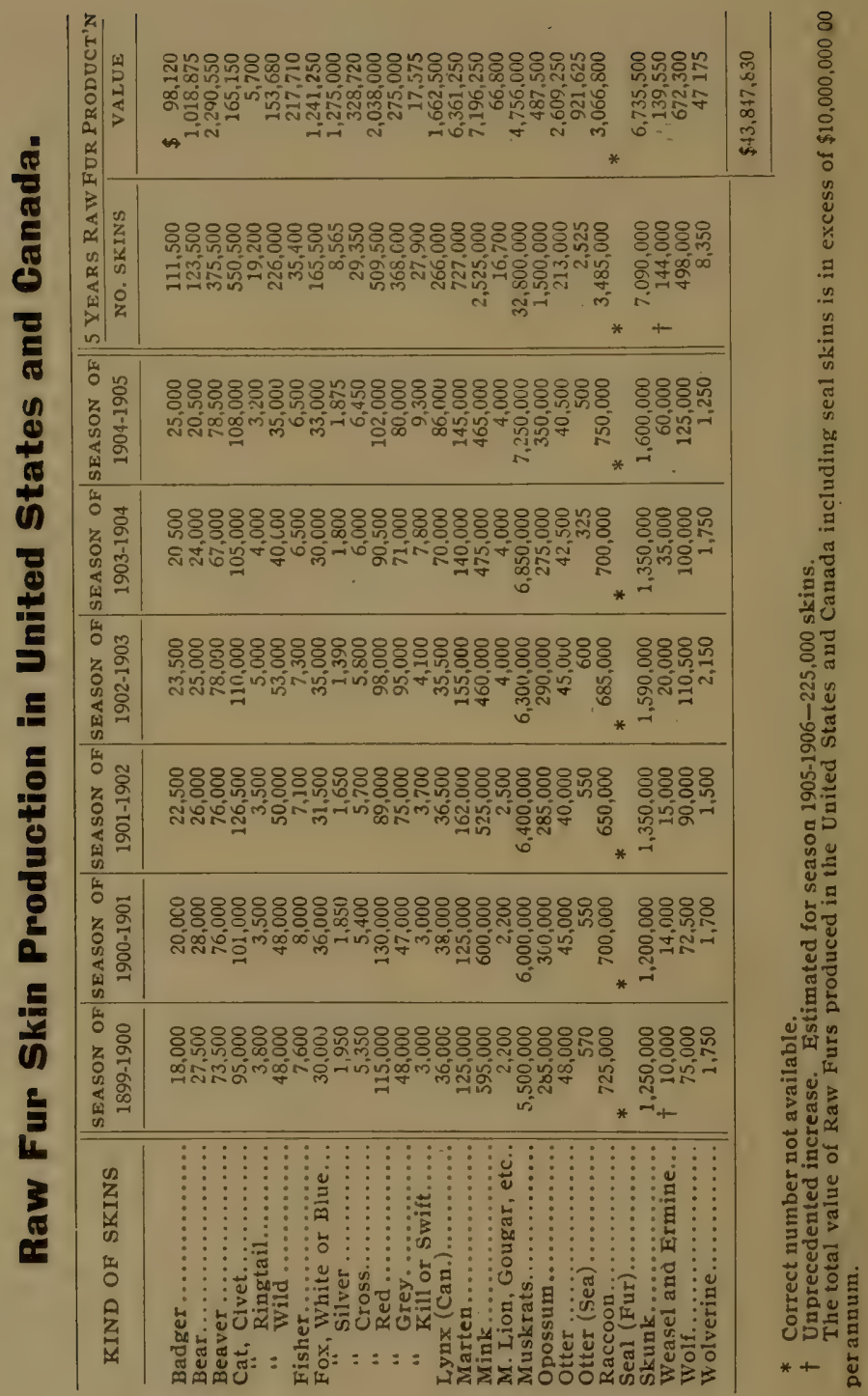


KEY

1 Animal is numerous.

2 Animal is rather scarce.

3 Animal is in sections only.

4 Animal is scarce.

5 None exist or unknown.

6 Animal is nearly extinct.

7 Animal is extinct.
Geographical Distribution

of

Fur Bearing Animals of North America
KEY

* Regulated by Law.

t No Law.

\& Panthers, Gaugars or

Jaguars.

State or Co. pays Bounty.

Special Park Law.

Special Laws in Various Provinces.

\begin{tabular}{|c|c|c|c|c|c|c|c|c|c|c|c|c|c|c|c|c|c|c|c|c|c|c|c|c|c|}
\hline *+ & $\frac{\vec{c}}{\vec{v}}$ & ఱే & 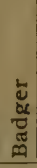 & 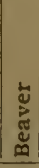 & $\mid \begin{array}{c}\pi \\
0 \\
0 \\
z\end{array}$ & $\begin{array}{l}\pi \\
\tilde{u} \\
\tilde{u}\end{array}$ & 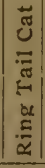 & $\mid \begin{array}{c}\frac{a}{v} \\
i\end{array}$ & $\left\{\begin{array}{l}0 \\
0 \\
y \\
0 \\
\frac{\pi}{0} \\
0\end{array}\right.$ & $\left|\begin{array}{c}0 \\
0 \\
5 \\
w \\
0 \\
3 \\
3\end{array}\right|$ & $\begin{array}{l}0 \\
0 \\
12 \\
0 \\
0 \\
0 \\
0 \\
0\end{array}$ & 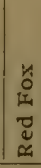 & $\begin{array}{l}0 \\
0 \\
0 \\
0 \\
0 \\
0\end{array}$ & 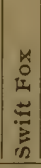 & 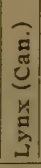 & 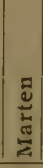 & $\frac{1}{2}$ & 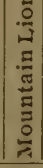 & $\begin{array}{l}5 \\
0 \\
0\end{array}$ & $\left|\begin{array}{c}0 \\
E \\
0 \\
0 \\
0 \\
0 \\
0 \\
0\end{array}\right|$ & 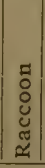 & 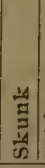 & 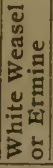 & 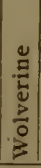 & $\frac{\pi}{0}$ \\
\hline labama & 1 & 3 & 7 & 6 & 1 & 2 & 4 & 5 & 5 & 5 & 5 & 2 & 2 & 5 & 5 & 5 & 1 & $*_{2}$ & 3 & 1 & 1 & 1 & 5 & 5 & 3 \\
\hline laska. & 3 & 1 & 6 & 3 & 3 & 5 & 5 & 1 & 1 & 1 & 1 & 1 & 5 & 6 & 1 & 1 & 1 & 1 & 2 & 5 & 5 & 5 & 1 & 2 & 1 \\
\hline rizona.. & 3 & 31 & 1 & 2 & 81 & 3 & 4 & 5 & 5 & 5 & 5 & 1 & 1 & 5 & 6 & 5 & 1 & 83 & 4 & 1 & 3 & 1 & 5 & 5 & 31 \\
\hline ansas. & 1 & 2 & 1 & 2 & 3 & 1 & 4 & 5 & 5 & 5 & 5 & 2 & 1 & 5 & 5 & 5 & 3 & 3 & 2 & 1 & 1 & 1 & 5 & 5 & 1 \\
\hline ia. & 2 & 3 & 1 & 4 & 1 & 2 & 3 & 5 & 5 & 5 & 5 & 2 & 1 & 5 & & 5 & 2 & 4 & 2 & 3 & 1 & 1 & 5 & 5 & 1 \\
\hline lorado & 1 & 2 & 4 & $*_{4}$ & 1 & 2 & 5 & 7 & 5 & 5 & 5 & 2 & 1 & 5 & 4 & 6 & 2 & 3 & 6 & 6 & 2 & 2 & 5 & 7 & $\overrightarrow{1}$ \\
\hline Con & & 6 & 6 & 6 & 2 & 2 & 5 & 6 & 5 & 5 & 5 & $8=$ & 4 & 5 & & 6 & 1 & & 2 & 2 & 1 & 1 & 2 & 5 & 6 \\
\hline If & ${ }^{*} 1$ & 5 & 7 & 6 & 6 & 4 & 5 & 5 & 5 & 5 & 5 & 4. & 2 & 5 & 5 & 7 & 2 & 5 & 2 & 1 & 1 & 2 & 4 & 5 & 7 \\
\hline Florida. & 1 & 4 & 5 & 4 & 3 & 1 & 2 & 5 & 5 & 5 & 5 & 6 & 2 & 5 & 5 & 5 & 3 & $\ddagger 3$ & 1 & 1 & 1 & 1 & 5 & 5 & 4 \\
\hline in & 1 & 4 & 5 & 4 & 3 & 2 & 6 & 5 & 5 & 5 & 5 & 4 & 2 & 5 & 5 & 5 & 3 & $\$ 3$ & 1 & 1 & 1 & 2 & 5 & 5 & 4 \\
\hline I & 1 & 1 & 1 & $* 3$ & 1 & 4 & 5 & 4 & 5 & 6 & 3 & 1 & 4 & 3 & 3 & 2 & 1 & 3 & 3 & 5 & 2 & 1 & 2 & 7 & 1 \\
\hline is. & 1 & 6 & 6 & 6 & 4 & 1 & 5 & 5 & 5 & 5 & 5 & $*_{2}$ & $*_{2}$ & 5 & 5 & 5 & 2 & 5 & 4 & 2 & 1 & 1 & 2 & 5 & 4 \\
\hline & 1 & 6 & 6 & 6 & 4 & 2 & 5 & 5 & 5 & 5 & 5 & 2 & 2 & 5 & 5 & 7 & 2 & 5 & 6 & 1 & 2 & 2 & 2 & 5 & 6 \\
\hline IndianTerritor & 1 & 4 & 2 & 7 & 2 & 1 & 5 & 5 & 5 & 5 & 5 & 4 & 1 & 5 & 5 & 5 & 1 & 6 & 7 & 1 & 1 & 1 & 5 & 5 & 1 \\
\hline Iowa.... & ${ }^{*} 1$ & +6 & +4 & $*_{4}$ & $\dagger 4$ & $\dagger 1$ & †5 & †5 & †5 & †5 & †5 & $\dagger 2$ & $\dagger 2$ & +5 : & $\dagger 7$ & $\dagger 7$ & $*_{1}$ & †5 & $*_{4}$ & $\dagger 2$ & $\dagger 1$ & +1 & $† 2$ & $\dagger 5$ & $\dagger 3$ \\
\hline 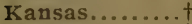 & 1 & 4 & 2 & 6 & 3 & 1 & 5 & 5 & 5 & 5 & 5 & 2 & 1 & 5 & 5 & 5 & 1 & 5 & 6 & 1 & 1 & 1 & 4 & 5 & 1 \\
\hline $\mathrm{K}$ & 1 & 3 & 7 & 4 & 3 & 1 & 5 & 5 & 5 & 5 & 5 & 2 & 2 & 5 & 5 & 5 & 1 & $\ddagger 3$ & 2 & 1 & 1 & 1 & 4 & 5 & 2 \\
\hline na & 3 & 4 & 6 & 4 & 2 & 1 & 1 & 5 & 5 & 5 & 5 & 4 & 1 & 5 & 5 & 5 & 2 & 5 & 2 & 1 & 1 & & 5 & 5 & 3 \\
\hline & 1 & 33 & 6 & $*_{4}$ & 2 & 5 & 5 & $*_{4}$ & 6 & 4 & 4 & 2 & 5 & 5 & 2 & $*_{2}$ & $*_{1}$ & 5 & 4 & 5 & 2 & 1 & 1 & 6 & 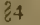 \\
\hline Maryland. & 1 & 6 & 5 & 4 & 2 & 2 & 5 & 5 & 5 & 5 & 5 & 2 & 3 & 5 & 5 & 4 & 1 & 5 & 4 & 1 & 1 & 1 & 3 & 5 & 6 \\
\hline setts & 1 & 6 & 7 & 6 & 24 & 5 & 5 & 6 & 5 & 5 & 5 & 2 & 5 & 5 & 34 & 4 & 1 & 5 & 6 & 5 & 2 & 1 & 2 & 7 & 4 \\
\hline M & $*_{1}$ & 3 & 3 & $*_{4}$ & $\varepsilon_{2}$ & 5 & 5 & $*_{4}$ & 5 & 4 & 4 & 1 & 5 & 5 & 64 & $* 3$ & $*_{1}$ & 5 & *3 & 5 & *1 & $*_{1}$ & 1 & 6 & 3 \\
\hline innesota & 1 & 3 & 4 & $*_{4}$ & 3 & 5 & 5 & 6 & 5 & 4 & 4 & 2 & 5 & 5 & 3 & 3 & $*_{1}$ & 5 & *6 6 & 5 & 2 & 1 & 1 & 6 & 2 \\
\hline Mississippi.. & 1 & 4 & 4 & 6 & 3 & 1 & 3 & 5 & 5 & 5 & 5 & 2 & 2 & 5 & 5 & 5 & $i$ & 5 & 4 & 1 & 2 & 1 & 5 & 5 & 2 \\
\hline & 1 & 4 & 3 & 4 & 3 & 1 & 5 & 5 & 5 & 5 & 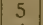 & 2 & 2 & 5 & 5 & 5 & 1 & 5 & 3 & 1 & 1 & 1 & 4 & 5 & 2 \\
\hline Iontana & 2 & 3 & 2 & $*_{2}$ & 3 & 5 & 5 & 6 & 5 & 4 & 4 & 1 & 5 & 3 & 3 & 2 & 1 & 2 & $*_{2}$ & 5 & 2 & 2 & 2 & 6 & 1 \\
\hline -a. & $\Uparrow 1$ & +6 & $\dagger 2$ & $*_{4}$ & $\dagger 2$ & $\dagger 1$ & †5 & t5 & †5 & t5 & $\dagger 5$ & $\dagger 2$ & $\dagger 3$ & †5 & $\lceil 7$ & $\dagger 7$ & $\dagger 1$ & +5 & +6 & $\dagger 1$ & $\dagger 2$ & $\dagger 1$ & t4 & T5 & $\dagger 1$ \\
\hline ada. & 2 & 2 & 1 & $*_{4}$ & 2 & 4 & 5 & 5 & 5 & 5 & 5 & 2 & 2 & 5 & 7 & 7 & 1 & 2 & $*_{4}$ & 4 & 2 & 1 & 3 & 5 & 1 \\
\hline lnire* & 1 & 3 & 7 & $*_{4}$ & 3 & 5 & 5 & $*_{4}$ & 6 & 4 & 4 & 2 & 5 & 5 & 3 & $*_{2}$ & 1 & 5 & $*_{4}$ & 5 & 1 & 1 & 1 & 6 & 4 \\
\hline New Jer & 3 & 4 & 7 & 3 & 3 & 4 & 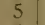 & 7 & 5 & 5 & 5 & 2 & 6 & 5 & 6 & 6 & 1 & 5 & 3 & 6 & 1 & 1 & 2 & 5 & 6 \\
\hline N & 143 & 1 & 1 & $* 4$ & $z_{1}$ & 3 & 4 & 5 & 5 & 5 & 5 & 2 & 1 & 5 & 5 & 6 & +3 & 3 & 6 & 2 & 1 & 1 & 5 & 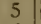 & 81 \\
\hline New York & 1 & 3 & 7 & $*_{4}$ & 4 & 5 & 5 & 6 & $*_{5}$ & *6 & $*_{4}$ & $*_{1}$ & *5 & 5 & 6 & 4 & $*_{1}$ & 5 & *6 & 5 & $\uparrow 2$ & $*_{1}$ & 1 & 6 & 6 \\
\hline h C & 1 & 3 & 7 & 4 & 3 & 2 & 2 & 5 & 5 & 5 & 5 & 2 & 2 & 5 & 5 & 5 & 1 & 5 & 2 & 1 & 1 & 1 & 2 & 5 & 6 \\
\hline 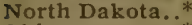 & 1 & 4 & 1 & *3 & 4 & 5 & 5 & 5 & 5 & 4 & 4 & 1 & 5 & 4 & 4 & 4 & 1 & 6 & $*_{3}$ & 5 & 4 & 1 & & & 31 \\
\hline & 1 & 6 & 6 & $*_{6}$ & 3 & 4 & 5 & 5 & 5 & 5 & 5 & 3 & 3 & 5 & 6 & 7 & $*_{1}^{1}$ & \pm 6 & 6 & 3 & $i$ & $* 1$ & 2 & 5 & 6 \\
\hline he & 1 & 4 & 3 & 6 & 4 & 1 & 5 & 5 & 5 & 5 & 5 & 3 & 1 & 5 & 5 & 5 & 1 & 5 & 6 & 1 & 1 & 1 & 3 & 5 & 1 \\
\hline & 1 & $?$ & 2 & $*_{2}$ & 1 & 4 & 5 & 4 & 5 & 5 & 3 & 2 & 3 & 3 & 2 & 2 & 1 & 2 & 3 & 5 & 1 & 1 & $i$ & & $\overline{7}$ \\
\hline ia. & 1 & $* 3$ & 7 & $*_{4}$ & 32 & 6 & 5 & 6 & 5 & 5 & 6 & 32 & 3 & 5 & 6 & 6 & 82 & $\$ 3$ & 4 & 3 & 1 & 3 & 2 & & 7 \\
\hline e Is & 1 & 7 & 7 & 7 & 4 & 6 & 5 & 7 & 5 & 5 & 5 & $\varepsilon_{2}$ & 84 & 5 & 5 & 6 & 2 & 5 & 4 & 6 & 2 & 1 & 2 & 5 & 7 \\
\hline ing & 1 & 3 & 5 & 3 & 2 & 1 & & 5 & 5 & 5 & 5 & 2 & $?$ & 5 & 5 & 5 & 1 & 5 & 2 & 1 & 1 & 1 & 4 & & 3 \\
\hline uth Dakota...* & 1 & 3 & 1 & $*_{4}$ & 4 & 4 & 5 & 5 & 5 & 5 & 6 & 1 & 4 & 2 & 6 & 6 & 1 & 83 & $*_{4}$ & 5 & 4 & 1 & 2 & 5 & 3,1 \\
\hline Temnesse & 1 & 6 & 7 & 6 & 3 & 2 & 7 & 5 & 5 & 5 & 5 & 2 & 1 & 5 & 5 & 5 & 3 & 13 & 4 & 1 & 1 & & 4 & & 6 \\
\hline & 1 & 3 & 2 & *6 & 3 & 1 & 3 & 5 & 5 & 5 & 5 & 3 & 1 & 5 & 5 & 5 & 1 & t & 4 & 1 & 1 & & 5 & & 31 \\
\hline Uta & 2 & 3 & 2 & $*_{4}$ & 2 & 4 & 5 & 5 & 5 & 5 & 5 & 2 & 1 & 3 & 7 & 5 & 1 & 2 & $* 4$ & 6 & 3 & 2 & 3 & 5 & 1 \\
\hline & 1 & 32 & 7 & $*_{4}$ & 2 & 5 & 5 & $*_{4}$ & 5 & 6 & 6 & $2 ?$ & 5 & $=$ & 23 & $?$ & I & 84 & $*_{4}$ & 5 & 2 & 1 & $?$ & & 34 \\
\hline & 1 & 4 & 7 & 7 & 4 & 2 & 5 & 5 & 5 & 5 & 5 & 3 & 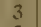 & 5 & 5 & 5 & 1 & 7 & 4 & 1 & 1 & 2 & 3 & 5 & 6 \\
\hline Washi & 3 & 3 & 2 & 4 & 82 & 5 & 5 & 4 & 5 & 6 & 4 & 1 & 5 & $=$ & 2 & 2 & 1 & 83 & 4 & 5 & 2 & 2 & 2 & 6 & $\xi_{1}$ \\
\hline Virginia & 1 & 4 & 7 & 6 & 4 & *3 & & 5 & 5 & 5 & 5 & 2 & 1 & 5 & 5 & 5 & 2 & $\$ 6$ & 4 & 1 & 1 & $*_{1}$ & 4 & 5 & 6 \\
\hline & 1 & 3 & 4 & $*_{4}$ & 3,2 & 6 & 5 & $*_{4}$ & 5 & 84 & 84 & 82 & 5 & 5 & 4 & *4 & $*_{1}$ & 5 & $*_{4}$ & 5 & 1 & 1 & 1 & 6 & 32 \\
\hline omi & 1 & $\| 2$ & 2 & $* 4$ & 1 & 5 & & 7 & & 1 & 6 & 1 & 1 & 5 & 6 & $* 4$ & 2 & 4 & 6 & 5 & 2 & 1 & 2 & & 1 \\
\hline (2) & 1 & 3 & 3 & 3 & 3 & 5 & 3 & 3 & 3 & 3 & 3 & 1 & $\because$ & 3 & 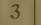 & 3 & 1 & 3 & 3 & 5 & 3 & 2 & 1 & 2 & 3 \\
\hline Mlexico. & 2 & & 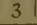 & 3 & 1 & 1 & & 3 & & & 3 & 3 & 2 & & 5 & 3 & 3 & $\uparrow 3$ & 6 & 2 & -3 & 1 & 5 & 3 & 1 \\
\hline
\end{tabular}

The above table, the result of a months' exhaustive inquiry and energy gives ready information as to "where and where not" any of the Fur Bearing Animals are to be found. "The legal regulation of Hunting and Trapping (Game Laws) also Bounty offered and paid are modified by the various Legislative bodies of our states also Congress, from year to year. Therefore one requiring latest informa. tion should write the Game Warden or to the Governor of the respective locality. For further particulars see page - 
The Following Table Shows Number and Kind of Raw Fur in London at Time

\begin{tabular}{|c|c|c|c|c|c|c|c|c|c|}
\hline \multirow[b]{2}{*}{ KINDS } & \multicolumn{6}{|c|}{ HUDSON'S BAY COMPANY } & \multicolumn{3}{|c|}{ * } \\
\hline & $\begin{array}{c}\text { TotaLS } \\
1900\end{array}$ & $\begin{array}{c}\text { Totals } \\
1901\end{array}$ & $\begin{array}{c}\text { Totals } \\
1902\end{array}$ & $\begin{array}{c}\text { TOTALS } \\
1903\end{array}$ & $\begin{array}{c}\text { Totals } \\
1904\end{array}$ & $\begin{array}{c}\text { Totals } \\
1905\end{array}$ & $\begin{array}{c}\text { Totals } \\
1901\end{array}$ & $\begin{array}{c}\text { Totals } \\
1902\end{array}$ & $\begin{array}{c}\text { Totals } \\
1903\end{array}$ \\
\hline Badger. & 655 & 1,141 & 824 & & & 489 & 1,070 & 20.915 & 13.5 \\
\hline Bear... & 8,856 & 8,206 & 7,512 & 6,969 & 5,276 & 5,483 & 13,618 & 14,030 & 12,834 \\
\hline Beaver............. & 42,582 & 45,001 & 49,190 & 38,636 & 30,056 & 48,255 & 17,655 & 15,334 & 16.504 \\
\hline Cat, Civet.......... & (........... & .......... & (n.......... & ….. & $\cdots \cdots$ & ........ & 67,476 & 102,955 & 73,635 \\
\hline $\begin{array}{c}\text { “ Rouse........ } \\
\text {. Ringtail..... }\end{array}$ & & & & & & ... & 57,536 & $\begin{array}{r}60,258 \\
\end{array}$ & 78,227 \\
\hline $\begin{array}{l}\text { Ringtai } \\
\text { Wild... }\end{array}$ & & & & & & & 29621 & 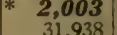 & * 4,456 \\
\hline Fisher...... & 3,437 & 3,679 & 3,223 & 2,580 & 2,090 & $2,80 i$ & $\mathbf{3}, \mathbf{4 8 1}$ & 2,669 & $\begin{array}{l}29.934 \\
2,535\end{array}$ \\
\hline Fox, Blue. & & & & & & 6 & & & \\
\hline $\begin{array}{l}\text { C Cro } \\
\text { Gre }\end{array}$ & 1,851 & 1,447 & 1,970 & 2,208 & 2,387 & 3,626 & 2,971 & 2,771 & 2,957 \\
\hline$\because$ Kitt(or Swift) & $\cdots$ & “.... & & •. & •. & - & $\begin{array}{l}29,638 \\
1,497\end{array}$ & $\begin{array}{l}37,824 \\
1.327\end{array}$ & $\begin{array}{r}64,431 \\
2.186\end{array}$ \\
\hline " Red.......... & 5,831 & 5,912 & 6,200 & 6,185 & 7.181 & 7.68 & 109,449 & 43,992 & $\begin{array}{r}2,186 \\
62,052\end{array}$ \\
\hline$\because$ Silve & 317 & 280 & 491 & 422 & 490 & 599 & 1,374 & 826 & 670 \\
\hline "White.. & 2,906 & 8,487 & 10,717 & 5.549 & 4.634 & 2,752 & 19,932 & 15,764 & 20,341 \\
\hline 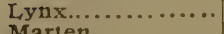 & 4,446 & 5,701 & 9,031 & 19,189 & 36,028 & 48,365 & 18,222 & 12,353 & 5,828 \\
\hline Marien. & $\begin{array}{r}55,329 \\
47,560\end{array}$ & 56,491 & 78,629 & 54,395 & 35,579 & 41,245 & 39,630 & 46,791 & 55,106 \\
\hline $\begin{array}{l}\text { Mink............ } \\
\text { Musquash........ }\end{array}$ & $\begin{array}{r}47,560 \\
928,199\end{array}$ & $\begin{array}{r}57,349 \\
1650,214\end{array}$ & $\mathbf{6 6 , 3 6 0}$ & $\mathbf{5 5 , 4 5 5}$ & $\mathbf{5 5 , 8 8 9}$ & 47,235 & $\begin{array}{r}\mathbf{3 3 3}, \mathbf{4 4 8} \\
2,201,121\end{array}$ & 295,702 & 253,001 \\
\hline Mlack . & 928,199 & $\begin{array}{l}1,050,214 \\
\ldots \ldots \ldots\end{array}$ & \begin{tabular}{|l}
$1,488,287$ \\
$\ldots \ldots \ldots \ldots$
\end{tabular} & $\begin{array}{r}924,439 \\
\ldots \ldots \ldots \ldots\end{array}$ & - & 689,611 & $\begin{array}{r}2,201,121 \\
\mathbf{8 8 , 2 0 8}\end{array}$ & $\begin{array}{r}2,958.508 \\
\mathbf{8 5 , 8 6 6}\end{array}$ & $\begin{array}{l}2,979.460 \\
117,412\end{array}$ \\
\hline $\begin{array}{l}\text { Opossum.......... } \\
\text { Otter................. }\end{array}$ & 9.160 & 8,675 & 10,273 & $\cdots 6,452$ & 88 & 9.843 & $\begin{array}{r}215,736 \\
16,215\end{array}$ & 167.324 & 168,396 \\
\hline 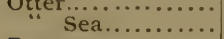 & & & & & & 9,843 & & $\begin{array}{r}I, 301 \\
406\end{array}$ & $\begin{array}{r}14,757 \\
463\end{array}$ \\
\hline Raccoon............ & 9,058 & 1,967 & 1,024 & 717 & 404 & 264 & 306,680 & 235,757 & 268,190 \\
\hline Seal, Fur....................... & $\mid \cdots \cdots \cdots \cdots$ & ........... & anc.... & $\cdots$ & $\cdots$ & - & n........ & $\ldots \ldots \ldots$ & \\
\hline $\begin{array}{l}\text { Skunk,........... } \\
\text { Wolf............ }\end{array}$ & $\begin{array}{r}6,027 \\
2,589\end{array}$ & $\begin{array}{r}5,682 \\
\mathbf{1}, \mathbf{3 4 7}\end{array}$ & $\begin{array}{r}5.206 \\
\boldsymbol{1}, 790\end{array}$ & $\begin{array}{r}5,427 \\
1,972\end{array}$ & $\begin{array}{r}6,090 \\
1,196\end{array}$ & $\begin{array}{r}9,032 \\
1,555\end{array}$ & $\begin{array}{l}700,041 \\
\mathbf{3 1}, \mathbf{8 3 9}\end{array}$ & $\begin{array}{r}835,677 \\
36,502\end{array}$ & $\begin{array}{r}948,447 \\
\mathbf{4 7}, 139\end{array}$ \\
\hline $\begin{array}{l}\text { Wolverine......... } \\
\text { Ermine(\& Wh.W. }\end{array}$ & $\begin{array}{r}772 \\
\ldots \ldots\end{array}$ & $\begin{array}{r}635 \\
\ldots \ldots\end{array}$ & $\begin{array}{r}695 \\
\ldots \ldots\end{array}$ & $\begin{array}{r}627 \\
\ldots \ldots\end{array}$ & $\begin{array}{r}412 \\
\ldots \ldots\end{array}$ & $\begin{array}{r}456 \\
\ldots \ldots\end{array}$ & $\begin{array}{r}876 \\
\ldots \ldots \ldots \\
\end{array}$ & $\begin{array}{rr}599 \\
* 13,520 \\
\end{array}$ & * 13,425 \\
\hline
\end{tabular}

* Estimated.

Newhouse Steel Traps.

All Steel Traps which are stamped "S. Newhouse, Oneida Community, N. Y." are warranted free from all defects. Defective parts are readily replaced by the Manufacturers.

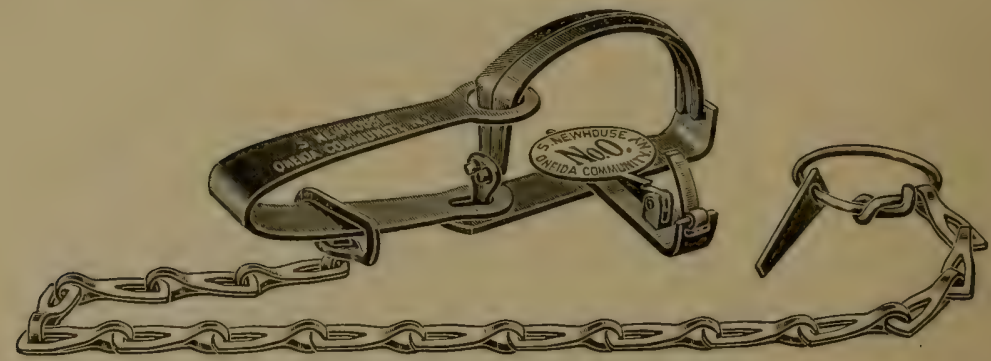

NO 0. NEWHOUSE GOPHER OR HOUSE RAT TRAP.

Spread of jaws $3 \frac{1}{2}$ inches; made with or without chain. This is the smallest steel trap made, and not strong enough for muskrats, though of ten used. Can be used for weasels and ermines. 


\section{Skins (American) Offered and Sold at the Auction Rooms and Year Stated.}

C. M. LAMPSON \& CO.

\begin{tabular}{|c|c|c|c|c|c|c|c|c|c|c|}
\hline $\begin{array}{l}\text { OTALS } \\
1904\end{array}$ & $\begin{array}{l}\text { JAN. } \\
1905\end{array}$ & $\begin{array}{c}\text { MARCH } \\
1905\end{array}$ & $\begin{array}{l}\text { JUNE } \\
1905\end{array}$ & $\begin{array}{l}\text { OCT. } \\
1905\end{array}$ & $\begin{array}{c}\text { Totals } \\
1905\end{array}$ & $\begin{array}{l}\text { JAN. } \\
1906\end{array}$ & $\begin{array}{c}\text { MARCH } \\
1906\end{array}$ & $\begin{array}{c}\text { JUNE } \\
1906\end{array}$ & $\begin{array}{c}\text { Totals } \\
3 \text { SALES } \\
1906\end{array}$ & $\begin{array}{c}\text { TOTALS, } \\
\text { OCT. } 1905 \\
\text { JAN.MAR.\& } \\
\text { JUNE } 1906\end{array}$ \\
\hline 8,625 & $\begin{array}{r}3,351 \\
\end{array}$ & $?$ & 2,10 & 552 & 13,2 & $?$ & 5.9 & 5, & 54 & 2,602 \\
\hline 0.135 & & 3,886 & & & & & $3, I$ & & & 1,126 \\
\hline & & & & 1,587 & 17. & 4.3 & & & & \\
\hline 0 , & 10,211 & 43,586 & 10,700 & 77 & 64,574 & 9,835 & 94,392 & 13,696 & 117,923 & 11,423 \\
\hline 55 & 860 & 23,982 & 10,958 & 7,529 & & 24,952 & 35.508 & 16.784 & & 6,452 \\
\hline 75 & 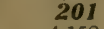 & 804 & 112 & one & I, & 210 & 772 & 350 & 1,332 & \\
\hline & 4 & $0-0$ & 3,1 & 369 & & & & & & 2,2 \\
\hline 2 , & & 2,583 & & & 2,5 & & 2,2 & 1,6 & 3,838 & 614 \\
\hline & & & 40 & 48 & & 1 & & 339 & & \\
\hline 2,8 & 371 & 1,951 & 373 & 183 & 2,8 & 53 & 3,6 & 8 & 5 & 395 \\
\hline & 15,8 & & 6.2 & & & & & & & 12,641 \\
\hline & 732 & 2,761 & 1.527 & 10 & 5 & 5 & 1,4 & & & 467 \\
\hline 605 & 8,865 & 41,731 & 11.673 & 1.397 & 63,6 & 11,464 & 25 & 15, & & 16,443 \\
\hline & 116 & & 155 & & & & & & & 79 \\
\hline 14 & & 11,7 & 3,740 & 4,413 & 23 & 3 & 3,7 & 4. & & 3.230 \\
\hline 17,657 &, 650 & 4,303 & 4,917 & 3,651 & 21,521 & 9,2 & 7,7 & 3,8 & 20 & 4,543 \\
\hline & & & & & & & 21. & & & 7,041 \\
\hline 35 & 920 &, 704 & 218 & 4,270 & 145,112 & 56,892 & 6,1 & 54,928 & 23 & 27,256 \\
\hline 3.54 & & 0,527 &, 772 & 671 & 8,505 & 1. & 4. & 35 & & 839,182 \\
\hline 77 & 551 & 969 & 811 & 2,593 &, 924 & 729 & 6 & $I$ & 9 & \\
\hline 99,474 & & 112,665 & 3,057 & 33 & 273,677 & 15 & & 2 & & 27 \\
\hline 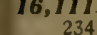 & & 2,207 & $6 \cap 5$ & & 9,164 & & 2,5 & 1,052 & 5,340 & 2,758 \\
\hline$+\infty$ & 86,717 & 168,662 & 64,420 & 6,632 & 326,431 & 64,606 & 135,350 & 60,366 & 260,322 & 26,509 \\
\hline & $\ldots \ldots \ldots$ & ……... & $\cdots \cdots$ & ....... & $\cdots$ & $=$ & $\cdots$ & $\cdots$ & $\ldots \ldots \ldots$ & $\cdots$ \\
\hline 847,60 & 288 & 824 & 847. & 4,153 & 776,933 & 274,544 & 445,051 & 205,420 & 925 & 165.490 \\
\hline 1 & 8,2 & 20,904 & & 889 & $38,1 / 18$ & I1 1,922 & 15,843 & 16,818 & 44,5 & 13,52 \\
\hline 1,9 & 5,047 & $\begin{array}{r}316 \\
20,109 \\
\end{array}$ & $\begin{array}{r}100 \\
5,472 \\
\end{array}$ & $\begin{array}{r}28 \\
1,253 \\
\end{array}$ & 31,881 & 18,007 & $\begin{array}{r}757 \\
93,735 \\
\end{array}$ & $\begin{array}{r}18,476 \\
\end{array}$ & $\begin{array}{r}1,223 \\
130,218 \\
\end{array}$ & 7,985 \\
\hline
\end{tabular}

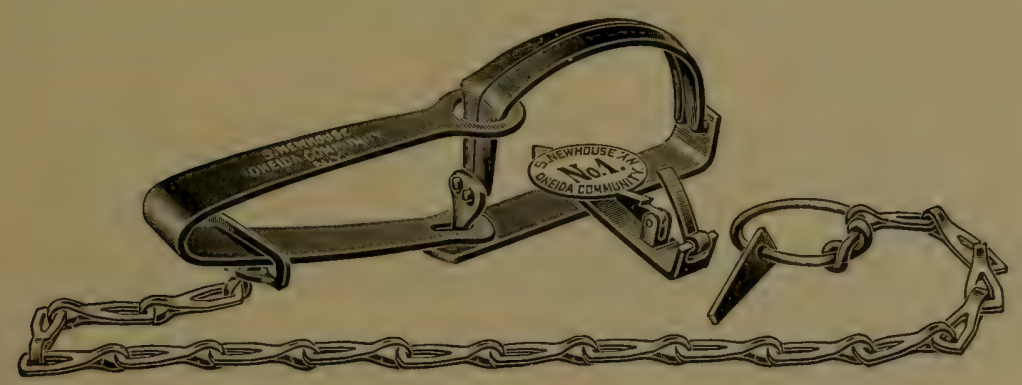

NO. 1. NEWHOUSE STEEL TRAP FOR MUSKRATS.

Spread of jaws, four inches; made with or without chains. While this trap is solely intended for muskrats, it will hold a mink, but it's not a good idea to overtax steel traps. Can be used for skunk, weasel, ermine, marten and other small animals. 


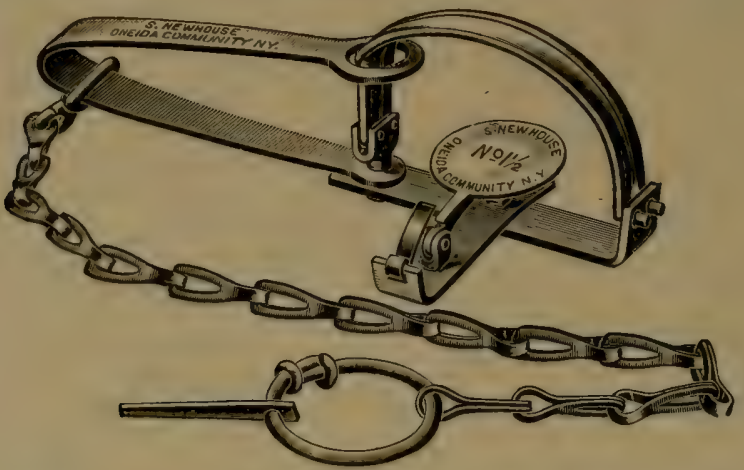

NO. 11/2. NEWHOUSE STEEL TRAP FOR MINK.

Spread of jaws, $4 \% / 8$ inches. Is especially made to hold mink, marten, skunk and swift fox. Will hold larger animals, but cannot recommend its use for fox, badger or raccoon. Probably more animals, the skins of which In the aggregate foot up a larger sum in dollars and cents, are caught in this size trap.

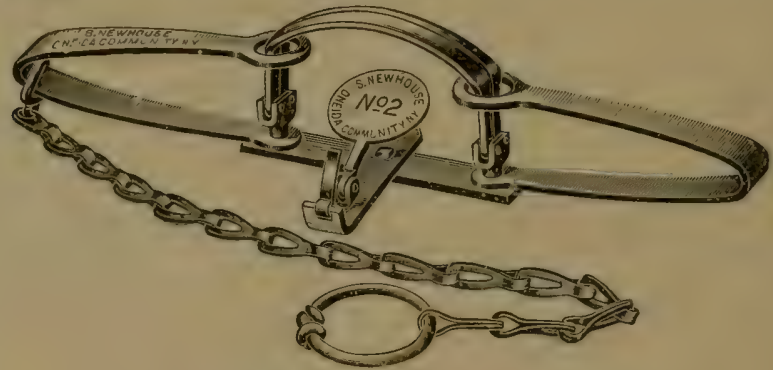

NO. 2. NEWHOUSE STEEL TRAP FOR FOX. - ’

This trap has $47 / 8$ inch jaws, and differs only from the No. $1 \frac{1 / 2}{2}$ trap in that it has two instead of one spring. This trap is recommended for capturing the red, gray and other foxes; is suitable for raccoon, badger and fisher.

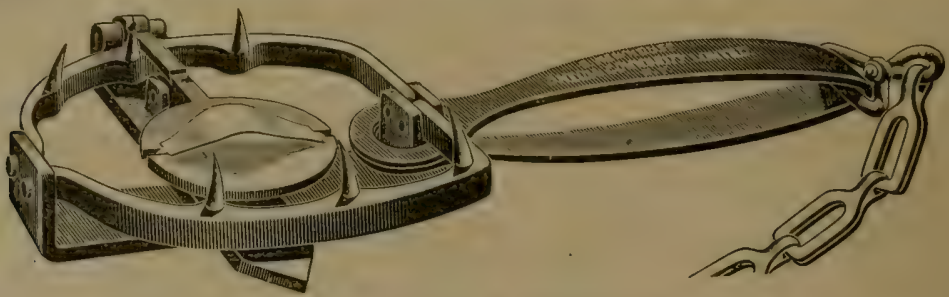

NO $21 / 2$. NEWHOUSE SINGLE SPRING STEEL TRAP.

This trap was built by the manufacturer on suggestions received from experienced trappers. It is set on otter slides, the teeth are very sharp, and the curved plate attached to the pan is higher than the teeth. The trap can be sprung, by the animal touching the curved piece of steel with its belly, foot or leg. The jaws have a spread of $51 / 4$ inches. The raised plate can be detached if desired, making the trap one of general utility. 


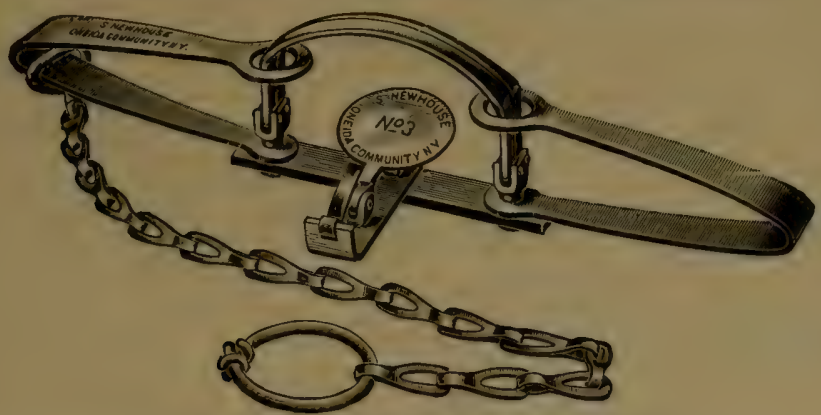

NO. 3. NEWHOUSE STEEL TRAP.

Spread of jaws, $5 \frac{1 / 2}{2}$ inches. Will hold otter, beaver, prairie wolf, red fox, fisher, wolverene. Is also used for wildcat and lynx, but is not strong enough for the gray wolf.

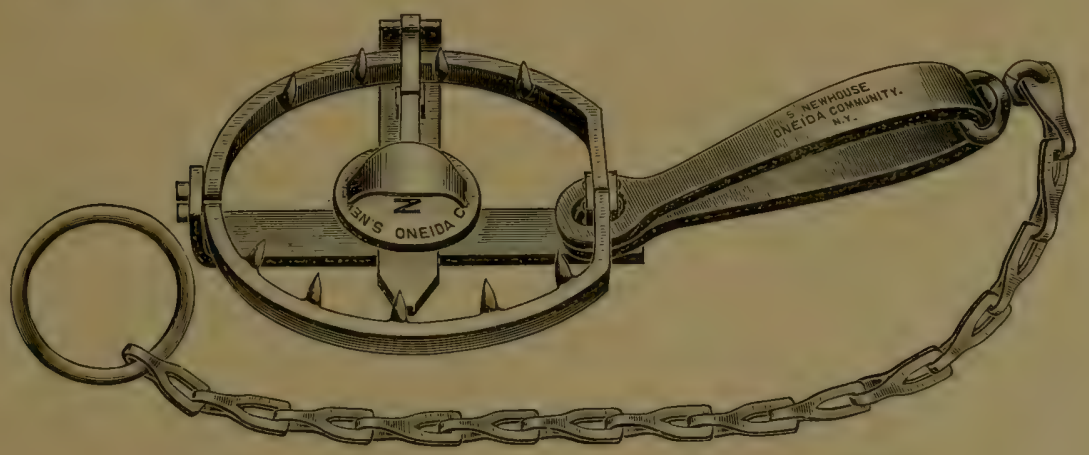

NO. 31/2. NEWHOUSE SINGLE SPRING STEEL TRAP.

This trap has jaws spreading $61 / 2$ inches. Is similarly constructed as the No. $2 \frac{1}{2}$ steel otter trap, but built expressly for trappers who desire a stronger single spring otter trap than the No. $21 / 2$.

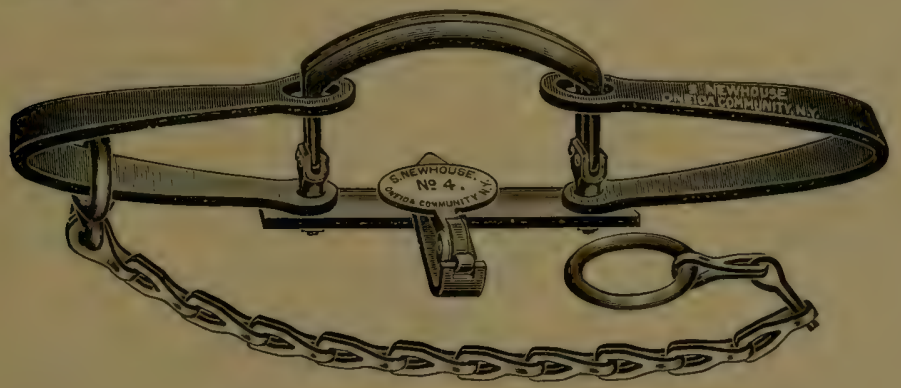

NO. 4. NEWHOUSE STEEL TRAP.

Spread of jaws, $61 / 2$ inches. This trap is expressly built for beaver and prairie wolf, but will hold most any animal, from the timber wolf down Trappers use this size for the Canadian lynx, also for the brush wole. 


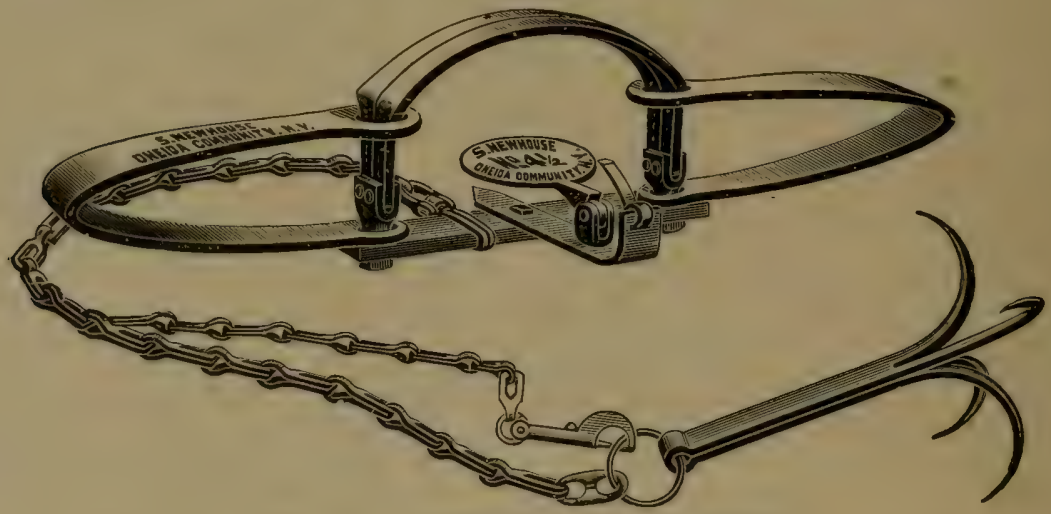

NO. $4 \frac{1}{2}$. NEWHOUSE WOLF TRAP.

Spread of jaws, eight inches, other parts in proportion; is provided with a pronged "drag," a heavy snap, extra heavy steel swivel and chain five feet long. The latter is warranted to hold two thousand pounds. As above shown the trap weighs eight pounds. It will hold the mountain lion.

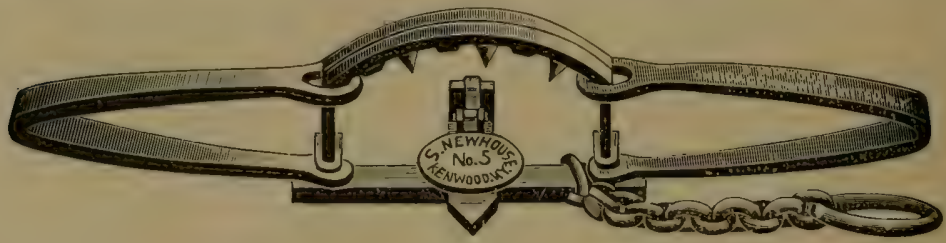

NO. 5. NEWHOUSE STEEL TRAP.

This trap has jaws spreading $11 \frac{3}{4}$ inches apart, and with a short chain weighs nineteen pounds. It is expressly made for the black and brown bear. The trap is furnished with a short swivel link, and large ring, all sufficiently strong to detain the monster, especially when its sharp steel teeth are impregnated in the skin or bone of his foot or leg.

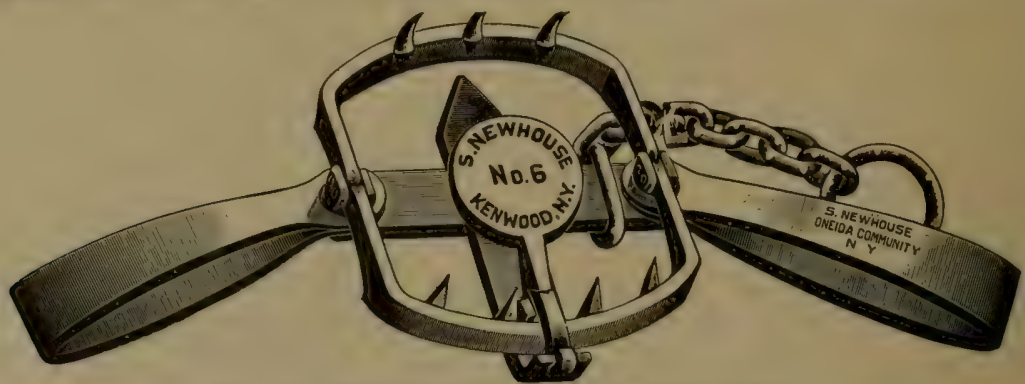

NO. 6. NEWHOUSE STEEL BEAR TRAP

This monster bear-trap is designed for the grizzly or polar bear, also shipped from this country to Africa, presumably to hold the lion. One of these traps was on exhibition at the Minnesota State Fair in connection with our (Andersch Bros.) fur exhibit in 1902, and thousands of trappers viewed this monster trap, all feeling assured of its holding the grizzly bear. The jaws have a spread of sixteen inches, and the entire trap as illustrated weighs forty-two pounds. 


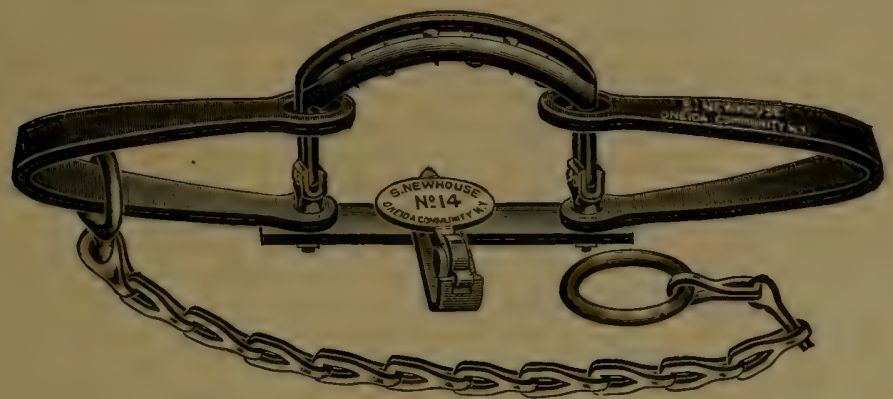

NO. 14. NEWHOUSE STEEL TRAP.

Spread of jaws $6 \frac{1 / 2}{2}$ inches. Is similar in size to the No. 4 beaver trap, except that it has 6 sharp steel teeth. The springs are also heavier and rise higher, thus readily holding the animal's leg in a vice-like grip.

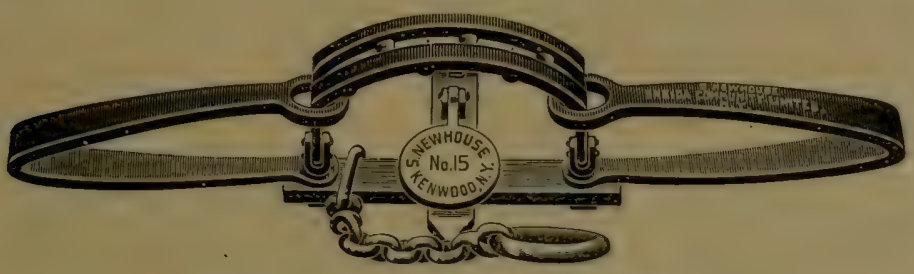

NO. 15. NEWHOUSE STEEL TRAP.

Spread of jaws $113 / 4$ inches. Has a $3 / 4$ inch off-set, otherwise similar to the No. 5. This trap was made to meet the wants of experienced trappers who claim many advantages over the old style No. 5 .

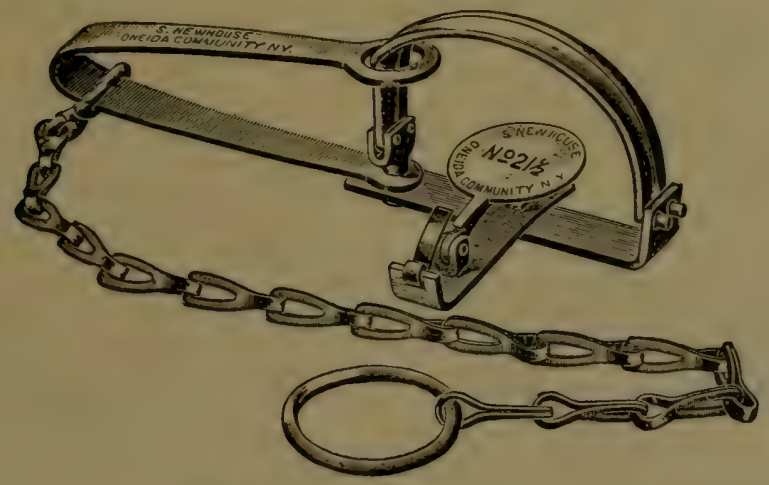

NO. $21 \frac{1}{2}$. NEWHOUSE STEEL TRAP.

This single spring trap is similar to the No. $2 \frac{1}{2}$, except it is minus the teeth and raised plate.

No. 311/2. The manufacturers also make a trap simflar to the No. $31 / 2$, minus teeth and raised plate, known as the No. $311 / 2$. 


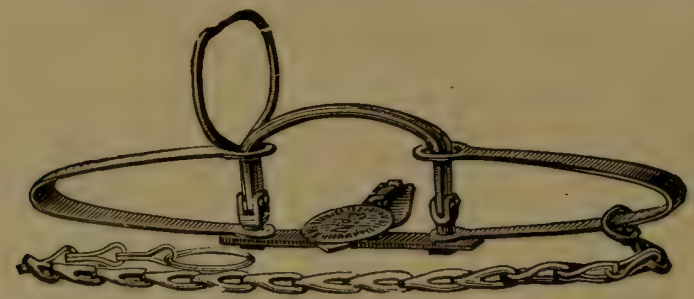

NO. 23. NEWHOUSE STEEL CLUTCH TRAP.

The above corresponds in size and spread of jaws with the No. 3 Newhouse. This clutch attachment was originally sent to the manufacturer by an old trapper, the inventor, who has had wonderful success with it in taking beaver. He sets it under water at the right depth, with the clutch end farthest from the shore, and sticks two small twigs upright in the ground just on the landward side of the trap. The beaver swims with his forelegs folded back against his body, propelling himself by his hind feet. When he feels his breast touch the bank or any obstruction, he puts down his forefeet. The trapper can calculate the position of the trap and upright twigs so that the beaver will put his forefoot into the trap and spring it, when the clutch will seize him securely. Clutch attachment can be removed.

No. 24. The manufacturers have a trap known as the No. 24, which in size and spread of jaws, corresponds with the No. 4 steel trap, but has the above clutch feature.

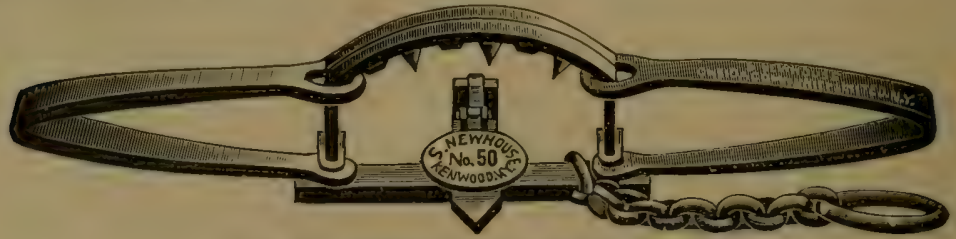

NO. 50. NEWHOUSE BEAR TRAP.

Spread of jaws 9 inches, weighs as above $11 \frac{1}{4}$ ibs. In construction it resembles the No. 5 , except being smaller. It is intended for smaller bears.

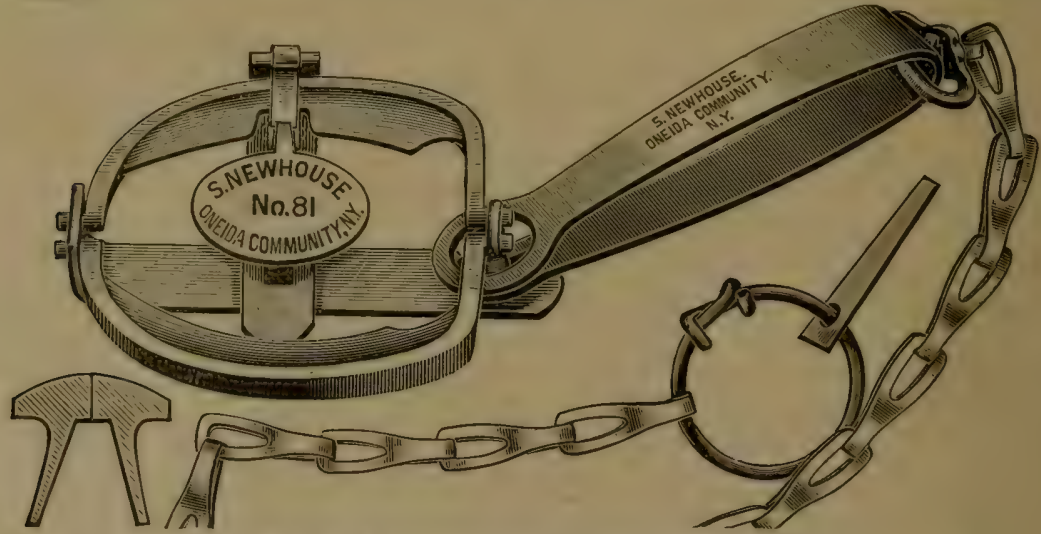

NO. 81. NEWHOUSE WEBBED JAW TRAP.

Spread of jaws 4 inches; corresponds in size and width to the No. 1. This style of trap is designed to prevent the animal from gnawing their legs off. 


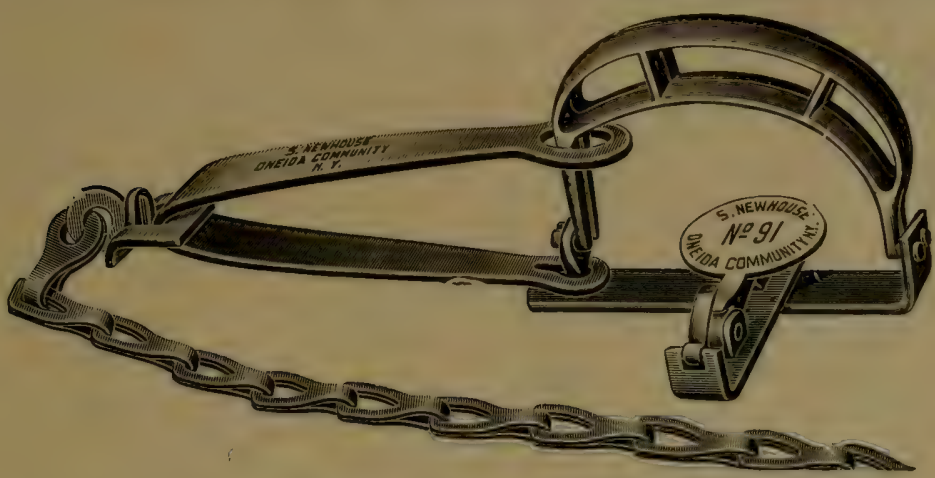

NO. 91. NEWHOUSE DOUBLE JAW TRAP.

A new style of trap that takes a firm grip high upon the animal's leg. Muskrats do not usually gnaw but twist their legs out, especially when caught by the foreleg which has much smaller bones and less muscle than the hind leg. These traps rarely break the leg bone, because of the double jaw surface. Spread of jaws $51 / 2$ inches.

No. $911 / 2$. The manufacturers make a double jaw trap, corresponding In size with the No. $1 \frac{1}{2}$ except width of jaws is $61 / 2$ inches.

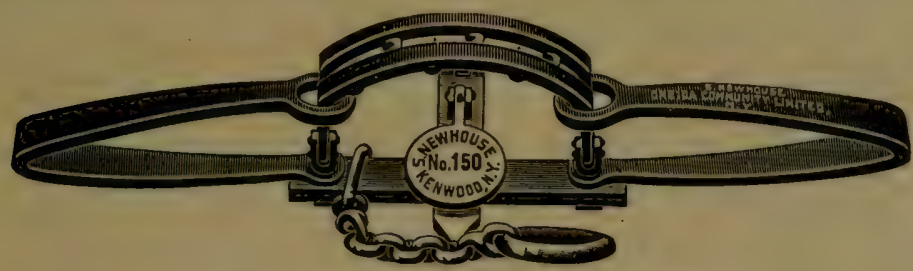

NO. 150. NEWHOUSE BEAR TRAP.

Spread of faws 9 inches. Is identical with trap No. 50, excepting trap has a $5 / 8$ inch off-set jaws, which allows the springs to come up higher, thus securing a better grip. Weight, as per illustration, 11/4/ lbs.

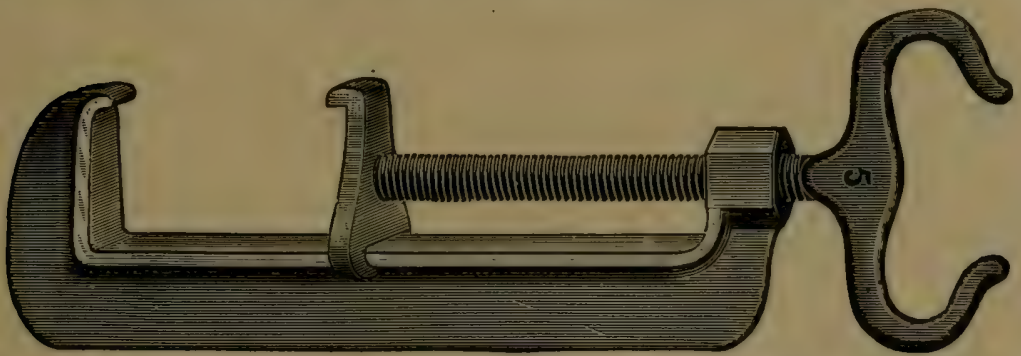

NEWHOUSE CLAMPS FOR SETTING STEEL TRAPS.

These clamps are made to overcome the difficulty and danger of setting steel traps, especially the larger size. They are made in three sizes.

No. 4. Clamp for traps up to No. 4.

No. 5 Clamp for all large sizes including No. 6 .

No. 6 Clamp a stilı stronger clamp than No. 5 , for same size traps. 


\section{Victor Steel Traps.}

The most popular cheap trap made. When in want of a low priced trap, call for the Victor and take no substitute.

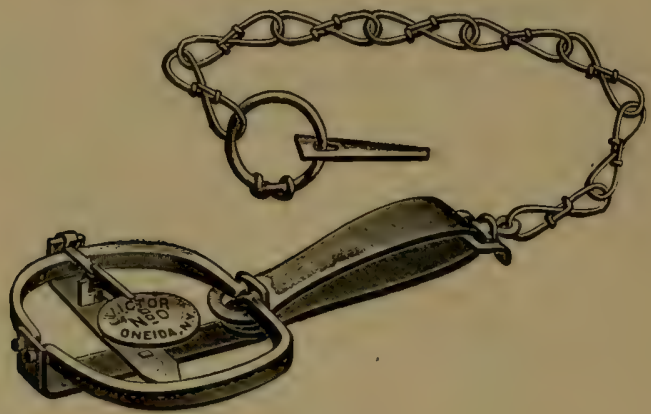

The above cut represents the single spring Victor traps, sizes $0,1,11 / 2$. These traps are used for catching small fur-bearing animals, such as skunk, opossum, muskrat, etc.

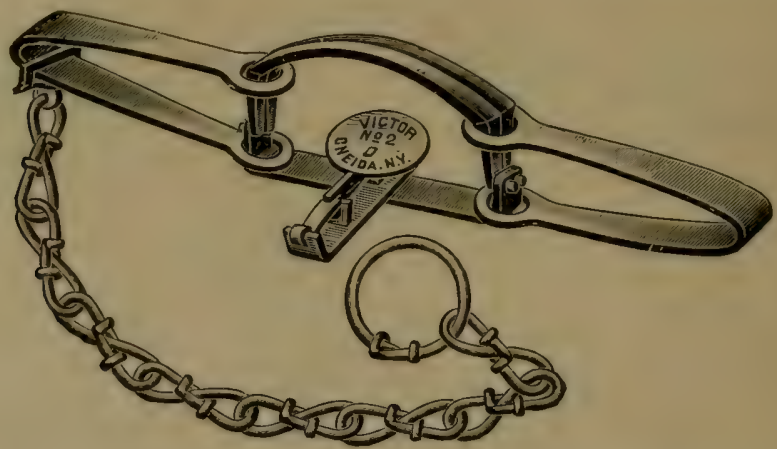

The Nos. 2, 3 and 4 Victor traps are made with strong double springs and are used for catching the fox, beaver and animals of similar size. All Victor traps are supplied.with patented wire chains.

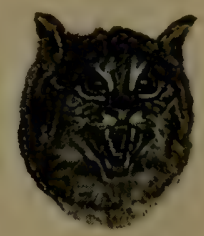




\section{Tree Trap.}

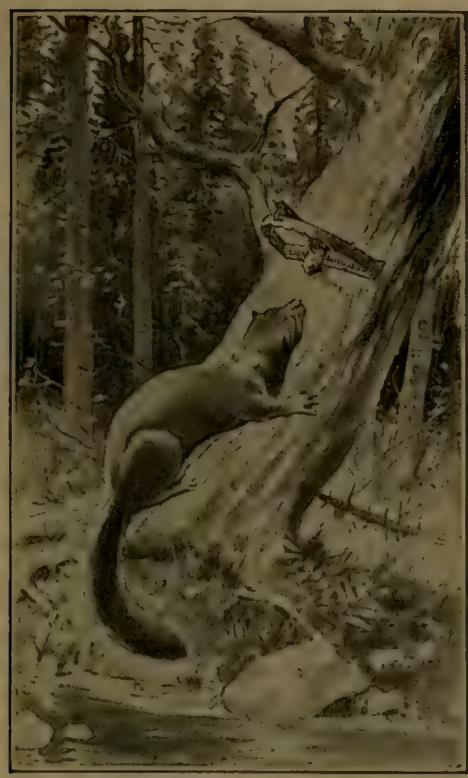

Cut shows a No. 1 Tree trap, properly fastened to a tree, set and ready for business.

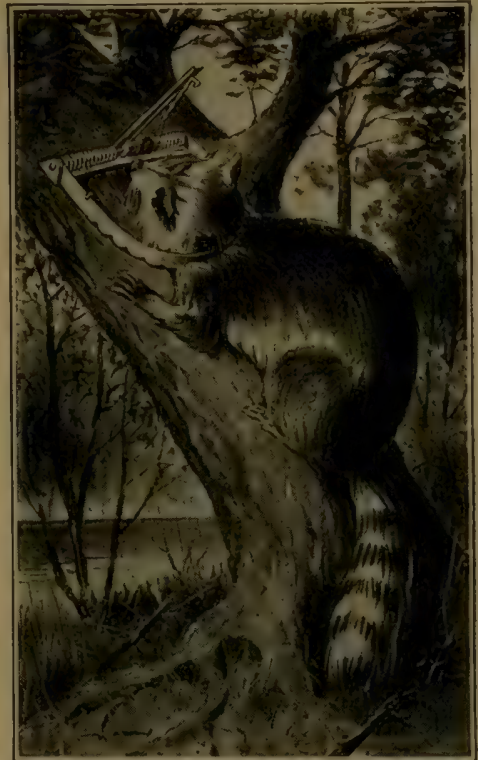

Cut shows a No. 2 Tree trap holding a raccoon in a vice-like grip.

No. 1. Tree traps are especially adapted to mink, inarten and similar sized animals. Traps are usually fastened on trees 3 to 5 feet above the ground, but can be utilized advantageously elsewhere.

No. 2 Tree traps are adapted to capture fisher, raccoon and opossum.

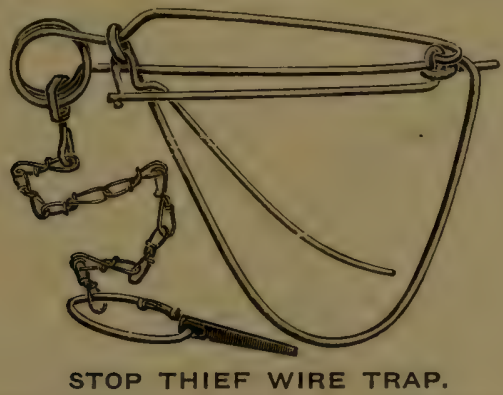

This trap is very effective, humane, and is highly endorsed by leading trappers, especially the first three sizes.

No. 1. Gopher or Squirrel.

No. 2. Mink or Marten.
Made in 4 Sizes.

No. 3. Skunk.

No. 31/2. Raccoon or Badger. 



\section{GENERAL INDEX.}

\section{Description of Fur Bearing Animals.}

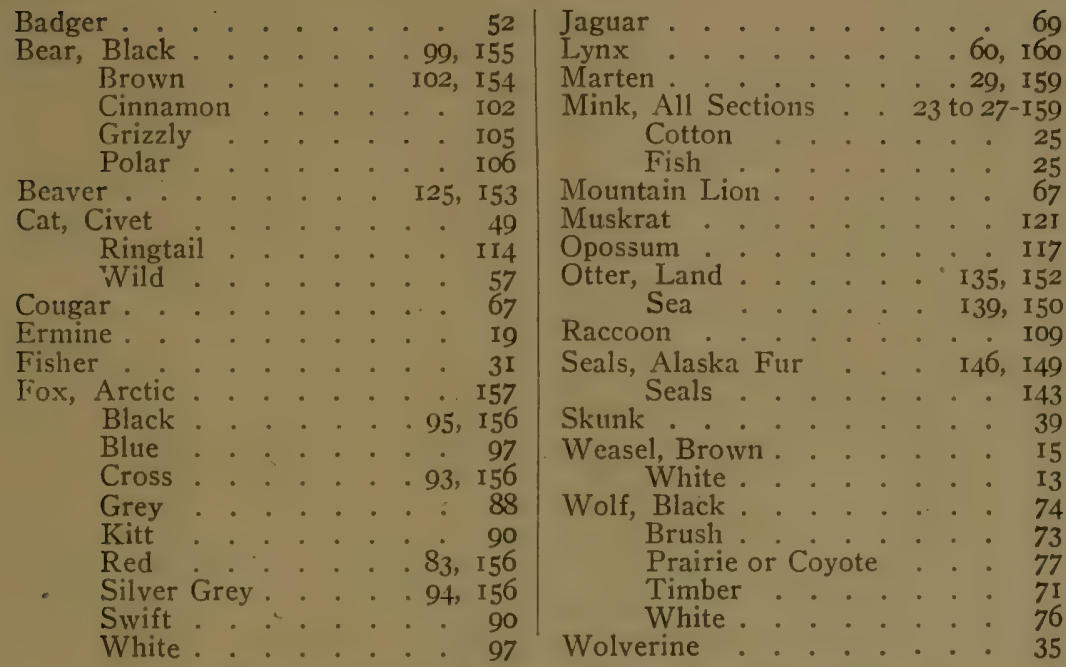

\section{Illustrations of Fur Bearing Animals.}

Badger

Bear, Black · : 88, 100, 192, 246 Grizzly . . . . . 104

Polar : . . . . . 93

Beaver, Beavers at Work . . I24 Male Beaver . . . . I26

Young Beaver. . . . . 206

Cat, Civet Civet . . . . . 50

Ring Tail . . . . II5

Wild . . . . . . . 56

Wild, Head : . . . 57

Wild, Northern . . . . 58

Wild . . . . . 59

Cougar, Rocky Mountain . . . 70

Ermine. . . . . . . . . . 18

Fisher : . . . . . . . 13, 32

Fox, Black . . . . . . . . 96

Grey * . . . . 89

Heads, . . . . . 93

Kitt . . . . . 84, 92

Red : . . . . . 84

Red and Family : . . . 82

Red, Northern . . . . 86

Silver Grey . . . . . 92
Fox, Swift . . . . . . 84, 92

White. . . . . . 96

Jaguar . . . . . . . . . 8

Lynx, Canadian : . . . . 206

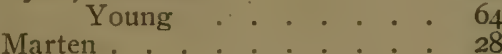

Mink . . . . . . . 39

Northern . . . . 22, 206

Mountain Lion . . . . . 66, 208

Young . . . . . . . 68

Muskrat, Group of . . . . 120

Muskrat . . . . . II2

Opossum, Opossum and Family 116 Southern. . . . . I18

Otters at Home . . . . . 134

Rabbit . . . . . . . 65

Rabbit and Fanily . : 99

Cottontail . . . . . II2

Jack . . . . . . . . II2

Raccoon . . . . . II2, 246

At Home . . . . . . IIo

Missouri . . . . . . 194

Northern . . . . . 108

So. Westerı . . . . . IOg 


\section{Illustrations of Fur Bearing Animals-Continued.}

Seals

Squirrel

$\cdots 40$

Weasel, White . . . . I8, II2

Wolf, Brush
Wolf, Coyote Hunt

Head of Wolf .

Prairie

Timber, Group of

Wolverine, Canadian
75

60

78

72

36

\section{Illustrations of Skins.}

American Raw Fur Skins . . . 390

Badger . . . . . . 202, 390

Baling Raw Fur Skins . . . 210

Bear, Black . . . . . . 190, 390 Brown . . . . . I90

Grizzly . . . . . . 190

Beaver...... . . 190, 216

Beaver . . . . 390

Cat, Civet . . . . . 200, 390

Wild . . . . 176, 390

Ermine.. . . . . . . 162,390

Fisher . . . . I68, 390

Fox, Black . . . . . . 390

Grey . . . . . I74, 390

Kitt . . . . . 174, 390

Red . . 174, I76, 214, 390

Silver Grey . . . . . . 390

Swift . . . . . I74, 390

174,390
204,390
Marten . . . . . . I66, 390

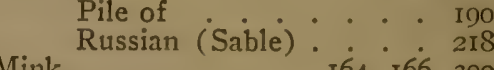

Mink . . . . . . I64, I66, 390

Muskrat . . . . . . 180,390

Opossum . . . . . . 202, 390

Otter . . . . . . . 390

Northern . . . . . 218

Sea . . . . 148

Raccoon . . . . . . . 390

Seal, Fur . . . . . . . . I48

Marbled . . . . . I48

Skunk, Miscellaneous . 196, I98, 390

Weasel . . . . . . . 390

White. . . . . . 162

Wolf, Black . . . . . . . I84

Prairie . . . I80, 390

Timber . . . . 178,390

Wolverine

390

\section{Illustrations of}

Traps, Snares, Trap Sets, Spring \& Sliding Poles, Etc.

Barrel Traps-

Muskrat and Mink . . . 264

Muskrat and Mink . . 354

Skunk ..... 264

Box Sets or Traps-

Floating Box for Muskrat 356

Animals and Birds . . 290

Animals and Birds . . 292

Mink, Fox, Raccoon, etc. 3I4

Muskrat . . . . . 273

Skunk \% . . . . 294

Deadfalls -

Skunk \& Rabbits . . . 264

All Kinds of Animals . . 270

All kinds of Animals . 2 271

All kinds of Animals . 328

Fox, Wolf, Lynx, etc. . 302

Lynx, Fox, Wolverine, etc.

Wild Cat, Lynx, Raccoon, etc.

Wolf, Fox, Mink, Raccoon

German
326

318

268

280
Hollow Log . . . . . 336

Plank . . . . : 284

Stone . . . . 320

Hollow Log Sets-

Mink, Marten and Weasel 264

Mink, Marten, Weasel,

Fisher . . • . . 266

Mink, Marten, Weasel,

Fisher . . . 380

Horseshoe Nail : : 264

Drag . . . . . . . . 238

Fur Stretchers . . . . 242

Raccoon Stretchers . . . . 338

Sliding Chain . . . . . . . 362

Sliding Pole. . . . . . . . 239

Spring Pole. . . . . . . . 264

Spring Pole. . . . . . 298

Spring Pole . . . . . . . . 300

Spring Pole . . . . . 340

Spring Pole. . . . . . 342

Spring Pole . . . . 360

Miscellaneous Sets-

Bear Pen . . . . . . 334

Beef Hoist . . . . . 324 


\section{Illustrations of}

Traps, Snares, Trap Sets, Spring \& Sliding Poles, Etc.-Continued.

Combination Bait, Mirror

$$
\text { \& Trap }
$$

Fish IJook \& Steel Trap. 348

Horseshoe Nail. . . 264

Horseshoe Nail : 372

Log Pen Trap for Bear : 332

Pitfall for Wolf, Bear, etc. 322

Snare Sets-

Screened Rooster Trap . 306

Mink, Marten, Raccoon . 264

Raccoon, Wild Cat . : 298

Raccoon . . . . . 210

Wolf, Fox . . . . 374

Steel Trap Sets-

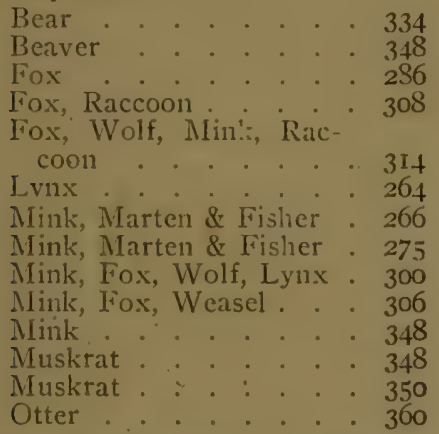

Otter . . . 364

Otter, Beaver, Mink : 362

Raccoon . . . . . . 286

Raccoon . . . . 340

Raccoon : . . 342

Raccoon, Mink . . . 348

Skunk . . . . - 286

Wild Cat, Raccoon . . 298

Wolf, Fox, Bear . : 322

Traps-

Wolf, Fox . . . . . . 324

Newhouse . . . 422 to 429

Newhouse Clamp . . . 429

Stop Thief . . . . . 43I

Tree Tran . . . . . 43I

Water Sets-

Victor . . . . . 430

Barrel . . . . . . 264

Box Trap for Mink,

Muskrat . . . . . 273

Floating Box. . . . 350

Floating Log . . . . . 348

Beaver . . . 348

Fox, Mink, Raccoun : 308

Muskrat . . . . . 350

Otter . . . . . 360

Otter : : 364

Raccoon . . . . 286

Log and Fish Hook . 348

\section{Illustrations of Game Birds and Animals.} (Other than Fur Bearing Animals.)

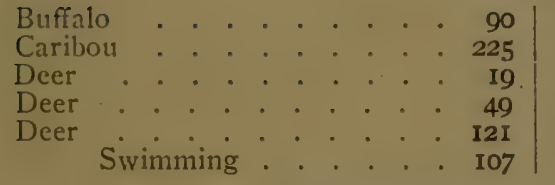

\section{Miscellaneous Illustrations.}

Andersch Bros. Place of

\section{Business}

Author Raw Furs . : . : . : : $\begin{array}{r}6 \\ \text { Baling }\end{array}$

Bear Hunter . . . . . . . 192

Beaver Castoriunis . . . . . I32

Beaver Cuttings . . . . . . . . 130

Beaver Generative Organs . . 132

Beaver Pelt . . . . . . . . 216

Beaver Tail . . . . . . . . . 216

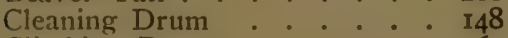

Climbing Bear . : : : : . 260

$\sim \sim$
Deer, Tracks . . . . . . . 256

Bull Moose . . . . . . . . 226

Quail . . . . . . 31

Prairie Chicken . . . . : : 67

Turkey, Wild : . . . : 94

Rocky Mountain Goat : . : . 95 


\section{Miscellaneous Illustrations-Continued.}

Nice Fur Collection

Prize Drawing of American Fur Skins

Result of Knowing How to

$$
\text { Hunt \& Trap }
$$

Scraping Skunk \& Raccoon Skins

376
390
246
248

Scene in Anderscl Bros' Fur Room . . . . . . 190

Skunk Farm, Diagram of : 392

Skunk Farm . . . . : : 394

Skunk Farm . . . . . . . 398

Skunk Trapper : . . . 388

We Were Seven . . . . 258

\section{Hunting and Trapping Fur Bearing Animals.}

\begin{tabular}{|c|c|c|c|c|c|c|c|c|c|c|c|c|c|c|c|c|c|}
\hline Badger & . & - & - & . & - & - & 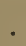 & 203 & Marten & & & & & & & & 167 \\
\hline Bear. & . & . & $\cdot$ & • & • & • & . & 189 & Mink & & & & 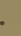 & & & & 163 \\
\hline Beaver. & - & 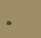 & & . & 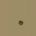 & . & . & 215 & Mountain & Lion & $\cdot$ & & 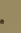 & & & & 209 \\
\hline Cat, Civet & & & - & - & • & $\cdot$ & • & $20 I$ & Muskrat & - & • & • & • & & & & $2 I I$ \\
\hline Ring & Tai & & • & . & . & 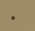 & & & Opossum & . & . & 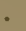 & . & 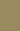 & & & $20 I$ \\
\hline Wilc & - & & • & - & - & - & - & 207 & Otter & . & . & - & • & & & & 219 \\
\hline Cougar. & - . & - & - & - & - & . & & 209 & Sea & . & • & • & • & & & & 224 \\
\hline Ermine & - & - & - & - & $\cdot$ & - & & I6I & Raccoon & - & • & • & 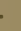 & & & & I93 \\
\hline Fisher & • & 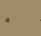 & • & - & - & - & - & 170 & Skunk & & & & : & & & & 19.5 \\
\hline Fox & . & • & • & • & • & . & & $175^{\circ}$ & Weasel & & & & & & & & 161 \\
\hline Jaguar . & - . & - & - & - & - & - & • & 209 & Wolf \& $C$ & oyote & . & $\cdot$ & $\cdot$ & & & & 179 \\
\hline $\operatorname{Lynx}$ & - & • & • & - & • & & . & 205 & Wolverine & & - & & & & & & 171 \\
\hline
\end{tabular}

Hunting and Trapping Fur Bearing Animals.

(By America's Most Experienced Hunters and Trappers.)

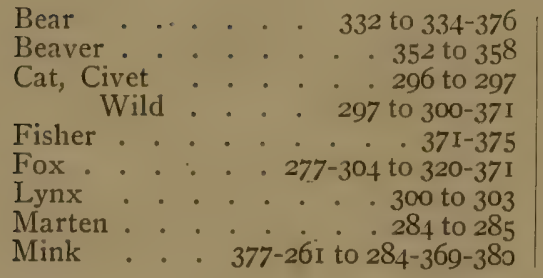

Mountain Lion . . . . 303 to 304 Muskrat . . 273-282-345 to 352 Miscellaneous Articles . . 369 to 389 Opossum . . . . . 343 to 344 Otter . . . . 358 to $368-379$ Raccoons . . . . 275-335-343-369 Skunk . : . . . 285 to $295-377$ Weasel . . . . . . 26I Wolf and Coyote . 320 to $331-369$

\section{Game Laws.}

U. S. Game Laws . . . . . . . . . . . . . . . . . . . . 418-419

Open and Closed Seasons : . . . . . . . . . . . . . . . . . . . . . $416-417$

How To Obtain Game Laws . . . . . . . . . . . . . . . . . 4I5

\section{Miscellaneous Hunting and Trapping.}

Additional Revenue for Trappers . . . . . . . . . . . 255 to 257

Deer Hunting . . . . . . . . . . . . . . . 257

Fishing for Bait or Food 382 to 384

Good Pointers . . . . . . . . . . . . . . . . . . . . 378

How to Skin for Mounting . . . . . . . . . . . . . . . . . 254

Suffocating Mink \& Skunk. . . . . . . . . . . . . . . . . . . . 377

To Eradicate Skunk Odor.

Trapper's Outfit. . . . . . . . . . . . 384 to 387 


\section{Skinning and Stretching.}

Directions

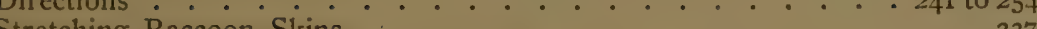

Stretching Raccoon Skins . . . . . . . . . . . . . 337

Sliding and Spring Poles, Drags, Etc.

Sliding Poles. . . . . . . . . . . . . . . . . . . 23S-239-240-3\$2

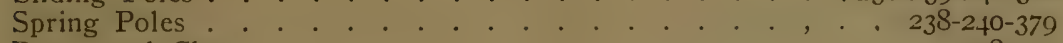

Drags and Clogs . . . . . . . . . . . . . . . . . . . . . $238-239$

\section{Tables and Statistics.}

Game Laws, Open and Closed Season . . . . . . . . . . . . 416

Geographical Distribution of Fur-Bearing Animals . . . . . . . . . . 42 I

How to Obtain Copies of State Game and Fish Laws . . . . . . . . 4I5

London Fur Sales. . . . . . . . . . . . . . . . . . . 422-423

Production of Raw Furs in U. S. and Canada . . . . . . . . . . . . 420

Showing What Skins Should Be Cased or Open . . . . . . . . . . 419

\section{Trappers Secrets.}

Notes About Trapping, Decoys, Bait, Scent, Poison, Natural and Artifical, Musk

\section{Raising Fur Bearing Animals For Profit.}

Skunk Farm . . . . . . . . . . . . . . . . . 393 to 402

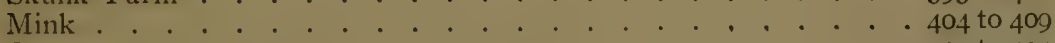

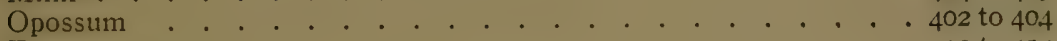

Fox . . . . . . . . . . . . . . . . . . . . . 409 to 414

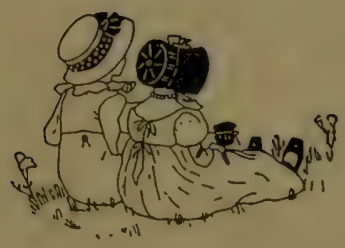




\section{ANDERSCH BROS.}

Deaters ix

\section{Country, UTD Packer,
Canadian \\ WOOL, SHEEP PELTS, TALLOW,}

Beeswax, Deerskins, Ginseng, Seneca Root, etc.

Hunters and Trappers will realize as much, if not more, for RAW FURS by shipping to us than to any other house:

\section{See Our Bank References.}

Ship us your CATTLE and HORSE HIDES, also CALF SKINS. Write for our price list, shipping tags, etc.

Outside market prices and prompt cash returns guaranteed.

\section{Andersch Bros:}

$411=413=415=417=419$ Main St.

MINNEAPOLIS, MINNESOTA.

BELOW FIND LIST OF OUR BANKERS.

First National Bank................. Minneapolis, Minn. Northwestern National Bank........... Minneapolis, Minn. Security Bank of Minn................ Minneapolis, Minn. East Side State Bank .............. Minneapolis, Minn. Second National Bank...................... Minot, N. D. Continental National Bank............... Chicago, Ill. Des Moines Savings Bank ............. Des Moines, Ia. Merchants' Bank of Canada..........Winnipeg, Canada. 



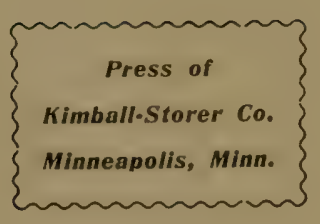





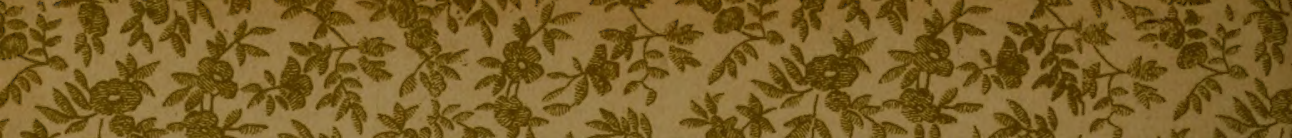
* 7.

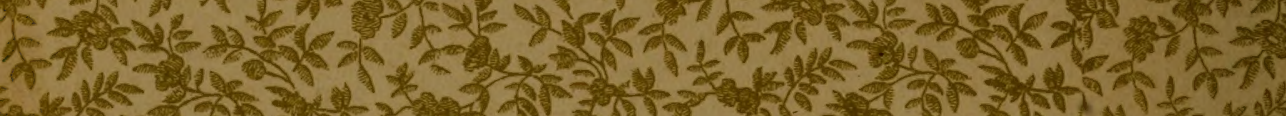

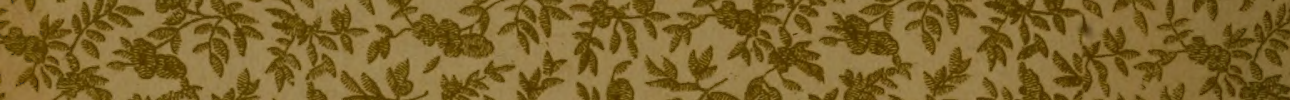

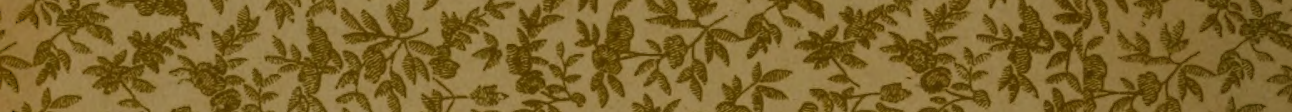

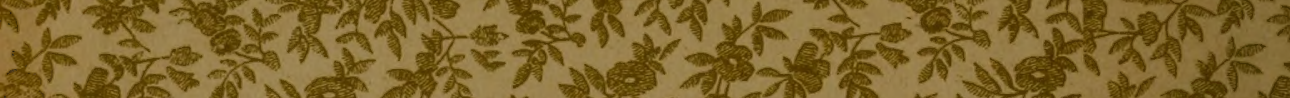
30 .

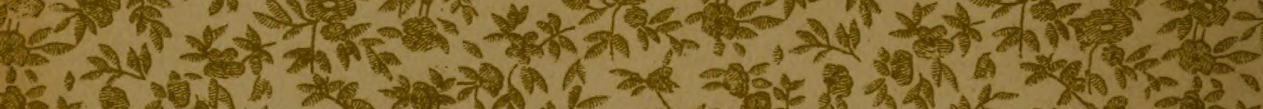

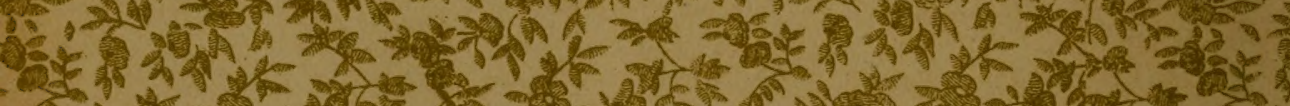
A. 1.

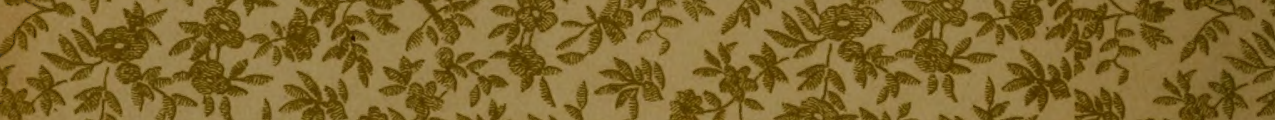

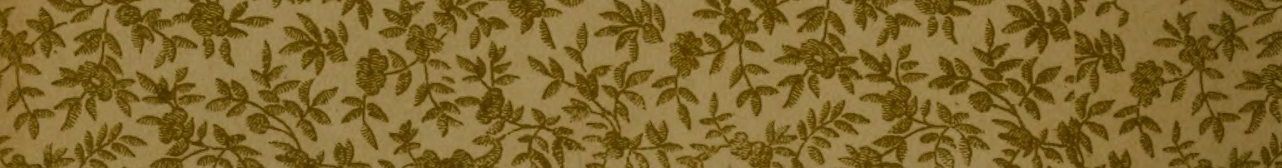

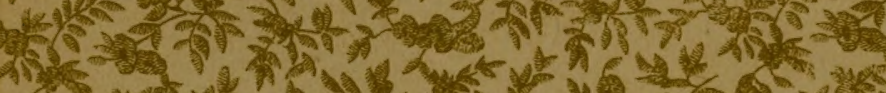

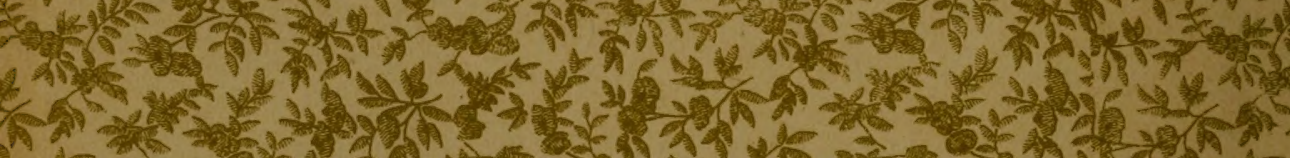

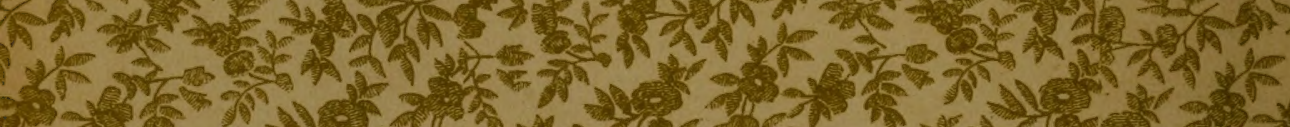

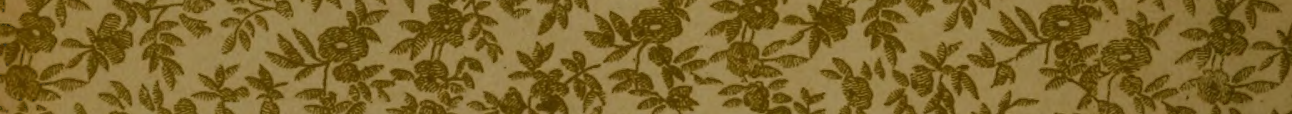
25 2 -

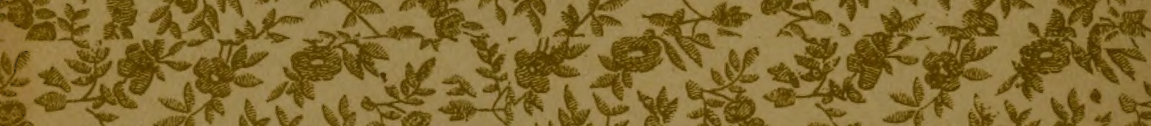

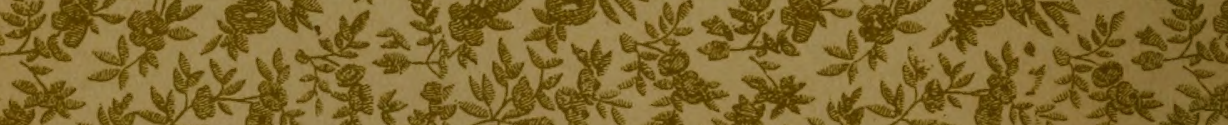

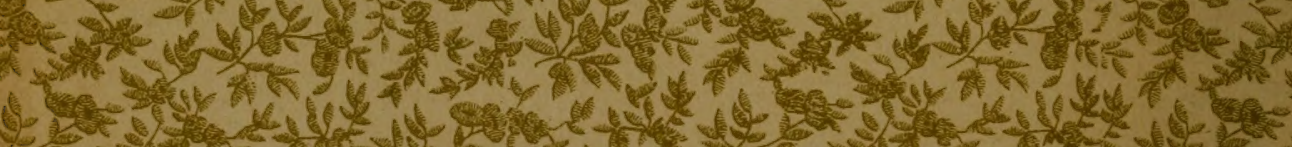
5 (1)

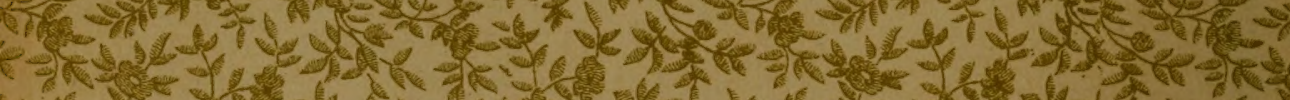

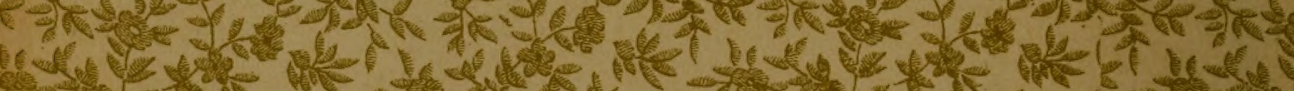
- 3.

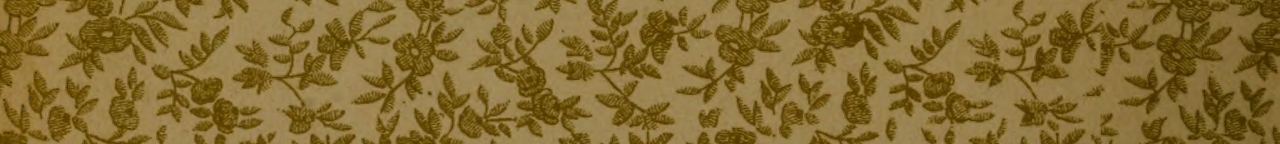
-

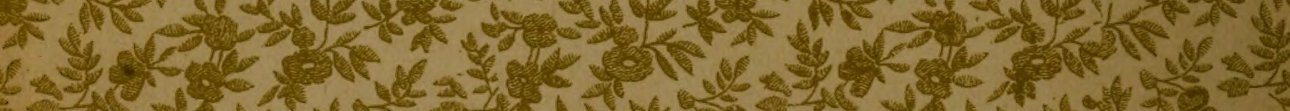

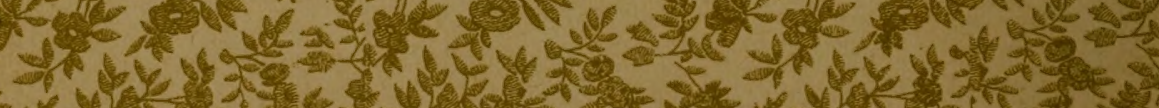
1 y) 


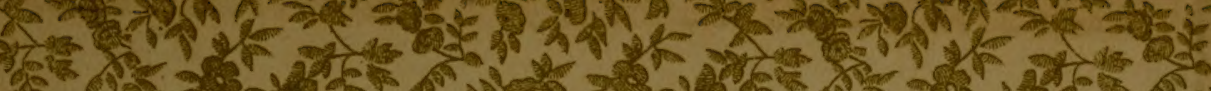

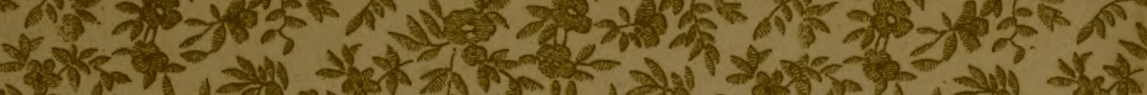

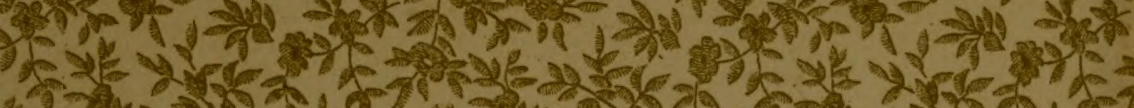

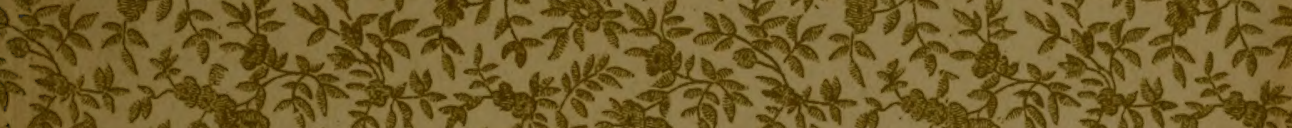

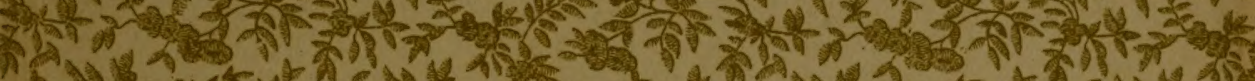

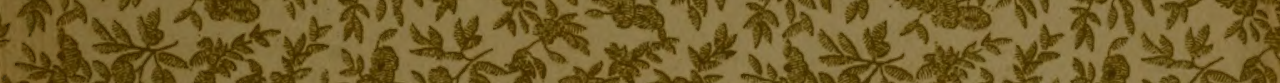

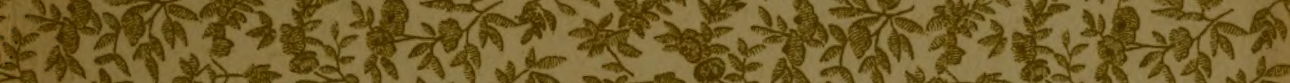

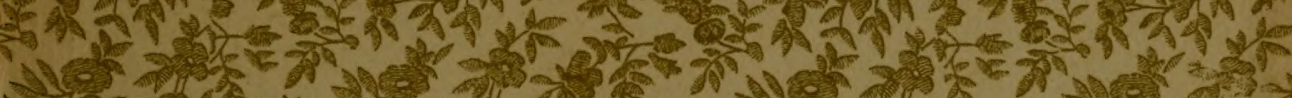
Fo

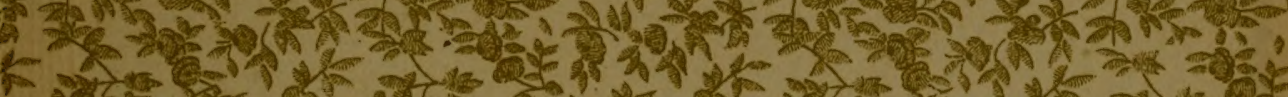
2.

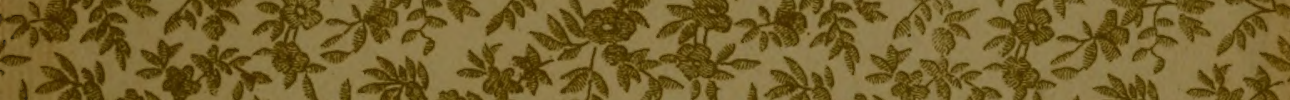

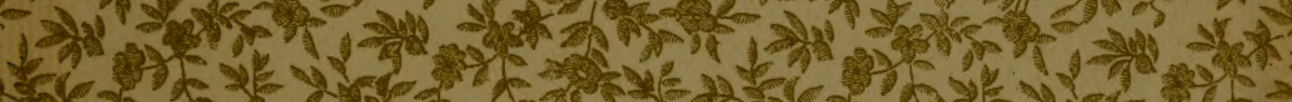

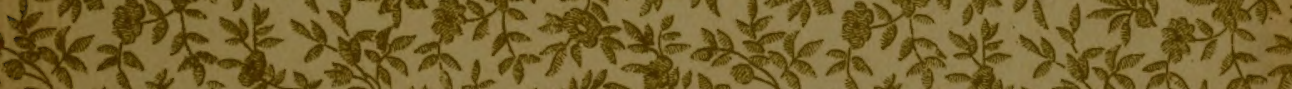

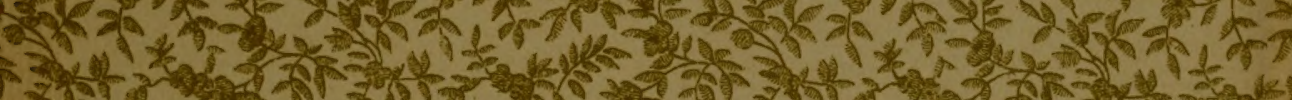

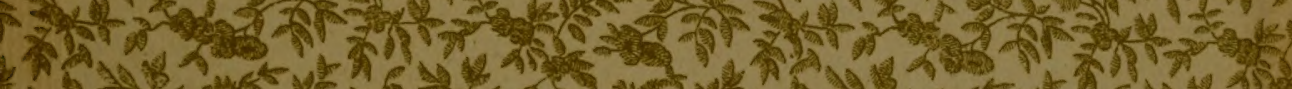

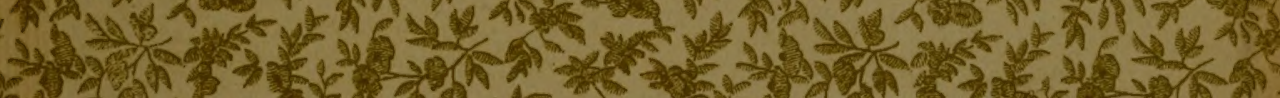

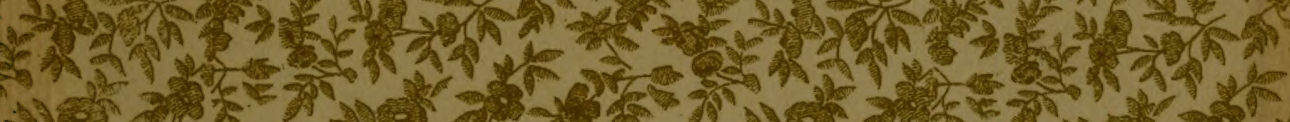
1

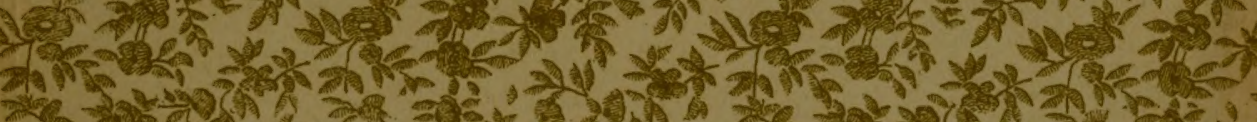
25.

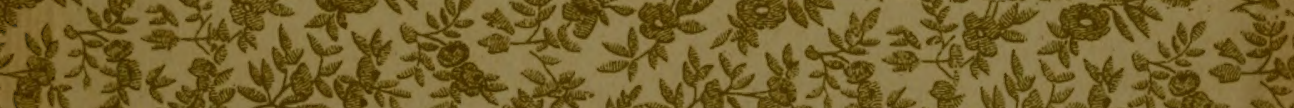

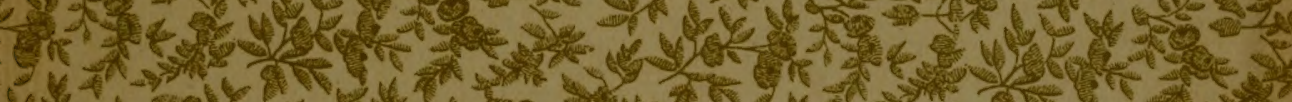

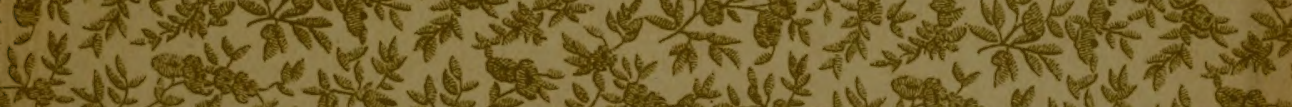
UQ

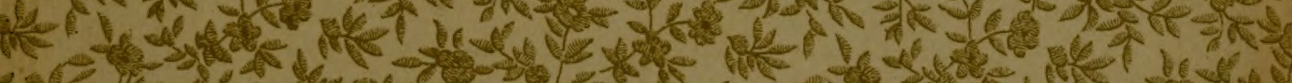

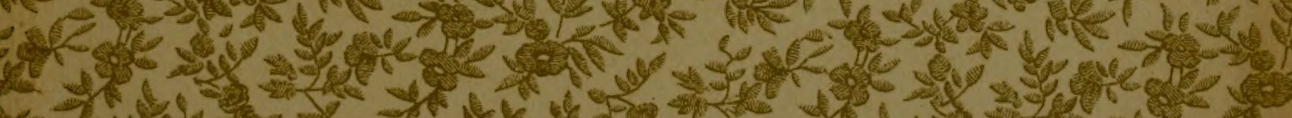
1. -1 -

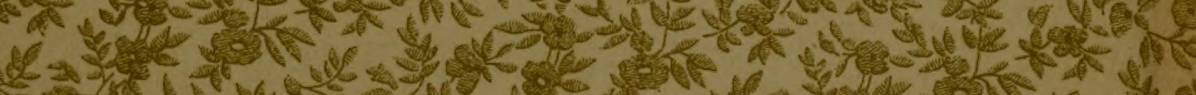

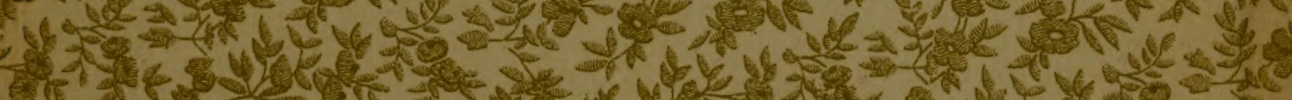

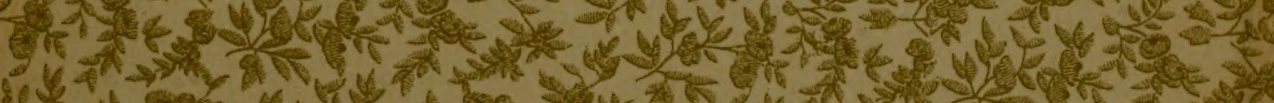

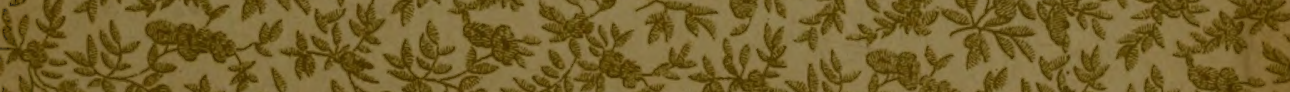

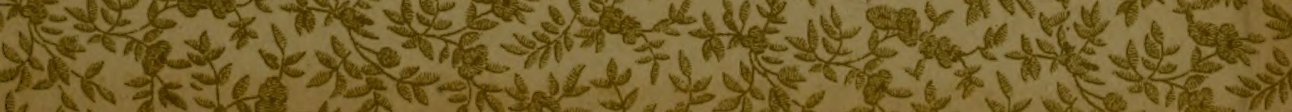


LIBRARY OF CONGRESS

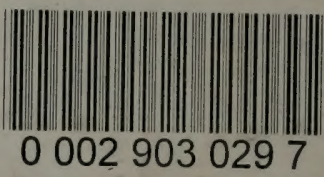

